\title{
Kritische Analyse der Rekonstruktionen der letztglazialen Vergletscherung im Nepal-Himalaja \\ (Himalaja Südabdachung)
}

\begin{abstract}
Dissertation
zur Erlangung des mathematisch-naturwissenschaftlichen Doktorgrades

'Doctor rerum naturalium'

der Georg-August-Universität Göttingen

im Promotionsprogramm Geowissenschaften / Geographie der Georg-August University School of Science (GAUSS)
\end{abstract}

vorgelegt von

Dipl.-Geogr. Elisabeth Spitzer

aus Heilbad Heiligenstadt

Göttingen 2020 
Betreuungsausschuss:

Prof. Dr. Daniela Sauer

apl. Prof. Lasafam Iturrizaga

Dr. Sigrid Meiners

$\underline{\text { Mitglieder der Prüfungskomission }}$

Referentin:

Prof. Dr. Daniela Sauer

Korreferentin:

apl. Prof. Dr. Lasafam Iturrizaga

weitere Mitglieder der Prüfungskomission:

Dr. Sigrid Meiners

Dr. Markus Wagner

Prof. Dr. Heiko Faust

Prof. Dr. Martin Kappas

Tag der mündlichen Prüfung: $\quad$ 7. Februar 2020 


\section{VORWORT}

Die vorliegende Dissertation wurde von Herrn Prof. Dr. Matthias Kuhle, Leiter der Abteilung Geographie und Hochgebirgsgeomorphologie des Geographischen Instituts der GeorgAugust-Universität Göttingen, initiiert und betreut. In ehrendem Gedenken an ihn möchte ich mich für seine fachlichen Hinweise, die konstruktiven Diskussionen zwischen uns sowie für viele Ratschläge bedanken. Für die Übernahme des Referats sei Frau Prof. Dr. Daniela Sauer und für die des Korreferates Frau apl. Prof. Dr. Lasafam Iturrizaga gedankt. Für die umfangreiche Bearbeitung der Stipendienanträge bzw. für das Verfassen der für die Stipendienbewerbungen notwendigen Gutachten danke ich ebenfalls den o.g. Betreuern Kuhle und Iturrizaga sowie Dr. Steffen Möller von der Abteilung Landschaftsökologie. Ohne die finanzielle Unterstützung in Form eines Ausrüstungsstipendiums der „Otto VahlbruchStiftung“ und eines Reisestipendiums der „FAZIT-STIFTUNG Gemeinnützige Verlagsgesellschaft $\mathrm{mbH}^{\star}$ wäre der kostspielige sechswöchige Geländeaufenthalt bzw. die Forschungsreise in den Solukhumbu-Himalaja nicht möglich gewesen. Hierfür bedanke ich mich auf diesem Wege nochmals bei diesen beiden Stiftungen. Auch meiner Familie, besonders meiner Mutter Christina Spitzer, sei an dieser Stelle für das eingeräumte Darlehen sowie für andere Hilfsangebote gedankt, wobei ich mich bei Frau Dr. Vera Spitzer besonders für die ärztlichen Ratschläge im Zusammenhang mit meinem Auslandsaufenthalt bedanken möchte. Für die Unterstützung bei der Logistik der Forschungsreise sei den Reiseleitern Herrn Kohlhase und Herrn Ngima Nuru Sherpa sowie den Reisebegleitern Ngima Nuru Sherpa und Basanta Rai gedankt. Herrn M. Sc. Matthias Koch gilt der Dank für die Mithilfe bei der praktischen Durchführung der Geländearbeiten in Nepal und Herrn Hellrung für die Bereitstellung von weiteren Fotos zu diesem Gebiet. Für die zur Verfügung gestellte Feldausrüstung und für die Möglichkeit der Durchführung der Sedimentanalysen im Geographischen Labor der Universität Göttingen danke ich dem Laborleiter Dr. Jürgen Grotheer. Für die Bereitstellung eines geeigneten Mikroskopes gilt Herrn Kuhle der Dank. Den Mitarbeitern des Arbeitsbereiches Geographie und Hochgebirgsgeomorphologie des Geographischen Instituts sei für klärende Diskussionen anlässlich meiner Kandidatenkolloquien gedankt. Zudem bedanke ich mich bei Herrn Dipl.-agr. Ing. Helfried Heinrich für die sorgfältige Korrektur des Manuskripts. Allen Freunden, besonders Natalia Hering, Verwandten und Bekannten, die mir für die Reise in den Himalaja und meine Dissertation insgesamt Mut machten, sei an dieser Stelle herzlich gedankt. 


\section{INHALTSVERZEICHNIS}

VORWORT III

INHALTSVERZEICHNIS IV

ABKÜRZUNGSVERZEICHNIS

1. EINFÜHRUNG 1

1.1. EINLEITUNG 1

1.1.1. Problemstellung 2

1.1.2. Fragestellung und Zielsetzung $\quad 4$

1.1.3. Vorgehensweise 5

1.1.4. Aufbau der vorliegenden Arbeit 6

1.2. DIE UNTERSUCHUNGSGEBIETE IM NEPAL-HIMALAJA

1.2.1. Auswahl der Untersuchungsgebiete 7

1.2.2. Erschließung der Untersuchungsgebiete 8

1.2.3. Landschaftliche Gliederung 9

1.2.4. Geologie 13

1.2.5. Klima 16

1.2.6. Rezente Vergletscherung 22

1.3. HAUPTUNTERSUCHUNGSGEBIET SOLUKHUMBU

1.3.1. Lage und naturräumliche Gegebenheiten 24

1.3.2. Geologie 25

1.3.3. Klima 27

1.3.4. Böden und Vegetation 29

1.3.5. Rezente Vergletscherung 30

1.4. VERGLEICHSUNTERSUCHUNGSGEBIETE 32

1.5. Eigene ANGEWENDETE Methoden BZW. Arbeitstechniken 36

1.5.1. Geomorphologische Analyse 36

1.5.2. Sedimentanalyse 43

1.6. WEITERE VON FORSCHERN ANGEWENDETE METHODEN BZW. ARBEITSTECHNIKEN

1.6.1. Datierungen 74

1.7. KURZZUSAMMENFASSUNG 81

2. FORSCHUNGSÜBERBLICK ZUR VERGLETSCHERUNGSGESCHICHTE DES NEPAL-HIMALAJA

2.1. HAUPTUNTERSUCHUNGSGEBIET SOLUKHUMBU 82

2.1.1. Forschungsergebnisse der Jahre 1950 bis 1970 - Beginn der Datierung mittels Lichenometrie

2.1.2. Forschungsergebnisse der Jahre 1971 bis 1990 - Beginn der ${ }^{14} \mathrm{C}$-Datierung 83

2.1.3. Forschungsergebnisse der Jahre 1991 bis heute - Beginn der TCN- und OSL-Datierung 96

2.2. VERGLEICHSUNTERSUCHUNGSGEBIETE 111

2.2.1. Forschungsergebnisse der Jahre 1971 bis $1990 \quad 111$

2.2.2. Forschungsergebnisse der Jahre 1991 bis heute 119

2.3. KURZZUSAMMENFASSUNG 135

3. VALIDIERUNG DER FORSCHUNGSERGEBNISSE RELEVANTER FORSCHER ANHAND VON EIGENEN GELÄNDEBEFUNDEN ZUM HAUPTUNTERSUCHUNGSGEBIET SOLUKHUMBU

3.1. BEFUNDE AUS DEM KHUMBU $\quad 138$

3.1.1. Lobuche Khola $r$

3.1.2. Imja Khola $\quad 152$

3.2. BEFUNDE AUS DEM SOLU

3.2.1. Dudh Khosi 181

3.3. KURZZUSAMMENFASSUNG 195 
4. KRITISCHE AUSEINANDERSETZUNG MIT DEN ANGEWENDETEN METHODEN BZW. ARBEITSTECHNIKEN UND FORSCHUNGSARBEITEN ZUR VERGLETSCHERUNGSGESCHICHTE DES HAUPTUNTERSUCHUNGSGEBIETES SOLUKHUMBU 200

4.1. Problematische ASPekTe Der Methoden BZW. ArbeitsteChniken 200

4.1.1. Geomorphologische Analyse 200

4.1.2. Relative Datierungen 202

4.1.3. Absolute Datierungen 202

4.2. FORSCHUNGSARBEITEN DER JAHRE 1950 BIS $1970 \quad 212$

4.3. FORSCHUNGSARBEITEN DER JAHRE 1971 BIS $1990 \quad 218$

4.4. FORSCHUNGSARBEITEN DER JAHRE 1991 BIS HEUTE 275

4.5. KURZZUSAMMENFASSUNG 347

5. BETRACHTUNG AUSGEWÄHLTER LITERATUR ZU DEN VERGLEICHSUNTERSUCHUNSGEBIETEN ZUR ÜBERPRÜFUNG GLEICHGEARTETER KRITIKPUNKTE ANALOG ZUM HAUPTUNTERSUCHUNGSGEBIET $\quad 357$

5.1. DHAULAGIRI- UND ANNAPURNA-Himal 357

5.1.1. Mayangdi Kola 357

5.1.2. Kali Gandaki 360

$\begin{array}{ll}\text { 5.1.3. Modi Khola } & 379\end{array}$

5.1.4. Madi Khola 387

$\begin{array}{ll}\text { 5.1.5. Seti Khola } & 389\end{array}$

5.1.6. Marsyandi Khola 393

5.2. LANGTANG-Himal 398

5.3. MaHALANGUR-HimaL

5.4. KANGCHENDZÖNGA-HIMAL 417

5.5. KURZZUSAMMENFASSUNG 433

6. ZUSAMMENFASSUNG DER ERGEBNISSE DER KRITISCHEN ANALYSE UND EINORDNUNG DIESER IN DEN KONTEXT DER LETZTEISZEITLICHEN VERGLETSCHERUNG DES NEPAL-HIMALAJA

440

LITERATURVERZEICHNIS

KARTEN- UND KARTENWERKSVERZEICHNIS

BILDBAND 


\section{ABKÜRZUNGSVERZEICHNIS}

AAR

Abb.

ABU

ABNU

$\mathrm{Al}$

$\mathrm{Be}$

bzw.

C

ca.

CD

$\mathrm{Cl}$

$\mathrm{cm}$

CRN

${ }^{14} \mathrm{C}$

${ }^{\circ} \mathrm{C}$

d.h.

DIN

E

ebd.

et al.

f.

$\mathrm{Fe}$

ff.

Fig.

g

g

gg

GA

GE

$\mathrm{GH}$

GLOFs

GPS

$\mathrm{He}$
Accumulation Area Ratio

Abbildung

Probenbezeichnung bei Richards et al. (2000)

Probenbezeichnung bei Richards et al. (2000)

Aluminium

Beryllium

beziehungsweise

Kohlenstoff

circa

Compact Disc

Chlor

Zentimeter

Cosmogenic Radioactive Nuclides

Kohlenstoff-14

Grad Celsius

das heißt

Deutsches Institut für Normung

Probenbezeichnung bei Barnard, Owen, Finkel (2006)

ebenda, eben dort

und andere

folgende

Eisen

fortfolgende

Figure, Abbildung

Gramm

gerundet

gut gerundet

Probenbezeichnung bei Zech et al. (2009)

Google Earth

Probenbezeichnung bei Zech et al. (2009)

Glacial Lake Outburst Floods

Global Positioning System

Helium 
Innertropische Konvergenzzone

Jhd.

Jahrhundert

Jt. v. Chr.

Jahrtausend vor Christus

K

Probenbezeichnung bei Bäumler (2001)

K.

KA

Khola

$\mathrm{kg}$

Probenbezeichnung bei Zech et al. (2009)

$\mathrm{km}$

kantengerundet

$\mathrm{km}^{2}$

Kilometer

$\mathrm{kt}$

Quadratkilometer

(1)

kantig

KTM

Probenbezeichnung bei Barnard et al. (2006)

LE

Probenbezeichnung bei Zech et al. (2009)

LGM

Last Glacial Maximum, Letztes Glaziales Maximum

$\mathrm{m}$

Meter

MCT

Main Central Thrust

MIS

Marine Isotopic Stage

$\min$.

Minuten

Mio.

Millionen

$\mathrm{m} / \mathrm{km}$

Meter pro Kilometer

$\mathrm{ml}$

Milliliter

$\mathrm{mm}$

Millimeter

$\mathrm{mm} / \mathrm{Jahr}$

Millimeter pro Jahr

Mt.

Mount

n.B.

nördliche Breite

n. Chr.

nach Christus

$\mathrm{Ne}$

Neon

o.g.

oben genannt

ö.L.

östliche Länge

OSL

Optisch Stimulierte Lumineszenz

PI

Periche I

PII

Periche II

$\mathrm{pH}$

potentia hydrogenii

$\mathrm{PN}$

Probenbezeichnung bei Finkel et al. (2003)

s.h.

siehe hierzu 
s.h.a.

SK

s.o.

sog.

TI

TII

T1

T6

Tab.

TCN

Th

TL

U

U1, U2, U3, U3B

u.a.

u.s.w.

ü. NN

vgl.

v.H.

v.u.Z.

z.B.

Zus.

ZW.

$\mu \mathrm{m}$ siehe hierzu auch

Probenbezeichnung bei Richards et al. (2000)

siehe oben

sogenannte

Thyangboche I

Thyangboche II

Thuklha 1

Thuklha 6

Tabelle

Terrestrische Cosmogene Nuklide

Thorium

Thermolumineszenz

Uranium

Trogtalserien bei Fushimi (1978)

unter anderen

und so weiter

über Normal Null

vergleiche

vor Heute

vor unserer Zeit

zum Beispiel

Zusammenfassung

zwischen

Mikrometer 


\section{EINFÜHRUNG}

\subsection{Einleitung}

Hochasien umfasst das Tibetische Plateau und dessen angrenzende Gebiete mit einer ungefähren Fläche von über 4 Mio. km² (vgl. Kuhle 1997b:85). Es ist ein Komplex aus Hochländern und -gebirgen und beherbergt die weltweit höchsten Gebiete, darunter auch den Nepal-Himalaja (Himalaja Südabdachung). Aktuell sind ca. $10 \%$ der Erdoberfläche vergletschert (während des Pleistozäns 25\%), ca. 69\% des globalen Süßwassers in Schnee und Eis gebunden, ca. $25 \%$ Permafrostgebiete und ca. $6 \%$ der Ozeane permanent eisbedeckt (vgl. Baumhauer, Winkler 2014:Vorwort, 10, 12). Hochasien stellt das meist vergletscherte Gebiet der Welt außerhalb der Pole dar und hat einen Einfluss auf globale Klimaveränderungen (vgl. Finkel et al. 2003:561; vgl. Owen, Dortch 2014:14). Diese höchsten Regionen können somit bezüglich ihrer Lage über der jeweiligen Schneegrenze mit einer heutigen und eiszeitlichen Vergletscherung und somit auch mit regionalen oder gar globalen Klimaveränderungen in Verbindung gebracht werden. Die rezente Gletscherbedeckung Hochasiens zeigt, dass das Relief dafür hoch genug ist (vgl. Kuhle 2013a:195). In der Nähe des Äquators liegt die rezente Schneegrenze auf ca. $5.500 \mathrm{~m}$ Höhe und ist somit in den semiariden Subtropen infolge der höchsten Einstrahlung und fehlenden Feuchtigkeit am höchsten (vgl. Kuhle 2012a:173 f.). Während des Pleistozäns wurde das subtropisch warme und aride Klima Hochasiens überkompensiert; der Monsun auf der Südseite des Himalaja kollabierte, wobei aber der Nordrand von Hochasien infolge des Vorhandenseins von Seen feuchter war als heute (vgl. Kuhle 2013a:1).

Mindestens sechs Eiszeiten traten auf der Erde auf (vgl. Kuhle 1986c:42). Penck und Brückner (1909) schlossen anhand von glazialmorphologischen und sedimentologischen Studien auf vier Eiszeiten im Alpenraum. Wieviele pleistozäne alpine Vereisungsphasen letztendlich existierten, ist unbekannt (vgl. Baumhauer, Winkler 2014:23). Während des letzteiszeitlichen Hochglazials war der Meeresspiegel um ca. $120 \mathrm{~m}$ abgesenkt (vgl. Baumhauer, Winkler 2014:12). Die heute sichtbaren glazialen Landformen und Sedimente stammen aus der känozoischen Eiszeit (vgl. Bennett, Glasser 1996:12). Glaziale Indizien der känozoischen Eiszeit sind aber nur unvollständig erhalten, wobei sich auf die letzte Vereisung beschränkt werden sollte, so wie es Bennett, Glasser (1996) wie folgt beschrieben: "In the case of glacial landforms these breaks occur because each successive glacier erodes the evidence of earlier glaciers." (ebd.:12); "Glaciers are erosive and recent glaciers tend to destroy the evidence left by earlier ones." (ebd.:20). Bereits Kuhle (1986c:44) machte darauf aufmerksam, dass Spuren der vorletzten oder vorvorletzten Eiszeit verwischt seien. 
Infolgedessen steht für die vorliegende Arbeit, da ältere Formen oft überfahren wurden, der Zeitraum der letzten Vereisung im Fokus. So schrieb auch Kuhle (2014:251), dass z.B. Gletscherspuren im steilen Himalajarelief jung sein müssen. Die ungefähre zeitliche Einordnung der verschiedenen Gletscherstadien seit der letzten Vereisung kann der Tab. 1 bei Kuhle (2005) entnommen werden.

\subsubsection{Problemstellung}

Es sollte angenommen werden, dass in der heutigen Zeit nach ca. 70 Jahren intensiver Forschungen die pleistozäne Gletschergeschichte Hochasiens aufgrund der mannigfaltigen Literatur eindeutig geklärt ist. Aktuell existieren aber zur eiszeitlichen Vergletscherungsart und zum Grad der Vergletscherung dieses Gebietes, insbesondere des Nepal-Himalaja (Himalaja Südabdachung), immer noch beträchtliche Unterschiede in den Forschungsergebnissen. Bezeichnenderweise und beispielhaft erwähnten dies in ihrer Arbeit Owen et al. (2008:514): "Reconstructions of the extent of former glaciations vary considerably between researchers [...].”. Dieses wird schon allein bei der Betrachtung der wissenschaftlichen Literatur (umfassend detaillierte gegenüber weniger umfassende Werke), der oft grundverschiedenen angewendeten Methoden bzw. Arbeitstechniken der Forscher (geomorphologische Reliefanalyse, relative Datierungen wie etwa Bodenanalyse und absolute Datierungen wie ${ }^{14} \mathrm{C}$, TCN bzw. OSL) und / oder der unterschiedlichen Lage und Größe der Untersuchungsgebiete (talaufwärtige gegenüber talabwärtigere) verständlich. Besonders die unterschiedlichen Interpretationen der geomorphologischen Kennformen und deren unterschiedliche zeitliche Einordnungen sind hierbei maßgebend.

Es ist für den derzeitigen Wissensstand also festzuhalten, dass das Ausmaß der Vergletscherung Hochasiens bzw. des Nepal-Himalaja während der letzten Eiszeit nicht eindeutig geklärt und bislang ungeklärt ist, ob einige Bereiche dieser Hochgebirge überhaupt eisbedeckt waren. Außerdem existieren keine kritischen Auswertungen der Literatur, die Widersprüche erkennen lassen würden, bzw. keine kritischen Analysen über diesen Sachverhalt, die zu einer einheitlichen wissenschaftlichen Ansicht über die Vergletscherung Anlass geben können. Dabei stehen die Betrachtungen der angewendeten Methoden / Arbeitstechniken im Fokus der vorliegenden Arbeit, die selbst bei gleicher Anwendung enorme Unterschiede aufweisen. Beispielsweise stehen detallierte geomorphologische Analysen bzw. Bestandsaufnahmen mit sedimentologischen Untersuchungen der Moränen und Schneegrenzberechnungen gegenüber weniger detaillierten Forschungsarbeiten mit 
Beschreibung nur weniger Kennformen, die ausschließlich deutlich ausgebildet sind. Da infolgedessen in vielen Forschungsarbeiten geomorphologische Kennformen außer Betracht gelassen oder keine Aussagen bzw. nur Annahmen über die Maximalvergletscherung getroffen oder sich anderen Forschungsergebnissen angeschlossen wurden, wird deutlich, dass nur einige dieser Forschungsergebnisse in Bezug auf die Fragestellung der vorliegenden Arbeit aussagekräftig sein werden.

Hochasien stellt aufgrund des hier auftretenden weltweit großräumigsten Massenerhebungseffektes im rezenten Klima die größte Heizfläche der Erde dar (s.h.a. Kuhle 2013a:204). Die heißesten Gebiete der Erde liegen in den trockenen Subtropen und den Wüstengebieten der subtropischen Trockengürtel (vgl. Kuhle, Roesrath 1990:35). Das größte Hochland der Erde hat somit, gerade wegen der subtropischen Lage, Einfluss auf das globale Klima (s.h.a. Kuhle 1986c:42). Dadurch wird verständlich, dass eine pleistozäne Eisbedeckung Hochasiens in Form einer Abkühlungsfläche einen enormen Einfluss auf das regionale oder gar globale Klima hatte. Kuhle ging von einem eiszeitlichen Inlandeis Tibets aus, wobei er aus den empirischen Befunden eine Eiszeittheorie ableitete. „Due to the energyrich geometry of its global radiation intake, it occupies an important position - if not a keyfunction - for the onset of Ice Ages and the climatic history in the Pleistocene." (Kuhle 1997b:85). Die derzeitigen generellen Zirkulationsmodelle berücksichtigen die Inlandeisbedeckung von Tibet nicht (vgl. Kuhle 2013a:211). Da die Wirkung einer solchen Abkühlungsfläche durch die Art des Vergletscherungsgrades - Gebirgsvergletscherung oder Inlandeisbedeckung - entscheidend beeinflusst wird, ist auch für heutige globale Klimaszenarien eine Klärung dieses Umstandes unbedingt notwendig. Das rekonstruierte Eiszeitklima kann gewissermaßen als Maßstab für aktuelle Klimaereignisse bzw. für natürliche Klimaschwankungen gegenüber anthropogenen verursachten dienen. Dabei spielt gerade der südliche Rand Tibets wegen des Monsuneinflusses für die Klimaentwicklung eine besondere Rolle (s.h.a. Kuhle 2014:236). Erst die Erforschung, Rekonstruktion und möglichst umfängliche Einbeziehung aller relevanten Aspekte zu den Vergletscherungen auf der Erde wird zu sinnvollen Einschätzungen des zukünftigen Klimas führen können. Die Eiszeitforschungen in Hochasien bzw. die grundsätzliche Klärung der Vergletscherungsgeschichte sind somit von großer Wichtigkeit und sollten deshalb im Vordergrund stehen. 


\subsubsection{Fragestellung und Zielsetzung}

Die grundlegende Aufgabenstellung der vorliegenden Dissertation ist, unter Berücksichtigung der heutigen Vergletscherung und geomorphologischer Kennformen, Rückschlüsse auf die pleistozäne - speziell auf die letzteiszeitliche - Vergletscherung des Nepal-Himalaja zu ziehen. Hierbei liegt der Schwerpunkt auf der Gegenüberstellung der wissenschaftlichen Literatur in Bezug auf Quartärgeomorphologie und Gletschergeschichte im Nepal-Himalaja (Himalaja Südabdachung) und der damit verbundenen Suche sowohl nach Gründen dieser verschiedenen Auffassungen als auch nach Widersprüchen und eventuellen Fehlerquellen. Es sollte sich die Frage gestellt werden, welche Methode bzw. Arbeitstechnik für die Rekonstruktion einer vorzeitlichen Vergletscherung prinzipiell anwendbar und zielführend ist bzw. zu wissenschaftlich belastbaren Ergebnissen führen kann und die wenigsten Unbekannten aufweist. Beispielsweise muss ein einzelner Block auf einer Moräne nicht unbedingt mit dem Alter des gesamten Moränenzuges übereinstimmen. Sind demnach alleinige Anwendungen von Datierungen ohne Berücksichtigung jeglichen Formeninventars inklusive Lagebezug ausreichend? Oder führen Mittelwerte mehrerer datierter Blöcke einer Moräne oder die alleinige Berücksichtigung von älteren Daten oder das Ausgrenzen von Daten zur Richtigkeit der datierten Alter? Zudem sollte anhand von Geländearbeiten und Satellitenbildanalysen zum ausgewählten Hauptuntersuchungsgebiet überprüft werden, in welchem Ausmaß eine Vergletscherung während der letzten Eiszeit stattgefunden hat bzw. wie die Befunde der hier relevanten Literatur einzuordnen sind. Somit können Aussagen über die klimatischen Verhältnisse in der Vergangenheit, speziell über das Pleistozän und Holozän - vor etwa 2,6 Mio. Jahren bis heute - im Zeitabschnitt des Quartärs, getroffen werden. Es kann besonders für das ausgewählte Hauptuntersuchungsgebiet des Solukhumbu und für die Vergleichsuntersuchungsgebiete im Himalaja der Klärungsbedarf dieser Fragestellung begrenzt werden und sich entweder Forschungsarbeiten angeschlossen oder nicht angeschlossen werden.

Zusammenfassend betrachtet ist das Ziel der vorliegenden Dissertation, den heutigen Forschungsstand aus inhaltlich- und methodenkritischer Sicht sowie bezüglich des Hauptuntersuchungsgebietes mit Testbegehungen im Gelände und Satellitenbildanalysen zu überprüfen und zu bewerten, um im bestmöglichen Falle eine einheitliche Auffassung zu etablieren. Hierbei stellen die in der Literatur gefundenen Gründe für die unterschiedlichen Forschungsergebnisse über die pleistozäne Vergletscherung Hochasiens die Schlüsselrolle dar. Mit der vorliegenden Dissertation wird somit ein Beitrag zur Aufhellung der Gletschergeschichte gegeben, vor allen Dingen in einem Gebiet, welches sehr gut zugänglich 
ist und bei den Forschungen die größte Aufmerksamkeit erfuhr; hier wurden geomorphologische Bestandsaufnahmen sowie auch relative und absolute Datierungen angewendet.

\subsubsection{Vorgehensweise}

Neben der analytischen Gegenüberstellung und kritischen Bewertung der Literatur zur eiszeitlichen Vergletscherung aller für die vorliegende Dissertation relevanten Untersuchungsgebiete sollen demgegenüber auch aussagekräftige geomorphologische Analysen einschließlich Sedimentanalysen bzw. Geländearbeiten und Satellitenbildanalysen eines ausgesuchten repräsentativen Hauptuntersuchungsgebietes anhand von 'Google Earth' und 'Google Maps Gelände' zum Einsatz kommen. Dadurch können weitere wichtige geomorphologische Indikatoren einer Vergletscherung mit in die Arbeit einbezogen werden. Das Gebiet Khumbu / Solukhumbu wird aufgrund seines immensen Bekanntheitsgrades ausgewählt.

Bei einer solchen kritischen Analyse werden die von den Forschern verwendeten grundlegenden Methoden bzw. Arbeitstechniken, die beschriebenen Sachverhalte und die sie unterstützenden Beweise, wie etwa Abbildungen und Fotos, überprüft und anschließend bewertet. Desweiteren müssen beispielsweise die klimatischen und geologischen Aspekte, aber auch die verschiedenen Interpretationen zu Oberflächenformen bzw. der Einordnung von Kennformen bezüglich ihrer Entstehungsweise sowie die Reichweite der Forschungsgebiete der einzelnen Forscher herauskristallisiert und in die kritische Analyse mit einbezogen werden.

Die im Hauptuntersuchungsgebiet zusätzlich anzuwendenden o.g. Methoden / Arbeitstechniken sind für diese Gebiete von sehr großer Wichtigkeit, da sich die Erreichbarkeit erst vor ca. 40 Jahren verbesserte und 'Google Earth', welches unter diesem Namen vor 10 Jahren entstand, erst seit sehr kurzer Zeit hochaufgelöste Satellitenbilder in diesen Gebirgsregionen bereitstellt. Abhängig von den ausgemachten eiszeitlichen Indikatoren - unter Verwendung einer detaillierten Bestandsaufnahme des geomorphologischen Formeninventars - und in Kombination mit der Satellitenbildanalyse können gegebenenfalls entweder Auffassungen aus der Literatur bestätigt oder nicht bestätigt werden. 


\subsubsection{Aufbau der vorliegenden Arbeit}

Die vorliegende Arbeit gliedert sich in sechs Abschnitte: Einführung, Forschungsüberblick zur Vergletscherungsgeschichte des Nepal-Himalaja, Validierung der Forschungsergebnisse relevanter Forscher anhand von eigenen Geländebefunden zum Hauptuntersuchungsgebiet Solukhumbu, Kritische Auseinandersetzung mit den Methoden bzw. Arbeitstechniken und Forschungsarbeiten zur Vergletscherungsgeschichte des Hauptuntersuchungsgebietes Solukhumbu, Betrachtung ausgewählter Literatur zu den Vergleichsuntersuchungsgebieten zur Überprüfung gleichgearteter Kritikpunkte analog zum Hauptuntersuchungsgebiet und Zusammenfassung der Ergebnisse der kritischen Analyse und Einordnung dieser in den Kontext der letzteiszeitlichen Vergletscherung des Nepal-Himalaja.

Mit dem Einführungsteil wird zunächst eine verständliche Basis für die nachfolgende Arbeit geschaffen. Hierbei ist eine Einführung in die Thematik, in die Untersuchungsgebiete, in die angewendeten Methoden bzw. Arbeitstechniken und in die von Forschern angewendeten Methoden bzw. Arbeitstechniken notwendig. Außerdem werden die im Hauptuntersuchungsgebiet vorgefundenen geomorphologischen Formen anhand individueller Charakteristika trennscharf gegeneinander abgegrenzt, sodass Unter- bzw. Mischformen ansprechbar sind. Der Kern der Arbeit ist die Vergletscherungsgeschichte der Untersuchungsgebiete. Unter Berücksichtigung der Forschungen zur Vergletscherung in diesen Gebieten und der eigenen Geländebefunde aus dem Hauptuntersuchungsgebiet erfolgt eine kritische Auseinandersetzung mit den Methoden bzw. Arbeitstechniken und der bis dato bestehenden Literatur - in den Vergleichsuntersuchungsgebieten wird lediglich ausgewählte Literatur betrachtet. Etliche Tabellen, Abbildungen, Karten und Fotos sind im separat gebundenen Bildband einsehbar. 


\subsection{Die Untersuchungsgebiete im Nepal-Himalaja}

\subsubsection{Auswahl der Untersuchungsgebiete}

Bei der vorliegenden Dissertation wurden Gebiete in Nepal bzw. im Zentralhimalaja ausgewählt, da Nepal eine zentrale Rolle im Himalaja darstellt (s.h.a Fort 2004:261), wobei der Himalaja das sich am schnellsten verändernde Gebiet der Welt darstellt (s.h.a. Fushimi 1978:71). Der Zentralhimalaja liegt im Bereich des monsunbeeinflussten Himalaja in Nepal. Dieser umfasst den ca. $800 \mathrm{~km}$ langen - in etwa 1/3 der Gesamtlänge - und maximal etwa $250 \mathrm{~km}$ breiten zentralen Bereich des Himalaja Bogens zwischen Indus und Brahmaputra (hierzu Karten bei Zurick, Pacheco 2007:15, 20 f.). Hochasien bzw. der Himalaja und Tibet erstreckt sich über eine Fläche von ca. $2.000 \mathrm{~km}$ Ostwestausdehnung und ca. $1.500 \mathrm{~km}$ Nordsüdausdehnung mit einer durchschnittlichen Höhe von 5.000 m (Fielding et al. $1994^{1}$ zitiert nach: Owen et al. 2008:514). Der Schwerpunkt der Arbeit lag auf dem ausgewählten Hauptuntersuchungsgebiet, dem Solukhumbu bzw. speziell dem Khumbu-Himal, welches in Ostnepal liegt. Diese Region wurde ausgewählt, da es sich hierbei um die meistbesuchte und am besten dokumentierte bzw. am meisten erforschte Region im Himalaja handelt (hierzu Richards et al. 2000:1621 und Finkel et al. 2003:561). Zudem ist dieses Gebiet gut erreichbar und weist in Bezug auf die Glazialgeomorphologie gut nachvollziehbare Gletscherchronologien auf (vgl. Barnard, Owen, Finkel 2006:383). Außerdem stellt Hochasien wie o.g. das meist vergletscherte Gebiet der Welt dar und hat einen Einfluss auf globale Klimaveränderungen (vgl. Finkel et al. 2003:561), sodass das rekonstruierte Eiszeitklima gerade in einem solchen monsunbeeinflussten Gebiet als Maßstab für aktuelle Klimaereignisse dienen kann.

Da die verschiedenen Forschungsergebnisse über die eiszeitliche Vergletscherung mit den angewendeten Methoden bzw. Arbeitstechniken in Verbindung gebracht werden können, ist die Khumbu Region von großem Vorteil, da dort die meisten relativen und absoluten Datierungen durchgeführt wurden (vgl. Finkel et al. 2003:564; vgl. Barnard, Owen, Finkel 2006:383). Das Gebiet des Solu wurde ebenfalls untersucht, da die in ausgewählter Literatur beschriebenen Forschungen über die Quartärgeomorphologie bis in diese Talabschnitte hinab reichten. Die Vergleichsuntersuchungsgebiete wurden ebenfalls in das monsunbeeinflusste Himalaja gelegt, da diese zum Hauptuntersuchungsgebiet vergleichbar sein sollten. Hierbei fiel die Wahl auf die Himalaja Gebiete Dhaulagiri- und Annapurna-Himal (Kali Gandaki, Modi Khola, Seti Khola), Langtang-Himal, Mahalangur-Himal (Aruntal) und Kangchendzönga-Himal. Bäumler, Kemp-Oberhettinger, Zech (1996:14 f., 29) sind der

\footnotetext{
${ }^{1}$ Fielding, E.; Isacks, B.; Barazangi M.; Duncan C. (1994): How flat is Tibet? Geology, 22. (S. 163-167)
} 
Auffassung, dass ein klimatischer Vergleich beispielsweise der Gebiete Khumbu und Langtang möglich, in Bezug zum Solu aber nur bedingt möglich ist: Sommerniederschläge Kyangjin $1.200 \mathrm{~mm}$ gegenüber Tengboche $1.030 \mathrm{~mm}$, Winterniederschläge im Khumbu geringer und Jahresmitteltemperatur bei beiden Orten bei ca. $3{ }^{\circ} \mathrm{C}$. Bei Owen et al. (2008:516/Fig. 3) ist zu erkennen, in welchen Gebieten die Forscher TCN-Datierungen anwendeten; im Zentralhimalaja waren das die Gebiete Langtang, Khumbu und Kangchendzönga. Auch dies stellte einen Faktor bei der Auswahl der Vergleichsuntersuchungsgebiete neben dem Hauptuntersuchungsgebiet dar.

\subsubsection{Erschließung der Untersuchungsgebiete}

Hochasien war früher aufgrund der Unzugänglichkeit kaum erforscht bzw. extrapolierten viele Forscher die Gletscherränder. Seit 1970 werden viele dieser Gebiete infolge des verbesserten Zuganges erforscht, sodass die heute gesteigerte Erreichbarkeit und die Verwendung von Fernerkundungstechnologien das Problem der geringen Erforschung bzw. der Extrapolation in diesen Regionen reduzierten. (vgl. Owen et al. 2008:515 f.)

Miehe (1982:4) schrieb, dass die Öffnung von Nepal im Jahr 1949 einsetzte. Ab 1960 ist der nepalische Himalaja zugänglich (vgl. Kuhle 1985:35). Das Hauptuntersuchungsgebiet des Solukhumbu ist inzwischen ein sehr gut erreichbares Gebiet, so wie es auch Barnard, Owen, Finkel (2006:383) über einen Teil dieses Gebietes - nämlich über das Khumbu Gebiet meinten. Im Gegensatz $\mathrm{zu}$ den in die vorliegende Arbeit integrierten Vergleichsuntersuchungsgebiete Dhaulagiri und Annapurna, Langtang, Mahalangur und Kangchendzönga-Himal ist das Gebiet des Solukhumbu infrastrukturell besser entwickelt. Der Ort Lukla, der einen ausgebauten Flugplatz namens 'Tenzing Hillary Airport' aufweist, stellt hierbei vorwiegend den Ausgangspunkt vieler Reisen in dieses Gebiet dar. Oberhalb dieses Flugplatzes existiert nur nördlich von Namche Bazar ein weiterer Flugplatz, der jedoch nicht ausgebaut ist und nur einen Schotterlandeplatz aufzeigt. Im Solukhumbu gibt es lediglich Fußwege und Pfade, keine Straßen. Bezeichnenderweise wurde die älteste Literatur zur Vergletscherungsgeschichte dieses Hauptuntersuchungsgebietes, die zudem auch Geländebefunde zeigt, erst im Jahre 1956 veröffentlicht und stammt von Heuberger.

Neben dem Gebiet des Khumbu stellen aber inzwischen auch die Thakkhola Region sowie das Langtang Gebiet gut erreichbare Gebiete dar (vgl. Iwata 1984:25; vgl. Bäumler, KempOberhettinger, Zech 1996:11). Das Helambu Langtang Gebiet zählt, gefolgt von dem 
Annapurna und Mt. Everest Gebiet, mit zu den wichtigsten Trekkingrouten in Nepal (vgl. Bäumler, Kemp-Oberhettinger, Zech 1996:11).

Heutzutage kann neben einer Bereisung der Untersuchungsgebiete per Fernerkundung auf Satellitenbilder von 'Google Earth' zurückgegriffen werden. Dieses Unternehmen wurde, früher jedoch unter einem anderen Namen, im Jahre 2001 gegründet; seit 2005 heißt dieses 'Google Earth'. 'Google Maps' stellt hierbei einen weiteren Dienst von 'Google' dar, der ab dem Jahr 2005 zur Verfügung steht, womit u.a. die Geländefunktion genutzt werden kann.

\subsubsection{Landschaftliche Gliederung}

Nepal erstreckt sich an der Südabdachung des 2.000 km langen, von Kaschmir im Westen und Burma im Osten ausgebildeten, Himalaja zwischen $26^{\circ} 20^{\prime}$ bis $30^{\circ} 26^{\prime}$ n.B. und $80^{\circ} 4^{\prime}$ bis $88^{\circ}$ 12’ ö.L. (vgl. Hagen, Wahlen, Corti 1960:35; vgl. Joshi 1986:51). Die größte Nordsüdausdehnung beträgt in etwa $230 \mathrm{~km}$, die Westostausdehnung $880 \mathrm{~km}$ (vgl. Joshi 1986:51). Das Land wird in vier Zonen gegliedert: Ost-, Zentral-, West- und Fernwestnepal (ebd.:51), kann aber auch in drei Bereiche der bedeutendsten Flüsse Karnali (zwischen Api und Dhaulagiri), Gandak (zwischen Annapurna-Himal und Langtang-Himal) und Kosi (zwischen Gosainthan und Kangchendzönga) aufgeteilt werden, die allesamt in den Ganges fließen (vgl. Tilman 1952:1 f.). Nepal stellt den zentralen Bereich des $2.700 \mathrm{~km}$ langen Himalaja Bogens zwischen Indus und Brahmaputra dar (hierzu Karte aus Zurick, Pacheco 2007:15, 20 f.). Die westliche Grenze Nepals zu Uttarakhand bilden der Fluss Mahakali / Sharada, das östliche Sikkim und Westbengalen, das südliche Uttar Pradesh im Südwesten (westlich des Flusses Narayani) und Bihar im Südosten (vgl. Joshi 1986:51, 54).

Die nördliche Grenze Nepals ist die autonome Region Tibet, wobei die restlichen angrenzenden Gebiete indische sind (ebd.:51). In Ostnepal bildet die Hauptkette die Grenze zwischen Nepal und Tibet (vgl. Kleinert 1973:10). Hingegen westlich des Längengrades von Kathmandu verläuft diese nördliche Grenze von Nepal nicht entlang der Hauptkette, sondern entlang des Tibetischen Randgebirges (vgl. Hagen, Wahlen, Corti 1960:35).

Nepal ist das gebirgsreichste Land (vgl. Tilman 1952:1) hoher Reliefenergie mit einer Spanne von $35 \mathrm{~m}$ bis zu $8.848 \mathrm{~m}$ (vgl. Joshi 1986:59, 61). Daneben weist es viele natürliche Seen, darunter solche in Karhöhe bei ungefähr 3.500 bis 4.500 m Höhe - im Khumbu auch bis $5.400 \mathrm{~m}$ - auf (ebd.:57). Vier Landschaftstypen lassen sich von Nord nach Süd untergliedern: der Hochhimalaja mit den höchsten Bergen der Erde $(>8.000 \mathrm{~m})$, der Vorderhimalaja in 
Zentralnepal mit Mittelgebirgscharakter (600-2.000 m), die Shiwalikette (bis $4.000 \mathrm{~m}$ ) und die Terai Region mit Tieflandcharakter (75-280 m) (vgl. Statistisches Bundesamt 1993:24). Nepal weist acht Berge höher als 8.000 m auf (vgl. Fort 2004:261). Hagen, Wahlen und Corti (1960:36) gliedern Nepal dagegen in sieben Landschaftseinheiten von Nord nach Süd: das Tibetische Randgebirge, den Inneren Himalaja, den Himalaja, das Nepalische Mittelland, die Mahabharat Lekh, die Siwalik Zone und den Terai, wobei die Mahabharat Lekh im Gegensatz zum Mittelland eine Gebirgskette darstellt. Die Siwalik Zone, das Mahabharat Lekh und das Nepalische Mittelland sind laut Kraus (1966:302) Mittelgebirgslandschaften.

Nördlich vor dem Himalaja gelagert ist, niedriger als dieser, das 5.000 bis ca. $6.000 / 7.000 \mathrm{~m}$ hohe Tibetische Randgebirge bzw. der Transhimalaja, was die Grenze zwischen Hochhimalaja und Tibet und die Hauptwasserscheide zwischen Ganges und Tsangpo darstellt (vgl. Hagen, Wahlen, Corti 1960:35, 40; vgl. Joshi 1986:54). Gebirgspässe zum Tibetischen Plateau sind u.a., von West nach Ost, Takhu, Namja, Mane, Lajing, Thaple, Salbu und Rakhala (vgl. Joshi 1986:54).

Mit dem Inneren Himalaja in etwa - ausgenommen das Thakkhola - 2.400 bis 5.000 m Höhe werden die nördlich der Hauptkette in Westostrichtung verlaufenden Täler Humla, Mugu, Langu, Thakkhola (Kali Gandaki), Manang, Kutang, Kyirong, Rongshar, Khumbu und Karme bezeichnet (vgl. Hagen, Wahlen, Corti 1960:40). Diese sind durch deren besondere Lage weitestgehend vor dem Monsuneinfluss geschützt (vgl. Kleinert 1973:10), können jedoch durch Quertäler vom Monsun erreicht werden (vgl. Miehe 1991:181). „In West- und in Zentralnepal hat das Land Anteil an der Hochebene der Nordhimalayischen Trockenzone, die sich auf der Leeseite des Hohen Himalaya anschließt. “ (Bäumler, Kemp-Oberhettinger, Zech 1996:4).

Nepal weist die größte Anzahl höchster Berge der Welt auf (vgl. Joshi 1986:56). Der in Nordwest-Südostrichtung verlaufende 4.000 bis ca. $8.850 \mathrm{~m}$ hohe Himalaja bzw. die Hauptkette wird durch die Durchbruchstäler, die nördlich derselben entspringen, in multizonale Teilgruppen gegliedert (vgl. Hagen, Wahlen, Corti 1960:39; vgl. Joshi 1986:54; vgl. Miehe 1991:181). Höhenbereiche über 7.000 m bzw. die höchsten Himalaja Ketten zeichnen sich als schmale Linien im Relief ab (vgl. Hagen, Wahlen, Corti 1960:36). Die einzelnen Gebirgszüge trennen verschiedene Bereiche des Inneren Himalaja voneinander ab, welche aber über $5.000 \mathrm{~m}$ hoch liegende Pässe miteinander vernetzt sind (vgl. Kleinert 1973:9). In Nordwestnepal lässt sich hauptsächlich im Humla Nampla-Himal die Api, Saipal und Nampa Gruppe unterscheiden; in Zentralnepal bzw. Dhaulagiri- und Annapurna-Himal 
die Dhaulagiri und Annapurna I-IV Gruppe; im Gorkha-Himal die Manaslu und Himalchuli Gruppe. In den ostnepalischen Gebieten Rolwaling, Khumbu, Khumba Karan und Kangchendzönga-Himal sind die Berge Gauri Shangkar, Cho Oyu, Mt. Everest, Lhotse Gruppe, Makalu und Kangchendzönga die markantesten (vgl. Joshi 1986:54, 56). Bedeutende Durchbruchsflüsse der Hauptkette sind Karnali, Bheri, Kali Gandaki, Marsyandi, Buri Gandaki, Trisuli, Sun Kosi und Arun (vgl. Hagen 1954:325). Die größten Flüsse des Himalaja, wie Indus, Sutley, Ganges und Brahmaputra, westlich und östlich von Nepal, fließen ebenfalls in Durchbruchstälern (hierzu Karten aus Zurick, Pacheco 2007:15, 20 f.). Im Gebiet des Annapurna und des Manaslu bzw. in den Durchbruchstälern finden sich, auf die Horizontaldistanz gesehen, die größten Vertikaldistanzen (vgl. Hagen, Wahlen, Corti 1960:36, 39). Der Kali Gandaki beispielsweise fließt auf 1.200 Höhenmetern zwischen dem $8.078 \mathrm{~m}$ hohen Annapurna und dem $8.172 \mathrm{~m}$ hohen Dhaulagiri (ebd.:39). Dies ist durch den direkten Übergang vom Mittelland zur Hauptkette zu erklären (ebd.:45).

Das von 600 bis 2.000 Höhenmeter zwischen Hochhimalaja und Mahabharat Lekh gelegene Nepalische Mittelland - nach Bäumler, Kemp-Oberhettinger, Zech (1996:4) auch Himalaja Vorketten genannt, die bis auf $4.000 \mathrm{~m}$ reichen und von Nord nach Süd verlaufen - wird stellenweise im Osten und Westen von 3.000 bis $4.000 \mathrm{~m}$ hohen Gebirgszügen durchzogen (vgl. Kleinert 1973:10). Dieses Nepalische Mittelland gliedert sich ebenfalls wegen der Durchbruchstäler in neun Gebiete: Chamlia, Seti, Karnali, Bheri, Kali Gandaki, Trisuli, Sun Kosi, Arun und Tamur (vgl. Hagen, Wahlen, Corti 1960:38). Es nimmt in etwa $30 \%$ der Landesfläche ein und stellt somit die größte Einheit dar (LRMP $1986^{2}$ zitiert nach: Kollmair 1999:22). Die Entwässerung dieses Gebietes erfolgt durch Nordsüd und Westost bzw. Ostwest verlaufende Flusssysteme.

Die nördlich an die Siwalik Zone angrenzende Mahabharat Lekh, eine Gebirgskette bis zu 3.000 m Höhe, weist Querflüsse auf 200 bis 400 Höhenmetern auf, die zur Ganges-Ebene fließen (vgl. Hagen, Wahlen, Corti 1960:38).

Das südlichste Gebirge des Himalaja Systems ist die in Nordwest-Südostrichtung (vgl. Joshi 1986:58) verlaufende Siwalik Zone bis auf durchschnittlich $1.500 \mathrm{~m}$ Höhe - bis maximal $1.200 \mathrm{~m}$ nach ebd.:53, bis maximal $1.500 \mathrm{~m}$ nach Miehe (1991:181), bis maximal $2.000 \mathrm{~m}$ nach Kleinert (1973:9), 300 bis maximal 1.500 m nach Kollmair (1999:22) - mit ausgebildeten Kerbtälern, wobei stellenweise zwischen Siwalik und Mahabharat Lekh breite Dun Täler wie etwa Rapti, Chitawan oder Dang auftreten (vgl. Hagen, Wahlen, Corti 1960:37

\footnotetext{
${ }^{2}$ LRMP (1986a): Summary report. Kenting Earth Sciences Limited, HMG, Gov. of Canada. Kathmandu.
} 
f.). Die Duns werden aufgrund ähnlicher landschaftsökologischer Bedingungen auch 'Innerer Terai' genannt und sind tektonischen Ursprungs (vgl. Kollmair 1999:22). Die landwirtschaftlich geringer nutzbare Siwalik Zone setzt sich aus zwei bis fünf parallelen Gebirgszügen zusammen, zwischen denen auch Duns existieren können (ebd.:22). Das Gebiet zwischen Siwalik und Hohem Himalaja in einem Höhenbereich von 1.000 bis 3.500 m nennt sich Vorderer Himalaja bzw. 'Lesser Himalaya', welches mit dem Bereich des Mahabharat Lekh in Verbindung gebracht werden kann (vgl. Joshi 1986:53 f.). Die Siwalik sind die jüngsten Ketten im Himalaja (vgl. Bäumler, Kemp-Oberhettinger, Zech 1996:4) bzw. Schichtkämme aus Schottern und Sanden (vgl. Miehe 1991:181). Auch Owen et al. (2008:514) gaben die Gliederung, über den Himalaja und Tibet betrachtet von Süd nach Nord, wie folgt an: Siwalik, Lesser Himalaya, Greater Himalaya, Transhimalaya, Nyainqentanggulha Shan, Tanggula Shan, Bayan Har Shan, Kunlun Shan, Qilian Shan und Pamir. Bei Miehe (1991:181) wurden die Siwalik als Vorhügelzone bezeichnet.

Der Terai bzw. das 200 bis 300 m - 70 bis 150 m nach Kollmair (1999:20) und nach Bäumler, Kemp-Oberhettinger, Zech (1996:4), < 100 m nach Kraus (1966:302) - hohe Schwemmland ist in Westnepal schmaler ausgebildet als in Ostnepal (vgl. Joshi 1986:53). Der gering geneigte Hauptwirtschafts- und Siedlungsraum des Terai kennzeichnet den nepalischen Bereich bzw. den nördlichen Bereich der Ganges Tiefebene, nimmt $14 \%$ der Landesfläche ein und stellt den landwirtschaftlich wertvollsten Bereich dar (vgl. Kollmair 1999:20 f.). Im nördlichen Bereich Bharbar befinden sich stärker geneigte quartäre Schwemm- und Schuttfächer (ebd.:22). Bei Miehe (1991:181) wurde dieser Bereich als Schwemmfächerzone des Gebirgsvorlandes beschrieben.

Im Hauptuntersuchungsgebiet treten die Naturräume `Hoher Himalaja' (4.000 bis ca. 8.850 m Höhe), 'Innerer Himalaja' (2.400 bis 5.000 m) und das 'Nepalische Mittelland' (600 bis 2.000 m) in den Vordergrund. Der erstgenannte Naturraum stellt die Hauptkette Everest Lhotse dar, der Innere Himalaja setzt sich südlich fort und das Mittelland schließt sich ungefähr im Bereich von Kharikhola an (hierzu Hagen, Wahlen, Corti 1960:37/Fig. 3).

Im Khumbu ist die Unterscheidung zwischen Innerem Himalaja und Himalaja Südabdachung infolge der nach Süden reichenden Quertäler mit ihrem dort herrschenden abweichenden Wettereinfluss nicht genau möglich, obwohl dieser zum Inneren Himalaja gezählt wird. Nach 
Miehe $(1991)^{3}$ zitiert nach: Bäumler, Kemp-Oberhettinger, Zech (1996:13) sind dort jedoch keine sehr starken Staueffekte des Monsuns bekannt. (vgl. Bäumler, Kemp-Oberhettinger, Zech 1996:13)

\subsubsection{Geologie}

Durch die Kontinentaldrift des indischen Subkontinentes ist das jüngste Kettengebirge, der Himalaja, entstanden (vgl. Hagen, Wahlen, Corti 1960:50, 53). Hierbei kollidierte die indischaustralische mit der eurasischen bzw. chinesischen Platte und es bildete sich eine Subduktionszone (hierzu Karte aus Alexander Pro Atlas:31). Somit stellt dies eine KontinentKontinent-Kollision von Indien und Eurasien dar. Das geschah vor ca. 58,5/60 Mio. Jahren (vgl. DeCelles et al. 2014:845). Der indische Subkontinent war ursprünglich ein Teil von Gondwana, welcher im frühen Mesozoikum auseinanderbrach; seit etwa 84 Mio. Jahren nähert sich Indien Eurasien. Früher driftete diese Platte mit $15 \mathrm{~cm}$, heute bewegt sie sich mit 2 cm pro Jahr nach Norden (Kassens, Wetzel 1989:154 zitiert nach: Kuhle 1991:198). Zwischen den Platten bestand einst das Himalaja Meer (vgl. Hagen, Wahlen, Corti 1960:50), die NeoThetys, ein Paläoozean. Dieses Himalaja Meer wurde als Tibetisches Randgebirge gehoben und in in Ostwestrichtung verlaufende Brüche bzw. Verwerfungen gegliedert (ebd.:50). Das tibetische Plateau entstand vor ca. 50 Mio. Jahren (vgl. Yin, Harrison 2000:261). Horizontale Schübe mit Aufpressen und direkte Hebungsvorgänge waren bedeutend gewesen (vgl. Hagen 1954:325). Danach wurde der nördliche Bereich des indischen Subkontinents gestaucht, gehoben und nach Süden überschoben, wodurch die Urhimalaja Decken entstanden und die Sedimentgebiete nördlich des Tibetischen Randgebirges letztlich zum Tibetischen Plateau angehoben wurden (vgl. Hagen, Wahlen, Corti 1960:51). Zu dieser Zeit war das Tibetische Randgebirge mit 6.000 m Höhe höher als der Urhimalaja, was dazu führte, dass dessen nördliche Gebiete infolge der Klimascheide austrockneten (ebd.:51 f.).

Krustale Überschiebungen führten zur Bildung von Zonen, die die Naturräume Hochhimalaja, 'Lesser Himalaya', Siwalik und Terai voneinander abtrennten. Die heutzutage inaktive 'Main Central Thrust' (MCT) ist mit rund 20 Mio. Jahren die älteste Faltungszone (vgl. Zech et al. 2009:1107). Sie markiert den Übergang der hochgradigen metamorphen `Greater Himalayan Sequence' und der niedrigergradigen 'Lesser Himalayan Sequence' (ebd.:1107). Metasedimentgesteine - hauptsächlich Schiefer, Sandstein, Quarzit und dolomitischer

\footnotetext{
${ }^{3}$ Miehe, G. (1991): Vegetationskarte des Khumbu Himal / Mt. Everest Südabdachung. Erdkunde 45. (S. 80-94)

${ }^{4}$ Kassens, H.; Wetzel, A. (1989): Das Alter des Himalaya. Geol. Dokumente aus dem Indischen Ozean. Die Geowissenschaften, 1/89. (S. 15-20)
} 
Kalkstein - kommen im 'Lesser Himalaya' vor, die durch vorwiegend Gneise des 'Higher Himalaya' überlagert werden (vgl. Fort 1986:105). 50 bis $70 \mathrm{~km}$ weiter südlich befinden sich im Himalaja Vorland nach DeCelles et al. (2001) $)^{5}$ zitiert nach: Zech et al. (2009:1107) die jüngeren 'Main Boundary Thrust' und 'Main Frontal Thrust'. Aktive Faltungszonen befinden sich aber nach Wobus et al. $(2005)^{6}$ zitiert nach: Zech et al. (2009:1107) auch am Fuß des Hohen Himalaja südlich der MCT.

Durch die Hebung des Plateau sollen sich die Flüsse schneller eingeschnitten haben, als der Himalaja angehoben wurde. Alte Querstörungen unterstützten die Ausbildung der Durchbruchstäler, wobei Schuttfächer in der Siwalik Zone auf vormalige Flussmündungen hindeuten (vgl. Hagen, Wahlen, Corti 1960:52 f.). Antezedente Durchbruchstäler sind im Kosi System Arun, Tama und Bhota sowie im Gandaki System Trishuli, Burhi, Marsyandi und Kali (vgl. Joshi 1986:58). Der Himalaja entstand durch fortwährende plattentektonische Bewegungen, wodurch im Inneren Himalaja Stauseen entstanden (vgl. Hagen, Wahlen, Corti 1960:52 f.). In einer weiteren Phase sanken Bereiche des Himalaja ein: es entstanden das Mahabharat Gebirge und das Nepalische Mittelland, wodurch es zur Aufstauung von Seen (z.B. Kathmandu See) sowie zur Bildung der Hauptflüsse Karnali, Narayani und Sapt Kosi entlang geologischer Schwächezonen des Mahabharat Gebirges kam (ebd.:53). Tektonische Hebungen der Mahabharat Lekh von ca. 200 m folgten seit etwa 200.000 Jahren, als auch der Kathmandu See verlandete (ebd.:53). Der Bereich der Siwalik Zone kennzeichnet die letzte markante Hebungsphase des Himalaja (vgl. Joshi 1986:53), wobei diese letzte Phase ins Pliozän fiel (vgl. Hagen 1954:325). Aktuell wird infolge der fortwährenden Plattenbewegung der Himalaja weiterhin gehoben. ,Wenn man modellhaft voraussetzt, daß die Hebung über die letzten Jahrtausende konstant geblieben ist, haben sich die asiatischen Hochgebirge während des Postglazials, also seit 10000 Jahren, um maximal 20-100 m gehoben." (Iturrizaga 1999:49).

Nepal gliedert sich geologisch: in vier bis fünf Kathmandu Decken (südliche Grenze ist Mahabharat Lekh), in die Zone des Himalchuli (nur in Westnepal), in fünf Piuthan Decken (nur in Westnepal), in sechs Nawakot Decken (in Zentralnepal am besten entwickelt) und in die Zone von Pokhara (am tiefsten). Die Kathmandu Decken bestehen aus Granitintrusionen und metamorphierten Nebengesteinen (Hagen $1952^{7}$ zitiert nach: Hagen 1954:326) und

\footnotetext{
${ }^{5}$ DeCelles, P.G.; Robinson, D.M.; Quade, J.; Ojha, T.P.; Garzione, C.N.; Copeland, P.; Upreti, B.N. (2001): Stratigraphy, structure, and tectonic evolution of the Himalayan fold-thrust belt in western Nepal. In: Tectonics 20. (S. 487-509)

${ }^{6}$ Wobus, C.; Heimsath, A.; Whipple, K.; Hodges, K. (2005): Active out-of-sequence thrust faulting in the central Nepalese Himalaya. In: Nature 434. (S. 1008-1011)

${ }^{7}$ Hagen, T. (1952): Flug eines Geologen über Nepal. Atlantis, Märzheft 1952.
} 
werden nördlich von der südlich verfalteten und verschuppten Tibet Zone begrenzt. Somit liegen die Bereiche der Hauptkette in den Wurzelzonen der Kathmandu Decken, , [...], die in einer relativ späten Phase horizontaler Zusammenschübe in die Höhe gepreßt worden sind. “ (Hagen 1954:331). (vgl. Hagen 1954:326- 327, 329- 331)

Die Himalaja Kette gliedert sich in einzelne Schubbögen: Kanjiroba, Saipal, Dhaulagiri, Annapurna, Manaslu, Ganesh, Langtang, Gaurisankar und Everest (ebd.:327). Im Hauptuntersuchungsgebiet Solukhumbu treten die Naturräume 'Hoher Himalaja' (4.000 bis ca. 8.850 m Höhe), 'Innerer Himalaja' (2.400 bis 5.000 m) und das 'Nepalische Mittelland' $(600$ bis $2.000 \mathrm{~m})$ in den Vordergrund. Erstgenannter Himalaja Naturraum stellt die Hauptkette Everest Makalu, der Innere Himalaja setzt sich südlich fort und letztgenanntes Mittelland schließt ungefähr im Bereich von Kharikhola an (hierzu Hagen, Wahlen, Corti 1960:37/Fig. 3). Die Täler des Inneren Himalaja konnten sich hauptsächlich in Westoststreichrichtung durch fluviale Prozesse in den weichen Sedimenten zwischen der Hauptkette, aus Gneisen bestehend, und des Tibetischen Randgebirges, aus Granit bestehend, bilden (ebd.:40). Das Tal Thakkhola verläuft im Gegensatz dazu von Nord nach Süd, da dort ein transversaler geologischer Einbruchsgraben besteht (ebd.:40). Die sog. Durchbruchstäler sind unterschiedlich erklärbar: entweder bestand das Gewässernetz schon vor der Hebung des Himalaja oder sie sind durch rückschreitende Erosion bzw. durch Anzapfen tibetischer Flüsse vom Süden her im Nachhinein entstanden (vgl. Hagen 1954:325). Laut Odell (1925) ${ }^{8}$ zitiert nach: Hagen (1954:325) z.B. hob sich der Tibetische Plateaurand infolge des Abtauens eines vorzeitlichen Eisschildes im oberen Aruntal durch Isostasie und ließ das Durchbruchstal entstehen.

Das Mittelland ist das Übergangsgebiet zwischen Hauptrandstörung und zentraler Hauptüberschiebung (LRMP $1986^{9}$ zitiert nach: Kollmair 1999:22). Die Mahabharat Lekh besteht aus kristallinen Gesteinen, darunter Granit (vgl. Hagen, Wahlen, Corti 1960:38). Die Siwalik Zone ist eine Molasse Zone von harten und weichen Schichten, wodurch sich eine Schichtrippenlandschaft ausgebildet hat (ebd.:37). Der Bereich der Siwalik Zone stellt Molasse am Rand der Ganges Ebene dar (vgl. Hagen 1954:327). Die Siwalik Zone ist das jüngste Himalaja Glied und besteht aus gefalteten pliozänen bis altpleistozänen Ablagerungen aus dem Hochgebirge, wie Sandsteinen und Konglomeraten (vgl. Kollmair 1999:22). Die Bereiche der Duns bestehen aus alluvialen und lakustrinen Sedimenten, woraus sich

\footnotetext{
${ }^{8}$ Odell (1925): Geogr. Journal 66.

${ }^{9}$ siehe Quelle LRMP 1986a in der Fußnote
} 
landwirtschaftlich wertvolle Böden entwickelten (ebd.:22). Der Terai besteht aus $7.500 \mathrm{~m}$ mächtigen pleisto- bis holozänen Sedimenten (LRMP 1986a ${ }^{10}$ zitiert nach: Kollmair 1999:20).

\subsubsection{Klima}

Für das Klima von Nepal sind die Faktoren geographische Breite, Höhenlage, Monsun und Exposition ausschlaggebend. Nepal umfasst infolge der enormen Höhenunterschiede vom Terai bis zur Hauptkette nahezu alle Klimazonen der Erde - tropisch bis arktisch (vgl. Hagen, Wahlen, Corti 1960:47; vgl. Kleinert 1973:13 f.). Demgegenüber liegen die nördlich angrenzenden alpinen Steppen des Tibetischen Plateau auf etwa 5.000 m Höhe (vgl. Miehe 1991:181). Das Klima ist demnach nicht einheitlich gestaltet, wobei die Temperaturen im Jahr in den niedrigeren Gebieten bis zum Mittelland ausgeglichener sind - wie z.B. Kathmandu mit $10{ }^{\circ} \mathrm{C}$ Januarmitteltemperatur und $25^{\circ} \mathrm{C}$ Julimitteltemperatur zeigt (vgl. Hagen, Wahlen, Corti 1960:41). In höheren Lagen herrschen jahreszeitliche Unterschiede (ebd.:41). Das Klima von Nepal wird somit - aufgrund der enormen Höhe, Lage bzw. lokalem Relief, Streichrichtung, Klimazone, Wind sowie Luv- und Leeeffekt (ebd.:40; vgl. Joshi 1986:59) von der absoluten und relativen Höhe (vgl. Kraus 1966:311) und vom Monsun bestimmt (vgl. Statistisches Bundesamt 1993:24). Ohne diese höhenbedingte Klimaverschiebung wäre Nepal der tropisch-subtropischen Zone zuzuordnen (vgl. Hagen, Wahlen, Corti 1960:35). Die Jahresdurchschnittstemperatur von Nepal auf $1.000 \mathrm{~m}$ Höhe beträgt in etwa $20^{\circ} \mathrm{C}$ und ändert sich pro $100 \mathrm{~m}$ um $0,6{ }^{\circ} \mathrm{C}$ (vgl. Kollmair 1999:39). In Nepal (z.B. Kathmandu, Jiri) zeigen die Temperaturen um den Monat Juli herum ein Maximum, da schon im März Konvektionsprozesse zunehmen (vgl. Kraus 1966:313). Tägliche Temperaturschwankungen, vor allen Dingen in Tallagen, sind im Gegensatz zum mitteleuropäischen Raum im Sommer viel geringer als im Winter, wobei Temperaturmaxima während des Sommermonsuns vormittags erreicht werden (ebd.:313, $316 \mathrm{f}$.).

Für den Himalaja lassen sich zwei Humiditätsklassen beschreiben: die Himalaja Südabdachung mit bis auf maximal 3.600 m Höhe reichenden enormen Sommerregen und der Innere Himalaja mit deutlich abgeschwächten Sommerregen, wobei zwischen 3.000 und 3.600 / 3.900 m Höhe die meisten Niederschläge - über $4.000 \mathrm{~mm} / \mathrm{Jahr}$ - fallen (vgl. Miehe 1990:376). Der südliche Teil Nepals hat hauptsächlich ein warm-humides Klima, einige Bereiche dort sind jedoch kalt-humid (vgl. Joshi 1986:59). Speziell der Terai hat ein monsunal-subtropisches Klima mit sommerlicher Regenzeit und winterlicher Trockenzeit

\footnotetext{
${ }^{10}$ LRMP (1986b): Geology report. Kenting Earth Scienes Limited, HMG, Gov. of Canada. Kathmandu.
} 
unter ganzjährig frostfreien Bedingungen (vgl. Kollmair 1999:21). Laut der Klimaklassifikation nach Köppen zählt der Terai zum Cwa-Klima (warmgemäßigt, im Winter Trockenzeit, heißer Sommer - höchstes Monatsmittel über $22{ }^{\circ} \mathrm{C}$ ); die Siwalik Zone, das Mahabharat Lekh und Nepalische Mittelland hingegen bis etwa 3.300 m Höhe zum CwbKlima (höchstes Monatsmittel unter $22{ }^{\circ} \mathrm{C}$ ), Täler in diesem Bereich jedoch zum Cwa-Klima ohne Trockenklima (vgl. Kraus 1966:319 f.). Bis auf eine Höhe von $1.800 \mathrm{~m}$ ist das Klima subtropisch, bis auf 4.000 m gemäßigt bzw. über etwa $3.500 \mathrm{~m}$ sub-alpin (vgl. Joshi 1986:61). Somit folgen sub-alpine und alpine Zonen, wobei über $4.500 \mathrm{~m}$ Höhe kalt-arides Klima vorherrscht (ebd.:59). Zu der Eisklimate gehören die höchsten Gebiete mit allen Monatsmitteln unter $10{ }^{\circ} \mathrm{C}$ (vgl. Kraus 1966:320). Das Tal des Chenab bildet beispielsweise den Übergang vom monsunfeuchten Äußeren Himalaja zur trockenen alpinen Steppe des Tibetischen Plateau - das Kali Gandaki zeigt den deutlichsten Übergang (vgl. Schweinfurth 1957:149), wobei das Tal der Ganga einen dreiteiligen Übergang zwischen monsunfeuchtem Äußeren Himalaja, mäßig feuchtem Inneren Himalaja (hauptsächlich Niederschläge im Winter) und dem Tibetischen Himalaja (vgl. Schweinfurth 1956:298) darstellt. Der nordwestliche Bereich von Nepal ist gemäßigter als die östlichen Bereiche (vgl. Joshi 1986:52). Nach Miehe (1990:9, 13) existiert die tropische Talstufe in der Himalaja Südabdachung bis auf $1.200 \mathrm{~m}$ Höhe, die subtropische Kammlage in der Himalaja Südabdachung bis auf $2.000 \mathrm{~m}$ und die subtropische Talstufe im Bereich des Himalaja Hauptkammes bis auf 2.200 m, wobei die Kammlage der oberen Montanstufe in der Himalaja Südabdachung und die Hochtalböden im Inneren Himalaja folgen. Steigungsregenlagen bilden sich bei den Gebirgszügen Siwalik, Mahabharat Lekh und Himalaja Hauptkette (vgl. Miehe 1991:181). In den Leelagen existieren dann trockenadiabatisch absteigende Luftmassen, Föhn genannt (ebd.:184).

Der Himalaja ist eine wichtige Klimascheide. Die Täler des Inneren Himalaja stellen eine Übergangszone zwischen indischem Monsungebiet und trockenem Plateau dar (vgl. Hagen, Wahlen, Corti 1960:40). Auf der Luvseite des Himalaja treten orographische Niederschläge und in Berg- und Hanglagen Konvektionsniederschläge auf, wobei letztgenannte schon im Frühjahr einsetzen und dadurch im Gebirge das Einsetzen des Monsuns verschleiern (vgl. Kraus 1966:304). Im Mittelland und zum Teil im Himalaja und im Inneren Himalaja existieren tiefe wüstenähnliche Trockentäler, die durch trockene Fallwinde infolge der stärkeren Erwärmung der umgebenden Gratverläufe, vor allen Dingen im Karnali Tal in Westnepal ausgeprägt, gegenüber den feuchten Talhängen abgegrenzt werden können (ebd.:44 f.). Schweinfurth (1956:299) beschrieb, dass die Trockentäler am deutlichsten im 
feuchten Ostnepal auftreten. Dieses Phänomen spiegelt sich auch in der Vegetationsbedeckung wieder (vgl. Hagen, Wahlen, Corti 1960:44 f.). Am Tage bis Dunkelheitseinbruch bestehen Talwinde und Hangaufwinde, was an den Hängen zur Konvektionsbewölkung und über der Talmitte zu keinerlei Wolkenbildung führt (vgl. Schweinfurth 1956:299). An den Hängen herrscht somit ununterbrochen hohe Luftfeuchtigkeit, wobei es im Talsohlenbereich kaum regnet (ebd.:299). Teile des Hangaufwindes ändern ihre Richtung zum Tal hin, was zu einer Abwärtswindbewegung über der Talmitte und zur Austrocknung führt (ebd.:299). Je stärker die Hangaufwinde sind, desto stärker ist auch der Effekt der Austrocknung der Talsohle (ebd.:299). Bei niedrigen Hängen kann Luft auch darüber hinweg strömen (Troll 1952:140 f. ${ }^{11}$ zitiert nach: Schweinfurth 1956:299). In der Nacht drehen sich die Verhältnisse aber nur sehr schwach zu Bergwinden und Hangabwinden um (vgl. Lüdecke 1983:21).

Auf der Südseite des Himalaja sind Jahresniederschläge bis $6.000 \mathrm{~mm}$ möglich (vgl. Miehe 1991:184) bzw. über 6.000 mm (Ort Lumle), im Regenschatten des Inneren Himalaja sind dagegen $270 \mathrm{~mm}$ Jahresniederschläge bekannt (Ort Jomosom, oberes Kali Gandaki) (vgl. Kleinert 1973:11). Das Niederschlagsmaximum des Himalaja bei 2.000 bis $2.500 \mathrm{~m}$ Höhe fällt in den Monat Juli mit ausgeprägten Ostwinden, wobei im Winter Westwinde herrschen und die Schneegrenze infolge des Staueffekts bei $4.600 \mathrm{~m}$ liegt (vgl. Lüdecke 1983:18). Durch Monsun und Schneeschmelze können die großen Flüsse Nepals bis zum 60-fachen des Niederwasserstandes ansteigen (vgl. Hagen, Wahlen, Corti 1960:43). Allgemein werden Jahresniederschläge im Regenschatten des Hohen Himalaja von < 200 mm angenommen (vgl. Soliva 2002:77). Das Mittelland und der Hochhimalaja sind ebenfalls niederschlagsarme Leegebiete - beispielsweise beim Khumbu Gletscher von April bis November nur $39 \mathrm{~cm}$ (in etwa auch die Jahressumme) Niederschlagsmenge gegenüber $166 \mathrm{~cm} 40 \mathrm{~km}$ südlich im Dudh Khosi Tal (vgl. Hagen, Wahlen, Corti 1960:44). Dadurch und infolge des Reliefs - viele Steilwände, keine großen Firnbecken - sind die hauptsächlich lawinenernährten Gletscher dort weniger bedeutend ausgebildet (ebd.:45).

Im Frühjahr existiert ein heißer trockener Wind aus Westindien, wobei dadurch höhere Temperaturen im Terai herrschen. Mitte Juni weht der Sommermonsun aus Südost, der gen Westen Nepals an Einfluss abnimmt und bis September $90 \%$ des Niederschlages darstellt. Von Oktober bis Februar ist ein trockener kalter Wind von Nordwesten zu verzeichnen. Für

\footnotetext{
${ }^{11}$ Troll, C. (1952): Die Lokalwinde der Tropengebirge und ihr Einfluß auf Niederschlag und Vegetation (Studien zur Vegetations- und Landschaftskunde der Tropen III). Bonner Geogr. Abh., H. 9. (S. 124-182)
} 
Nepal ergibt sich eine Niederschlagsveränderung von Ost nach West und mit der Höhe. Bis auf eine Höhe von ca. 3.500 m nehmen die Jahresniederschläge zu - in der Nebelwaldstufe Niederschläge bis $4.000 \mathrm{~mm}$, und oberhalb nach Müller (1958) ${ }^{12}$ und Miehe (1991) ${ }^{13}$ zitiert nach: Bäumler, Kemp-Oberhettinger, Zech (1996) ab. Beim Mt. Everest Basislager in 5.300 m Höhe sind nur noch 400 mm Jahresniederschläge zu verzeichnen. (vgl. Bäumler, KempOberhettinger, Zech 1996:4 f.)

Im Winter treten in Nepal von Westen stammende Niederschläge auf, da dort Tiefdruckgebiete über dem Meer ausgebildet sind. Die westlichen Strahlströme sind im Gebiet 25 bis $45^{\circ}$ geographischer Breite in rund $10 \mathrm{~km}$ Höhe am stärksten ausgebildet, wobei Hochasien ein Hindernis für diese Ströme darstellt (vgl. Flohn 1958:304).

Nepal ist durch die Monsunzirkulation mit Ostwinden während des Sommers und Westwinden im Zeitraum von Oktober bis Mai charakterisiert (vgl. Kraus 1966:301). Dagegen ist das nordwestliche Himalaja Gebiet und der Karakorum vorwiegend durch Westwinde bestimmt, wodurch die Niederschläge dort von Dezember bis Mai bedeutend sind (ebd.:306). Nach Lüdecke (1983:21) weht an den Gipfeln oberhalb $8.000 \mathrm{~m}$ der Westjetstream schon von Oktober mit einer Beaufort-Windstärke von neun bis elf. In den vier bis fünf Monsunmonaten des Sommers, ungefähr Juni bis September (vgl. Kleinert 1973:15), wird das Tibetische Plateau infolge der enormen Höhe und der reinen dünnen bzw. dunst- und wolkenleeren Luft sehr stark durch solare Strahlung aufgeheizt (vgl. Hagen, Wahlen, Corti 1960:41). Im Mittel sind dies 5 bis $8{ }^{\circ} \mathrm{C}$ Erwärmung, wodurch die höchsten Atmosphärentemperaturen in dieser Höhe entstehen (vgl. Flohn 1958:304) und die größte Wärmequelle der Atmosphäre entsteht (vgl. Lüdecke 1983:17). Es bildet sich ein Unterdruck, der dazu führt, dass Luft aus den Nachbarregionen, wie z.B. aus der indischen Ebene, angezogen wird, wobei speziell in Nepal dann feuchte Südwinde aus der Richtung des Indischen Ozeans vorherrschen (vgl. Hagen, Wahlen, Corti 1960:41). Die Innertropische Konvergenzzone mit deren verbundenen Windgürteln des subtropischen Strahlstroms im Norden und den Ostwinden im Süden wandert mit dem Sonnenstand nach Norden (vgl. Flohn 1958:304 f.). Im Juli verlagert sie sich über Indien bis $25^{\circ}$ n.B., wodurch sich die Südostwinde über der Gangesebene und die Südwestwinde über dem Arabischen Meer erklären lassen (vgl. Kraus 1966:303). Durch das Abkühlen der Luftmassen über den Gebirgsketten des Himalaja bilden sich Wolken, die dann abregnen (vgl. Hagen, Wahlen,

\footnotetext{
12 in der vorliegenden Arbeit unter Müller (1959) aufgeführt

${ }^{13}$ siehe Quelle Miehe (1991) in der Fußnote
} 
Corti 1960:41). „Demzufolge spielt die Konvektion an den Talhängen eine wichtige Rolle für die räumliche Niederschlagsverteilung. “ (Dittmann 1970:58). Der indische Sommermonsun ist somit ein jahreszeitlicher Südost- bis Südwestwind, der im Sommer, vor allen Dingen während der Nacht, reichlich Niederschläge bringt, da der Himalaja eine einseitige Wetterscheide ist (vgl. Hagen, Wahlen, Corti 1960:41-43). Dies ist z.B. in Zentralnepal mit 1.500-2.000 mm von Mai bis September der Fall (vgl. Statistisches Bundesamt 1993:24); nach Miehe (1991:184) im Zentralhimlaja ab Juni bis Mitte September, wobei es im August zu einer kurzen Trockenzeit kommen kann. In Nepal und Nordindien herrschen vor allen Dingen Ostwinde, in den untersten Luftschichten eher Südostwinde vor (vgl. Kraus 1966:303). Im gesamten Nepal sind besonders südlich des Himalaja Hauptkammes die Monate Juli und August die regenreichsten (vgl. Dittmann 1970:53); es fallen 75-80 \% des Gesamtniederschlages zwischen Juni und September (vgl. Soliva 2002:77). Nördlich des Hauptkammes bzw. in West- und Zentralnepal tritt im Frühjahr gegenüber Ostnepal ein weiteres Niederschlagsmaximum auf, welches in Zentralnepal südlich der Hauptgipfel noch angedeutet sein kann (vgl. Dittmann 1970:53 f.). Im Süden von Nepal können ungefähr 1.000 bis $2.000 \mathrm{~mm}$, im Nordosten und im Zentrum des Hohen Himalaja ca. $3.000 \mathrm{~mm}$ sowie über $4.500 \mathrm{~m}$ Höhe ca. 2.000 bis $3.000 \mathrm{~mm}$ Niederschlagsmenge angenommen werden (vgl. Joshi 1986:59 f.). In Südostnepal treten die Niederschläge mit durchschnittlich $400 \mathrm{~mm}$ hauptsächlich im Juli bis August auf, wobei sie von November bis April die geringsten Werte unter $50 \mathrm{~mm}$ annehmen (vgl. Dittmann 1970:47 f., Abb. 2). Im Zeitraum der Übergangsmonate Mai und Oktober fallen mit über $75 \mathrm{~mm}$ jedoch immer noch mehr Niederschläge als in Mitteleuropa (ebd.:48, Abb. 2). Konvektionsprozesse ermöglichen im östlichen Nepalischen Mittelland gegenüber der Gangesebene höhere Niederschläge von März bis Mai, wodurch auch ein vorgerücktes Maximum der Niederschläge in den Monat Juni gegenüber dem im Juni einsetzenden indischen Monsun erklärt werden kann (ebd.:51; Kraus $1967^{14}$ zitiert nach: Dittmann 1970:51). Vormonsunale konvektive Niederschläge können laut obigen Ausführungen also auftreten (hierzu Kraus 1966:301), Monsunpausen bzw. Trockenperioden im Juli und August demgegenüber auch (vgl. Dittmann 1970:51 f., Tab. 4).

Ende Mai / Anfang Juni erreichen die Monsunniederschläge den Terai, wobei diese schon im April durch Aufwinde mit daraus entwickelten Gewittern z.B. südlich der Mahabharat Lekh und des Hochhimalaja einsetzen können (vgl. Hagen, Wahlen, Corti 1960:42). In Zentralnepal reicht der Monsun von Anfang Juni bis Ende September (ebd.:43). Im Bereich des Mt.

\footnotetext{
${ }^{14}$ Kraus, H. (1967): Das Klima von Nepal. Khumbu Himal, Liefg. 4. (S. 301-321)
} 
Everest kann das Einsetzen des Sommermonsuns durch das Abnehmen der Westwindstärke sowie das Umkehren in Ostwinde mit zeitweise schwachen Westwinden und anhand der steigenden Dauer und Intensität der Niederschläge festgestellt werden (vgl. Kraus 1966:305 f.). Die nordindische Tiefebene wird gegenüber Nepal vollständig vom indischen Sommermonsun beeinflusst (vgl. Dittmann 1970:59). In Indien setzt der Monsun zuerst im Süden und Westen ein, wobei der Nordwesten und Pakistan erst später beeinflusst werden und der Monsun dort bis in den Juli hineinreichen kann (vgl. Kraus 1966:304).

In Nepal nimmt der Einfluss des Monsuns von Süden nach Norden unter Betrachtung der Gebiete Terai, Mittelland und Innerer Himalaja - also mit Einbezug von den Leegebieten ab, von West- nach Ostnepal gesehen jedoch zu (vgl. Kleinert 1973:11, 13). Erstgenannte Abnahme tritt jedoch in Westnepal aufgrund der geringeren Gebirgshöhe von Saipel nach Kanjiroba-Himal nicht so ausgeprägt auf; die Niederschläge sind eher gleichmäßiger verteilt (ebd.:13). Prinzipiell nehmen die Niederschläge aber mit zunehmender Höhe zu, wobei auf ca. 3.000-3.500 m Höhe ein Jahresniederschlagsmaximum von 5.000 mm auf der Luvseite des Hohen Himalaja zu verzeichnen ist (vgl. Soliva 2002:77). Auch sollen sie im Süden höher als im Norden sein (vgl. Lüdecke 1983:20). Die Station Walung Chung in Ostnepal zeigte einen Jahresniederschlag von $1.700 \mathrm{~mm}$ an (vgl. Kleinert 1973:13). In Ostnepal tritt der Monsun somit länger und heftiger auf (vgl. Hagen, Wahlen, Corti 1960:43) und reicht dort am weitesten nach Tibet hinein (vgl. Kleinert 1973:13). Im Sommer fällt in Ostnepal 2/3 mehr Niederschlag, wobei die Grenze bei ca. $78^{\circ}$ ö.L. liegt; im Herbst verringert sich der Unterschied (vgl. Lüdecke 1983:20). In Westnepal setzt der Monsun etwa zwei Wochen später ein (vgl. Soliva 2002:77). Der in Ostnepal von Sikkim kommende, nach Assam und nach Westen geleitete Sommermonsun setzt aufgrund der Nähe zum Golf von Bengalen eher ein und klingt später ab (vgl. Hagen, Wahlen, Corti 1960:44; vgl. Kleinert 1973:13). Der Westhimalaja weist jedoch infolge der Westwindzirkulation in den Wintermonaten mehr Niederschläge als Ostnepal auf (vgl. Joshi 1986:52). Der Monsunbereich grenzt sich im Norden von regenfeuchten Gebirgswäldern schlagartig durch Vegetationsänderung zu Steppen bzw. Wüsten ab, wobei o.g. Bereich in den Durchbruchstälern weiter nach Norden reicht, weshalb der Innere Himalaja stellenweise auch unter dem Einfluss des Monsuns steht (vgl. Hagen, Wahlen, Corti 1960:45). Selbst die Talhänge des trockensten Gebietes von Nepal - das obere Kali Gandaki Tal - und Tibet liegen unter einem sehr geringen Monsuneinfluss (vgl. Kleinert 1973:14 f.). 
Der Sommermonsun kann auch Schwankungen ausgesetzt sein oder zwischenzeitlich zwei Wochen in Nord- und Zentralindien aussetzen, wenn sich die ITC zu weit nach Norden verlagert - aus den Ostwinden über der Ganges Tiefebene und der Südabdachung des Himalaja werden Westwinde und die Niederschläge bleiben aus. Für Nepal kann jedoch ein Aussetzen des Monsuns in Indien verstärkte Niederschläge bedeuten. (vgl. Kraus 1966:305)

Im September bis November zieht sich der Sommermonsun zurück, wobei Oktober den Übergangsmonat vom Sommer- zum Wintermonsun darstellt (ebd.:305, 316). Acht Monate, von Oktober bis Mai (vgl. Kleinert 1973:15), drehen sich die Verhältnisse im Winterhalbjahr um, wodurch sich über dem wärmeren Indischen Ozean ein Tiefdruckgebiet ausbildet und die schwere abgekühlte trockene Luft des Himalaja nach Süden strömt (vgl. Hagen, Wahlen, Corti 1960:41). Hochasien stellt im Winter infolge seiner Höhe und der dadurch folgenden stärkeren Abkühlung eine Kältequelle dar (vgl. Flohn 1958:305), wodurch der indische Nordostmonsun entsteht (vgl. Kraus 1966:303). Dieser Wintermonsun bringt nur kurzfristige Niederschläge - in Zentralnepal z.B. Ende Dezember / Anfang Januar, wobei die Winterschneedecke in Ostnepal bis auf ca. 2.800 Höhenmeter und in Westnepal bis auf etwa 2.000 m Höhe reicht (vgl. Hagen, Wahlen, Corti 1960:44). Diese Niederschläge können zu enormen Tagessummen - wie im März 1963 in Chukhung: in 30 Stunden $32 \mathrm{~mm}$ - führen (vgl. Kraus 1966:311). Die Westwinde überwehen aber die Nordostwinde, sodass Westwinde nördlich und Ostwinde südlich von ca. $20-15^{\circ}$ n.B. existieren (ebd.:303). Demnach herrschen im Winter in Nepal Westwinde und in Südindien Ostwinde vor (ebd.:304).

Die Trockenzeit kann vor allem in Gebieten enormer Reliefenergie durch Niederschläge im Januar (vgl. Hagen, Wahlen, Corti 1960:35) und ab Ende März (vgl. Kleinert 1973:15) durchbrochen werden. Im Nordwesthimalaja werden im Winter durch den Westwindzoneneinfluss Niederschlagsmaxima verzeichnet (vgl. Lüdecke 1983:20). Die Winterniederschläge nehmen von Nordosten des Himalaja nach Südosten ab (vgl. Miehe 1991:184).

\subsubsection{Rezente Vergletscherung}

Laut Hagen, Wahlen, Corti (1960:45) befanden sich die meisten Gletscher in Nepal im Rückzug, jedoch existierten auch solche, die alte vegetationsbedeckte Moränen überfuhren, wie z.B. nördlich des Manaslu. Auch aktuell sind die Gletscher in Nepal - Shorong, Khumbu, Langtang, Dhaulagiri und Kangchenjunga - aufgrund der steigenden Temperaturen mit bis zu 
0,06 ${ }^{\circ} \mathrm{C}$ pro Jahr weiterhin im Rückzug (vgl. Shrestha, Aryal 2011:65, 75, Fig. 5). Auf der Südseite des Himalaja müsste infolge der höheren Niederschläge eine bedeutendere Vergletscherung existieren als auf der Nordseite, jedoch erlauben die steilen Wände eine solche Vergletscherung nicht (vgl. Hagen, Wahlen, Corti 1960:45). Auf der Nordseite können infolge der größeren Flächen trotz Niederschlagsarmut zwischen 3.500 und $5.000 \mathrm{~m}$ lange Talgletscher entstehen (ebd.:45). Die längsten Gletscher finden sich aber aufgrund hoher Niederschläge und günstigem Relief in Ostnepal (ebd.:46). Dort reichen die Gletscher bis auf durchschnittlich $4.500 \mathrm{~m}$ Höhe hinab (Vohra $1981^{15}$ zitiert nach: Joshi 1986:56). Das Tibetische Randgebirge ist heute nur gering vergletschert (vgl. Kleinert 1973:10).

Generell liegt die Schneegrenze Hochasiens - mit Ausnahme des Karakorums und des Pamirs sowie einiger Massive im Tienshan und im Himalaja - in Nähe der Gipfel (vgl. Kuhle, Roesrath 1990:145). Im Zentralhimalaja ist die ungefähre Höhe der klimatischen Schneegrenze $5.400 \mathrm{~m}$ (ebd.:35).

Die heutige Schneegrenze steigt in Asien von Norden nach Süden und von den ozeanischen zu den kontinentalen sowie zum Inneren des Tibetischen Hochlandes bzw. zu den Massenerhebungsbereichen an. Im Himalaja erheben sich die Schneegrenzflächen von Süd nach Nord. Die Hochsommer- und nicht die Jahrestemperatur, aber auch die Niederschlagsverhältnisse werden als Faktoren zur Schneegrenzhöhenlage gesehen, wobei an den Luvseiten von Gebirgen in schneereichen Gebieten (z.B. südliche und westliche Randgebirge) primär die Niederschläge gegenüber den Temperaturen für die Schneegrenzlage bedeutend sind. Schneearme Gebiete sind beispielsweise Nord- und Zentralasien. Winterliche Niederschläge spielen für die Schneegrenzlage eine bedeutende Rolle. Expositionsunterschiede sind im Bereich von 30 bis $40^{\circ}$ Breite am stärksten ausgebildet, sodass, wenn Sonnen- und Trockenseite zusammenfallen, die Schneegrenze auf der Südseite durchschnittlich 300-400 m weiter nach oben reichen kann als auf der Nordseite. Ist es aber der Fall, dass Sonn- und Regenseite zusammenfallen, kann dies dazu führen, dass die Schneegrenze auf der Luvseite niedrigere Werte als die auf der Leeseite aufweist - z.B. Karakorum, Zentral- und Westkaukasus. (vgl. Wehlmann 1955:2-4)

\footnotetext{
${ }^{15}$ Vohra, C.P. (1981): Himalayan Glaciers, in the Himalaya, (Ed. J.S. Lall), Calcutta.
} 


\subsection{Hauptuntersuchungsgebiet Solukhumbu}

\subsubsection{Lage und naturräumliche Gegebenheiten}

Das ausgewählte Hauptuntersuchungsgebiet des Khumbu und Solu liegt in Südasien bzw. in Ostnepal, genauer betrachtet in einer der fünf Entwicklungsregionen namens 'Ost-Region', in der Verwaltungszone 'Sagarmatha', und dort im nördlichsten Distrikt, dem 'Solukhumbu' (siehe Karte II, Bildband). Dieser gliedert sich weiterhin in unterste Verwaltungsebenen bzw. Gemeinden auf; in beispielsweise Namche, Khumjung, Chaunrikharka, Chheskam, Takasindu, Jubing, Bung, Beni, Basa, Baku, Mabe u.s.w.. Der Solukhumbu grenzt im Norden an China; im Süden an die nepalesischen Distrikte Okhaldhunga und Khotang (Verwaltungszone Sagarmatha, Entwicklungszone Ost), im Westen an Dolkha und Ramachhan (Verwaltungszone Janakpur, Entwicklungsregion Mitte) und im Osten an Sankhuwasabha und Bhojpur (Verwaltungszone Kosi, Entwicklungszone Ost). In Ostnepal trennt demnach die Himalaja Hauptkette (Mt. Everest, Makalu und Kangchendzönga) Tibet von Nepal (vgl. Hagen, Wahlen, Corti 1960:35). Die äußeren Grenzen des Solukhumbu bilden die etwaigen Koordinaten aus Google Earth: im Norden $28^{\circ} 6.399^{\prime}$ n.B.; im Süden $27^{\circ}$ 19.399' n.B.; im Westen $86^{\circ} 21.764^{\prime}$ ö.L. und im Osten $87^{\circ} 2.866^{\prime}$ ö.L.. Die in Google Earth über die Linealfunktion bestimmte maximale Nordsüdausdehnung beträgt ca. $87 \mathrm{~km}$ und die maximale Westostausdehnung ca. $66 \mathrm{~km}$. Laut Statistik ist das Gebiet insgesamt etwa 3.312 $\mathrm{km}^{2}$ groß. Nepal hingegen weist eine Fläche von $147.181 \mathrm{~km}^{2}$ auf (vgl. Auswärtiges Amt 2013), was weniger als der halben Fläche von Deutschland entspricht. Die niedrigsten Bereiche des Solukhumbu liegen bei ca. $530 \mathrm{~m} / \mathrm{GE}$, den höchsten Punkt stellt der Mt. Everest mit etwa $8.848 \mathrm{~m}$ dar, wodurch sich ein Reliefhöhenunterschied von $8.318 \mathrm{~m}$ berechnet. Hochasien bzw. der Himalaja und Tibet erstrecken sich über eine Fläche von ca. $2.000 \mathrm{~km}$ Ostwestausdehnung und ca. $1.500 \mathrm{~km}$ Nordsüdausdehnung mit einer durchschnittlichen Höhe von 5.000 m (Fielding et al. $1994^{16}$ zitiert nach: Owen et al. 2008:514).

Der Khumbu liegt etwa 200 km nordöstlich von Kathmandu in Ostnepal (vgl. Barnard, Owen, Finkel 2006:383). Zum Khumbu-Himalaja werden drei Hochtäler und mehrere Nebentäler des südlichen Gebietes zwischen Mt. Everest $(8.848 \mathrm{~m})$ und Cho Oyu $(8.153 \mathrm{~m})$ gezählt (vgl. Haffner 1979:92). Die durch Gebirgskämme verbundenen und in Gletscher übergehenden Flusstäler Bhote Khosi, Dudh Khosi und Imja Khola trennen den Khumbu im Bereich von Namche Bazar vom Khumbu Vorland, dem Solu (häufig auch Shorong genannt), ab. Hierbei ist beim Khumbu nur der obere Talbereich des Dudh Khosi gemeint, wobei dieser laut

\footnotetext{
${ }^{16}$ siehe Quelle Fielding et al. (1994) in der Fußnote
} 
Heuberger und Weingartner (1985:71) die Mt. Everest Gruppe entwässert. Beide Gebiete zusammen bilden einen von 75 Distrikten in Nepal namens Solukhumbu. Das Gebiet wird hauptsächlich von Sherpas besiedelt. Die Hauptstadt ist Salleri.

Der Khumbu ist innerhalb des Solukhumbu eine landschaftliche Region und keine administrative Einheit. Drei Landesteile des Distriktes Solukhumbu sind demnach im Norden der Khumbu, im Süden der Solu und im Osten der Hinku. Höchste Berge im Khumbu Gebiet sind nach den Höhendaten sortiert beispielsweise Mt. Everest, Lhotse, Cho Oyu, Nuptse, Baruntse, Pumori, Ama Dablam und Kantega, wobei hier drei der 14 Achttausender der Erde genannt wurden. Der sich über das Khumbu Gebiet erstreckende Teil des Himalaja nennt sich Mahalangur-Himal, wobei der Begriff Khumbu neben Makalu (Barun bis Arun) und Barun (Imja Khola bis Barun) das westliche Unterteilungsgebiet, ungefähr zwischen den Flüssen Nangpa Tshola und Imja Khola, meint (hierzu Carter 1985:118). Somit liegen beispielsweise die Berge Everest, Lhotse und Cho Oyu im Khumbu, die Berge Ama Dablam, Baruntse und Chamlang im Unterteilungsgebiet Barun und der Makalu im Unterteilungsgebiet Makalu. An den Mahalangur-Himal angrenzend sind der Rolwaling-Himal im Westen und der UmbakHimal im Osten. Die Chomolungma Gruppe wird östlich vom Aruntal begrenzt (vgl. Kuhle 1984:300). Die Forschungsroute im Hauptuntersuchungsgebiet Solukhumbu wurde auf den Karten III und IV im Bildband visualisiert.

\subsubsection{Geologie}

Die geologischen Gegebenheiten im Hauptuntersuchungsgebiet Solukhumbu sind für die Rekonstruktion der vorzeitlichen Vergletscherung dieser Talbereiche von enormer Wichtigkeit. Hierbei können abgelagerte Gesteine unter Betrachtung der anstehenden Gesteine auf deren Herkunftsgebiet schließen lassen. Sog. Erratika - ortsfremde weit transportierte Gesteine, die vor Ort geologisch ursprünglich nicht vorkommen - verweisen auf einen glazialen Transport. In der vorliegenden Arbeit wurden erratische Blöcke vorgefunden und Aufschlüsse mit Grobsedimenten untersucht, die erratisches Material aufwiesen. Da eine Ansprache von erratischen Gesteinen eine gründliche Überprüfung des anstehenden Gesteins vor Ort bedingt, wurden im Khumbu und im Solu Gebiet fünf geologische Karten und eine geomorphologische herangezogen und in die Auswertung mit einbezogen. Bei jedem einzelnen Foto wurden die anstehenden Gesteine dokumentiert (siehe Bildband). 
Im gesamten Khumbu Gebiet treten vorwiegend metamorphe Gesteine - vor allem Gneise ${ }^{17}$ auf, daneben aber auch magmatische Granit- und wenige Sedimentgesteine ${ }^{18}$. Nach der geomorphologischen Karte Khumbu (1:50.000) nach Kalvoda (1978) können im gesamten Khumbu Gebiet Granite, Kalksteine, Pelite, Gneise und Migmatite vorkommen. Detailliertere großmaßstäbigere geologische Karten deuten im Talbereich von Thokla bis Periche hauptsächlich auf Gneise ${ }^{19}$, im Talbereich von Chhukhung bis Dingboche auf Gneise und Granite ${ }^{20}$ und im Talbereich von Orsho bis Namche auf Gneise, Granite und Schiefer ${ }^{21}$ hin. Auch die geologische Karte Khumbu 1 (1:50.000) nach Bordet, Latreille (1954-1955) verweist oberhalb von Orsho auf Migmatite, Gneise und Granite ${ }^{22}$. (siehe Karte V, Bildband)

Nach Bäumler, Kemp-Oberhettinger, Zech (1996:13) existiert im Solukhumbu ab Lukla mit steigendem Metamorphierungsgrad bis beinahe an die tibetische Grenze die Khumbu Serie, $\mathrm{zu}$ der migmatische Orthogneise und hochmetamorphe Paragneise mit Granitpegmatiten gehören. Im Solu treten talabwärts Magmatite und vor allem Sedimentite zurück und Metamorphite hervor.

Von dem Ort Namche bis etwa zum Ort Baghkor im Solu Gebiet treten vor allem Gneise (vgl. geologische Karte Solukhumbu 1:1.000.000 und Khumbu 1:50.000 nach Vuichard 1985), daneben aber auch Migmatite und Schiefer (vgl. geologische Karte Nepal 1:250.000) sowie auch Pegmatite (Monjo talaufwärts, von Chheplung bis Chaunrikharka), Granite (Ghat talabwärts, bei Chhechhewa bis Wapsa), Schiefer (bei Bupsa) sowie Phyllite und Quarzit (bei Jubing) auf (vgl. geologische Karte Nepal 1:125.000). Talabwärts des Ortes Baghkor im Solu sind hauptsächlich Phyllite, Quarzite und Schiefer (vgl. geologische Karte Nepal 1:125.000), aber auch Karbonate und Paragranite möglich (vgl. geologische Karte Solukhumbu

\footnotetext{
${ }^{17}$ hauptsächlich Himalaja Gruppe (mittlere bis grobkörnige texturierte Augengneise, Granitglimmergneise, Kyanitsillimanitgneise, Migmatite und dünne Bänder von Marmor) (vgl. geologische Karte Solukhumbu $1: 1.000 .000)$

18 Thetys Gruppe (Kalkstein, Dolomit, Schiefer, Sandstein, Konglomeratschiefer, niedriggradige kristalline Schiefer, Fossilien) (vgl. geologische Karte Solukhumbu 1:1.000.000)

${ }^{19}$ Gneise verschiedener Varietäten, einige Marmore; Glimmergneis, Schiefer, Quarzit (vgl. geologische Karte Nepal 1:125.000); dunkle Gneise, migmatitische Orthogneise und hochgradige Paragneise (vgl. geologische Karte Khumbu 1:50.000 nach Vuichard 1985)

${ }^{20}$ Gneise verschiedener Varietäten, einige Marmore; Turmalingranit; auf der orographisch linken Imja Khola Talseite auch Granite und verwandte Gesteine - auch metamorphe möglich (vgl. geologische Karte Nepal 1:125.000); dunkle Gneise (vgl. geologische Karte Khumbu 1:50.000 nach Vuichard 1985)

21 auf der orographisch linken Imja Khola Talseite hauptsächlich Granite und verwandte Gesteine - auch metamorphe möglich; auf der orographisch rechten Imja Khola Talseite Gneise verschiedener Varietäten, einige Marmore, aber auch zwischen Pangboche und Tengboche Schiefer, Phyllite und Gneise möglich sowie zwischen Tengboche und Namche Granitglimmergneis (vgl. geologische Karte Nepal 1:125.000); migmatitische Orthogneise und hochgradige Paragneise; auf der orographisch linken Imja Khola Talseite auch Augengneis möglich (vgl. geologische Karte Khumbu 1:50.000 nach Vuichard 1985)

${ }^{22}$ Migmatite, dunkle Gneise, Granite, Gesteine der Everestgruppe und der Lhotse- und Everestgruppe
} 
1:1.000.000). Die geologische Karte Nepal (1:250.000) verweist daneben generell in diesem Bereich auch auf Gneise. Phyllite und Schiefer treten bei Kharikhola, Phyllite und Quarzite talabwärts von Jubing sowie Feldspatschiefer, Augengneis und Granitintrusionen bei Jubing und Mukli auf. (siehe Karte VI und VII, Bildband)

\subsubsection{Klima}

Der Himalaja stellt ein subtropisches Hochgebirge dar. Die Gebiete des Himalaja und Transhimalaja liegen in der Grenzzone zwischen Monsuneinfluss und den vorherrschenden Westwinden (vgl. Finkel et al. 2003:561). Langzeitige Veränderungen dieser Windsysteme sind mit Einstrahlungsveränderungen der Nordhemisphäre in Verbindung zu bringen; kurzzeitigere Veränderungen zeigen sich bei der eurasischen Schneebedeckung, der El Nino Oszillation und tropischen Ozeanoberflächentemperaturen (u.a. Hahn, Shukla $1976^{23}$ zitiert nach: Owen et al. 2008:514).

Das Hauptuntersuchungsgebiet Solukhumbu unterteilt sich in die Naturräume 'Hoher Himalaja' (4.000 bis ca. 8.850 m Höhe), 'Innerer Himalaja' (2.400 bis $5.000 \mathrm{~m}$ ) und das 'Nepalische Mittelland' (600 bis 2.000 m). Erstgenannter Himalaja stellt die Hauptkette Everest Makalu dar, der Innere Himalaja folgt südlich fort und letztgenanntes Mittelland setzt ungefähr im Bereich von Kharikhola ein (hierzu Hagen, Wahlen, Corti 1960:37/Fig. 3). Der Khumbu-Himalaja wird nach Bäumler (2001:7) dem Inneren Himalaja zugerechnet, wobei dieser jedoch dem Wettergeschehen von Süden angeschlossen ist. Auf der Südseite des Himalaja sind Jahresniederschläge von 300 bis 500 mm in Höhen zwischen 5.000 und 6.000 m typisch, 3.000 bis $6.000 \mathrm{~mm}$ zwischen 1.500 und $3.000 \mathrm{~m}$ Höhe sowie unter $1.000 \mathrm{~mm}$ zwischen 3.500 und 4.000 m Höhe (vgl. Kuhle, Roesrath 1990:36). In den Hochtälern der Mt. Everest Südabdachung treten neben den Sommerregen weiter im Januar und März bedeutende Niederschläge auf (vgl. Miehe 1991:184). Auf dem Gebirgskamm fallen im Bereich der Föhnmauer bis $1.500 \mathrm{~mm}$ im Jahr, wobei auf der Mt. Everest Nordseite jedoch nur $341 \mathrm{~mm}$ fallen (ebd.:185). Die konvektive Kondensationsniveauobergrenze liegt im Sommer auf 5.000 bis $5.400 \mathrm{~m}$, im Winter durch den Einfluss der Westwinde bei 3.500 bis $3.900 \mathrm{~m}$ Höhe (ebd.:186). Die ganzjährig höchste Humidität tritt zwischen 3.000 bis $3.500 \mathrm{~m}$ Höhe auf (ebd.:186). Der Bereich des Ablationsgebietes des Khumbu Gletscher weist zur Monsunzeit täglich zwei unterschiedliche Wetterphänomene auf: aus dem Süden wirkt der Einfluss des Monsuns und aus dem Norden der mit Eigenschaften eines Föhns ausgestattete trockene Wind

\footnotetext{
${ }^{23}$ Hahn, D.G.; Shukla, J. (1976): An apparent relationship between Eurasian snow cover and Indian monsoon rainfall. Journal of Atmospheric Science 33. (S. 2461-2462)
} 
aus Tibet (vgl. Müller 1959:205). In der Monsunzeit fallen dort maximal 32,6 cm Niederschläge (ebd.:205). Die Sommermonsunniederschläge gehen oberhalb von $5.500 \mathrm{~m}$ Höhe vorwiegend nachts als Schneefall nieder und machen mengenmäßig 10 mal so viel wie im restlichen Jahr aus (vgl. Fushimi 1977:61). In Nepal auf der Südseite des Himalaja ist das Relief gegenüber der Nordseite in Tibet steiler, wobei sich 70 bis $80 \%$ der Niederschläge auf der Südseite über die vier Sommermonate verteilen (vgl. Williams 1983:202). Nach Yasunari, Inoue (1978:27) ${ }^{24}$ zitiert nach: Williams (1983:202) fallen dort $2.100 \mathrm{~mm}$ im Jahr. Im Mt. Everest Gebiet sind nach Yasunari (1976:74) ${ }^{25}$ zitiert nach: Williams (1983:209) drei Faktoren für die rezenten Niederschläge bedeutend: starkes Hochdruckgebiet in Tibet während der Monsunzeit, subtropischer Jetstream während des restlichen Jahres und die Menge der Feuchtigkeit vom Indischen Ozean. Nach Benn, Owen (1998) ${ }^{26}$ zitiert nach: Barnard, Owen, Finkel (2006:384) kommt durch den Westwindjet im Winter Feuchtigkeit vom Mittel-, Schwarzen und Kaspischen Meer heran, wobei sich der Schneefall hauptsächlich auf den Westhimalaja beschränkt. Der Jetstream soll im Herbst und Winter auf der Südseite der Himalaja Berge liegen - demgegenüber während der Monsunzeit nördlich der Hauptkette, wodurch Ostwinde möglich sind - und gegenüber dem Frühjahr sehr stark sein (vgl. Müller 1959:205).

Das Klima des Solu unterscheidet sich deutlich von dem des Khumbu (vgl. Bäumler 2001:11). In Dingboche auf 4.355 Höhenmetern im Khumbu Gebiet sind eine Jahresdurchschnittstemperatur von $-0,7{ }^{\circ} \mathrm{C}$ und Jahresniederschläge von etwa $435 \mathrm{~mm}$ typisch, in Lukla auf $2.600 \mathrm{~m}$ im Solu Gebiet hingegen viel höhere Jahresniederschläge mit über 1.500 mm (vgl. Barnard, Owen, Finkel 2006:384). Bei Bäumler, Zech (1998:440) wurden im Dudh Khosi Tal bei Lukla 2.700 mm angegeben.

In Namche Bazar in 3.450 m Höhe kann auf der Klimadiagrammkarte nach Miehe (1990) ein Jahresniederschlag von $1.052 \mathrm{~mm}$ bei einer Jahresdurchschnittstemperatur von $6,5{ }^{\circ} \mathrm{C}$ abgelesen werden, in Chaunrikharka in $2.619 \mathrm{~m}$ Höhe $2.137 \mathrm{~mm}$ bei $11,3{ }^{\circ} \mathrm{C}$ sowie in Tengboche auf $3.857 \mathrm{~m}$ Höhe $1.030 \mathrm{~mm}$ bei $3,1^{\circ} \mathrm{C}$; bei Lhajung auf $4.420 \mathrm{~m}$ Höhe liegen die

\footnotetext{
${ }^{24}$ Yasunari, T.; Inoue, J. (1978): Characteristics of monsoonal precipitation around peaks and ridges in Shorong and Khumbu Himal. In: Higuchi, K. et al. (eds.): Glaciers and Climates of Nepal Himalayas; Report of the Glaciological Expedition to Nepal (Part 3). Japanese Society of Snow and Ice Journal, 40. (S. 26-32)

${ }^{25}$ Yasunari, T. (1976): Seasonal weather variations in the Khumbu Himal. In: Higuchi, K. et al. (eds.): Glaciers and Climates of Nepal Himalayas; Report of the Glaciological Expedition to Nepal (Part 1). Japanese Society of Snow and Ice Journal, 38. (S. 74-83)

${ }^{26}$ Benn, D.I.; Owen, L.A. (1998): The role of the Indian summer monsoon and the mid-latitude westerlies in Himalayan glaciation; review and speculative discussion. In: Journal of the Geological Society, London, 155. (S. 353-364)
} 
Jahresniederschläge bei $528 \mathrm{~mm}$ mit einer Jahresdurchschnittstemperatur von $-1,3{ }^{\circ} \mathrm{C}$ (vgl. Miehe 1991:Abb. 4.21). Bei Ringmo sind $1.935 \mathrm{~mm} / \mathrm{Jahr}$ und 9,6 ${ }^{\circ} \mathrm{C} / \mathrm{Jahr}$ typisch (vgl. Bäumler, Kemp-Oberhettinger, Zech 1996:14). Miehe (1991:187) gab für Syangboche eine Jahresdurchschnittstemperatur von $3,6{ }^{\circ} \mathrm{C}$ an. Das Khumbu Gebiet liegt im monsunbeeinflussten Himalaja, wobei ersichtlich wird, dass die durchschnittlichen jährlichen Niederschläge mit der Höhe nicht zu-, sondern abnehmen (vgl. Owen et al. 2008:Fig. 3). Im Khumbu sind z.B. im Juli durchschnittlich 50-500 mm, im Januar durchschnittlich 10-50 mm Niederschlag möglich; im tiefer liegenden Solu im Sommer nach vorgenanntem Aspekt demnach höhere Niederschlagswerte. Die Stationen Khumjung und Syangboche liegen im Regenschatten, geben infolgedessen trockenere Verhältnisse wieder (vgl. Bäumler, KempOberhettinger, Zech 1996:13). Die Stationen von Namche Bazar und Tengboche sind repräsentativer und deuten auf humides Klima mit einem Maximum im Sommer bei einem Jahresniederschlag von $1.050 \mathrm{~mm}$ (ebd.:13). Die Temperatur ist bei Tengboche mit $3,1^{\circ} \mathrm{C}$ im Jahr mit mehreren Frosttagen und in Syangboche mit 6,5 ${ }^{\circ} \mathrm{C}$ angegeben (ebd.:13).

\subsubsection{Böden und Vegetation}

Die Böden und die Vegetation verweisen im Solukhumbu auf eine bioklimatische Zonierung: 0 - 1.000 Höhenmeter (Tropische Zone - ferralitische Böden - halbimmergrüne Wälder); 2.000 m (Subtropische Zone - Parabraunerden und Ferralite - Nadelmischwälder; Kolline Zone - Braunerden und Parabraunerden - sommergrüne Wälder); 3.000 m (Untere montane Zone - Braunerden - sommer- bis immergrüne montane Wälder); 4.000 m (Obere montane Zone - Braunerden und Podsole - Mischwälder; Subalpine Zone - Podsole - Nadel- und Rhododendronwälder); $5.000 \mathrm{~m}$ (alpine Zone, Waldgrenze 3.800 - $4.200 \mathrm{~m}$ - Ranker / Regosole und Podsole - Zwergstrauchvegetation; Alpine Zone - Syroseme und Ranker / Regosole - alpine Rasenvegetation); $6.000 \mathrm{~m}$ (klimatische Schneegrenze 5.000-6.000 m Syroseme / Lockersyroseme) (Bäumler, Zech 1998 zitiert nach: Bäumler 2001:Tab. 1). Auch Kuhle, Roesrath (1990:50) und Miehe (1991:181) gaben die Lage der Waldgrenze im Zentralhimalaja bzw. auf der Südseite des Himalaja auf 3.800 m Höhe an. Auf der Nordseite des Himalaja verläuft die Waldgrenze auf 4.000 bis 4.400 m Höhe (vgl. Kuhle, Roesrath 1990:50). Die Waldgrenze muss aber nicht unbedingt dem heutigen Klima entsprechen (ebd.:52). Der Föhn bewirkt, dass die Baumgrenze auf der Leeseite des Himalaja höher liegt als auf der Luvseite -4.400 m gegenüber 3.600 bis 3.800 m Höhe (ebd.:37). Die Baumgrenze wurde bei Williams (1983:203) ebenfalls mit 3.800 m Höhe angegeben. 
Es treten im Solukhumbu saure Ausgangsgesteine auf und somit nährstoffarme Böden; unterhalb von $2.000 \mathrm{~m}$ Höhe rubifizierte, tonreiche und teilweise pseudovergleyte Böden, zwischen 2.000 und $3.000 \mathrm{~m}$ hauptsächlich Braunerden mit hochwärts anschließenden podsolierten Böden, oberhalb von $4.500 \mathrm{~m}$ flachgründige, skelettreiche Böden (vgl. Bäumler 2001:9). Es wird typischerweise Viehhaltung, Weidewirtschaft und monsunaler Regenfeldbau betrieben (ebd.:9). Die Böden sind durch Hangterrassierung, Überweidung und Entwaldung verändert und degradiert (ebd.:9). Auf der Südseite des Himalaja reichen die Dauersiedelungen kaum über 2.000 m Höhe, im Himalajadurchbruchstal bis auf maximal 3.300 m Höhe (vgl. Kuhle, Roesrath 1990:53). Im Khumbu existieren Yakweiden bei Pheriche sowie Kartoffel- und Gerstenfelder bei Dingboche (vgl. Müller 1959:211). Kuhle, Roesrath (1990:53, 136) beschrieben Kartoffelfelder bei Chhukhung und beim Ngozumpa Gletscher zwischen 4.600 und 4.750 m Höhe. Nach Owen et al. (2008:513) sind die Länder im und rund um das Himalaja Tibet Gebirge zumeist landwirtschaftlich geprägt.

Im Khumbu Gebiet treten, da hier die Frostschutt- und Mattenstufe ausgebildet ist und erst ab einer Höhe von ca. $4.070 \mathrm{~m} / \mathrm{GE}$ die Waldstufe bzw. Birkenwald einsetzt, vorwiegend Flechten, Matten und Zwergsträucher auf. Talaufwärts von Pheriche und Dingboche treten stellenweise Grünland oder Ackerflächen und Weiden auf. Bei Shomara sind in Talnähe daneben auch Birkenwälder und Weidebuschwälder ausgebildet, unterhalb des Ortes auch Tannenwälder und Rhododendron-, Krummholzwälder sowie talabwärts von Phungi Thanga auch Kiefernwälder. (vgl. Vegetationskarte Khumbu 1:70.000)

Nach der Gefahrenkarte Solukhumbu (1:50.000) hat der Waldbestand im Gebiet ab der Höhe von Pangboche bis Phungi Thanga sowie in der Nähe von Monjo, Phakding und Chaunrikharka stellenweise eine vor Gefahren schützende Wirkung.

\subsubsection{Rezente Vergletscherung}

Die Gebiete des Himalaja und Transhimalaja stellen die am meisten vergletscherten Gebirgsregionen der Erde dar (vgl. Finkel et al. 2003:561). Fast 1/4 der Hochhimalajafläche sind vergletschert (vgl. Kollmair 1999:26). In Nepal finden sich die längsten Gletscher (Langtang Gletscher 25 km; Ngozumpa Gletscher 24 km; Kangchendzönga Gletscher 20 km) aufgrund hoher Niederschläge und günstigem Relief in Ostnepal, wie beispielsweise im Khumbu-Himalaja (vgl. Hagen, Wahlen, Corti 1960:46). Der Ngozumpa Gletscher ist ca. 18 km lang (vgl. Joshi 1986:56). Ostnepalische Gletscher sind meist schuttbedeckte (vgl. Hagen, 
Wahlen, Corti 1960:46) und reichen bis auf durchschnittlich $4.500 \mathrm{~m}$ Höhe (Vohra $1981^{27}$ zitiert nach: Joshi 1986:56). Im Khumbu-Himalaja existieren über 50 Kar- und Talgletscher (vgl. Barnard, Owen, Finkel 2006:384). Der Khumbu Gletscher ist 15 km lang, schuttbedeckt und befindet sich aktuell im Rückzug (vgl. Shrestha, Aryal 2011:71). Er weist eine geringe Fließgeschwindigkeit von 50 m / Jahr auf (vgl. Hagen, Wahlen, Corti 1960:46). Die Firnlinie des Khumbu Gletscher liegt nach Müller (1959:207) bei 5.600 m. Nach Heuberger (1956:350, 352) befindet sich dort die rezente Schneegrenze bei 5.500 Höhenmetern, weiter im Norden hingegen auf $5.900 \mathrm{~m}$. Kuhle (1986b:73) ermittelte im Tibetischen Himalaja und im Transhimalaja ebenfalls eine klimatische Schneegrenze auf 5.900 m Höhe. Die klimatische Schneegrenze im Khumbu wird jedoch laut Bäumler, Zech (1998:440) und Bäumler (2001:7) mit $5.700 \mathrm{~m}$ angegeben. Die unterste Grenze der periglazialen Formen liegt laut Fujii (1976) ${ }^{28}$ zitiert nach: Fushimi (1977:61) im Khumbu bei 4.200 m Höhe.

\footnotetext{
${ }^{27}$ siehe Quelle Vohra (1981) in der Fußnote

${ }^{28}$ Fujii, Y. (1976): Ground temperature and ist relation to permafrost occurences in the Khumbu Himal and Hidden Valley. Seppyo, 38, special issue. (S. 125-128)
} 


\subsection{Vergleichsuntersuchungsgebiete}

Die in der vorliegenden Arbeit betrachteten Vergleichsuntersuchungsgebiete befinden sich wie das Hauptuntersuchungsgebiet ebenfalls in Nepal bzw. im Zentralhimalaja. Nach Carter (1985:118, 128, 132) gliedert sich Nepal - von West nach Ost betrachtet - in folgende Gebiete des Himalaja: Nalakankar, Chandi, Gurans, Changla, Gorakh, Kanti, Palchung Hamga, Kanjiroba, Gautam, Dolpo, Mustang, Dhaulagiri, Damodar, Annapurna, Peri, Mansiri, Kutang, Serang, Ganesh, Langtang, Jugal, Pamari, Rolwaling, Mahalangur, Umbak, Janak und Kangchendzönga-Himal. Der Himalaja ist somit infolge des Vorhandenseins von Durchbruchstälern in einzelne Blöcke aufgeteilt (vgl. Kuhle 1984:300). Hiervon wurden fünf verschiedene Himalaja Gebiete ausgewählt: Dhaulagiri, Annapurna, Langtang, Mahalangur und Kangchendzönga-Himal, wobei die beiden erstgenannten zusammen betrachtet wurden. Die untersuchten Gebiete liegen in Zentral- bis Ostnepal (siehe Karte I, Bildband).

Der Dhaulagiri- und Annapurna-Himal erstreckt sich über $130 \mathrm{~km}$ des Zentralhimalaja (vgl. Kuhle 1982a:169) und liegt zwischen 83 und $85^{\circ}$ ö.L. und 28 und $29^{\circ}$ n.B. (vgl. Kuhle 1980:244). Die Annapurna Region weist maximalste topographische und bioklimatische Verläufe bzw. Gradienten auf (vgl. Fort 1986:105). Die enorme Steilheit ist Folge der geologischen Gegebenheiten (ebd.:105). Es wurden in der vorliegenden Arbeit anhand von Literatur die Täler Mayangdi Khola, Kali Gandaki, Modi Khola, Madi Khola, Seti Khola und Marsyandi Khola untersucht. Die Thakkhola Region ist der obere Teil des Kali Gandaki zwischen Kagbeni und Ghasa (vgl. Iwata 1984:26). Das Thakkhola Tal ist ein Himalaja Quertal bzw. ein antezedentes Durchbruchstal mit Ursprung beim Kore La in Tibet (vgl. Kuhle 1983:25 f.). Die über $3.500 \mathrm{~m}$ hohe Mustang Region erstreckt sich nördlich der Thakkhola Region (vgl. Iwata 1984:26). Das Kali Gandaki Tal ist die tiefste Schlucht der Welt, umgeben vom Dhaulagiri im Westen und Annapurna im Osten (vgl. Zech et al. 2009:1107). Der Kali Gandaki Fluss fließt vom Tibetischen Plateau durch den Mustang Thakkhola Graben. Unterhalb von Ghasa wird das Tal zu einer kerbförmigen Schlucht (vgl. Iwata 1984:26). Im Dhaulagiri- und Annapurna-Himal sind im Luv Jahresniederschläge von $6.000 \mathrm{~mm}$ und im Lee solche von $300 \mathrm{~mm}$ typisch, wobei die obere Waldgrenze von Süd nach Nord betrachtet von $3.800 \mathrm{~m}$ (Himalaja Vorketten) bis auf 4.400 m Höhe (Innerer Himalaja) reicht (vgl. Miehe 1982:184). Die Solifluktionsuntergrenze liegt zwischen 3.000 und $3.100 \mathrm{~m}$ Höhe, wobei die klimatische Solifluktionsobergrenze bei ca. 5.600 bis $6.000 \mathrm{~m}$ Höhe liegt mit anschließenden pergeliden Verhältnissen (vgl. Kuhle 1980:244 f.). Die häufigsten 
Gletschertypen im Dhaulagiri- und Annapurna-Himal sind über Eislawinen ernährte Wandfußgletscher, sog. Lawinenkegelgletscher (ebd.:245 f.).

Der Langtang-Himal liegt 60 km nördlich von Kathmandu und weist im Nepal-Himalaja den höchsten Tal / Berg Gradienten auf - innerhalb von 7 km von 3.850 Höhenmetern bei Kyanjin Gompa auf $7.239 \mathrm{~m}$ des Langtang Lirung (vgl. Barnard et al. 2006:2162, 2164). Das Langtang Tal gehört zum Inneren Himalaja, wobei es südlich von der südlichsten Kette des Hohen Himalaja sowie nördlich und östlich von den Ketten des Himalaja Hauptkammes namens Langtang-Himal und Pangsang Lekh begrenzt wird (vgl. Bäumler, KempOberhettinger, Zech 1996:8). Dieses Tal ist ein von Ostwest verlaufendes zwischen dem Manaslu- und Khumbu-Himal (vgl. Abramowski 2004:9). Der Konfluenzbereich von Langtang Khola und Bhote Khosi bzw. Trisuli Ganga liegt auf 1.450 m Höhe (vgl. Bäumler, Kemp-Oberhettinger, Zech 1996:9). Die höchste Erhebung ist nach Miehe (1990:4) der Langtang Lirung mit 7.233 Höhenmetern. Langtang ist das größte Dorf des Gebietes mit 50 Häusern (vgl. Bäumler, Kemp-Oberhettinger, Zech 1996:11). Die Dörfer von Kyanjin Gompa, Sindum, Langtang, Thyangshap und Gora Tabela liegen auf Fächern und / oder Terrassen (vgl. Barnard et al. 2006:2165). Im Mahalangur-Himal wurde sich bei den Vergleichsuntersuchungsgebieten auf das Arun Tal beschränkt. Dieses antezedente Durchbruchstal entstand durch rückschreitende Erosion durch den Hohen Himalaja bis nach Südtibet (vgl. Kuhle 1984:300). Es reicht bis auf 300 m Höhe hinab und weist demnach eine enorme Reliefenergie mit einer Vertikaldistanz von $8.550 \mathrm{~m}$ auf (ebd.:300).

Der Kangchendzönga-Himal liegt in Ostnepal und weist drei Gipfel mit Höhen von mehr als $8.000 \mathrm{~m}$ und mehrere mit Höhen über $7.000 \mathrm{~m}$ auf (vgl. Meiners 1999:368). Das sechs km lange Kangchendzöngamassiv, welches $8.000 \mathrm{~m}$ nicht unterschreitet, stellt die größte einzelne Bergform dar und liegt etwa 160 km östlich vom Mt. Everest (vgl. Kuhle 1984:300; vgl. Kuhle 1998:86). Der Kangchendzönga ist $8.586 \mathrm{~m}$ hoch (ebd.:86; vgl. Tsukamoto et al. 2002:Fig. 1). Die zwei Haupttäler Yalung (Simbua Khola) und Ghunsa gehen auf ca. 1.500 Höhenmetern bei den Orten Sakathon und Hellok in das Tamur Tal über (vgl. Meiners 1999:371). Zahlreiche Gletscher existieren auf über 5.000 m Höhe, das vergletscherte Gebiet beträgt in etwa $400 \mathrm{~km}^{2}$ (vgl. Tsukamoto et al. 2002:57). Die Vergletscherung unterteilt sich in drei Typen: die zwei großen Haupttalgletscher Yalung und Kangchendzönga, mittelgroße Gletscher sowie kleine Hängegletscher (vgl. Meiners 1999:368). Der Haupttalgletscher 
Yalung endet auf einer Höhe von 4.200 m und der Kangchendzönga auf etwa $4.580 \mathrm{~m}$ (ebd.:369).

Alle Untersuchungsgebiete liegen im monsunbeeinflussten Himalaja in Nepal. Die Nordflanke des Himalaja weist hingegen ein arides und kaltes Klima auf (vgl. Fort 1985:159), wobei Innerasien durch Winterniederschläge geprägt ist (vgl. Kuhle 1983:8). Solche Störungen der Westdrift äußerten sich z.B. im oberen Mayangdi Khola durch enormen Schneefall an einem Tag (vgl. Kuhle 1983:9 f.). Somit werden die weiter nördlich gelegenen ariden / semiariden Verhältnisse des Tibetischen Plateau verständlich (vgl. Zech et al. 2009:1106). Im Zentralhimalaja ist die Feuchte im Winter durch die Westwinde zu erklären. Im Annapurna Gebiet fallen $5.000 \mathrm{~mm}$ Niederschläge im Jahr, hauptsächlich während der Monsunzeit (vgl. Fort 1986:105) bzw. es wurden bei Lumle $6.170 \mathrm{~mm}$ im Jahr 1970/71 gemessen (vgl. Kuhle 1983:8). In Jomosom auf 2.744 m Höhe fielen in den Jahren 1957-86 Jahresniederschläge von etwa $260 \mathrm{~mm}$ bei einer Jahresdurchnittstemperatur von $11,7{ }^{\circ} \mathrm{C}$, in Marpha auf 2.550 m Höhe in den Jahren 1967-86 etwa $387 \mathrm{~mm}$ bei $11{ }^{\circ} \mathrm{C}$ sowie bei Lete auf $2.384 \mathrm{~m}$ Höhe in den Jahren 1976-86 etwa $1.164 \mathrm{~mm}$ bei 11,7 ${ }^{\circ} \mathrm{C}$ (vgl. Miehe 1990:Klimadiagrammkarte). Stainton (1972:10) gab für Jomosom 295 mm / Jahr an. Das Annapurna Massiv weist einen Übergang von perhumiden zu semiariden Gebieten auf (vgl. Zech et al. 2001:160). Die rezente Schneegrenze lässt sich nach Anwendung von vier verschiedenen Methoden bzw. Berechnungen an 46 Gletschern auf ca. $5.550 \mathrm{~m}$ Höhe festmachen (vgl. Kuhle 1988a:142). Das breite tiefe Thakkhola im Dhaulagiri- und Annapurna-Himal führt zu einer abwärtsgerichteten Konvektionsströmung in der Talmitte, was zu einem semiariden Klima führt (vgl. Iwata 1984:26). Der Modi Khola wird von Gletscherschmelzwasser gespeist, wobei der Fluss auf 686 m Höhe südlich von Kusma in den Kali Gandaki fließt (vgl. Zech et al. 2001:161). Das Einzugsgebiet des Seti Khola ist das Gebiet, welches von den Bergen Machhapuchhare, Annapurna III und Annapurna IV umrahmt wird (ebd.:160). In Pokhara fallen $3.477 \mathrm{~mm}$ Jahresniederschlag (vgl. Stainton 1972:8). Im Langtang Tal ist die Niederschlagsverteilung wie für den Inneren Himalaja typisch bi- bis trimodal, jedoch mit ausgeprägten Maxima im Sommer (vgl. Bäumler 2001:11). Im Khumbu sind die Winterniederschläge nicht so deutlich (ebd.:11). Die Klimastation in Kyangjing verweist auf humides Klima mit einem Jahresniederschlag von 1.224 mm in den Jahren 1985 bis 1986 (vgl. Bäumler, Kemp-Oberhettinger, Zech 1996:10). Bei Bäumler, Zech (1998:440) wurde der Jahresniederschlag mit 1.200 mm angegeben. 1993 und 1995-97 lag der jährliche Niederschlag bei $622 \mathrm{~mm}$ bei einer durchschnittlichen Temperatur von $2,0{ }^{\circ} \mathrm{C}$ (vgl. Barnard et al. 2006:2165). Das Maximum der Niederschläge 
liegt im Sommer, zwischen Mai und September (ebd.:2165), wobei auch im Winter und Frühjahr bedeutende Niederschläge fallen und keine Wintertrockenheit auftritt (vgl. Bäumler, Kemp-Oberhettinger, Zech 1996:10). Die Jahresmitteltemperatur von Kyangjing beträgt 2,7 ${ }^{\circ} \mathrm{C}$ bei einer maximalen Monatsmitteltemperatur von $9,4{ }^{\circ} \mathrm{C}$ (ebd.:10). Beim Ort Trisuli auf $595 \mathrm{~m}$ Höhe wurde eine Jahresdurchschnittstemperatur von $22,2{ }^{\circ} \mathrm{C}$ bei einem Jahresniederschlag von etwa 1.767 angegeben (vgl. Miehe 1990:Klimadiagrammkarte). Die Schneegrenze liegt bei 5.300 m Höhe (vgl. Bäumler, Zech 1998:440). Im MahalangurHimalaja fallen laut Kuhle (2005:276) 4.000 mm Niederschlag im Jahr. Beim Ort Num kann bei Miehe (1990:Klimadiagrammkarte) ein Jahresniederschlag von $4.477 \mathrm{~mm}$ und eine Jahresdurchschnittstemperatur von $17,3{ }^{\circ} \mathrm{C}$ abgelesen werden. Im Kangchendzönga-Himal liegt die rezente Schneegrenze allgemein betrachtet auf etwa $5.560 \mathrm{~m}$ Höhe (vgl. Kuhle 1998:86). 


\subsection{Eigene angewendete Methoden bzw. Arbeitstechniken}

Im Hauptuntersuchungsgebiet Solukhumbu fanden geomorphologische Analysen in Kombination mit Satellitenbildanalysen und Sedimentanalysen - Grob- und Feinsedimentanalysen - Anwendung. In den Vergleichsuntersuchungsgebieten wurde sich auf die Auswertung der Literatur beschränkt.

\subsubsection{Geomorphologische Analyse}

„Die Geomorphologie kann ihrem komplexen Gegenstand nur durch eine pluralistische Methodik gerecht werden. " (Leser 1977:108). Die geomorphologische Analyse zielt darauf ab, anhand von geomorphologischen Kennformen und deren Lagebeziehung zueinander Rückschlüsse auf die Entstehung der Formen zu ziehen. Es spielen die Morphographie, metrie, -analyse und -genese eine entscheidende Rolle. Die Befunde dürfen hierbei nicht vom Klima oder der Ökologie abgeleitet werden, sondern sollen der Beobachtung (vgl. Bremer 1989:92) bzw. der visuellen Beschreibung entstammen. Somit wurden rezente Prozesse und Formen im Gelände beobachtet, beschrieben sowie kausale Beziehungen hergestellt (z.B. Prozesse aus Formen abgeleitet) und durch eine Detailanalyse Rückschlüsse auf die Entstehung vorzeitlicher Formen gezogen. „Bei der Geländearbeit werden naturgemä $\beta$ sowohl die Prozesse unmittelbar beobachtet als auch die Formen analysiert." (Bremer 1989:19). „Beobachtete Prozesse werden in der gedanklichen Konstruktion extrapoliert.“ (ebd.:54). Die Lagebeziehungen sind bei der geomorphologischen Reliefanalyse das wichtigste (vgl. Kuhle 1991:190, 194). Somit sollten nicht einzelne Indikatoren, sondern mehrere mit ihren Lagebeziehungen untereinander betrachtet werden (ebd.:190). Um auf die Entstehungsweise einer Form schließen zu können, müssen neben den klimatischen folgende Gesichtspunkte mit einbezogen werden: „, Arbeitet der Geomorphologe heute im Felde nach dem Prinzip der Korrelate, so muß er auch die geologischen, petrographischen und pedologischen Arbeitsweisen kennen.“ (Leser 1977:85); „Beobachten, Vergleichen, Abstrahieren und Generalisieren sind, wie auch in anderen Geowissenschaften, die Methoden der klimatischen und klimagenetischen Geomorphologie.[...] Beim Vergleich werden die übrigen Geofaktoren: Untergrund, Boden, Wasser, Vegetation und Klima mit herangezogen. “ (Bremer 1989:66).

Die geomorphologische Analyse ist eine Methode bzw. Arbeitstechnik, mit der u.a. großräumige geomorphologische Detailanalysen und Sedimentanalysen betrieben werden. Sie stellt die Basis der Eiszeitrekonstruktionen dar, wobei Aussagen anhand der rezenten und vorzeitlichen Schneegrenze sowie anhand des Erhaltungszustandes der geomorphologischen 
Kennformen über das Vergletscherungsausmaß bzw. die Vergletscherungsart getroffen werden können. (vgl. Kuhle, Kuhle 2010:105-107)

Somit werden anhand der geomorphologischen Methode sehr viele Formen beachtet und anhand deren Lagebeziehung Aussagen getroffen. Mehrere Forscher wendeten diese Methode bzw. Arbeitstechnik im Khumbu-Himalaja an, jedoch beachtete Kuhle die meisten Formen und Talbereiche bis weit unterhalb von Lukla. Hierbei stellte die Deutung der Form eine Schlüsselrolle dar. So können beispielsweise 'debris flows' ein indirekter Indikator für eine vorzeitliche Vergletscherung sein (vgl. Kuhle 2007:105).

Die numerischen Datierungen gehören nicht zur Glazialgeomorphologie, sondern sind importiert bzw. stammen von Nachbarwissenschaften und sind weniger gut für glazialgeologische Forschungen geeignet (vgl. Kuhle, Kuhle 2010:105-107).

\subsubsection{Geländearbeiten mit fotografischer Dokumentation}

Bei den Forschungsarbeiten im Frühjahr 2012 wurden im Hauptuntersuchungsgebiet Solukhumbu Talabschnitte der Flüsse Dudh Khosi und Imja Khola untersucht. Im Gebiet des Khumbu erstreckte sich die Route über die Orte Namche Bazar - Khumjung - Phungi Thanga - Phortse - Tengboche - Pangboche - Pheriche - Thokla - Dingboche und Chhukhung. Zwischen Namche Bazar und Chhukhung verläuft der Imja Khola, welcher durch Zuflüsse wie z.B. aus dem Fluss Lobuche Khumbu Tshola, allgemein als Lobuche Khola bezeichnet, gespeist wird. Im Bereich des Solu erstreckte sich die Route entlang des Flusses Dudh Khosi über die Orte Monjo - Phakding - Ghat - Lukla - und unterhalb von Lukla über Poyan Kharikhola - Budhubar / Bagi - Budhidanda / Burku, Maidel / Mukli nach Kangel. Der Schwerpunkt der Arbeit lag im Khumbu Gebiet im Bereich der Ortschaften Thokla sowie Chhukhung bis Namche Bazar im Talabschnitt des Lobuche Khola bzw. Imja Khola. Die Forschungsroute wurde auf den Karten III und IV im Bildband visualisiert.

Während des Geländeaufenthaltes wurden die vorgetroffenen geomorphologischen Kennformen indentifiziert, kartiert, charakterisiert und genetisch interpretiert, auf Fotos festgehalten und anhand deren Lagebezug in den Kontext der eiszeitlichen Vergletscherung gestellt. Diese Kennformen konnten anhand der erstellten Fotografien mit den entsprechenden Standorten dokumentiert werden und dienten somit als ein Indikator für die Existenz der jeweiligen Form. Die Formen wurden entweder einzeln fotografiert oder Panoramen für einen 
besseren Überblick über die auftretenden Formengemeinschaften erstellt. Die jeder Form zugeordnete Signatur konnte jeweils unter Hinzunahme des Programmes Adobe Photoshop konstruiert und auf den Fotos eingefügt werden. Für die fotografische Dokumentation fanden zwei Digitalkameras Anwendung, wovon eine eine integrierte GPS-Funktion besaß (Samsung WB650). Für die Angabe der GPS-Koordinaten wurde hauptsächlich das Garmin eTrex Vista HCx GPS-Gerät verwendet. In den Bildunterschriften wurden mehrere Höhenwerte angegeben, da sich diese voneinander unterschieden: absolute Höhenangaben konnten dem GPS-Gerät, der Kamera, Google Earth und Google Maps Gelände entnommen werden, relative Höhen vielmehr den beiden letztgenannten Programmen. Bei jeder vorgefundenen Form erfolgte der Abgleich mit den Forschungsergebnissen der dort bis dato betriebenen Forschungsarbeiten (siehe Bildband, Fotobeschreibungen). Das Hauptaugenmerk bei der geomorphologischen Analyse lag auf der scharfen Abgrenzung der unterschiedlichen Formen untereinander. Die Beschreibungen wichtiger voneinander abgetrennten Formen sind in der vorliegenden Arbeit vorhanden. „Das methodische Vorgehen der Geomorphologie beruht daher auf der erklärenden Beschreibung. " (Leser 1977:2). Die zeitliche Einordnung der Formen passierte - unter Berücksichtigung der Befunde anderer Forscher - aufgrund deren Formengestaltung und unter Hinzunahme umgebender geomorphologischer Formen, die auf eine maximale Vergletscherungsausdehnung hindeuteten. Auf absolute Datierungsmethoden wurde verzichtet. Es wurde sich auf die zeitliche Einordnung von Kuhle (2005) bezogen, die auf der Grundlage von ${ }^{14} \mathrm{C}$-Datierungen basierte.

Da aber die Quartärgeologie mit dem Substrat / Material in Verbindung gebracht werden kann, wurden ebenfalls zu den geomorphologischen Formen Aufschlüsse - siehe Grobsedimentanalysen - untersucht und Sedimentproben - siehe Feinsedimentanalysen entnommen. „Formen, Sedimente und Böden bilden einen genetischen Zusammenhang, der sich als wichtigstes Prinzip geomorphologischen Arbeitens erweist. “ (Leser 1977:98). Die in der vorliegenden Arbeit zu Hilfe genommenen geologischen Karten dienten der Ansprache des dort anstehenden Gesteins. Die in den Aufschlüssen entnommenen Grobsedimente wurden anhand deren Größen (kleinere und bis $\mathrm{zu}$ faustgroße Gesteine) und Formen (Rundungsdiagramme kantig, kantengerundet, gerundet, gut gerundet) klassifiziert und anhand deren Längsachseneinregelung (Längsachsendiagramme nach Himmelsrichtung Vollkreis, Längsachsendiagramme nach Himmelsrichtung - Halbkreis, Längsachsendiagramme abgewandelt nach den Einregelungsklassen nach Poser, Hövermann 
1951) und petrographischen Zusammensetzung (z.B. Vorkommen von Erratika) den entsprechenden Ablagerungsprozessen zugeordnet.

\subsubsection{Satellitenbildanalysen mit Karten- und Talprofilerstellung}

Satellitenbildanalysen anhand der Programme Google Earth und Google Maps Gelände ermöglichten neben der Kartierung im Gelände aufgrund der hochaufgelösten Bilder umfassende geomorphologische Bestandsaufnahmen der dort vorkommenden Formen, auch in Talbereichen abseits der Forschungsroute. Google Earth verfügt im Hauptuntersuchungsgebiet Solukhumbu über mehrere Satellitenbilder mit verschiedenen Erstellungsdaten und Urheberschaften und stellt diese farblich, mit Koordinaten, in 2D und über die Geländefunktion auch in 3D dar. Google Maps Gelände ermöglicht den Zugriff auf das Relief des Gebietes ohne Koordinaten, ab einem Maßstab von 1:50.000 mit Höhenlinien. Zusätzlich erstellte Talquerprofile untermauerten die tatsächlich ausgebildeten Talformen. Diese Talprofile konnten mittels des Programmes Global Mapper Version 11.00 und des im Internet frei zur Verfügung gestellten digitalen Höhenmodelles (90 m DEM Version 4; CGIAR - Consortium for Spatial Information, 2004), basierend auf SRTM-Daten (Shuttle Radar Topography Mission) der NASA, erstellt werden. Die Standorte der Fotos, Sedimentproben, Aufschlüsse und die Verläufe der Talquerprofile sind anhand von Markierungen auf Google Earths Satellitenbildern nachvollziehbar (siehe Bildband). Auch eine mittels der Satellitenbilder von Google Earth erstellte Oberflächenbedeckungskarte (siehe Bildband) zeigte gegenüber der dargestellten Oberflächenbedeckung aus der topographischen Karte Khumbu Himal 1:50:000 eine präzisere Ausmachung von Oberflächenformen. Hierfür wurde die topographische Karte Khumbu Himal eingescannt und die entsprechenden Oberflächen anhand des Programmes Adobe Photoshop visualisiert. Für eine Vergleichskarte wurden Screenshots von den Satellitenbildern aus Google Earth für das entsprechende Gebiet zu einer Karte zusammengefügt und die zu erkennenden Oberflächen anhand des Programmes Adobe Photoshop visualisiert. Diese visualisierten Karten konnten dann als Bild-Overlay in Google Earth eingefügt werden. Außerdem konnte eine detallierte Darstellung der im Gelände und anhand der Satellitenbilder ausgemachten Formen in Google Earth erfolgen (siehe geomorphologische Karten, Bildband) und folgende Formen kartiert werden: Trogtal, Schlucht, Rundhöcker, Gletscherschliff, Strudeltopf, glazifluviale Terrasse, erratischer Block, Grundmoränenmaterial, Ufer- bis Endmoränen, subglaziale Schmelzwasserrinne, Berg- / Felssturzablagerungen, glaziäre Dreieckshänge, Blockgletscher / Schuttloben, deutlich erkennbare Moränenzüge, übrig gebliebene zerschnittene Moränengrate, 
Gletscher, Lawinenkegel, Seen, Fächer / Kegel, Sturzfächer / Kegel (Sturzschuttfächer / kegel, welche, die Moränenmaterial überlagern, Schnee, Lawinen überlagerte), Sturzmoränenfächer / -kegel aus Moränenmaterial oder glazifluvialen Materialien, Mischfächer / Kegel (hauptsächlich aus Schutt, hauptsächlich aus Moränenmaterial, welche, die präexistierendes Moränenmaterial überlagern, von anderen Prozessen überlagerte), Murfächer / Kegel (Murschuttfächer / -kegel mit einem hohen Schuttanteil, Murmoränenfächer / -kegel mit einem hohen Moränenanteil, Murschwemmfächer / -kegel mit viel Feinmaterial, von anderen Prozessen überlagerte), Schwemmfächer / Kegel (Schwemmschuttfächer / -kegel mit Schutt- und Moränenmaterial, Sander aus Moränenmaterial mit Bezug zum Gletscherrand, Schwemmfächer / -kegel aus hauptsächlich Moränenmaterial), Fächer- / Kegelform und zerschnittene Grundmoränen. Ausgewählte geomorphologische Formen wurden in der vorliegenden Arbeit besonders gegeneinander abgetrennt. Mittels der Erstellung dieser geomorphologischen Karten und Talquerprofilen ließen sich dann alle aufgefundenen Formen in Beziehung zueinander setzen. Im Vergleich zum eigenen kartierten Formenschatz konnte sich den geomorphologischen Formen der in der vorliegenden Arbeit kritisch überprüften Forschungsarbeiten anderer Forscher wie etwa von Kuhle (2005) oder Barnard, Owen, Finkel (2006) entweder angeschlossen oder nicht angeschlossen werden.

\subsubsection{Begriffsklärung zu ausgewählten geomorphologischen Kennformen}

Das Hauptaugenmerk bei der geomorphologischen Analyse liegt auf der genauen Abgrenzung der unterschiedlichen Formen untereinander. Es wurden in der vorliegenden Arbeit besonders die verschiedenen Fächer / Kegel voneinander abgegrenzt. Barnard et al. (2006) bezeichneten die Fächer lediglich mit einem weitgefassten Begriff 'fan'.

Im Hauptuntersuchungsgebiet Solukhumbu sind verschiedene Fächer- bzw. Kegeltypen in Form von Schutt- Mur-, und Schwemmfächern bzw. -kegeln aufzufinden. Generell verweisen die Begriffe Fächer auf geringer geneigte und Kegel auf stärker geneigte Formen. Allgemein betrachtet konnten Schutt-, Mur- und Schwemmfächer / -kegel durch deren Neigung, Komponentensortierung / -anteil / -form, Oberflächenprofil, Ausdehnung, Zerschneidungsgrad, Farbgebung und Feuchtegehalt beim Transport voneinander unterschieden werden. Da aber auch Mischformen bzw. Kombinationen dieser Formen existieren, ist es wichtig, auch diese Übergangsformen genauer zu betrachten. Schon Louis, Fischer (1979) oder Iturrizaga (1999) wiesen auf diese Tatsache hin: „, Die reinen Formen der 
Sturzkegel, Murkegel und Schwemmkegel sind nicht selten durch Übergangserscheinungen miteinander verbunden.“ (Louis, Fischer 1979:235); „, Reine Formen der vorgestellten klassischen Schuttkörpertypen sind selten. Zumeist findet man Mischformen vor. So muß die Wahl der Schuttkörperbenennung auf den/die dominierenden genetischen Prozeß/sse fallen (z.B. Mursturzkegel, Murschwemmkegel etc.). “ (Iturrizaga 1999:30). Beispielsweise können Muren auf Schutthalden, Lawinen- und Wildbachkegeln entstehen (vgl. Louis, Fischer 1979:107, 233) oder ausfließendes Wasser der Mure zur Bildung von feinkörnigen, gering geneigten Schwemmkegeln führen (vgl. Leser 2009:190).

Die Schutt-, Mur- und Schwemmfächer / -kegel wurden sinnvollerweise genauer voneinander unterschieden und in Untertypen eingeteilt. Sturzkegel sind laut Louis, Fischer (1979:235) über $20^{\circ}$ geneigt und zeigen eine Abgrenzung der Korngrößen - größere Blöcke im unteren Bereich. Murkegel sind $8-12^{\circ}$ geneigt, unsortiert und zeigen aufgrund der schubweisen Bewegung keine stärkere Abrollung des Schutts (ebd.:235). Schwemmkegel sind unter $4^{\circ}$ geneigt, sortiert - kleinere Korngrößen im unteren Bereich - und zeigen eine Abrollung des Schutts (ebd.:235). In natura und auf den Satellitenbildern in Google Earth grenzten sich Schuttablagerungen durch die graue Farbgebung, Murablagerungen durch deren meist bräunliche und Schwemmablagerungen durch die eher hellgraue bis graue Farbgebung gegeneinander $a b$. Murablagerungen ließen sich aufgrund der hohen Beteiligung von Moränenmaterial von der Farbgebung her nur sehr schwer von Moränenablagerungen unterscheiden, fielen aber durch deren Formung - steiler, konvexer, mit nicht so ausgeglichener Oberfläche - und durch die größere Menge an enthaltenen Grobmaterialien pro Fläche gegensätzlich zu den feiner erscheinenden Grundmoränenmaterialien auf.

Weiterhin fiel bei den Schuttablagerungen auf, dass diese durch überwiegend grobe, eckige Komponentenformen und verschiedene Komponentengrößen sowie durch ein unregelmäßiges Oberflächenprofil charakterisiert sind, welche meistens durch Sturzprozesse nach der Größe sortiert sind. Murablagerungen hingegen enthalten Grob- und Feinmaterialen aus im Gegensatz zu Schuttablagerungen vorwiegend gerundeteren und im Gegensatz zu den Schwemmablagerungen kantigeren Komponenten, wobei keinerlei Sortierungen auftreten. Bei Murschuttablagerungen kann jedoch infolge des kurzen Transportweges, des enthaltenen Materials oder durch den stoßweisen Abfluss der Schuttanteil bedeutender sein. Murfächer / kegel zeigten ebenso ein unregelmäßiges Oberflächenprofil, allerdings mit Schutt- oder Randwülsten. Die fluvialen Schwemmablagerungen weisen im Allgemeinen infolge des 
weiteren Transportes gegenüber den Schutt- und Murablagerungen feineres und viel mehr gerundeteres Material auf - es sei denn, Moränen- und Schuttablagerungen lassen die Ausbildung von Schwemmschuttfächern zu oder aber der Abfluss ist stoßweise, was zur polygenetischen Bildung von Murschwemmfächern führen kann. Schwemmfächer / -kegel zeigen ein ausgeglichenes Oberflächenprofil (vgl. Iturrizaga 1999:133) und sind stark ausgeweitet. Murschwemmfächer sind gegenüber Schwemmfächern weniger ausgedehnt (ebd.:131) und gegenüber Murfächern ohne Schutt- oder Randwülste ausgebildet. Generell betrachtet besitzen Schutt- und Murfächer gegenüber den Schwemmfächern also eine konvexere Formung. Zerschnittene Grundmoränen bestehen pro Fläche gesehen gegenüber Schutt- und Murfächern aus feineren und gegenüber Schwemmfächern aus gröberen Materialien. Der Zerschneidungsgrad bzw. die Anzahl der Abflussrinnen von Schuttfächern ist gegenüber dem von Murfächern sehr viel geringer, da oft das Feinmaterial bei erstgenannten fehlt. Schwemmfächer sind am meisten zerschnitten, wobei aber wiederum die Tiefe der Abflussrinnen wesentlich geringer ist als bei den ungefähr gleichen Zerschneidungsgraden der Murfächer und der zerschnittenen Grundmoränen. Die zwei letztgenannten Akkumulationen unterscheiden sich jedoch ebenfalls in der Tiefenausdehnung der Rinnen, die bei den zerschnittenen Grundmoränen bedeutend ausgeprägter ist.

Unter einem Schuttfächer / -kegel - oder besser unter einem Sturzschuttfächer / -kegel oder Sturzfächer / -kegel - wurden aus Verwitterungsvorgängen hervorgegangene fächer- / kegelförmige Ablagerungen unterhalb von Steinschlagrinnen im Hangbereich verstanden. In der vorliegenden Arbeit wurden Sturzfächer / -kegel in Sturzschuttfächer / -kegel und Sturzmoränenfächer / -kegel unterteilt. Hierbei wurde also nach verstürzendem Schutt- oder Moränenmaterial unterschieden. Bei letztgenanntem sind aber oft auch verstürzte glazifluviale Ablagerungen mit enthalten. Sturzschuttfächer / -kegel wurden weiterhin in welche, die Moränenmaterial überlagern, und in solche, die von Schnee bzw. Lawinen überlagert werden, unterschieden. Sturzschuttfächer / -kegel können aber beispielsweise auch von Muren überlagert sein. Zudem existieren gegenüber den genannten Sturzschuttfächern / -kegeln und Sturzmoränenfächern / -kegeln sog. Mischfächer / -kegel. Darunter wurden Fächer / Kegel verstanden, die aus beiden Materialen - Schutt- und Moränenmaterial - entstehen. In der vorliegenden Arbeit wurden solche unterschieden, die hauptsächlich aus Schutt bestehen, solche, die aus hauptsächlich Moränenmaterial bestehen, solche, die präexistierendes Moränenmaterial überlagern sowie solche, die von anderen Prozessen überlagert sind. 
Murfächer / -kegel sind typische, aus etwa gleichen Anteilen an Grob- und Feinmaterialien bestehende Murablagerungen mit Aufwölbungen, wobei hier kantige bis kantengerundete Gesteine enthalten sind. Dabei konnten Murschuttfächer / -kegel mit einem hohen Schuttanteil, Murmoränenfächer / -kegel mit einem hohen Moränenanteil, Murschwemmfächer / -kegel mit viel Feinmaterial und solche Fächer / Kegel, die von anderen Prozessen überlagert wurden, unterschieden werden. Letztgenannte Fächer / Kegel sind polygenetische Formen (hierzu Iturrizaga 1999:242), wobei in den Murschwemmschuttfächern / -kegeln kantige bis kantengerundete Materialien in größeren Mengen enthalten sind.

Schwemmfächer / -kegel sind flache fluviale Ablagerungen, die im Tiefland feinmaterial- und im Gebirge eher schotterreich sind; deswegen kann im Hochgebirge wohl eher die Bezeichnung Schotterfächer / -kegel oder Schotterschwemmfächer / -kegel gelten. Wenn überwiegend kantige- bis kantengerundete Materialien enthalten sind, dann sind solche Akkumulationen als Schwemmschuttfächer / -kegel zu bezeichnen, wobei hier Schutt- und Moränenmaterial enthalten sein kann. Dahingegen werden von diesen Schwemmfächer / kegel aus hauptsächlich Moränenmaterial unterschieden. Solche Schwemmfächer / -kegel aus Moränenmaterial, die in Bezug zu einem Gletscherrand stehen, werden Sander genannt.

\subsubsection{Sedimentanalyse}

1.5.2.1. Beschreibung typischer Erscheinungsbilder von Sedimentaufschlüssen

\section{OBERFLÄCHENSTRUKTUR DER GESTEINE}

Im Feld werden die Oberflächenstrukturen der Gesteine > $2 \mathrm{~mm}$ untersucht (vgl. Hubbard, Glasser 2005:237). "Features commonly recorded in the field are the occurrence of faceted clasts (flat surfaces with rounded edges), bullet-shaped clasts and those with a stoss-and-lee form, as well as clasts with striations, grooves, gouges and cracks." (Hubbard, Glasser 2005:237).

Harte kristalline Gesteine (Quarzit, Granit, Gneis, Schiefer) weisen seltener Schrammen auf als feinkörnige magmatische Gesteine oder Karbonate, jedoch können Facettierungen bei allen Gesteinsarten gleich auftreten (vgl. Hubbard, Glasser 2005:237). Dadurch wird auch verständlich, warum in den Feinsedimenten eines Gletschers vorwiegend Quarze oder Feldspäte vorhanden sind (Wilding 1970 zitiert nach: Goldthwait 1971:10). Gletscherschrammen sind der eindeutigste Beweis für Abrasionsprozesse (vgl. Goldthwait

\footnotetext{
${ }^{29}$ Wilding, L. P.; Drees, L. R.; Smeck, N. E.; Hall, G. F. (1971): Mineral and elemental composition of Wisconsin-age till deposits in west-central Ohio. In: Goldthwait, R.P. (1971): Indroduction to Till, Today. In: Goldthwait, R. P. (ed.) (1971): Till / a symposium. Ohio State University Press.
} 
1971:12), die jedoch laut Flint $(1957: 117)^{30}$ zitiert nach: Goldthwait (1971:12) nur bei 5-10\% der Gesteine auftreten.

Parallele Schrammen deuten auf eine Überfahrung, kreuz und quer verlaufende auf Rotationsbewegungen der Gesteine oder auf Gegeneinanderbewegen von Moräne und Anstehendem: "Soled or 'rocker-shaped' facets with slightly criss-crossing striae are ascribed to rotational forces tipping the stone forward into the place of greatest shear as it moves differently over englacial debris below, or as it slides against till and bedrock beneath a wet, melting base. Perfectly flat facets with parallel striae indicate the more fixed grip of a rock held rigidly in compact till and abraded by the dragging of rock tools over it." (Goldthwait 1971:12).

\section{SEDIMENTTEXTUR}

Die Textur beschreibt die Bodenart bzw. die Kornzusammensetzung eines Bodens (vgl. Leser et al. 2001:879). Hauptsächliche Ansammlungen von Grobmaterial können mit glazifluvialen oder fluvialen Prozessen in Verbindung gebracht werden, Feinmaterialansammlungen hingegen mit Seesedimenten oder Schwemmland (vgl. Hubbard, Glasser 2005:266).

\section{SEDIMENTSORTIERUNG}

Die Sortierung hängt vom Ausgangsgestein / Substrat (Granit gegenüber Sandstein bzw. grobkörnige Sedimente gegenüber feinkörnigeren schlechter sortiert), vom Prozess (Massentransportprozesse gegenüber fluvialen / äolischen schlechter sortiert) und vom Transportweg (kurztransportierte gegenüber weittransportierten schlechter sortiert) ab. Zur Sedimentsortierung können die Begriffe sehr gut sortiert $(<0,5)$, gut sortiert $(0,5-1)$, schlecht sortiert (1-2) und sehr schlecht sortiert (2-4), unimodal (nur eine Korngröße dominierend), bimodal (Maxima sind erkennbar) und polymodal (keine einzelne Fraktion überwiegt) Anwendung finden (vgl. Hubbard, Glasser 2005:231).

Moränen sind schlecht sortierte Akkumulationen (vgl. Hubbard, Glasser 2005:251). Moränen können aber auch Einschlüsse bzw. Linsen von gutsortiertem Ton, Silt oder Sand, ebenso auch Kiesen / Schottern aufweisen, vor allen Dingen aber in der oberen Moräne oder Lockermoräne (vgl. Goldthwait 1971:5 f., 19).

\footnotetext{
${ }^{30}$ Flint, R. F. (1957): Glacial drift I. Till; Moraines: in Glacial and Pleistocene geology: New York, John Wiley. (S. 108-35)
} 
Gut sortierte Sedimente zeigen separierte Fraktionen - z.B. bei fluvialen Prozessen Grobmaterial, da das Feinmaterial ausgewaschen worden sein kann (vgl. Hubbard, Glasser 2005:266). Grobes Ausgangsgestein führt z.B. zum Vorhandensein von groben Körner in der Korngrößenverteilung (hierzu z.B. Kuhle 2001b:Fig. 13, Fig. 14).

\section{SCHICHTUNGSBESTIMMUNG / LAGERUNG}

Neben der Einregelung der Einzelkomponenten muss die Lagerung des Gesamtkomplexes die Art und Neigung der Schichtung - Beachtung finden (vgl. Stäblein 1970:71). Bei der Schichtung werden die einzelnen Schichten charakterisiert wie z.B. Mächtigkeit, Geometrie und Struktur (vgl. Hubbard, Glasser 2005:239, 242). Die Lagerung gibt also an, ,, in welcher Art und Weise die Bodenpartikel zueinander in Lagebeziehung stehen. “ (Goudie 1998:156).

Hierbei lassen sich gestörte (Rupturen, Diskordanzen, Stauchungen) von ungestörten Schichtungen unterscheiden (vgl. Stäblein 1970:71 f.). Beispiele für ungeschichtete Grobsedimentdecken sind Hangschutt oder Moränen, wohingegen Solifluktionsschutt pseudound Flussschotter parallel- oder kreuzgeschichtet sind (ebd.:73; vgl. Leser 1977:236). „, Schichtungsverschiedenheiten entstehen bei fluvialen, litoralen und äolischen Ablagerungen infolge Änderung von Bewegungsrichtung und Stromstärke." (Leser 1977:206). „Feinkörnige, gebänderte und gleichmäßig geschichtete Sedimente weisen auf ruhige Bildungsbedingungen hin. Unter solchen Bedingungen entsteht die Parallel- oder Horizontalschichtung. Sie tritt meist in Feinsedimenten auf, seltener in Grobsedimenten, die bei geringen Fließgeschwindigkeiten bekanntlich nicht transportiert werden." (ebd.:238). Murschutt zeigt genauso wie Moräne einen schichtungslosen Aufbau und ist somit kaum von letztgenannter zu unterscheiden (vgl. Fischer 1966:5). Akkumulationen ohne nachweisbare Schichtung werden als massig oder massiv bezeichnet (vgl. Hubbard, Glasser 2005:239, 242). Einige Wildbachablagerungen weisen keine eindeutige Schichtung auf (vgl. Fischer 1966:5).

Die Struktur der Ablagerung gibt einen Hinweis auf die verschiedenen Moränentypen, wobei kantige gebrochene Gesteine und fehlendes Feinmaterial auf einen Transport an der Gletscheroberfläche hindeuten (vgl. Goldthwait 1971:15). Ablationsmoränen weisen mehr Sand gegenüber Silt und Ton auf als Grundmoränen (ebd.:17). Auf einer Moräne überlagernde gefaltete glazifluviale Ablagerungen (Sand und Schotter) deuten auf eine erneute Eisüberfahrung hin (vgl. Evenson 1971:362). 


\section{MÄCHTIGKEIT}

Die Mächtigkeit von Akkumulationen kann beispielsweise anhand der rezenten Flusseinschneidung ermittelt werden (hierzu Hövermann, Poser 1951:142 f.). Sie verweist auf die für die Entstehung erforderliche Transportkraft bzw. auf den Umfang der Abtragung (vgl. Bremer 1989:28; vgl. Stäblein 1970:72). Leitwerte finden sich bei Hjulström (1932, 1935:298 $)^{31}$ und Cailleux-Tricart $(1963: 167)^{32}$ zitiert nach: Stäblein (1970:72). Es klassifizieren sich: sehr mächtige Schichten (> $100 \mathrm{~cm}$ ), mächtige Schichten $(30$ bis $100 \mathrm{~cm})$, mittelmächtige Schichten (10 bis $30 \mathrm{~cm}$ ), dünne Schichten (1 bis $10 \mathrm{~cm}$ ) und sehr dünne Schichten (< $10 \mathrm{~mm}$ ) (vgl. Hubbard, Glasser 2005:242/Tab. 8.5). Zudem muss auf die Sortierung eingegangen werden (hierzu Stäblein 1970:123). „Bei intensiver Einwirkung von Klima, Wasser und Vegetation können Moränen und Terrassen so tiefgründig verwittern, daß vom Ausgangsmaterial nichts Sichtbares mehr übrigbleibt; das richtet sich aber nach der Mächtigkeit. “(Leser 1977:107)

\section{KOMPAKTION / ZEMENTATION / EINDRINGWIDERSTAND}

Die Kompaktion und die Zementation einer Akkumulation kann im Feld ermittelt werden (vgl. Hubbard, Glasser 2005:232). Hierzu dient die Tabelle 8.3. von ebd.:232, die eine Skala von unverfestigt bis extrem hart vorgibt. Der Eindringwiderstand mit einem Handpenetrometer kann zudem genauere Werte liefern.

Die Kompaktheit einer Moräne kann durch die verschiedenen Korngrößen und den Druck erklärt werden (vgl. Goldthwait 1971:5). Nach Torrell (1877) ${ }^{33}$ und Upham (1891) ${ }^{34}$ zitiert nach: Goldthwait (1971:15) weisen Grundmoränen durch den enormen Druck des Eises einen hohen Kompaktionsgrad auf. Grundmoränen sind hart, sie weisen gegenüber Superglazialmoränen mehr gerundete und geschrammte Gesteine auf (ebd.:19).

\footnotetext{
31 Hjulström, F. (1932): Das Transportvermögen der Flüsse und die Bestimmung des Erosionsbetrages. Geografiska Annaler, Stockholm. (S. 244-258); Hjulström, F. (1935): Studies on the morphological activity of rivers. Bull. Geol. Inst. Of Uppsala, 25, Uppsala. (S. 221-527)

32 Cailleux, A.; Tricart, J. 1959 (1963-1965): Initiation à l'etude des sables et galets. (3 Bde.) Centre de Documentation Universitaire, Paris.

${ }^{33}$ Torrell, O. (1877): On the glacial phenomena of North America: Amer. Jour. Sci., ser. 3, v. 13.(S. 76-79)

${ }^{34}$ Upham, W. (1891): Distribution of englacial drift: Geol. Soc. America Bull., v. 3, no. 1. (S. 134-48)
} 


\section{FARBE VON MORÄNEN}

Häufig kann eine graue Farbgebung bei Moränen nahe legen, dass diese einen sehr geringen Verwitterungsgrad aufweisen und somit auf ein junges Alter deuten. Auch der lockere Aufbau von Moränen lässt eine junge Entstehungsphase vermuten. (ebd.:18)

\subsubsection{Grobsedimente}

Grobsedimente wurden aufgrund ihrer enormen Beweiskraft für vergangene morphologische Prozessabläufe untersucht (hierzu Stäblein 1970:188 und Leser 1977:248 f.). Hierdurch wird die Sicherheit der Entstehungsbestimmungen von Lockermaterialen erhöht (vgl. Fischer 1966:1). Die Grobsedimentanalyse zielt also darauf ab, die Genese unter Berücksichtigung weiterer Feld- und Laborbefunde in etwa nachzuvollziehen (vgl. Leser 1977:201, 204, 248 f.).

\subsection{Gesteinsentnahme}

„Die einzelnen Sedimentstücke unterscheiden sich außer durch das unterschiedliche Ausgangsgestein in vierfacher Hinsicht: in der Größe, in der Form, in der Lagerung und in der Entstehung. Dazu kommt die verschiedene Zusammensetzung und Lage der Sedimentstücke im Sedimentverband." (Stäblein 1970:5). Auch Bremer (1989:299) wies darauf hin, dass , ,...] die Zusammensetzung des Materials, die Menge und die Lagerung. “ von Geomorphologen untersucht werden können. Deswegen wurden in der vorliegenden Arbeit Größenklassen, Formen, Längsachseneinregelungen und petrographische Zusammensetzungen eines jeden Aufschlusses bestimmt. Für die Untersuchung ist die Entnahme von 100 Gesteinen pro Aufschluss unabdingbar, da die Genauigkeit bei einer hohen Anzahl wächst (hierzu Köster 1964:10). Gesteinsstücke über 2 cm Länge gelten als Grobsedimente (hierzu Stäblein 1970:5).

\subsection{Gesteinsgrößen}

Der Einbezug der Größenverhältnisse der Gesteine steigert die Auswertungsgenauigkeit (vgl. Köster 1964:139). Die Einteilung der verschiedenen Größenklassen von Grobsedimenten wird im Gegensatz zu den Feinsedimenten, bei denen eine Einteilung auf deren mittleren Durchmessern basiert, nach den größten Durchmessern bzw. nach den Längen bestimmt (vgl. Stäblein 1970:6 ff., Tab. 1). Gesteinsstücke des Größenbereiches von 2 bis $20 \mathrm{~cm}$ liefern die besten Ergebnisse (hierzu Köster 1960:83). Auch der Gliederung der Korngrößen nach Büdel 
$1977^{35}$ zitiert nach: Busch (1986:8/Abb. 9) ist zu entnehmen, dass die Korngrößen zwischen 2,5 mm und $25 \mathrm{~cm}$ bzw. Fein- bis Großgeschiebe für Einregelungs-, Gesteinsbestandes- und Zurundungsmessungen geeignet sind und die Masse der Moränengeschiebe in diesem Korngrößenbereich auftritt. Infolgedessen wurden Gesteine der Größe 2 bis $18 \mathrm{~cm}$ entnommen.

\section{VORGEHENSWEISE}

Es wurden jeweils 100 Gesteine der Größe 2 bis $20 \mathrm{~cm}$ pro Aufschluss direkt mit einem Maßband ausgemessen und die Anzahl der Gesteine der unterschiedlichen Größenklassen 2$10 \mathrm{~cm}$ und 10-18 cm angegeben bzw. die prozentualen Größenanteile mit Hilfe der Gesamtanzahl berechnet - und nicht wie bei den Feinsedimenten Gewichtsanteilprozente (hierzu Stäblein 1970:6 und Hubbard, Glasser 2005:229).

\subsection{Gesteinsformen}

Die Formanalyse bzw. die Morphometrie ist laut Poser, Hövermann (1952:12) für die Geomorphologie bedeutungsvoll. Grobsedimente werden durch Reibungsprozesse infolge von Transportprozessen mechanisch abgeschliffen oder auch zerbrochen (Material / Agens, Material / Material und Material / Untergrund); dabei soll je Agens ein typisches Mischungsverhältnis entstehen, wodurch beispielsweise bimodale Verteilungen verständlich werden (vgl. Leser 1977:214; vgl. Stäblein 1970:58, 119; vgl. Valeton 1955:17). „Diese verschiedenen Maxima werden bedingt durch Variabilität von Untergrund, Geröllmenge, Fließgeschwindigkeit und Weglänge." (Leser 1977:224 f.). Somit können auch Grobsedimente gleicher Gesteinsart in einer Akkumulation trotz identischer Entstehung (vgl. Stäblein 1970:58) oder verschiedene Gesteine trotz gleicher Transportbeanspruchung unterschiedlich geformt sein (vgl. Valeton 1955:16 f.). Die Formgestalt ist als eine polygenetische zu verstehen, wodurch auch Charakteristika vorhergehender Prozesse sichtbar sein können (vgl. Stäblein 1970:119, 189) bzw. diese können auch bei unzureichender Anpassung an das Transportmedium bzw. zu kurzem Transportweg einen sehr bedeutenden Anteil an der Gesamtmenge ausmachen (hierzu Poser, Hövermann 1952:24). Hierbei muss darauf hingewiesen werden, dass scharfkantiges Material höchst empfindlich auf Zurundungsprozesse reagiert und sich mit fortschreitender Transportlänge der Umwandlungsprozess von kantigen zu kantengerundeten Gesteinen verlangsamt (hierzu ebd.:22, 31 f.). Nach einem gewissen Transportweg - im Harz z.B.: solifluidal bei der Länge

\footnotetext{
${ }^{35}$ Büdel, J. (1977), Quelle bei Busch (1986) nicht genauer angegeben
} 
von ca. $2 \mathrm{~km}$, moränisch bei ca. 1,5 - $2 \mathrm{~km}$ - soll dieser Prozess zum Erliegen kommen und sich ein reifes, an das Transportmedium gut angepasstes, somit also mit fortschreitendem Transport ungefähr konstant bleibendes, Morphogramm einpegeln (ebd.:22, 25). Demgegenüber sollen aber gleich entstandene und gleich transportierte Sedimente Formähnlichkeiten anzeigen (vgl. Köster 1964:206). Die Formanalysen besitzen nur regionale Gültigkeit innerhalb eines Einzugsgebietes (vgl. Stäblein 1970:71, 121, 189; Schreiner 1997:138). Harte Gesteine wie etwa Granit, Gneis oder Quarzit führen oft zu guten Ergebnissen (vgl. Köster 1964:139).

Anhand von Form- bzw. Rundungsanalysen können der Abnutzungs-, Abschleif- oder Beanspruchungsgrad von Grobsedimentmaterialien ermittelt und somit Grobsedimente sehr gut voneinander abgetrennt werden (vgl. Leser 1977:208; vgl. Stäblein 1970:58). „Daraus werden Schlüsse auf die vermutliche Ausgangsgestalt gezogen und aus dieser wiederum auf die Beanspruchung durch Transportagenzien und Verwitterungsprozesse geschlossen." (Leser 1977:208). Somit können beispielsweise Moränen voneinander und von glazifluvialen Akkumulationen unterschieden oder der glazifluviale Anteil in einer Moräne herausgestellt werden (vgl. Winkler 1996:273). Ebenso können Aussagen über die klimatischen Verhältnisse zur Entstehungszeit der Akkumulationen (vgl. Köster 1964:155) und zur Entstehung selber getroffen werden (vgl. Schreiner 1997:136). Folgende Bedingungen sind hierfür aber einzuhalten: „[...] Maximal- und Minimalgrößen, Unterteilung nach Größengruppen, Gruppierung nach gleichem Gestein [...]. “ (Leser 1977:210).

Letztgenannte Gruppierung sollte deshalb beachtet werden, weil die Rundung auch von der Gesteinsart - primär Struktur, Textur und sekundär Härte (vgl. Stäblein 1970:118; vgl. Köster 1964:142) - abhängig ist (vgl. Schreiner 1997:136). Hierbei spielt die Widerstandsfähigkeit der Gesteine eine bedeutende Rolle (vgl. Poser, Hövermann 1952:34) und somit der gesteinsabhängige Abrieb (vgl. Fischer 1966:4). Geschichtete oder spröde Gesteine können leicht zerbrechen, wobei weiche schnell gerundet werden (vgl. Valeton 1955:16 f.). Bezugnehmend zu glazialen Prozessen würde das folgendes bedeuten: "The stronger or more resistant a particle is to crushing, the more rounded it may become." (Bennett, Glasser 1996:159). Die Form der Grobsedimente ist folglich ein Erzeugnis aus mehreren Bearbeitungsvorgängen, wobei bereits die Gesteinsbildung und nicht nur die Verwitterungsund Transportvorgänge für die Formgestaltung ausschlaggebend sind (vgl. Leser 1977:226). Verschiedene verwitterte Gesteinsarten in Wanderschuttdecken wie etwa Grauwacke und 
Granit zeigen jedoch bei gleichem Transportweg sehr ähnliche Zurundungsmorphogramme (vgl. Poser, Hövermann 1952:Abb. 3).

Eine Größengruppenzuordnung von 2 bis $15 \mathrm{~cm}$ ist zulässig, da erst oberhalb dieses Größenbereichs signifikante Schwankungen der Einzelmesswerte auftreten (vgl. Stäblein 1970:50 f.). Außerdem sollen Gesteine über $15 \mathrm{~cm}$ Größe , [...] infolge ihrer Schwere nicht die gleichen Bewegungen durchmachen wie leichtere Gerölle und besonders beim glazialen Transport wegen ihrer Größe durch eine zweite Scherfläche in ihrer Bewegung beeinflußt sein können." (Leser 1977:210). Allgemein soll die Größe der für die Rundungsanalyse herangezogenen Gesteine zwischen 1 und $20 \mathrm{~cm}$ sein (vgl. Köster 1964:149). Cailleux (1952:11) hingegen äußerte, dass diese Methode für 15 bis > $1.000 \mathrm{~mm}$ große Gesteine gilt. Hubbard, Glasser (2005:234) schrieben: “In glacial environments, fieldwork normally involves measuring clasts with $\alpha$-axis between 20 and $100 \mathrm{~mm}$. Some subjectivity is inevitable in using this scale in glacial environments, for example in dealing with a rounded clast that has one broken corner (this clast should still be classified as rounded).”. Eine größenbezogene Untersuchung der Gesteine steigert die Auswertungsgenauigkeit (vgl. Köster 1964:139), da der Rundungsgrad bei größeren Gesteinen niedriger sein kann (hierzu Valeton 1955:16).

„In der Hauptsache hängt die Rundung aber von der Transportart ab [...]." (Schreiner 1997:136), wobei allerdings innerhalb einer Transportart Gesteins- und Neigungsunterschiede (Aufschlagen und Brechen bei Gefällsbrüchen) sowie klimatische Einflüsse eine Rolle für die Zurundung spielen können (hierzu Hövermann, Poser 1951:153; Poser, Hövermann 1952:29, 35). Mit zunehmender Länge des Transportweges werden Gesteine aber nicht nur zugerundet, sondern auch verkleinert (vgl. Bremer 1989:298), wobei bei „[...] starker Beanspruchung [...] durch Zerbrechen allerdings die scherbigen Komponenten auch wieder zunehmen." (Bremer 1989:298) können. Bei den Formanalysen wurden die Formarten und -typen berücksichtigt (hierzu Stäblein 1970:9 ff.). Unter Formarten werden neben Kanter, Scherben, Knollen und Wollsäcken hauptsächlich Schutt, Geschiebe, Fanger und Geröll verstanden (vgl. Stäblein 1970:9 ff., Tab. 2). Schutt ist kantiges; Geschiebe kantengerundetes nicht gerolltes, Schubflächen bzw. Abschiebungsflächen aufweisendes; Fanger grob kantengerundetes kurzzeitig fluvial gerolltes sowie geschobenes und Geröll gerundetes Material (ebd.:9, 117; vgl. Leser 1977:Tab. 7). Bei Schottern kann der Grad der Rundung mit ansteigendem Transportweg zunehmen (vgl. Schreiner 1997:138). Grundmoränen, die Schotter beinhalten, können demnach einen hohen Rundungsgrad anzeigen (ebd.:138). Formtypen beziehen eine Unterscheidung in transportierte oder in situ entstandene Grobsedimente mit ein (vgl. Stäblein 
1970:11). Autochthone Typen sind beispielsweise Verwitterungsschutt- bzw. blöcke; allochthone z.B. Steinschlag-, Hang-, Wander-, Solifluktionsschutt oder Moränengeschiebe und Schotter (ebd.:Tab. 3). Es können aber auch autochthone Typen, wie etwa Schutt, kurzzeitig gravitativ, fluvial oder solifluidal transportiert werden (vgl. Leser 1977:Tab. 7). Frost- bzw. Hangschutt, der durch Gravitations- und Solifluktionsprozesse transportiert wird, kann verändert und zu Solifluktionsgeschiebe mit Abschiebungsspuren werden (vgl. Stäblein 1970:117, Abb. 4). Moränenmaterial unterscheidet sich gegenüber Solifluktionsschutt über die zunehmende Zurundung (vgl. Hövermann, Poser 1951:139 f., 146 ff.), die sich infolge des Zerbrechens während des Transports, hauptsächlich am Grund und an der Oberfläche, und des partiellen Abschleifens durch Abrasion als Kantenrundung aller Gesteinsgrößen äußert (vgl. Goldthwait 1971:5, 20).

Eine verlässlichere Interpretation der Ergebnisse kann aber nur bei eindeutigen Formen unter Einbeziehung von Struktur-, Textur- und Oberflächenformgegebenheiten der Lockermaterialmasse und anhand von längsprofilgebundenen Morphogrammreihen bzw. Historiogrammen geschaffen werden (vgl. Hövermann, Poser 1951:135 f.; vgl. Poser, Hövermann 1952:34). Letztgenannter Aspekt ist bedeutsam, da Änderungen in den Transportbedingungen erst nach einer Verzögerung von drei bis fünf Kilometern Transportweg eindeutig eintreten, wodurch es vorkommen kann, dass in einzelnen, wohl unausgereiften Morphogrammen nur vorangegangene Transportprozesse charakteristisch sind (vgl. Hövermann, Poser 1951:141 f.). Somit können solche einzelnen morphometrischen Analysen Übergangsbereiche unterschiedlicher Prozesse anzeigen bzw. charakteristisch für mehrere Prozesse sein (hierzu ebd.:141-154). Überlagerungen rezenter Prozesse, wie etwa Schuttzufuhr, führen zur Verfälschung der Werte und bei einer Morphogrammreihe zu inhomogenen Historiogrammen (ebd.:142; vgl. Poser, Hövermann 1952:14). Zudem können auch quantitative Veränderungen des Transportagens (hierzu Hövermann, Poser 1951:150) und Reliefgegebenheiten (vgl. Fischer 1966:5) verantwortlich für die unterschiedliche Gesteinsrundung sein. Anhand von Historiogrammen werden Lockermaterialen über große Strecken verfolgt, was aber z.B. in Hochgebirgen wie den Alpen nicht immer möglich ist (ebd.:4). Nichtsdestotrotz können einzelne Morphogramme ,[...] ein gutes Mittel zur Entschleierung der formenden Kräfte, [...]. “ (Hövermann, Poser 1951:154) sein.

\section{VORGEHENSWEISE}

Die Rundungsgrade der einzelnen Gesteine wurden visuell anhand der Vergleichstafel und der Beschreibungen nach Reichelt (1961) bestimmt. Diese Einordnung ist laut Stäblein 
(1970:50, 60) die eindeutigste und erfasst somit typische Formeigenschaften. Auch nach Valeton (1955:15) ist eine visuelle Bestimmung in fünf Gruppen wohl genauer als eine Berechnung. „Die Form als Ganzes exakt zu beschreiben und zu vermessen ist unmöglich.“ (Stäblein 1970:50).

Reichelt (1961) unterschied nach dem Grad der Zurundung folgende vier Rundungsgruppen: 'kantig', 'kantengerundet', 'gerundet' und 'gut gerundet'. Bei den kantigen Gesteinen sind über die Hälfte der Kanten scharf, wobei die Oberfläche deutlich rauh ist. Kantengerundete Gesteine zeigen bereits geglättete Oberflächen; mehr als die Hälfte der Kanten sind leicht abgerundet. Gerundete Gesteine sind deutlich konvex mit nur wenigen Unregelmäßigkeiten auf der Oberfläche, stark gerundete hingegen regelmäßig konvex mit glatter Oberfläche.

Zudem konnten Rundungsgrade - gg mal $4+$ g mal $3+\mathrm{kg}$ mal $2+\mathrm{kt}$ mal 1 - für die einzelnen Analysen berechnet werden (vgl. Schreiner 1997:136). Werte von 100 deuten hierbei auf kantigen Schutt, solche um die 400 auf gut gerundetes Material (ebd.:136). „Gegenüber den Abplattungs- und Dissymmetriewerten ist der Zurundungsgrad von Grobsedimentkomponenten genetisch deutlich aussagekräftiger. “ (Leser 1977:214). Deswegen wurde sich hier in der vorliegenden Arbeit auf die Zurundung beschränkt. Zudem meinte Olsen (1983) ${ }^{36}$ zitiert nach: Hubbard, Glasser (2005), dass die visuelle Bestimmung nach Powers (1953) ${ }^{37}$ zitiert nach: Hubbard, Glasser (2005) in sechs Gruppen - very angular', 'angular', 'sub-angular', 'sub-rounded', 'rounded', 'well-rounded' - nur den Prozess der Abrasion und nicht den des Zerbrechens involviert und schlägt ebenfalls eine in vier Kategorien vor, aber mit einem Index für das Zerbrechen (vgl. Hubbard, Glasser 2005:235 f.).

Um eine subjektive visuelle Bestimmung auszuschließen und somit das Ergebnis zu verbessern, wurden in der vorliegenden Arbeit die Rundungsgrade mehrmals nacheinander ohne Kenntnis der vorher festgelegten bestimmt. Ebenfalls erfolgte eine Sortierung nach petrographischen Gruppen, wobei in der Auswertung das Hauptaugenmerk auf den härtesten Gesteinsarten lag (vgl. Köster 1964:175), da ,[...] die weicheren Steine unter dem gemeinsamen Transport einer größeren Beanspruchung unterliegen. “ (Köster 1964:175). Da Reichelt (1961) für eine solche Untersuchung 100 Gesteine als günstig ansieht, 50 als ausreichend, wurden pro Aufschluss jeweils 100 Gesteine untersucht. Hövermann, Poser (1951:138) sowie Poser, Hövermann (1952:13) gaben ebenfalls einen solchen Probenumfang

\footnotetext{
${ }^{36}$ Olsen, L. (1983): A method for determining total clast roundness in sediments. Boreas, 12. (S. 17-21)

${ }^{37}$ Powers, M.C. (1953): A new roundness scale for sedimentary particles. Journal of Sedimentary Petrology, 23. (S. 117-119)
} 
an. Diese wurden verschiedenen Gesteinsartengruppen zugeordnet (hierzu Hövermann, Poser 1951:138). Alle Ergebnisse wurden prozentual in Histo- bzw. Morphogrammen visualisiert.

Für die Auswertung waren die Beispiele bei Schreiner (1997:136) von Vorteil, da diese Werte für Frostschutt aus Gneis (95\% kt, $5 \%$ kg), Grundmoräne aus alpinen Gesteinen (18\% kt, 50 $\% \mathrm{~kg}, 30 \% \mathrm{~g}, 2 \% \mathrm{gg}$ ), Fließerde aus Moräne (33\% kt, $40 \%$ kg, $25 \% \mathrm{~g}, 2 \% \mathrm{gg}$ ) und glazifluviale Schotter (0 \% kt, 5-15\% kg, $70 \% \mathrm{~g}, 5-25 \% \mathrm{gg})$ anzeigten, an denen sich ungefähr orientiert werden konnte. Der Anteil der kantigen Gesteine kann bei Fließerde über $70 \%$ betragen und somit höher als bei Grundmoränen sein (ebd.:138). Auch diese Gesichtspunkte nach Reichelt (1961) zitiert nach: Leser (1977:216) waren hilfreich: solifluidal (> $70 \% \mathrm{kt}$, selten g, $0 \% \mathrm{gg})$, moränisch $(<40 \% \mathrm{kt},>40 \% \mathrm{~kg},<10 \% \mathrm{gg})$, fluvial (> $50 \% \mathrm{~g}$ und gg; selten $\mathrm{kg}$ und kt - durch Verwitterung oder Bäche mit kurzem Transportweg zu erklären), fluvioglazial (Werte zw. Moränen und Schottern), Schuttkegel (50-60 \% kt, ca. $40 \%$ kg und selten g) und Seitenmoräne (Maximum bei g).

Fluviale Prozesse sind also mit einer guten Rundung in Verbindung zu bringen, Grundmoränen mit Kantenrundung, supraglaziales Material und Schutthaldenmaterial mit den Begrifflichkeiten sehr kantig bis kantig (vgl. Hubbard, Glasser 2005:266). Kantiger Schutt kann mit Frostsprengung in Verbindung gebracht werden, wobei Trockenschutt oft durch Abgrusen runde Kanten aufweist (vgl. Bremer 1989:26 f.). Solifluktionsprozesse führen zu einer begrenzten Kantenzurundung bis auf $<30 \%$, wobei das Maximum im Bereich kantig von > $60 \%$ Kantigkeit der Gesteine andeutet (vgl. Poser, Hövermann 1952:21 f.). Es wird Gehängewander- von Muldenwanderschutt, der durch stärkere Wassereinwirkung mehr kantengerundetere Gesteine aufweist als erstgenannter, unterschieden (ebd.:23). Chemische Verwitterung kann aber auch z.B. beim Basalt zur verstärkten kantengerundeten Formausbildung beitragen (hierzu ebd.:24).

Alle Moränen zeigen hingegen trotz der größeren Variationsbreite ein deutliches, bereits nach etwa $100 \mathrm{~km}$ auftretendes Maximum im kantengerundeten Bereich, wobei alle anderen Bereiche schwach ausgebildet sind (ebd.:24 f.). Seitenmoränen zeigen infolge Hangschuttzuführung gegenüber Grund- und Endmoränen hohe Werte im kantigen Bereich an, wobei letztgenannte bei Zurücktreten der Gruppen kantig und kantengerundet höhere Zurundungsgrade infolge Schmelzwasserbeteiligung aufweisen (ebd.:26). Nach ebd.:26, 29 könnten sich würmeiszeitliche von rezenten Moränen durch deren geringeren Zurundunsgrad, wohl infolge des kalten Klimas, unterscheiden. Zudem sollten die Bewegungsprozesse der 
Gletscher in die Analyse mit einbezogen werden (vgl. Fischer 1966:5). Facetten auf den Gesteinen, die infolge schiebenden Transports unter Druck bei Moränen zu 20-40 \% entstehen, trennen glaziale Blöcke eindeutig von fluvialen Schottern (vgl. Reichelt 1964:65). Wenn eine Verschachtelung mit fluvialen Prozessen gegeben ist, dann verändern sich die Rundungsgrade (hierzu Leser 1977:103).

Bei fluvialen Akkumulationen zeigen sich deutliche Minima oder sogar keinerlei Ausbildung im kantigen und kantengerundeten Bereich, dagegen Maxima in höheren Zurundungsgraden (vgl. Poser, Hövermann 1952:27). Stoßweiser und turbulenter Transport in Wildbächen führt gegenüber quasilaminarem oder strömendem Abfluss zu mehr Kantenerneuerungen (ebd.:31; vgl. Fischer 1966:5).

\subsection{Situmetrie}

„Als Situmetrie wird die Methode bezeichnet, mit welcher die quantitative Bestimmung der Grobsedimentkomponenten-Einregelung erfolgt [...]. “ (Leser 1977:227). Vorreiter solcher systematischen Längsachseneinregelungsmessungen waren Richter (1932, 1933) ${ }^{38}$ und Hövermann, Poser $\left(1951^{39}\right.$, 1952) (s.h. Stäblein 1970:75). Ziel dieser Anwendung ist es, aus der Hauptausrichtung der Längsachsen Transportprozess oder -richtung abzuleiten (vgl. Leser 1977:230). Dies ist nur möglich, wenn einer dieser beiden Aspekte bekannt ist (ebd.:228; vgl. Stäblein 1970:73). „Aufgrund des Spektrums der Längsachsenrichtungen im Sediment allein ohne weitere Annahmen wäre man ratlos. " (Stäblein 1970:75). Einflussfaktoren für die Einregelung stellen Größe und Form der Grobsedimente, Untergrundbeschaffenheit sowie Transportart und -geschwindigkeit dar (vgl. ebd.:80, 118). Nichtsdestotrotz können die Längsachseneinregelungen aller Gesteine, gleich welcher mineralischen Zusammensetzung, bestimmt werden (vgl. Köster 1964:203).

Für die vorliegende Arbeit waren die horizontalen Längsachseneinregelungen in Richtung der Fallrichtung der im nachfolgenden geschilderten Prozesse wesentlich.

Beim fluvialen Transport sind die Längsachsen infolge rollender Bewegung (vgl. Schreiner 1997:133) zu 40-60 \% in der Gruppe III angesiedelt, also senkrecht zur Fließrichtung

\footnotetext{
${ }^{38}$ Richter, K. (1932): Die Bewegungsrichtung des Inlandeises, rekonstruiert aus den Kritzen und Längsachsen der Geschiebe. Die Bewegungsrichtung des Inlandeises, rekonstruiert aus den Kritzen und Längsachsen der Geschiebe. In: Zeitschr. f. Geschiebeforschung und Flachlandgeol, Bd. VIII. Berlin. (S. 62-66); Richter, K. (1933): Gefüge und Zusammensetzung des norddeutschen Jungmoränengebietes. Abh. Geol. Pal. Inst. Univ. Greifswald, 11. (S. 1-63)

39 Hövermann, J.; Poser, H. (1951): Untersuchungen zur pleistozänen Harzvergletscherung. In: Abh. Braunschweig. Wiss. Ges., 3. Braunschweig. (S. 61-115)
} 
ausgebildet, wobei die Gruppe der über $45^{\circ}$ geneigten sehr wenig vertreten ist (Hövermann, Poser $^{40}$ zitiert nach: Leser 1977:235). Gruppe II kann ebenfalls Prozente in diesem Bereich anzeigen (hierzu Stäblein 1970:Tab. 9). Das gilt aber hauptsächlich für Flachland- bzw. Gebirgsvorlandflüsse, wodurch die typische, gegen die Strömungsrichtung einfallende (ebd.:85), dachziegelartige Lagerung entsteht (vgl. Leser 1977:227, Abb. 61). Bei Gebirgsflüssen zeigen die Längsachsen in Richtung der Fließrichtung (ebd.:227, Abb. 61), wobei diese Einregelungsart Ausnahmefälle darstellen soll (vgl. Schreiner 1997:135). Bei Wildbachablagerungen beispielsweise in Alpen- und Harztälern sind die Längsachsen senkrecht zur Fließrichtung mit einem zweiten Maximum in Fließrichtung eingeregelt (vgl. Fischer 1966:6; vgl. Reichelt 1964:65). Eine Transportrichtung kann bei Schotterfeldern im einfachsten Fall aus dem Gefälle der Oberfläche abgeleitet werden (vgl. Schreiner 1997:135).

Längsachseneinregelungen glazifluvialer Schotter unterscheiden sich nur unwesentlich von denen fluvialer und sind somit überwiegend quer und dachziegelförmig eingeregelt (vgl. Stäblein 1970:80, 82, 117).

„Demgegenüber zeigen eistransportierte Geschiebe nur geringe Neigung, eine bestimmte Achsenrichtung einzunehmen; immerhin kann man in manchen Fällen ein Maximum feststellen, wie bei den Grobsedimentkomponenten der Grundmoräne. “ (Leser 1977:227). Diese regeln sich aufgrund gleitender Bewegungen hauptsächlich in Eisstromrichtung ein (vgl. Schreiner 1997:133), was mit Scherprozessen in Verbindung gebracht werden kann (vgl. Evenson 1971:355). Gelangen im Gletscher Gesteine an die Oberfläche, wird deren Einregelung verändert (vgl. Goldthwait 1971:20). Nach Holmes $(1941)^{41}$ zitiert nach: Evenson (1971:355 f.) tendieren Moränen zu Einregelungen entgegen des Eisschubs parallel zur Fließrichtung oder durch Drehbewegungen quer zu dieser. Für die parallele Einregelung und die Längsachsenneigung entgegen der Fließrichtung wurden drei Theorien aufgestellt: Eisschub, Neigung und Moränenschub (ebd.:357-360). Quereinregelungen könnten mit einem zeitlich ausgedehnten Fließen (hierzu auch Taylor $1923^{42}$ zitiert nach: Evenson 1971:356) und häufigen Steinkollisionen in Verbindung gebracht werden (ebd.:363).

\footnotetext{
${ }^{40}$ siehe Quelle Hövermann, Poser (1951) in der Fußnote

${ }^{41}$ Holmes, C.D. (1941): Till Fabric: Geol. Soc. America Bull., v. 52. (S. 1299-1354)

42 Taylor, G.I. (1923): The motion of ellipsoidal particles in a viscous fluid: Royal Soc. London Proc. Ser. A., v. 103, no. 720. (S. 58-61)
} 
Hövermann, Poser (1951:79-85) ${ }^{43}$ und Schulz (1956:63) ${ }^{44}$ zitiert nach: Köster (1960:89) nahmen für Moränen eine $30 \%$-ige Einregelung in Gruppe I und eine ungefähr gleichmäßige Verteilung an. Auch Richter (1932:63) ${ }^{45}$ zitiert nach: Köster (1960:88) verwies auf eine solche Einregelung, wobei er diese Aussage auf fingernagel- bis handgroße Geschiebe einschränkte. Moränen weisen ein Maximum von $30 \%$ in der Gruppe I auf, wobei dieses durch unterschiedliche Transportwege, Eisschmelzvorgänge und Solifluktionsmaterialzufuhr variabel ist (Hövermann, Poser $^{46}$ zitiert nach: Leser 1977:235). Stauchmoränen weisen einen hohen Anteil über $50 \%$ in der IV. Gruppe auf (Hövermann, Poser $^{47}$ zitiert nach: Leser 1977:235). Endmoränen zeigen häufig keine bedeutende Einregelung (vgl. Fischer 1966:6). Stromrichtungsschwankungen sowie Umlagerungsprozesse durch z.B. Bodenfrost können diese typischen Einregelungen jedoch abändern (vgl. Köster 1960:88; vgl. Köster 1964:200). Bei Grund- und Fließmoränen sind die Längsachsen zumeist gegen die Fließrichtung, aber auch in Fließrichtung geneigt (vgl. Schreiner 1997:134). Nach Kuhle, Roesrath (1990:76) weisen End- und Grundmoränen mehr als $30 \%$ quergelagerte Blöcke und Ufermoränen 30 bis $40 \%$ parallel zur Gletscherfließrichtung eingeregelte auf. Die Gesteinseinregelung in einer präexistierenden Moräne kann aber auch durch eine erneute Gletscherüberfahrung modifiziert werden bzw. die Gesteine neu orientiert werden (vgl. Ramsden, Westgate 1971:335). Daraus können auch abweichende oder zerstreute Einregelungen resultieren (vgl. Schreiner 1997:134). Aber auch andere Umlagerungsprozesse - wie etwa Rutschungen können zur Längsachsenneigungsveränderung führen (hierzu Evenson 1971:362) oder auch fluviale Prozesse (vgl. Leser 1977:103).

Murfächer zeigen eine ähnliche Einregelung wie Moränen in Bewegungsrichtung, aber mit einem geringeren Maximum in Gruppe I und einem Minimum in Gruppe II (vgl. Fischer 1966:6).

Solifluktions- bzw. Frostverlagerungsprozesse sind durch einen Peak von 55-75 \% in Bewegungsrichtung charakterisiert, wobei die Längsachsen selten im Bereich der Gruppen III und IV (< $10 \%$ vgl. Hövermann, Poser 1951:79-85 ${ }^{48}$ und Schulz 1956:63 ${ }^{49}$ zitiert nach: Köster 1960:89) eingeregelt sind (Hövermann, Poser $^{50}$ zitiert nach: Leser 1977:235; vgl.

\footnotetext{
${ }^{43}$ siehe Quelle Hövermann, Poser (1951) in der Fußnote

${ }^{44}$ Schulz, H. (1956): Über neuere Forschungsmethoden in der Geomorphologie. In: Geogr. Berichte (Mitt. d. Geogr. Gesellsch. in der DDR), 1. Jg. (S. 53-64)

${ }^{45}$ siehe Quelle Richter (1932) in der Fußnote

${ }^{46}$ siehe Quelle Hövermann, Poser (1951) in der Fußnote und (1952)

${ }^{47}$ siehe Quelle Hövermann, Poser (1951) in der Fußnote und (1952)

${ }^{48}$ siehe Quelle Hövermann, Poser (1951) in der Fußnote

${ }^{49}$ siehe Quelle Schulz (1956) in der Fußnote

${ }^{50}$ siehe Quelle Hövermann, Poser (1951) in der Fußnote und (1952)
} 
Leser 1977:227). Nach nur wenigen hundert Metern kann die Einregelung charakteristisch

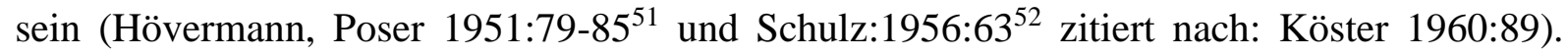
Eine solifluidale Einregelung kann sich nur bei hinreichender Durchfeuchtung ausbilden, die bei pleistozäner gegenüber rezenter Solifluktion vorwiegend gegeben ist (vgl. Köster 1964:201; vgl. Köster 1960:89). Beim Hangschutt zeigt die maximale Anzahl der Längsachsen die Transportrichtung an (vgl. Stäblein 1970:75).

Zusammenfassend ist zu sagen, dass fluviale Grobsedimente hauptsächlich in der günstigsten Angriffsstellung transportiert werden, Solifluktions-, Schutt- und Moränenmaterial hingegen nach dem geringsten Widerstand. Dennoch kann es vorkommen, dass Sedimente identischer Genese unterschiedlich eingeregelt sind. (vgl. Leser 1977:233-235)

\section{VORGEHENSWEISE}

$\mathrm{Zu}$ Beginn einer Längsachseneinregelungsmessung werden vier gleiche Bereiche mit jeweils 50 mal $50 \mathrm{~cm}$ Ausmaß ausgemessen und abgesteckt, damit ein Stichprobenbereich von $1 \mathrm{mal}$ $1 \mathrm{~m}$ entsteht und jeweils 25 Grobsedimente pro Viertel entnommen werden können (hierzu Stäblein 1970:122). Der Boden wird ca. 0,3 m tief in den Aufschluss abgetragen (hierzu Schreiner 1997:133). Nun wurden von oben her Gesteine vorsichtig herausgelöst (hierzu ebd.:133) und die Längsachsen in der Horizontalen in Richtung der Fallrichtung mit einer vorgefertigten Einregelungstafel in Form eines Vollkreises (hierzu ebd.:134; hierzu Hubbard, Glasser 2005:255), welcher mit seiner $0^{\circ}$ Nordrichtung senkrecht zur Aufschlusswand angelegt wurde, bestimmt. Dadurch konnten ebenfalls die Fallrichtungen der Grobsedimente - Gruppen I-III unter $45^{\circ}$ - mit einbezogen (hierzu Schreiner 1997:133; hierzu Hubbard, Glasser 2005:252) und die Maxima außerordentlich gut herausgestellt werden (vgl. Stäblein 1970:82). Da laut Goudie (1998:156), Schreiner (1997:133) und Hubbard, Glasser (2005:255) zumindest 50 Messungen pro Aufschluss nötig sind, wurden jeweils 100 vorgenommen.

Damit die Einregelungsmessungen in die entsprechenden Gruppen, angelehnt an die von Hövermann und Poser (1951), eingeordnet werden konnten, wurden die Ergebnisse aus dem Vollkreis $\left(0-360^{\circ}\right)$ übersichtshalber auf Nordrichtung und auf einen Halbkreis (90 bis $270{ }^{\circ}$ ) umgerechnet. Da „[...] die Zusammenfassung der Achsenrichtungen auf je $30^{\circ}$ für die Analyse genügt." (Leser 1977:230), ergaben sich folgende Einregelungswerte für die

\footnotetext{
${ }^{51}$ siehe Quelle Hövermann, Poser (1951) in der Fußnote

${ }^{52}$ siehe Quelle Schulz (1956) in der Fußnote
} 
Gruppen: III von $90-120^{\circ}$ und $240-270^{\circ}$, II von $120-150^{\circ}$ und $210-240^{\circ}$ sowie I von 150 $210^{\circ}$. Messwerte, die genau auf die Übergangsbereiche der Gruppen fielen (III / II bei $120^{\circ}$ und $240^{\circ}$; II / I bei $150^{\circ}$ und $210^{\circ}$ ), wurden zu gleichen Teilen auf die entsprechend angrenzenden Gruppen verteilt. War die Anzahl der Werte in den Übergangsbereichen jedoch ungerade, wurden diese Gesteine nicht den Gruppen zugeordnet und somit generell außer Betracht gelassen. Gebrochene Gesteine (hierzu Köster 1964:143) und solche mit einer Neigung von über $45^{\circ}$ (hierzu Stäblein 1970:122) wurden nicht eingemessen, aber zusätzlich registriert und der Klasse IV (hierzu Hövermann und Poser 1951) zugeordnet. Alle Klassen wurden im Nachhinein grafisch in Form von Histogrammen bzw. Situgrammen dargestellt.

Bei der Längsachseneinregelung sollte sich auf deutlich längliche Gesteine (vgl. Schreiner 1997:133) mit einem Längen-Breitenverhältnis größer als drei zu zwei (vgl. Hubbard, Glasser 2005:255) beschränkt werden. Solche Gesteine sind in Fig. 8.9 bei ebd.:236 zu betrachten. Die Größenklassen 2 bis 15, maximal $20 \mathrm{~cm}$, sind vorzuziehen; kleinere Gesteine liefern keine deutlichen Ergebnisse (vgl. Leser 1977:228). Hubbard, Glasser (2005:255) deuteten dagegen darauf hin, dass z.B. Benn $(1995)^{53}$ Gesteine von 30 bis 125 mm Größe untersuchte. Auch Lineback (1971:333) untersuchte die Längsachsen von sehr, 5 bis 25 mm, kleinen moränischen Gesteinen. Laut der Klassifikation der Gesteine von Kugler (1964) ${ }^{54}$ zitiert nach: Leser (1977:88) befinden sich diese dann im Korngrößenbereich der Steine: Geröll, Schotter und Schutt. Da auch Moränen zu untersuchen waren, wurde nicht ganz klar, warum die Blöcke, die ausschließlich nur durch glaziale Prozesse bewegt werden konnten, nicht in diese Methode bzw. Arbeitstechnik eingebunden werden sollten. Köster (1960:88), hierzu auch Köster (1964:200), ging auf diesen Sachverhalt wie folgt ein: „Blöcke verhalten sich beim Transport turbulent und sind daher für die Untersuchung unbrauchbar.". Bei der vorliegenden Arbeit wurden diese Blöcke trotzdem zusätzlich auf deren ungefähre Längsachseneinregelung im Gelände untersucht. Somit wurden alle Korngrößenbereiche ab 2 cm Größe in die Analysen mit einbezogen, wobei von den 2 bis $15 \mathrm{~cm}$ großen Gesteinen jeweils 100 Exemplare untersucht wurden, von den größeren dagegen nur wenige.

\footnotetext{
${ }^{53}$ Benn, D.I. (1995): Fabric signature of till deformation, Breidamerkurjökull, Iceland. Sedimentology, 42. (S. 735-747)

${ }^{54}$ Kugler, H. (1964): Die geomorphologische Reliefanalyse als Grundlage großmaßstäbiger geomorphologischer Kartierung. In: Wiss. Veröff. Dt. Inst. F. Länderkunde, N. F. 21/22, Leipzig. (S. 541-655)
} 


\subsection{Petrographische Zusammensetzung}

Anhand der petrographischen Zusammensetzung von glazialen und fluvialen Akkumulationen können Aussagen über das Einzugsgebiet, einstige Fließrichtungen und eventuell über das relative Alter getroffen werden (vgl. Schreiner 1997:139). Es erweist sich jedoch als sehr schwierig, ein Alter zu bestimmen, , [...] da unterschiedlich altes Material in den Transport eingehen kann. “ (Bremer 1989:28). Umso größer das Einzugsgebiet ist, desto höher auch die Anzahl der petrographischen bzw. mineralischen Verschiedenheiten. „Extremumfang erreicht sie mit den Ablagerungen im Einflußgebiet der Inlandeise. “(Leser 1977:206).

Aussagen über die Transportstrecke und über den regionalen geologischen Untergrund können ebenfalls getroffen werden (vgl. Stäblein 1970:33). „Das Auslesebild ist gewöhnlich umso klarer, je älter die Schotter sind und je weiter sie sich vom Liefergebiet entfernt befinden, weil beim Transport die wenigwiderständigen Gesteine meistens zermahlen werden. Allerdings ist bei alten Schottern auch die postsedimentäre Verwitterungsauslese mitzuberücksichtigen, [...]. “ (Leser 1977:244). Da der Transportweg bei Glazialablagerungen enorm lang sein kann, ist die Bestimmung der petrographischen Zusammensetzung für die Quartärgeologie bzw. Glazialgeomorphologie von enormer Wichtigkeit (vgl. Leser 1977:245). Die Festlegung von Leitgesteinen vereinfacht die Forschungsarbeiten - gerade bei Geschiebe- und glazifluvialer Schotteranalyse (hierzu Stäblein 1970:21), weil Herkunftsort und Transportweg besser nachzuvollziehen sind (vgl. Leser 1977:206). Leitgesteine oder sedimente sind solch außergewöhnliche Materialien, die ,[...] ausschließlich in einem abgrenzbaren Gebiet anstehend vorkommen. “ (Stäblein 1970:21).

Glaziale Sedimente von ein und derselben Eismasse müssen eine ähnliche Spannweite von Gesteinstypen aufweisen (vgl. Bennett, Glasser 1996:21).

\section{VORGEHENSWEISE}

Parallel zu den Messungen der Längsachseneinregelungen wurden die Gesteinsarten, d.h. pro Aufschluss jeweils 100 Exemplare (hierzu Stäblein 1970:123 und Köster 1964:207) der Größen 2 bis $20 \mathrm{~cm}$, bestimmt. Leser (1977:246) vertrat aber die Position, dass hier 100 Grobsedimente nicht genügen. Deswegen durften die Befunde dieser Messung nicht überschätzt werden. Zur Bestimmung bzw. Abgrenzung der Gesteine untereinander wurden diese mit Hilfe eines Geologenhammers frisch aufgeschlagen. Durch Hinzunahme von geologischen Karten konnten anhand der regionalen und lokalen geologischen Bedingungen 
die vor Ort vorkommenden Gesteine von den erratischen, nicht vor Ort anstehenden, abgegrenzt werden (hierzu Hubbard, Glasser 2005:237 ff.). Die prozentuale Verteilung der petrographischen Zusammensetzung eines Aufschlusses wurde grafisch in einem Petrogramm bzw. Prozentkreisdiagramm dargestellt (hierzu Stäblein 1970:19).

\subsubsection{Feinsedimente}

Zur Unterstützung der Feldbefunde wurden Feinsedimente untersucht: Die Laborarbeiten „[...] sollen die Geländearbeit nicht ersetzen, sondern sind [...] Verfeinerungen der Geländebeobachtungstechniken mit anderen Mitteln, [...].“ (Leser 1977:197). Hierbei wurden die Parameter Korngröße, Kornform, Kalkgehalt, Wassergehalt, organische Substanz und Sedimentfarbe berücksichtigt. „,...] Korngrößenanalysen, $\mathrm{pH}$-Wert- oder $\mathrm{CaCO}_{3^{-}}$ Bestimmungen sagen selten etwas direkt zum vorzeitlichen geomorphologischen Prozeß (manchmal auch kaum etwas zum rezenten) aus, [...]. “ (ebd.:197). Somit sind für die Grobund Feinsedimentanalyse Geländebeobachtungen und Kartierungen von enormer Wichtigkeit, wobei die Labordaten mit den Feldbefunden in Beziehung $\mathrm{zu}$ stellen sind und bei der Interpretation in ihrer Bedeutung nicht überschätzt werden dürfen (vgl. ebd.:14, 277).

\subsection{Probenentnahme}

Bei den Geländearbeiten wurden 18 Sedimentproben entnommen, anhand deren im Labor Skelettanteils-, Korngrößen- und morphoskopische Analysen, Kalkgehalts-, Wassergehaltsorganische Substanz- und Farbbestimmungen durchgeführt wurden. Hierbei wurden an einigen Stellen zum Vergleich zwei Proben an einem Ort entnommen. Diese sedimentologischen und bodenkundlichen Untersuchungen sind für eine geomorphologische Reliefanalyse von großer Relevanz, da „,[...] Sedimente und Böden wichtige Bestandteile des oberflächennahen Untergrundes sind und weil sie als Korrelate für die genetische Deutung der Landformen eine große Rolle spielen. “ (Leser 1977:186). Die Probeentnahmen erfolgten an im Gelände existenten natürlichen Aufschlusswänden bzw. Steilhängen als Einzelproben (hierzu Köster 1964:225 f. und Hubbard, Glasser 2005:222) oder auch an künstlich hervorgerufenen Aufschlüssen (hierzu ebd.:222 und Leser 1977:184). Hierbei wurde darauf geachtet, repräsentative Sedimentproben zu entnehmen, sodass diese ein ungefähres Abbild des gesamten Sedimentgemenges darstellten (hierzu Köster 1964:224 und Leser 1977:190). Etwa 100 g Probenmaterial der Matrix - Ton bis Sand - etwa einer Moräne wurden bei vorheriger Aufschlussbeschreibung über die gesamten Korngrößenanteile für weitere Korngrößenuntersuchungen im Labor entnommen (vgl. Hubbard, Glasser 2005:248). Größere 
Komponenten in Gesteinsgröße wurden demnach heraus sortiert (hierzu ebd.:250). Da es sich hierbei um Feinsedimentanalysen - von Ton bis Sand - handelte, wurde dadurch die Repräsentativität der Probe nicht verändert (hierzu Leser 1977:190). Vor der Entnahme wurden die Aufschlüsse fotografiert, dokumentiert bzw. angesprochen (Lage - GPS Daten; Auffälligkeiten - wie hier beispielsweise Topographie, Farbe, Korngröße, Bodenart, Sortierung, Horizontierung) und so bearbeitet, dass frisches Lockermaterial frei lag (hierzu ebd.:185, 187 und Hubbard, Glasser 2005:222, 225 f.). "Carefully collect the matrix by scraping material into an open sample bag held beneath the desired deposit." (Hubbard, Glasser 2005:250). Zum Transport wurden die Proben in Plastikbeuteln verpackt (hierzu Leser 1977:192). Im Geographischen Institut in Göttingen konnten die Proben lufttrocknen (hierzu Rowell 1997:12).

\subsection{Skelettanteilsbestimmung}

Skelett bezeichnet den Grobsedimentbereich über 2 mm Größe (vgl. Rowell 1997:31). Für die Modalitäten der Probeentnahme stehen die Informationen unter Gliederungspunkt Probeentnahme. Vor den weiteren Untersuchungen der Sedimentproben musste das Grobvom Feinsediment getrennt werden.

\section{VORGEHENSWEISE}

Die Proben trockneten im Trockenschrank des Geographischen Instituts in Göttingen lufttrocken. Durch die Trennung des Grob- vom Feinsediment bei der Grenze von $2 \mathrm{~mm}$ Korndurchmesser (hierzu Leser 1977:201) wurde der Skelettanteil auswägbar und prozentual berechnet. Die somit vom Skelett getrennten lufttrockenen Feinbodenproben wurden für weitere Laboranalysen verwendet.

\subsection{Korngrößen}

Da sich die Korngrößenanteile verschiedener Ablagerungen voneinander unterscheiden bzw. typisch verteilen, können anhand der Korngrößenanalyse gesicherte Lockermaterialsbestimmungen vollzogen werden (vgl. Fischer 1966:7 f.; vgl. Sindowski 1957:240). Dadurch können Aussagen über die Sedimentation bzw. über die alluvialen Prozesse getroffen werden (vgl. Gee, Bauder 1986:384 f.). „Die Korngrößenanalyse oder granulometrische Analyse stellt die Zusammensetzung eines Gesteins, eines Lockersediments oder eines Bodens, d.h. eines Mineralkörnergemischs, nach Größengruppen fest. “ (Leser 1977:255). Die Einteilung der verschiedenen Korngrößen basiert auf deren mittleren 
Durchmessern (vgl. Stäblein 1970:6, Tab. 1; vgl. Leser 1977:Tab. 11). Da weitere Bodeneigenschaften von der Korngrößenverteilung abhängig sind, stellt sie die wichtigste Eigenschaft der o.g. Akkumulationen dar (ebd.:255). „Aus dem Verhältnis der Größengruppen zueinander lassen sich in manchen Fällen Schlüsse auf pedogenetische Prozesse und Vorgänge der exogenen Dynamik ziehen." (Leser 1977:256). Transportvorgänge spiegeln sich beispielsweise in der Zusammensetzung der Sedimente und deren Struktur, wie u.a. Schichtung und Einregelung, wider (vgl. Bremer 1989:28). Hierdurch können beispielsweise fluviale von glazialen Ablagerungen anhand des Ton- und Schluffgehaltes voneinander abgegrenzt werden (vgl. Kuhle 2001b:Fig. 27). Somit verweisen hohe Ton- und Schluffgehalte nicht auf einen fluvialen Transport (ebd.:Fig. 27). Ein Vorherrschen von Feinerde schließt eine starke Wasserführung aus, sodass ebenso dort enthaltene kantengerundete Gesteine nicht darauf zurückzuführen sind (hierzu Reichelt 1964:65). Häufig sind Sedimente aber polygenetisch (vgl. Bremer 1989:25 f.). Haupteinflussfaktoren der Korngrößenzusammensetzung einer Ablagerung sind Ausgangsmaterialkorngröße und Transportprozessgeschwindigkeit, wobei wiederum u.a. Transportart und Bodenrauhigkeit eine Rolle spielen (vgl. Sindowski 1957:240).

Aus den Korngrößenverteilungen kann die Sortierung abgeleitet werden: „Je weniger Kornfraktionen in einem Sortiment vorkommen desto besser ist die Sortierung, umso steiler die Summenkurve und dadurch umso kleiner der Abstand von Q3 und Q1, also auch So gleich 1. Je größer So umso schlechter die Sortierung." (Stäblein 1970:45). Je flacher eine Summenkurve, desto schlechter ist die Ablagerung sortiert (vgl. Sindowski 1957:239). Beispielsweise sind Strandsande gegenüber Flusssanden besser sortiert (ebd.:237). Die Sortierungswerte können verschiedenen Ablagerungstypen zugeordnet werden, variieren allerdings innerhalb von Sedimenten gleicher Genese und können sich mit anders entstandenen überlagern (vgl. Stäblein 1970:47, Tab. 5).

Dreimanis und Vagners $(1971: 237,241,244)$ gingen davon aus, dass die Feinmatrix einer Grundmoräne typischerweise bimodale oder auch trimodale - bei polymineralischer Zusammensetzung mit verschiedenen physikalischen Eigenschaften Korngrößenverteilungen kennzeichnen (hierzu auch Bennett, Glasser 1996:158). Diese als sog. 'terminal grades' bezeichneten bi- oder trimodalen Verteilungen stellen von der Mineralzusammensetzung - Form, Größe der Minerale im Gestein; Resistenz der Minerale gegenüber glazialen Prozessen wie Abrasion, Zerkleinern und Lösung - abhängige 
Endkorngrößenbereiche dar (vgl. Dreimanis, Vagners 1971:242 f., 245). Umso weiter eine Moräne transportiert wird, desto deutlicher werden solche Maxima in der Matrix ausgebildet (ebd.:237, 242). 'Terminal grades' sind aber auch in anderen klastischen Sedimenten vorhanden (ebd.:246). Feinsande sind das Endstadium von granitischen und metamorphen Gesteinen, Silt von Karbonaten und Tone von Schiefer (Dreimanis, Vagners 1971:237 zitiert nach: Goldthwait 1971:13).

"Glacigenic sediments typically comprise particles from the smallest fraction (clay) to the largest (boulders). ” (Hubbard, Glasser 2005:248). Moränen weisen gegenüber Murschutt und Flussablagerung einen bedeutenderen Anteil der Korngrößen unter $1 \mathrm{~mm}$ auf (bis zu 70 Gewichtsprozent), gröbere Fraktionen über $8 \mathrm{~mm}$ sind hingegen weniger vertreten (vgl. Fischer 1966:7). Ein geringer Anteil von Feinsand und Schluff bei z.B. Murfächern oder Gebirgsbächen kann auf Auswaschungsprozesse hinweisen (ebd.:7 f.).

\section{VORGEHENSWEISE}

Die ungefähre Korngrößenzusammensetzung der Aufschlüsse wurde im Vorhinein durch Fingertests bestimmt: "Sand feels gritty [...], silt feels silky [...] and clay feels sticky and will normally roll into a ball." (Hubbard, Glasser 2005:229). Zusätzlich konnten die Korngrößenzusammensetzungen der im Gelände entnommenen Proben mithilfe des kombinierten Sieb- und Sedimentations- bzw. Pipettverfahrens bestimmt werden. Sandfraktionen können nicht mit der Pipettanalyse ermittelt werden, da die Sedimentteilchen aufgrund ihrer Schwere zu schnell sinken würden, was zu erheblichen Analysefehlern führen würde (vgl. Leser 1977:266). „Daraus wird deutlich, weshalb die Grobfraktionen [...] mit der Siebanalyse ermittelt werden müssen. Die Pipettanalyse beschränkt sich auf die Schluffund Tonfraktion, wobei der Ton gewöhnlich nicht weiter unterteilt, [...] wird." (Leser 1977:267). Auch nach den Angaben von Krumbein (1938:93) lag die Grenze der Anwendungen des Sieb- und Pipettverfahrens bei $0,05 \mathrm{~mm}$.

Vor der Anwendung der Sieb- und Pipettanalyse wurde der Skelettanteil vom Feinsediment getrennt, welches letzteres für die Korngrößenanalyse interessant war. Da die feinen Lockermaterialien, jeweils $10 \mathrm{~g}$ je Sedimentprobe (hierzu Rowell 1997:46), für die Sieb- und Pipettanalyse frei von organischer Substanz und Bindemitteln sein mussten, wurden diese mit 30 \%-igem Wasserstoffperoxid in Bechergläsern und - nach dem Beseitigen des verbliebenen Wasserstoffperoxids mittels Erhitzen auf einem Sandbad - mit $25 \mathrm{ml}$ des Dispergierungsmittels Natriumphosphat in Schüttelflaschen auf einem mechanischen 
Schüttler zerstört bzw. gelöst (hierzu Leser 1977:258 f.; Schlichting, Blume, Stahr 1995:114; Kunze, Dixon 1986:95; Gee, Bauder 1986:390). „Dies ist notwendig, um Meßfehler durch Zusammenhaftungen zu verhindern, die eine Gröberkörnigkeit der Probe vortäuschen. Verbackene Mineralien [...] werden aus ihren Bindemitteln herausgelöst. Diese bestehen im wesentlichen aus tonigen, hämatitischen, kaolinitischen, kalkigen oder kieseligen Bestandteilen, [...]. “ (Leser 1977:257). Bindemittel können also vorwiegend Eisenoxid-, wie etwa Goethit und Hämatit, oder Karbonatkrusten sein (vgl. Gee, Bauder 1986:386, 390). Demzufolge sollen anhand der Korngrößenanalyse nur die Größen der mineralischen Komponenten bestimmt werden (vgl. Rowell 1997:46).

Um die Sandfraktionen - Grob-, Mittel-, und Feinsand - untereinander und die Sandfraktionen (63-2000 $\mu \mathrm{m})$ von den Schluff- und Tonfraktionen $(0-63 \mu \mathrm{m})$ nach der Atterberg-Skala (vgl. Leser 1977:Tab. 11) oder DIN 4188 / 1957 (vgl. Stäblein 1970:Tab. 1) zu trennen, wurden die Proben zuerst manuell nass und im Nachhinein trocken durch einen aufeinander gesetzten Siebsatz gesiebt (hierzu Leser 1977:259 f.; Schlichting, Blume, Stahr 1995:114). Eine Siebung wurde nur bei den Sandpartikeln durchgeführt, da der Bereich von 50 bis $2000 \mu \mathrm{m}$ den für Siebungen typischen darstellt (hierzu Gee, Bauder 1986:392). Diese Unterteilung der Korngrößenbereiche ist zudem laut Schlichting, Blume, Stahr (1995:115) die übliche.

Bei der Nasssiebung wurden die Suspensionen mit destilliertem Wasser durch die Siebsätze der Größe $63 \mu \mathrm{m}$ mit Hilfe von Trichtern in $1.000 \mathrm{ml}$ Glaszylinder hinein gespült (hierzu Schlichting, Blume, Stahr 1995:114). Die somit vom Schluff und Ton getrennten Sandfraktionen trockneten bei $105{ }^{\circ} \mathrm{C}$ im Trockenschrank und wurden anschließend mit den Siebsätzen 63, 200 und $630 \mu \mathrm{m}$ trocken voneinander getrennt und ausgewogen, wobei die Fraktionen unter $63 \mu \mathrm{m}$ mit Hilfe eines Pinsels in die Glaszylinder gegeben wurden (hierzu ebd.:114). Hierbei konnten Verluste infolge der Staubwirkung auftreten (hierzu Köster 1960:112). Bei der Trockensiebung wurde darauf geachtet, alle Sedimentproben in etwa durch die gleiche Bewegungsdynamik (hierzu Köster 1964:60) und gleich lang zu sieben. Da laut Köster (1960:94) Quarzkörner größer 0,15 mm schon nach vier Minuten sehr gut gesiebt sind, konnte sich hier - da vorher die Ton- und Schlufffraktionen durch Nasssiebung von den Sandfraktionen getrennt wurden - an diese Zeit angelehnt werden. Alle gesiebten Sandfraktionen wurden für die Kornformbestimmungen aus den Sieben mit Hilfe eines Pinsels aussortiert bzw. eingetuitet. 
Ton (0-2 $\mu \mathrm{m})$ wurde anhand der Pipettanalyse von Grob-, Mittel-, und Feinschluff getrennt. Nach einer Homogenisierung der Ton- und Schlufffraktionen durch Hin- und Herschwenken der Glaszylinder, wurden in bestimmten Zeitabständen aus 15 und $5 \mathrm{~cm}$ Tiefe jeweils zwei Proben mit der Pipette (hierzu Köster 1964:Abb. 9) entnommen, bei $105{ }^{\circ} \mathrm{C}$ getrocknet und das Trockengewicht ausgewogen. Die Pipettmethode zielt darauf ab, „[...], daß sich Konzentrationsveränderungen in einer sich setzenden Suspension durch Entnahme definierter Volumina per Pipette verfolgen lassen. “ (Goudie 1998:128). Die Eintauchtiefen der Pipette in den Glaszylindern hängen von den Temperaturen der Suspension ab (vgl. Leser 1977:Tab. 12). „Das Korngemisch der Probe, [...], trennt sich also auf Grund der verschiedenen Sinkgeschwindigkeiten der verschieden großen Körner. “ (Leser 1977:264). Die Berechnungen zur Korngrößenbestimmung basieren auf dem Stokes`schen Fallgesetz (vgl. Goudie 1998:128; vgl. Köster 1960:47), wobei die Menge des vorher zugeführten Dispergierungsmittels mit einbezogen wird (vgl. Leser 1977:266). Mit der Formel von Stokes $(1845)^{55}$ zitiert nach: Köster (1964) kann durch den zu berechnenden Widerstand der kugeligen Körner gegenüber dem Medium bzw. einer ruhenden Flüssigkeit anhand der gemessenen Fallgeschwindigkeit auf die Größe der Sedimente geschlossen werden (vgl. Köster 1964:67 ff.). Die Beschreibung des Analysenablaufs findet sich bei Köster (1964:80 ff.), bei Leser (1977:266) und bei Schlichting, Blume, Stahr (1995:114). Temperaturschwankungen, die Viskositätsveränderungen und Konvektionsströme auslösen können (vgl. Köster 1964:70, 122 f.), wurden durch die Ausführung in einem thermokonstanten Raum ausgeschaltet.

Alle insgesamt ausgewogenen Gewichtsanteile und die summierten Hauptkorngrößenklassen der Feinerden wurden prozentual als Korngrößenhisto- bzw. Granulogramm mit errechneten Kornverteilungssummenkurven visualisiert (hierzu Schlichting, Blume, Stahr 1995:116 und v. Engelhardt 1973:132). Letztgenannte Kurven waren für den Vergleich mit abweichend unterteilten Korngrößendiagrammen und für das Ablesen der Quartilmaße 25, 50 und $75 \%$ von Vorteil (vgl. Stäblein 1970:43 ff.). „Beim Wert Q1 gehören also 25\% einem kleineren und 75\% einem größeren Durchmesser und beim Wert Q3 75\% einem kleineren und 25\% einem größeren Durchmesser an. Aus der Lage von Q1 und Q3 können Schlüsse auf eine Feinverteilung gezogen werden." (Köster 1960:140). Da die erarbeiteten Korngrößeneinteilungen die einzelnen Fraktionen, wie z.B. Feinsand, in lediglich einer Gruppe darstellt und nicht weiter unterteilt, konnte der Sortierungskoeffizient nicht genau

\footnotetext{
${ }^{55}$ Quelle bei Köster (1964) nicht angegeben
} 
berechnet werden. Allerdings konnten anhand des Summenkurvenverlaufes diverse Schlussfolgerungen getroffen werden.

\subsection{Kornformen / Kornbearbeitung}

„Die Bedeutung der Mineralkornanalyse liegt für die Geomorphologie in der Möglichkeit, Sedimentkörper nicht nur wie bisher durch ihre Form zu beschreiben, sondern über die Kenntnis des Bearbeitungsgrades ihres Materials zur Genesis der Form und damit zu einer klimatisch morphologischen Aussage fortzuschreiten." (Pachur 1966:22). Infolgedessen wurden zur Unterstützung der morphologischen Befunde die Sandkörner der im Gelände entnommenen Sedimentproben - zusätzlich zur angewendeten Korngrößenanalyse - mittels der morphoskopischen Analyse nach Cailleux (1952) untersucht. Diese Methode bzw. Abeitstechnik basiert darauf, dass die Kornoberflächengestaltung mit der Kornform in Verbindung gebracht wird (vgl. Pachur 1966:5). Hierbei sind Quarzsandkörner im Korngrößenbereich von 0 bis 1,6 mm gemeint (vgl. Cailleux 1952:15).

Cailleux (1952:16) unterschied drei maßgebliche Korntypen voneinander: 'Unbearbeitet', 'Abgerundet-glänzend' und 'Rund-matt'. Zum erstgenannten Typ zählen scharfkantige und unregelmäßige, frisch verwitterte, nach kurzem Transportweg sedimentierte oder ehemals runde Körner, die zerschlagen wurden (vgl. Pachur 1966:5, Abb. 1 und 2). Dadurch geht das unter dem Auflichtmikroskop zu betrachtende Reflexionsbild nur von den Kristallflächen aus (vgl. Cailleux 1952:16, Abb. 5). Somit erscheinen solche Bilder unbearbeiteter Körner nur teilweise hell und klar und werden bei Verschieben des Objektträgers oder der Lichtquelle schlagartig undeutlich (ebd.:16). „Übereinstimmend mit Cailleux (1948) wurde erkannt, daß dieser Korntyp charakteristisch für Sedimente aus Gebirgsflüssen und für Verwitterungsprodukte kristalliner Gesteine ist. “(Pachur 1966:5). Mahaney (1995:506) wies darauf hin, dass Moränen glazial gebrochene bzw. unbearbeitete Körner unterschiedlicher Ausbildungsstadien beinhalten, wobei einige Moränen auch durch Schmelzwasser oder durch äolische Prozesse gerundete Körner aufweisen. Glazial gebrochene Körner können nach Mahaney (1995:488) aber erst ab einer Eismächtigkeit von über 200 m entstehen. Körner, die durch glaziale Prozesse verändert wurden, können demnach nicht von denen durch Verwitterungsprozesse entstandenen unterschieden werden (hierzu Pachur 1966:7). Pettijohn (1938:303) verwies jedoch darauf, dass Wentworth (1936:85) ${ }^{56}$ glaziale Körner durch Schrammen charakterisierte. Somit nahm Pettijohn (1938:Tab. 35/307) diese Schrammen

\footnotetext{
${ }^{56}$ Wentworth, C. K. (1936): An analysis of the shapes of glacial cobbles. Jour. Sed. Petrology, vol. 6.
} 
unter der Kornoberflächeneigenschaft der Begrifflichkeit rau mit auf: 'striated' / 'usually glacial action'; 'faceted' / 'secondary growth'; 'frosted' / 'groundglass surface'; 'etched' / 'solvent action'; 'pitted'. Auch Goldthwait (1971:19) meinte, dass solche auf glazialen Mineralkörnern existieren. Moränen können Sedimentkörner verschiedenster Grade des 'glacial-crushing' aufweisen, aber auch vorverwitterte Körner, Quarzkörner mit lediglich Bruchstellen und glazifluvial oder äolisch gerundete (vgl. Mahaney 1995:506).

Abgerundet-glänzende Körner sind hingegen durch allmählich verschiebende Reflexionsbilder auszumachen (vgl. Cailleux 1952:16). Solche Körner sind typisch für fluviale, limnische und marine Prozesse, wobei sie auch stets in den glazialen Ablagerungen auftreten (vgl. Pachur 1966:5). Bei dem letztgenannten Korntyp 'Rund-matt' kann das Mineralkorn infolge krater- oder halbmondartiger, als Mattierung erscheinende (ebd.:5, Abb. 9), Oberflächenunebenheiten deutlich unter dem Auflichtmikroskop erkannt werden (vgl. Cailleux 1952:16 f.). Solche Körner mit sog. Perkussionstrichtern entstehen infolge äolischen Transportes (ebd.:17; vgl. Pachur 1966:5, Abb. 20). Fluviale sind von äolischen Körnern bei einer Größe von 0,7 mm am besten, aber auch infolge der Farbe - transparent gegenüber goldgelb bis rötlichgelb - unterscheidbar (vgl. Cailleux 1952:18; vgl. Pachur 1966:28, Abb. 3 und 4). Die Korngrößenfraktion 0,25 mm reagiert in der Regel am schnellsten auf die äolische Bearbeitung (ebd.:26). Bei den in Schwebe transportierten Kornfraktionen ist die Mattierung nicht mechanisch, sondern durch Verwitterungsprozesse erklärbar (ebd.:18). Weiteres Unterscheidungsmerkmal ist bei den chemisch verwitterten Körnern das ausgebildete Ätzmuster (ebd.:7). Quarzkörner sind allerdings gegenüber der Verwitterung sehr resistent, bei intensiver Verwitterung weisen sie jedoch Lösungskavernen auf (vgl. Bremer 1989:361).

Pachur (1966:16, 32) wandelte die Methode nach Cailleux etwas ab, indem er die Kornform von der Kornbearbeitung unterschied. Er sprach von Übergangskorntypen. Demzufolge können auch Oberflächenskulptierungen bei unbearbeiteten Körnern durch Verwitterungsvorgänge auftreten, äolische Körner glänzend-abgerundete Ecken oder fluviale Körner an exponierten Stellen Schäden aufweisen (ebd.:21, Abb. 10). „Somit erweitert sich die Zahl der drei Grundtypen [...] um die des mattierten-ungerundeten (Alimen 1951) und des glänzenden-ungerundeten Korns. “ (Pachur 1966:16). Jedoch ist eine Unterscheidung der glänzenden-ungerundeten von den in situ entstandenen Körnern wegen glänzender Kristallbruchflächen sehr schwierig (vgl. ebd.:16). Leser (1977:139) wies zudem darauf hin, dass mehrere Prozesse auf einem Korn ausgebildet sein können, aber der letzte wohl am 
deutlichsten ist. Auch Hubbard, Glasser (2005:264) meinten, dass Prozesse vor der Ablagerung, wie z.B. der des Transportes, sichtbar sein könnten. Der letzte stattgefundene Transportprozess ist wohl auf den Körnern am besten ausgebildet, wobei somit unterschiedliche Oberflächenstrukturen auf eine Durchmischung unterschiedlicher Sedimente und / oder auf eine unvollständige Überarbeitung hindeuten können (vgl. Pettijohn 1938:303 f.). Nichtsdestotrotz soll eine bestimmte Oberflächenausformung überwiegen (ebd.:304).

Eissele (1957) ${ }^{57}$ zitiert nach: Leser (1977:271) sah mit der wachsenden Rundung der Mineralkörner eine immer höhere Transportbeanspruchung: völlig eckige Körner - keine Beanspruchung, eckige - keine oder geringe, angerundete - mittlere, gerundete - hohe und gut gerundete - maximale. Cailleux zitiert nach: Pachur (1966:21) schloss ebenfalls aus dem Abnutzungsgrad glänzender Körner auf den Transportweg. Eine Anwendung dieses Ansatzes auf Eisrandablagerungen sah Pachur (1966:21) dagegen als problematisch an.

\section{VORGEHENSWEISE}

Die Durchführung der Analysen bzw. das Auszählen der Quarzkörner erfolgte anhand eines Auflichtmikroskops (Binokular) im Geographischen Institut in Göttingen, da „Nur bei Auflicht [...] die Oberflächenstrukturen des Kornes genügend scharf erkennbar. " (Pachur 1966:5) sind. Quarzkörner wurden an deren Farblosigkeit und häufig am muscheligen Bruch als solche erkannt; Feldspäte anhand der plattigen zwillingsbildenden Form sowie an den enormen Verwitterungsgraden gegenüber Quarz (vgl. Pettijohn 1938:443, 445). Hierbei wurde sich auf die im Voraus durch die Korngrößenanalyse getrennten Korngrößenbereiche Fein-, Mittel- und Grobsand beschränkt, wobei die Aufteilung der Körner in Korngrößenbereiche eine genauere Auswertung zur Folge haben sollte (hierzu Köster 1964:139). Quarz und Feldspat können im Sand- und Siltkorngrößenbereich durch Auszählen unter einem Mikroskop bestimmt werden (vgl. Jackson, Lim, Zelazny 1986:105). Da besonders die quantitative Bestimmung von Kornformen die zentralste Aufgabe der Morphometrie darstellt (vgl. Köster 1964:138), wurden maximal 539 Quarzkörner ausgezählt. Die Umgestaltung der Körner - speziell durch Mattierung und Polierung - war für eine geomorphologische Auswertung in Bezug auf den Standort hinzunehmbar, da nicht nur ein Korn, sondern mindestens über 100 Körner untersucht wurden (hierzu Pachur 1966:15). Das Hauptaugenmerk mit ca. 200-500 (hierzu Leser 1977:270) untersuchten Quarzkörnern lag auf

\footnotetext{
57 Eissele, K. (1957a): Kritische Betrachtungen einer Methode zur Bestimmung des Rundungsgrades von Sandkörnern. In: Neues Jb. f. Geol, Paläont., Mh.. (S. 410-419)
} 
der Mittelsandfraktion, damit ein Vergleich mit den Befunden anderer Forscher im Untersuchungsgebiet, wie etwa mit Kuhle (2005), möglich war. Der Bereich zwischen Grobsand und Feinsilt ist der geeignetste, wobei die optische Betrachtung des Grobsandes und Feinsiltes selber schwierig ist (vgl. Cady, Wildung, Drees 1986:187). Bei der Fein- und Grobsandformenanalyse wurde sich auf 100 Quarzkörner beschränkt, wobei selbst diese geringe Anzahl in der Grobsandfraktion - auch durch Siebung der gesamten Probe - oft nicht erreicht werden konnte. Um die Oberfläche genauestens deuten zu können, wurde die Vergrößerung bei der Betrachtung der Körner häufig geändert (hierzu Pachur 1966:5), wodurch ein einheitliches und vergleichbares Beobachten von Körnern unterschiedlicher Größe gegeben war (hierzu Cailleux 1952:15 f.). Die genannten Korngrößenbereiche wurden betrachtet, da Kornformen unterhalb der Grenze von minimal 0,10 mm (nach Guggenmoos $1934^{58}$ und Eißele 1957 ${ }^{59}$ ) oder maximal 0,07 mm (nach Russel und Taylor $1937^{60}$ ) nicht mehr richtig auszumachen sind (zitiert nach: Köster 1964:139). Auch die von Dücker (1937) ${ }^{61}$ zitiert nach: Pachur (1966:8) angenommene untere Korngrößengrenze durch Frostsprengung liegt bei 0,1 bis $0,01 \mathrm{~mm}$. Zudem endet die Kornbearbeitung bei fluvialer und äolischer Einwirkung im Feinsandbereich bzw. bei der Fraktion 0,125 mm (ebd.:6). Laut Kuhle, Roesrath (1990:60) werden Körner nur bis zu einer Größe von 0,25 mm durch Wassertransport zugerundet, die durch Wind bis auf 0,1 $\mathrm{mm}$. Ein weiterer Grund für die Untersuchung der Feinsandfraktion war, dass Quarz bei langen Transportwegen in diesem Bereich, vermutlich infolge der Abnutzung gröberkörniger Minerale, am besten konserviert sein soll (vgl. Mahaney 1995:488). Die obere Betrachtungsgrenze sollte zwischen 0,5 bzw. 0,7 und 1,6 mm (vgl. Köster 1964:140) im Grobsandbereich liegen, in welchem auch die Frostwirkung auf Quarzkörner der Größe 0,5 mm experimentell von Walter (1951) ${ }^{62}$ zitiert nach: Pachur (1966:7) nachgewiesen wurde.

Die ausgezählten Quarzsandkörner wurden vorher festgelegten Formklassen verschiedener Formeigenschaft zugeordnet und das prozentuale Vorkommen im Nachhinein grafisch dargestellt. Es wurde sich auf die fünfklassige Kornformeinteilung nach Guggenmoos

\footnotetext{
${ }^{58}$ Guggenmoos, T. (1934): Über Korngrößen und Kornformenverteilung von Sanden verschiedener geologischer Entstehung. In: Neues Jb. f. Min., Geol., Paläont., Abt. B, Abh. 72, Beil. Bd. (S. 429-487)

${ }^{59}$ Eissele, K. (1957a); Eissele, K. (1957b): Sedimentpetrographische Untersuchungen am Buntsandstein des Nordschwarzwaldes. Jb. d. Geol. Landesamtes Nr. 2. (S. 69-117)

${ }^{60}$ Russel, R.D.; Taylor, R.E. (1937): Roundness and shape of Mississippi river sands. In: J. Geol., Bd. 45. (S. 225-267)

${ }^{61}$ Dücker, A. (1937): Über Strukturböden im Riesengebirge. Ein Beitrag zum Bodenfrost- und Lößproblem. Ztschr. Dtsch. Geol. Ges. Bd. 89.

${ }^{62}$ Walter, W. (1951): Neue morphologisch-physikalische Erkenntnisse über die Flugsande und Dünen. RheinMain. Forschg. H. 31. (S. 1-34)
} 
$(1934)^{63}$, Russel und Taylor $(1937)^{64}$, Eissele $(1957)^{65}$ sowie Schultze, Muhs $(1967)^{66}$ bezogen (hierzu Leser 1977:269 f. und Köster 1964:183-188), wobei die Formklassen in der vorliegenden Arbeit etwas abgewandelt wurden: 'scharfkantig', 'kantig bis rundkantig', 'rundkantig bis angerundet', 'gerundet' und 'stark gerundet'.

Scharfkantige bzw. völlig eckige Mineralkörner wiesen nur Kanten, kantige bzw. eckige daneben auch schwach gerundete auf. Rundkantige bzw. angerundete erschienen überwiegend konvex gewölbt, wobei in der vorliegenden Arbeit unter 'angerundet' auch gebrochene gerundete Körner verstanden wurden. Gerundete Mineralkörner zeigten eine beginnende und stark gerundete bzw. gut gerundete eine deutlich ausgeprägte Kugelgestalt (hierzu Leser 1977:Abb. 72, Tab. 13 und Köster 1964:183-188).

Scharfkantige bis angerundete konnten der Gruppe glazial gebrochen / frisch verwittert, gerundete der fluvial polierten und stark gerundete der äolisch mattierten zugeordnet werden. Kantige Körner mit deren gering ausgebildeten Rundungen konnten eher wie bei Pettijohn 1938:445 (Fig. 232, h-i) - dort mit `angular grains, glacial outwash’ bezeichnet - mit glazifluvialen Prozessen in Verbindung gebracht werden und somit als eine Übergangsgruppe von glazial gebrochen und fluvial poliert gelten. So meinte auch Pachur (1966:25), dass angerundete und / oder polierte Flächenteile eines unbearbeiteten Kornes eine fluviale Bearbeitung erkennen lassen. Jedoch waren hierbei Variationen verschiedener Quarzarten nicht auszuschließen und die Befunde somit nur behutsam zu deuten. Da die Kornformen in den drei verschiedenen Korngrößenbereichen Fein-, Mittel- und Grobsand untersucht wurden, wurde davon ausgegangen, dass in den jeweiligen Größenklassen eine verschiedene Bearbeitung stattfand. Pachur (1966:10) kam zum Ergebnis, dass Körner verschiedener Größe trotz konstanter Bedingungen und homogenem Ausgangsmaterial Bearbeitungsunterschiede aufweisen. In der vorliegenden Arbeit wurde davon ausgegangen, dass kleinere Körner langsamer umgestaltet wurden als größere und somit eine Einwirkung länger andauern musste (hierzu ebd.:15). Besonders die Feinsandfraktion $(0,125 \mathrm{~mm})$ soll träge reagieren, wobei aber die Fehlerrate bei der Analyse am größten sein soll (ebd.:26). Die Kornformung und bearbeitung laufen ebenfalls nach Pachur $(1966: 10,16)$ nicht in der selben Zeit ab - die Kornformänderung dauert länger. Die Umgestaltung glänzender Körner zu mattierten dauert

\footnotetext{
${ }^{63}$ siehe Quelle Guggenmoos (1934) in der Fußnote

${ }^{64}$ siehe Quelle Russel und Taylor (1937) in der Fußnote

${ }^{65}$ siehe erste Quelle Eissele (1957) in der Fußnote

${ }^{66}$ Schultze, E,; Muhs, H. (1967): Bodenuntersuchungen für Ingenieurbauten. Berlin-Heidelberg-New York. (722 Seiten)
} 
nicht so lange wie die Bearbeitung von unbearbeiteten Körnern (ebd.:13). Somit konnte bei auftretenden fluvial polierten Körnern in allen Kornfraktionen auf eine intensive fluviale Bearbeitung geschlossen werden (hierzu ebd.:23).

Zudem wurden Rundungswerte nach Sindowski (1961) ${ }^{67}$ und Guggenmoos (1934) ${ }^{68}$ berechnet (hierzu Leser 1977:271). Beim erstgenannten ergaben sich Werte zwischen 1 (kantig) und 5 (stark gerundet). Der Rundungswert nach Guggenmoos ${ }^{69}$ zitiert nach: Leser (1977) gab hingegen folgendes an: „Bei einem Quotienten über 1 überwiegen kantengerundete und gerundete Formen, unter 1 überwiegen kantige und Körner mit beginnender Verrundung. “ (Leser 1977:271).

Rotbraune farbliche Veränderungen auf den Quarzsandkörnern konnten mit Eisenverbindungen in Zusammenhang gebracht werden (vgl. Schnitzer 1957:12). Hierunter zählen beispielsweise das gelb hellrote Goethit und das nahezu undurchsichtige Hämatit (vgl. Cady, Wilding, Drees 1986:197). Diese oft auf Quarzkörnern ausgebildete rötlichbraune Kruste deutet auf fossile und nicht auf rezente Ablagerungen hin (vgl. Pachur 1966:27). Quarz und Feldspat kommen oft in Böden vor, letztgenannter vor allem im Sand- und Siltbereich (vgl. Jackson, Lim, Zelazny 1986:104 f.). Quarz ist polymorph, wie z.B. der weniger resistente Cristobalit und der Tridymit, aber auch kristalliner Quarz (ebd.:105, 113). Einige Quarzkörner weisen „,...] Zurundungen durch Kieselsäureausscheidungen, [...]“ (Bremer 1989:285) auf.

\subsection{Kalkgehalt}

Der Kalkgehalt von Mineralböden kann mit Hilfe des Salzsäuretests bestimmt werden (hierzu Köster 1960:74; vgl. Ad-hoc-AG Boden 2005:168). Zum Kalkgehalt zählen die Verbindungen Calcium- und Magnesiumkarbonat (vgl. Rowell 1997:53). Durch den entweichenden Kohlenstoff, der in Form eines schwachen bis sehr starken Aufbrausens sichtund hörbar wird, wird der Kalkgehalt abgeleitet (vgl. Köster 1960:74). Ist kein Aufbrausen zu erkennen, liegt der Kalkgehalt unter 0,5\% und das Sediment wird als kalkfrei oder kalkarm bezeichnet (ebd.:74). Der Kalkgehalt von Moränen dient zur Festlegung des Liefergebietes; beim Vergleich dieser Gehalte untereinander können Aussagen darüber getroffen werden, ob dasselbe Liefergebiet vorrangig war (vgl. Steiger, Holowaychuk 1971:287).

\footnotetext{
${ }^{67}$ Sindowski, K.-H. (u.a.) (1961): Mineralogische, petrographische und geochemische Untersuchungsmethoden. In: Lehrb. d. Angew. Geol., Bd. I, Stuttgart. (S. 161-278)

${ }^{68}$ siehe Quelle Guggenmoos (1934) in der Fußnote

${ }^{69}$ siehe Quelle Guggenmoos (1934) in der Fußnote
} 


\section{VORGEHENSWEISE}

Der Kalkgehalt der Sedimentproben wurde im Labor bestimmt. Hierbei wurde tröpfchenweise verdünnte $10 \%$-ige Salzsäure auf das Sediment gegeben und anhand der Reaktionen der Kalkgehalt erfasst (hierzu Köster 1960:74 und Ad-hoc-AG Boden 2005:168).

\subsection{Wassergehalt}

Der Wassergehalt luftgetrockneter Lockermaterialien hängt von deren spezifischen Oberflächen bzw. von der Korngröße, von der Mineralogie der Tonminerale und des Humus (austauschbare Kationen verbinden sich mit Wasser) sowie von der relativen Luftfeuchte ab. Luftgetrocknete Tonböden weisen somit einen höheren Wassergehalt auf als Sandböden. (vgl. Rowell 1997:144, Abb. 5.6)

\section{VORGEHENSWEISE}

Für die Bestimmung des Wassergehaltes, der weiterhin für die Berechnung der organischen Substanz benötigt wurde, wurden anhand der direkten Wassergehaltsbestimmungsmethode Teile der vorher zwei Wochen luftgetrockneten Sedimentproben zwischen 100 und $110{ }^{\circ} \mathrm{C}$, also bei ca. $105{ }^{\circ} \mathrm{C}$, im Trockenschrank bis zur Gewichtskonstanz getrocknet (hierzu Leser 1977:252, 276 und Gardner 1986:493, 495 f.). Die Differenz des luftgetrockneten Sedimentes zum bei $105{ }^{\circ} \mathrm{C}$ getrockneten Sediment ergab den Wassergehalt in Gewichtsprozent (hierzu Leser 1977:252).

\subsection{Organische Substanz}

Die organische Substanz bezeichnet lebende, abgestorbene oder umgewandelte pflanzliche und tierische Stoffe und beinhaltet gegenüber den Huminstoffen auch Nichthuminstoffe (vgl. Leser 1977:276; vgl. Leser et al. 2001:590; vgl. Ad-hoc-AG Boden 2005:110). Sie kann im Labor durch Verbrennung bestimmt werden, wobei genauer betrachtet nicht nur die organische Substanz, sondern auch Tone und Sesquioxide dabei verglühen können (vgl. Rowell 1997:66).

Die organische Substanz ist in vergletscherten Gebieten bzw. in Moränen sehr gering vertreten oder gar nicht vorhanden, in Schwemm- und Seesedimenten jedoch enorm (vgl. Hubbard, Glasser 2005:266, 339 f.). 


\section{VORGEHENSWEISE}

Für die Bestimmung der organischen Substanz konnten die Proben für die Wassergehaltsbestimmung weiter verwendet und der Glühverlust bestimmt werden, dieser aber nur bei glühresistenten Mineralkörpern, z.B. quarzreichen (hierzu Schlichting, Blume, Stahr 1995:158). Demnach wurden diese Proben aus dem Trockenschrank mit der Temperatur von $105^{\circ} \mathrm{C}$ in den Muffelofen überführt (hierzu ebd.:159). Die Erwärmung des Materials auf $425{ }^{\circ} \mathrm{C}$ hat einen weiteren Wasserverlust zur Folge, wobei sich der gesamte Masseverlust als Glühverlust bezeichnet (vgl. Rowell 1997:77). Der größte Anteil der organischen Substanz verglüht jedoch auch schon bei $325{ }^{\circ} \mathrm{C}$. Nach Erreichen der Gewichtskonstanz wurde die organische Substanz anhand der Differenz des Gewichts der im Trockenschrank bei $105{ }^{\circ} \mathrm{C}$ und anschließend im Muffelofen bei $425{ }^{\circ} \mathrm{C}$ getrockneten Sedimente in Gewichtsprozent ermittelt (hierzu Leser 1977:276). Fehlerquellen liegen bei der Annahme, dass zwischen 105 und $430{ }^{\circ} \mathrm{C}$ nur Humusabbauprodukte entweichen, was z.B. bei hohen Ton- und Sesquioxidgehalten infolge der Kristallwasserabgabe nicht stimmt (vgl. Schlichting, Blume, Stahr 1995:159). Dieser Fehler kann größtenteils durch Subtraktion von 0,1 \% je \% Ton vermieden werden (ebd.:159).

Die organische Substanz konnte aber schon allein bei der Betrachtung der Proben anhand enthaltener Wurzeln, Äste oder durch eine schwarze / braune oder unreine Farbgebung zur Kenntnis genommen werden (hierzu Hubbard, Glasser 2005:228).

\subsection{Farbe}

Die Farbe von Lockermaterialen ist nicht nur von den Mineralgehalten, sondern auch vom Humusgehalt / der organischen Substanz abhängig: je höher der Gehalt des / der letzteren, desto dunkler die Farbgebung (vgl. Ad-hoc-AG Boden 2005:110). Daneben spielen Verwitterungs- bzw. Bodenbildungsprozesse und Feuchtigkeitsbedingungen eine Rolle (vgl. Leser 1977:251). Somit ist die Ansammlung von Eisenoxiden (rot, braun) und Mangan (schwarz) bedeutsam (vgl. Hubbard, Glasser 2005:266). Abweichende Farbgebungen können aber auch auf verschiedene Materialherkünfte bzw. eine unterschiedliche Lithologie hinweisen (ebd.:266).

\section{VORGEHENSWEISE}

Die Farbgebungen der im Gelände entnommenen Feinsedimentproben wurden im trockenen Zustand im Labor bestimmt, da sich der Feuchtigkeitsgrad innerhalb eines Aufschlusses und 
je Entnahmeort sehr unterscheiden kann (hierzu Leser 1977:251). Vor den Farbbestimmungen trockneten die Proben bei $105^{\circ} \mathrm{C}$, sodass der Wassergehalt gering war.

\subsection{Weitere von Forschern angewendete Methoden bzw. Arbeitstechniken}

\subsubsection{Datierungen}

Bei den Datierungsmethoden unterscheiden sich relative, die einen möglichen Zeitraum der Entstehung anzeigen, von absoluten, die ein numerisches Alter angeben (vgl. Hubbard, Glasser 2005:340).

\subsubsection{Relative Datierungen}

$\mathrm{Zu}$ den relativen Datierungsmethoden zählen 'Intact rock strength' - Intakte Gesteinsfestigkeit, 'Weathering rind thickness' - Verwitterungskrustenmächtigkeit, 'Weathering pits' - Narbenverwitterung, Lichenometrie, Dendrochronologie und -glaziologie, Biogeographie von Gletschervorländern, Biostratigraphie und Aminosäure-Geochronologie. Veränderungen der Gesteinsoberfläche durch Verwitterung (u.a. Farbe, Härte, Verwitterungskrusten) oder Pflanzenbewuchs sind also ausschlaggebend bei der relativen Datierung. Daneben sind die Eigenschaften der Sedimente sowie Fossilien von Bedeutung. (vgl. Hubbard, Glasser 2005:350-364)

In der vorliegenden Arbeit wurde lediglich auf Verwitterungsindizes, Lichenometrie sowie Bodenentwicklung Bezug genommen.

\subsection{Verwitterungsindizes}

Die intakte Gesteinsfestigkeit kann nach Selby (1980) ${ }^{70}$ zitiert nach: Hubbard, Glasser (2005) mit Hammer und Messer bestimmt werden. Dazu dient die Tabelle 10.2 bei Hubbard, Glasser (2005:352). Die relative Altersbestimmung der Verwitterungskrustenmächtigkeit basiert auf der Tatsache, dass frische Gesteine mit der Zeit eine Verwitterungskruste ausbilden. Je mächtiger die Verwitterungskruste, desto länger war das Gestein der Verwitterung ausgesetzt (ebd.:354/Box 10.7). Ungefähr 50 Gesteine pro Ort sollten untersucht werden, wenn die Werte wenig voneinander abweichen. Nach Anderson, Anderson (1981) ${ }^{71}$ und Whithouse,

\footnotetext{
${ }^{70}$ Selby, M.J. (1980): A rock mass strength classification for geomorphological purposes: With tests from Antarctica and New Zealand, Zeitschrift für Geomorphologie, 24. (S. 31-51)

${ }^{71}$ Anderson, L.W.; Anderson, D.S. (1981): Weathering rinds on quartzarenite clasts as a relative-age indicator and the glacial chronology of Mount Timpanogos, Wasatch Range, Utah. Arctic and Alpine Research, 13. (S. 25-31)
} 
McSavaney (1983) ${ }^{72}$ zitiert nach: Hubbard, Glasser (2005) kann die Verwitterungskruste durch Absplitterprozesse und in Übergangszonen zwischen verwittertem und unverwittertem Gestein variieren. Bei Korngrößen- und Metamorphosegradvariationen könnte die Verwitterungskruste zu einer anderen zeitlichen Einordnung führen (Chinn $1981^{73}$ zitiert nach: Hubbard, Glasser 2005:353). Die Verwitterungskrusten bestehen aus Magnesium und eisenreichen Mineralen (ebd.:354/Box 10.7). (vgl. Hubbard, Glasser 2005:351-355)

Die durch Lösungsprozesse entstehende Narbenverwitterung existiert nicht bei allen Gesteinen, besonders aber beispielsweise bei Graniten. Je länger ein Gestein den Verwitterungsprozessen ausgesetzt war, desto größer und tiefer werden die Narben auf dem Gestein. Bei Hubbard, Glasser (2005) wurde für eine Narbenverwitterung von $1 \mathrm{~m}$ Durchmesser ein Alter von 100.000 Jahren nach Fahay (1986) ${ }^{74}$ und von 500.000 bis 1 Mio. Jahre nach McSavaney, Stirling (1992) ${ }^{75}$ angegeben. (vgl. Hubbard, Glasser 2005:355)

\subsection{Lichenometrie}

Gesteinsflechten siedeln sich auf einer Gesteinsoberfläche an und können somit maximal so alt sein wie das Gestein selber. Je größer die Lichen, desto älter sind sie. Zumeist wachsen Lichen kreisförmig bis zu einem bestimmten Durchmesser ein paar Jahrzehnte beschleunigt und dann konstant langsamer weiter. Die Wachstumsgeschwindigkeit hängt vom Klima ab, besonders von der Feuchtigkeit - da Flechten jene brauchen, um zu assimilieren und zu wachsen -, weniger aber von der Höhenlage. Daneben spielen auch der Gesteinsuntergrund sowie dessen Verlagerung oder Zerstörung eine Rolle - glatte und in Bewegung gehaltene Flächen sind für die Besiedlung ungeeignet. (vgl. Beschel 1950:152 f.)

Lichenometrie kann als relative Datierungsmethode für Landformen und Sedimente angewendet werden. Lichen sind komplexe erstbesiedelnde symbiotische Algen- und Pilzorganismen. Im Gelände werden die größten Kreisdurchmesser der Lichen bestimmt. In der Literatur existieren verschiedene Bestimmungsmethoden. Hauptsächlich werden die grünen und schwarzen, in polaren bzw. alpinen Gegenden vorkommenden, erstbesiedelnden

\footnotetext{
${ }^{72}$ Whithouse, I.E.; McSavaney, M.J. (1983): Diachronous talus surfaces in the Southern Alps, New Zealand, and their implications to talus accumulation. Arctic and Alpine Research, 15. (S. 53-64)

${ }^{73}$ Chinn, T.J.H. (1981): Use of rock weathering-rind thickness for Holocene absolute age-dating in New Zealand. Arctic and Alpine Research, 13. (S. 33-45)

${ }^{74}$ Fahay, B.D. (1986): Weathering pit development in the Central Otago mountains of southern New Zealand. Arctic and Alpine Research, 18. (S. 337-348)

${ }^{75}$ McSavaney,M.J.; Stirling, M.W. (1992): Central Otago: Basin and Range Country. In: Soons, J.M.; Selby, M.J. (eds) Landforms of New Zealand. $2^{\text {nd }}$ edition. Auckland, Longman Paul.
} 
und langsam wachsenden Lichen 'Rhizocarpon geographicum' bestimmt. Es sollten repräsentative Lokalitäten für die entsprechende Form oder Oberfläche bestimmt werden. (vgl. Hubbard, Glasser 2005:355, 357-359)

Lichenometrie wird vor allen Dingen in der Glazialgeomorphologie verwendet, um das Alter der Formen zu bestimmen. Durch die Gesetzmäßigkeiten des Flechtenwachstums bei sonst gleichen Bedingungen stellen Flechten ein geeignetes Mittel zur Bestimmung des Alters frührezenter bis rezenter Moränen dar (vgl. Beschel 1950:161). Der Begründer der Methode bzw. Arbeitstechnik war Beschel. Er ermittelte Flechtenwachstumsraten von altersbekannten Moränen (ebd.:154). Die Landkartenflechte 'Rhizocarpon geographicum’ wächst bei mittlerer Feuchtigkeitsexposition in 60 Jahren mit ihrer Rosette einen $1 \mathrm{~cm}^{2}$ großen Felsfleck zu (vgl. Kuhle, Roesrath 1990:107).

\subsection{Bodenentwicklung}

Von einigen Forschern wurde die Bodenentwicklung als relative Datierungsmethode herangezogen. Hierbei untersuchten sie Bodenprofile bzw. Bodenmächtigkeiten, um Rückschlüsse auf die zeitliche Entwicklung zu erhalten. Ein gering entwickelter Boden soll im Gegensatz zu einem stärker verwitterten Boden jünger sein.

\subsubsection{Absolute Datierungen}

$\mathrm{Zu}$ den numerischen Altersbestimmungen gehören die Radiokarbon-, Lumineszenz- und kosmogene Nukleiddatierung (vgl. Hubbard, Glasser 2005:340).

\subsubsection{1. ${ }^{14} \mathrm{C}$}

Die Radiokarbonmethode ${ }^{14} \mathrm{C}$ ist die am häufigsten angewendete Datierungsmethode für glazigene Akkumulationen, in denen u.a. Pflanzenreste konservierten (vgl. Hubbard, Glasser 2005:341 f.). Sozusagen stellt diese Methode bzw. Arbeitstechnik für Glazialgeomorphologen eine Standardarbeitsmethode dar (vgl. Owen et al. 2008:527). Diese basiert nicht direkt auf der kosmischen Strahlungsintensität, sondern hängt nur indirekt von der ${ }^{14} \mathrm{C}$ Isotopenproduktion in der Atmosphäre ab (vgl. Kuhle, Kuhle 2010:110). Die Daten der Radiokarbonmethode geben in Bezug auf glazigene Sedimente ein Minimumalter von Moränen an, da sich nach Gletscherrückgang Vegetation ausbilden kann, was aber wiederum von anderen Aspekten wie Klima, Mikrorelief und Oberflächenmaterialzusammensetzung beeinflusst wird (vgl. Hubbard, Glasser 2005:341/Box 10.5). 
${ }^{14} \mathrm{C}$ wird in der Atmosphäre durch die Reaktion Stickstoff mit kosmischer Strahlung gebildet und reichert sich in der Atmosphäre, in den Ozeanen, in Pflanzen und Tieren an. Lebende Pflanzen und Tiere assimilieren ${ }^{14} \mathrm{C}$ aus der Atmosphäre durch Photosynthese bzw. Respiration. Sterben diese Organismen, wird die ${ }^{14} \mathrm{C}$-Assimilation eingestellt und das vorhandene ${ }^{14} \mathrm{C}$ zerfällt wieder zu Stickstoff mit einer Halbwertszeit von $5.568 \pm 30$ Jahre. Bei einem angenommenen ${ }^{14} \mathrm{C}$-Gehalt zur Zeit des Absterbens wird durch die Bestimmung des restlichen ${ }^{14} \mathrm{C}$ der Zeitraum des Absterbens ermittelt. Bei der Probenentnahme sollte darauf geachtet werden, dass ein Zusammenhang zwischen dem Absterben und dem Alter des gesuchten Prozesses besteht. (vgl. Hubbard, Glasser 2005:341-343)

Beispielsweise gaben Owen et al. (2008:518 f.) eine Forschungsübersicht über die angewendeten Methoden bzw. Arbeitstechniken in Hochasien: die ersten Arbeiten mit der ${ }^{14}$ C-Methode machten Röthlisberger, Geyh $(1985)^{76}$, welche 68 Radiokarbondaten vom Vorland von 16 verschiedenen Gletschern im Himalaja und Karakorum bestimmten (Gletschervorstöße vor ca. 19.000, 12.700, 7.400, 4.900-4.600, 3.700-3.100, 2.700-2.100, 1.700-1.500, 1.200-950, 800, 500 und 400-100 ${ }^{14}$ C-Jahren v.H.). Radiokarbondaten sind für die feuchteren Gebiete der Himalaja Tibet Region vorhanden (Röthlisberger, Geyh 198577, Lehmkuhl 1995, $1997^{78}$ zitiert nach: Owen et al. 2008:518). Kuhle lieferte erste ${ }^{14} \mathrm{C}$-Daten aus Tibet, Kuhle (1986a) aus dem Khumbu-Himalaja.

\subsection{OSL}

Lumineszenz ist eine Methode bzw. Arbeitstechnik, mit der das Alter von Sedimentkörnern, die vor der Ablagerung Strahlung bzw. Licht ausgesetzt waren, bestimmt wird (vgl. Hubbard, Glasser 2005:345). Sie ist definiert als wärmestrahlungsunabhängige Emission von Energie in Form von Photonen infolge des Hineingelangens der Elektronen in einen tieferen Energiezustand (vgl. Greilich 2004:4).

Datiert wird der Zeitraum, ab der das beprobte Material der letzten Lichtexposition ausgesetzt war (vgl. Greilich 2004:141). OSL-Datierungen zählen zu den 'Strahlendosimetrie'Methoden, da Minerale als Dosimeter fungieren. Natürlich radioaktive Isotopenstrahlung und kosmische Höhenstrahlung wirken auf diese ein (ebd.:10). OSL wird wiederum unterteilt in

\footnotetext{
${ }^{76}$ siehe Quelle Röthlisberger, Geyh (1985) in der Fußnote

77 siehe Quelle Röthlisberger, Geyh (1985) in der Fußnote

${ }^{78}$ Lehmkuhl, F. (1995): Geomorphologische Untersuchungen zum Klima des Holozäns und Jungpleistozäns Osttibets. In: Göttinger Geographische Abhandlungen, 102. (S. 1-184); Lehmkuhl, F. (1997): Late Pleistocene, Late-glacial and Holocene glacier advances on the Tibetan Plateau. In: Quaternary International, 38/39. (S. 7783)
} 
die durch 'Infrarot stimulierte Lumineszenz' (IR-OSL), die auf Feldspat angewendet wird, und die durch blaues Licht stimulierte Lumineszenz (B-OSL), die auf Quarz angewendet wird. Bei der Zitierung von Godfrey-Smith et al. (1988) ${ }^{79}$ zitiert nach: Richards et al. (2000:1622) fiel auf, dass dort widersprüchlicherweise im Abschnitt Methodik OSLDatierungen verwendet werden, um die vergangene Zeit zu bestimmen, ab der eine Probe dem Tageslicht ausgesetzt war.

Sedimente weisen langlebige radioaktive Isotope $\left({ }^{238} \mathrm{U},{ }^{235} \mathrm{U},{ }^{232} \mathrm{Th}\right.$ und / oder $\left.{ }^{40} \mathrm{~K}\right)$ auf, die mit ionisierten Alpha-, Beta- oder Gammapartikeln reagieren. Dadurch werden metastabile Elektronen verlagert - was als Null-Alter angenommen wird - und in Kristallgitterdefekte eingeschlossen. Umso länger die Bestrahlung, desto mehr Elektronen werden verlagert. (vgl. Hubbard, Glasser 2005:345 f.)

Es existiert die 'Thermolumineszenz'-Datierung (Verlagerung der Elektronen durch Hitze) nach Richards et al. (2000:1622) als Vorgänger zur 'Optisch Stimulierte Lumineszenz'Datierung (Verlagerung der Elektronen durch Laserlicht). Bei der Probenahme werden normalerweise Röhren verwendet.

Als 'Bleichung' wird die Exposition der Mineralkörner an Licht bzw. die Nullstellung des Lumineszenz-Signals oder die Signalreduktion verstanden. Nach dieser Nullstellung kann dann aus dem Lumineszenz-Signal die natürliche Strahlendosis des Mineralkornes bestimmt werden.

Die OSL-Methode / Technik verlässt sich laut Richards et al. (2000) auf die Interaktion zwischen ionisierter Strahlung und Elektronen in halbleitenden Kristallen, die sich in einer Ansammlung von Ladung in metastabilen Bereichen in den Körnern auswirkt. Diese Ladung kann z.B. bei Beleuchtung (OSL) der Körner und Wiederfreigabe der Ladung bestimmt werden, was in der Emission von Photonen (Lumineszenz) resultiert. Durch künstliche Dosierung der Teilproben und einen Vergleich der emittierten mit der natürlichen Lumineszenz wird die Beziehung zwischen Strahlungsflux und Lumineszenz hergestellt. Die entsprechende Dosis, die die Körner während der Akkumulation im Boden besaßen, kann somit festgestellt werden. Die andere Größe, die zur Berechnung des Alters benötigt wird, ist die Dosisrate, welche durch direkte Messungen oder gemessene Konzentrationen von 'radionuclides' abgeleitet wird. (vgl. Richards et al. 2000:1622 f.)

Das Alter berechnet sich wie folgt: Alter $=$ Dosis / Dosisrate. Heutzutage existieren über 100 Lumineszenz-Daten für glaziale Ablagerungen und Landformen im Himalaja Tibet Gebiet

\footnotetext{
${ }^{79}$ siehe Quelle Godfrey-Smith et al. (1988) in der Fußnote
} 
(vgl. Owen et al. 2008:519). OSL-Datierungen entstanden in den 1980-iger und 1990-iger Jahren (ebd.:518). Im Khumbu-Himal existieren OSL-Daten von Richards et al. (2000).

\subsection{TCN}

Anhand der TCN-Methode / -Technik werden die Mengen der kosmogenen Isotope $\left({ }^{3} \mathrm{He}\right.$, ${ }^{10} \mathrm{Be},{ }^{14} \mathrm{C},{ }^{21} \mathrm{Ne},{ }^{26} \mathrm{Al}$ und ${ }^{36} \mathrm{Cl}$ ) in den Mineralkörnern der Gesteine, die kosmischer Strahlung ausgesetzt waren, bestimmt (vgl. Hubbard, Glasser 2005:347 f./Box 10.6). Die kosmische Strahlung, welche in die Erdatmosphäre eintritt - auch Primärstrahlung genannt, besteht aus hochenergetischen galaktischen kosmischen Strahlen und aus niedrigenergetischen solaren kosmischen Strahlen (vgl. Abramowski 2004:28 f.), wobei letztgenannte die obere Lithosphäre nur in sehr geringen Mengen erreichen und für die in-situ Produktion nicht von Bedeutung sind (Lal, Peters $1967^{80}$ zitiert nach: Abramowski 2004:28 f.). Durch nukleare Reaktionen in der Gesteinsoberfläche entstehen in-situ kosmogene Nukleide (vgl. Reuther 2007:24). Diese entstehen kontinuierlich in den oberen ein bis drei Metern der Lithosphäre (vgl. Abramowski 2004:28). Die meist gemessenen terrestrischen kosmogenen Radionuklide sind ${ }^{10} \mathrm{Be},{ }^{14} \mathrm{C},{ }^{26} \mathrm{Al}$ und ${ }^{36} \mathrm{Cl}$ mit einer Halbwertszeit von über $10^{3}$ bis $10^{6}$ Jahren (vgl. Reuther 2007:24). Daneben existieren atmosphärische kosmogene Nukleide (ebd.:25). CRN's werden also demnach durch das Auftreffen der kosmischen Strahlung auf Mineralien bei unbedeckten bzw. freiliegenden Gesteinen gebildet, wobei die Produktionsrate der CRN's im Verhältnis zur Intensität der primären kosmischen Strahlung steht (vgl. Aoki, Imamura 1999:134). Diese Produktionsrate ist durch den Neutronenflux bestimmt, der sich im Bezug zur geographischen Breite / Höhenlage ändert (ebd.:134). Nach Gosse und Phillips (2001) ${ }^{81}$ zitiert nach: Zech et al. (2009:1108) passiert die Akkumulation der terrestrischen Nuklide in den oberen Dezimetern der Erdoberfläche.

TCN-Daten werden direkt an Gesteinsoberflächen, Moränenrücken und anderen glazialen Ablagerungen für einen Zeitrahmen von 1.000 bis Mio. von Jahren ermittelt. Die Variationen der atmosphärischen Produktionsrate der Isotope, der topographische Abschirmungseffekt und die Dicke bzw. Mächtigkeit der Probe werden berücksichtigt (vgl. Hubbard, Glasser 2005:348/Box 10.6). Laut Gosse, Phillips (2001) ${ }^{82}$ zitiert nach: Hubbard, Glasser (2005) sind bei der Anwendung der TCN-Datierung weiterhin u.a. Bestimmungen von Erosionsraten von Blöcken und Anstehendem, fluviale Erosionsraten, Denudationsraten, Hangrückverlegungen

\footnotetext{
${ }^{80}$ Lal, D.; Peters, B. (1967): Cosmic ray produced radioactivity on the Earth. In: Flugge, S.: Handbuch der Physik 4612. (S. 551-612)

${ }^{81}$ siehe Quelle Gosse, Phillips (2001) in der Fußnote

${ }^{82}$ siehe Quelle Gosse; Phillips (2001) in der Fußnote
} 
$\mathrm{zu}$ involvieren. "Care must therefore be taken to avoid sampling boulders on moraines that are not in their original position, through either sliding, slumping or upheaval by vegetation or tree roots." (Hubbard, Glasser 2005:349). Proben sollten nach Gosse, Phillips (2001) ${ }^{83}$ zitiert nach: Hubbard, Glasser (2005) von großflächigen, flachen und horizontalen Gesteinen oder Landformen entnommen werden. Die Proben werden mit Hammer und Meißel oder mit Bohrer und Trennsäge entnommen. Ort, Höhe, Größe, Form, Farbe, Oberflächenstruktur, Orientierung, Dicke bzw. Mächtigkeit u.a. sollten verzeichnet sowie Fotos und Skizzen angefertigt werden. (vgl. Hubbard, Glasser 2005:347-350)

Heutzutage sind seit den 1990-iger und 2000-er Jahren über 800 TCN-Daten in der Literatur der Vergletscherungsgeschichte im Himalaja Tibet Gebiet veröffentlicht (vgl. Owen et al. 2008:519). Kosmogenes ${ }^{10}$ Be wurde zum ersten Mal im Jahre 1950 in marinen Sedimenten entdeckt (vgl. Abramowski 2004:27). 'Terrestrische Kosmogene Radionuklide'-Datierungen wurden überall dort durchgeführt, wo Owen et al. in Fig. 3 rote Punkte visualisierten (vgl. Owen et al. 2008:516/Fig. 3). Trotz der enormen Anzahl der TCN-Datierungen sind die Vergletscherungszeiträume noch nicht genau geklärt (ebd.:519). Viele dieser Daten basierten auf ${ }^{10} \mathrm{Be}$, da es das am einfachsten zu verstehende chemische und physikalische System sein soll und außerdem im Quarz entsteht, der sehr oft in den Gesteinen des Himalaja und Tibet Gebietes vorkommt (ebd.:519).

Owen et al. (2008:518 f.) gaben eine Forschungsübersicht über die angewendeten Methoden in Hochasien: die ersten, die TCN-Datierungen anwendeten, waren Phillips et al. $(2000)^{84}$ in Nordpakistan. Es folgten in Hochasien viele weitere Arbeiten. Nishiizumi et al. (1989) ${ }^{85}$ zitiert nach: Abramowski (2004:28) präsentierte die erste Kalibrierung der terrestrischen ${ }^{10} \mathrm{Be}$ Produktionsrate in der Sierra Nevada. Lal (1991) ${ }^{86}$ zitiert nach: Abramowski (2004:28) veröffentlichte das erste geographische Skalierungssytem für diese kalibrierte Produktionsrate; Kohl, Nishiizumi (1992) ${ }^{87}$ zitiert nach: Abramowski (2004:28) entwickelten die Standard-Laborverfahren für die Extraktion des ${ }^{10} \mathrm{Be}$ vom Quarz.

\footnotetext{
${ }^{83}$ siehe Quelle Gosse, Phillips (2001) in der Fußnote

${ }^{84}$ Phillips, W.M.; Sloan, V.F.; Shroder, J.F. Jr; Sharma, P., Clarke, M.L., Rendell, H.M. (2000): Asynchronous glaciation at Nanga Parbat, northwestern Himalaya Mountains, Pakistan. Geology 28. (S. 431-434)

${ }^{85}$ Nishiizumi, K.; Winterer, E. L.; Kohl, C. P.; Klein, J., Middleton, R., Lal, D., Arnold, J. R. (1989): Cosmic ray production rates of $10 \mathrm{Be}$ and $26 \mathrm{Al}$ in quartz from glacially polished rocks. Journal of Geophysical Research B 94.

${ }^{86}$ siehe Quelle Lal (1991) in der Fußnote

${ }^{87}$ Kohl, C. P.; Nishiizumi, K. (1992): Chemical isolation of quartz for measurement of in-situ produced cosmogenic nuclides. Geochimica et Cosmochimica Acta 56. (S. 3583-3587)
} 


\subsection{Kurzzusammenfassung}

Das Thema der vorliegenden Arbeit wurde ausgewählt, da die Problematik enorm voneinander abweichender Forschungsergebnisse sowohl zur eiszeitlichen Vergletscherungsart als auch zum Vergletscherungsgrad des Gebietes Hochasien besteht. Die Fragestellung, wie besonders das ausgewählte Hauptuntersuchungsgebiet während der letzten Eiszeit vergletschert war, ergab sich aus dem Kontext der Aussagen dieser unterschiedlichen Forschungen. Das Ziel des Dissertations-Projektes war es also, den heutigen Forschungsstand aus inhaltlich- und methodenkritischer Sicht durch Testbegehungen im Gelände sowie durch Geländearbeiten und Satellitenbildanalysen zu überprüfen und zu bewerten, um im bestmöglichen Falle eine einheitliche Auffassung zu etablieren. Hierbei stellte die Gegenüberstellung der relevanten wissenschaftlichen Literatur sowie die damit verbundene Suche nach Gründen dieser verschiedenen Forschungsergebnisse bzw. das Auffinden von Widersprüchen und Fehlerquellen die Schlüsselrolle dar.

Die Einführung in das $\mathrm{zu}$ bearbeitende Thema verwies darauf, dass das Hauptuntersuchungsgebiet in einem solchen Gebiet liegen sollte, in welchem verschiedene Forscher eine Vielzahl unterschiedlicher Methoden bzw. Arbeitstechniken anwendeten. Vor allen Dingen fanden die gegenwärtig überwiegend eingesetzten TCN- und OSL-Datierungen Berücksichtigung. Die Vergleichsuntersuchungsgebiete stellten demzufolge vergleichbare Gebiete dar. Somit fiel das Hauptaugenmerk auf Gebiete in Nepal, besonders auf den Solukhumbu und auf die Vergleichsuntersuchungsgebiete im Dhaulagiri und Annapurna, Langtang, Mahalangur und Kangchendzönga-Himal (siehe Karte I-II, Bildband). Bei der Einführung in die Untersuchungsgebiete wurde für das übergeordnete Gebiet Nepal auf die Aspekte der landschaftlichen Gliederung, der Geologie, des Klimas sowie der rezenten Vergletscherung eingegangen und für das Hauptuntersuchungsgebiet, auch teilweise für die Vergleichsuntersuchungsgebiete, auf die Aspekte Lage und naturräumliche Gegebenheiten, geologische Gegebenheiten (siehe Karte V-VII, Bildband), Klima, Böden und Vegetation sowie rezente Vergletscherung. Es fanden die Methoden bzw. Arbeitstechniken der geomorphologischen Analyse mit Sedimentanalysen und Satellitenbildanalysen Anwendung, wobei explizit verschiedene Fächer- und Kegelformen voneinander abgegrenzt wurden. Weitere von Forschern angewendete Methoden bzw. Arbeitstechniken wie etwa relative und absolute Datierungen wurden vorgestellt. Die detaillierte geomorphologische Analyse stellte sich als bislang brauchbarste, aussageträchtigste, geringst fehlerbehaftete und 
ergebnisschärfste Methode für die Rekonstruktion einer vorzeitlichen Vergletscherung dar (s.h.a. Kapitel 4).

\section{FORSCHUNGSÜBERBLICK ZUR VERGLETSCHERUNGS- GESCHICHTE DES NEPAL-HIMALAJA}

2.1. Hauptuntersuchungsgebiet Solukhumbu

\subsubsection{Forschungsergebnisse der Jahre 1950 bis 1970 - Beginn der Datierung mittels Lichenometrie}

Im Zeitraum der Jahre 1950 bis 1970 betrieben im Solukhumbu Heuberger (1956), Müller (1959) und Miller (1970) Forschungen zur Vergletscherungsgeschichte. Die Arbeit von Heuberger (1956) mit dem Titel 'Beobachtungen über die heutige und eiszeitliche Vergletscherung in Ost-Nepal' wurde in der vorliegenden Arbeit nicht berücksichtigt, da Heuberger diese 1979 öffentlich zurücknahm - so wie Kuhle (2005:316) angab. Heuberger (1956:356) beschrieb im Originaltext eine letztglaziale maximale Eisrandlage in ca. $2.500 \mathrm{~m}$ Höhe in Dudh Koshi Nadi südlich der Ghat Siedlung. Er erwähnte, dass dort in der Nähe Moränen an den Hängen bzw. Erratika, Rundhöcker bzw. eisgerundete Felsen auftreten. Müller (1959) machte langfristige Wetterbeobachtungen im Solukhumbu, aber auch Gletscheruntersuchungen im Khumbu Gebiet. In Hinblick auf die vorzeitliche Vergletscherung des Solukhumbu gab er drei unterschiedliche Moränenstände an: subrezente Seiten- und Stirnmoränen - die vor 4 bis 5 Jahrzehnten entstanden, älterer Stand - Moränen bei Pheriche - und noch älterer Stand - Moränenreste, Schliffspuren, eisfreie Kare als Hinweis auf die ehemalige Firnlinie (ebd.:210 f.). Im Dudh Khosi Tal bis talabwärts von Aisyalukharka traten viele Quartärablagerungen auf, jedoch keine eindeutig zuordbare (ebd.:201). Beispielsweise fand er Moränenreste bei Phaphlu, wobei er unterhalb dieses Ortes aber keinerlei eindeutige Indikatoren einer ehemaligen Vergletscherung fand (ebd.:201). Bei Taksindhu machte Müller Erratika und an den Hängen Terrassen unbekannter Entstehungsart aus (ebd.:201). Eindeutige Aussagen über die letztglaziale Maximalvergletscherung des Solukhumbu wurden allerdings nicht getroffen. Miller (1970) untersuchte den Khumbu Gletscher und Randmoränen desselben. Er ging von einer pleistozänen Vergletscherung aus, die sich nicht maßgeblich von der rezenten Vergletscherung abhob. 


\subsubsection{Forschungsergebnisse der Jahre 1971 bis 1990 - Beginn der ${ }^{14} \mathrm{C}$-Datierung}

Im Zeitraum der Jahre 1971 bis 1990 führten im Solukhumbu Benedict (1976), Iwata (1976), Fushimi (1977), Fushimi (1978), Müller (1980), Fushimi (1981), Williams (1983), Kuhle (1984), Heuberger und Weingartner (1985), Heuberger (1986), Kuhle (1986a), Kuhle (1987a, b) und Kuhle (1988a) Forschungen zur Vergletscherungsgeschichte durch. Benedict (1976) machte keinerlei Angaben zur letzteiszeitlichen maximalen Vergletscherung, einige andere hingegen nur ungenaue.

In der letzten Eiszeit ging Iwata (1976) anhand angewendeter relativer Datierungsmethoden wie etwa der Vegetations- und Bodenentwicklungsgrade im Khumbu-Himalaja von vier Gletschervorstößen aus: Lobuche I-III, Thuklha, Periche und Thyangboche. Ältere glaziale Formen legte er in die Zeit vor dem letzten Interglazial bzw. in die vorletzte Eiszeit. Lobuche und Thuklha Moränen stellten neoglaziale Vorstöße dar, wobei erstgenannte Moränen aus den letzten Jahrhunderten stammen und die Endmoränen der Gletscher berührten. Lobuche Moränen von kleinen schuttfreien Gletschern formten einfache Moränenkränze, die nicht mit dem Eiskörper verbunden waren. Lobuche I Moränen waren dort vegetationsfrei und frisch. Bei den schuttbedeckten Gletschern kamen Lobuche Moränen als zwei bis drei Moränenrücken neben den Gletscherzungen vor. (vgl. Iwata 1976:109, 110, 113)

Beim Khumbu Gletscher waren drei Rücken mit verschiedenen Merkmalen ausgebildet. Der innerste Moränenrücken - die Lobuche I Moräne - war ein scharfgezeichneter zumeist lichenfreier Rücken ohne Verwitterungs- und Zersplitterungsspuren der Blöcke, wobei der Außenhang vereinzelt Pflanzen aufwies, aber der Innenhang vegetationsfrei war. Diese Moräne war einige Meter höher als die heutige Gletscheroberfläche, an der Gletscherfront jedoch gleich hoch, da dort Ablationsmoräne überlagert war. Am Khumbu Gletscherende war eine Eiskernmoräne entwickelt mit den Eigenschaften eines aktiven Blockgletschers, was einen rezenten langsamen Vorstoß annehmen ließ, obwohl Teile des Ablationsgebietes stagnierten (ebd.:110, 111/Fig. 4). Die Endmoränen des Lobuche Stadium vom Ama Dablam Gletscher und Lhotse Gletscher unterschieden sich etwas von denen des Khumbu Gletscher: Lobuche II und III waren weit von Lobuche I entfernt, Lobuche I war niedriger. Der Frischegrad und die Vegetationsfreiheit der Lobuche I Moränen legte den Zeitraum des 19.20. Jahrhunderts nahe. Danach wichen die schuttfreien Gletscher zu ihrer heutigen Lage zurück und die schuttbedeckten blieben aufgrund des Ablationsschutzes stagnant. Die hauptsächlich aus kantigen Blöcken bestehende Lobuche II Moräne des Khumbu Gletscher war die höchste, mit bis zu 70-80 m über der Gletscheroberfläche. Bei dieser Moräne war 
kein Boden entwickelt, wobei aber mehr Graspflanzen auftraten als bei Lobuche I. Die Lobuche III Moräne war mit geringfügig verwitterten Blöcken bedeckt und wurde an mancher Stelle von der Lobuche II Moräne überlagert. Gras- und Buschvegetation war gering ausgebildet und am Fuß der Lobuche II Moräne angehängt. Nach Fig. 6 endete die Endmoräne des Lobuche Stadium im Khumbu Tal zwischen Thukla und Dusa auf ca. $4.500 \mathrm{~m}$ Höhe. Die Lobuche III Moränen stammen aus der Kleinen Eiszeit bzw. aus dem 15.-16. Jahrhundert. Iwata (1976) trennte die Thuklha Moränen von den Lobuche Moränen ab, da ein enormer Unterschied zwischen diesen bestand (Verwitterungsgrad, Modifikation, Vegetationsbedeckung). Thuklha Stadium Moränen waren mit Boden und Vegetation bedeckt und an der Außenseite der Lobuche Moräne lokalisiert. Einige Thuklha Moränen waren bei Chukhung verbreitet, lagen also demnach in den Trogtälern, und waren durch jüngere Moränen der Gletscher überschüttet oder zerstört worden. Mehrere aufgereihte Rücken teilweise mit Lössbedeckung - wiesen einen entwickelten Boden bzw. Vegetationsbedeckung in Form von ausgewachsenem Gras und Busch und vereinzelte verwitterte Blöcke auf. Die Thuklha und die Lobuche Moränen waren ähnlich, unterschieden sich aber in der Höhe der Oberfläche, wobei die erstgenannten niedriger waren - s.h.a. das Querprofil des Khumbu Gletscher in der Nähe von Lobuche nach Iwata (1976:111/Fig. 3). Nach Fig. 6 endete die Endmoräne des Thuklha Stadium im Khumbu Tal zwischen Thukla und Dusa auf ca. $4.500 \mathrm{~m}$ Höhe. Die Thuklha Moränen stammen aus der Zeit von 2.000 bis 6.000 Jahre v.H.. Periche und Thyangboche Stadium Moränen zeigten gut verwitterte und vegetationsbedeckte Oberflächen auf und lagen im Tal talabwärts der Gletscher. Die Periche Moränen waren durchgehend unterhalb des Khumbu Gletscher auf der orographisch linken Talseite, in den anderen Tälern hingegen nur sporadisch ausgebildet. Bei Periche waren deutliche bis zu 200 $\mathrm{m}$ hohe End- und Lateralmoränen ausgebildet, die komplett mit Gras und Buschvegetation und einzelnen großen Blöcken bedeckt waren. Beim betrachteten Bodenprofil der Periche Moräne in der Nähe von Periche entdeckte Iwata (1976:112/Fig. 5) eine dünne humose Bodenschicht mit organischem Material über dem Löss in $20 \mathrm{~cm}$ Tiefe. Nach Fig. 6 endete die Endmoräne des Periche Stadium im Khumbu Tal zwischen Periche und Ralha auf ca. 4.200 m Höhe. Die Thyangboche Moräne bei der Lhajung Station wies auf der Oberfläche Löss, verdeckten Boden, Vegetation und einige 3 bis $5 \mathrm{~m}$ große Blöcke auf. Die Periche und Thyangboche Moränen waren beide mit Boden bedeckt, der sich nach der letzten Eiszeit bildete. Entlang des Tales war die Thyangboche Moräne mit jüngeren Moränen, Schutthalden und fluvialen Ablagerungen überlagert. Die Lateralmoräne des Thyangboche Stadium 3 km südlich von Periche war mit Moränen des Mingbo und des Omoga Tales bedeckt und ging in 
die Endmoräne bei Thyangboche über. Nach Fig. 6 endete diese Endmoräne des Thyangboche Stadium im Khumbu Tal talabwärts von Thyangboche auf ca. 3.625 m Höhe. Die Plattformen waren flach, mit Boden und Vegetation bedeckt und waren nördlich von Chukhung und Pibre oder auch auf der orographisch rechten Seite des Khumbu Gletscher ausgebildet (ebd.:122, 110/Fig. 1, 111/Fig. 3/Fig. 4). Blöcke oder anstehendes Gestein kamen nicht auf der Oberfläche vor. Die Plattformen traten auf über 5.000 m Höhe auf. Nach Fig. 6 lagen die tiefsten Plattformreste aus der vorletzten Eiszeit jedoch zwischen Thukla und Lobuche auf ca. 4.875 m Höhe. Die Plattformen wurden entlang der Täler höher, sodass Glazialerosion oder akkumulation möglicherweise eine Rolle spielte. Es wurde jedoch nicht geklärt, ob die Plattformen aus anstehendem Gestein oder Moräne bestehen. Die Plattformen waren nach Iwata (1976) als aus dem Präinterglazial stammend angenommen. Das letztglaziale Maximum ordnete er in das Periche und Thyangboche Stadium ein, wobei bei beiden Stadien eine spätglaziale Entstehung nicht auszuschließen war. Fig. 1 war zu entnehmen, das Iwata (1976) Periche Moränen bis in eine Höhe von ca. 4.200 m sowie Thyangboche Moränen bis auf ca. $4.000 \mathrm{~m}$ ausmachte. Jedoch stellte die in Fig. 6 dargestellte End- bis Ufermoräne bei Thyangboche auf ca. $3.625 \mathrm{~m}$ das maximale Vergletscherungsende dar. (vgl. Iwata 1976:109113)

Das würde bedeuten, dass der Khumbu Gletscher während der letzten Eiszeit 600 bis 1.175 m weiter talabwärts reichte $(4.800 \mathrm{~m}$ minus $4.200 \mathrm{~m} / 3.625 \mathrm{~m})$. Daraus konnte eine Schneegrenzdepression von 300 bis $587,5 \mathrm{~m}$ und dementsprechend eine vorzeitliche Schneegrenze auf 4.912,5 m bis $5.100 \mathrm{~m}$ Höhe $(5.500 \mathrm{~m}$ minus $300 \mathrm{~m} / 587,5 \mathrm{~m})$ berechnet werden.

Im Khumbu-Himalaja machte Fushimi (1977) heutige und rezente Moränen aus, desweiteren aber auch - jedoch ohne zeitliche Angaben - Periche Moränen und Moränen, die älter als Periche waren. Fig. 11 verwies auf kartierte Periche Moränenbögen südlich von Periche. Die rezenten Thuklha Moränen wurden in sechs Unterstadien und die Trogtäler in drei Serien mit jeweils weiteren Unterteilungen eingestuft.

Die Hongu Region war zu diesem Zeitpunkt nach Fushimi (1978) im Gegensatz zur Hinku Region mehr vergletschert, mehr schneebedeckt, mehr moränenbedeckt und wies weniger Gesteinswände und mehr Seen auf (ebd.:75/Tab. 1). Die Khumbu Region war jedoch rezent gegenüber diesen beiden Regionen mehr vergletschert (170 gegenüber $72 \mathrm{~km}^{2}$ ). Im Hinku und Hongu Khola waren während des Thuklha Stadium Gletscher auf der Süd- und Westhangseite kleiner geworden als auf der Nord- und Osthangseite - siehe Gletscher HX 050 gegenüber Gletscher GX 670, Gletscher HX 200 gegenüber Gletscher HX 230. Das hing mit den 
steileren Kliffen, der höheren Schuttproduktion und Massenbewegungen (Blockgletscher) auf der Süd- und Westseite zusammen. Das hieß, dass die Gletscher auf der Süd- und Westhangseite sich rezent schneller zurückzogen. (ebd.:74-77)

Die vorzeitlichen Vergletscherungen im Khumbu, Hinku und Hongu wurden durch die topographischen Eigenschaften der Trogtäler und Endmoränen in drei Serien - U1, U2 und U3 - eingeteilt (Fushimi 1977 zitiert nach: Fushimi 1978:74). Periche und Thuklha Stadien waren in U3 eingeschlossen, wobei Thuklha in sechs Unterstadien eingeteilt wurde (das heutige ist T6 und das älteste T1). Je älter ein Trogtal, desto größer war die Höhendifferenz zwischen Flussbett und Talboden des Trogtales. Das älteste Trogtal U1 war talabwärts in der Nähe der M.C.T. mehr gehoben, sodass die Endposition höher als der mittlere Teil des Trogtales war. Während der Maximalvergletscherung lagen die Untersuchungsgebiete allerdings nicht in der heutigen Höhenlage, sondern tiefer. (ebd.:71, 72, 74, 76)

Im Khumbu Gebiet verwies Fushimi (1978:76/Fig. 10, 73, 73/Fig. 6) auf eine maximale letzteiszeitliche Eisrandlage (U1 Serie, Luklha Stadium) auf ca. 2.000 m Höhe südlich von Lukla, wobei letztgenannter Ort zwischen Trogtal im Norden und Kerbtal im Süden lag. Da Fushimi (1978:72) die Ausbildung des Kerbtales als fluvial deutete, war unterhalb von Lukla eine glaziale Entstehungsweise des Talprofiles ausgeschlossen. Hinweise für dieses vorzeitliche Eisstromnetz fand er in den ausgedehnten U1 Moränenablagerungen rund um Lukla, die Bergsturzablagerungen und Fächern ähnelten; zudem war dort eine Endmoräne ausgebildet (ebd.:73, 75, Fig. 6, Fig. 10). Letztere war teilweise zementiert und durch die Nord-Süd Bruchlinie zerschnitten (ebd.:73). Rund um Lukla war eine flache Topografie ausgebildet (ebd.:72). Diese Region wies somit, als Vorland des Hohen Himalaja, eine eigene charakteristische Geologie und Topografie auf (ebd.:72). Kantige Blöcke mit einer feinen Matrix überlagerten die älteren Moränen und beide zusammen formten bei der Lukla Siedlung diese weit ausgedehnte flache Oberfläche (ebd.:73). Die Verteilung der Sedimente ähnelte teils einem Fächer und teils einem 'landslide'; die Matrix bestand teilweise aus feinen grauen Tonen, wobei er annahm, dass es glaziale Tone waren (ebd.:73). Im Süden dieses Gebietes lagen die M.C.T. und tiefe Kerbtäler vom Süden Luklas bis nach Khari Khola (ebd.:72).

Wird der angegebene Wert der Maximalvergletscherung auf das Khumbu Gletscherende in $4.800 \mathrm{~m}$ Höhe bezogen, berechnet sich eine Schneegrenzdepression von $1.400 \mathrm{~m}(4.800 \mathrm{~m}$ minus $2.000 \mathrm{~m}:$ 2) und eine vorzeitliche Schneegrenze auf $4.100 \mathrm{~m}$ (5.500 m minus $1.350 \mathrm{~m})$. 
Während der U2 Serie, Ghat Stadium, reichte das vorzeitliche Eis bis ungefähr nach Ghat. Seesedimente des Ghat Stadium der U2 Serie in der Nähe von Ghat waren durch die lokale Blockbewegung nach Osten geneigt, verursacht durch das Ost-West und Nord-Süd Faltensystem. Topographische Veränderungen waren z.B. geneigte Seesedimente oder gefaltete Moränen. (vgl. Fushimi 1978:73, 76/Fig. 10)

Die Haupttalgletscher reichten während der U3 Serien bis nach Periche, Periche Stadium, nach Thukla, Thuklha Stadium, und bis nach Lobuche, T6 Unterstadium (ebd.:76/Fig. 10). Es wurden zwei ${ }^{14} \mathrm{C}$-Proben von Moränen des ältesten Thuklha und Periche Stadium in der Nähe des Kyuwo Gletscher südöstlich von Lhajung gesammelt (ebd.:74 f.; 71/Fig. 1). Die Probe vom Thuklha Stadium (T1) wurde dem Wald entnommen und ist 410 +/- 110 Jahre v.H. (16. Jhd.) entstanden; die Probe von Periche war Holzkohle und bildete sich vor 1.200 +/- 100 Jahren v.H. (8. Jhd.) (ebd.:75, 77).

Im Hinku reichten die Gletscher während des letzteiszeitlichen Maximums bis auf eine Höhe von etwa 1.600 m ungefähr bei der Ortschaft Juge, im Hongu dagegen bis auf 1.800 bis 2.000 m Höhe in etwa beim Ort Mudi Kharka hinunter (ebd.:75/Fig. 9).

Auch im Hongu Khola war ein Kerbtal nördlich der M.C.T. ausgebildet. Gneise und Migmatite waren im Hinku und Hongu Khola gut ausgebildet. Der Streichen verlief von Nordwest nach Südost, der Fallen nach Nordost; die steilen Hänge waren auf der Südwestseite und die flachen auf Nordostseite. Die klimatischen Bedingungen konnten anhand der oberen Grenze verschiedener Vegetation, der Höhenlage der temporären Schneegrenze und der Endmoräne (T1) bestimmt werden. Unterschiede waren zwischen den Ost- und Westhängen von Zatrwa La (Teilungspunkt zwischen Dudh Khosi und Hinku Khola) zu beobachten: die oberen Vegetationsgrenzen waren im Durchschnitt um 195 m niedriger am Westhang; die ehemalige Endmoräne und Schneegrenze vom 4. Oktober 1976 durchschnittlich $140 \mathrm{~m}$ niedriger. Daraus folgte, dass die Westseite ein kälteres Klima aufweist. (ebd.:72, 73)

Nach Müller (1980) stieg die rezente Schneegrenze mit 5.200 m von den südlichen Bereichen bis zum Hauptkamm an, wo der maximale Schneegrenzwert von $6.300 \mathrm{~m}$ östlich des Rongbuk Gletscher aufgrund des Regenschattens erreicht wurde, aber gen Norden, Osten und Westen wieder abnahm. Die Schneegrenze war hier hauptsächlich vom Niederschlag, aber auch von der Temperatur und der Topographie abhängig, wobei die Schneegrenzen in der Mt. 
Everest Region im Gegensatz zu anderen Gebieten von niedrigen zu hohen Breitengraden zunahmen. Auf der Südseite des Himalaja sanken die Niederschläge durch den Sommermonsuneinfluss mit der Höhe, wodurch 75 bis > $80 \%$ des Regens in den Monaten Juni bis Mitte Oktober fielen. Die Temperaturgefälle während der Vormonsunzeit wurden mit 0,71 ${ }^{\circ} \mathrm{C}$ pro $100 \mathrm{~m}$, die der Monsunzeit mit $0,52{ }^{\circ} \mathrm{C}$ pro $100 \mathrm{~m}$ angegeben - woraus sich ein mittlerer Wert von $0,63{ }^{\circ} \mathrm{C}$ pro $100 \mathrm{~m}$ ergab, wobei der allgemeine Wert für die gesamte Mt. Everest Region mit $0,60{ }^{\circ} \mathrm{C}$ pro $100 \mathrm{~m}$ angegeben wurde. (ebd.:82, 84, 86)

Müller (1980) erstellte eine Karte - Teile davon waren in Fig. 3 dargestellt - von holozänen und spätpleistozänen Moränen und der rezent eisfreien Kare des Imja Khola talaufwärts von Phortse und Tengboche. Er nahm somit vier Vergletscherungshauptstadien der oberen Khumbu Region an: Rezent, Dughla (Kleine Eiszeit $-{ }^{14} \mathrm{C}$, Lichenometrie), Periche sowie ein Stadium, das älter als Periche war und anhand von Moränenresten und glazialen Terrassen festgelegt wurde. Die Stadien Ghat und Lukla von Fushimi (1977) stellten jedoch noch ältere Stadien dar als das Stadium, das älter als Pheriche war. Das Periche Stadium wurde laut diesem Zitat: "[...] in age likely to correspond to those of the Egesen and Daun Stages in the Alps, [...]." (Müller 1980:86) als spätglaziales Stadium angesehen. Die mit Lichen und Vegetation bedeckten Dughla Moränen mit zwei bis drei Unterstadien waren am eindrucksvollsten und wurden durch lichenometrische Messungen und ${ }^{14} \mathrm{C}$-Datierung frühere Arbeit von Müller - in die Kleine Eiszeit eingeordnet. Die Moränen des rezenten Stadiums mit mehreren Unterstadien waren frisch und entstanden seit der Kleinen Eiszeit. (ebd.:86)

Für die letzteiszeitliche Eisausdehnung waren demnach die Periche Moränen und die Moränenreste bzw. -terrassen von Wichtigkeit. Laut Fig. 3 machte Müller (1980) letzteiszeitliche Moränen bis unterhalb von Periche auf ca. 4.200 m Höhe aus, wobei weiter talabwärts auf dem orographisch rechten Hang ebenfalls solche Moränen bis auf ca. $4.000 \mathrm{~m}$ Höhe existierten. Das würde bedeuten, dass der Khumbu Gletscher während der letzten Eiszeit 600-800 m weiter talabwärts reichte (4.800 m minus $4.200 \mathrm{~m} / 4.000 \mathrm{~m}: 2$ ). Daraus konnte eine Schneegrenzdepression von 300 bis $400 \mathrm{~m}$ und dementsprechend eine vorzeitliche Schneegrenze auf 5.200 bis $5.100 \mathrm{~m}$ Höhe $(5.500 \mathrm{~m}$ minus $300 \mathrm{~m} / 400 \mathrm{~m})$ berechnet werden.

Die Unterschiede zwischen rezenter und spätpleistozäner Schneegrenze betrugen $100 \mathrm{~m}$ beim Hauptkamm und 600 m im Süden, was Müller (1980) mit der unterschiedlichen Hebung des Gebietes in Verbindung brachte. Daraus schlussfolgerte er eine Temperaturdepression von 4 
bis $5{ }^{\circ} \mathrm{C}$ auf der monsunbeeinflussten Seite und 2 bis $3{ }^{\circ} \mathrm{C}$ in der Nähe des Hauptkammes. (ebd.:75)

Im Khumbu bzw. in der Nähe von Pheriche machte Fushimi (1981) drei unterschiedliche Trogtalserien - wobei die Erosion der Gletscher durch die Hebung des Himalaja verstärkt gewesen war - und drei Serien von Moränenformationen aus. Die älteste Trogtalserie (U1, $680 \mathrm{~m}$ über dem Talboden) war gegenüber den jüngeren (U2, $380 \mathrm{~m}$ über dem Talboden und U3, $170 \mathrm{~m}$ über dem Talboden) nur teilweise ausgebildet. Sämtliche Trogtalserien wurden anhand der Moränentopografie - Korngröße und Farbe des Moränenmaterials (Fig. 5), Neigung der Moränenform, Eigenschaften des Bodens wie Farbe und Mächtigkeit, Orte von 'springs' - in mehrere Stadien unterteilt. U3 wurde in drei Stadien A, B (Pheriche) und C (Thuklha) eingeteilt. Die älteste Trogtalserie fand er $50 \mathrm{~km}$ talabwärts der Khumbu Gletscherzunge in der Nähe von Lukla auf $2.500 \mathrm{~m}$ Höhe. Dort existierte eine teilweise erhaltene LGM ('Letztes Glaziales Maximum’) Endmoräne. In Fig. 6 waren die Gletscherausdehnungen aller Stadien dargestellt. (ebd.:1643, Fig. 5 und 6)

Fig. 6 bei Fushimi (1981) war evident mit Fig. 10 bei Fushimi (1978), infolgedessen konnte auf ein Gletscherende auf ca. $2.000 \mathrm{~m}$ geschlossen werden.

Fushimi (1981) bezog sich auf seine ${ }^{14}$ C-Daten vom Thuklha und Periche Stadium aus der Veröffentlichung des Jahres 1978, wobei ersteres Stadium jünger als das 16. Jhd. und letzteres älter als 700 Jahre v.H. war. U2 war älter als 3.630 Jahre v.H. und U1 älter als 6.100 v.H.. (ebd.:1644)

Im Khumbu-Himalaja ging Williams (1983) von einer sehr geringen Vergletscherung bis auf maximal $4.200 \mathrm{~m}$ Höhe unterhalb von Periche aus. Jedoch berechnete er im viel südlicher liegenden, westlich an das Dudh Kosi Tal angrenzende Dudh Khunda Tal eine maximale spätpleistozäne Schneegrenze auf $4.250 \mathrm{~m}$ Höhe, wobei er in Bezug auf die heutige Schneegrenze bei 5.200 m eine Schneegrenzdepression von 950 m berechnete. (ebd.:209, Fig. 2)

Williams (1983) lieferte sowohl anhand von Feldkartierungen als auch Interpretationen topographischer Karten und Landsat-Satellitenbildern Befunde über Schneegrenzen der heutigen und vorzeitlichen Vergletscherung. Die heutige Schneegrenze reichte von Süd nach Nord durch den Himalaja gesehen von 5.200 m Höhe beim Dudh Khunda Gletscher bis auf $5.800 \mathrm{~m}$ Höhe in Tibet; Schneegrenzen während des Maximums des Spätpleistozän stiegen von 4.300 bis auf $5.500 \mathrm{~m}$ an. Die niedrigste Schneegrenze wurde im Dudh Khunda Tal mit 
$4.250 \mathrm{~m}$ angegeben, die höchste in Tibet. Schneegrenzdepressionen während des Spätpleistozän waren südlich des Gebirgskammes mit $950 \mathrm{~m}$ mehr als doppelt so groß als nördlich davon mit $400 \mathrm{~m}$. Wenn auch die heutige nordwärtige Niederschlagsabnahme die Schneegrenze um $85 \mathrm{~km}$ ansteigen ließ $(7,1 \mathrm{~m} \mathrm{/} \mathrm{km),} \mathrm{lag} \mathrm{der} \mathrm{Gradient} \mathrm{während} \mathrm{des}$ Spätpleistozän bei $11 \mathrm{~m} / \mathrm{km}$. Dieser Umstand zeigte die steigende Aridität in Richtung Tibet. Bei vier holozänen Gletschervorstößen waren die Schneegrenzen bis zu 30 \% des maximalen Stadiums verringert. Im Dudh Khunda Tal lagen die niedrigsten holozänen Schneegrenzen bei $4.900 \mathrm{~m}$ Höhe - $300 \mathrm{~m}$ Schneegrenzdepression, im Yuligolcha Tal hingegen bei $4.800 \mathrm{~m}$. (ebd.:201, 209 f.)

Williams erstellte eine Karte über die rezente und vorzeitliche Vergletscherung rund um die Mt. Everest Region. Während des LGM waren gegenüber den heutigen 2,6 \% 5,8 \% bzw. $3.440 \mathrm{~km}^{2}$ im Sapta Kosi Drainagebecken vergletschert, wobei neben Tal- und Kargletschern fünf Eiskappen in Tibet bestanden. Die Moränen der vorzeitlichen Eiskappen waren gegenüber denen der vorzeitlichen Talvergletscherung kleiner, da hier wahrscheinlich der durch Steinschlag entstandene bedeutsame Schutt bei den Eiskappen geringer anfiel. Berechnete rezente und pleistozäne Schneegrenzen waren Fig. 3 zu entnehmen. Während des Holozän bestanden diese Eiskappen nicht mehr. (ebd.:201, 203 f., 210, Fig. 3)

Der Dudh Khunda Gletscher war während des LGM 8 km länger und insgesamt 12 km lang. Hinweise hierfür fand Williams in Moränen bzw. 'till' und Lateralmoränen. Die spätpleistozänen Ablagerungen - die auf eine maximale spätglaziale Vergletscherung schließen lassen - nannte er Lhaog (Indikator: Endmoräne im Nachbartal); die holozänen Moränen zeigten vier verschiedene Gletschervorstöße an. Die älteste Moräne des inneren Komplexes nannte er Tamba Moräne und nahm an, dass sie eine ältere holozäne oder spätpleistozänen Alters sei. Die drei jüngsten, am deutlichsten zu unterscheidenden, holozänen Moränen im Yuligolcha Tal nannte er Yuligolcha I, II und III. Während des Holozän war der Dudh Khunda Gletscher $7 \mathrm{~km}$ lang und reichte $5 \mathrm{~km}$ talaufwärts des maximalen pleistozänen Gletscherstadiums. (vgl. Williams 1983:201, 207, 210)

In der Forschungsarbeit Kuhle (1984) zeigten die Geländeanalysen im Jahr 1982 im Solukhumbu hauptsächlich, dass dort Trogtäler mit talabwärts anschließenden glazigenen Kerbtälern existieren, die einen Hinweis auf tiefere Eisrandlagen gaben. 
Für den Talabschnitt Khumjung bis Lukla gingen Heuberger, Weingartner (1985) von einer Talvergletscherung aus (ebd.:72). Oberhalb von Namche waren die eiszeitlichen Indizien deutlich, unterhalb von Namche im Pharag aber aufgrund der Talenge, des schluchtartigen Talgrundes und der enormen Steilheit der Hänge schwierig zu erkennen und kaum erhalten (ebd.:71, 73). Der Talgletscher reichte mit einer Länge von ca. $52 \mathrm{~km}$ vom $5.716 \mathrm{~m}$ hoch gelegenen Nangpa La bis talabwärts nach Ghat unterhalb von 2.500 m Höhe (ebd.:79). Bei Nachprüfung legten aber Heuberger und Weingartner laut der Abb. 2 das Gletscherende auf ca. 2.450 m / GE Höhe fest, ungefähr im Talbereich auf der Höhe von Nachipang und Nyerse - erstes auf der orographisch linken, zweites auf der orographisch rechten Talseite - bzw. oberhalb von Chheplung und Sengma - erstes auf der orographisch linken, zweites auf der orographisch rechten Talseite. Bei Bezug des angegebenen Wertes der Maximalvergletscherung lediglich auf das Khumbu Gletscherende ohne weiteren Einbezug von Gletschern und anderen Faktoren in $4.800 \mathrm{~m}$ Höhe ließen sich eine Schneegrenzdepression von $1.175 \mathrm{~m}$ (4.800 m minus $2.450 \mathrm{~m}: 2)$ und eine vorzeitliche Schneegrenze auf $4.325 \mathrm{~m}$ (5.500 m minus $1.175 \mathrm{~m})$ berechnen. Schneegrenzwertangaben von 4.400 bis $4.500 \mathrm{~m}$ machten Heuberger, Weingartner (1985:79) in Bezug auf die Moränenwälle des eiszeitlichen Khumbui Yul Lha Gletscher (Profil 6), deuteten aber darauf hin, dass es sich bei den Lokalmoränen nicht um den Höchststand des Hauptgletschers handelte, sondern um die des ältesten Spätglazial nach dem Höchststand, und dass sich außerdem der Lokalgletscher aufgrund der ungenauen Kenntnis des Einzugsgebietes bzw. der Karwände nicht eingrenzen ließ. Schneegrenzwerte neuzeitlicher Gletscherhochstände, wie z.B. die 1850-iger Moränen der Alpen, lagen im Bereich des Khumbui Yul Lha bei kleineren Gletschern bei ca. $5.500 \mathrm{~m}$ Höhe. Somit bestimmten Heuberger und Weingartner eine Schneegrenzdepression von etwa 1.000 bis $1.100 \mathrm{~m}$. „Da der eiszeitliche Schneegrenzhöhenwert wohl nicht genau mit dem Maximum zusammenfällt, liegt die Schneegrenzdepression etwa im Bereich der Erwartungen, ohne daß sich eine besondere Verzerrung durch die Hebung des gesamten Bereichs seit der letzten Eiszeit nachweisen ließe. “ (Heuberger, Weingartner 1985:79). Der Eisrand wurde anhand von Moränenformen lediglich bei Khumjung (Profil 6) und Phakdingma (Profil 4) festgelegt (ebd.:79). Ansonsten verwendeten sie pedologische Befunde bzw. Bodenverwitterungsgrade (ebd.:80).

Im Gelände überprüften sie die unterschiedlichen Bodenverwitterungsstadien inner- und außerhalb des letzteiszeitlichen Gletscherrandes anhand von Bodenprofilen. Braunerden mit Verwitterungstiefen von 1 bis $2 \mathrm{~m}$ waren mit spät- und postglazialer Bodenbildung in 
Verbindung $\mathrm{zu}$ bringen. Intensiver gefärbte, mächtigere, tonreiche, grobblockfreie Parabraunerden mit mächtigem $\mathrm{C}_{\mathrm{v}}$-Horizont entwickelten sich außerhalb der Gletschergrenzen. Gekappte ältere Böden - hier Parabraunerden - bzw. zweistöckige Profile, die dann durch Eisrandsedimente verschüttet wurden, entstanden dort, wo der letzteiszeitliche Talgletscher im Bereich des Eisrandes die älteren Böden nicht ganz abtransportierte. Auf den umgelagerten Sedimenten entstand ein jüngerer Boden (weniger intensive Verwitterungsfarbe, geringerer Tongehalt, kein intensiv verwitterter $C_{v}$-Horizont). (ebd.:76, 79 f.)

Heuberger, Weingartner (1985:77-79) erforschten sechs Bodenprofile, darunter auch Moränen: das hauptsächlich ungestörte Profil 1 bei Moro Kharka auf $3.530 \mathrm{~m}$ Höhe am Rande einer muldenartigen Hangverflachung unter einem immerfeuchten Bergwald war ein Parabraunerdenprofil mit aus dem Anstehenden entstandenen tiefgründigem, grobanteilfreiem Boden hohen Tongehalts. Ein letztglazialer Einfluss konnte ausgeschlossen werden, da das Bodenprofil eine lange Verwitterungsdauer aufzeigte. Die Eigenschaften waren folgende: vollständiges Fehlen von Grobanteilen; Bodenart Lehm; ab $80 \mathrm{~cm}$ Tiefe steigt Feinsandanteil an; obere Bodenhorizonte durchwurzelt, porös; untere Horizonte $\mathrm{B}_{\mathrm{v} 2}$ und $\mathrm{B}_{\mathrm{v} 3}$ Dichtlagerung; Verwitterungshorizonte $\mathrm{B}_{\mathrm{v} 1}$ und $\mathrm{A}_{2} \mathrm{~B}_{\mathrm{v} 1}$ Rostflecken und Eisen- und Mangankonkretionen mit vereinzelten Fahlflecken; Bodendynamik mit Ausfällung von Sequioxiden und Tonverlagerung; Tonanlagerung im $\mathrm{B}_{\mathrm{v} 2}=$ wasserstauend, mäßige Vergleyung (Parabraunerdedynamik).

Das gestörte, durch Um- und Überlagerung gekennzeichnete Profil 2 auf einer Höhe von $2.780 \mathrm{~m}$ oberhalb von Ghat verwies oberhalb des Waldrandes beim Hangknick bei der Verflachung in den Steilhang auf eine Braunerde. Bei diesem vielgestaltigen Bodenprofil waren zwei Böden verschiedenen Alters übereinander gelagert, wobei dieses durch die Kappung eines chemisch tiefenverwitterten Bodens durch das Eis der letzten Vergletscherung entstand. Im Liegenden fand sich eine intensivere Verwitterungsfarbe, unterhalb des $\mathrm{B}_{\mathrm{v}} \mathrm{C}$ Horizonts waren fossile $\mathrm{B}_{\mathrm{v}}$-Horizonte mit Eisrandablagerungen abgelagert und ein $\mathrm{C}_{\mathrm{v}^{-}}$ Horizont war ausgeprägt. Im Hangenden war der Boden auf umgelagerten Feinsedimenten entstanden. Oberhalb dieses Bodenprofils wurde mittels Aufgrabungen kein Einfluss der letzten Vereisung mehr festgestellt.

Beim Profil 3 in der Nähe von Ghat auf $2.660 \mathrm{~m}$ Höhe handelte es sich um eine Lockersedimentbraunerde, die sich auf dem Rand der entstandenen Hauptterrasse, dem Stausedimentterrassenrand, talaufwärts des Bergsturzriegels von Chaunrikharka entwickelte. Die Merkmale des Profils waren folgende: A-Horizont schwach humos; im B-Horizont 
starker Grobanteil; $\mathrm{B}_{\mathrm{v} 1}$ schwach lehmig; $\mathrm{B}_{\mathrm{v} 2}$ Tonanteil abnehmend, Grobanteil zunehmend; beim BC-Übergang Grobanteil $2 / 3$ des Gesamtvolumens, steigender Feinsandgehalt; Bodenart meist Feinsand. Die Grobanteile wiesen keine Verwitterungsspuren auf, was auf die Jugendlichkeit oder - etwa im Vergleich $\mathrm{zu}$ Moränen - auf ungünstige Verwitterungsbedingungen in den Stausedimenten hindeutete.

Gut ausgebildete Ufermoränen fanden Heuberger, Weingartner (1985:76) im Pharag nur oberhalb von Phakdingma im Seitental Panyali Drangka. Diese drei langen formfrischen mit Blöcken versehenen Ufermoränen des Haupttalgletschers erstreckten sich auf einem Felsrücken ab einer Höhe von 2.970 m. Der mittlere war am besten erhalten, der äußerste zeigte stellenweise eine Neigung von $40^{\circ}$ und der innerste zerfiel abwärts. Weitere Wallreste fanden sie in 3.030 und 3.060 m Höhe. Der Haupttalgletscher riegelte das Seitental ab; eine Talverfüllung und Seebildung wurde nicht nachgewiesen. „Fortsetzungen dieser Eisränder südlich der Panyali Drangka scheinen am Haupttalhang stellenweise erhalten zu sein, doch konnten diese Örtlichkeiten nicht besucht werden. " (Heuberger, Weingartner 1985:76). Das Profil 4 wurde an der Innenseite des äußersten Moränenwalles oberhalb von Phakdingma auf 2.970 m Höhe aufgenommen und zeigte demnach eine Moräne, auf der sich eine Braunerde $\left(\mathrm{A}_{1}-\mathrm{A}_{2}-\mathrm{B}_{\mathrm{v} 1}-\mathrm{B}_{\mathrm{v} 2}\right.$; in $\mathrm{B}_{\mathrm{v}}$ höherer Tongehalt als Profil 3), begünstigt durch den hohen Feinanteil des Ausgangsmaterials, ausbildete. Der Eisrand wurde beim Wallansatz auf $3.060 \mathrm{~m}$ Höhe festgelegt. Auf einer Höhe von 3.120 bis $3.130 \mathrm{~m}$ traten die Bodenmerkmale der Parabraunerde, wie beim Profil 1 (tiefgründige Verwitterung; Grobanteil im $\mathrm{C}_{\mathrm{v}}-$ dieser klebrig, plastisch; Profil außerhalb des Eisrandes) auf. Die Bodenart war feinsandig-lehmig mit Plastizität und Klebrigkeit.

Profil 5 oberhalb von Monjo auf 3.450 m Höhe, auf dem Rücken der Kyashar Drangka, wies auf einen geringmächtigen, überwiegend grobanteilfreien Braunlehm hin. Im liegenden $\mathrm{B}_{\mathrm{v}^{-}}$ Horizont vorkommende Steine waren durchverwittert. Oberflächlich kamen Moränenblöcke bis auf $3.500 \mathrm{~m}$ Höhe vor, wobei dort auch die Anzeichen einer jungen Bodenbildung endeten. Erst ab einer Höhe von $3.550 \mathrm{~m}$ zeigte das Bodenprofil Merkmale der Parabraunerde, wie bei Profil 1 (tiefgründiger Lehm; wenige und durchverwitterte Gesteine; Grobmaterial im Übergang $\mathrm{zu} \mathrm{C}_{\mathrm{v}}$ ), welches nicht mehr vom Eis erreicht wurde.

Die bedeutendsten hochglazialen Eisrandablagerungen im Pharag und unteren Khumbu befinden sich laut Heuberger, Weingarten $(1985: 73$, 75) nördlich von Khumjung und Khunde (P6) von 3.920 bis auf 4.130 m Höhe. Der letzteiszeitliche Eisrand wurde in Abb. 2 bei der 
abbrechenden linken Ufermoräne des Lokalgletschers bei $4.150 \mathrm{~m}$ eingezeichnet. Zum letzteiszeitlichen Eisrand äußerten sich Heuberger, Weingartner (1985:76) wie folgt: „,Wahrscheinlich lag er noch etwas höher.“. Die Eisrandablagerungen waren als zerschnittene Terrassen oder als Wälle ausgebildet und unterschieden sich von den blockigeren, unruhigen und steileren Bergsturzablagerungen südlich von Khumjung / Khunde (ebd.:73). Diese stellten Eisrandformen der vereinigten Talgletscher des Imja Tal und Nangpo Tal dar, wobei sie aber mehrere Eisrandlagen einer dichten Zeitfolge kennzeichneten (ebd.:75). Drei Formenkomplexe machten Heuberger, Weingartner (1985:75) aus: ein östlicher als langer Rücken über Khumjung, ein mittlerer zwischen Khumjung und Khunde talaufwärts bis 4.130 m Höhe mit einer Verflachung, auf der ein 8 bis 10 m großer Moränenblock lag, und ein westlicher über Khunde talabwärts bis auf 3.920 m, der am meisten zergliedert war. Zwischen dem östlichen und mittleren existierte eine breite Erosionsrinne und zwischen dem mittleren und westlichen eine tiefe Murrinne. Die mittlere Bastion konnte für eine Endmoräne eines Lokalgletschers des Khmbui Yul Lha gehalten werden; ausgebildete Ufermoränen (orographisch linke verschwindet auf einer Höhe von $4.150 \mathrm{~m}$ ) deuteten aber darauf, dass dieser in den Hauptgletscher floss. Heuberger, Weingartner (1985:75) trennten diese Moränen also durch geomorphologische Analysen, gaben aber an, dass eine sedimentpetrographische Analyse besser wäre. Geschiebeanalysen (z.B. Zurundung, Petrographie) im Gelände brachten aber keine Ergebnisse, da der Haupttalgletscher auch schlecht gerundete Gesteine und viele schlecht auseinanderhaltbare Migmatite mit sich führte. „, Typische Granite oder Gneise oder Vertreter der Everest-Serie aus den inneren Tälern wurden jedenfalls nicht gefunden.“ (Heuberger, Weingartner 1985:75). Eisgeschliffene Formen befanden sich oberhalb der Moränenablagerungen und wurden mit den Lokalgletschern der mittleren Bastion in Verbindung gebracht (ebd.:76). Das Profil 6 oberhalb von Khunde auf 4.000 Höhenmetern zeigte, dass auf den Eisrandablagerungen der letzten Vereisung eine schwächere Bodenbildung als bei Profil 4 entwickelt war.

Während des letzten Glazialmaximums ging Heuberger (1986) von einer Talvergletscherung auf der Südseite des Himalaja im Gebiet des Solukhumbu bzw. im Mt. Everest Gebiet in den Tälern des Pharag - Dudh Khosi, Beni Khola - Shorong / Solu und Basa Drangka - Junbesi Khola, Shorong / Solu aus. Die Gletscher reichten im Pharag bis auf ca. $2.500 \mathrm{~m}$ Höhe bei Ghat, im Beni Khola bis auf $2.550 \mathrm{~m}$ bei Ringmo und im Basa Drangka bis auf $3.200 \mathrm{~m}$ bei Phukmoche hinab. Demnach verlief der vorzeitliche Talgletscher im Bereich des Dudh Khosi / Pharag am weitesten talabwärts. Ältere Literatur schloss Heuberger in Bezug auf die 
Maximalvergletscherung der Mt. Everest Südseite aus, da sich diese nur mit dem Spät- und Postglazial beschäftigte. (ebd.:29 f.)

Bei Bezug des angegebenen Wertes der Maximalvergletscherung ohne Betrachtung anderer Gletscher oder Faktoren auf das Khumbu Gletscherende in $4.800 \mathrm{~m}$ Höhe konnte eine Schneegrenzdepression von $1.150 \mathrm{~m}$ (4.800 m minus $2.500 \mathrm{~m}: 2)$ und eine vorzeitliche Schneegrenze auf $4.350 \mathrm{~m}(5.500 \mathrm{~m}$ minus $1.150 \mathrm{~m})$ berechnet werden.

Indizien für die größte Gletscherausdehnung fand Heuberger (1986) in der Entwicklung des Bodens: ein fortgeschrittener Grad der Bodenbildung in Moränen deutete auf Interglaziale und ältere Eiszeiten. Bei zwei Forschungsreisen - insgesamt etwa vier Monate im Jahre 1984 - sammelte er diese Bodenbefunde. Die drei Hauptvereisungen benannte er nach den Ortsnamen. Die letzte Hauptvereisung 'Tega' - nach dem Weiler Tega nordwestlich von Ghat benannt - verursachte im Pharag bzw. Dudh Khosi Tal eine Talgletscherlänge von etwa 52 km; die vorletzte Vereisung 'Surke' reichte bis unterhalb der Khari Khola Mündung bis auf ca. $1.580 \mathrm{~m}$ bei einer etwaigen Gletscherlänge von $64 \mathrm{~km}$. In den Tälern des Beni Khola und des Basa Drangka reichte die letzte Vergletscherung wie o.g. bis auf eine Höhe von ca. 2.550 und $3.200 \mathrm{~m}$, die vorletzte auf ca. 2.480 und $3.000 \mathrm{~m}$ und eine älteste Vereisung 'Ringmo' im Beni Khola bis auf ca. $2.400 \mathrm{~m}$ Höhe. Die Gletscherlängen betrugen in etwa 9 bis $22 \mathrm{~km}$. Die letzte Vereisung war jedoch in den drei untersuchten Tälern nicht die umfangreichste, wodurch es auch schwierig war, anhand einer Vergletscherung auf Hebungstendenzen zu schließen. (ebd.:29 f.)

In den engen Tälern des Pharag und Shorong waren nach Heuberger (1986) nur wenige Eisrandformen z.B. in Form von Moränenwällen vorhanden, wobei er diese Gegebenheit mit einer kurzfristigen Vergletscherungsphase der unteren Talabschnitte in Verbindung brachte. Das Auffinden von Erratika sah er als schwierig an, da in diesem Gebiet Migmatite auftraten, die sehr unterschiedlich ausgebildet waren. Jedoch betrachtete er die Bodenbildung als entscheidendes Indiz für die Maximalausdehnung der letzten Vereisung und ordnete drei Talgletscher der letzten Eiszeit zu. Die Bodenbildung bzw. Bodentypen und -mächtigkeit seit der letzten Eiszeit soll in diesem Gebiet in etwa der der Alpen seit der letzten Würmeiszeit entsprechen. In Moränenablagerungen hingegen war die Bodenbildung weiter vorangeschritten, was auf ein Interglazial schließen ließ. Bei Ringmo im östlichen Shorong / Solu fand Heuberger wiederum noch ältere Moränenreste mit intensiverer Bodenbildung, die er einer älteren Hauptvereisung zuordnete, obwohl keinerlei Altersbestimmungen möglich waren. (ebd.:29 f.) 
Kuhle (1986a) legte im Khumbu - schwerpunktmäßig im Ngozumpa Gebiet - durch geomorphologische Analysen, Schneegrenzberechnungen und ${ }^{14} \mathrm{C}$-Datierungen, aber auch durch Lichenometrie, verschiedene Gletscherstadien bzw. zwölf spätglaziale, neoglaziale und rezente Gletscherstadien fest.

Kuhle (1987a) datierte 1987 ebenfalls dort im Gebiet Westkhumbu verschiedene Moränenstadien. Genauso fand er dazu vergleichbare Moränensequenzen im Dhaulagiri- und Annapurna-Himalaja in den Jahren 1976 / 77 und in Nord- und Osttibet. Weiterhin wurde ein Verfahren zur Korrektur von Schneegrenzberechnungen vorgestellt, dass es ermöglichte die Schneegrenze überregional zu vergleichen. (ebd.:200 f.)

Im Gebiet des Khumbu verwies Kuhle (1987b) auf Formen wie Kar, Ufermoräne und glaziolimnische Sande. Er gab eine eiszeitliche Schneegrenzabsenkung von 900 bis $1.000 \mathrm{~m}$ an, wobei die hochglaziale Eismächtigkeit im Konfluenzbereich zum Imja Drangka 600 bis $850 \mathrm{~m}$ betrug und verwies darauf, dass der hocheiszeitliche Rongbuk Gletscher gen Süden als Auslassgletscher abfloss. Die Vergletscherung des Haupttales reichte laut Kuhle bis auf 1.580 m Höhe hinab.

Der Dudh Khosi Gletscher wurde von Kuhle (1988a) als Auslassgletscher bis auf eine Höhe von $1.800 \mathrm{~m}$ beschrieben; Schliffhohlkehlen und junge Moränen auf der Nordseite und Glättungen auf der Südseite waren Indikatoren für den südlichen Abfluss des hochglazialen Rongbuk Gletscher.

\subsubsection{Forschungsergebnisse der Jahre 1991 bis heute - Beginn der TCN- und OSL- Datierung}

Im Zeitraum von 1991 bis heute betrieben im Solukhumbu Bäumler et al. (1991), Bäumler, Kemp-Oberhettinger, Zech (1996), Bäumler, Zech (1998), Kuhle (1998), Aoki, Imamura (1999), Richards et al. (2000), Bäumler (2001), Kuhle (2001a), Finkel et al. (2003), Kuhle (2005), Barnard, Owen, Finkel (2006), Kuhle (2007a), Rai, Yoshida, Upreti (2007), Owen et al. (2008) sowie Kuhle (2011b, 2013a) Forschungen zur Vergletscherungsgeschichte.

Anhand von Eisenfraktionierung, Tonmineralanalysen und Verwitterungsindizes unterschieden Bäumler et al. (1991) zwei Böden - P2, P3, P5 und P6 als junge Böden aus der letzten Eiszeit oder dem Postglazial sowie P1, P4 und P7 als ältere Böden aus dem Interglazial (ebd.:223, 237). 
Die Alter der jungen Böden P3 und P5 wurden mit ${ }^{14} \mathrm{C}$-Analysen bestimmt und verwiesen auf ein Alter von $4.815 \pm 70$ Jahre vor 1950 und $2.785 \pm 85$ Jahre vor 1950 (ebd.:236). Die Bodenproben wurden im Dudh Khosi Tal bzw. Solu Tal zwischen 2.670 und 4.490 m Höhe entnommen (ebd.:225). In Tabelle 1 und im Text auf Seite 225 und 228 wurden sieben Bodenprofile - südöstlich von Lukla, oberhalb von Phakdingma, zwei oberhalb von Monjo, westlich von Duglha, bei Ringmo und bei Tongnasa - beschrieben. Hierbei machten Bäumler et al. Angaben über die Lage derselben anhand von Beschreibungen, Koordinaten und Höhen sowie über die Eigenschaften wie etwa Material, Horizont, Farbe, pH-Wert, Kohlenstoffgehalt, Kationenaustauschkapazität und Korngrößenverteilung.

Bäumler et al. (1991:241) gingen anhand der Bodenbefunde davon aus, dass die Bodenprofile P4 und P7 nicht mehr vom letztglazialen Eis erreicht wurden. Für das Dudh Khosi Tal gaben sie an, dass das junge Bodenprofil P2 oberhalb von Phakdingma auf Moränen der letzten Eiszeit entwickelt und das P1 in der Nähe von Lukla komplett entwickelt war und demnach ebenso nicht mehr vom letztglazialen Eis erreicht wurde (ebd.:241). Somit reichte das letzteiszeitliche Eis nach Bäumler et al. (1991) nicht bis nach Lukla.

In der Forschungsarbeit von Bäumler, Kemp-Oberhettinger, Zech (1996) ergab sich bei Bäumler (1988) ${ }^{88}$ zitiert nach: Bäumler, Kemp-Oberhettinger, Zech (1996), teilweise mit ${ }^{14} \mathrm{C}$ Datierungen bewiesen, dass die Böden in zwei Gruppen eingeteilt werden konnten: junge Bodenprofile mit einer geringen Bodenentwicklung, die sich vermutlich auf Ablagerungen der jüngsten Vergletscherung oder auf jüngeren bildeten und vier ältere mit einer stärkeren Bodenentwicklung, die nicht mehr vom Eis erreicht wurden und sich bei Lukla, Monjo und Ringmo befinden. Der Eisrand einer älteren mittelpleistozänen Vergletscherung lag demnach bei Monjo zwischen 3.480 und 3.550 m Höhe, bei Ringmo zwischen 2.670 und $2.870 \mathrm{~m}$. Der Ort Lukla wurde von der jüngsten Hauptvergletscherung nicht mehr erreicht. (vgl. Bäumler, Kemp-Oberhettinger, Zech 1996:27)

Die Bodenprofile im Solukhumbu ergaben eine fortgeschrittenere Entwicklung als im Langtang-Himal. Typisch für das Khumbu Gebiet waren die äolischen oder äolisch beeinflussten Deckschichten und die enorme Podsolierung (Profile Khumbu 1 und 2), für den Solu die stärkere Versauerung als im Langtang. Die äußere Omoga Moräne (Bodenprofil Khumbu 3) im Imja Drangka stammte, gegenüber der benachbarten (Bodenprofil Khumbu 2,

\footnotetext{
${ }^{88}$ Bäumler, R. (1988): Untersuchungen zur Verwitterungsintensität von Böden aus glazialen und fluvioglazialen Ablagerungen als Beitrag zur Klärung der pleistozänen Verhältnisse im Mt. Everest-Gebiet, Khumbu Himal, Ostnepal. Diplomarbeit, Lehrstuhl f. Bodenkunde u. Bodengeographie, Universität Bayreuth, unveröffentlicht.
} 
Podsol) und der Ufermoräne beim Nangpo Tsangpo Tal (Bodenprofil Khumbu 1), welche beiden letztgenannten wahrscheinlich spätglazial waren, vermutlich aus dem Neoglazial und war die jüngste. Khumbu 2 war intensiver verwittert als Khumbu 1 und demnach älter. Jedoch war es auch intensiver verwittert als Khumbu 3, welches aber die äußere Moräne darstellt. Das Hangprofil (Solu 1) bei Tongnosa war weniger verwittert als ein $10 \mathrm{~m}$ höheres gelegenes Profil bei Bäumler (1988) ${ }^{89}$ zitiert nach: Bäumler, Kemp-Oberhettinger, Zech (1996) und stärker verwittert als ein $200 \mathrm{~m}$ tiefer liegendes ebenfalls bei diesem Forscher auf einer Moräne. Somit war dieser Standort vermutlich eine hochglaziale Eisrandlage. Jedoch war Solu 1 gegenüber den anderen Profilen in dieser Arbeit stärker verwittert und lessiviert. Die Profile Solu 2 und 3 im Basa Drangka Tal waren jungen holozänen Alters. Die Profile lagen in der Solu Gneis Zone. (vgl. Bäumler, Kemp-Oberhettinger, Zech 1996:Zus., 13, 83-85)

Bäumler, Zech (1998) definierten drei Gruppen von jüngeren Böden aus der letzten Eiszeit und aus dem Holozän - spät-, mittel- und frühholozän bis spätpleistozän - und ältere Böden aus dem Mittelpleistozän (ebd.:439). Die ermittelten Parameter der Böden wurden dort auf Seite 442 beschrieben. Da die Ausarbeitung von Bäumler, Zech (1998) eine Zusammenfassung bzw. Ergänzung der Arbeit von Bäumler, Kemp-Oberhettinger, Zech (1996) darstellt, wird der Ort Lukla - den Ergebnissen dieser Forschungen folgend - von der jüngsten Hauptvergletscherung nicht mehr erreicht worden sein.

Kuhle (1998) bezog sich auf Geländearbeiten aus dem Jahr 1982, rekonstruierte also einen hochglazialen Dudh Khosi Auslassgletscher bis zur Lumding Drangka Konfluenz auf 1.800 m Höhe. Indikatoren hierfür waren junge Moränen auf der Himalaja Nordseite, Glättungen im Talbereich zwischen Nangbug und Surke und eine Lateralmoräne mit glazilimnischen Sanden bei Namche Bazar, Nyambua Thyang, Chhutawa und Julming. (vgl. Kuhle 1998:85 f.)

Aoki, Imamura (1999) bestimmten absolute ${ }^{10} \mathrm{Be}$-Alter von Pheriche Moränen, die darauf hindeuteten, dass die Moräne vor 25.000 bis 20.000 oder vor 15.000 bis 12.000 Jahren entstand. Die unterschiedlichen Altersangaben waren durch die verschiedenen Produktionsraten auf Basis der verschiedenen Breitenlage - geomagnetisch und geographisch - zu erklären. Hierbei stellten sie fest, dass die TCN-Daten unter Berücksichtigung der geomagnetischen Breitenlage für die ${ }^{10}$ Be-Produktionsrate mit den OSL-Daten von Richards übereinstimmten. Somit war diese Breitenlage für den Nepal-Himalaja besser geeignet, 
wodurch gezeigt wurde, dass die Produktionsrate regionale Unterschiede aufzeigte. Dennoch sollte bedacht werden, dass die OSL-Datierungen ebenfalls von den Veränderungen der Intensität der kosmischen Strahlung abhängig und weitere Forschungen nötig sind. (ebd.:135)

Somit reichte das letzteiszeitliche Eis nach Aoki und Imamura bis maximal südlich von Periche auf ca. 4.200 bis $4.000 \mathrm{~m}$ Höhe. Bei Bezug des angegebenen Wertes der Maximalvergletscherung lediglich auf das Khumbu Gletscherende ohne weiteren Einbezug von Gletschern und anderen Faktoren in $4.800 \mathrm{~m}$ Höhe, lassen sich eine Schneegrenzdepression von $300 \mathrm{~m}$ (4.800 m minus $4.200 \mathrm{~m}$ : 2) und eine vorzeitliche Schneegrenze auf $5.200 \mathrm{~m}(5.500 \mathrm{~m}$ minus $300 \mathrm{~m})$ berechnen.

Abschließend nannten Aoki und Imamura (1999:135) Voraussetzungen für zukünftige Probenahmestellen: Beprobung von freiliegenden und unerodierten Oberflächen sowie quarzreichem Gestein, Anwendung von absoluten Datierungen $\left({ }^{14} \mathrm{C}\right.$-Datierungen waren besser als OSL und TL).

Anhand von OSL-Datierungen und morphostratigraphischen Merkmalen kamen Richards et al. (2000) im Untersuchungsgebiet Khumbu-Himalaja zum Ergebnis von drei Gletschervorstößen: Lobuche (ca. 1.000-2.000 Jahre v.H., Spätholozän), Chhukung (ca. 10.000 Jahre v.H., Spätglazial oder Frühholozän) und Periche (ca. 18.000-25.000 Jahre v.H., MIS $2=$ LGM). Das Periche Stadium legten sie durch Datierungen der Probenahmestellen SK 09-14 und SK 16-18 bzw. von Randmoränen bis ca. 1,8 km südlich von Pheriche und südwestlich von Thyangboche fest. (vgl. ebd.:1621, Tab. 1, Fig. 2)

Das bedeutet, dass das letzteiszeitliche Gletscherende ca. 4,5 km vom heutigen Khumbu Gletscherende entfernt lag und bis auf ca. 4.200 Höhenmeter reichte (Fig. 2A), wodurch sich unter Betrachtung lediglich des Khumbu Gletscher eine vorzeitliche Schneegrenze auf 5.200 $\mathrm{m}$ und eine Schneegrenzdepression von $300 \mathrm{~m}$ ergibt (4.800 m minus $4.200 \mathrm{~m}: 2,5.500 \mathrm{~m}$ minus 300 m). Richards et al. (2000:1629) gingen davon aus, dass der Khumbu und der Imja Gletscher hinab bis zu deren Konfluenz im LGM reichten; die Lateralmoränen reichten bis auf maximal ca. $5.400 \mathrm{~m}$ Höhe. Die Schneegrenze war lediglich etwa 200 bis $300 \mathrm{~m}$ abgesenkt bei einer heutigen Schneegrenze nach Inoue $(1977)^{90}$ und Müller (1980) zitiert nach: Richards et al. (2000:1629) auf 5.600 bis 5.700 m Höhe.

\footnotetext{
${ }^{90}$ Inoue, J. (1977): Mass budget of Khumbu Glacier: Seppyo, v. 39. (S. 15-19)
} 
Die Sandproben SK 04-06 wurden von einem als Lateralfrontalkomplex interpretierten Moränenbogen etwa $1 \mathrm{~km}$ südwestlich der Endmoräne des Lhotse Nup Gletscherendes, SK 06, in der Nähe des Grates und die anderen in der obersten Lage der untersten stratigraphischen Schicht entnommen. SK 08 wurde aus einer Sandlinse eines Moränenrückens etwa 600 bis $800 \mathrm{~m}$ südwestlich von Chukhung und $2 \mathrm{~km}$ talabwärts des Lhotse Gletscher entnommen. SK 09 und ABNU-147 entstammten einer äußersten Moräne südlich von Pheriche, die als älteste Lateralmoräne des vorzeitlichen Khumbu Gletscher interpretiert wurde. Die glazifluviale Probe SK 10 wurde etwa 500 m talabwärts von SK 09 von einem jüngeren Lateralmoränenbogen genommen. Die Probenahmestelle SK 13 lag talabwärts des rezenten Khumbu Gletscher und SK 14 zwischen den großen Lateralmoränen des vorzeitlichen Khumbu Gletscher. Die Sande SK 16-18 basierten auf der Entnahme westlich von Thyangboche auf der Südseite von einem etwa 300 m hohen Moränenrücken ca. $80 \mathrm{~m}$ unterhalb des Grates, wobei dieser eine Lateralmoräne des Phunki Gletscher darstellte. (ebd.:1625 f.)

Bei Bäumler (2001) wurden im Solukhumbu gegenüber eindeutigen Moränen - die durch tiefstreichende Gletscher entstanden und zwischen 3.800 und 4.300 m Höhe lagen - zum Vergleich zwei jüngere Stadien oberhalb von $4.300 \mathrm{~m}$ und eine Toposequenz ab $2.670 \mathrm{~m}$ beprobt (ebd.:26, 39 f.).

Im Khumbu wurden sieben Standorte beprobt. Der erste lag auf einer Ufermoräne bei der Siedlung Thame auf 3.815 m Höhe (Khumbu 1, Braunerde-Podsol, maximale Verwitterung), der zweite und dritte auf Ufermoränen nördlich von Tengboche gegenüber von Pangboche auf 4.020 und $4.070 \mathrm{~m}$ (Khumbu 2, Braunerde über Braunerde-Podsol und Khumbu 3, podsolige Braunerde über Podsol-Braunerde), der vierte auf einer Moräne bei Khumjung auf $3.910 \mathrm{~m}$ (Khumbu 4, Podsol), der fünfte auf einer Ufermoräne bei Pheriche auf $4.310 \mathrm{~m}$ (Khumbu 5, Podsol-Braunerde), der sechste auf einer Stirnmoräne bei Duglha auf 4.490 m (Khumbu 6, Braunerde über gekapptem Podsol, ältestes Stadium) und der siebente bzw. jüngste zwischen Lobuche und Tschobolari auf $4.830 \mathrm{~m}$ (Khumbu 7, Braunerde-Regosol). Die genauen Standorte von K 4-7 waren nicht zu erkennen, da diese auf keiner Skizze dargestellt wurden. Bei K 4 war nicht eindeutig, ob sich diese Moräne vom Haupt- oder Nebengletscher bildete (hierzu Heuberger, Weingartner 1985). Um was es sich bei K 7 für eine geomorphologische Form handelte, wurde nicht deutlich. (vgl. Bäumler 2001:24-26)

Im Solu wurden sechs Standorte beprobt. Profile Solu 1 bis Solu 3 wurden im Beni Khola gegenüber von Ringmo aufgenommen (Solu: Braunerde, 2.670 m Höhe, Genese nicht ganz 
geklärt - Situmetrie, Gesteinsformen; Solu 2: Parabraunerde, 2.860 m Höhe; Solu 3: Braunerde über rotem Paläoboden, 2.870 m Höhe). Die Genese von Solu 2 und 3 wurde nicht erwähnt. Profil Solu 4 wurde im Beni Khola angelegt (Podsol, 3.860 m), wobei auf etwa $4.000 \mathrm{~m}$ Höhe bei Lhagyelwa eindeutige Moränen vorkommen. Solu 5 (Podsol-Braunerde, Ufermoräne, 4.000 m Höhe) und Solu 6 (Braunerde-Regosol, Stirnmoräne, 4.050 m Höhe, möglicherweise erodiert) lagen auf den tiefstliegenden eindeutigen Moränen im Basa Drangka bei Basa. (ebd.:26-28)

Es ergaben sich vier relative Bodenalter aus dem Holozän (K 6 bei Duglha, K 7 bei Lobuche), dem Spätpleistozän bis älterem Spätglazial und dem Interglazial (Toposequenz: S 2 letztes Interglazial, S 3 vorletztes Interglazial oder noch älter). Nach Heuberger (1956), Heuberger, Weingartner (1985) wurden die Thame und Lhagyelwa Moränen dem Spätglazial und die Khumjung Moränen dem Hochglazial zugeordnet; die Pheriche Moränen laut Heuberger (1956) dem Spätglazial oder laut Röthlisberger (1986) ${ }^{91}$ zitiert nach: Bäumler (2001) dem Hochglazial. Die Ablagerungen von Khumjung und Pheriche bzw. die Moränen zwischen 3.800 und 4.300 m Höhe waren nach Bäumler (2001:41) spätpleistozäne. (ebd.:41)

Somit reichte das letztglaziale Eis nach Bäumler (2001) bis auf ca. 3.500 bis $3.800 \mathrm{~m}$ Höhe (ebd.:103), wobei keine genauen Aussagen über die Maximalausdehnung gemacht werden konnten, da nicht alle Moränen Endmoränen darstellten. Bei Bezug des angegebenen Wertes der Maximalvergletscherung lediglich auf das Khumbu Gletscherende in 4.800 m Höhe ohne weiteren Einbezug anderer Aspekte lassen sich eine Schneegrenzdepression von 500 / 650 m (4.800 m minus $3.500 / 3.800 \mathrm{~m}:$ 2) und eine vorzeitliche Schneegrenze auf 4.850 / $5.000 \mathrm{~m}$ (5.500m minus $500 / 650 \mathrm{~m})$ berechnen.

Kuhle (2001a) korrigierte seine bisherigen Befunde in Bezug auf die letzteiszeitliche Maximalvergletscherung im Solukhumbu, fand glaziale Indikatoren in Form von Abrasionsformen bei Jubing und rekonstruierte somit den Dudh Khosi Haupttalgletscher nicht bis auf eine Höhe von 1.800 oder 1.580 m hinab, sondern bis auf eine Höhe zwischen 1.100 und 900 Höhenmetern beim Konfluenzbereich zum Hinku Khola. (ebd.:391)

Bereits der Titel des Papers von Finkel et al. (2003) verwies darauf, dass sie Moränen anhand von ${ }^{10} \mathrm{Be}$-Datierungen untersuchten und diese einen starken Monsuneinfluss und eine glaziale zeitliche Übereinstimmung im gesamten Himalaja andeuteten. Vergleiche mit Regionen wie

\footnotetext{
${ }^{91}$ Röthlisberger, F. (1986): 10000 Jahre Gletschergeschichte der Erde. Verlag Sauerländer, Aarau. (S. 78-152)
} 
Hunzatal, Nanga Parbat, Garhwal, Langtang und Lahul-Himalaja zeigten diese Synchronität an (Fig. 3). Die Befunde verwiesen jedoch auch darauf, dass die Vergletscherung auf der Südseite des Mt. Everest nicht synchron mit dem Vorstoß der Eisdecken der Nordhemisphäre war. Gletschervorstöße während der Zeitabschnitte erhöhter Einstrahlung deuteten darauf hin, dass erhöhte Feuchtigkeit durch einen aktiven Sommermonsun in dieses Gebiet gekommen und für die Gletschervorstöße in diesem Teil des Himalaja verantwortlich war. Es wurde dort ein globaler Klimazusammenhang bei einem Gletschervorstoß während des globalen LGM, wenn auch mit einer sehr begrenzten Ausdehnung (Periche Stadium), trotz reduziertem Niederschlag veranschaulicht. Anhand der Daten bewerteten sie, welchen Einfluss der globale Klimawandel und der Monsuneinfluss auf die Vergletscherung im Himalaja hatten. Von besonderer Bedeutung war die Realisierung, dass Gletschervorstöße greifbar in Zeiten von angestiegener Einstrahlung und globaler Erwärmung auftraten. Diese Erkenntnis unterstützte die Auffassung, dass das nordwärtige Eindringen des Monsuns - einhergehend mit ansteigendem Schneefall in hohen Höhenlagen - ein Hauptfaktor der Vergletscherung im gesamten Himalaja war. Während Zeiten geringer Einstrahlung, wie im MIS 2, waren Gletscher als Folge niedriger Temperaturen lediglich fähig kleine Vorstöße zu machen. Der Schwerpunkt der Arbeit von Finkel et al. (2003) bestand darin, anhand der CRN-Daten eine Chronologie für die glazialen Abfolgen im Khumbu zu geben, was Aussagen über die Vergletscherung in Beziehung zum regionalen und globalen Klimawandel zuließ, wobei die Arbeit die erste darstellte, die eine Übereinstimmung von CRN- und OSL-Daten prüfte. Die CRN-Datierungen bestätigten die OSL-Datierungen von Richards et al. (2000) für drei Gletschervorstöße und die Radiokarbondaten von Müller (1980), Benedict (1976) und Fushimi (1978) für einen Gletschervorstoß. Die CRN-Daten der Gletscherabfolge rund um den Khumbu Gletscher und Chhukhung, zusammen mit den vorher veröffentlichten OSL- und Radiokarbondaten, lieferten das umfassendste Set von numerischen Daten im gesamten Himalaja. (vgl. Finkel et al. 2003:561, 564, Fig. 3)

Finkel et al. (2003:561, 564) wiesen im Talabschnitt unterhalb des Khumbu Gletscher anhand von CRN-Datierungen (kosmogene Radionukliddatierungen, ${ }^{10} \mathrm{Be}-\mathrm{Daten}$ ) verschiedener Blöcke einzelner Moränen acht Gletschervorstöße nach. Die größte Vergletscherung machten sie während des MIS 3, begrenztere während des MIS 2 (LGM) und des Holozän aus. Erstgenannten Vergletscherungszeitraum setzten sie mit dem Thyangboche Stadium gleich (ebd.:561). Anhand von morphostratigraphischen Merkmalen und anhand der Daten teilten sie dieses Stadium in Thyangboche I - 59.000 +/- 29.000 Jahre v.H. und Thyangboche II - 
35.000 +/- 3.000 Jahre v.H. (ebd.:561). Finkel et al. (2003:Fig. 1) datierten daneben Periche Moränen größtenteils ca. $5 \mathrm{~km}$ vom heutigen Khumbu Gletschereisrand entfernt, nur dass sie diese in die Stadien Periche I - 23.000 +/- 3000 Jahre v.H. = globales LGM und Periche II 16.000 +/- 2.000 Jahre v.H. unterteilten. Somit reichte die maximalste letzteiszeitliche Gletscherausdehnung unterhalb des Khumbu Gletscher südlich von Periche bis auf ca. 4.200 m Höhe (ebd.:Fig. 1). Daraus resultierte bei Betrachtung des Khumbu Gletscher, ausgeschlossen anderer Gletscher und Faktoren, eine vorzeitliche Schneegrenze auf $5.200 \mathrm{~m}$ Höhe und eine Schneegrenzdepression von $300 \mathrm{~m}$ (4.800 m minus $4.200 \mathrm{~m}:$ 2, $5.500 \mathrm{~m}$ minus $300 \mathrm{~m})$.

Das älteste Vergletscherungsstadium war das Thyangboche Stadium, wobei das Thyangboche Stadium II einen jüngeren Gletschervorstoß als Thyangboche I darstellte, und die Daten bei letztgenanntem Stadium sich in zwei Gruppen teilten $(86.000 \pm 6.000$ Jahre v.H. und $33.000 \pm$ 7.000 Jahre v.H.). Über das wahre Alter der letzten Moränen konnte laut Finkel et al. (2003) nur spekuliert werden. Das ältere CRN-Alter war eventuell mit bereits existierenden CRN durch Vorbelichtung, das jüngere mit Verwitterung, verstürzten Blöcken und / oder Exhumierung in Verbindung zu bringen. Wären alle Blöcke exhumiert, verwittert oder verstürzt, könnten diese laut Finkel et al. älter als 90.000 Jahre sein. Glaziale Akkumulationen der Thyangboche Stadien waren auf breite, separierte und erodierten Schultern sowie Rücken in Höhe von $4.500 \mathrm{~m}$ begrenzt, wobei diese Vergletscherung aufgrund der Zerstörung vieler glazialer Formen durch intensive Erosion und Hanginstabilität nicht weit bis unterhalb des Tshola Gletscher verfolgt werden konnte. Nichtsdestotrotz bestand laut Finkel et al. während der Thyangboche Stadien eine breite Talvergletscherung, wobei diese die meist ausgedehnte Vergletscherung im Khumbu-Himalaja darstellte. Die ausgedehnte Vergletscherung während des MIS 3 ließ auf einen verstärkten Niederschlag in Form von Schnee in höheren Lagen schließen - während eines Zeitraums verstärkter Einstrahlung und größeren Monsuneinflusses im Himalaja. Durch die resultierende positive glaziale Massenbilanz rückten die Gletscher unter dem Monsuneinfluss vor, wobei die Einstrahlung während des MIS 3 und MIS 5 höher war. (ebd.:561 f.)

Das ältere Periche I Stadium (E 41 und E 59 ausgenommen) zeigte eine gering intensivere Vergletscherung als das jüngere Periche II Stadium (E 71 ausgenommen). Die Gletscherausdehnung während des Periche Glazial war auf rund $5 \mathrm{~km}$ jenseits des heutigen Eisrandes beschränkt. Ähnliche Vorstöße traten zu dieser Zeit in anderen Bereichen des Himalaja auf, was weitere Forscher im Hunza und mittleren Industal von Nordpakistan sowie im Kangchendzönga-Himal belegen. Die Daten unterstützten diese Gletscherausdehnung und 
erklärten den Gletschervorstoß nur anhand der Abkühlung. Die CRN-Daten des Periche Stadiums oberhalb von Periche stimmten mit den ${ }^{10}$ Be-Daten von Aoki and Imamura (1999) und den OSL-Daten von Richards et al. (2000) überein. Bei letztgenannten wurden die Daten anhand von glazifluvialen Sedimenten in der Nähe der Moränenbasis, wobei diese den frühen Teil des Periche Glazialstadiums repräsentierten, erhoben. Diese wurden dem Periche I zugeordnet, halfen aber nicht das Periche II Stadium festzulegen. (vgl. Finkel et al. 2003:562 f.)

Holozäne Gletschervorstöße wurden in die Stadien Chhukung $(9.200 \pm 200$ Jahre, Frühholozän), Thuklha (3.600 \pm 300 Jahre, Neoglazial) und Lobuche (< 1.000 Jahre, `little climatic optimum'); historische in den Zeitraum < 500 Jahre eingeordnet (ebd.:Tab.1, 563, 564). Die Chhukhung Daten des frühen Holozän (E 29 ausgenommen) unterstützen die OSLDaten von Richards et al. (2000) und weiterhin die Sicht, dass die Vergletscherung in diesem Teil des Himalaja während der Zeiten von Einstrahlungsmaxima in hohen Höhenlagen stark vom ansteigenden Monsunniederschlag beeinflusst war. Dieser Gletschervorstoß beschränkte sich auf Bereiche, die etwa $1 \mathrm{~km}$ von den heutigen Gletschereisrändern entfernt liegen. Ähnliche Vorstöße dokumentierten auch andere Forscher im Lahul-Himalaja, Hunzatal, Nanga Parbat und Kangchendzönga-Himalaja. (vgl. Finkel et al. 2003:563 f., Tab. 1)

Das vorher undatierte Thuklha Glazialstadium zeigte ein Alter von ca. 3.000 bis 4.000 Jahren an. Dieser Vorstoß trat etwas später ein als das Einsetzen der neoglazialen Vergletscherung, welches Grove (1988) ${ }^{92}$ zitiert nach: Finkel et al. (2003) in den meisten Gebirgsregionen nach ca. 5.000 Jahren aufzeigte. Ähnliche Gletschervorstöße verzeichneten andere Forscher im Chitral, Garhwal, Langtang und Kangchendzönga-Himal. Spätholozäne Lateral- bis Frontalmoränen waren entlang der heutigen Gletscher aufzufinden. CRN-Daten lieferten Alter jünger als 1.000 Jahre (E 32 und E 38), die dem Lobuche Stadium zugeordnet wurden. Die Proben E 36 und E 37 wiesen extrem junge Alter auf, was darauf schließen ließ, dass ihre Oberflächen vor kurzem - z.B. durch Sturzprozesse hervorgerufen - belichtet worden waren. Dennoch halfen diese Daten die OSL-Daten von Richards et al. (2000) zu bekräftigen und stimmten mit den Radiokarbondaten von Müller (1980), Benedict (1976) und Fushimi (1978) überein, welche zeigten, dass diese Moränen eventuell mit dem kleinen Klimaoptimum korrelierten. Ein Vorstoß während eines solchen Optimums unterstützte die Sichtweise, dass die positive Massenbilanz in einem Zeitraum erhöhter Wärme, wenn der Monsun weiter in die

\footnotetext{
${ }^{92}$ Grove, J.M. (1988): The Little Ice Age: London, Routledge. 489 S.
} 
Gebirge voranschritt um reichlich Schnee in hohe Höhenlagen zu deponieren, erreicht wurde. (vgl. Finkel et al. 2003:563)

Müller (1980), Benedict (1976) und Fushimi (1978) zeigten, dass Gletscher vor etwa 400 bis 500 Jahren v.H. $\left({ }^{14} \mathrm{C}\right.$-Daten) einige hundert Meter von der heutigen Position aus gesehen vorstießen. Infolge der anhaftenden bzw. vorgegebenen Ungenauigkeit von sehr jungen CRNAltern sammelten Finkel et al. (2003) keine Proben von diesen Moränen, welche dem historischen Stadium zuzuordnen waren. Radiokarbondatierungen zeigten, dass dieser Vorstoß kurz vor oder etwa übereinstimmend mit dem generellen Einsetzen der Kleinen Eiszeit in anderen Teilen der Welt auftrat (Grove $1988^{93}$ zitiert nach: Finkel et al. 2003). Deswegen sahen Finkel et al. (2003) davon ab, diese Moränen als 'Kleine Eiszeit Moränen' zu benennen, sondern bezeichneten diese lediglich als historische Gletschervorstöße, obwohl keine historischen Daten entdeckt wurden, die ihre ehemalige Position dokumentierten. (ebd.:563 f.)

Die Probenahmestellen wurden vorher anhand von Luftfotos bzw. zusätzliche im Gelände parallel während morphostratigraphischer Untersuchungen ausgewählt. Diese Stellen wurden nach Zugänglichkeit und unter Berücksichtigung der Probenahmestellen von Iwata (1976) und Richards et al. (2000) festgelegt. Die Lage der Probenahmestellen konnten Fig. 1 entnommen werden. Es wurden mehrere Blöcke von jedem Moränenrücken beprobt, um die Reproduzierbarkeit der Ergebnisse und die Möglichkeit der CRN-Vererbung zu überprüfen. (vgl. Finkel et al. 2003:561)

Die Proben wurden also von den Oberflächen metergroßer Blöcke, die teilweise von der Moränenoberfläche überdeckt waren, entnommen. Solche Blöcke waren nicht verstürzt und wiesen keine Sedimentbedeckung für einen signifikanten Zeitabschnitt auf. Es wurden Blöcke ausgesucht, die keine tiefen Verwitterungsspuren oder Anzeichen rezenter Exhumation aufwiesen. Die Standorte der Blöcke bestimmten Finkel et al. mit einem GPS-Gerät. Höhenangaben, Einfallen und Streichen der Proben und die Dicke wurden bestimmt, um die ‘skyline shielding' zu korrigieren. Fotos von jedem Block können in Form einer CD bei Robert Finkel oder Lewis Owen angefordert werden, wobei die angewandten Laborverfahren der Probenbehandlung der angegebenen Internetseite entnommen werden können. (vgl. Finkel et al. 2003:angegebene Internetseite)

Bezüglich der Proben waren die Daten in Tab. 1 auffindbar. Aufgrund der Ähnlichkeit der Daten pro jeweils beprobter Moräne - ausgenommen der ältesten bzw. Thyangboche I Moränen - und wegen des Vergleiches der Morphostratigraphie mit dem Alter der Moränen

\footnotetext{
${ }^{93}$ siehe Quelle Grove (1988) in der Fußnote
} 
schlossen sie auf die Richtigkeit der Daten und anhand erstgenanntem Aspekt darauf, dass die CRN-Daten nicht von Erosionsprozessen verändert waren. (ebd.:561)

Kuhle (2005) ging von einer maximalen letzteiszeitlichen Vergletscherung bis hinunter auf 880 m Höhe östlich der Bakhor Siedlung in der Nähe des Hinku Khola Konfluenzbereiches aus (ebd.:315). Diese Annahme belegte Kuhle:Fig. 3 und 11 im gesamten Imja Drangka und Dudh Kosi anhand eindeutiger glazialgeomorphologischer Indikatoren, wie etwa Trogtäler, schluchtförmiger Tröge, glaziärer Dreieckshänge, Erratika, Rundhöcker, Strudeltöpfe und Moränen, wobei sich letztgenannte durch sedimentologische Untersuchungen als solche bestätigten und durch ${ }^{14} \mathrm{C}$-Datierungen sowie durch Lichenometrie zeitlich einordnen ließen. Bedeutend waren die talabwärts von Lukla aufgefundenen Grundmoränenreste mit $3 \mathrm{~m}$ großen gerundeten Gneisblöcken ca. 200 bis 450 m über dem Talboden (ebd.:315, Foto 232 und 233) und der schluchtförmige Trog unterhalb von Khari Khola (ebd.:315).

Kuhle (2005) rekonstruierte ein würmeiszeitliches (MIS 2 bis 4, vor 18.000-60.000 Jahren) Eisstrom- und Talgletschernetz, welches in Verbindung $\mathrm{zu}$ den westlich und östlich angrenzenden Eisstromnetzen der Himalaja Gebiete stand. Im Norden war dieses durch das tibetische Eisstromnetz - durch die Auslassgletscher Kyetrak-Nangpa-Bote Koshi Drangka, W-Rongbuk-Ngozumpa Drangka, Rongbuk-Khumbu Drangka und Arun Nadi - gespeist. Auslassgletscher flossen vom nördlich angrenzenden tibetischen Eisstromnetz über Transfluenzpässe in diese Täler des Himalaja, wobei diese die tiefsten eiszeitlichen Gletscherränder und Zungenenden in Hoch- und Südasien darstellten. Der zweitlängste Hauptgletscher im Khumbu- und Khumbakarna-Himal war der 70 km lange Dudh Khosi Gletscher mit dem Einzugsgebiet der Himalaja Hauptgipfel. Über der Schneegrenze erreichten die dortigen Gletscher Mächtigkeiten von 1.000 bis 1.450 m, wobei es sich bei dem Eis um ein semi-arid kontinentales kaltes handelte. Im Gebiet des Khumbu Gletscher reichte der Rongbuk Gletscher bis auf 6.400-6.500 m Höhe bzw. mit einer Mächtigkeit von $450 \mathrm{~m}$ über den Lho La Pass, was u.a. durch nach Süden einfallende Schliffgrenzen an der orographisch linken Seite des Mt. Everest West Rückens, der Unterschneidung auf ca. 6.500 m Höhe und der ebenen Fläche zwischen Lho La und Chang La belegt wurde. Die oberen 400 $\mathrm{m}$ des Rongbuk Gletscher flossen gegensätzlich zur heutigen Fließrichtung. Der Khumbu Gletscher reichte gegenüber seinem heutigen Gletscherzungenende auf ca. $4800 \mathrm{~m}$ Höhe während des neoglazialen Stadiums V mit einer Mächtigkeit von 200 bis $120 \mathrm{~m}$ bei einer Schneegrenzdepression von ca. $300 \mathrm{~m}$ bis auf $4.150 \mathrm{~m}$ bzw. bis zum Imja Khola 
Konfluenzbereich. Pheriche liegt auf einer glazifluvialen Schotterflur der Stadien -1 bis -8. Das Tsholo Drangka war über einen Transfluenzpass mit dem Ngozumpa Gletscher vorzeitlich verbunden und Taboche stellte ein glaziales Horn dar. Das Imja Drangka war polyglazial entstanden. (ebd.:193, 207, 277, 279 f., 285)

Insgesamt wies Kuhle 14 Gletscherstadien - ein hochglaziales, vier spätglaziale, drei neoglaziale, sechs historische - nach, welche laut ihm mit denjenigen weltweit bzw. aus den Alpen und Rocky Mountains übereinstimmten (ebd.:193, 204). Die Stadien 0 bis IV gehörten dem letzten Hoch- und Spätglazial an. Während des Stadiums I reichte der Dudh Khosi Hauptgletscher bis auf 1.800 m Höhe nahe der Lumding Khola Konfluenz unterhalb des Handi Khola herab, während des Stadiums II bis auf $2.500 \mathrm{~m}$ bzw. 1,5 bis $3 \mathrm{~km}$ talabwärts der Thado Koshi Konfluenz und während des Stadiums III bis auf $2.750 \mathrm{~m}$ bzw. bis 1,5 km unter die Kyashar Khola Konfluenz (ebd.:316). Kuhle (2005:Fig. 11) gab eine vorzeitliche Schneegrenze auf 3.850 bis 3.900 Höhenmetern sowie eine Schneegrenzdepression von 1.630 $\mathrm{m}$ an. Bei Bezug der oben angegebenen Maximalausdehnung bis auf $880 \mathrm{~m}$ lediglich auf das Khumbu Gletscherende in 4.800 m Höhe und nicht auf das von Kuhle beachtete gesamte Einzugsgebiet, ergaben sich eine Schneegrenze auf $3.540 \mathrm{~m}$ (5.500 m minus $1.960 \mathrm{~m})$ sowie eine Schneegrenzdepression von $1.960 \mathrm{~m}$ (4.800 m minus $880 \mathrm{~m}$ : 2). Während des Hochglazial bestand laut Kuhle in diesem Gebiet eine etwaige vorzeitliche Schneegrenze auf 3.870 Höhenmetern sowie eine Schneegrenzdepression von $1.630 \mathrm{~m}$ bei einer heutigen Schneegrenze auf $5.500 \mathrm{~m}$ (ebd.:193).

Barnard, Owen, Finkel (2006) kartierten geomorphologische Formen im Khumbu-Himalaja, wobei sie in den Gebieten Pangboche Yaral, Orsho und Dingboche Fächer und Terrassen anhand der CRN-Methode datierten (ebd.:Fig. 2). Die in Fig. 2 visualisierten glazigenen Akkumulationen deuteten darauf hin, dass die tiefstreichenden Moränen bis unterhalb von Periche auf ca. 4.200 m Höhe hinab reichten. Somit kann bei ausschließlicher Betrachtung des Khumbu Gletscher eine vorzeitliche Schneegrenze auf 5.200 Höhenmetern und eine Schneegrenzdepression von $300 \mathrm{~m}$ für die maximalste Vergletscherungsausdehnung angenommen werden (4.800 m minus $4.200 \mathrm{~m}: 2,5.500 \mathrm{~m}$ minus $300 \mathrm{~m}$ ).

Die Fächer entstanden durch zwei Prozesse, durch 'hyperconcentrated flows' und durch 'debris flows'. Sie bestanden aber hauptsächlich aus Diamikten, die durch 'debris flow', 'hyperconcentrated flow' und / oder fluviale Prozesse zu erklären waren und eventuell durch Schmelzwässer entstanden bzw. eine paraglaziale Entstehung hatten. Ob sich diese nun vor, 
während oder nach dem Gletschervorstoß herausbildeten, blieb trotz der Datierungen ungeklärt. Die 'bouldery diamicts' und die 'cobble diamicts' in den Fächern und Terrassen wiesen Eigenschaften der 'debris flows' auf, die aus glazialen Ablagerungen entstanden, ähnelten aber auch den `hyperconcentrated flows`. Somit nahmen sie an, dass die Fächer und Terrassen aus einer Kombination beider Prozesse entstanden. Die erstgenannten tendierten eher zu 'debris flows' und die anderen zu 'hyperconcentrated flows'. Deswegen verwendeten sie für diese Fächer den nicht die Genese derselben benennenden Oberbegriff 'fan'. Die Fächer und Terrassen entstanden durch glaziale Drainage und waren zerschnitten und teilweise ineinander verschachtelt. Die Fächer wurden anhand der Neigung und Position von den Terrassen unterschieden: die Fächer wiesen steile Abflüsse und Neigungsverhältnisse über $7^{\circ}$ auf, Terrassen waren annähernd eben ausgebildet bzw. unter $7^{\circ}$ geneigt. (ebd.:383$385,390,392,394)$

Sedimentologische, morphostratigraphische und geomorphologische Zusammenhänge ließen diese Fächer und Terrassen als paraglazial bzw. als während der Gletscherrückzugsphase entstandene annehmen. Die CRN-Datierungen der mächtigen Blöcke $\left({ }^{10} \mathrm{Be}-\right.$ Gehalt im Quarz) dieser Terrassen und Fächer deuteten auf Entstehungsperioden vor ca. 16.000, 12.000, 8.000, 4.000 und 1.500 Jahren hin, wobei diese Formen - ausgenommen des Alters von 12.000 Jahren - auf einen zeitlichen Zusammenhang zwischen Entstehung der Form und dem Gletscherstadium bzw. dem Gletscherrückzug hindeuten. Barnard, Owen, Finkel (2006) bezogen sich hierbei auf die Gletscherstadien von Finkel et al. (2003). (vgl. Barnard, Owen, Finkel 2006:383, 394-397)

In der Pangboche Yaral Region fanden Barnard, Owen, Finkel (2006) zehn Fächer- oder Terrassenlevel, wobei sie neun in Fig. 3 visualisierten. Die oberen drei Level stellten Fächer mit über $5 \mathrm{~m}$ großen Blöcken auf der Oberfläche dar; der größte Fächer existierte bei Pangboche $\left(\mathrm{t}_{\mathrm{p} 6}\right)$, wobei hangabwärts fünf Terrassen folgten. $\mathrm{T}_{\mathrm{p} 2}$ stammte von einem Gletscherseeausbruch aus dem Jahre 1977, wobei die Literatur Cendereli, Wohl (2001) ${ }^{94}$ angeführt wurde. $\mathrm{T}_{\mathrm{p} 7}$ war im Mittel 12.000 Jahre, $\mathrm{t}_{\mathrm{p} 6} 8.100, \mathrm{t}_{\mathrm{p} 3} 1.500, \mathrm{t}_{\mathrm{p} 2} 720 \pm 80, \mathrm{f}_{\mathrm{p} 3}$ etwa $58.000, \mathrm{f}_{\mathrm{p} 2} 17.000$ und $\mathrm{f}_{\mathrm{p} 1} 14.000$ Jahre alt. $\mathrm{F}_{\mathrm{p} 2}$ wurde beispielsweise mit dem Periche I oder II Stadium von Finkel et al. (2003) in Verbindung gebracht, $t_{p 6}$ mit dem Chukhung, $t_{p 3}$ mit Lobuche und $t_{\mathrm{p} 2}$ mit der Kleinen Eiszeit. In der Orsho Region war auf der Westseite des Tales der Fächer $f_{\text {ot }} 19-23^{\circ}$ geneigt, wobei sich weitere Terrassen hangabwärts befanden, die durch Sedimentation aus dem Imja Drangka entstanden. Auf der Ostseite wurden Fächer und

${ }^{94}$ Cenderelli, D.A.; Wohl, E.E. (2001): Peak discharge estimates of glacial-lake outburst floods and 'normal' climatic floods in the Mount Everest region, Nepal. Geomorphology, 40. (S. 57-90) 
Terrassen durch Hangprozesse zerstört oder überlagert. $\mathrm{T}_{06}$ war vor durchschnittlich 11.000 Jahren entstanden, $t_{04}$ vor 4.800 und $t_{03}$ vor etwa 4.400 . Bei Dingboche gab es Terrassen $t_{d 1}$ bis $t_{d}$, wobei die letzte älter war. $T_{\mathrm{d} 3}$ verwies nämlich auf ein Alter zwischen 12.200 und 14.700 Jahren v.H., $t_{\mathrm{d} 2}$ und $t_{\mathrm{d} 1}$ auf eines zwischen 4.000 und 5.000. Die vier Erosionsterrassen ('strath terraces`) im Imja Khola wiesen ein Alter von $3.700 \pm 100$ Jahren, $6.600 \pm 300$ und $16.200 \pm 400$ auf, woraus sich Erosionsraten von 3,4 bis 4,3 mm im Jahr - durchschnittlich 3,9 mm - ergaben. (vgl. Barnard, Owen, Finkel 2006:386, 388-390, Fig. 3)

Kuhle (2007a) beschrieb den vorzeitlichen Dudh Khosi Haupttalgletscher bis auf eine Höhe von ca. 900 m, welcher als Auslassgletscher mit dem tibetischen Eis über den Nangpa La und Lho La in Verbindung stand. Indizien waren Lateralmoränen bei Namche Basar, Nyambua Thyang, Chhutawa und Julming, aber auch die nach Süden geneigten hoch- bis spätglazialen Lateralmoränen 900 m über dem rezenten Talboden des Rongbuk Tales sowie die bei der Ortschaft Jubing ausgemachten glazialen Abrasionsformen an den Talflanken. (vgl. Kuhle 2007a:125 f.)

Die von Rai, Yoshida und Upreti (2007) untersuchten Bereiche im Gebiet rund um Lukla, also von Nachipan, Rondinma, Chaunrikharka, Muse, Nakchun, Tate, Surke und von Lukla selbst, stellten verschiedene Plattformen unterschiedlicher Höhe dar, die sich aus Moräne, Hangablagerungen ('colluviums') und Flussterrassenablagerungen zusammensetzten. Es standen dort Biotitsillimanit-Granatgneise, aber auch Quarzite und Granite / Pegmatite an.

Die Nachipan Plattform bestand aus Moräne, Hangablagerungen bzw. 'landslides' und Terrassenablagerungen, woraus unterschiedliche Entstehungsphasen abgeleitet wurden. Die Plattform bei Rondinma wies gerundete Gesteine, die bei Chaunrikharka als untere Schicht Moräne sowie die bei Muse in einer unteren Schicht gerundete Schotter auf. Die Plattform bei Lukla bestand aus kantigen bis kantengerundeten Hangablagerungen und teilweise Terrassensedimenten, wobei auch große Blöcke gefunden wurden, und die bei Tate aus großen Blöcken von Hangablagerungen und einigen fluvialen Sedimenten.

Da die Plattformen - wie etwa bei Nachipan und Chaunrikharka - laut Angabe von Rai, Yoshida und Upreti aus Moränenmaterial bestanden, musste die vorzeitliche Vergletscherung bis in diese Talbereiche hinab gereicht haben. Somit wäre eine maximale Vergletscherung südlich von Lukla ansprechbar, jedoch nicht genau festlegbar, da es sich bei der hier zitierten Arbeit von Rai, Yoshida und Upreti (2007) lediglich um eine Zusammenfassung handelte. 
Owen et al. (2008) gaben einen Überblick über die Vergletscherungsgeschichte von Hochasien. Die Zusammenfassung dieser Literaturquellen ergab, dass während des Spätpleistozän im Gebiet Himalaja Tibet ausgedehnte Eiskappen und Talvergletscherungen existierten. Diese waren weitestgehend und größtenteils monsunbeeinflusst, wobei aber die westliche Region asynchron zu den hochasiatischen Gebieten und von den Abkühlungsphasen der Nordhemisphäre dominiert gewesen war. (ebd.:513, 527)

Owen, Benn (2005) nahmen im Khumbu-Himalaja eine sehr geringe Vergletscherung bis auf maximal $4.200 \mathrm{~m}$ Höhe unterhalb von Periche an bei einer Schneegrenzdepression von ca. 200-300 m (hierzu Owen et al. 2008:526/Fig. 13B, 525). In Fig. 13A nach Shi (2002) ${ }^{95}$ zitiert nach: Owen et al. (2008) wurden jedoch in diesem Gebiet - von höheren zu tieferen Höhenbereichen gesehen - Schneegrenzdepressionen für das letzte glaziale Maximum von 500 bis $1.000 \mathrm{~m}$ angezeigt. Bei Bezug dieser Werte der genannten Forscher auf die aktuelle Schneegrenze bei $5.500 \mathrm{~m}$ im Khumbu ergab die Berechnung eine vorzeitliche Schneegrenze bei 5.200 bis $5.300 \mathrm{~m}$ Höhe bzw. bei 4.500 bis $5.000 \mathrm{~m}$. Der Khumbu Gletscher war somit beispielsweise bis auf ca. 4.400 bzw. 4.200 m Höhe (4.800 m minus 400 m; 4.800 m minus $600 \mathrm{~m}$ ) und bis auf ca. 3.800 bzw. 2.800 Höhenmeter (4.800 m minus $1.000 \mathrm{~m}$; $4.800 \mathrm{~m}$ minus $2.000 \mathrm{~m}$ ) abgesenkt. Die eigentliche Arbeit von Owen et al. (2008) im Khumbu war die Neuberechnung der OSL- und TCN-Daten von Richards et al. (2000) und Finkel et al. (2003).

Nach Kuhle (2011b) reichte der Imja-Dudh Khosi Hauptgletscher bis auf eine Höhe von ca. $900 \mathrm{~m}$ hinab - das ergaben die geomorphologischen, sedimentologischen Analysen in Kombination mit den ${ }^{14} \mathrm{C}$-Datierungen im Ngozumpa Drangka.

Kuhle (2013a) lieferte neue Erkenntnisse in Form von drei Sedimentproben, die auch bei Jubing auf Moränenmaterial hindeuteten, und zwei Fotos von Moränen in den Tälern Poyan Khola und Khari Khola aus dem Gebiet Solukhumbu, was seine bisherige Rekonstruktion weiterhin untermauerte. In den Nachbartälern Solu Khola bzw. beim Konfluenzbereich Junbesi und Beni Khola gab Kuhle (2013a) eine LGM Eisrandlage auf ca. 2.380 m Höhe an, im Hinku Khola eine auf ca. 1.680 m. Indikatoren waren Moränenablagerungen bei beiden

\footnotetext{
95 Shi, Y. (2002): Characteristics of late Quaternary monsoonal glaciations on the Tibetan Plateau and in East Asia. Quaternary International 97/98. (S. 79-91)
} 
genannten Tälern sowie bei letztgenanntem außerdem ein Trogtalprofil. (vgl. Kuhle 2013a:22-31)

Die Befunde von Kuhle (2013a) reichten somit gegenüber denen von Kuhle (2005:Fig. 11) talabwärts gesehen im Solukhumbu bis unterhalb des Deku Khola ins Gebiet der Siedlung Jubing.

\subsection{Vergleichsuntersuchungsgebiete}

\subsubsection{Forschungsergebnisse der Jahre 1971 bis 1990}

Im Annapurna- und Dhaulagiri-Himal bzw. im Mayangdi Khola waren für den Zeitraum 1971 bis 1990 neben anderen Kuhle (1980) bzw. im Kali Gandaki Kuhle (1982 / 1983), Iwata (1984) und Fort (1985) sowie im Seti Khola Fort (1986) mit ihren Arbeiten vertreten. Im Kangchendzönga-Himal ist die Arbeit von Kuhle (1990a) zu nennen.

\section{DHAULAGIRI- UND ANNAPURNA-HIMAL / MAYANGDI KHOLA}

Im Mayangdi Khola dokumentierte Kuhle (1980) eine Talvergletscherung bis auf eine Höhe von $1.100 \mathrm{~m}$ anhand von Hinweisen wie z.B. Moränen, Gletscherschrammen, Talquerprofilen in Form glazigener Kerbtäler sowie elf Gletscherstadien. Die hocheiszeitliche Schneegrenze rekonstruierte er auf etwa 4.030 m Höhe bei einer Schneegrenzdepression von ca. $1.460 \mathrm{~m}$. (ebd.:246 f.)

\section{DHAULAGIRI- UND ANNAPURNA-HIMAL / KALI GANDAKI}

Neben der vorzeitlichen Vergletscherungsgeschichte ermittelte Kuhle (1982 / 1983) auch Fakten über die rezente geomorphologische Höhenstufung. (vgl. Kuhle 1982a:1)

\section{REZENTE VERGLETSCHERUNG}

Kuhle (1982a / 1983) gab für den Dhaulagiri- und Annapurna-Himal eine rezente Schneegrenze bei 5.551 Höhenmetern an. Der rezente Einfluss des Monsuns auf die Vergletscherung zeigte sich im Verlauf der Schneegrenze des Hohen Himalaja: nach Kuhle (1982a) lag die rezente Schneegrenze in der Dhaulagiri Annapurna Region nördlich des Hohen Himalaja auf 5.615 m Höhe und südlich des Hohen Himalaja auf 5.487 m. Jedoch war wohl der Einfluss des Monsuns auf die Vergletscherung in diesem Gebiet während des Dampu Stadiums (III) größer und während des Hochglazial geringer als heute, wobei der Monsun während des Älteren Dhaulagiri Stadiums (VI) am geringsten war und auf eine 
unsignifikante Abhängigkeit von hocheiszeitlicher Abkühlung und Abschwächung des Monsuns ohne Betrachtung der absoluten Niederschlagssummen hinwies. (ebd.:151 f., 169 f.)

\section{VORZEITLICHE VERGLETSCHERUNG}

Kuhle (1982 / 1983) betrachtete glaziale, periglaziale und nivale Formen - daneben auch fluviale - als Anzeiger einer vorzeitlichen Vergletscherung. Er kam zum Ergebnis, dass teilweise ein Eisstromnetz im Inneren Himalaja und zusammengesetzte Talgletscher im Hohen Himalaja existierten. Die tiefste hochglaziale Eisrandlage südlich des Hohen Himalaja Hauptkammes lag nach Kuhle auf 1.010-1.160 m bei einer hocheiszeitlichen Schneegrenze bei ca. $4.019 \mathrm{~m}$, was auf eine Schneegrenzdepression von $1.532 \mathrm{~m}$ bei einer rezenten Schneegrenze bei etwa $5.551 \mathrm{~m}$ schließen ließ. Der Schneegrenzberechnung wurde hierbei der Wert der Eisrandlage von 1.160 m zugrunde gelegt, da diese anhand von Moränenmaterial belegt wurde. Kuhle bemerkte, dass die dazu gehörige Schneegrenze auf 4.030-4.105 Höhenmetern wahrscheinlich nach oben durch den Thak Khola Südwind verschoben wurde. Zusammengefasst ergab sich für die Dhaulagiri Annapurna Region eine hocheiszeitliche Schneegrenze bei ca. $4.019 \mathrm{~m}$ Höhe mit einer Schneegrenzdepression von $1.532 \mathrm{~m}$ bei einer rezenten Schneegrenze von $5.551 \mathrm{~m}$. Somit reichte dieser vorzeitliche Gletscher bis weit in die Himalaja Vorketten. Die hocheiszeitliche Vergletscherung des Dhaulagiri- und Annapurna-Himal charakterisierte sich durch eine Vertikaldistanz von ca. $7.100 \mathrm{~m}$, Gletscherlängen von ca. 50 km bzw. eine siebenfache Höhendistanz und eine Unterschreitung der orographischen Schneegrenzen um 3.000 m, wodurch unterhalb von 3.800 bis $4.200 \mathrm{~m}$ Höhe besonders schluchtförmige Tröge auftreten. Typische Trogtäler waren eher im Inneren Himalaja und nicht im Hohen Himalaja anzutreffen, vielmehr existierten dort Kerbformen bzw. trogförmige Schluchten. Trogförmige Schluchten waren durch eine glazigene Entstehung konkav geformte Flanken mit Gletscherschliff. Die hocheiszeitliche Eisrekonstruktion war bei Tukche am eindeutigsten fassbar. Kuhle (1982b:Abb. 7 und 8) zeichnete - belegt durch vermutlich aus dem Würm stammende hocheiszeitliche Moränen das hochglaziale Gletscherende etwa bei Ranipauwa im Thak Khola ein, auf ca. $1.010 \mathrm{~m}$ Höhe. (vgl. Kuhle 1982a:2 f., 42, 50 f., 152, 171, 173 f.; vgl. Kuhle 1982b:Abb. 7 und 8)

Kuhle (1982 / 1983) gab eine hocheiszeitliche klimatische Schneegrenzhöhe der Dhaulagiri Annapurna Region nördlich des Hohen Himalaja auf $3.981 \mathrm{~m}$ und eine Schneegrenzdepression von $1.634 \mathrm{~m}$ an. Gegenüber der südlichen Seite lag diese Schneegrenzhöhe 76 m tiefer. Die tiefste hochglaziale Eisrandlage legte Kuhle (1982) beim 
Yamkim Khola Gletscher auf 2.580 m fest, wobei er dazu bemerkte, dass die dazu gehörige Schneegrenze auf $4.290 \mathrm{~m}$ wahrscheinlich 100 bis $150 \mathrm{~m}$ niedriger lag. Südlich des Hohen Himalaja Hauptkammes der Dhaulagiri Annapurna Region berechnete Kuhle eine hocheiszeitliche klimatische Schneegrenzhöhe auf $4.057 \mathrm{~m}$ Höhe und eine Schneegrenzdepression von 1.430 m. (vgl. Kuhle 1982a:151 f., 169)

Kuhle (1982a:150-168 / 1983) teilte die vorgefundenen Formen unter Betrachtung des Lagebezuges und der ermittelten Schneegrenzen einzelnen 12 Stadien sowie Prä Ghasa Stagnationen zwischen dem letzten Hochglazial und dem Spätglazial zu: Hochglazial (0); Prä Ghasa Stagnationen; Ghasa Stadium (I); Taglung Stadium (II); Dhampu Stadium (III); Sirkung Stadium (IV); Nauri Stadium (V); Älteres Dhaulagiri Stadium (VI); Mittleres Dhaulagiri Stadium ('VII); Jüngeres Dhaulagiri Stadium (VII); Stadium VIII; Stadium IX und rezente Vergletscherung. Auf der geomorphologischen Karte wurden jedoch insgesamt 16 Stadien und 2 Prä Ghasa Stagnationen dargestellt: Eiszeitlich (vermutlich Riss); Hocheiszeitlich (Würm); Ghasa Stadium (I); Ghasa Stadium zweite Staffel (I’); Taglung Stadium (II); Dhampu Stadium ältere Staffel (III'); Dhampu Stadium (III); Sirkung Stadium (IV); Nauri Stadium (V); Nauri Stadium zweite Staffel (V’); Älteres Dhaulagiri Stadium (VI); Mittleres Dhaulagiri Stadium ('VII); Jüngeres Dhaulagiri Stadium (VII); Stadium VIII; Stadium IX und Stadium X. Kuhle (2001b:125/Tab.1) gab insgesamt 14 Stadien in Hochasien an.

Neben Angaben über die vorzeitliche Vergletscherung machte Iwata (1984) auch Aussagen über die rezente Vergletscherung.

\section{REZENTE VERGLETSCHERUNG}

Die rezente Vergletscherung der Thakkhola Muktinath Region beschränkt sich laut Iwata (1984:29) auf das Muktinath Becken und auf die Talhänge zwischen Ghasa und Tukche.

\section{VORZEITLICHE VERGLETSCHERUNG}

In der Thakkhola Muktinath Region im oberen Bereich des Kali Gandaki fand Iwata glaziale Formen, Massenbewegungsformen, Flussterrassen sowie die diese aufbauenden Sedimente und Seesedimente. Bei Larjung befanden sich beispielsweise große 'landslides’ und glaziale Akkumulationen, wobei letztgenannte zu einem Abdämmen des Tales vor dem letzten Interglazial führten und einen $400 \mathrm{~m}$ tiefen Paläo Marpha See im vorletzten Interglazial entstehen ließen, der mit der Marpha Formation und mit fluvioglazialen Akkumulationen in 
frühen und späten Unterteilungen des letzten Glazials befüllt wurde. Es wurde angenommen, dass der See während zweier verschiedener Perioden - der jüngere war kleiner und lag talaufwärtiger bzw. nördlicher - existierte. Die auf höheren Hangbereichen nach Fort (1980) ${ }^{96}$ und Fort et al. (1981) ${ }^{97}$ vorkommenden 'Larjung landslides' wurden bei Iwata (1984:39) als Tukche Moränen bezeichnet. (ebd.:25, 38, 39, 41)

Daneben wurden drei verschiedene Massenbewegungsformen in Gebieten mit verschiedenen Gesteinen und unterschiedlicher Topographie ausgemacht: "Large-scale landcreep masses in the Muktinath basin; depositional forms of debris flows related to glacier avalanches around Jomosom; and landslides between Dhampu and Ghasa." (Iwata 1984:33). Im Norden des Jhong Khola kommt die Khingar Stadium Moräne durch 'landcreeping' in mehrere Stufen zerteilt vor. Die 'debris flow' Ablagerung zwischen Jomosom und Syang und oberhalb von Tukche wurde vom Moränenmaterial aufgrund der Homogenität der Blöcke - die meisten waren Kalksteine - und des begrenzten Matrixanteiles unterschieden. Der beachtlichste 'landslide' wurde bei Dhampu ausgemacht. Außerdem konnten die Flussterrassen in sieben Level eingeordnet werden: von hoch $\mathrm{zu}$ niedrig $\mathrm{H} \mathrm{1,} \mathrm{H} \mathrm{2,} \mathrm{M} \mathrm{1,} \mathrm{M} \mathrm{2,} \mathrm{M} \mathrm{3,} \mathrm{M} 4$ und L. Unterhalb von Ghasa wurde keine Flussterrasse gefunden. Der alluviale Fächer bei Lete besteht aus Auswaschmaterialien des damaligen Lete Khola Gletscher. Die Flussterrassen zwischen Larjung und Chimgaon waren fluvioglaziale Terrassen oder alluviale Kegel / Fächer. Die relative Höhe der Flussterrassen H 1, M 1 und M 2 stieg talabwärts und verwies auf vertikale Krustenbewegungen. Die aus bis zu einigen Zentimeter dicken Ton-, Silt-, Mittelsand- und Feinsandschichten bestehende, mehr als 420 m mächtige Marpha Formation mit eingelagerten Schotterschichten - ohne organisches Material - südlich von Marpha verwies auf lakustrine Ablagerungen. (ebd.:33-35, 38, 40 f.)

Iwata unterschied vier Moränengruppen voneinander: Rezent, Tukche Stadium, Khingar Stadium Moränen, Moränen / Till von älteren Vergletscherungen. Moränen machte er bei Jomosom, zwischen Tukche und Ghasa aus sowie auch Till im Muktinath Becken, wobei aber bei den Moränen die Morphologie nicht geklärt war, da sie überformt wurden. Die

\footnotetext{
${ }^{96}$ Fort, M. (1980a): Les formations quaternaires lacustves de la Basse Thakkhola (Himalaya du Nèpal): intéret paléogéographique, néotectonique et chronologique. C.R. Acad. Sco. Paris, t. 290 (21 janvier 1980) Série D. (S. 171-174)

${ }^{97}$ Fort, M.; Bassoulet, J.P.; Colchen, M.; Freytet, P. (1981): Sedimentological and structural evolution on the Thakkhola-Mustan graben (Nepal Himalaya) during late Neogene and Pleistocene. Neogene / Quaternary Boundary Field Confevence, India, 1979, Proceedings. (S. 25-35)
} 
Gletscherstadien unterschied Iwata anhand des Lagebezuges und des Frischegrades voneinander. (ebd.:29)

Die jüngsten bzw. die rezenten Moränen zeichnete er in der Nähe der existierenden Gletscher ein (siehe Fig. 1) - an den Osthängen des Dhaulagiri oder an den West- und Nordhängen des Nilgiri sowie unterhalb des Thorong Pass im Muktinath Becken - und beschrieb sie als neoglaziale frische Moränen mit scharfen Graten. Die Tukche Moränen - verortet zwischen Tukche und Lete, im Kaiku und Lete Khola, begrenzt im Muktinath Becken und bei Tukuche (siehe Fig. 2) - waren ebenfalls neoglaziale Ablagerungen. Stellenweise wiesen sie Vegetationsbedeckung in Form von Wald auf, zeigten aber eindeutige Moränenrücken. Die Tukche Moränen reichten bis $200 \mathrm{~m}$ über den heutigen Talboden. (ebd.:29)

Die Khingar Stadium Moränen - auftretend bei Khingar, nördlich vom Jhong Khola im Muktinath Becken, südlich von Thini und rund um Tagrung - entstanden laut Iwata et al. $(1982)^{98}$ zitiert nach: Iwata (1984:30) in der frühen Unterteilung des letzten Glazial, was er anhand paläomagnetischer Relativdatierungen von Seesedimenten bei Khingar festlegte.

Ältere Kaltzeiten zeigten umfangreichere Vergletscherungen auf; die vor dem letzten Interglazial war ausgedehnter. Indikatoren für ältere Vergletscherungen fand Iwata (1984) in Moränen und Till im Norden des Beckens von Muktinath hinter Tukche - hier verliefen die Oberflächen $400 \mathrm{~m}$ über der Taltiefenlinie, nordöstlich von Dhampu - hier 430 bis $460 \mathrm{~m}$ darüber, im Bereich vom Muktinath Becken, im Syang Khola, im Langpoghyn Khola, bei Jhong im Muktinath Becken und bei Marpha. Iwata unterschied diese deutlich von den jüngeren Moränen, aber legte keinen genauen Entstehungsraum fest. Die Terrassen M 1 und M 3 wurden im frühen und späten Stadium des letzten Glazial abgelagert. (ebd.:30 f., 41)

Somit stellte Iwata (1984) zwei Stadien in das Neoglazial, eins in eine frühe Phase des letzten Glazial und das älteste in das vorletzte Glazial. Die ungefähren Zeiten konnten Fig. 14 entnommen werden: rezent (< 500 Jahre), Tukche (ca. 2.000 Jahre), Khingar (ca. 4.500 Jahre), ältere (zwischen 10.000 und 15.000 Jahre). Die tiefste Eisrandlage bzw. die tiefstreichenden kartierten Moränen lagen nach Iwata (1984:Fig. 1 - `Older Glaciations’) im Bereich der Siedlung Ghasa auf 1.870 m Höhe. Diese wurde nach der genannten zeitlichen Einteilung in Fig. 14 als Maximum des letzten Glazial angenommen.

\footnotetext{
${ }^{98}$ Iwata, S.; Yamanaka, H.; Yoshida, M. (1982): Glacial landforms and river terraces in the Thakkhola region, Central Nepal. Jour. Nepal. Geol., Soc. 2 Special Issue. (S. 81-94)
} 
Fort (1985) fand mehr als 300 m mächtige Moränen in Form von Frontal-, Lateral- und Grundmoränen bei der Konfluenz von beispielsweise Sammargaon Khola, Jhong und Langpoghyun Khola und zudem sehr mächtige glazifluviale Schotter, die auf ein kaltes Klima während des mittleren bis späten Pleistozän hindeuteten. Die Gletscher vom West Thakkhola, nördlich des Dhaulagiri, Nilgiri und des Thorung-Himal reichten nach Fort $(1976,1980)^{99}$ und Dollfuss, Usselmann (1971) ${ }^{100}$ zitiert nach: Fort (1985) im Zeitraum mittleres bis spätes Pleistozän von Jhong Khola auf 3.200 m Höhe bis nach Ghasa auf 2.000 m hinunter. (vgl. Fort 1985:164)

Diesem Hauptstadium folgten drei weitere Stadien (ebd.:166). In der nach Fort et al. (1981) ${ }^{101}$ und (1982) ${ }^{102}$ modifizierten Tabelle 1 zitiert nach: Fort (1985:162) war ebenso zu erkennen, dass sie von mehreren Stadien ausging, wie etwa im Holozän (`staged dissection (terraces)’, 'late and neoglacial stages’) sowie im späten und mittleren Pleistozän ('glacial shaping of the mountain slopes`). In Fig. 24.58b war die tiefste Ausdehnung von moränischen Ablagerungen bei Jhong zu entnehmen. Diese gehörten vermutlich - sie wurden mit einem Fragezeichen versehen - in die Zeit des letzten Glazial. Talabwärts von Jhong visualisierte Fort in dieser Abbildung bei Khingar glazifluviale Ablagerungen, vermutlich aus dem letzten Glazial. Im niedrigeren Thakkhola lagerten sich, aufgrund der Abdämmung des Kali Gandaki durch 'landslide' Material und durch die Gletscherzunge, die vom Dhaulagiri kam, lakustrine Schichten rund um Marpha ab (Fort 1980a ${ }^{103}$ zitiert nach: Fort 1985:164).

\section{DHAULAGIRI- UND ANNAPURNA-HIMAL / SETI KHOLA}

Fort (1986) machte im Seti Khola Angaben über die rezente und vorzeitliche Vergletscherung (ebd.:107).

\section{REZENTE VERGLETSCHERUNG}

Die rezente Vergletscherung des Seti Khola zwischen den Bergen Machapuchare, Annapurna III und Annapurna IV ist auf kleine Plateaugletscher beschränkt (ebd.:107, 108/Fig. 2).

\footnotetext{
${ }^{99}$ Fort, M. (1976): Quaternary deposits of the Middle Kali Gandaki Valley (Central Nepal). In: Himalayan Geology, 6. (S. 499-507); siehe Quelle Fort (1980a) in der Fußnote; Fort, M. (1980b): La formation de la Kali Gandaki et l'histoire récente de la haute chaine himalayenne. Bull. Assoc. Géogr. Franc., Paris, 471. (S. 237247)

100 bei Fort (1985) nur Quelle Dollfuss, O.; Usselmann, P. (1972) angegeben

${ }^{101}$ Fort, M.; Bassoullet, J. P.; Colchen, M. ; Freytet, P. (1981): Sedimentological and structural evolution on the Thakkhola-Mustan graben (Nepal Himalaya) during late Neogene and Pleistocene. Neogene / Quaternary Boundary Field Confevence, India, 1979, Proceedings. (S. 25-35)

102 bei Fort (1985) nur Quelle Fort et al. (1981) angegeben

103 siehe Quelle Fort (1980a) in der Fußnote
} 


\section{VORZEITLICHE VERGLETSCHERUNG}

Während des Neoglazial vor der Entstehungszeit der Pokhara und nach der der Gachok Akkumulation im Korva Stadium reichten die Gletscher bis unterhalb von 1.500 m Höhe bis zu den Rücken des Midlands Pahar Beckens (ebd.:118). Indikatoren einer vorzeitlichen Vergletscherung des Seti Khola gab es nach Fort $(1986: 107,111)$ bis nördlich von Pokhara. Fort (1986:107, 108/Fig. 2) fand dort eine 500 m mächtige Moräne, wahrscheinlich eines spätneoglazialen Alters (Kleine Eiszeit? - mit Fragezeichen in Fig. 2 angegeben), in der Nähe des Seti Gletscher, welcher auf $3.800 \mathrm{~m}$ Höhe endete. Hinweise für eine vorzeitliche Vergletscherung sah Fort (1986:107) in den polierten und geschrammten Schluchtwänden des Seti Khola; der beste Indikator waren sehr gut erhaltene Endmoränenrücken (Fort 1985104 zitiert nach: Fort 1986), die das Tal dämmen wie etwa bei der Mijbe Kkola Konfluenz, nördlich der Nanhe Khola Konfluenz und bei Korua. Diese Ablagerungen bestanden aus heterometrischen kantigen Kalksteinen und kalkhaltigen Sandsteinen, waren außerdem 200 m hoch und sehr gering mit Boden bedeckt (vgl. Fort 1986:107).

Andere Ablagerungen bzw. kalkhaltige Brekzien von Kahure Gachok mit Moränencharakter gehörten einer älteren glazialen Ausdehnung an (ebd.:Fig. 2). Über das Alter meinte Fort (1986:108/Fig. 2) folgendes: “4: calcareous breccia of Kahure-Gachok, with till-fabric characteristics, which might belong to a former (Late Glacial) glacial extent." und ordnete diese somit in das Spätglazial ein. Fig. 2 verwies auf eine dazugehörige Eisrandlage auf ca. $1.100 \mathrm{~m}$ Höhe bei Puranchaur (ebd.:114). Eine hochglaziale Eisrandlage wurde nicht beschrieben.

Im Pokhara Becken fanden sich verschiedene Ablagerungstypen wie Hangakkumulationen sog. Gharjati und Thak Bhaise Brekzien (ebd.:109/Fig. 3), alluviale Akkumulationen - sog. Rithepani Formationen (ebd.:110/Fig. 4) und zwei Sets von Ablagerungen - Dhiprang Brekzie und Pokhara Schotter (ebd.:115/Fig. 7) sowie Kahure Brekzie und Gachok Konglomerate (ebd.:113/Fig. 6). Die ältesten Formationen, die Gharjati und Thak Bhaise Brekzien, waren $50 \mathrm{~m}$ mächtig und wiesen tropische, karstige Oberflächenformen auf (ebd.:107). Diese beiden letztgenannten Formationen stellten Hangakkumulationen, die lokal in Form von 'debris flows' auftraten, dar (ebd.:111). Es kamen hauptsächlich dolomitische Kalksteine, Schiefer, Sandsteine, Quarzite und selten auch Gneise vor (ebd.:111). Die 20 bis

\footnotetext{
${ }^{104}$ Fort, M. (1985): Contribution of sedimentary and geomorphic data to the knowledge of paleoclimates in Nepal Himalayas. In: Current Trends in Geology, VI, Climate and Geology of Kashmir for the last Four Million Year, New Delhi. (S. 159-189)
} 
$40 \mathrm{~m}$ mächtige Rithepani Formation auf niedrigeren Höhen bestand aus kristallinen gut gerundeten Schottern und Sanden (ebd.:111).

Die etwa 60 bis $100 \mathrm{~m}$ mächtige Pokhara Formation stellte einen 'debris flow' dar, der vor 500 Jahren v.H. $\left({ }^{14}\right.$ C-Alter) entstand. Nach Gurung $(1970)^{105}$, Hormann $(1974)^{106}$, Fort und Freytet (1983) ${ }^{107}$ zitiert nach: Fort (1986) entstammt die Pokhara Formation auf der Basis der petrographischen Zusammensetzung und der sedimentologischen Eigenschaften jedoch glazifluvialer Auswaschung und dem LGM. Über $90 \%$ der Ablagerung kamen aus dem Gebiet des Sabche Kar. Die Dhiprang Formation im äußersten Norden des Beckens bestand hauptsächlich aus dem Sabche Kar entstammenden kalkigen kantigen Blöcken und könnte als Moräne interpretiert werden. Das Alter der Pokhara Formation gaben andere genannte Forscher mit durchschnittlich 1.100 bis 400 Jahren v.H. $\left({ }^{14} \mathrm{C}\right)$ an. (vgl. Fort 1986:112, 114 , 115/Fig. 7, 116 f.)

Die Kahure Brekzie unterschiedlicher Mächtigkeit nördlich von Puranchaur Lachok bestand aus kantigem Kalkstein, kalkhaltigem Sandstein vom Sabche Kar und teilweise aus Gneis mit einer 'muddy' Matrix. Die Gachok Formation / Konglomerate - von anderen Forschern als Gaunda bezeichnet - bestand aus gut gerundeten Schottern und Sandkörnern. Diese Formation stammte laut den von Fort 1986 zitierten Forschern aus der vorletzten oder der letzten Vergletscherung und überlagerte die Kahure Brekzie. Über $70 \%$ der Schotter bzw. Kalksteine und kalkhaltigen Sandsteine kamen aus dem Sabche Kar. Die Kahure Gachok Konglomerate stellten nach Gurung (1970) ${ }^{108}$ zitiert nach: Fort (1986) Fächer dar bzw. eine glazifluviale Auswaschung. (vgl. Fort 1986:112 f.)

\section{KANGCHENDZÖNGA-HIMAL}

Kuhle (1990a) fand heraus, dass der Eisrand zur Zeit des letztglazialen Maximums bis auf $890 \mathrm{~m}$ bei Thoma herabreichte, wobei Auslassgletscher von Südtibet mit diesem Gebiet in Verbindung standen und ein dendritisches Talgletschersystem bestand (s.h.a. Kuhle 1982). Diesen Eisrand rekonstruierte er anhand von vom Eisrand weiter talaufwärts liegenden Randformen über Tapethok und Khejinim, glaziärem Flankenschliff und Strudeltöpfen $500 \mathrm{~m}$ über dem Talboden bei Shirwa und über Midlung, sowie von Gletscherschrammen und

\footnotetext{
105 Gurung, H.B. (1970): Geomorphology of Pokhara valley. Himalayan Review, Kathmandu, 2-3. (S. 29-49)

106 Hormann, K. (1974): Die Terrassen an der Seti Khola. Ein Beitrag zur Quartären Morphogenese in Zentral Nepal. Erdkunde, 28, 3. (S. 161-176)

${ }^{107}$ Fort, M. und Freytet, P. (1983): The Quaternary sedimentary evolution of the intramontane basin of Pokhara, in relation to the Himalayan Midlands and their hinterlands (West central Nepal). In: Contemporary Geoscientific Researches in Himalaya, 2, A.K. SINHA ed., Dehra Dun. (S. 91-96)

${ }^{108}$ siehe Quelle Gurung (1970) in der Fußnote
} 
Rundhöckern $250 \mathrm{~m}$ über dem Talboden 1,5 km talaufwärts von Thoma bzw. anhand von Endmoränen direkt bei Thoma. 1,2 km talabwärts von Thoma wurden zwar weiterhin Polierformen, aber keinerlei Moränenreste aufgefunden. Die zur Eisrandlage bei dieser Ortschaft gehörige Schneegrenze lag auf 3.900 Höhenmetern, was bei einer rezenten Schneegrenze auf 5.560 m einer Schneegrenzdepression von 1.660 m entsprach. (vgl. Kuhle 1990a:419 f.)

\subsubsection{Forschungsergebnisse der Jahre 1991 bis heute}

Im Annapurna- und Dhaulagiri-Himal bzw. im Mayangdi Khola waren im Zeitraum 1991 bis heute neben anderen die Arbeiten von Kuhle (1998, 2007a, 2013a) bzw. im Kali Gandaki die von Kuhle (1998, 2007a), Zech et al. (2009) sowie Kuhle (2011a, 2013a, b) bekannt, im Annapurna- und Dhaulagiri-Himal bzw. im Modi Khola die Arbeiten von Kuhle (2001a), Zech et al. (2001) und Kuhle (2007a, 2013a) bzw. im Madi Khola die Arbeiten von Kuhle (1998, 2001a, 2007a, 2013a) bzw. im Seti Khola die Arbeit von Kuhle (2001a, 2007a, 2013a) sowie im Marsyandi Khola die Arbeiten von Kuhle (1997a, 1998, 2007a, 2013a, b, 2014). Im Langtang-Himal waren es die Arbeiten von Shiraiwa, Watanabe (1991), Bäumler, KempOberhettinger, Zech (1996), Kuhle (2001a) Barnard et al. (2006) und Kuhle (2013a), im Mahalangur-Himal die Arbeit von Kuhle (1997a, 1998, 2005, 2007a) sowie im Kangchendzönga-Himal die Arbeiten von Kuhle (1998), Meiners (1999), Kuhle (2001a), Tsukamoto et al. (2002) sowie Kuhle (2007a, 2013a, 2014).

\section{DHAULAGIRI- UND ANNAPURNA-HIMAL / MAYANGDI KHOLA}

Im Mayangdi Khola beschrieb Kuhle (1998) mit Verweis auf seine älteren Quellen LGM Moränen bis auf eine Höhe von 1.100 m, Kuhle (2007a) gab ebenfalls ein Gletscherende bei 1.100 m Höhe an. Indikatoren einer einstmaligen Vergletscherung der Südseite des Himalaja waren Moränenterrassen, gut ausgeprägte Endmoränen mit Erratika, Trogprofile mit Gletscherschrammen und Polierungen (vgl. Kuhle 1998:85, 2007a:124, 2013a:16 f.). Kuhle (2013a) legte das hochglaziale vorzeitliche Gletscherende auf ca. 1.150 bis $1.100 \mathrm{~m}$ Höhe beim Ort Dharbang, was mit einer Schneegrenzdepression von etwa 1.425 bis $1.450 \mathrm{~m}$ in Verbindung gebracht wurde (ebd.:17). 


\section{DHAULAGIRI- UND ANNAPURNA-HIMAL / KALI GANDAKI}

LGM Moränen machte Kuhle (1998, 2007a) im Thakkhola bis auf eine Höhe von 1.100 m aus, hierbei verwies er auf seine älteren Quellen. Die Schneegrenze lag allgemein betrachtet bei ca. 4.020 m. (vgl. Kuhle 1998:85, 2007a:124)

Der Himalaja ist laut Zech et al. (2009) für die Rekonstruktion vergangener Vergletscherungen und vergangenen Klimas eine Schlüsselregion. Verschiedene Faktoren spielen eine Rolle, weswegen es noch nicht viele Kenntnisse über die spätquartäre Vergletscherung gibt: geringe Zugänglichkeit zu vielen Regionen (Relief, politische Unruhen); geringer Erhaltungsgrad der Formen auf der Südseite (hohes Relief, reichlich Niederschläge), Komplikation der glazialen Geschichte durch 'landslides' und Fehlen einer Alterskontrolle der erhaltenen Akkumulationen. (ebd.:1106)

'Landslides' und 'debris flows' spielen für die Denudation im Himalaja eine große Rolle. Das Kali Gandaki Tal war mit 600 m hohen Sedimenten vor etwa $2.100 \pm 600$ Jahren verfüllt. Der 'Dhampu Chooya 'landslide' in der Nähe von Lete entstand vor etwa $4.100 \pm 600$ Jahren, eine glazifluviale Terrasse östlich vom Dhampu Chooya ‘landslide’ vor ca. $28.000 \pm 3.000$ Jahren. (ebd.:1106, 1116)

Im oberen Kali Gandaki Tal beprobten Zech et al. (2009) drei Blöcke (LE 61, 63 und 64; Fig. 2b, 5a-d) einer fluvioglazialen Terrasse nordöstlich von Dhamp Chooya. Diese erbrachten die Daten $27.300 \pm 3.000,25.900 \pm 2.700$ und $28.200 \pm 2.900$ Jahre. Somit hat die glazifluviale Terrasse ein ungefähres Alter von $28.000 \pm 3.000$ Jahren (MIS 3) und konnte mit dem Ende der Abdämmung des Tales - entweder mit einem großen `landslide` oder Gletschervorstößen vom Dhaulagiri oder Nilgiri - in Zusammenhang gebracht werden. Diese Terrasse stellt das Ende der Periode hoher Monsunniederschläge und des maximalen Vorstoßes der Dhaulagiri und Nilgiri Gletscher dar. Somit befand sich bei Lete der maximale Eisrand. Owen et al. (2008) meinten, dass der monsunbeeinflusste Himalaja wegen des Monsuneinflusses während des MIS 3 (60.000 bis 28.000 Jahre v.H.) stärker vergletschert war als während des LGM. Demgegenüber verweisen z.B. neoglaziale Moränen im Dudh Khola Tal und mittelholozäne in der Nähe von Lete (vgl. Zech et al. 2009:Fig. 6) auf Gletschervorstöße, die mit globalen kälteren Temperaturen in Verbindung gebracht werden: "Monsoonal forcing alone obviously cannot explain all glacier advances." (Zech et al. 2009:1115). Die Forscher datierten eine Moräne unter dem Dhampu Chooya 'landslide' und neoglaziale Moränen im Dudh Khola Tal. Auf der Basis anderer Quellen schlussfolgerten sie, dass einige Gletscher ihr Maximalstadium 
während des MIS 3 und dem früheren Holozän aufzeigten, aber andere wie die der Nordhemisphäre reagierten. Zwei Blöcke (LE 41 und 51) in der Nähe von Titigaon verwiesen auf ein jüngeres Alter der Dhampu Chooya Ablagerung von $4.100 \pm 600$ bzw. $4.000 \pm 700$ Jahren, wobei auch der Block LE 12 (4.800 \pm 1.200 Jahre v.H.; Fig. 5a, d) auf einem Moränenrücken bzw. einer eventuellen Lateralmoräne am Südrand der Dhampu Chooya Akkumulationen auf 2.440 m Höhe auf ein solches Alter deutete. LE 32 außerhalb der Pangbu Flutebene $(300 \pm 100$ Jahre v.H.) zeigte ein noch jüngeres 'landslide' Ereignis an. (vgl. ebd.:1110 f., 1115 f., Fig. 6)

Nach Kuhle (2013b:1, 296, 301) floss jedoch der LGM Gletscher des Dudh Khola mit 32 km Länge ins Marsyandi Khola, wobei dort im Tal ein Auslassgletscher bis auf eine Höhe von $400 \mathrm{~m}$ bestand.

Im unteren Kali Gandaki Tal konnten die Ghasa Gompa und die Kopchepani 'landslides` aufgrund des mangelnden brauchbaren Quarzes in den Proben nicht datiert werden. Nichtsdestotrotz vermuteten die Forscher anhand der anderen ermittelten Daten ein Alter jünger als 2.100 Jahre, was jünger war als das von Kuhle (1982) und Fort (2000) ${ }^{109}$ zitiert nach: Zech et al. (2009) angenommene spätglaziale Moränenalter. Zwei Blöcke (GH 21, GH 24) der Terrasse nördlich von Tatopani auf $1.950 \mathrm{~m}$ Höhe zeigten aufgrund von Gesteinsoberflächenerosion und Umlagerung oder Freilegung mögliche Minimumdaten von $2.100 \pm 1.700$ Jahren und $2.100 \pm 600$, zwei Blöcke $(\mathrm{GH} 11, \mathrm{GH} 12)$ des Diamiktes im Ghaleti Khola auf 1.850 m Höhe von $1.200 \pm 300$ Jahren und $200 \pm 100$ an. Die Daten wurden als Minimumalter verstanden und als Beweis für rezente $600 \mathrm{~m}$ mächtige Talverfüllungen interpretiert, wobei die jüngeren Proben GH 11 und 12 als Beleg für enorme Sedimenterosionsraten (etwa $100 \mathrm{~m} / 1.000$ Jahre, totale Sedimentverfüllung $600 \mathrm{~m} / 2.000$ Jahre) gesehen wurden. Der Diamikt von GH 11 und 21 stammte von einem separierten späteren 'landslide’, wobei weitere Forschungen notwendig seien. Nichtsdestotrotz fanden sie heraus, dass die Ghasa Gompa und Kopchepani 'landslides' jünger sein sollen (<2.100 Jahre) als das von Kuhle (1982) und von Fort (2000) $)^{110}$ zitiert nach: Zech et al. (2009) angenommene spätglaziale Moränenalter. (vgl. ebd.:1111)

Zech et al. (2009) gaben außerdem einen Überblick über weitere Forschungsarbeiten im Gebiet des Kali Gandaki. Zwischen Jomosom auf 2.730 m Höhe und Tukche bei ca. 2.580 m existierten zwei Diamikte: die ältere Syang Formation und die jüngere Jomosom Formation.

\footnotetext{
${ }^{109}$ Fort, M. (2000): Glaciers and mass wasting processes: their influence on the shaping of the Kali Gandaki valley (higher Himalaya of Nepal). Quaternary International 65/66. (S. 101-119)

110 siehe Quelle Fort (2000) in der Fußnote
} 
Andere Forscher betrachteten diese Formationen, aber auch andere Akkumulationen - wie etwa die $250 \mathrm{~m}$ hohe Terrasse, auf welcher der Ort Ghasa auf ca. $2.000 \mathrm{~m}$ Höhe lag - als glazial oder aber als `landslide’. (vgl. Zech et al. 2009:1107)

Kuhle (2011a, 2013a, b) rekonstruierte einen hochglazialen Mustang Thak Khola Auslassgletscher bis auf ca. 1.000 m bzw. 1.010 m Höhe bei der Mayangdi Konfluenz (vgl. Kuhle 2011a:175, 198; 2013a:17, 2013b). Charakteristika hierfür fand er in Rundhöckern und ähnlichen Schliffformen, Grundmoränen mit erratischen Blöcken, Gletschertorschotterfluren und Gletschertorschotterflurterrassen, Schwemmschuttfächern und Schotterflurfächern, Schutt- und Murkegeln oder -fächern, durch fluviale Unterschneidung entstandenen Felshohlkehlen, Kames und subglazialen Schotterablagerungen, Karen, Transfluenzpässen, glaziären Flankenschliffen, glaziären Dreieckshängen u.s.w. (vgl. Kuhle 2011a:Fig. 2 und 3). Kuhle (2013a) gab beispielsweise Reste von Podestgrundmoränen mit erratischen Blöcken, Flankenabrasion und Polierungen für eine glazigene Gestaltung des Tales an.

\section{DHAULAGIRI- UND ANNAPURNA-HIMAL / MODI KHOLA}

Nach Kuhle (2001a) reichte das Eis während der letzten Eiszeit bis auf etwa 800 m Höhe herab bis nach Dobila bei der Konfluenz zum Jahre Khola, wobei der Modi Khola Gletscher in der Nähe von Birethanti etwa $400 \mathrm{~m}$ mächtig war (ebd.:176). Indikatoren einer vorzeitlichen Vergletscherung fand er in eindeutigen glazialgeomorphologischen Formen wie etwa Trogtalprofil, Kamesterrasse, Moräne und subglazialer Strudeltopf. Bereits bei Kuhle (1982:Abb. 8) wurde im Modi Khola eine Vergletscherung bis oberhalb der Konfluenz zum Chomromg Khola vermutet - die Darstellung wurde mit einem Fragezeichen versehen. Kuhle (2001a) ging auf diese damaligen Befunde ein.

Zech et al. (2001) machten Aussagen über die rezente und die vorzeitliche Vergletscherung.

\section{REZENTE VERGLETSCHERUNG}

Der Gletscher vom Annapurna I und Annapurna Südgipfel endete auf 3.700 Höhenmetern, was eine rezente Schneegrenze nach Höfer (1879) ${ }^{111}$ zitiert nach: Zech et al. (2001) bei etwa $5.350 \mathrm{~m}$ impliziert (vgl. ebd. 2001:163).

\footnotetext{
${ }^{111}$ Höfer, H. v. (1879): Gletscher- und Eiszeitstudien. In: Sitzungsberichte der Akademie der Wissenschaften, Wien. Math.-nat. Klasse, 1. Abt. 79. (S. 331-367)
} 


\section{VORZEITLICHE VERGLETSCHERUNG}

Die maximale Vergletscherung reichte nach Zech et al. (2001) bis etwa nach Birethanti bei 1.100 m Höhe. Hinweise hierfür sahen sie in folgenden Aspekten: das Tal wies dort noch ein ungefähres trogförmiges Querprofil auf und es schloss sich talabwärts ein oberes Terrassenniveau von fluvioglazialen Schotterterrassen mit rubifizierten Böden und mächtige konglomeratisierte Schotterterrassen mit großen kantengerundeten glazifluvialen Gneisblöcken mindestens - da mit rötlich braunem Verwitterungslehm verfüllte Karstorgeln existierten - mittelpleistozänen Alters an. Sie berechneten eine letzteiszeitliche Schneegrenzdepression von 1.250 bis $1.300 \mathrm{~m}$ bei einer rezenten Schneegrenze auf etwa 5.350 Höhenmetern. (ebd.:159, 179, $181 \mathrm{f}$.)

Nördlich von Chomrong existierte ein Trogtal mit geschliffenen Trogwänden, wobei eventuell vorhandene Moränen aber durch Hangschutt überlagert waren. Nordöstlich von Chomrong auf 2.520 m, 400 m über dem Talboden, kamen Parabraunerden mit rubifiziertem Bt-Horizont vor, die aus dem letzten Interglazial stammen könnten. Diese deuteten auf eine Eismächtigkeit kleiner oder gleich $400 \mathrm{~m}$, was auch durch $2 \mathrm{~m}$ große Geschiebeblöcke in schluffiger sandiger Matrix auf 2.100 bis $2.200 \mathrm{~m}$ Höhe südwestlich der rubifizierten Parabraunerden belegt wäre. Im Gegensatz zu den neoglazialen Böden war das Bodenprofil Braunerde 97/8 vermutlich aus spät- oder hochglazialen Akkumulationen hervorgegangen. Der LGM Eisstrom überquerte aufgrund der Befunde mit fehlenden schluffigen sandigen Sedimenten und des stark verwitterten Skeletts des Bodens die Bodenprofile 97/1 und 97/2 nicht. (ebd.:166)

Unterhalb von Tarapani auf $2.721 \mathrm{~m}$ Höhe deuteten hingegen seitenmoränenähnliche Hangleisten und abflusslose toteislandschaftsähnliche Hohlformen (ebd.:Foto 3) auf eine letztinterglaziale oder ältere Entstehung bzw. auf eine Karstentstehung. Das Anstehende war Kalkphyllit und die Böden in den Hohlformen (97/11, 12 und 13) wiesen Hydromorphiemerkmale auf. Die Bodenprofile 97/9 und 97/14 belegten durch Rubifizierung keinerlei letztglazialen Eiseinfluss. Diese Böden wurden durch Solifluktion, nicht aber durch Gletscher zerstört. (ebd.:173 f., Foto 3)

Die in drei bis vier Phasen abgelaufenen neoglazialen Gletschervorstöße reichten gegenüber den historischen bis neuzeitlichen bis auf eine Höhe von $3.350 \mathrm{~m}$ herab, bei einer Schneegrenzabsenkung von $175 \mathrm{~m}$. Ähnliche Werte zeigten die Stadien Nauri und älteres Dhaulagiri bei Kuhle (1997a). Neoglaziale Moränen konnten deutlich von jüngeren anhand von Bodenprofilen unterschieden werden; bei erstgenannten waren es Braunerden $(\mathrm{Ah} / \mathrm{Bw} / \mathrm{C})$ 
und bei letztgenannten $\mathrm{Ai} / \mathrm{C}$ und Aih/C Profile. ${ }^{14} \mathrm{C}$-Analysen von bedeckten Humusschichten wiesen auf wärmere Phasen etwa bei 3.270, 2.000 und 1.300 Jahre v.H. hin. Vor 3.270 bis 3.200 Jahren v.H. kam es zu einer vermehrten Bodenerosion, wobei die Gletscher zu dieser Zeit vorstießen. Bodenprofil 97/13 zeigte anhand der ${ }^{14} \mathrm{C}$-Analysen ein Alter von $1.372 \pm 128$ Jahre v.H., 97/11 eines von $1.304 \pm 127$. Älteste Horizonte bei letztgenanntem Profil wurden mit $3.200 \pm 130$ Jahren v.H. und mit $3.273 \pm 131$ datiert. Der Torf im Kyopreng See (Profil 12a) ergab ein Alter von $1.938 \pm 132$ Jahren v.H.. Zwei Bodenprofile (N 97/11, N 97/13) dienten für Pollenanalysen, wobei bei beiden auf Bewaldung - bei letztgenanntem auf immergrünen Nebelwald der mittleren Stufe - geschlossen wurde. Die Pollenuntersuchungen zeigten, dass humide Waldvegetation bei etwa $3.000 \mathrm{~m}$ Höhe seit ca. 1.500 Jahren existierte. (vgl. Zech et al. 2001:159, 182-184, 187)

Neuzeitliche bzw. Kleine Eiszeit Moränen (16. bis 20. Jhd.) und neoglaziale Moränen machten Zech et al. (2001:163, 164/Abb. 2) in der Nähe des Annapurna I Gletscher aus, die sich wie o.g. im Bodenprofil unterschieden. Die erstgenannten Ablagerungen endeten auf 3.600 Höhenmetern, wodurch sich eine Schneegrenzdepression von ca. $50 \mathrm{~m}$ ergab - diese stimmte mit dem historischen Stadium VIII von Kuhle (1997a) überein, vor 300 bis 400 Jahren v.H. (vgl. Zech et al. 2001:163).

Kuhle (2007a, 2013a) beschrieb den LGM Modi Gletscher bis auf ca. $800 \mathrm{~m}$ Höhe in der Nähe des Ortes Dobila - bei der Konfluenz zum Jahre Khola; dabei bezog er sich auf seine älteren Quellen.

\section{DHAULAGIRI- UND ANNAPURNA-HIMAL / MADI KHOLA}

Kuhle (1998, 2001a, 2007a, 2013a) beschrieb den tiefsten Eisrand im Madi Khola auf ca. $630 \mathrm{~m}$ Höhe, was durch eine über zwei km lange Lateralmoräne und erratische Blöcke begründet wurde (vgl. Kuhle 1998:87, 2001a:391, 2007a:125, 2013a:17).

\section{DHAULAGIRI- UND ANNAPURNA-HIMAL / SETI KHOLA}

Bereits bei Kuhle (1982b:Abb. 8) wurde im Seti Khola eine Vergletscherung bei etwa 1.2001.300 m Höhe talaufwärts von Gachok vermutet - diese Darstellung wurde mit einem Fragezeichen versehen. Kuhle (2001a) extrapolierte $6 \mathrm{~km}$ talabwärts - anhand von 2 bis zu 3 $\mathrm{m}$ großen Gneisblöcken auf anstehendem Schiefer bzw. Erratika vom Bereich des Hauptkammes Annapurna III-IV bei 1.500 bis $1.540 \mathrm{~m}$ und 350 bis $390 \mathrm{~m}$ über dem Talboden 
- das letztglaziale Gletscherende auf eine Höhe von ca. 1.000 m. Der hocheiszeitliche Gletscher erreichte den Konfluenzbereich des Yamdi Khola.

Kuhle (2007a) gab an, dass der LGM Eisrand im Seti Khola unsicher ('uncertain') war. Zwei erratische Blöcke bei Gachok auf 1.500 bis 1.540 m Höhe 350 bis 390 m über dem rezenten Talboden ließen darauf schließen, dass die vorzeitliche Seti Khola Gletscherzunge bis auf etwa $1.000 \mathrm{~m}$ Höhe hinab reichte, wobei die Seti und Yamdi Khola Konfluenz höchstwahrscheinlich erreicht wurde. Bei Kuhle (2013a) wurde ebenfalls zum Tal Seti Khola erwähnt, dass der tiefste LGM Eisrand bei einer Höhe von etwa 1.000 m lag (ebd.:17).

\section{DHAULAGIRI- UND ANNAPURNA-HIMAL / MARSYANDI KHOLA}

Im Tal Marsyandi rekonstruierte Kuhle (1997a, 1998, 2007a, 2013a, b, 2014) einen hochglazialen Marsyandi Khola Auslassgletscher, welcher bis zum Ort Dumre auf $460 \mathrm{~m}$ Höhe hinab floss. Hinweise hierfür waren bei Kuhle Trogtäler, glaziale Hörner, Flankenabrasion- und polierung, Grund-, Lateral- und Endmoränen mit großen bis sehr großen erratischen Blöcken sowie Strudeltöpfe. (vgl. Kuhle 1997a:127, 1998:87, 2007a:127, 2013a:Foto 4, 2014)

Kuhle (2013b:1, 301) schrieb, dass im Einzugsgebiet des Marsyandi Khola ein dendritisches Eisstromnetz bestand; die vorzeitlichen Gletscher des Nar, Dudh, Dana, Myardi und Nadi Khola flossen beispielsweise ins Marsyandi Khola, wobei in diesem Tal ein 120 km langer, maximal 2.200 m mächtiger Auslassgletscher bis auf eine Höhe von 400 m existierte. Der Dudh Khola Gletscher war 32 km lang (vgl. Kuhle 2013b:296, 2014:236, Fig. 4). Die dazugehörige Schneegrenze lag bei 3.900 bis 4.000 m Höhe (vgl. Kuhle 2013a:18). Die Temperatur war um mehr als $9{ }^{\circ} \mathrm{C}$ abgesenkt (vgl. Kuhle 2013b:302).

\section{LANGTANG-HIMAL}

Shiraiwa, Watanabe (1991) machten in ihren Ausführungen Angaben über die rezente und vorzeitliche Vergletscherung.

\section{REZENTE VERGLETSCHERUNG}

Shiraiwa, Watanabe (1991) zeigten in Fig. 1 die rezente Vergletscherung des Langtang Khola an. 


\section{VORZEITLICHE VERGLETSCHERUNG}

Shiraiwa und Watanabe kamen zum Ergebnis, dass die maximalste Vergletscherung im Langtang Khola bis auf ca. 2.400 bis 2.600 m Höhe (wie bei Heuberger et al. $1984^{112}$, Ono $1986^{113}$ und Usslemann $1980^{114}$ ), etwa $11 \mathrm{~km}$ talabwärts von Langtang hinab reichte, wobei sie diese gegenüber den anderen Stadien nicht anhand der relativen Altersbestimmung, sondern anhand des Überganges vom Trog- zum Kerbtalprofil festlegten (vgl. Shiraiwa, Watanabe 1991:414 f.). Eine stark zerschnittene Endmoräne bei Gora Tabela deutete auf das letztglaziale Maximum auf 3.200 Höhenmetern. Hierbei wurde der Verwitterungsgrad der Endmoräne als Indikator für die zeitliche Einordnung in das Gora Tabela Stadium gewertet, wobei auch glazifluviale Schotter zwischen Gora Tabela und Lama auf ein Interglazial ebendort und somit auf einen Altersunterschied verwiesen (ebd.:415). Shiraiwa, Watanabe (1991) datierten jedoch im Gegensatz zu Heuberger et al. (1984) ${ }^{115}$ und Ono (1986) ${ }^{116}$ die Shingdum und Kyangjin Terrassen ins späte Mittelholozän bzw. in die Kleine Eiszeit und nicht ins Spätglazial (vgl. Bäumler, Kemp-Oberhettinger, Zech 1996:24). Somit ordneten sie also die äußeren und äußersten Moränenkomplexe anhand der ${ }^{14} \mathrm{C}$-Daten und der relativen Datierungen nicht wie Heuberger et al. (1984) ${ }^{117}$, Ono (1986) $)^{118}$ und Zheng (1988) $)^{119}$ zitiert nach: Shiraiwa, Watanabe (1991) ins Spätglazial, sondern ins Neoglazial ein (2.800-550 Jahre v.H. und 3.650-3.000) (vgl. Shiraiwa, Watanabe 1991:414).

Shiraiwa, Watanabe (1991) gingen von vier verschiedenen Moränenkomplexen - innerste / rezent, innere / Yala I, äußere / Lirung und äußerste / Langtang - aus. Rezente Endmoränen mit fehlender Vegetationsbedeckung stellten den innersten Moränenkomplex dar, der beim Lirung und Khumjung Gletscher zwei Rücken, beim Langtang Gletscher vier und einen entlang der Langshisa und Shalbachum Gletscher aufwies. Die älteren, leicht erodierten Moränen waren der innere Moränenkomplex, ausgebildet beim Yala, Lirung und Langtang Gletscher. Der sich anschließende äußere Komplex - oft drei bis vier äußere Endmoränenwälle, aber nur ein Seitenmoränenwall - entsprach dem Lirung Stadium von

\footnotetext{
${ }^{112}$ Heuberger, H.; Masch, L.; Preuss, E.; Schröcker, A. (1984): Quaternary landslides and rock fusion in central Nepal and in the Tyroleon Alps. Mountain Research and Development, Vol. 4, No. 4. (S. 345-362)

113 Ono, Y. (1986): Glacial fluctuations in the Langtang valley Nepal Himalaya. In: Kuhle, M. (Hrsg.): Int. Symposium über Tibet und Hochasien. Verlag Erich Goltze GmbH, Göttingen.

114 Usslemann, P. (1980): Cartographie geomorphologique et evolution quaternaire d une haute valle Himalayenne: Le Langtang. Revue de géomorphologie dynamique, 29. (S. 1-7)

115 siehe Quelle Heuberger et al. (1984) in der Fußnote

${ }^{116}$ siehe Quelle Ono (1986) in der Fußnote

${ }^{117}$ siehe Quelle Heuberger et al. (1984) in der Fußnote

118 siehe Quelle Ono (1986) in der Fußnote

${ }^{119}$ Zheng Benxing (1988): Quaternary glaciation of Mt. Qomoangma - Xixabangma region. GeoJournal, 17. (S. 525-543)
} 
Heuberger et al. (1984) ${ }^{120}$. Nach Ono (1986) ${ }^{121}$ zitiert nach: Shiraiwa, Watanabe (1991) wurde die glazifluviale Terrasse Kyangchen mit dem äußeren Moränenkomplex in Verbindung gebracht. Shiraiwa, Watanabe (1991:407) meinten aber, dass diese älter sein müsste. Talabwärts des äußeren Moränenkomplexes des Lirung Gletscher waren nur wenige Moränen aufzufinden, lediglich die von Ono (1986) ${ }^{122}$ benannte Shingdum Oberfläche. Shiraiwa, Watanabe (1991) erforschten die aus glazialen und fluvioglazialen Materialschichten bestehende Shingdum Terrasse. Die Chomki Terrasse bestand ebenfalls aus glazialem und fluvioglazialem Material und wurde teilweise von Bergsturzmaterial überlagert. Nach Ono $(1986)^{123}$ zitiert nach: Shiraiwa, Watanabe (1991) könnte ein zerschnittener Wall bei Ghora Tabela als Endmoräne mit dieser Terrasse korrelieren. Die Terrasse bei Ghora Tabela dagegen bestand vermutlich aus zusammengeschobenem verwittertem Moränenmaterial von der Südseite des Langtang Khola. Unterhalb von Ghora Tabela (ca. 3.200 m Höhe) fanden sich keinerlei glaziale Akkumulationen, wobei aus dem Wechsel von Trog- zu Kerbtal bei ca. 2.600 Höhenmetern auf die maximale Vergletscherungsausdehnung im Langtang Tal geschlossen wurde. (vgl. Shiraiwa, Watanabe 1991:407 f.)

Shiraiwa, Watanabe teilten die Moränen in fünf Stadien bzw. sechs Gletscherstadien ein: Lama, Gora Tabela, Langtang, Lirung, Yala I und Yala II. Die jüngste Vergletscherung zeigte das Yala II Stadium, welches sich kaum von Yala I unterschied. ${ }^{14} \mathrm{C}$-Daten gaben für das Yala II Stadium einen Zeitpunkt des jüngsten Lirung Gletscher Vorstoßes von 1.910 n. Chr. an. Der innere Moränenkomplex gehörte zum Yala I Stadium, welches jünger als das Lirung Stadium bzw. als 550 Jahre v.H. war. Für dieses Yala I Stadium wurden keinerlei numerische Daten erfasst, aber es wurde in den Zeitraum der Kleinen Eiszeit gelegt, da bei diesem kein begrabener A-Horizont - im Gegensatz zum Lirung Stadium - vorhanden war. (vgl. Shiraiwa, Watanabe 1991:404, 415)

Der äußere und der äußerste Moränenkomplex wurden von Heuberger et al. (1984) ${ }^{124}$, Ono $(1986)^{125}$ und Zheng (1988) $)^{126}$ zitiert nach: Shiraiwa, Watanabe (1991) als spätglazial betrachtet; Shiraiwa, Watanabe (1991) erhielten durch ihre Forschungen jedoch neoglaziale Alter zwischen 2.800 und 550 Jahren v.H. sowie zwischen 3.650 und 3.000 Jahren v.H.

\footnotetext{
${ }^{120}$ siehe Quelle Heuberger et al. (1984) in der Fußnote

121 siehe Quelle Ono (1986) in der Fußnote

122 siehe Quelle Ono (1986) in der Fußnote

123 siehe Quelle Ono (1986) in der Fußnote

${ }^{124}$ siehe Quelle Heuberger et al. (1984) in der Fußnote

125 siehe Quelle Ono (1986) in der Fußnote

${ }^{126}$ siehe Quelle Zheng (1988) in der Fußnote
} 
(ebd.:414). Sie gehörten zu den Stadien Lirung und Langtang (ebd.:414). Die äußere Moräne bzw. das Lirung Stadium war durch drei bis vier Gletschervorstöße in dem o.g. Zeitraum charakterisiert, wobei die Lateralmoränen talabwärts von Langtang dazu gehörten (ebd.:415). Shiraiwa, Watanabe (1991) nahmen im Gegensatz zu Heuberger et al. (1984) ${ }^{127}$ und Ono $(1986)^{128}$ an, dass die Kyangjin Terrasse nicht mit dem äußeren Moränenkomplex des Lirung Gletscher korrelierte, sondern älter war (zitiert nach: Bäumler, Kemp-Oberhettinger, Zech 1996:23).

Das Langtang Stadium (zwischen 3.650 und $3.000{ }^{14}$ C-Jahren v.H.) war der größte Vorstoß des Holozän, welches von mehreren kleineren Vorstößen im Lirung Stadium (2.800 bis 550 ${ }^{14}$ C-Jahren v.H.) und von zwei kleineren Kleinen Eiszeit Stadien Yala I und II gefolgt war. Die Stadien Lirung, Yala I und II waren spätneoglaziale Stadien, wobei sich die beiden letztgenannten kaum voneinander unterschieden. Der Lirung Gletscher reichte während des Langtang Stadium bis nach Langtang, wobei die Shingdum Terrasse aufgeschüttet wurde. Die tiefste Endmoräne des Langtang Gletscher war bei Markujung Kalkha auszumachen, wobei die kleinen Endmoränen bei Mendang und Chadang Rückzugsphasen des Langtang Stadiums kennzeichneten und die Kyangjin Terrasse beim Rückzug aufgeschüttet wurde. (vgl. Shiraiwa, Watanabe 1991:404, 415 f.)

Das Gora Tabela Stadium wurde anhand der stark zerschnittenen Endmoräne bei Ghora Tabela bis auf eine Höhe von 3.200 m bestimmt (ebd.:404, 415). Während dieser Zeit wurde die Chomki Terrasse aufgeschüttet. „Der hohe Verwitterungsgrad des Materials aus der Chomki-Terrasse läßt darauf schließen, daß dieses Stadium wesentlich älter ist als das folgende Langtang-Stadium. “ (Bäumler, Kemp-Oberhettinger, Zech 1996:23). Das Lama Stadium konnte nur durch den glazialen Trog bis auf ca. $2.600 \mathrm{~m}$ Höhe belegt werden (vgl. Shiraiwa, Watanabe 1991:404), wobei sich talabwärts ein Kerbtal anschloss. In diesen beiden Stadien Gora Tabela und Lama waren die Vergletscherungen sehr umfangreich - im Gegensatz zum Langtang Stadium (ebd.:416). Beide Stadien waren älter als das Langtang Stadium (3.650-3.000 Jahre v.H.) (ebd.:416). Die Verwitterungsunterschiede der Moränen spielten für die Rekonstruktion eine besondere Rolle (ebd.:415 f.). Es wurde angenommen, dass die tiefe Moräne des Gora Tabela Stadium in die letzte Vergletscherung des Pleistozäns fällt, wobei mächtige glazifluviale Schotter ein Interglazial zwischen dem Lama und Gora Tabela Stadium anzeigten (ebd.:416). Die stärkste Vergletscherung war das Lama Stadium (ebd.:414).

\footnotetext{
127 siehe Quelle Heuberger et al. (1984) in der Fußnote

${ }^{128}$ siehe Quelle Ono (1986) in der Fußnote
} 
Shiraiwa (1993) ${ }^{129}$ zitiert nach: Barnard et al. (2006:2163) vermutete basierend auf Gletschervorstößen anderer Himalaja Regionen, dass das Lama Stadium mit dem frühen letzten Glazial und das Gora Tabela Stadium mit dem LGM in Verbindung stand.

Bäumler, Kemp-Oberhettinger, Zech (1996) machten Angaben über die rezente und vorzeitliche Vergletscherung. Die Ergebnisse der Laboranalysen wurden dort auf Seite 43 bis 77 und die der Radiokarbonanalysen auf Seite 78 erklärt.

\section{REZENTE VERGLETSCHERUNG}

Informationen über das rezente Klima konnte ebd. der Seite 10 entnommen werden.

\section{VORZEITLICHE VERGLETSCHERUNG}

Nach den Befunden von Franceschetti (1968) ${ }^{130}$ zitiert nach: Bäumler, Kemp-Oberhettinger, Zech (1996) und nach den Befunden von Bäumler, Kemp-Oberhettinger, Zech (1996:9) existierte talabwärts der Lama Lodge ein kerbförmiges Talprofil, wobei talaufwärts bis Ghora Tabela ein breiter Schuttfächer möglicherweise glazialer Genese bestand. Ab Ghora Tabela bis Langsisa Kharka auf 4.150 m Höhe - wo ungefähr der rezente Haupttalgletscher endete wurde ein breites, nur gering fluvial umgestaltetes Trogtalprofil mit ebenem Talboden aus fluvioglazialen Akkumulationen ausgemacht (vgl. ebd.:9).

Die Böden im Himalaja waren unterhalb von 2.000 Höhenmetern tonreich, rubifiziert, obwohl jedoch noch nicht geklärt wurde, ob diese rezent oder reliktisch waren. Über $2.000 \mathrm{~m}$ Höhe waren Braunerden, ab etwa 3.000 m Podsole und ab $4.500 \mathrm{~m}$ skelettreiche, flachgründige Rohböden entwickelt. (ebd.:7)

Bäumler, Kemp-Oberhettinger, Zech (1996) beprobten eine Moränestaffel des Lirung Gletscher, einen dazu benachbarten Hang, die Kyangjin Stauterrasse und zwei Moränen des Langtang Gletscher sowie einige fossile Ah-Horizonte, wobei bei letztgenannten ${ }^{14} \mathrm{C}$-Daten bestimmt wurden, die auf ein Minimumalter zwischen 3.100-450 Jahren v.H. deuteten. Anhand von Verwitterungsindizes und dem Mineralverwitterungsindex unterschieden sie sehr junge, junge und ältere Böden. (ebd.:Zus.)

\footnotetext{
129 Shiraiwa, T. (1993): Glacial fluctuations and cryogenic environments in the Langtang Valley Nepal Himalaya. Contributions from the Institute of Low Temperature Science. The Institute of Low Temperature Science, Hokkaido University, Sapporo, Japan. (98 Seiten)

${ }^{130}$ Franceschetti, B. (1968): Osservazioni sulla mofolgia glaciale della media valle del Langtang (Nepal centrale). Memoria della Societa Geologica Italiana, 7. (S. 345-360)
} 
Die Ergebnisse von Shiraiwa, Watanabe (1991) stimmten ungefähr mit denen von Bäumler, Kemp-Oberhettinger, Zech (1996) überein: der Endmoränenwall des Lirung Gletscher fiel in die Kleine Eiszeit und die vorgelagerten in den Zeitraum am Ende des Lirung Stadiums zwischen 2.800 und 550 Jahren v.H., die Kyangjin Terrasse und die Langtang Gletscher Ablagerungen bei der Flugpiste vermutlich ins Langtang Stadium (3.000-3.500 Jahre v.H.). Jedoch wurde eine Seitenmoräne des Langtang Gletscher ins Spätglazial datiert. Im Zeitraum von 3.100-450 Jahren v.H. datierten Shiraiwa und Watanabe mehrere Gletschervorstöße. (ebd.:Zus.)

Die acht Profile bei Bäumler, Kemp-Oberhettinger, Zech (1996) zeigten Böden von Regosol, Braunerde-Regosol, podsolige Braunerde-Regosol, Braunerde-Podsol, Braunerde, Podsol an. Die neun Geländebeobachtungen / -profile bzw. geomorphologischen Formen wie Moränen mit Bodenprofilen und -typen wurden dort auf Seite 37 beschrieben. Die ${ }^{14} \mathrm{C}$-Analysen ergaben folgendes: A-rezentes Alter, Akkumulation von Schwemmsanden; B-vermutlich Toteisloch, $465 \pm 65$ Jahre v.H., $480 \pm 75$, vor etwa 600 Jahren wärmere Temperaturverhältnisse; C-1.550 \pm 120 , äolische Einwehung, kältere klimatische Bedingungen vermutet; D-2.020 \pm 85, Bodenbildung unterbrochen, kältere Periode; E-2.500 \pm 115; F-Shingdum Terrasse $3.140 \pm 80$, Bodenbildung unterbrochen.

Bodenprofil 1 zeigte laut der Verwitterungsintensität und der relativen chronologischen Einordnung das jüngste Bodenentwicklungsalter auf mit einer Entstehungszeit vermutlich aus dem Jahr 1815 als letztem Vorstoß der Kleinen Eiszeit. Profile 2 und 3 indizierten fortgeschrittenere Bodenentwicklungen mit einem beginnenden Verbraunungshorizont, die aus Ablagerungen der Vorstöße des Lirung Stadiums (2.800 bis 550 Jahre v.H.) entstanden. Auch diese deuteten gegenüber den weiteren anderen Profilen auf sehr junge Bildungen hin. (vgl. Bäumler, Kemp-Oberhettinger, Zech 1996:81 f.)

Bodenprofil 4 ähnelte dem Profil 5, wobei beim erstgenannten Hangschutt darüber gelagert wurde. Seit etwa 2.200 bis 2.100 Jahren v.H. hat der Gletscher das Gebiet des Profils Nummer 4 nicht mehr erreicht. Profil 5 war in etwa gleich oder etwas weiter fortgeschritten als Profil 6 und 7. Profil 6 war jedoch weiter entwickelt als die Bodenprofile 2, 3 und 7. Boden Nummer 7 mit deutlich ausgeprägter Podsolierung und starker Verwitterung entstand vor etwa $2.500 \pm 115$ Jahren v.H.. (ebd.:81 f.) 
Profil 8 verwies auf die stärkste Verwitterungsintensität und demnach auf eine spätglaziale oder sogar ältere Moränenablagerung, vermutlich auf das Gora Tabela Stadium oder das Lama Stadium nach Shiraiwa, Watanabe (1991).

Laut Kuhle (2001a) reichte das letzteiszeitliche Eis im Trisuli Tal bis auf etwa 900 bis 1.000 Höhenmeter in der Nähe von Donga herab (ebd.:391). In dieser Höhe fand er die am tiefstliegensten Grundmoränen, die jedoch auf ein noch weiter talabwärtigeres Gletscherende hindeuteten.

Barnard et al. (2006) untersuchten mittel- und spätholozäne Moränenchronologien, paraglaziale Fächer sowie Terrassen. Sie bestimmten 33 Alter. Denudationsraten von Fächern und Terrassen mit rund $33 \mathrm{~mm}$ pro Jahr waren in diesem Gebiet enorm, sodass keine Ablagerungsform bis zu 250 m über dem Talboden älter als 5.000 Jahre sein konnte. Hohe Denudationsraten während des Spätquartär waren durch tektonische Hebung, mehrere Gletschervorstöße und intensive Verwitterung mittels des aktiven Monsunklimas zu erklären. (ebd.:2162)

Die Dörfer von Kyanjin Gompa, Sindum, Langtang, Thyangshap und Gora Tabela lagen auf Fächern und / oder Terrassen. Moränen traten westlich von Kyanjin Gompa - hier vom Ostlirung Gletscher stammend - und bei Langtang und Thyangshap auf. (ebd.:2165).

Die CRN-Daten zeigten, dass in Gebieten mit hoher Erosionsrate Vererbung unwichtig war und das Datenannäherungen für extrem junge Ablagerungen $(<1.000$ Jahre) erreicht werden konnten (ebd.:2174).

Kuhle (2013a) belegte anhand von Grundmoränen in entsprechenden Lagen, dass der vorzeitliche Langtang Hauptgletscher bis zur Mailung Khola Konfluenz auf eine Höhe von ca. 930 m hinunter reichte, wobei er sich auf seine eigenen älteren Quellen bezog (ebd.:21).

\section{MAHALANGUR-HIMAL}

Kuhle (1997a) rekonstruierte den hochglazialen Arun Gletscher, welcher talabwärts bis auf $500 \mathrm{~m}$ Höhe hinab reichte. Diese Vergletscherung bis auf ca. $500 \mathrm{~m}$ oder tiefer beschrieb Kuhle (1998) beispielsweise anhand von großen erratischen Blöcken, Lateralmoränen, Rundhöckern und Strudeltöpfen.

Kuhle (2005) rekonstruierte ein würmeiszeitliches (MIS 2-4, vor 18.000-60.000 Jahren) Eisstrom- und Talgletschernetz, welches in Verbindung $\mathrm{zu}$ den westlich und östlich 
angrenzenden Eisstromnetzen der Himalaja Gebiete stand. Im Norden war dieses durch das tibetische Eisstromnetz - durch die Auslassgletscher Kyetrak-Nangpa-Bote Koshi Drangka, West Rongbuk-Ngozumpa Drangka, Rongbuk-Khumbu Drangka und Arun Nadi - gespeist. Der längste Hauptgletscher im Khumbu- und Khumbakarna-Himal war der Arun Gletscher mit 80 km Länge neben dem 70 km langen Dudh Khosi Gletscher sowie dem 67 km langen Barun Gletscher und reichte gegenüber dem im Dudh Khosi ca. $400 \mathrm{~m}$ tiefer bis auf eine Höhe von ca. 500 m herab. Die tiefste Eisrandlage lag bei der Sankhuwatar Siedlung auf ca. 450 m Höhe. Von Num bis Simle nahm der Arun Gletscher von 700-830 m Mächtigkeit bis auf ca. $250 \mathrm{~m}$ ab. Von $710 \mathrm{~m}$ bis auf $450 \mathrm{~m}$ Höhe nahm der Gletscher ca. $750 \mathrm{~m}$ ab. Der Arun Hauptgletscher bzw. der hocheiszeitlich 2.000 m mächtige Arun Auslassgletscher, von Kada stammend, war ca. $110 \mathrm{~km}$ lang und wurde durch das südtibetische Eisstromnetz (siehe Kuhle $1991^{131}$ ) sowie durch die Gletscher Karma, Barun und Irkhuwa Gletscher und vom Hohen Himalaja gespeist. Während Stadium I des Spätglazial hatte dieser Arun Auslassgletscher noch eine Mächtigkeit von 1.130 m. Der Barun Gletscher floss auf ca. 1.100 m Höhe in den Arun Gletscher und war insgesamt 94 km lang. Während des Hochglazial bestanden eine etwaige vorzeitliche Schneegrenze auf 3.870 m Höhe sowie eine Schneegrenzdepression von $1.630 \mathrm{~m}$ bei einer heutigen Schneegrenze auf $5.500 \mathrm{~m}$ und bei einem Temperaturunterschied von 8-10 ${ }^{\circ} \mathrm{C}$. Insgesamt wies Kuhle (2005:Tab. 1) 14 Gletscherstadien - ein hochglaziales, vier spätglaziale, drei neoglaziale, sechs historische - nach. (vgl. Kuhle 2005: 193, 243, 246 f., 262 f., 265, Tab. 1)

Kuhle (2007a) bezog sich auf seine früheren Quellen, die darauf hinwiesen, dass der vom tibetischen Eis stammende ca. $110 \mathrm{~km}$ lange Aruntalauslassgletscher bei Kada eine Eismächtigkeit von ca. $2.000 \mathrm{~m}$ und bei Num von $700 \mathrm{~m}$ aufwies. Die Vergletscherung des Aruntales bis auf ca. $450 \mathrm{~m}$ Höhe stellte Kuhle beispielsweise anhand von großen erratischen Blöcken und Lateralmoränen dar.

\section{KANGCHENDZÖNGA-HIMAL}

Während des letzthochglazialen Stadiums reichte der Gletscher laut Kuhle (1998) bis auf eine Höhe von 890 m beim Ort Thuma. Das Ghunsa und Simbua Tal wiesen laut Kuhle während des LGM lange Eisströme auf, die in Verbindung zum tibetischen Eis über den Jongsang La standen. Erkennungszeichen einer Vergletscherung der Täler sah er z.B. in Trogtälern, Endmoränen, Gletscherschliffen, Rundhöckern und Strudeltöpfen.

${ }^{131}$ Kuhle, M. (1991): Observations supporting the Pleistocene inland glaciation of High Asia. GeoJournal 25 (2/3) (Kuhle M. and Xu Daoming (eds), Tibet and High Asia (II). Results of the Sino-German Joint Expeditons): 133-233. 
Die Arbeiten von Meiners (1999) aus dem Kangchendzönga bauten auf den Befunden von Kuhle (1990a) auf, wobei sie sich letztendlich dessen Forschungen anschloss, da sie hochglaziale Moränenterrassenreste bei der Yarlung Ghunsa Khola Konfluenz auf der orographisch linken Talseite auffand, die zu der hocheiszeitlichen Eisrekonstruktion von Kuhle passten. Ähnliche Reste fand Kuhle (1990a) zitiert nach: Meiners (1999) beim Ausgang des Yalung Khola. Außerdem deutete der polierte und abradierte Gebirgsrücken zwischen den zwei parallel verlaufenden Tälern auf eine solche Eisbedeckung hin. Meiners berechnete anhand dieser vorgefundenen Moränenreste eine Schneegrenzdepression von 1.350 m. (vgl. Meiners 1999:341, 367/Fig. 2, 371)

Zudem fand sie zwischen historischem / jüngstem Neoglazial einen Eisrand aus dem frühesten Neoglazial bei einer Schneegrenzdepression von 300-600 m. Die spätglaziale Schneegrenzdepression berechnete sie mit 900-1.200 m. Ein großer spätglazialer Endmoränenkomplex befand sich auf 2.700 Höhenmetern. (ebd.:341)

Kuhle (2001a) beschrieb den LGM Tamur Gletscher bis zur Ortschaft Thuma auf $890 \mathrm{~m}$ Höhe und spätglaziale Stadium I Lateralmoränen bei Hellok, wobei er sich hierbei auf ältere Befunde aus dem Jahr 1990 bezog (ebd.:391).

Tsukamoto et al. (2002) nahmen anhand der Ergebnisse der OSL-Datierungen an, dass es Gletschervorstöße vor 5.000-6.000, 8.000-10.000 und vor 20.000-21.000 Jahren gab (ebd.:57). Die OSL-Proben der ersten Probenahmestelle verwiesen auf OSL-Alter von 5.300 \pm 1.200 und $6.100 \pm 1.000$ Jahren v.H. (ebd.:Tab. 3). Die Proben der Lokation 2 deuteten auf OSL-Alter von $38.800 \pm 6.300$ und $36.500 \pm 2.800$ Jahren v.H. (ebd.:Tab. 1). Die Moränen und das Alter des 2. Standortes zeigten die stärkste Vergletscherung während des MIS 2 bei Gyabla an (ebd.:66). Der 3. beprobte Standort brachte OSL-Alter von $21.100 \pm 3.200$ und $20.200 \pm 2.200$ Jahren v.H. (ebd.:Tab. 3). Bei dieser Probe 3 im Bereich der Lateralmoränen auf 2.730 m Höhe befand sich laut Tsukamoto et al. (2002:61) der Übergang vom Trog- zum Kerbtal, wodurch diesen Ablagerungen ein maximales Gletscherende zugesprochen wurde. Bei der letzten Probenahmestelle 4 verwiesen die Proben auf OSL-Alter von 8.100 \pm 700 , $9.800 \pm 600$ und $9.000 \pm 1.400$ Jahren v.H. (ebd.:Tab. 3 ).

Kuhle (2007a, 2013a) bezog sich besonders auf die Befunde von Kuhle (1990a). Über den Jongsang La standen die letztglazialen Eisströme der Täler Ghunsa und Simbua mit dem 
tibetischen Eis in Verbindung und reichten im Spätglazial Stadium I zusammen im Tamur Haupttal bis auf eine Höhe von $1.500 \mathrm{~m}$ - dem Konfluenzbereich in der Nähe des Ortes Hellok. Indikatoren sah er in spätglazialen Lateral- bis Endmoränen. Über den Lamite Bhanjyang bestand zudem eine Eisstromverbindung zum Nachbartal Kabeli Khola. Der hochglaziale Eisrand lag bei Thuma auf 890 m Höhe; eine Endmoräne mit einem Sander stellten die Nachweise hierfür dar. Talaufwärts machte er im Haupt- und in den Nebentälern Trogtalprofile, Flankenabrasionen, Strudeltöpfe, Rundhöcker sowie Moränenreste mit Erdpyramiden aus. Zudem gab Kuhle Moränen bei Marijam an. 


\subsection{Kurzzusammenfassung}

Bis dato existieren nach langjährigen Forschungen zum Hauptuntersuchungsgebiet des Solukhumbu und auch zu den Vergleichsuntersuchungsgebieten verschiedene Ergebnisse über das eiszeitliche Vergletscherungsausmaß, was sich deutlich in der relevanten wissenschaftlichen Literatur widerspiegelt. Zum Solukhumbu wurden in der vorliegenden Arbeit die Literaturquellen ab dem Jahre 1956 vollständig betrachtet, in den Vergleichsuntersuchungsgebieten hingegen nur bestimmte Forschungsarbeiten ausgewählt.

Die maximale letzteiszeitliche Eisrandlage reichte im Hauptuntersuchungsgebiet von einer etwaigen Höhe bei 880 m (Kuhle 2005) über ca. 900 m (Kuhle 2007a, 2011b, 2013a), 900 bis $1.100 \mathrm{~m}$ (Kuhle 2001a), $1.580 \mathrm{~m}$ (Kuhle 1987b), $1.800 \mathrm{~m}$ (Kuhle 1988a, 1998), $2.000 \mathrm{~m}$ (Fushimi 1978, 1981), 2.450 bis $2.500 \mathrm{~m}$ (Heuberger, Weingartner 1985), $2.500 \mathrm{~m}$ (Heuberger 1956 - in der vorliegenden Arbeit nicht berücksichtigt, 1986), 3.500 bis $3.800 \mathrm{~m}$ (Bäumler 2001), 3.625 bis $4.200 \mathrm{~m}$ (Iwata 1976), 4.000 bis $4.200 \mathrm{~m}$ (Müller 1980, Aoki, Imamura 1999) bis auf $4.200 \mathrm{~m}$ (Williams 1983, Richards et al. 2000, Finkel et al. 2003, Barnard, Owen, Finkel 2006, Owen et al. 2008 - bezogen sich auf Owen, Benn 2005). Das bedeutet einen sehr großen Eisrandlagenhöhenunterschied von 3.320 m (siehe Karte VIII, Tab. I und II sowie Diagramm I, Bildband). Bei Iwata (1976) können diese Eisrandlagen jedoch auch spätglaziale sein. Andere genannte Forscher wie etwa Müller (1959), Miller (1970), Benedict (1976), Fushimi (1977) oder auch Kuhle (1984, 1986a, 1987a) - diese Arbeiten können allerdings zu seiner umfassenderen Arbeit aus dem Jahr 2005 hinzugezählt werden - gaben nur allgemeine bzw. ungenaue oder keine Angaben über eine vorzeitliche hochglaziale Vergletscherung. Miller (1970) ging beispielsweise von einer pleistozänen Vergletscherung aus, die sich nicht maßgeblich von der rezenten abhebt. Bäumler et al. (1991) sowie auch Bäumler, Kemp-Oberhettinger, Zech (1996) gaben an, dass das letztglaziale Eis den Ort Lukla nicht mehr erreichte. Da die Arbeit von Bäumler, Zech (1998) eine Zusammenfassung bzw. Ergänzung zu der von Bäumler, Kemp-Oberhettinger, Zech (1996) darstellt, wird der Ort Lukla auch hier von der jüngsten Hauptvergletscherung nicht mehr erreicht worden sein. Da Rai, Yoshida, Upreti (2007) bei ihren Forschungen Plattformen aus Moränenmaterial - etwa bei Nachipan und Chaunrikharka - ausmachten, sollte die vorzeitliche Vergletscherung bis in diese Talbereiche südlich von Lukla hinab gereicht haben. Infolgedessen war dort eine maximale Vergletscherung zwar ansprechbar, jedoch nicht gesichert festzulegen, da bei der hier zitierten Arbeit von Rai, Yoshida und Upreti (2007) lediglich eine Zusammenfassung auffindbar war. 
$\mathrm{Zu}$ den vier Vergleichsuntersuchungsgebieten Dhaulagiri- und Annapurna-, Langtang-, Mahalangur- und Kangchendzönga-Himal unterschieden sich ebenfalls die Forschungsergebnisse über die Vergletscherungsausdehnung (siehe Karte IX und X, Bildband). Zum Tal Mayangdi Khola im erstgenannten Himalaja Bereich schlussfolgerte Kuhle (1980, 1998, 2007a, 2013a) unter Berücksichtigung von glazialgeomorphologischen Formen, dass eine Talvergletscherung bis auf eine Höhe von ca. 1.150 bis $1.100 \mathrm{~m}$ in der Nähe des Ortes Dharbang bestand. Zum Tal Kali Gandaki gab Kuhle (1982 / 1983) an, dass das letzthochglaziale Eis bis auf eine Höhe von 1.010-1.160 m hinab reichte. Nach Iwata (1984) lagen die tiefste Eisrandlage bzw. die tiefstreichenden kartierten Moränen im Bereich der Siedlung Ghasa auf 1.870 m Höhe. Fort (1985) zitierte andere Forscher sowie eigene ältere Forschungsarbeiten für die letztglaziale Ausdehnung - hierbei reichte das Eis im Zeitraum des mittleren bis späten Pleistozän bis nach Ghasa auf etwa 2.000 m Höhe hinunter. LGM Moränen machte Kuhle (1998, 2007a) im Thakkhola bis auf eine Höhe von 1.100 m aus. Nach Zech et al. (2009) befand sich der maximale Eisrand bei Lete, wobei pleistozäne Moränen nicht datiert werden konnten. Kuhle (2011a, 2013a, b) rekonstruierte den hochglazialen Mustang Thak Khola Auslassgletscher ebenfalls bis auf ca. 1.000 m bzw. 1.010 m Höhe bei der Mayangdi Konfluenz. Zum Tal Modi Khola im Dhaulagiri- und AnnapurnaHimal belegte Kuhle (2001a) sowie auch Kuhle (2007a, 2013a), dass das letztglaziale Eis während des Maximalstadiums bis auf eine Höhe von $800 \mathrm{~m}$ bis nach Dobila bei der Konfluenz zum Jahre Khola hinab reichte. Zech et al. (2001) kamen hingegen auf eine Vergletscherung bis etwa nach Birethanti auf 1.100 Höhenmeter. Im Tal Madi Khola stellte Kuhle (1998, 2001a, 2007a, 2013a) den tiefsten Eisrand auf ca. 630 m Höhe dar. Im Tal Seti Khola dieses Himalaja Bereiches extrapolierte Kuhle (2001a) - auch bei Kuhle 2007a und 2013a beschrieben - hingegen das hochglaziale Gletscherende auf ca. $1.000 \mathrm{~m}$ Höhe beim Konfluenzbereich des Yamdi Khola. Fort (1986) traf keine Aussagen über das Hoch-, sondern nur über das Spätglazial. Im Marsyandi Khola rekonstruierte Kuhle (1997a, 1998, 2007a, 2013a, b, 2014) einen hochglazialen $120 \mathrm{~km}$ langen und maximal $2.200 \mathrm{~m}$ mächtigen Marsyandi Khola Auslassgletscher, welcher bis zum Ort Dumre auf ca. 400 bzw. 460 m Höhe hinab floss. Zum Langtang-Himal standen sich die Aussagen von Shiraiwa, Watanabe (1991), Kuhle (2001a), Barnard et al. (2006) und Kuhle (2013a) gegenüber. Die erstgenannten Forscher kamen zum Ergebnis, dass die letztglaziale maximale Vergletscherung im Langtang Khola bis auf 3.200 Höhenmeter bei Gora Tabela hinab reichte. Laut Kuhle (2001a) langte das letzteiszeitliche Eis im Trisuli Tal auf 900 bis 1.000 m Höhe in der Nähe von Donga 
herab, wobei ein tieferes Gletscherende nicht auszuschließen war, da nur Grundmoränen aufgefunden wurden. Kuhle (2013a) beschrieb ebenfalls, dass der vorzeitliche Langtang Hauptgletscher bis zur Mailung Khola Konfluenz auf eine Höhe von ca. 930 m hinunter reichte. Im Mahalangur-Himalaja bzw. im Arun Tal verwies Kuhle (1997a, 1998) auf einen hochglazialen Arun Gletscher, welcher talabwärts bis auf ca. 500 m Höhe oder tiefer hinab reichte. Kuhle (2005) beschrieb diese vorzeitliche hochglaziale Gletscherendlage auf 450 bis 500 m Höhe, Kuhle (2007a) ebenso auf ca. 450 m Höhe. Zum Kangchendzönga-Himalaja fanden Kuhle (1990a) sowie auch die sich seinen Befunden anschließende Meiners (1999) heraus, dass das letztglaziale Eis bis auf maximal 890 m Höhe bei Thoma hinab floss. Kuhle (1998, 2001a, 2007a, 2013a) verwies ebenfalls auf ein solches hochglaziales Maximalgletscherende. Tsukamoto et al. (2002) gaben hingegen an, dass bei Probe 3 im Bereich der Lateralmoränen auf 2.730 m Höhe der Übergang vom Trog- zum Kerbtal bestand, wodurch diesen Ablagerungen ein maximales Gletscherende zugesprochen wurde. Probe 2 deutete auf die stärkste Vergletscherung während des MIS 2. 
3. VALIDIERUNG DER FORSCHUNGSERGEBNISSE RELEVANTER FORSCHER ANHAND VON EIGENEN GELÄNDEBEFUNDEN ZUM HAUPTUNTERSUCHUNGSGEBIET SOLUKHUMBU

3.1. Befunde aus dem Khumbu

\subsubsection{Lobuche Khola}

3.1.1.1. Vom Khumbu Gletscher bis zum Konfluenzbereich zum Imja Khola (ThoklaPeriche)

Im Talabschnitt vom Khumbu und Tshola Gletscher bis zum Konfluenzbereich zum Imja Khola wurden zur Dokumentation 27 Fotos (Foto 1-27) aus einer großen Anzahl ausgesucht. Die Standorte für die Fotos und der Sedimentproben sowie der Verlauf der Talquerprofile können der Karte 1 entnommen werden. Die geomorphologische Analyse im Tal Lobuche Khola ergab folgende Ergebnisse für die hocheiszeitliche Vergletscherung:

\section{TALQUERPROFILE UND SCHLIFFGRENZEN}

Das Tal talabwärts des rezenten Khumbu Gletscher bis zum Konfluenzbereich zum Imja Khola stellte ein typisches Trogtal mit glazifluvialer Schotterflur dar (Talquerprofil 1; Foto 6, 15). Nach Kuhle (2005:Fig. 3) fiel die Schotterflur in das neoglaziale bis heutige Stadium -1 bis -8. Wie bei den Fotos 5, 8, 18 und 22 - aber auch auf den Fotos 35, 41, 44, 52 und 55 - zu sehen, wurden im Lobuche Khola auf der orographisch linken und rechten Talseite höchstliegende Schliffgrenzen ausgemacht. Am orographisch linken Talhang konnte auf ca. 5.390 bis $5.400 \mathrm{~m}$ diesbezüglich eine Höhe abgelesen werden, welche in etwa der von Kuhle (2005:Fig. 22) entsprach. In Bezug zum rezenten mit Schottern aufgeschütteten Haupttalboden auf ca. 4.350 Höhenmetern ergab sich somit eine ungefähre hochglaziale Eismächtigkeit von ca. 1.040 bis 1.050 m. Nach Kuhle (2005:Fig. 3/Profil 12, Fig. 22) - der den vorzeitlichen Haupttalboden rekonstruierte - betrug die maximale Eismächtigkeit in diesem Talabschnitt ca. $1.200 \mathrm{~m}$ und nach Kuhle (2005:Fig. 3/Profil 11) im Bereich des rezenten Khumbu Gletscher etwa 1.000 m. Beim Berg Pokalde zwischen Thokla und Pheriche konnte eine Eismächtigkeit von ca. 1.100 m (Foto 198) bestimmt werden: Schliffgrenze auf ca. 5.410 m; rezenter Talboden bei ca. 4.310 m. Die Schliffgrenze beim Taboche Peak auf ca. $5.440 \mathrm{~m}$ Höhe (Foto 35) deutete in Bezug auf den rezenten Talboden auf ca. $4.010 \mathrm{~m}$ auf eine Eismächtigkeit von ca. $1.430 \mathrm{~m}$ (nach Kuhle 2005:Fig. 3/Profil $161.450 \mathrm{~m}$ ). 


\section{WEITERE GEOMORPHOLOGISCHE FORMEN}

Neben den ausgemachten Schliffgrenzen konnten vor allem jüngere Ufermoränen spätglaziale bis historische - gegenüber älteren hochglazialen Grundmoränen abgegrenzt werden. Letztere traten zumeist auf den mittleren bis oberen Hangbereichen - wobei sie dort an vielen Stellen durch jüngere überlagert wurden - auf oder wurden durch Hangprozesse hangabwärts in Form von Fächern / Kegeln abgelagert. Es traten auf der orographisch rechten Lobuche Khola Talseite neben den eben genannten Formen an Fächer- und Kegelformen reine Schuttfächer / -kegel (Foto 1, 8, 14, 15, 22), Sturzmoränenfächer / -kegel (Foto 27), Mischfächer /-kegel (Foto 6, 8, 14, 16, 17, 22), Murmoränenfächer /-kegel (Foto 6, 16, 17, 22) sowie Murschwemmfächer / -kegel (Foto 6, 8, 16, 17) auf. Daneben fiel ein Fels- bzw. Bergsturzereignis (Foto 6, 8, 16, 17) ins Auge. Bis auf die reinen Schuttfächer / -kegel waren die Formen nur in Verbindung mit Grundmoränenmaterial zu erklären. Somit stellten selbst diese Formen ein Indiz für eine ehemalige Vergletscherung dieses Talbereiches dar. Auf der orographisch linken Lobuche Talseite konnten vor allem folgende Formen ausgemacht werden: Ufermoränen (Foto 5, 6, 8, 9-13, 15, 18, 19-22, 23), Mischfächer / -kegel (Foto 5, 41, 44), Sturzschuttfächer / -kegel (Foto 41, 44), Sturzmoränenfächer / -kegel (Foto 23), Murmoränenfächer / -kegel (Foto 18, 22), zerschnittene Grundmoränen (Foto 22) sowie Erosionsrinnen (Foto 18). Auf beiden Talseiten traten oft glaziäre Dreieckshänge auf, die neben den Schliffgrenzen und den Grundmoränenablagerungen einen Hinweis auf die maximale hocheiszeitliche Vergletscherung gaben. Im Talbodenbereich konnten hinter der

Endmoräne des Khumbu und des Tshola Gletscher Sanderflächen (Foto 8, 16) mit anschließenden Schwemmschuttfächer- / -kegelflächen (Foto 5, 16, 22) kartiert werden.

\section{SEDIMENTPROBEN}

Im Talabschnitt vom Khumbu und Tshola Gletscher bis zum Konfluenzbereich zum Imja Khola wurde eine Sedimentprobe (1. Probe, Foto 5) entnommen.

\section{ABGLEICH DER BEFUNDE MIT ANDEREN FORSCHUNGSARBEITEN RUND UM DEN KHUMBU GLETSCHER}

\section{Endmoräne des Khumbu Gletscher - Foto 8}

Die durch Schmelzwässer zerschnittene Endmoräne des Khumbu Gletscher fiel nach Kuhle (2005:Fig. 3) in die historischen Stadien VII bis X (1.700-400 bis 180-30 Jahre vor dem Jahr 1950). Iwata (1976:Fig. 4) teilte die Endmoräne des Khumbu Gletscher in Lobuche I bis III Moränen - Lobuche I / innerste: scharfer Gratverlauf, zumeist lichenfrei, keine Verwitterung, 
einzelne Pflanzen auf Außenhang, höher als Gletscher, 19.-20. Jhd.; Lobuche II: höchste, mehr Graspflanzen, kein Boden entwickelt; Lobuche III: verwitterte Blöcke, Gras- und Buschvegetation, Kleine Eiszeit bzw. aus dem 15.-16. Jhd. (ebd.:Fig. 1, Fig. 3, Fig. 4) - und Thuklha Stadium Moränen (2.000 bis 6.000 Jahre v.H.) ein. Fushimi (1978:Fig. 10) ordnete alle Moränen unterhalb des Khumbu Gletscher in das Thukla Stadium (16. Jhd., $\left.{ }^{14} \mathrm{C}-\mathrm{Daten}\right)$ ein, Müller (1980:Fig. 3) alle in die Zeit der Kleinen Eiszeit bzw. in das Dughla Stadium oder in das Unterstadium. Haffner (1972:Fig. 6) stellte die Endmoräne als rezent, Kalvoda (19711975) sie als Khumbu Moränentyp dar. Iwata (1976:Fig. 1) sowie Barnard, Owen, Finkel (2006:Fig. 2) visualisierten die Endmoräne des Khumbu Gletscher als einen Endmoränenzug bzw. als mehrere Moränenrücken mit hangabwärts verlaufenden Moränenrücken, Kuhle (2005:Fig. 3) stellte sie als Grundmoränenpodest dar. Unterhalb des Khumbu Gletscher entnahmen Richards et al. (2000:Fig. 2A, Probe SK 13) eine Probe und kamen auf ein OSLAlter von $10.900 \pm 2.400$ Jahren v.H. bzw. auf das Chhukung Stadium (vor ca. 10.000 Jahren v.H., Spätglazial oder Frühholozän). Talabwärts schlossen sich Sanderflächen an die Endsowie an die Seitenmoränen (Foto 8) und auch an die erstgenannten Schwemmschuttfächer / kegel (Foto 185) an. Auf der Karte von Bordet, Latreille (1954-1955) waren talabwärts des Khumbu Gletscher aktuelle Moränen und fluvioglaziale Materialien sowie im Hangbereich alte Moränen verzeichnet; auf der Karte von Kalvoda (1971-1975) wurden Moränen des Changri Typs, Moränen des Dusa Typs, eine fluvioglaziale Terrasse und im Hangbereich neben Anstehendem Schuttkegel aus polygenetischem Detritus, bei Haffner (1972:Fig. 6) mäßig steile bis steile Hänge aus pleistozänem Moränenmaterial sowie ein breiter Talboden fluvioglazialer Entstehung visualisiert.

\section{$\underline{\text { Schlussfolgerungen }}$}

Die zeitlichen Einordnungen der Endmoräne des Khumbu Gletscher stellten nach Kuhle (2005) und Iwata (1976) die jüngsten Spannweiten - bei letztgenanntem aber auch die älteste Spannweite mit 2.000 bis 6.000 Jahren v.H. - und nach Richards et al. (2000) die älteste Einordnung dar mit ca. 10.000 Jahren v.H.. Die OSL-Probenahmestelle SK 13 im Sandlinsenbereich von Richards et al. (2000:Fig. 2A) konnte nicht exakt aufgefunden werden - genaue Koordinatenangaben hätten dieses ermöglicht. Die Einordnung von Kuhle (2005) als jüngste bis weniger alte war unter Betrachtung der umgebenden Formen, wie etwa der seitlich an den Khumbu Gletscher angrenzenden Ufermoränen und der an den Hängen auftretenden hochglazialen Grundmoränendecken, am wahrscheinlichsten, was auch der Anwendung der ${ }^{14} \mathrm{C}$-Methode gegenüber anderen Datierungsmethoden geschuldet sein wird. Diese zeitliche 
Einordnung anhand von ${ }^{14} \mathrm{C}$-Datierungen wurde bereits bei Kuhle (1986a, 1987a) veröffentlicht. Ergänzend zu den Befunden von Kuhle (2005:Fig. 3) wurden talabwärts des Khumbu Gletscher fächer- / kegelförmige Sander (Foto 8) aufgenommen.

\section{Orographisch rechte Seite des Khumbu Gletscher - Foto 1}

Auf der orographisch rechten Talseite des Lobuche Khola abseits der Seitenmoräne des Khumbu Gletscher - nach Kuhle (2005:Fig. 3) historisches Stadium VII bis X (1.700-400 bis 180-30 Jahre vor 1950) - wurden Sander und in der Höhe des Lobuche Camps eine ältere Ufermoräne ausgemacht, welche nach Müller (1980:Fig. 3) in die Zeit der Kleinen Eiszeit bzw. in das Unterstadium des Dughla Stadium oder undeutliche Dughla Moränen, nach Iwata (1976:Fig. 1) ins Spät- oder Hochglazial der letzten Eiszeit bzw. ins Thyangboche Stadium und nach Kuhle (2005:Fig. 3) ins neoglaziale Stadium V (5.500 bis 4.000 Jahre vor dem Jahr 1950) eingeordnet wurden. Außerdem fanden sich glaziäre Dreieckshänge am Südosthang des Lobuche (East) und hochglaziale Grundmoränenmaterialien auf den Hängen sowie postglaziale reine Sturzschuttfächer / -kegel (Foto 1). Auf der Karte von Bordet, Latreille (1954-1955) waren in diesem Bereich fluvioglaziale Materialien sowie im Hangbereich alte und aktuelle Moränen dargestellt. Auf der Karte von Kalvoda (1971-1975) waren dort eine fluvioglaziale Terrasse sowie im Hangbereich Moränen des Changri Typs und neben Anstehendem Schuttkegel aus polygenetischem Detritus visualisiert, nach Haffner (1972:Fig. 6) existierten da mäßig steile bis steile Hänge aus pleistozänem Moränenmaterial.

\section{$\underline{\text { Schlussfolgerungen }}$}

Im Gegensatz zu anderen Forschern war die Einordnung der Ufermoräne auf Höhe des Lobuche Camps nach Kuhle (2005:Fig. 3) ins neoglaziale Nauri Stadium V als eine jüngere am besten nachvollziehbar: die Ufermoräne trat sehr dicht am heutigen Khumbu Gletscher auf - wobei nach Kuhle (2005:Foto 63) Reste der Stadium VI Moränen noch näher am Khumbu Gletscher auftraten, hangaufwärts waren hochglaziale Grundmoränen, glaziäre Dreieckshänge und glaziärer Flankenschliff (Foto 1, 5, 7, 8, 22) sowie oberste Schliffgrenzen (Foto 5, 8) ausmachbar. Diese zeitliche Einordnung basierte auf geomorphologischen Befunden und ${ }^{14} \mathrm{C}$ Datierungen, die bereits bei Kuhle (1986a, 1987a) veröffentlicht wurden. Müller (1980:Fig. 3) ordnete die o.g. Ufermoräne hingegen in die Zeit der Kleinen Eiszeit - Unterstadium des Dughla Stadium oder undeutliche Dughla Moränen - und Iwata (1976:Fig. 1) diese ins Spätoder Hochglazial der letzten Eiszeit - Thyangboche Stadium - ein. Die zeitliche Einordnung Iwatas (1976) ins Hochglazial sollte hinterfragt werden, da die o.g. Indizien für eine viel 
mächtigere hochglaziale Vergletscherung dieses Talbereiches sprachen. Auch eine spätglaziale Entstehung wäre im Vergleich zur hochglazialen Vergletscherung dieses Talbereiches nicht denkbar. Da Iwata (1976) und auch Müller (1980) keine weiteren Indizien außer Moränen mit einbezogen, war die Interpretation dieser Forscher zu überdenken, obwohl die Einordnung der Ufermoräne nach Müller in das angegebene Entstehungszeitintervall von Kuhle passen würde. Ergänzend $\mathrm{zu}$ den Befunden von Kuhle (2005:Fig. 3) wurden Sturzschuttfächer / -kegel (Foto 1) sowie Sturzmoränenfächer / -kegel (Foto 7, 8) aufgenommen.

\section{Orographisch rechte Ufermoräne des Khumbu Gletscher - Foto 3, 4, 7}

Westlich von Thokla zog sich ein älterer Ufermoränenrest weiter talabwärts (Foto 7). Dieser zeigte stellenweise Abbruch- / Abrutschbereiche auf (Foto 8). Nach Iwata (1976:Fig. 1) gehörte die Ufermoräne ins Thyangboche Stadium (Spät- oder Hochglazial der letzten Eiszeit), nach Finkel et al. (2003:Fig. 1, 2) ins Thyangboche I Stadium (ca. 40.000-90.000 Jahre v.H.) und nach Kuhle (2005:Foto 63) ins neoglaziale Stadium V (5.500 bis 4.000 Jahre vor dem Jahr 1950). Auf der Karte von Bordet, Latreille (1954-1955) waren hier alte Moränen und auf der Karte von Kalvoda (1971-1975) Moränen des Changri Typs visualisiert. Die Fotos 3 und 4 zeigen die Ufermoräne von Nahem. Der Awi Peak wies ähnlich wie der Lobuche (East) einen glaziären Dreieckshang mit darauf lagernden hochglazialen Grundmoränen auf, wobei die Moränenmaterialien heutzutage verstürzen / abrutschen. Auf der Karte von Bordet, Latreille (1954-1955) waren hier alte Moränen, auf der Karte von Kalvoda (1971-1975) Moränen des Changri Typs visualisiert, nach Haffner (1972:Fig. 6) existierten dort mäßig steile bis steile Hänge aus pleistozänem Moränenmaterial.

\section{$\underline{\text { Schlussfolgerungen }}$}

Die zeitliche Einordnung der orographisch rechten Ufermoräne des Khumbu Gletscher (Foto 2, 3, 4, 7, 8) war nach Kuhle (2005) die jüngste und somit unter Betrachtung der außerdem aufgefundenen glazialen Formen wie etwa hochglaziale Grundmoränendecken (Foto 1, 5, 7, 8), glaziärer Flankenschliff (Foto 7), glaziäre Dreieckshänge (Foto 5, 7, 8) und Schliffgrenzen (Foto 5) am wahrscheinlichsten. Diese zeitliche Einordnung gründete auf geomorphologischen Befunden und ${ }^{14} \mathrm{C}$-Datierungen, die bereits bei Kuhle (1986a, 1987a) veröffentlicht wurden. Die Zuordnung der Ufermoräne nach Iwata (1976) zum Hochglazial oder nach Finkel et al. (2003) als noch älter konnte nicht zutreffend sein, da die Indizien für eine viel mächtigere hochglaziale Vergletscherung dieses Talbereiches sprachen. Auch eine 
spätglaziale Entstehung wäre unter der Prämisse der hochglazialen Vergletscherung dieses Talbereiches nicht denkbar. Da Iwata (1976) und auch Finkel et al. (2003) keine weiteren Indizien außer Moränen - bei Finkel et al. nur Berücksichtigung von Wallmoränen - mit einbezogen, konnte die Interpretation dieser Forscher in Frage gestellt und sich den Ergebnissen von Kuhle angeschlossen werden. Finkel et al. (2003:Fig. 1) datierten Blöcke anhand der TCN-Methode in das Thyangboche Stadium. Die TCN-Probenahmestellen von Finkel et al. (2003:Fig. 1) konnten nicht genau aufgefunden werden, da ungenaue Koordinatenangaben dieses unmöglich machten. In Fig. 1 bei Finkel et al. (2003) war nur zu erkennen, wo die Blöcke mit den Nummern 84 bis 89 ungefähr lagen. Allerdings erschien die Ufermoräne auf der Oberfläche sehr blockreich (Foto 3, 4, 7, 8), sodass es auch deshalb schwierig nachzuvollziehen war, welche sechs Blöcke Finkel et al. (2003) beprobten. Ergänzend zu den Befunden von Kuhle (2005:Fig. 3) wurden Sturzmoränenfächer (Foto 7, 8) aufgenommen.

\section{RUND UM DEN TSHOLA GLETSCHER - FOTO 2}

Der Tshola Gletscher mit seinen Seiten- bis Endmoränen - nach Kuhle 2005:Fig. 3 Grundmoränenpodest, nach Iwata 1976:Fig. 1 Lobuche Stadium Moränen - staute talaufwärts den See Tshola Tsho auf (Foto 2). Am Nordosthang des Arakam Tse, auf der orographisch rechten Talseite des Tshola Khola, waren neben Seiten- bis Endmoränen des Arakam Tse Nordostgletscher mit darüber lagerndem aktiven Lawinenkegel (siehe hierzu Kuhle 2005:Foto 65) und glaziären Dreieckshängen mehrere Fächer- / Kegelformen ausgebildet. Vor allen Dingen fanden sich Mischfächer / -kegel aus verstürztem Schutt- und Moränenmaterial sowie aus diesen Moränenmaterialien an den Seiten der Sturzfächer / -kegel entstandene Murschwemmfächer / -kegel. Erstgenannte Sturzfächer / -kegel waren dadurch entstanden, dass vorher auf dem Hang des Arakam Tse abgelagerte Grundmoränen zusammen mit Schutt aus postglazialen Sturzprozessen im Anstehenden verstürzten. Bei der Entstehung der Fächer / Kegel waren jedoch fluviale Hangabwärtsprozesse nicht ganz auszuschließen, sodass sie auch Mischformen darstellen konnten, wobei aber klar die Sturzprozesse überwogen haben müssen. Die Murschwemmfächer entstanden nachfolgend zur Sturzfächer- / -kegelentstehung aus den beteiligten Grundmoränenmaterialien durch vorwiegend fluviale Prozesse. Auf der Karte von Kalvoda (1971-1975) waren im Hangbereich neben Anstehendem Schuttkegel aus polygenetischem Detritus visualisiert, wobei rund um den Tshola Gletscher Moränen des Khumbu Typs gekennzeichnet waren, auf der Karte von Bordet, Latreille (1954-1955) aktuelle Moränen; Haffner (1972:Fig. 6) kennzeichnete dort rezente Moränen. Rund um den 
Tshola Gletscher visualisierten Barnard, Owen, Finkel (2006:Fig. 2) Moränen und auf der orographisch rechten Seite die Form 'landslide'.

\section{$\underline{\text { Schlussfolgerungen }}$}

Die Seiten- bis Endmoränen müssten nach der Klassifikation von Kuhle (2005) ebenso wie die Endmoräne des Khumbu Gletscher in die historischen Stadien VII bis X (1.700-400 bis 180-30 Jahre vor dem Jahr 1950) fallen, waren aber dort in Fig. 3 nicht angegeben. Nach Iwata (1976) fielen diese Formen in den Zeitraum des Lobuche Stadium bzw. in die Spanne 15. bis 20. Jhd.. Somit würde die zeitliche Einordnung von Iwata in das Entstehungszeitintervall von Kuhle passen. Da aber Iwata keinerlei Bezug zu anderen glazialen Formen nahm und Kuhle hingegen eine detaillierte Bestandsaufnahme machte, war die Einordnung von Kuhle am aussagekräftigsten. Ergänzend zu den Befunden von Kuhle (2005:Fig. 3) wurde ein glaziärer Dreieckshang und verschiedene Fächer- / Kegeltypen auf der orographisch linken Seite und Sturzschuttfächer / -kegel auf der orographisch rechten Seite des Tshola Gletscher aufgenommen (Foto 2, 8, 16). Die nach Barnard, Owen, Finkel (2006:Fig. 2) visualisierte Form 'landslide' beim Tshola Gletscher war genetisch nicht zuzuordnen. Es handelte sich hierbei um Sturzschuttfächer / -kegel (Foto 2, 8, 14).

\section{OROGRAPHISCH LINKE LOBUCHE TALSEITE - FOTO 5, 6, 8, 9-13, 15, 18-23}

Die deutlich erkennbare orographisch linke Ufermoräne auf Foto 5 (in Höhe der entnommenen Sedimentprobe, weißes Symbol einer Ufermoräne) und 8 (mit dem Symbol einer Ufermoräne gekennzeichnet) in der Nähe des Khumbu Gletscher fiel laut Kuhle (2005:Fig. 3) ins Stadium IV, nach Finkel et al. (2003:Fig. 1) in das Periche II Stadium $(16.000 \pm 2.000$ Jahre v.H.) und nach Iwata (1976:Fig. 1) ins Thyangboche Stadium (Spätoder Hochglazial der letzten Eiszeit), wobei sich unterhalb dieser Form fünf weitere kürzere Ufermoränen auf einer zerschnittenen glazifluvialen Sanderfläche ausmachen ließen, die die Forscher durchgängig als einen Moränenzug - Finkel et al. (2003) als Chhukhung Stadium (9.200 \pm 200 Jahre v.H.) auf Fig. 1 (Proben 79 bis 81) und Iwata (1976:Fig. 1) als Thuklha Stadium (2.000 bis 6.000 Jahre v.H.) - visualisierten. Diese Darstellung ließ sich auch anhand der Höhenlinien bei Finkel et al. (2003:Fig. 1) nachvollziehen, wobei der unterste Moränenzug südlich des Khumbu Gletscher stellenweise unterhalb von 4.600 Höhenmetern lag. Die von Finkel et al. datierten Blöcke 79 bis 81 mussten hierbei ungefähr auf $4.600 \mathrm{~m}$ Höhe liegen. Bei Iwata (1976:Fig. 1) war das deutlich durch den gut nachvollziehbaren visualisierten Moränenrückenverlauf zu sehen. Nach Kuhle (2005:Fig. 3) fiel der oben 
erstgenannte Moränenbogen in das spätglaziale Stadium IV / Sirkung Stadium (13.500-13.000 Jahre vor 1950). Hierbei war zu bemerken, dass Finkel et al. (2003:Fig. 1), aber auch Barnard, Owen, Finkel et al. (2006:Fig. 2) die von Kuhle (2005:Fig. 3) gekennzeichneten Stadium IV und V Ufermoränen südlich von Periche zwar noch als zwei Ufermoränen kennzeichneten Periche I und Periche II Moränen, diese beiden aber nach Norden gen Khumbu Gletscher nur noch als eine Ufermoräne - als Periche II Moräne - darstellten. Auf der Karte von Kalvoda (1971-1975) waren im Bereich der Ufermoränen erosionale Denudationshänge auf Gneisen und Migmatiten visualisiert, auf der Karte von Bordet, Latreille (1954-1955) alte Moränen; Haffner (1972:Fig. 6) kennzeichnete mäßig steile bis steile Hänge aus pleistozänem Moränenmaterial.

Die Ufermoränen auf der Höhe des Ortes Periche (Foto 5, 6 - Foto 15, 19, 21, 22, 23 nur talbodennähere Ufermoräne, 18) wurden von Iwata (1976:Fig. 1) als Periche und Thyangboche Stadium (Spät- oder Hochglazial der letzten Eiszeit), von Fushimi (1977:Fig. 11) als Periche Stadium (Spät- oder Hochglazial), von Müller (1980) als Pheriche Stadium und älter (Spätglazial und älter), von Finkel et al. (2003:Fig. 1) als Periche II (16.000 \pm 2.000 Jahre v.H.) und Periche I (23.000 \pm 3.000 Jahre v.H. = globales LGM), von Kuhle (2005:Fig. 3) als Stadium IV und V (13.500-13.000 Jahre vor 1950 und 5.500-4.000 Jahre vor 1950) und von Barnard, Owen, Finkel (2006:Fig. 7) als Stadium Periche II und Periche I (keine Angaben der Alter der Probenahmestellen E1 bis E7 in Tab. 1 angegeben) eingeordnet. Auf den Hängen - die oft zu glaziären Dreieckshängen umgestaltet waren - lagerten demgegenüber viel ältere Grundmoränenreste (Sedimentprobe 1), die jedoch stellenweise verstürzt waren und zusammen mit Schutt von Sturzprozessen aus dem Anstehenden Sturzfächer / -kegel aus Schutt- und Moränenmaterialien formten (Foto 5). An vielen Orten waren diese Mischfächer/ -kegelformen durch reine Sturzfächer / -kegel aus Schutt überlagert, sodass die maximale Vergletscherung nicht überall an Fächer- / Kegelformen nachvollzogen werden konnte. Bereits Kuhle (2005:Fig. 3) kennzeichnete in diesem Talbereich glaziäre Dreieckshänge, glaziäre Flankenschliffe und Grundmoränen mit nicht erratischen Blöcken.

Auf der orographisch linken Lobuche Talseite waren weiterhin folgende Formen zu erkennen: Ufermoränenzüge - nach Kuhle 2005:Fig. 5 Ufermoränen Stadium V und IV aus dem Zeitraum 5.500-4.000 Jahre vor 1950 und 13.500-13.000 Jahre vor 1950 (Foto 5, 6, 8, 15, 1822, 23-26, 27), durch Schmelzwasserabflüsse des Khumbu Gletscher entstandene Anrissbereiche im Moränenmaterial (Foto 5, 23), Murmoränenfächer / -kegel (Foto 18, 22), Mischfächer / -kegel (Foto 5), glaziäre Dreieckshänge (Foto 5, 8, 18, 22), Grundmoränen 
(Foto 5, 8, 18, 22), zerschnittene Grundmoränen (Foto 22) und Schliffgrenzen (Foto 5, 8, 18, 22). Auf der Karte von Bordet, Latreille (1954-1955) waren auf dieser Talseite neben Anstehendem und Schuttfächern alte und aktuelle Moränen und auf der Karte von Kalvoda (1971-1975) neben Anstehendem und den Denudationshängen Schuttkegel aus polygenetischem Detritus und Moränen des Dusa Typs visualisiert. Bei Haffner (1972:Fig. 6) wurden dort mäßig steile bis steile Hänge aus pleistozänem Moränenmaterial sowie ein breiter Talboden fluvioglazialer Entstehung gekennzeichnet. Die Murmoränenfächer / -kegel (Foto 18) bezeichnete Kuhle (2005:Fig. 3) als Schutt- und Murkegel und Barnard, Owen, Finkel (2006:Fig. 2) als 'fan'. Daneben zeichneten letztgenannte Forscher noch mehrere 'landslides' ein und Haffner (1972:Fig. 6) neben den mäßig steilen bis steilen Hängen aus pleistozänem Moränenmaterial Bergsturzhalden.

\section{$\underline{\text { Schlussfolgerungen }}$}

Die auf den Fotos 5 und 8 deutlich zu sehende Ufermoräne wurde von Kuhle (2005) als spätglazial angesehen und demnach jünger als von Finkel et al. (2003) eingeordnet. Hier standen sich ${ }^{14} \mathrm{C}$-Datierungen und TCN-Datierungen gegenüber, wobei Kuhle zudem sehr detaillierte geomorphologische Analysen lieferte. Die ${ }^{14} \mathrm{C}$-Daten wurden bereits bei Kuhle (1986a, 1987a) veröffentlicht. Iwata (1976) legte die Ufermoräne ins Spät- oder Hochglazial der letzten Eiszeit. Fig. 3 bei Kuhle (2005) zeigte talabwärts dieser Ufermoräne eine weitere des neoglazialen Stadiums V (5.500-4.000 Jahre vor 1950), welche aber nicht bis zum Khumbu Gletscherende visualisiert war. Finkel et al. (2003) visualisierten in Fig. 1 jedoch in diesem Bereich wie o.g. eine durchgängige Chhukhung (9.200 \pm 200 Jahre v.H.) Ufermoräne, genauso wie Iwata (1976:Fig. 1) eine des Thuklha Stadiums (2.000 bis 6.000 Jahre v.H.). Diese existierte aber in natura nicht durchgängig - es waren nämlich mehrere Moränenzüge auf einer zerschnittenen glazifluvialen Terrasse erkennbar. Somit wäre die zeitliche Einordnung der Moräne nach Kuhle - da sich der Ufermoränenbogen nach ihm in etwa auf der Höhenlage dieser von Finkel et al. visualisierten Moräne weiter verfolgen lassen würde eine jüngere. Die zeitliche Einordnung der Moräne nach Finkel et al. war in Bezug auf die vorgefundenen umgebenden glazialen Formen - Grundmoränen und Mischfächer / -kegel auf den Hängen, glaziäre Dreieckshänge, Schliffgrenzen (Foto 5, 8) - zu hinterfragen. Auch die angewendete Methode der TCN-Datierung - gegenüber etwa einer geomorphologischen Detailanalyse mit ${ }^{14} \mathrm{C}$-Datierungen - führte dazu, dass dieses Alter angezweifelt werden konnte. Auf dieser Moräne wurden von Finkel et al. (2003) die Blöcke 79 bis 81 beprobt. Ob es sich bei den aufgenommenen Blöcken auf den Fotos 9 und 10 um die Blöcke 79 bis 81 
handelte, konnte nicht geklärt werden. Genaue Koordinatenangaben hätten diesbezüglich den Standort von Finkel et al. (2003) präzisieren können. Ähnlich verhielt es sich mit den von Finkel et al. (2003) datierten Blöcken 75 bis 77 auf einer Thyangboche II Moräne (Foto 1113). Hierbei fiel wieder auf, dass Finkel et al. (2003:Fig. 1), aber auch Barnard, Owen, Finkel et al. (2006:Fig. 2), die von Kuhle (2005:Fig. 3) gekennzeichneten Stadium IV und V Ufermoränen südlich von Periche als zwei Ufermoränen - Periche I und Periche II Moränen, diese beiden aber nach Norden gen Khumbu Gletscher nur noch als eine Ufermoräne - als Periche II Moräne - visualisierten. Somit war die ältere Periche I Ufermoräne ungefähr ab dem Ort Periche nicht berücksichtigt, obwohl der Verlauf des älteren Moränenrückens als Periche II gekennzeichnet wurde. Aufgrund dessen bedurfte dieser in Fig. 1 gekennzeichnete Periche II Moränenrücken im Gelände einer genaueren Untersuchung, da es sich laut der Ufermoränenverläufe auch um die von Finkel et al. (2003:Fig. 1) dargestellten Thyangboche II Moränen oder um die Periche I Moräne handeln konnte.

Die Ufermoränen auf der Höhe des Ortes Periche wurden von den relevanten Forschern bis auf Fushimi (1977) und Müller (1980) in zwei deutlich abgegrenzte Stadien eingeteilt und die dem Talboden am nächsten verlaufende von Kuhle (2005) als jüngste bzw. neoglaziale (Stadium V: 5.500-4.000 Jahre vor 1950) abgegrenzt. Die Ufermoränen wurden durchgängig von Kuhle (2005:Fig. 3) eingezeichnet, waren in natura aber als nicht ganz durchgängig zu erkennen. Bei Iwata (1976:Fig. 1) und Barnard, Owen, Finkel (2006:Fig. 2) wurden nicht zwei unterschiedliche Moränenzüge visualisiert, sondern beim erstgenannten Forscher als durchgängig und beim letztgenannten als nur stellenweise vorhanden dargestellt. Die höher liegende Ufermoräne ordnete Kuhle (2005) als spätglazial (Stadium IV: 13.500-13.000 Jahre vor 1950) ein. Auch bei Iwata (1976), Fushimi (1977) und Müller (1980) war eine spätglaziale Entstehungszeit, aber auch eine hochglaziale nicht auszuschließen (siehe Kritiken zu den Forschern). Bei Iwata (1976:Fig. 1) ließen auch die mit Fragezeichen unterhalb Periche bzw. auf den Hängen gekennzeichneten unklassifizierten Moränen - zusätzlich zur Thyangboche Stadium Moräne - auf eine jüngere Entstehung der Ufermoränen schließen. Auch nach Finkel et al. (2003) fiel der Entstehungszeitraum der jüngeren Ufermoräne in die Zeit nach dem LGM, aber im Gegensatz zu Kuhle trotzdem noch in eine ältere Zeit als die von diesem als spätglazial eingestufte höher liegende Ufermoräne. Die Sichtweise der Forscher, ausgenommen die von Kuhle, bzw. die Einordnung der letztgenannten höher liegenden Ufermoräne als hochglaziale konnte in jedem Fall angezweifelt werden. Die ausgemachten Formen allein ließen darauf schließen, dass dieses Tal einstmalig enorm 
vergletschert gewesen sein musste. Die Befunde der Forscher, bis auf die von Kuhle, mussten somit kritisch hinterfragt werden, da keine geomorphologische Bestandsaufnahme zu Grunde lag und Finkel et al. (2003) TCN-Datierungen anwendeten und dabei die ${ }^{14} \mathrm{C}$-Daten von Kuhle nicht einbezogen bzw. diese nicht mit ihren TCN-Daten abglichen. Die ${ }^{14} \mathrm{C}$-Daten würden die TCN-Daten widerlegen bzw. müssten diese Daten die TCN-Daten eichen. Ob es sich bei den fotografierten Blöcken auf den Fotos 19 und 20 um die Blöcke 5 bis 7 handelte, konnte nicht geklärt werden. Genaue Koordinatenangaben hätten den Standort der von Finkel et al. (2003) untersuchten Blöcke auffindbar machen können. Ähnlich verhielt es sich mit den von Finkel et al. (2003:Fig. 1) datierten Blöcken 71 und 73 ebenfalls auf der Periche II Ufermoräne, mit den Blöcken 9 bis 11 auf der Periche I Ufermoräne und mit den Probenahmestellen SK 09, 10 und 14 von Richards et al. (2000:Fig. 2A).

Ergänzend zu den Befunden von Kuhle (2005) wurden auf der orographisch linken Lobuche Talseite folgende Formen ausgemacht: durch Schmelzwasserabflüsse des Khumbu Gletscher entstandene Anrissbereiche im Moränenmaterial (Foto 5, 23), weitere glaziäre Dreieckshänge (Foto 18), Mischfächer / -kegel (Foto 5, 41, 44, 52), zerschnittene Grundmoränen (Foto 22) sowie Anrissbereiche von Sturzschuttfächern / -kegeln (Foto 18, 41, 44, 52). Die Murmoränenfächer / -kegel (Foto 18) wurden von Kuhle (2005:Fig. 3) als Schutt- und Murkegel bezeichnet und konnten als solche bestätigt werden sowie auch die von ihm weiterhin visualisierten Formen wie etwa Grundmoränen und glaziäre Dreieckshänge. Barnard, Owen, Finkel (2006:Fig. 2) bezeichneten diese Murmoränenfächer / -kegel als 'fans', wobei sie viel zu weit den Hang hinauf visualisiert wurden. Denn im oberen bis mittleren Hangbereich bestanden nur glaziäre Dreieckshänge mit überlagernden Grundmoränenablagerungen, so wie sie auch Kuhle (2005:Fig. 3) weiter talaufwärts kennzeichnete. Der Begriff 'fan' ließ keine genaue genetische Zuordnung der Form zu; es konnte damit eine Vielzahl von Prozessen bzw. durch letztere entstandene Formen verstanden werden. Außerdem waren die Fächer zwar fluvial erklärbar, schlossen aber eine glaziale Entstehung der enthaltenen Materialien nicht aus. Es handelte sich bei den Fächern um disloziertes Moränenmaterial, was auf ursprüngliches Grundmoränenmaterial auf den Hängen schließen ließ. Auch Iwata (1976:112) gab an, dass die Thyangboche Moränen mit neueren Moränen, Schwemmfächern und fluvialen Akkumulationen bedeckt waren, was jedoch die Herkunft der Materialien nicht klärte. Auch der Begriff 'landslide' ließ keine genetische Erklärung der Formen zu. Die von Haffner (1972:Fig. 6) gekennzeichneten Bergsturzhalden 
wurden in der vorliegenden Arbeit als Sturzschuttfächer / -kegel und Mischfächer / -kegel (Foto 41, 44, 52) bezeichnet.

\section{OROGRAPHISCH RECHTE LOBUCHE TALSEITE - FOTO 6, 8, 14-17, 22}

Auf Foto 16 ist ein guter Überblick über die Fächer- / Kegeltypen auf der orographisch rechten Lobuche Talseite erkennbar. Es wurden hier neben glaziären Dreieckshängen und Fels- / bzw. Bergsturzablagerungen Murmoränenfächer / -kegel, Murschwemmfächer / -kegel und Mischfächer / -kegel unterschieden. In diesem Talbereich kennzeichnete Kuhle (2005:Fig. 3) glaziäre Dreieckshänge sowie Schutt- und Murkegel, Barnard, Owen, Finkel (2006:Fig. 2) 'landslides' und 'fans' und Haffner (1972:Fig. 6) einen fluvioglazialen Schwemmkegel. Die Murmoränenfächer / -kegel aus disloziertem Grundmoränenmaterial und die Mischfächer / -kegel auf dem Foto 22 (Foto 6 Mitte, Foto 16 Mitte, Foto 17 links) waren nach Kuhle (2005:Foto 66) unter Murfächer und 'alluvial debris cone’ bzw. nach ebd.:Fig. 3 als Schutt- und Murkegel aufgeführt. Foto 17 deckt den mittleren Bereich des Fotos 16 ab, das Foto 14 den rechten Bereich des Fotos 16, die Fotos 6 und 8 den mittleren und den rechten Bereich des Fotos 14.

Das Foto 15 zeigt talabwärtigere Sturzschuttfächer / -kegel und Grundmoränenreste, die im unteren Hangbereich teilweise durch Hangabtragungsprozesse talabwärts transportiert oder zerschnitten wurden. Barnard, Owen, Finkel (2006:Fig. 2) kennzeichneten in diesem Bereich vier kleine Fächer, Kuhle (2005:Fig. 3) Grundmoränen mit erratischen Blöcken und einen glaziären Dreieckshang. Foto 27 zeigt die orographisch rechte Ufermoräne des vorzeitlich mächtigeren Khumbu Gletscher, die nach Kuhle (2005:Fig. 3, Foto 66) eine neoglaziale Stadium V, nach Finkel et al. (2003:Fig. 1) eine Periche I Stadium, nach Müller (1980:Fig. 3) eine 'Pheriche Stage and older' und nach Iwata (1976:Fig. 1) eine Periche Stadium Ufermoräne sein sollte. Auf der Karte von Bordet, Latreille (1954-1955) waren auf der orographisch rechten Talseite des Lobuche Khola fluvioglaziale Materialien auf dem Talboden und alte Moränen im Hangbereich sowie Schuttfächer visualisiert - auf der Karte von Kalvoda (1971-1975) eine fluvioglaziale Terrasse auf dem Talboden und neben Anstehendem Schuttkegel aus polygenetischem Detritus sowie Moränen des Dusa Typs im Hangbereich.

\section{$\underline{\text { Schlussfolgerungen }}$}

Auf der orographisch rechten Lobuche Talseite konnten die von Kuhle (2005) ausgewiesenen glaziären Dreieckshänge, Schutt- und Murkegel bzw. Murfächer und 'alluvial debris cone' 
bestätigt werden, wobei die letztgenannten allerdings in der vorliegenden Arbeit anders benannt wurden. Ergänzend zu den Befunden von Kuhle konnten daneben als weitere die o.g. Fächer- / Kegelformen, aber auch Fels- / bzw. Bergsturzablagerungen aufgefunden werden. Vor allen Dingen wurden Sturzfächer / -kegel (Sturzschuttfächer / -kegel und Mischfächer / kegel) und weitere Grundmoränenreste auf den Hängen aufgenommen (Foto 6, 8, 14, 16, 17, 22). Die von Barnard, Owen, Finkel (2006:Fig. 2) ausgewiesenen Formen 'landslide' und 'fan’ ließen keine genaue genetische Zuordnung der Formen zu. Unter den Begriffen konnte eine Vielzahl von Prozessen bzw. durch solche entstandene Formen verstanden werden. Der von Haffner (1972:Fig. 6) dargestellte fluvioglaziale Schwemmkegel wurde in dieser Arbeit als Murschwemmfächer / -kegel (Foto 16 links) bezeichnet.

Bei Barnard, Owen, Finkel (2006:Fig. 2) existierten auf der orographisch linken Lobuche Khola Seite aber auch 'fans', die ohne Schraffur als Fächerform visualisiert waren; demnach waren diese nicht als solche auslegbar. Auch wurden sog. Fächer als solche gekennzeichnet, die aber zerschnittene Grundmoränen (Foto 15, 22) oder einen glaziären Dreickshang mit überlagernden Grundmoränen (Foto 22) darstellten, wie auf Fig. 2 bei Barnard, Owen und Finkel unter und über dem Schriftzug FIGURE 7 zu sehen war. Auch Kuhle (2005:Fig. 3) verwies in diesem Bereich schon auf Grundmoränen mit erratischen Blöcken und einen glaziären Dreieckshang. Ergänzend zu den Befunden von Kuhle in diesem Talbereich wurde in der vorliegenden Arbeit lediglich ein Sturzschuttfächer / -kegel (Foto 15, 22) aufgenommen.

\section{WEITERE GEOMORPHOLOGISCHE ANALYSEN GEOMORPHOLOGISCHE KARTE}

Die mittels der Anwendung Google Earth auf einer geomorphologischen Karte (siehe Karte 2) visualisierten Formen im Tal Lobuche Khola vom Khumbu Gletscher bis zum Konfluenzbereich zum Imja Khola bzw. ungefähr von den Orten Thokla bis Periche hinab wurden mit Hilfe von Geländebegehungen und Google Earth Satellitenbildanalysen ausgemacht.

Die Befunde von Kuhle (2005:Fig. 3) wurden mit der vorliegenden Arbeit bestätigt. Die in der Karte 3, welche Fig. 3 von Kuhle zur Grundlage hatte, hellgrün visualisierten geomorphologischen Formen verweisen auf die Bestätigung bzw. Übereinstimmung dieser Formen mit denen in der vorliegenden Arbeit. Die dunkelgrün gekennzeichneten Formen bzw. die Grundmoränen wurden nicht daraufhin überprüft, ob sie erratische oder nicht 
erratische Blöcke enthielten, konnten jedoch als Moränenmaterial identifiziert werden. Die Formen, die keinerlei grüne Färbung aufweisen, wurden in der vorliegenden Arbeit nicht überprüft.

Ergänzend zu den Befunden von Kuhle (2005:Fig. 3) wurden in diesem Talabschnitt folgende Formen ausgemacht: weitere glaziäre Dreieckshänge, weitere deutlich erkennbare Moränenwälle bzw. übrig gebliebene zerschnittene Moränengrate, Rundhöcker, ein Berg- / Felssturz, Blockgletscher / Schuttloben sowie verschiedene Fächer- / Kegeltypen wie etwa Sturzschuttfächer / -kegel (Nummer 1 = welche, die Moränenmaterial überlagern (1a) oder von Schnee, Lawinen überlagerte (1b)) oder Sturzfächer / -kegel aus Moränenmaterial oder glazifluvialen Materialien (Nummer 2), Mischfächer / -kegel (Nummer 3 = hauptsächlich aus Schutt (3a), welche, die präexistierendes Moränenmaterial überlagern (3c) oder von anderen Prozessen überlagerte (3d)), Murfächer / -kegel (Nummer 4 = Murmoränenfächer / -kegel mit einem hohen Moränenanteil (4b), Murschwemmfächer / -kegel mit viel Feinmaterial (4c) oder von anderen Prozessen überlagerte (4d)), Schwemmfächer $/$-kegel (Nummer $5=$ Sander aus Moränenmaterial mit Bezug zum Gletscherrand (5b)) und zerschnittene Moränen (Nummer 6). Die Gletscherflächen wurden der topographischen Karte 'Lukla to Everest Base Camp' im Maßstab 1:60.000 entnommen, wobei die Seen den Satellitenbildern von Google Earth entstammen.

Die Befunde von Barnard, Owen, Finkel (2006:Fig. 2) wurden ebenfalls mit dieser Arbeit überprüft. Die in der - wieder auf Grundlage der Karte der zu überprüfenden Forscher (ebd.:Fig. 2) - erstellten Karte 4 grün gekennzeichneten Formen wurden ebenfalls aufgefunden, wobei für die Formen, welche von den Forschern mit dem weitgefassten Begriff 'fan' bezeichnet wurden, in der vorliegenden Arbeit eindeutigere Zuordnungen erfolgten. Die rot visualisierten Formen waren hingegen nicht nachweisbar bzw. nicht aufzufinden. Hierbei handelte es sich bei den von den Forschern kartierten 'fan' um glaziäre Dreieckshänge mit darüber abgelagerten Moränen, die zerschnitten wurden. Die gelb gekennzeichneten Formen konnten anhand der von den Forschern angegebenen Legende nicht eindeutig identifiziert werden. Es handelte sich höchstwahrscheinlich vielerorts um bebaute Flächen bzw. Orte und mancherorts um Fächer. Die orange gekennzeichneten Formen stellen die von Barnard, Owen, Finkel (2006:Fig. 2) kartierten 'landslides’ dar. Mit der vorliegenden Arbeit konnten für diesen weitgefassten Begriff im Sinne einer terminologischen Schärfung andere Bezeichnungen festgelegt werden: bei Nummer 1 handelte es sich bei der orographisch rechten Ufermoräne des vorzeitlich mächtigeren Khumbu Gletscher bzw. entlang der Endmoräne des Khumbu Gletscher um Nachbruchgebiete im Moränenmaterial oder um 
Sturzmoränenfächer / -kegel; dieses ließ sich auch bei Nummer 6 bei der Ufermoräne südlich von Periche erkennen, wobei dort auch Fächer / Kegel auszumachen waren; unter Nummer 2 ist die orographisch rechte Ufermoräne des Tshola Gletscher zu verstehen, die durch überfließende Schmelzwässer und Sturzprozesse überarbeitet wurde; die Nummer 3 stellt Sturzschuttfächer / -kegel, die Nummer 4 Bergsturz- / Felsturzablagerungen dar. Was Barnard, Owen und Finkel bei den Formen unter Nummer 5 meinten, blieb offen. Auf der orographisch rechten Lobuche Khola Talseite waren Fächer und auf der orographisch linken Talseite glazifluviale Schotterterrassen mit darüber lagernder zerschnittener Ufermoräne auszumachen.

\section{OBERFLÄCHENBEDECKUNGSKARTE}

Im Khumbu bzw. im Talabschnitt Lobuche Khola vom Khumbu Gletscher bis zum Konfluenzbereich zum Imja Khola bzw. ungefähr von dem Ort Thokla bis Periche hinunter wurden Oberflächenbedeckungskarten erstellt. Zum einen wurde eine Karte auf Grundlage der topographischen Karte Khumbu-Himal im Maßstab 1:50.000 (siehe Karte 5) und zum anderen eine Karte aus Satellitenbildern von Google Earth (siehe Karte 6) erstellt. Rötliche Bereiche deuten auf bebaute Flächen, dunkelblaue auf Flüsse / Seen, hellblaue auf ungefähre Gletscherbegrenzungen, weiße auf Eis- / Schneebedeckung, dunkelgraue auf anstehendes Gestein, mittelgraue auf stärkere Schuttbedeckung, hellgraue auf schwächere Schuttbedeckung sowie braune auf übrige Tal- und Hangbereiche, die teilweise bewachsen sind. Hierbei fiel auf, dass die o.g. topographische Karte gegenüber der den Satellitenbildern zu entnehmenden wirklichen Ausgestaltung der Oberflächen ungenau war. Vor allen Dingen ließen sich Unterschiede in der Schuttbedeckung ausmachen.

\subsubsection{Imja Khola}

3.1.2.1. Von den Gletschern Nuptse, Lhotse Nup, Lhotse / Imja und Ama Dablam / Chhukhung bis zum Konfluenzbereich zum Lobuche Khola (Chhukhung-Dingboche) Im Talabschnitt der Gletscher Nuptse, Lhotse Nup, Lhotse / Imja und Ama Dablam / Chhukhung bis zum Konfluenzbereich zum Lobuche Khola wurden 20 Fotos (Foto 28-47) aus einer großen Anzahl ausgesucht. Die Standorte der Fotos, der Sedimentproben sowie der Verlauf der Talquerprofile können der Karte 7 entnommen werden. Die geomorphologische Analyse im oberen Abschnitt des Tales Imja Khola ergab folgende Ergebnisse für die hocheiszeitliche Vergletscherung: 


\section{TALQUERPROFILE UND SCHLIFFGRENZEN}

Das Imja Khola talabwärts der genannten Gletscher bis zum Konfluenzbereich zum Lobuche Khola stellte ein typisches Trogtal mit glazifluvialer Schotterflur dar (Talquerprofil 2; Foto 35, 36, 39). Nach Kuhle (2005:Fig. 3) fiel diese Schotterflur in die neoglazialen Stadien -1 bis -2. Wie bei den Fotos 39 und $44 \mathrm{zu}$ sehen ist, wurden im oberen Imja Khola auf der orographisch rechten Talseite höchstliegende Schliffgrenzen ausgemacht. Es konnte eine Schliffgrenze zwischen den Bergen Nuptse und Lhotse auf ca. 5.950 Höhenmetern abgelesen werden. Diese deutete auf eine hochglaziale Eismächtigkeit im Imja Tal zwischen Chhukhung und Dingboche von ca. $1.200 \mathrm{~m}$ hin (Erosionsrinne unterhalb des Lhotse Nup Gletscher bei ca. $4.750 \mathrm{~m}$ Höhe). Nach Kuhle (2005:Fig. 3/Profil 14, 15) - der den vorzeitlichen Haupttalboden rekonstruierte - betrug die maximale Eismächtigkeit in diesem Talabschnitt ebenfalls ca. 1.200 m. Die Fotos 5, 6, 8, 35 sowie auch 83 und 94 verweisen aufgrund einer hochglazialen Schliffgrenze beim Ama Dablam auf ca. 5.330 m Höhe auf eine Eismächtigkeit wiederum von $1.200 \mathrm{~m}$ (rezenter Talboden auf ca. $4.130 \mathrm{~m}$ ). Diese stimmte mit der angegebenen 1.200 m mächtigen rekonstruierten Eisdecke von Kuhle (2005:Fig. 3/Profil 15) überein.

\section{WEITERE GEOMORPHOLOGISCHE FORMEN}

Neben den ausgemachten Schliffgrenzen konnten im oberen Teil des Imja Khola zwischen den rezenten Gletscherendbereichen bei Chhukhung und dem Konfluenzbereich zum Lobuche Khola folgende Formen ausgemacht werden: Ufermoränen (Foto 28-32, 35, 36, 38-45, 47), Seiten- bis Endmoräne (Foto 29, 31), Sanderflächen (Foto 29, 30, 32, 36), glaziäre Dreieckshänge (Foto 29, 33, 35, 39, 41, 44), Grundmoränen (Foto 29, 33, 34, 35, 36, 39, 41, 44), Sturzschuttfächer / -kegel (Foto 29, 31, 33, 35, 41), Sturzmoränenfächer / -kegel bzw. teilweise Sanderfächer / -kegel (Foto 30-34, 35, 36, 38, 40, 45, 46), Mischfächer / -kegel (Foto 33, 35), Schwemmschuttfächer / -kegel (Foto 30), Murschuttfächer / -kegel (Foto 33, 34, 36) und Blöcke mit glazifluvialen Spülformen (Foto 37, 38, 46).

\section{SEDIMENTPROBEN UND AUFSCHLÜSSE}

Im Talabschnitt der Gletscher Nuptse, Lhotse Nup, Lhotse / Imja und Ama Dablam / Chhukhung bis zum Konfluenzbereich zum Lobuche Khola wurde eine Sedimentprobe (2. Probe, Foto 36) entnommen und ein Aufschluss (1. Aufschluss, Foto 36) untersucht. 
ABGLEICH DER BEFUNDE MIT ANDEREN FORSCHUNGSARBEITEN OROGRAPHISCH RECHTE SEITEN- / UFERMORÄNE DES AMA DABLAM UND CHUKHUNG GLETSCHER SOWIE LHOTSE GLETSCHERENDES - FOTO 29, 31

Die rechte Seitenmoräne des Ama Dablam Gletscher (Foto 29) war nicht durchgängig erhalten und zeigte demnach viele Stellen, die von Schmelzwasser überspült wurden und sie fiel nach Kuhle (2005:Fig. 3) in das historische bis rezente Stadium VIII-XII (400 bis 300 Jahre vor 1950 bis 0 bis +30 Jahre (1950-1980)), nach Finkel et al. (2003:Fig. 1, Proben 3638) ins Lobuche und historische Stadium (vor ca. 1.000 bis vor 500 Jahren v.H.) und nach Iwata (1976:Fig.1) ins Thuklha bis Lobuche Stadium (Thukla: 2.000 bis 6.000 Jahre v.H., Lobuche: 19.-20. Jhd. sowie Kleine Eiszeit, 15.-16. Jhd.). Bei Haffner (1972:Fig. 6) war beim Ort Chhukhung ein breiter Talboden fluvioglazialer Entstehung kartiert, wobei der Ama Dablam mit rezenter Moräne umgeben war. Auf der Karte von Bordet, Latreille (1954-1955) waren fluvioglaziale Materialien auf dem Talboden sowie aktuelle Moränen bei den Gletschern und auf der Karte von Kalvoda (1971-1975) eine fluvioglaziale Terrasse auf dem Talboden bei Chhukhung, Moränen des Changri Typs auf dem unteren Hangbereich sowie bei den Gletschern Moränen des Khumbu Typs und rezente Moränen visualisiert.

Auf Foto 31 kann die orographisch linke Seiten- bis Endmoräne des Ama Dablam Gletscher erkannt werden, die nach Kuhle (2005:Fig.3) in das historische bis rezente Stadium VIII-XII (400 bis 300 Jahre vor 1950 bis 0 bis +30 Jahre (1950-1980)), nach Finkel et al. (2003:Fig. 1, Proben 36-38) ins Lobuche und historische Stadium (vor ca. 1.000 bis vor 500 Jahren v.H.), nach Richards et al. (2000:Fig. 2A, Probe SK 08, Tab. 1) ins 'Late Holocene' (2.500 \pm 400 Jahre v.H.) sowie nach Iwata (1976:Fig. 1) ins Lobuche Stadium (19.-20. Jhd. sowie Kleine Eiszeit, 15.-16. Jhd.) gehörte. Bei Haffner (1972:Fig. 6) war in diesem Bereich ein breiter Talboden fluvioglazialer Entstehung gekennzeichnet, wobei der Ama Dablam mit rezenter Moräne umgeben war. Auf der Karte von Bordet, Latreille (1954-1955) waren fluvioglaziale Materialien auf dem Talboden sowie aktuelle Moränen bei den Gletschern und auf der Karte von Kalvoda (1971-1975) eine fluvioglaziale Terrasse auf dem Talboden, Moränen des Changri Typs auf dem unteren Hangbereich sowie bei den Gletschern Moränen des Khumbu Typs und rezente Moränen visualisiert.

Die Ufer- bis Endmoräne des Chhukhung Gletscher (Foto 29) fiel nach Kuhle (2005:Fig. 3, Tab. 1) ins neoglaziale bis historische Stadium V-X (5.500-4.000 bis 180-30 Jahre vor 1950), nach Finkel et al. (2003:Fig. 1, Fig. 2, 564) ins Lobuche und historische Stadium (vor ca. 1.000 bis vor 500 Jahren v.H.) und nach Iwata (1976:Fig. 1) ins Lobuche Stadium. Bei 
Haffner (1972:Fig. 6) war der Chhukhung Gletscher mit rezenter Moräne umgeben. Auf der Karte von Bordet, Latreille (1954-1955) waren fluvioglaziale Materialien auf dem Talboden und aktuelle Moränen bei den Gletschern und auf der Karte von Kalvoda (1971-1975) Moränen des Khumbu Typs und rezente Moränen visualisiert.

Das Lhotse Gletscherende (Foto 29) war nach Kuhle (2005:Fig. 3) historisch bzw. Stadium VII-X (1.700-400 bis 180-30 Jahre vor 1950) und nach Iwata (1976:Fig. 1) Lobuche Stadium (aus dem 19.-20. Jhd. sowie aus der Kleinen Eiszeit bzw. aus dem 15.-16. Jhd.). Bei Haffner (1972:Fig. 6) war in diesem Bereich ein breiter Talboden fluvioglazialer Entstehung visualisiert, wobei der Lhotse Gletscher mit rezenter Moräne umgeben war. Auf der Karte von Bordet, Latreille (1954-1955) waren fluvioglaziale Materialien auf dem Talboden sowie aktuelle Moränen bei den Gletschern und auf der Karte von Kalvoda (1971-1975) eine fluvioglaziale Terrasse auf dem Talboden, Moränen des Changri Typs auf dem unteren Hangbereich sowie bei den Gletschern Moränen des Khumbu Typs und rezente Moränen kartiert.

\section{$\underline{\text { Schlussfolgerungen }}$}

Die rechte Seitenmoräne des Ama Dablam Gletscher wurde im Gegensatz zu Iwata (1976) und Finkel et al. (2003) von Kuhle als jüngstes Stadium eingeordnet (Foto 29). Die zeitliche Einordnung der linken Seiten- bis Endmoräne des Ama Dablam Gletscher war nach Kuhle (2005) ebenfalls die jüngste, gefolgt von der von Iwata (1976), Finkel et al. (2003) und Richards et al. (2000) (Foto 31). Unter Betrachtung der umgebenden anderen geomorphologischen Formen wie etwa glaziäre Dreieckshänge (Foto 29, 33, 35, 39, 41, 44, 52), Grundmoränen (Foto 29, 33, 34, 35, 36, 39, 41, 44, 52), Mischfächer / -kegel (Foto 35), Sturzmoränenfächer / -kegel (Foto 34, 36 links) sowie Schliffgrenzen (Foto 5, 6, 8, 35, 39, 44, 52, 55) war eine rezente bis historische Einordnung der Moränen in unmittelbarer räumlicher Nähe zu den heutigen Gletschern am wahrscheinlichsten.

Die Spanne des Entstehungszeitraumes der Ufer- bis Endmoräne des vorzeitlich mächtigeren Chhukhung Gletscher und des Lhotse Gletscherendes war nach Kuhle (2005) die größte, wobei jüngste und älteste Entstehungsalter angegeben werden. Ergänzend zu den Befunden von Kuhle (2005:Fig. 3) konnten Sturzmoränenfächer / -kegel (Foto 30, 31, 32) ausgemacht werden. 


\section{OROGRAPHISCH RECHTE UFERMORÄNE DES LHOTSE NUP GLETSCHER UND}

OROGRAPHISCH LINKE UFERMORÄNE DES NUPTSE GLETSCHER - FOTO 28, 30, 32

Das Foto 28 zeigt die orographisch rechte Ufermoräne des Lhotse Nup Gletscher, auf der Finkel et al. (2003:Fig. 1) die Blöcke 39 bis 41 datierten. Der Block Nummer 39 verwies auf ein Alter von über 20.000 Jahren, der Block Nummer 41 auf ein Alter von ca. 53.000 Jahren und der Block 40 auf ein Alter von 25.000 Jahren. Diese Ufermoräne wurde von Finkel et al. in das Pheriche I Stadium $(23.000 \pm 3.000$ Jahre v.H. = globales LGM) eingeordnet. Nach Kuhle (2005:Fig. 3, Foto 70) lag in diesem Bereich eine Grundmoränenterrasse mit erratischen Blöcken des Stadiums 0-IV (60.000-18.000 bis 13.500-13.000 Jahre vor 1950). Auf der Karte von Bordet, Latreille (1954-1955) waren hier Moränen des Changri Typs und auf der Karte von Kalvoda (1971-1975) alte Moränen visualisiert.

Die auf den Fotos 30 und 32 abgebildete Ufermoräne - die orographisch linke des Nuptse Gletscher - teilten die verschiedenen Forscher unterschiedlichen Entstehungszeiten zu. Nach Kuhle (2005:Fig. 3) gehörte diese ins Stadium 0 bis IV / Grundmoräne mit erratischen Blöcken und nach Finkel et al. (2003:Fig. 1) ins Periche I Stadium. Block 45 verwies bei Finkel et al. (2003:Fig. 2) auf ein Alter von über 20.000 Jahren (Periche I Stadium) und Block 46 auf ein Alter von ca. 30.000 Jahren (Thyangboche II Stadium). Die Ufermoräne rechts im Bild wurde nach Kuhle (2005:Fig. 3) in das neoglaziale Stadium VI bis VII gelegt. Auf der Karte von Bordet, Latreille (1954-1955) waren hier alte Moränen und auf der Karte von Kalvoda (1971-1975) Moränen des Changri Typs eingezeichnet. Haffner (1972:Fig. 6) kennzeichnete mäßig steile bis steile Hänge aus pleistozänem Moränenmaterial.

\section{$\underline{\text { Schlussfolgerungen }}$}

Die orographisch rechte Ufermoräne des Lhotse Nup Gletscher wurde von Finkel et al. (2003) trotz des Datenausreißers bezüglich des Blockes Nummer 41 - der eigentlich in das Stadium Thyangboche I (ca. 40.000-90.000 Jahre v.H.) fiel und der somit verursachten auftretenden enormen Schwankungsspanne von 33.000 Jahren - in das Pheriche I Stadium (23.000 \pm 3.000 v.H.) eingeordnet. Kuhle machte in diesem Bereich hingegen eine hoch-spätglaziale Grundmoränenterrasse aus. Ebenso verhielt es sich mit der orographisch linken Ufermoräne des Nuptse Gletscher. Hierbei unterschieden sich wiederum die von Finkel et al. (2003) datierten Blöcke Nummer 45 und 46 bezüglich der zeitlichen Einordnung enorm voneinander. 
Ergänzend zu den Befunden von Kuhle (2005:Fig. 3) konnten Sturzmoränenfächer / -kegel (Foto 30, 31, 32) ausgemacht werden.

OROGRAPHISCH RECHTE IMJA KHOLA TALSEITE - FOTO 33, 34, 35, 39, AUFSCHLUSS 1, PROBE 2

Auf der orographisch rechten Imja Khola Talseite kamen verschiedene Fächer- / bzw. Kegeltypen vor: in den oberen Hangbereichen vorwiegend Sturzschuttfächer / -kegel oder Mischfächer / -kegel sowie auf den mittleren bis unteren Hangbereichen eher Grundmoränenmaterial, welches oft zerschnitten war (Foto 33) oder als Fächer / Kegel postglazial umgelagert wurde. Nach Kuhle (2005:Fig. 3) war das Material auf Foto 33 Grundmoränenmaterial mit nicht erratischen Blöcken - Barnard, Owen, Finkel (2006:Fig. 2) bezeichneten es als 'landslide' und hangaufwärts als 'fan'. Das Foto 34 zeigt den darüber befindlichen Murschuttfächer / -kegel aus disloziertem Schutt- und Moränenmaterial. Nach Kuhle (2005:Fig. 3) war dies ein Schutt- und Murkegel, nach Barnard, Owen, Finkel (2006:Fig. 2) wurde dieser als 'fan’ bezeichnet. Auf der Karte von Bordet, Latreille (19541955) waren fluvioglaziale Materialien auf dem Talboden sowie alte Moränen im unteren Hangbereich und auf der Karte von Kalvoda (1971-1975) eine fluvioglaziale Terrasse auf dem Talboden, Moränen des Dusa Typs auf dem unteren Hangbereich sowie Anstehendes und Schuttkegel aus polygenetischem Detritus im oberen Hangbereich visualisiert. Haffner (1972:Fig. 6) stellte mäßig steile bis steile Hänge aus pleistozänem Moränenmaterial und einen breiten Talboden fluvioglazialer Entstehung dar.

Die Grundmoränenablagerungen zogen sich bis zum Ort Dingboche am orographisch linken Imja Khola Talhang entlang, wobei in Richtung Konfluenzbereich zum Lobuche Khola Ufermoränen ausgemacht werden konnten (Foto 35, 36, 39). Nach Kuhle (2005:Fig. 3) handelte es sich rund um Dingboche um Grundmoränen mit nicht erratischen Blöcken.

\section{$\underline{\text { Schlussfolgerungen }}$}

Auf der orographisch rechten Imja Khola Talseite wurden verschiedene geomorphologische Formen wie Fächer- / Kegeltypen ergänzend zu den Befunden von Kuhle (2005) aufgenommen, wie etwa Sturzschuttfächer / -kegel (Foto 33, 41), Sturzmoränenfächer / -kegel (Foto 33, 34), Mischfächer / -kegel (Foto 33, 35), Murschuttfächer / -kegel (Foto 34), aber daneben auch ein glaziärer Dreieckshang (Foto 41, 44). Die zerschnittene Grundmoräne auf Foto 33 bezeichneten Kuhle (2005) als Grundmoränenmaterial mit nicht erratischen Blöcken 
und Barnard, Owen, Finkel (2006:Fig. 2) als `landslide' und höher darüber liegend als 'fan'. Hierbei konnte sich der Auffassung von Kuhle angeschlossen werden. Die Bezeichnung 'landslide' und 'fan' ließen außerdem keine genaue genetische Deutung zu. Auch der darüber befindliche Murschuttfächer / -kegel aus disloziertem Schutt- und Moränenmaterial wurde von Kuhle (2005) viel genauer als ein Schutt- und Murkegel festgelegt - im Gegensatz zum von Barnard, Owen, Finkel (2006:Fig. 2) hier verwendeten weitläufigen und ungenauen Begriff 'fan'.

Nach Kuhle (2005:Fig. 3) handelte es sich rund um Dingboche um Grundmoränen mit nicht erratischen Blöcken. Anhand des untersuchten Aufschlusses 1 und der entnommenen Sedimentprobe Nummer 2 konnte durch verschiedene Analysen bestätigt werden, dass es sich auf den Hängen um Moränenmaterial handelte. Die darin vorhandenen Granitgesteine in Form von Erratika sprachen jedoch die Grundmoräne als eine mit erratischen Blöcken an.

\section{UFERMORÄNEN BEI DINGBOCHE - FOTO 40}

Auf Foto 40 sind zwei Ufermoränenzüge zu sehen, wobei davon der rechts im Bild (Foto 44 links im Bild, 45, 47) nach Kuhle (2005:Fig. 3) ins neoglaziale Stadium V und nach Finkel et al. (2003:Fig. 1) ins Periche II eingeordnet wurde - der links im Bild (Foto 41) nach Finkel et al. ins Periche I Stadium. Sowohl nach Iwata (1976:Fig. 1) als auch Fushimi (1977:Fig. 11), Fushimi (1978:Fig. 10) und Richards et al. (2000:Fig. 2A, Tab. 1) fielen die auf den Fotos 40, 41, 44 auszumachenden Moränenwälle ins Periche Stadium, nach Müller (1980) ins `Pheriche Stage and older’. Bei Haffner (1972:Fig. 6) waren im Bereich der Ufermoränen mäßig steile bis steile Hänge aus pleistozänem Moränenmaterial gekennzeichnet. Auf der Karte von Bordet, Latreille (1954-1955) waren alte Moränen sowie bei Kalvoda (1971-1975) Moränen des Dusa Typs visualisiert.

\section{$\underline{\text { Schlussfolgerungen }}$}

Die Ufermoräne rechts auf Foto 40 wurde nach Kuhle (2005) gegenüber Finkel et al. (2003) als jüngste eingeordnet. Die Ufermoräne links im Bild fiel nach Finkel et al. (2003), Richards et al. (2000), Müller (1980), Fushimi (1978), Fushimi (1977) und Iwata (1976) ins Periche Stadium, wobei erstgenannte Forscher diese in ein Periche I Stadium legten, und Müller diese Moränen auch älter als Periche einordnete. Auffällig war, dass Richards et al. (2000) sowie auch Finkel et al. (2003) die Periche I Ufermoräne als durchgängig visualisierten, welche jedoch in natura verschiedene Moränenzüge darstellte. Barnard, Owen, Finkel (2006:Fig. 2), Müller (1980:Fig. 3), Fushimi (1977:Fig. 11) und Iwata (1976:Fig. 1) kartierten zwei 
unterschiedliche Moränenzüge, die bei Iwata ins Periche und ins Thyangboche Stadium fielen. Kuhle (2005) visualisierte diese Ufermoräne links auf dem Foto 40 in Fig. 3 nicht. Würde der zeitlichen Einordnung von Kuhle (2005) gefolgt werden, müsste diese in das Stadium V fallen. Die von Finkel et al. (2003) datierten Blöcke 9 bis 11 auf dem Moränenzug (Foto 41, auf dem Foto 40 linker Moränenzug, auf dem Foto 44 rechter Moränenzug) wären bei genaueren Koordinatenangaben zuordbar gewesen (Foto 42, 43). Viele Indizien sprachen aber dafür, dass es sich bei diesen Moränenzügen um jüngere handelte als die meisten Forscher angaben. Somit war die zeitliche Einordnung von Kuhle wohl am wahrscheinlichsten. Dass es sich bei diesen Moränenwällen nicht um hochglaziale handelte, konnte aufgrund der Einbeziehung umgebender Formen wie etwa Grundmoränen auf den Hängen (Foto 5, 6, 8, 18, 22, 35, 39, 41, 44, 52, 57), glaziären Dreieckshängen (Foto 5, 6, 18, 22, 35, 41, 44, 52, 57) sowie durch die höher liegenden Schliffgrenzen (hierzu auch Kuhle 2005:Foto 78) ausgeschlossen werden (Foto 5, 6, 8, 18, 22, 35, 41, 44, 52, 55). Ebenfalls deuteten Fächer- / Kegelformen wie Mischfächer auf verstürztes Moränenmaterial bzw. auf Moränenmaterial auf dem Hang hin, welches oft durch Sturzprozesse von Schutt überlagert wurde (Foto 35, 41, 44, 52), wobei die Sturzschuttfächer auf reines verstürztes Schuttmaterial verwiesen.

\section{TALBODEN / UFERMORÄNEN - FOTO 37, 38}

Auf dem Talboden des Imja Khola wurden in Verbindung mit der glazifluvialen Schotterflur vorwiegend kantengerundete bis gerundete Blöcke mit deutlichen Spülformen in einer verdichteten Matrix ausgemacht (Foto 37, 38).

\section{$\underline{\text { Schlussfolgerungen }}$}

Die vorgefundenen Blöcke mit deutlichen Spülformen konnten als Bestätigung der Befunde anderer Forscher wie etwa Kuhle (2005:Fig. 3) gelten, da diese Blöcke Teil der glazifluvialen Terrasse bei Dingboche waren. Auch auf den Karten von Haffner (1972:Fig. 6), Bordet, Latreille (1954-1955) sowie bei Kalvoda (1971-1975) waren fluvioglaziale Materialien auf dem Talboden visualisiert.

\section{OROGRAPHISCH LINKE IMJA KHOLA TALSEITE - FOTO 35, 36, 38, 39}

Auf der orographisch linken Imja Khola Talseite unterhalb des Berges Ama Dablam waren auf den glaziären Dreieckshängen Schuttansammlungen zu erkennen, die durch Sturzprozesse entstanden und Sturzschuttfächer / -kegel bildeten, aber auch an der Bildung von 
Mischfächern / -kegeln (Foto 35) beteiligt waren. Die Grundmoränen wurden durch Schuttakkumulationen überlagert, wobei daneben jüngere Ufermoränen ausgemacht werden konnten (Foto 35, 36). Die Ufermoräne links auf Foto 35 gehörte nach der zeitlichen Einordnung von Kuhle (2005:Fig. 3) ins Stadium IV (13.500 bis 13.000 Jahre vor 1950). Nach Müller (1980:Fig. 3) fiel diese ins Pheriche Stadium und älter (Spätglazial und älter), nach Iwata (1976:Fig. 1) ins Thyangboche Stadium (Spät- oder Hochglazial der letzten Eiszeit). Bei Barnard, Owen, Finkel (2006:Fig. 2) wurde ein Teil dieser Moränenleiste visualisiert, jedoch von der Endmoräne hinab bzw. hangabwärts gezeichnet. Es handelte sich nach Kuhle (2005:Fig. 3) rund um Dingboche um Grundmoränen mit nicht erratischen Blöcken. Auf der Karte von Bordet, Latreille (1954-1955) waren in diesem Talbereich fluvioglaziale Materialien auf dem Talboden und alte Moränen im unteren Hangbereich sowie neue Moränen im oberen Hangbereich eingezeichnet. Auf der Karte von Kalvoda (19711975) war eine fluvioglaziale Terrasse auf dem Talboden und Moränen des Dusa Typs auf dem unteren Hangbereich sowie Schuttkegel aus polygenetischem Detritus im oberen Hangbereich grafisch dargestellt. Bei Haffner (1972:Fig. 6) waren mäßig steile bis steile Hänge aus pleistozänem Moränenmaterial sowie die dortigen Gletscher mit rezenten Moränen - also ohne den Tsuro Gletscher - gekennzeichnet.

Auf der orographisch linken Imja Khola Talseite talaufwärts vom Ort Dingboche waren Sturzmoränenfächer / -kegel, Murschuttfächer / -kegel und Ufermoränen zu erkennen (Foto 36, 39). Im Sturzschutt waren Solifluktionsprozesse sichtbar.

\section{$\underline{\text { Schlussfolgerungen }}$}

Die Ufermoräne wurde von Kuhle als jüngste eingestuft, wobei aber Iwata und Müller das Spätglazial als möglichen Entstehungszeitraum nicht ausschließen konnten - jedoch gaben diese auch ältere Entstehungszeiträume an. Zusätzlich zu den Befunden von Kuhle (2005:Fig. 3) wurden auf der orographisch linken Imja Khola Talseite bei Dingboche glaziäre Dreieckshänge (Foto 35) und Mischfächer / -kegel (Foto 35) sowie talaufwärts von Dingboche Sturzmoränenfächer / -kegel, Murschuttfächer / -kegel und Solifluktionsprozesse (Foto 36) ausgemacht.

TSURO GLETSCHER - FOTO 35, 36, 38, 40, 46, 48, 49

Im Zungenbereich des Tsuro Gletscher sammelten sich viele kantengerundete bis gerundete Blöcke in Form eines Fächers / Kegels bzw. bei der vorhandenen starken Hangneigung 
verstürzten diese Gesteine und bildeten einen Sturzmoränenfächer / -kegel bzw. einen Sander. Nach Kuhle (2005:Foto 80) wurde die Endmoräne durch 'moraine slides' und 'debris flows' glazifluvial hangabwärts transportiert. Barnard, Owen, Finkel (2006:Fig. 2) bezeichneten den o.g. Fächer / Kegel als `fan’. Bei Haffner (1972:Fig. 6) war dieser Bereich als Gletscherzunge ohne End- oder Seitenmoränen visualisiert, ebenso wie auf der Karte von Bordet, Latreille (1954-1955).

Nach Kuhle (2005:Fig. 3) gehörten die End- bis Seitenmoränen des Tsuro Gletscher in das Stadium VIII bis XII (400 bis 300 Jahre vor 1950 bis 0 bis +30 Jahre (1950-1980)), nach Finkel et al. (Fig. 1) ins Stadium Lobuche und historisch (jünger als 1.000 Jahre bzw. vor etwa 400 bis 500 Jahren v.H.), nach Müller (1980:Fig. 3) war dies Rezentes bis Dughla Stadium (Kleine Eiszeit) sowie nach Iwata (1976:Fig. 1) Lobuche Stadium (19.-20. Jhd. sowie Kleine Eiszeit bzw. 15.-16. Jhd.).

\section{$\underline{\text { Schlussfolgerungen }}$}

Die zeitliche Einordnung der End- bis Seitenmoränen des Tsuro Gletscher waren bei den vorgenannten Forschern in etwa gleich. Weiterführend zu den Befunden von Kuhle zum Thema des Abtransportes der Endmoräne wurde in der vorliegenden Arbeit erwähnt, dass die Blöcke bei der Endmoräne auch verstürzt sein könnten und dadurch Sturzmoränenfächer bildeten. Die Bezeichnung als `fan’ ließ keine genetische Zuordnung zu.

\section{WEITERE GEOMORPHOLOGISCHE ANALYSEN}

\section{GEOMORPHOLOGISCHE KARTE}

Die auf der mit Google Earth erstellten geomorphologischen Karte 8 eingezeichneten Formen im Tal Imja Khola von den Gletschern Nuptse, Lhotse Nup, Lhotse / Imja und Ama Dablam / Chhukhung bis zum Konfluenzbereich zum Lobuche Khola wurden auf der Grundlage von Geländebegehungen und Google Earth Satellitenbildanalysen angesprochen.

Die Befunde von Kuhle (2005:Fig. 3) bestätigten sich mit der vorliegenden Arbeit. Die Bedeutungen der hell- und dunkelgrünen Visualisierungen auf der Karte 3 waren die gleichen wie beim vorherigen Talabschnitt.

Zusätzlich zu den Befunden von Kuhle (2005:Fig. 3) wurden in diesem Talabschnitt folgende Formen ausgemacht: weitere glaziäre Dreieckshänge, weitere deutlich erkennbare Moränenwälle bzw. übrig gebliebene zerschnittene Moränengrate, Blockgletscher / Schuttloben sowie verschiedene Fächer- / Kegeltypen wie etwa Sturzschuttfächer / -kegel 
(Nummer 1 = welche, die Moränenmaterial überlagern (1a) oder von Schnee, Lawinen überlagerte (1b)) oder Sturzfächer / -kegel aus Moränenmaterial oder glazifluvialen Materialien (Nummer 2), Mischfächer / -kegel (Nummer 3 = welche, die präexistierendes Moränenmaterial überlagern (3c) oder von anderen Prozessen überlagerte (3d)), Murfächer / kegel (Nummer $4=$ Murschuttfächer / -kegel mit einem hohen Schuttanteil (4a), Murmoränenfächer / -kegel mit einem hohen Moränenanteil (4b) oder von anderen Prozessen überlagerte (4d)), Schwemmfächer / -kegel (Nummer 5 = Sander aus Moränenmaterial mit Bezug zum Gletscherrand (5b)) und zerschnittene Moränen (Nummer 6). Die Gletscherflächen wurden der topographischen Karte 'Lukla to Everest Base Camp' im Maßstab 1:60.000 entnommen, wobei die Seen den Satellitenbildern von Google Earth entstammen.

Mit der vorliegenden Arbeit fand ebenfalls eine Überprüfung der Befunde von Barnard, Owen, Finkel (2006:Fig. 2) statt. Die farblichen Kennzeichnungen auf Karte 4 entsprechen in ihren Bedeutungen denen des vorhergehenden Talabschnittes - ebenso wurde die begriffliche Schärfung für die Termini 'fan' und 'landslide' hier gleich verwendet. Bei Nummer 11 handelte es sich bei den rot dargestellten Bereichen teilweise um glaziäre Dreieckshänge mit darauf abgelagertem Moränen- / Schuttmaterial bzw. darauf ab- oder vorgelagerte Blockgletscher / Schuttloben. Bei den grünen Bereichen waren es tatsächlich verschiedene Fächer- / Kegeltypen. Bei Nummer 12 handelte es sich bei der hier gekennzeichneten 'landslide' Fläche um Nachbruchgebiete am Rand der glazifluvialen Terrasse, auf der der Ort Dingboche lag. Was Barnard, Owen und Finkel unter der gekennzeichneten 'landslide’ Fläche bei Nummer 13 meinten, blieb offen. In diesem Bereich hangabwärts des Duwo Gletscher waren Murfächer sowie viele Schuttmaterialien $\mathrm{zu}$ erkennen, wobei in letztgenannten stellenweise Blockgletscher / Schuttloben ausgebildet waren. Bei Nummer 14 waren es Nachbruchgebiete im Moränenmaterial.

\section{OBERFLÄCHENBEDECKUNGSKARTEN}

Im Khumbu bzw. im Talabschnitt von den Gletschern Nuptse, Lhotse Nup, Lhotse / Imja und Ama Dablam / Chhukhung bis zum Konfluenzbereich zum Lobuche Khola wurden Oberflächenbedeckungskarten (siehe Karte 5 und 6) erstellt. Die Vorgehensweise und die Ergebnisse waren dabei die gleichen wie im Talabschnitt zuvor beschrieben. 


\subsubsection{Von den Orten Dingboche / Periche zum Ort Pangboche}

Im Talabschnitt von den Orten Dingboche / Periche zum Ort Pangboche wurden 38 Fotos (Foto 48-85) aus einer großen Menge ausgesucht. Die Standorte für die Fotos und Sedimentproben sowie der Verlauf der Talquerprofile können der Karte 9 entnommen werden. Die geomorphologische Analyse im oberen bis mittleren Abschnitt des Tales Imja Khola ergab folgende Ergebnisse für die hocheiszeitliche Vergletscherung:

\section{TALQUERPROFILE UND SCHLIFFGRENZEN}

Das Imja Khola talabwärts der Orte Dingboche / Periche beim Ort Orsho und zwischen den Orten Shomare und Pangboche stellte ein typisches Trogtal mit glazifluvialer Schotterflur bzw. Terrassen dar (Talquerprofil 3, Foto 55, 58 und Talquerprofil 4, Foto 70). Wie bei den Fotos 52, 55, 70, 74 und $83 \mathrm{zu}$ sehen ist, wurden im oberen bis mittleren Imja Khola Tal höchstliegende Schliffgrenzen ausgemacht. Auf den Fotos 75 und 77 sind talabwärts von Pangboche und beim Ort Pangboche keine hochglazialen Schliffgrenzen gekennzeichnet. Die Fotos 52 und 55 bei Periche und Dingboche sowie die Fotos 18, 22, 41 und 44 deuteten auf eine Schliffgrenze auf ca. 5.390 bis 5.400 m Höhe, welche in etwa der von Kuhle (2005:Fig. 22) entsprach. In Bezug zum rezenten, mit Schottern aufgeschütteten Haupttalboden auf ca. 4.350 Höhenmetern ergab sich eine ungefähre hochglaziale Eismächtigkeit von 1.040 bis 1.050 m. Nach Kuhle (2005:Fig. 3/Profil 12, Fig. 22) - der den vorzeitlichen Haupttalboden rekonstruierte - betrug die maximale Eismächtigkeit in diesem Talabschnitt ca. $1.200 \mathrm{~m}$. Auf Foto 83 wurden zwei Schliffgrenzen - eine beim Ama Dablam (wie auch auf den Fotos 5, 6, 8, 35, 94 erkennbar) und eine bei dem Ort Pangboche mit Symbolen gekennzeichnet. Unterhalb des Ama Dablam verwies die Schliffgrenze auf eine Eismächtigkeit von $1.200 \mathrm{~m}$ (Schliffgrenze auf $5.330 \mathrm{~m}$ Höhe, Talboden auf ca. $4.130 \mathrm{~m}$ ). Diese stimmte mit der angegebenen $1.200 \mathrm{~m}$ mächtigen rekonstruierten Eisdecke von Kuhle (2005:Fig. 3/Profil 15) überein. Die Schliffgrenze bei Pangboche belegte ein ungefähres hochglaziales Gletscherlimit auf ca. 5.050 m Höhe. Bei einem rezenten Talboden auf ca. 4.000 Höhenmetern ergab das eine hochglaziale Eismächtigkeit von ca. 1.050 m. Dieses Ergebnis stimmte in etwa mit dem von Kuhle (2005:Fig. 3) überein. Er kam durch das Profil 17 auf eine Eismächtigkeit von 900 m. Weitere Schliffgrenzen beim Ort Pangboche (Foto 70 und 74) verwiesen auf ein hochglaziales Gletscherlimit auf ca. $4.700 \mathrm{~m}$ Höhe (Foto 70) und ca. $5.050 \mathrm{~m}$ (Foto 74). Bei einem rezenten Talboden auf ca. 3.680 Höhenmetern und auf ca. $4.000 \mathrm{~m}$ ergab dieses hochglaziale Eismächtigkeiten von ca. $1.020 \mathrm{~m}$ (Foto 70) und $1.050 \mathrm{~m}$ (Foto 74). Diese Ergebnisse stimmten ebenfalls in etwa mit denen von Kuhle (2005:Fig. 3) überein. Er kam 
durch das talaufwärtigere Profil 22 auf eine Eismächtigkeit von 1.250 m, im Nachbartal des Ngozumpa Drangka durch das Profil 26 auf eine Eismächtigkeit von 1.000 m sowie durch das Profil 17 auf eine Eismächtigkeit von 900 m.

\section{WEITERE GEOMORPHOLOGISCHE FORMEN}

Neben den Schliffgrenzen konnten im oberen bis mittleren Teil des Imja Khola talabwärts der Orte Periche und Dingboche folgende Formen nachgewiesen werden: Ufermoränen (Foto 49, 52, 57, 70, 71, 73, 74, 75, 76, 77, 80, 82, 84), Seiten- bis Endmoräne (Foto 48), Sanderflächen (Foto 48, 49, 52), glaziäre Dreieckshänge (Foto 52, 57, 71, 74, 75, 76, 83, 85), Grundmoränenmaterial (Foto 52, 54, 55, 57, 59, 60, 67, 73, 74, 76, 77, 79, 80, 83, 85), Sturzschuttfächer / -kegel (Foto 52), Sturzfächer / -kegel aus Moränenmaterial und glazifluvialem Material (Foto 48, 49, 52, 55, 56, 57, 70, 71, 74, 75, 77, 78, 80, 82, 85), Mischfächer / -kegel (Foto 52), Murmoränenfächer / -kegel (Foto 67, 74, 80), glazifluviale Terrassen (Foto 49, 50, 52, 53, 55, 57, 58, 61, 66, 80, 83, 85) sowie Blöcke (Foto 51, 53, 54, 56, 69), oft in Rundhöckerform (Foto 51) oder mit glazifluvialen Spülformen (Foto 56, 69, 73), und glazial überschliffenes anstehendes Gestein, oft mit glazifluvialen Spülformen (Foto 62, 63, 64, 65, 67, 68, 72, 84) bzw. Strudeltöpfe (Foto 67).

\section{SEDIMENTPROBEN UND AUFSCHLÜSSE}

Im Talabschnitt von den Orten Dingboche / Periche bis zum Ort Pangboche wurden zwei Sedimentproben (3. Probe, Foto 57; 4. Probe, Foto 81) entnommen und ein Aufschluss (2. Aufschluss, Foto 81) untersucht.

\section{ABGLEICH DER BEFUNDE MIT ANDEREN FORSCHUNGSARBEITEN UFERMORÄNEN TALABWÄRTS VON PERICHE}

Die Ufermoränen talabwärts von Periche auf der orographisch linken und rechten Lobuche Khola Talseite (Foto 49, 50) gehörten nach Kuhle (2005:Fig. 3) dem neoglazialen Stadium V an. Iwata (1976), Fushimi (1977, 1978), Müller (1980), Richards et al. (2000), Finkel et al. (2003) und Barnard, Owen, Finkel (2006) ordneten sie älteren Stadien zu.

\section{TERRASSEN UND FÄCHER BEI ORSHO}

Talabwärts der Ufermoränen südlich von Periche entstanden glazifluviale Terrassen (Foto 49, 50, 52, 53, 55, 57). Auf dem Foto 50 sind die von Barnard, Owen, Finkel (2006) in Fig. 6 ausgewiesenen Terrassen to1, to4, to5, to6 und der Fächer fo1, auf dem Foto 55 die Terrassen 
to1, to2, to 3 und to6 und auf dem Foto 57 die Terrassen to 3 und to6 zu sehen. Terrasse to 3 war laut Fig. 6 rund 4.400 Jahre, to4 rund 4.800 Jahre und to6 rund 11.000 Jahre alt. Das Alter der Terrassen to1, to2 und to5 und des Fächers fo1 waren Fig. 6 und Tab. 1 nicht zu entnehmen und wurden folglich nicht beprobt.

Auf den nach Barnard, Owen, Finkel (2006:Fig. 6) ausgewiesenen Terrassen to2 (Foto 56), to3 (Foto 58) und to6 (Foto 53, 54) lagen Blöcke, oft mit glazifluvialen Spülformen versehen. Einige davon wurden von ihnen beprobt.

\section{$\underline{\text { Schlussfolgerungen }}$}

Die Terrassen bei Orsho wurden mit der vorliegenden Arbeit zwar wie von Barnard, Owen, Finkel (2006) als glazifluviale Terrassen angesprochen, der Fächer jedoch nicht insgesamt als solcher erkannt. Auch auf der Karte von Kalvoda (1971-1975) wurde eine fluvioglaziale Terrasse visualisiert. Kuhle (2005:Fig. 3) kartierte direkt in diesem Talbereich keinerlei Gletschertorschotterfluren / Gletschertorschotterflurterrassen, jedoch weiter talabwärts beim Ort Pangboche solche der Stadien 1 bis -8. Müller (1980:Fig. 3) stellte auf beiden Talseiten vorwiegend Moränen des Periche Stadiums und ältere dar, Iwata (1976:Fig. 1) auf der orographisch linken Imja Khola Seite lediglich Thyangboche und unklassifizierte Moränen.

Bei den Terrassen to3, to4 und to6 von Barnard, Owen, Finkel (2006) fiel anhand der Daten in Tab. 1 auf, dass diese enorm schwankten: bei to 4 von ca. 4.000 bis ca. 35.000 und bei to6 von ca. 10.000 bis ca. 14.000 Jahre. Das hieß, dass die Alter in der Spanne von 4.000 bis 35.000 Jahren schwankten, aber trotz dessen ein Alter, ohne das Ausreißer mit berücksichtigt waren, angegeben wurde. Dieser von Barnard, Owen und Finkel als solcher bezeichnete 'fan' fo1 stellte wohl eher einen glaziären Dreieckshang mit überlagerter zerschnittener Grundmoräne und wenigen Schuttpartikeln, die von oberen Hangbereichen aus dem Anstehenden stammten, dar. Auf jeden Fall stellten nicht der gesamte Hang, sondern nur einzelne Partien einen typischen Fächer dar. Auch Kuhle (2005:Fig. 3) verwies auf einen glaziären Dreieckshang, auf dem Grundmoränen mit erratischen Blöcken vorkamen.

Bei den der von Barnard, Owen, Finkel (2006:Fig. 6) ausgewiesenen Terrasse to6 aufliegenden Blöcken war nicht eindeutig, ob es sich bei diesen um solche der von ihnen untersuchten (E 12, E 13 oder E 14) in diesem Umfeld handelte. Genauere Koordinatenangaben hätten den Standort der von ihnen untersuchten Blöcke präzisieren können. Dass es sich bei dem Block auf Terrasse to3 um einen der von ihnen untersuchten 
Blöcke (E 18 bis E 20) handelte, konnte anhand Fig. 6 ausgeschlossen werden, da die datierten Blöcke direkt am Rand zur darunterliegenden Terrasse to2 eingezeichnet waren. Jedoch war dieses der größte Block auf Terrasse to 3 und weitere kleinere lagen nordöstlich von diesem. Es wird sich wohl bei dem in der vorliegenden Arbeit dazu fotografierten Block um den von ihnen datierten Block E 18 handeln. Exakte Standortangaben hätten zur Präzisierung bzw. Eindeutigkeit beigetragen.

$\mathrm{Zu}$ den Befunden von Kuhle (2005:Fig. 3) wurden beim Ort Orsho außerdem folgende Formen ausgemacht: glazifluviale Terrassen (Foto 49, 50, 52, 53, 55, 57), Blöcke in Form eines Rundhöckers (Foto 51) oder mit deutlich glazifluvialen Spülformen (Foto 56) sowie Sturzfächer aus Moränenmaterial und glazifluvialen Materialien (Foto 55, 56, 57). Talabwärts von Orsho bis Pangboche wurden am Hang durch Erosionsrinnen zerschnittenes Grundmoränenmaterial bzw. in den oberen Schichten zerschnittenes disloziertes Moränenmaterial bzw. ein Sturzfächer (Foto 59, 60), Murmoränenfächer / -kegel (Foto 67), Sturzfächer aus Moränenmaterial und glazifluvialen Materialien (Foto 71), gerundete bis gut gerundete Gesteine (Foto 66), Blöcke mit glazifluvialen Spülformen (Foto 69, 73), glazifluviale Terrassen (Foto 61, 69), geschliffenes Anstehendes zumeist mit glazifluvialen Spülformen (Foto 61, 62, 63, 64, 65, 67, 68, 71) sowie Strudeltöpfe (Foto 67) kartiert.

\section{TERRASSEN UND FÄCHER BEI PANGBOCHE}

Die Fotos 70, 74-81, 83, 85 zeigen insgesamt die von Barnard, Owen, Finkel (2006:Fig. 3) ausgewiesenen Terrassen tp1-7 und Fächer fp1 und fp3 rund um den Ort Pangboche. Nach Kuhle (2005:Foto 87) gehörten die Schotterflurterrassen in das Stadium 1 bis -8. Laut Barnard, Owen, Finkel (2006:Fig. 6) handelte es sich bei der Terrasse, auf der der untere Teil von Pangboche lag, um die ca. 8.500 Jahre alte tp6, und bei der, auf der der obere Teil von Pangboche lag, um tp7. Unterhalb von tp6 waren jüngere Terrassen ausgebildet - nach den Forschern die Terrassen tp5, tp4 und tp2. Für tp5 wurde kein Alter durch TCN-Datierung ermittelt, für tp4 jedoch ein Alter von ca. 5.800 Jahren und für tp2 eines von ca. 300 Jahren.

Auf der orographisch linken Imja Khola Talseite waren ebenfalls Terrassen ausgebildet: nach Barnard, Owen, Finkel (2006:Fig. 3) waren das die Terrassen tp7 mit einem Alter von 12.300 Jahren, tp6 mit 7.800 Jahren sowie tp3 mit 1.500 Jahren. Daneben datierten sie einen Fächer fp1 auf ca. 13.600 Jahre. Die Forscher idealisierten die Werte der Terrasse tp6 auf etwa 8.100 Jahre und die bei tp7 auf etwa 12.000 Jahre. Der Fächer fp3 war laut Barnard, Owen, Finkel (2006:Fig. 3) etwa 57.600 Jahre alt (Foto 85). 


\section{$\underline{\text { Schlussfolgerungen }}$}

Der untere Teil des Ortes Pangboche lag auf einer glazifluvialen Terrasse, so wie sie auch Kuhle (2005) und Barnard, Owen, Finkel (2006) kennzeichneten. Die Sortierung des Materials war sehr gering, nur an wenigen Stellen war eine solche zu erkennen (Foto 74, 75, 78, 80). Die darunter liegenden Terrassen waren ebenfalls glazifluviale und die darüber liegende Terrasse zeigte sich stellenweise als Grundmoränenterrasse (Foto 79), auf der sich ein Fächer aus Moränenmaterial postglazial bildete (Foto 74, 76). Somit handelte es sich bei der Terrasse tp6, auf der der untere Teil des Ortes Pangboche lag, übereinstimmend um eine glazifluviale, aber bei der darüber liegenden Terrasse tp7 wohl teilweise um eine Grundmoränenterrasse. Kuhle (2005:Foto 88, 89) machte bei Pangboche ab einer Höhe von $4.400 \mathrm{~m}$ Grundmoränenmaterial mit erratischen Turmalingranitblöcken, neben verschiedenen Phylliten und Gneisen, aus; weiter westsüdwestlich von Pangboche schon in einer Höhe von $4.100 \mathrm{~m}$ (ebd.:Foto 92, 93). Die 4. Sedimentprobe und der 2. untersuchte Aufschluss bei Pangboche zeigten, dass auch oberhalb des unteren Teiles des Ortes glazifluviales Material auftrat. In diesem Bereich verwiesen Barnard, Owen, Finkel (2006:Fig. 3) auf einen Fächer fp3. Dass dieser Talbereich einstmalig enorm vergletschert war, konnte an den oberhalb der Terrassen existierenden glaziären Dreieckshängen mit darauf abgelagerten Grundmoränen festgemacht werden. Hierdurch wurde ersichtlich, dass es sich bei dem von Barnard, Owen, Finkel (2006:Fig. 3) festgelegten Fächer nicht um einen solchen handelte, sondern um einen glazialen Dreieckshang mit darauf abgelagerten Grundmoränen und davor gelagerter glazifluvialer Terrasse.

Die von ihnen auf beiden Talseiten insgesamt gekennzeichneten Terrassen 1-7 verwiesen auf unterschiedliche Alter. Die Alter der Terrassen tp6, tp4 und tp2 wurden in Fig. 3 ungefähr festgelegt, obwohl die Werte in Tab.1 Schwankungen aufzeigten. Die Werte von tp6 (Blöcke E 109 bis 111) schwankten von etwa 8.000 bis 22.000 Jahren, die von tp4 (Blöcke E 118 und 119) von etwa 6.000 bis 10.000 Jahren und die von tp2 (Blöcke E 105 und 106) von etwa 200 bis 1.300 Jahren. Nach Kuhle (2005:Foto 87) gehörten die Schotterflurterrassen in das Stadium 1 bis -8 (spätglazial bzw. 13.500 bis 13.000 Jahre vor 1950 bis rezent bzw. bis 1950). Demnach meinte Kuhle, dass die Terrassen auch älter als für tp6 bei Barnard, Owen, Finkel (2006) angegeben und auch jünger als für tp2 angegeben sein könnten. Wie alt die bei Barnard, Owen, Finkel (2006) angeführte Terrasse tp1 war, blieb ungeklärt.

Auf der orographisch linken Imja Khola Talseite wurden die Alter der Terrassen tp7, tp6, tp3 und des Fächers fp1 ebenfalls nur ungefähr in Fig. 6 festgelegt, obwohl die Werte dafür in 
Tab.1 Schwankungen aufzeigten. Die Werte von tp7 (Blöcke E 95 bis 98) schwankten von etwa 12.000 bis 13.000 Jahren, die von tp6 (Blöcke E 99 bis 101) von etwa 7.700 bis 7.800 Jahren, die von tp3 (Blöcke E 102 bis 104) von etwa 1.300 bis 1.800 Jahren und die von fp1 (Blöcke E 107 bis 108) von etwa 9.000 bis 14.000 Jahren. Selbst dass die niveaumäßig gleich hohen Terrassen auf der orographisch rechten und linken Talseite nicht dasselbe Alter, sondern Schwankungen aufzeigten - tp6 bei Pangboche ca. 8.500 Jahre, aber bei Yaral ca. 7.800 Jahre und tp7 bei Pangboche ca. 11.800 Jahre, aber bei Yaral ca. 12.300 Jahre - ließ die Ergebnisse der Datierungen fraglich erscheinen. Barnard, Owen und Finkel idealisierten die Werte der Terrasse tp6 auf etwa 8.100 Jahre und die bei tp7 auf etwa 12.000 Jahre. Die Werte von tp7 bei Pangboche (Blöcke E 112 bis 114) schwankten von etwa 11.000 bis 14.000 Jahren, die von tp7 bei Yaral (Blöcke E 95 bis 98) von etwa 12.000 bis 13.000 Jahren und die von fp3 bei Pangboche (Blöcke E116 und 117) von etwa 50.000 bis 130.000 Jahren.

Ergänzend zu den Befunden von Kuhle (2005) konnten rund um den Ort Pangboche neben Erosionsrinnen (Foto 75, 76, 80) folgende Formen aufgenommen werden: Sturzfächer aus Moränenmaterial und glazifluvialen Materialien (Foto 70, 74, 75, 76, 77, 78, 80, 82, 85), ein Murschuttfächer / -kegel (Foto 80), glaziäre Dreieckshänge (Foto 74, 75, 76, 83, 85), Uferbis Endmoränen (Foto 74, 75, 76, 77, 80), zerschnittenes Grundmoränenmaterial (Foto 79) und geschliffenes Anstehendes mit glazifluvialen Spülformen (Foto 84; Kuhle 2005:Fig. 3 kennzeichnete in diesem Bereich Rundhöcker und Strudeltöpfe).

\section{GRUNDMORÄNENABLAGERUNGEN BEI PANGBOCHE}

Die auf dem Foto $74 \mathrm{zu}$ erkennende orographisch rechte Imja Khola Talseite war durch glaziäre Dreieckshänge und darauf abgelagerte Grundmoränen gekennzeichnet. Nach Müller (1980:Fig. 3) sollen diese Moränen aus dem Pheriche Stadium und älter (Spätglazial und älter) stammen. Nach Kuhle (2005:Fig. 3; Foto 88, 89 und 92) waren es hochglaziale (60.000 bis 18.000 Jahre vor 1950) Grundmoränen mit erratischen Blöcken - die Blöcke waren neben anstehendem Schiefer, Phyllit und Gneis über $6 \mathrm{~km}$ transportierter erratischer Turmalingranit.

\section{$\underline{\text { Schlussfolgerungen }}$}

Die Einordnung dieser Moränen am Hang war nach Kuhle (2005) eine hochglaziale und nach Müller (1980) eine spätglaziale oder ältere. Infolgedessen legte sich letztgenannter Forscher zeitlich nicht genau fest. Ebenfalls spezifizierte er keinen Moränentyp, sodass nicht eindeutig war, ob es sich um Grund- oder um Ufermoränenablagerungen handelte. Die Visualisierung 
der Moränen in Fig. 3 ließ jedoch darauf schließen, dass es sich um Moränenrücken bzw. um Ufermoränen handelte, da beispielsweise die Moränen bei Periche dieselbe Zuordnung aufwiesen. Wenn es sich also bei Müller (1980) um Ufermoränen handelte - die nach seiner zeitlichen Einordnung ins Spätglazial und älter fielen - müssen diese durch Nebentalgletscher entlang der Hänge entstanden sein: die Ausbildungen bzw. Formungen der Moränenrücken ließen keine Entstehung durch einen Haupttalgletscher zu, sonst wären sie parallel zum Haupttalboden bzw. höhenlinienparallel angeordnet. Insofern war nicht verständlich, warum Müller (1980) beispielsweise die dem Haupttalboden parallelen Ufermoränen bei Periche die nicht durch Nebentalgletscher, sondern durch den Haupttalgletscher entstanden derselben Entstehungszeit zuordnete. Nebentalgletscher können nicht zeitgleich weiter talabwärts gereicht haben als ein mächtiger Haupttalgletscher. Aufgrund dessen war die von Müller (1980) angegebene zeitliche Einordnung der Ufermoränen zu hinterfragen; dass dort Ufermoränen existieren, stand jedoch außer Frage. Es traten neben diesen auch flachausgebildete Grundmoränen am Hang auf, die, wie Kuhle belegte, den maximalen hochglazialen Vergletscherungsstand anzeigten.

\section{WEITERE GEOMORPHOLOGISCHE ANALYSEN GEOMORPHOLOGISCHE KARTE}

Die auf der mit Google Earth erstellten geomorphologischen Karte 10 eingezeichneten Formen im Tal Imja Khola im Talabschnitt von den Orten Dingboche / Periche bis zum Ort Pangboche wurden auf der Grundlage von Geländebegehungen und Google Earth Satellitenbildanalysen angesprochen.

Die Befunde von Kuhle (2005:Fig. 3) bestätigten sich mit der vorliegenden Arbeit. Die Bedeutungen der hell- und dunkelgrünen Visualisierungen auf der Karte 11 waren die gleichen wie beim vorherigen Talabschnitt.

Zusätzlich zu den Befunden von Kuhle (2005:Fig. 3) wurden in diesem Talabschnitt folgende Formen ausgemacht: geschliffenes Anstehendes oft mit glazifluvialen Spülformen, ein Strudeltopf, glazifluviale Terrassen, Rundhöcker, weitere glaziäre Dreieckshänge, weitere deutlich erkennbare Moränenwälle bzw. übrig gebliebene zerschnittene Moränengrate, Blockgletscher / Schuttloben sowie verschiedene Fächer- / Kegeltypen wie etwa Sturzschuttfächer / -kegel (Nummer 1 = welche, die Moränenmaterial überlagern (1a) oder von Schnee, Lawinen überlagerte (1b)) oder Sturzfächer / -kegel aus Moränenmaterial oder glazifluvialen Materialien (Nummer 2), Mischfächer / -kegel (Nummer 3 = hauptsächlich aus Schutt (3a), welche, die präexistierendes Moränenmaterial überlagern (3c) oder von anderen 
Prozessen überlagerte (3d)), Murfächer / -kegel (Nummer 4 = Murmoränenfächer / -kegel mit einem hohen Moränenanteil (4b), ), Murschwemmfächer / -kegel mit viel Feinmaterial (4c)), Schwemmfächer / -kegel (Nummer 5 = Schwemmschuttfächer / -kegel mit Schutt- und Moränenmaterial (5a), Sander aus Moränenmaterial mit Bezug zum Gletscherrand (5b), Schwemmfächer / -kegel aus hauptsächlich Moränenmaterial (5c)) und zerschnittene Moränen (Nummer 6). Die Gletscherflächen wurden der topographischen Karte 'Lukla to Everest Base Camp' im Maßstab 1:60.000 entnommen, wobei die Seen den Satellitenbildern von Google Earth entstammen.

Die Befunde von Barnard, Owen, Finkel (2006:Fig. 2) überprüfte die vorliegende Arbeit ebenfalls. Die farblichen Kennzeichnungen auf Karte 4 entsprechen in ihren Bedeutungen denen des vorhergehenden Talabschnittes - ebenso war die begriffliche Schärfung für die Termini 'fan' und 'landslide' hier gleich verwendet. Die bei Nummer 7 gekennzeichneten 'landslide' Flächen wurden in der vorliegenden Arbeit als Nachbruchgebiete im Moränenmaterial und als Sander bezeichnet. Bei Nummer 8 war nicht eindeutig, was die Forscher mit dem angegeben 'landslide' meinten; es kamen dort Schuttakkumulationen - mit Blockgletschern / Schuttloben - und Moränenmaterial vor. Nummer 9 verwies ebenfalls auf Bewegungen in den Schuttmaterialien. Bei den 'landslide' Bereichen bei Nummer 10 handelte es sich um Nachbruchgebiete im Moränen- und glazifluvialen Material.

\section{OBERFLÄCHENBEDECKUNGSKARTEN}

Im Khumbu bzw. im Talabschnitt von den Orten Dingboche / Periche bis zum Ort Pangboche wurden Oberflächenbedeckungskarten (siehe Karte 12 und 13) erstellt. Die Vorgehensweise und die Ergebnisse waren dabei die gleichen wie im ersten Talabschnitt beschrieben.

\subsubsection{Vom Ort Pangboche bis zu den Orten Phortse / Tengboche}

Im Talabschnitt vom Ort Pangboche bis zu den Orten Phortse / Tengboche wurden 22 Fotos (Foto 86-107) aus einer großen Anzahl ausgesucht. Die Standorte für die Fotos und die Sedimentproben sowie der Verlauf der Talquerprofile können der Karte 14 entnommen werden. Die geomorphologische Analyse im mittleren Abschnitt des Tales Imja Khola ergab folgende Ergebnisse für die hocheiszeitliche Vergletscherung:

\section{TALQUERPROFILE UND SCHLIFFGRENZEN}

Das Imja Khola talabwärts des Ortes Pangboche stellte ein Trogtal mit glazifluvialer Schotterflur bzw. Terrassen dar (Talquerprofil 5, Foto 94, 97, 101). Wie bei den Fotos 97, 
106, aber auch beim Foto $123 \mathrm{zu}$ sehen ist, wurden im mittleren Imja Khola Tal höchstliegende Schliffgrenzen im Talabschnitt zwischen den Orten Pangboche und Phortse / Tengboche ausgemacht. Die Schliffgrenze auf der orographisch linken Imja Khola Talseite bei Tengboche verwies auf ein ungefähres Gletscherlimit auf ca. 4.440 m (Foto 79, 123). Bei einem rezenten Talboden auf ca. 3.640 m Höhe ergab das eine hochglaziale Eismächtigkeit von ca. 800 m. Dieses Ergebnis stimmte in etwa mit dem von Kuhle (2005:Fig. 3) überein. Er kam durch das talaufwärtigere Profil 22 auf eine Eismächtigkeit von $1.250 \mathrm{~m}$ und im Nachbartal des Bhote Koshi durch das Profil 26 auf eine Eismächtigkeit von 1.000 m. Die Schliffgrenze auf der orographisch linken Imja Khola Talseite (Foto 70 und 123) verwies hingegen auf ein ungefähres hochglaziales Gletscherlimit auf ca. 4.700 Höhenmetern. Bei einem rezenten Talboden auf ca. 3.680 m Höhe ergab dies eine hochglaziale Eismächtigkeit von ca. 1.020 m. Das Ergebnis stimmte in etwa mit dem von Kuhle (2005:Fig. 3) überein. Er kam durch das talaufwärtigere Profil 22 auf eine Eismächtigkeit von $1.250 \mathrm{~m}$ und im Nachbartal des Ngozumpa Drangka durch das Profil 26 auf eine von $1.000 \mathrm{~m}$. Die Schliffgrenze auf der orographisch rechten Imja Khola Talseite bei Deboche (Foto 106) auf ca. $4.600 \mathrm{~m}$ Höhe deutete bei einem rezenten Talboden bei ca. $3.600 \mathrm{~m}$ auf eine hochglaziale Eismächtigkeit von $1.000 \mathrm{~m}$ hin (nach Kuhle 2005:Fig. 3/Profil $17900 \mathrm{~m}$ hochglaziale Eismächtigkeit).

\section{WEITERE GEOMORPHOLOGISCHE FORMEN}

Neben den ausgemachten Schliffgrenzen konnten im oberen bis mittleren Teil des Imja Khola talabwärts der Orte Periche und Dingboche folgende Formen ausgemacht werden: Ufermoränen (Foto 89, 97, 98, 99, 100, 107), glaziäre Dreieckshänge (Foto 97, 106, 107), Grundmoränenmaterial (Foto 97, 98, 99, 100, 101, 103, 104), Sturzschuttfächer / -kegel (Foto 95, 107), Sturzfächer / -kegel aus Moränen- und glazifluvialem Material (Foto 90, 91, 94, 97, 101, 102), Murfächer / -kegel aus Moränen- und glazifluvialem Material (Foto 89), glazifluviale Terrassen (Foto 96, 97, 101, 102) sowie erratische Blöcke (Foto 92, 105) und glazial überschliffenes anstehendes Gestein, oft mit glazifluvialen Spülformen (Foto 86, 87, 88, 94, 95, 96, 97,101, 102) bzw. Strudeltöpfe (Foto 93).

\section{SEDIMENTPROBEN UND AUFSCHLÜSSE}

Im Talabschnitt vom Ort Pangboche bis zu den Orten Phortse / Tengboche wurden keine Sedimentproben entnommen und kein Aufschluss untersucht. 


\section{ABGLEICH DER BEFUNDE MIT ANDEREN FORSCHUNGSARBEITEN OROGRAPHISCH RECHTE UFERMORÄNE DES OMOGA GLETSCHER}

Die orographisch rechte Ufermoräne des Omoga Gletscher gehörte nach Kuhle (2005:Fig. 3) ins spätglaziale Stadium IV, aber nach Müller (1980:Fig. 3) waren talaufwärts vorkommende Moränen am orographisch linken Imja Khola Talhang aus dem Pheriche Stadium und älter (Foto 84, 89). Auf dem Foto 73 sind fünf Ufermoränenzüge zu sehen. Vier waren orographisch rechte Ufermoränen und eine war eine orographisch linke Ufermoräne des vorzeitlich mächtigeren Omoga Gletscher. Nach Kuhle (2005:Fig. 3) gehörten diese dem spätglazialen Stadium IV an. Richards et al. (2000:Fig. 2) kartierten Ufermoränen ebenfalls im Minmo Khola.

\section{$\underline{\text { Schlussfolgerungen }}$}

Es konnte sich bei den Ufermoränen des Omoga Gletscher der zeitlichen Einordnung von Kuhle (2005) angeschlossen werden. Hierfür sprachen die glazialgeomorphologischen Formen, die rund um diese Moränen aufgefunden wurden und die für eine mächtigere hochglaziale Vergletscherung sprachen. Darunter zählten beispielsweise Grundmoränen, glaziäre Dreieckshänge oder Schliffgrenzen (Foto 97, 103-107). Da bei Müller (1980) in Fig. 3 nur talaufwärts Moränen des Periche Stadiums und älter eingezeichnet waren, blieb ungeklärt, ob er diese Moränen ebenfalls in dieses Stadium eingeordnet hätte.

\section{OROGRAPHISCH RECHTE UFERMORÄNE DES PHUNKI GLETSCHER}

Die Ufermoräne bei Tengboche (Foto 108, 109; Sicht auf die Ufermoräne: Foto 84, 97, 127; Sicht von der Ufermoräne: Foto 107, 110; im Konfluenzbereich zum Imja Khola: Foto 111 114) gehörte nach Kuhle (2005:Fig. 3) in das spätglaziale Stadium III (14.250 bis 13.500 Jahre vor 1950). Bei Heuberger (1956:Fig. 2) war diese ebenfalls als eine spätglaziale Wallmoräne angegeben, was jedoch inzwischen unerheblich ist, da die Arbeit vom Verfasser zurückgenommen wurde. Iwata (1976) visualisierte zwar in Fig. 6 eine Endmoräne beim Ort Thyangboche und ging auch im Text auf Thyangboche Moränen ein, kennzeichnete sie aber in Fig. 1 nicht. Nach Fig. 2 bei Finkel et al. (2003) fielen die Thyangboche Stadien hingegen in einen Zeitraum von ca. 25.000 bis ca. 90.000 Jahren v.H.. Richards et al. (2000) visualisierten die Ufermoräne bei Tengboche in Fig. 2. Die von Richards et al. (2000:Fig. 2B, Fig. 5F, Proben SK 16-18) auf der orographisch rechten Pungi Khola Talseite entnommenen Proben zeigten OSL-Alter von $21.300 \pm 2.700$ Jahren, $24.400 \pm 2.500$ und $25.300 \pm 6.900$ 
Jahren, diese also in das Periche Stadium fielen. Iwata und Richards et al. - aber auch Heuberger - gingen davon aus, dass diese Moräne bei Tengboche eine Endmoräne darstellte.

\section{$\underline{\text { Schlussfolgerungen }}$}

Die Ufermoräne bei Tengboche stellte keine Endmoräne des vorzeitlichen Haupttalgletschers, sondern die orographisch rechte Ufermoräne des vorzeitlichen Nebentalgletschers Punki dar. Nach Kuhle (2005) wurde sie als jüngste angenommen, wobei auch Iwata (1976) als Entstehungszeit das Spätglazial nicht ausschloss. Iwata ordnete nämlich diese Ufermoräne ins Thyangboche Stadium ein, wobei er damit den Zeitraum Spät- oder Hochglazial meinte. Nach Fig. 2 bei Finkel et al. (2003) fielen die Thyangboche Stadien in einen Zeitraum von ca. 25.000 bis ca. 90.000 Jahren v.H.. Nach Richards et al. (2000) fiel die Moräne ins Periche Stadium (ca. 18.000 bis 25.000 Jahre v.H.). Die Alter der drei OSL-Proben wiesen hier jedoch Schwankungen von bis zu 4.000 Jahren auf. Die Probenahmestellen für die Proben SK 16 bis 18 lagen bei Richards et al. (2000:Fig. 2B) auf einer Höhe zwischen 3.400 und 3.600 m, bei Fig. 5F jedoch auf etwa $3.830 \mathrm{~m}$. Wo sich die Probenahmestellen genau befanden, konnte nicht geklärt werden (siehe Foto 109).

Im Weiteren zu den Befunden von Kuhle (2005:Fig. 3) wurden zwischen den Orten Pangboche und Phortse / Tengboche folgende Formen ausgemacht: geschliffenes Anstehendes zumeist mit glazifluvialen Spülformen (Foto 86, 87, 88, 93, 94, 95, 96, 97, 101, 102), Strudeltöpfe (Foto 93; Kuhle 2005:Fig. 3 machte in diesem Bereich ebenfalls Strudeltöpfe und Rundhöcker aus), Sturzfächer aus Moränenmaterial und glazifluvialen Materialien (Foto 89, 90, 91, 94, 97, 101), Sturzschuttfächer / -kegel (Foto 95, 107), glazifluviale Terrassen (Foto 96, 97, 101, 102), glaziäre Dreieckshänge (Foto 97, 106, 107, 123), zerschnittenes Ufer- und Grundmoränenmaterial (Foto 98, 99, 100). Die von Kuhle (2005:Fig. 3) gekennzeichneten Grundmoränen mit erratischen Blöcken konnten bestätigt werden (Foto 92, 103, 105).

\section{WEITERE GEOMORPHOLOGISCHE ANALYSEN}

\section{GEOMORPHOLOGISCHE KARTE}

Die auf der mit Google Earth erstellten geomorphologischen Karte 15 visualisierten Formen im Tal Imja Khola im Talabschnitt vom Ort Pangboche bis zu den Orten Phortse / Tengboche wurden auf der Grundlage von Geländebegehungen und Google Earth Satellitenbildanalysen angesprochen. 
Die Befunde von Kuhle (2005:Fig. 3) bestätigten sich mit der vorliegenden Arbeit. Die Bedeutungen der hell- und dunkelgrünen Visualisierungen auf der Karte 16 waren die gleichen wie beim vorherigen Talabschnitt.

Ergänzend zu den Befunden von Kuhle (2005:Fig. 3) wurden in diesem Talabschnitt folgende Formen ausgemacht: geschliffenes Anstehendes oft mit glazifluvialen Spülformen, Strudeltöpfe, glazifluviale Terrassen, weitere glaziäre Dreieckshänge, weitere deutlich erkennbare Moränenwälle bzw. übrig gebliebene zerschnittene Moränengrate, Blockgletscher / Schuttloben sowie verschiedene Fächer- / Kegeltypen wie etwa Sturzschuttfächer / -kegel (Nummer 1 = welche, die Moränenmaterial überlagern (1a) oder von Schnee, Lawinen überlagerte (1b)) oder Sturzfächer / -kegel aus Moränenmaterial oder glazifluvialen Materialien (Nummer 2), Mischfächer / -kegel (Nummer 3 = hauptsächlich aus Schutt (3a), hauptsächlich aus Moränenmaterial (3b), oder welche, die präexistierendes Moränenmaterial überlagern (3c)), Murfächer / -kegel (Nummer 4 = Murmoränenfächer / -kegel mit einem hohen Moränenanteil (4b) sowie einen Schwemmfächer / -kegel hauptsächlich aus Moränenmaterial (5c). Die aufgefunden Erratika passten zu den Befunden von Kuhle (2005), nämlich den Grundmoränen mit erratischen Blöcken.

\subsubsection{Von den Orten Phortse und Tengboche bis zum Ort Namche Bazar}

Im Talabschnitt von den Orten Phortse und Tengboche bis zum Ort Namche Bazar wurden 29 Fotos (Foto 108-136) aus einer großen Menge ausgewählt. Die Standorte für die Fotos und die Sedimentproben sowie der Verlauf der Talquerprofile können der Karte 17 entnommen werden. Die geomorphologische Analyse im unteren Abschnitt des Tales Imja Khola ergab folgende Ergebnisse für die hocheiszeitliche Vergletscherung:

\section{TALQUERPROFILE UND SCHLIFFGRENZEN}

Das Imja Khola talabwärts der Orte Phortse und Tengboche bei Phortse und bei Phungi Thanga stellte ein Trogtal - bei erstgenanntem Ort als Übergang zu einem schluchtförmigen Trogtalprofil ausgeprägt - dar (Talquerprofil 6, Foto 118, 120, 124, 125 und Talquerprofil 7, Foto 110, 111, 114). Die Schliffgrenze beim Khumbi Yul Lha (Foto 101, 106) auf $4.800 \mathrm{~m}$ Höhe deutete bei einem rezenten Talboden bei $3.300 \mathrm{~m}$ auf eine hochglaziale Eismächtigkeit von ca. $1.500 \mathrm{~m}$ hin (nach Kuhle 2005:Fig. 3/Profil $221.250 \mathrm{~m}$ im Imja Khola bei Khumjung). Auf den Fotos 38, 40 und 137 ist die Schliffgrenze beim Thamserku auf ca. 4.700 Höhenmetern ablesbar. Bei einem rezenten Talboden auf ca. 3.680 m Höhe ergab das eine hochglaziale Eismächtigkeit von ca. 1.020 m. Dieses Ergebnis stimmte in etwa mit dem 
von Kuhle (2005:Fig. 3) überein. Er kam durch das talaufwärtigere Profil 22 auf eine Eismächtigkeit von $1.250 \mathrm{~m}$ und im Nachbartal des Bhote Koshi durch das Profil 26 auf eine von $1.000 \mathrm{~m}$.

\section{WEITERE GEOMORPHOLOGISCHE FORMEN}

Neben den ausgemachten Schliffgrenzen konnten im oberen bis mittleren Teil des Imja Khola talabwärts der Orte Periche und Dingboche folgende Formen ausgemacht werden: Ufermoränen (Foto 123, 127,129, 130, 131), Seiten- bis Endmoräne (Foto 123), glaziäre Dreieckshänge (Foto 110, 117, 123, 128), Grundmoränenmaterial (Foto 109, 110, 117, 123, 124, 125, 127, 128, 129), Sturzschuttfächer / -kegel (Foto 118, 120, 124, 125), Sturzfächer / kegel aus Moränenmaterial und glazifluvialem Material (Foto 110, 111, 124, 127), Mischfächer / -kegel (Foto 124), Murmoränenfächer / -kegel, glazifluviale Terrassen (Foto 110, 111, 112, 114, 116, 117) sowie Blöcke (Foto 108, 109, 113, 135), oft mit glazifluvialen Spülformen (Foto 135) und glazial überschliffenes anstehendes Gestein, oft mit glazifluvialen Spülformen (Foto 115, 118, 119, 120, 121, 122, 124, 125, 126, 128, 129, 132, 133, 134, 135, 136) bzw. Strudeltöpfe (Foto 122, 124).

\section{SEDIMENTPROBEN UND AUFSCHLÜSSE}

Im Talabschnitt von den Orten Phortse und Tengboche bis zum Ort Namche Bazar wurden zwei Sedimentproben (5. Probe, Foto 129-131; 6. Probe, hangaufwärts vom Standort Foto 137) entnommen und ein Aufschluss (3. Aufschluss, Foto 129-131) untersucht.

\section{ABGLEICH DER BEFUNDE MIT ANDEREN FORSCHUNGSARBEITEN ERRATISCHE BLÖCKE IM PUNGI UND IMJA KHOLA}

Kuhle (2005:Fig. 3) machte im Pungi Khola Grundmoränen mit erratischen Blöcken aus. Andere Forscher wendeten in diesem Gebiet keinerlei geomorphologische Analysen an.

\section{$\underline{\text { Schlussfolgerungen }}$}

In Bezug auf die erratischen Blöcke im Pungi Khola und in der Nähe von Pungi Thanga konnte Kuhle (2005) zugestimmt werden. Auf dem Weg zwischen Pungi Thanga und Tengboche (Ufermoräne Tengboche; Foto 108, 109) und auf dem Talboden des Imja Khola (glazifluviales Material, Foto 113) konnten beispielsweise ebenfalls erratische Granitblöcke ausgemacht werden. Grundmoränen wurden desgleichen aufgefunden - auf der orographisch 
rechten Imja Khola Talseite (Foto 110) sowie auf der orographisch linken Imja Khola Talseite (Foto 123-125, 127, 128).

Zusätzlich zu den Befunden von Kuhle (2005:Fig. 3) konnten im Imja Khola in der Nähe des Ortes Pungi Thanga weitere glaziäre Dreieckshänge (Foto 110), Sturzfächer / -kegel aus Moränenmaterial und glazifluvialem Material (Foto 110, 111), glazifluviale Terrassen (Foto 110, 111, 112, 114, 116), geschliffenes Anstehendes zumeist mit glazifluvialen Spülformen (Foto 115) identifiziert werden.

\section{NGOZUMPA DRANGKA}

Kuhle (2005:Fig. 3) machte im Ngozumpa Drangka ein Grundmoränenpodest mit erratischen Blöcken aus. Auf diesem lag der Ort Phortse. Außerdem schien eine orographisch linke Ufermoräne des vorzeitlich existierenden Nebentalgletschers des Kohanar Khola ausgebildet zu sein. Nach Kuhle (2005:Fig. 3, Foto 144) stellte diese jedoch ein zerschnittenes Grundmoränenpodest dar. Zudem machte Kuhle (2005:Foto 147) unterschiedlich alte bzw. hohe glazifluviale Terrassen aus. Andere Forscher führten in diesem Gebiet keinerlei geomorphologische Analysen durch.

\section{$\underline{\text { Schlussfolgerungen }}$}

Das von Kuhle ausgemachte Grundmoränenpodest konnte bestätigt werden. Auf dem Foto 124 ist dieses zu sehen. Auch das zerschnittene Grundmoränenpodest im Nebental Kohanar Khola sowie die unterschiedlich alten bzw. hohen glazifluvialen Terrassen konnten als solche angesprochen werden (Foto 117). Ergänzend zu den Befunden von Kuhle (2005:Fig. 3) wurden im Ngozumpa Drangka folgende weitere geomorphologische Formen aufgefunden: glaziäre Dreieckshänge (Foto 117), Blöcke mit glazifluvialen Spülformen (Foto 117, 119), Sturzschuttfächer / -kegel (Foto 118, 120, 124, 125), Mischfächer / -kegel (Foto 124), Sturzfächer / -kegel aus Moränenmaterial und glazifluvialem Material (Foto 123, 124, 127), geschliffenes Anstehendes zumeist mit glazifluvialen Spülformen (Foto 118, 119, 120, 121, 122, 124, 125, 126) sowie Strudeltöpfe (Foto 122, 124 - Kuhle machte ebenfalls im Ngozumpa Drangka, aber weiter talabwärts, Strudeltöpfe aus).

\section{UFERMORÄNEN BEI KHUMJUNG}

Nördlich und oberhalb von Khumjung und Khunde kennzeichneten Heuberger, Weingartner (1985:Abb. 2; 73, 80) hocheiszeitliche Ufermoränen und Moränen in Form von zerschnittenen Terrassen, wobei die Orte auf Bergsturzablagerungen lagen. Die Moränen 
entstanden von den Gletschern des Imja und Nangpo Tales (ebd.:74). Geomorphologisch waren die Schuttablagerungen der Haupt- von denen der Nebentalvergletscherung des Khumbi Yul Lha unterscheidbar, petrographisch aber nicht (ebd.:75). Kuhle (2005:Fig. 3) visualisierte nördlich von Khumjung eine Ufermoräne aus dem spätglazialen Stadium IV und ein Stadium V Grundmoränenpodest. In der Nähe der Ufermoräne entnahm er eine Sedimentprobe, die mit der Zahl 13 in Fig. 3 versehen wurde. Nach Fig. 6 bei Kuhle (2005) war das die Probe 14.12.94/2 (224 untersuchte Körner, 57,1 \% frisch verwittert / glazigen gebrochen, 30,4 \% fluvial poliert, 12,5 \% äolisch mattiert). Götz et al. (2015:Fig. 3) visualisierten ebenfalls wie Heuberger und Weingartner Moränen nördlich und südlich von Khumjung bis südlich von Namche Bazar Bergsturzablagerungen. Andere Forscher wendeten in diesem Gebiet keine geomorphologischen Analysen an.

\section{$\underline{\text { Schlussfolgerungen }}$}

Die von Heuberger, Weingartner (1985) ausgemachten Ufermoränen waren eher nicht, wie sie angaben, durch die Haupttalgletscher des Imja Khola und des Bhote Khosi zu erklären, sondern vielmehr durch Nebentalgletscher. Auf dem Foto 129 ist die von Heuberger, Weingartner (1985) in Abb. 2 dargestellte rechte Ufermoräne zu sehen, wobei diese mit der vorliegenden Arbeit genauer untersucht wurde (Foto 130, 131). Hierbei handelte es sich eher nicht um die orographisch rechte Ufermoräne des vorzeitlichen Imja Khola Gletscher, sondern um die des Nebentalgletschers, welcher auf der Südostseite des Khumbi Yul Lha abfloss. Die von Heuberger, Weingartner (1985) in Abb. 2 dargestellte orographisch linke Ufermoräne war ebenfalls nicht die des vorzeitlichen Bhote Khosi Gletscher, sondern eine Ufermoräne des Nebentalgletschers, der auf der Südostseite des Khumbi Yul Lha abfloss. Somit handelte es sich bei den Ufermoränen bei Khumjung um keine hochglazialen, sondern um jüngere. Demnach konnte den Befunden von Kuhle (2005) zugestimmt werden. Götz et al. (2015:Fig. 3) visualisierten in diesem Bereich Moränen, gingen aber nicht auf deren Genese ein. Von Heuberger und Weingartner wurde angegeben, dass die Schuttablagerungen der Haupt- von denen der Nebentalvergletscherung nicht petrographisch unterscheidbar waren. Dieser genannte Aspekt ließe sich dadurch erklären, dass die durch die Nebentalgletscher entstandenen jüngeren Moränen aus dem Material der viel mächtigeren Haupttalgletschermoränen bestehen (Foto 130, 131).

Das Ergebnis der Sedimentprobe von Kuhle (2005) war mit der Mittelsandfraktion der in der vorliegenden Arbeit mit Nummer 5 bezeichneten Probe vergleichbar: bei beiden überwog der 
Anteil der frisch verwitterten / glazigen gebrochenen gegenüber dem der fluvial polierten Körner. Daneben erkannte Kuhle (2005) jedoch auch äolisch mattierte Körner.

\section{SEDIMENTPROBEN BEI NAMCHE BAZAR}

Bei Namche Bazar wurden von Kuhle (2005) Sedimentproben entnommen, die bestätigten, dass es sich dort um eine Grundmoräne handelte. Bei der vorliegenden Arbeit wurden ebenfalls in diesem Talbereich Proben entnommen.

\section{$\underline{\text { Schlussfolgerungen }}$}

Die Sedimentanalysen führten zum Ergebnis, dass es sich hier um eine Moränenablagerung handelte, da eine solche dadurch gekennzeichnet war, dass alle Korngrößen von Ton bis Sand vertreten waren, diese also unsortiert war. An den Probeentnahmestellen konnten zudem kleine und große Gesteine ausgemacht werden. Demnach kamen die Korngrößen Ton bis Gestein- / Blockgröße vor. Vorwiegend waren kantengerundete Blöcke in einer feinen Matrix aufzufinden, was ebenfalls für Moräne sprach. Ein glazifluvialer Einfluss konnte durch die Kornformenanalysen nachgewiesen werden. Nach der geomorphologischen Ausprägung der Moräne handelte es sich hier speziell um eine Grundmoränenablagerung auf dem Hang.

In Probe 6 waren 3,3\% Ton, 35,21 \% Schluff (4,77 \% Feinschluff, 10,99\% Mittelschluff, $19,45 \%$ Grobschluff) und 61,49\% Sand (48,05\% Feinsand, 11,16\% Mittelsand, 2,28\% Grobsand) enthalten. Es wurden insgesamt 562 Körner ausgezählt (125 aus der Feinsand-, 363 aus der Mittelsand- und 74 aus der Grobsandfraktion). Somit lag das Hauptaugenmerk der Untersuchung in der vorliegenden Arbeit auf der Mittelsandfraktion. In dieser Probe bestanden alle drei Fraktionen zu $100 \%$ aus glazial gebrochenen / frisch verwitterten Kornformen. In Probe 7 waren 4,42 \% Ton, 40,01 \% Schluff (6,32\% Feinschluff, 14,67\% Mittelschluff, 19,02\% Grobschluff) und 55,57\% (32,57\% Feinsand, 13,23\% Mittelsand, 9,77\% Grobsand) Sand enthalten. Es wurden insgesamt 521 Körner ausgezählt (100 aus der Feinsand-, 321 aus der Mittelsand- und 100 aus der Grobsandfraktion). In dieser Probe 7 waren bei zwei Sandfraktionen $100 \%$ glazial gebrochene / frisch verwitterte Kornformen und bei einer $97,5 \%$ glazial gebrochene / frisch verwitterte sowie 2,5 \% fluvial polierte Körner enthalten. Anhand der Klassifizierung in die fünf Kategorien scharfkantig, kantig-rundkantig, rundkantig-angerundet, gerundet und stark gerundet konnte gezeigt werden, dass es sich hierbei nicht um frisch verwittertes Material, sondern um Moränenmaterial handelte, da kantig bis rundkantige sowie rundkantig bis angerundete Körner und in Probe 7 sogar 
gerundete Körner in der Sedimentprobe vorhanden waren. Der Grobsandanteil zeigte die meisten kantig bis rundkantigen Körner, gefolgt von der Feinsandfraktion. Die Körner der Mittelsandfraktion tendierten bei der Probe 6 am meisten in die Gruppe rundkantig bis angerundet, gefolgt von der Grobsandfraktion. Bei Probe 7 tendierten die Körner der Mittelsandfraktion in die Gruppe fluvial poliert, wobei viele Körner der Fein- und Mittelsandfraktion im Gegensatz zur Grobsandfraktion rundkantig bis angerundet waren. Somit - da die Körner hin zum fluvial polierten Korn tendierten - wurde neben dem glazialen Einfluss auch eine glazifluviale Einwirkung auf die Sedimente deutlich. Diese Einwirkung kann vor oder während des glazialen Transportes - da die kleineren Körner diesen Prozess länger konservieren können als die größeren, oder auch während oder gar nach diesem stattgefunden haben - da die größeren Körner eher in die Richtung rundkantige bis angerundete Ausformung tendierten. Somit war auf jeden Fall eine starke bzw. längere Schmelzwassereinwirkung auf das Material nachweisbar - wann diese jedoch genau passierte, konnte durch diese Methode bzw. Arbeitstechnik nicht geklärt werden.

Die Korngrößenverteilungen waren mit denen von Kuhle (2005:Fig. 68/Fig. 3 11.3.03/2) und von Kuhle (2005:Fig. 69/Fig. 3 11.3.03/3) vergleichbar, da diese Proben ungefähr im selben Talbereich in 1,0 und 0,4 m Tiefe entnommen wurden. Kuhle kam auf bi- bzw. trimodale Verteilungen.

Kuhle (2005:Fig. 37) stellte bei den Proben 9 bzw. 10 bei 509 bzw. 491 ausgezählten Körnern 96,3/86,4 \% frisch verwitterte / glazial gebrochene, 3,7/13,6 \% fluvial polierte und somit keine äolisch mattierte fest.

Heuberger, Weingartner (1985:Abb. 2; 73, 80) verwiesen darauf, dass die Orte wie etwa Khumjung auf Bergsturzablagerungen lagen, auch Götz et al. (2015:Fig. 3) visualisierten in diesem Bereich Bergsturzablagerungen. Jedoch sprachen in dem gesamten bei Götz et al. (2015:Fig. 3) gekennzeichneten Bereich der Bergsturzablagerungen vor Ort aufgefundene kantengerundete Blöcke (Foto 135), Moränen (Foto 137) sowie anstehendes Gestein mit deutlich rund konkav ausgebildeten glazifluvialen Spülformen bei Khumjung und zwischen Khumjung und Namche Bazar (Foto 132, 133, 134, 136) gegen eine solche Deutung der Formen.

Ergänzend zu den Befunden von Kuhle (2005:Fig. 3) konnten im Talabschnitt zwischen den Orten Phortse und Namche Bazar weitere geomorphologische Formen wie geschliffenes Anstehendes bzw. Blöcke zumeist mit glazifluvialen Spülformen (Foto 128, 129, 132, 133, $134,135,136)$ ausgemacht werden. 


\section{WEITERE GEOMORPHOLOGISCHE ANALYSEN}

\section{GEOMORPHOLOGISCHE KARTE}

Die auf der mit Google Earth erstellten geomorphologischen Karte 18 visualisierten Formen im Tal Imja Khola im Talabschnitt von den Orten Phortse und Tengboche bis zum Ort Namche Bazar wurden auf der Grundlage von Geländebegehungen und Google Earth Satellitenbildanalysen angesprochen.

Die Befunde von Kuhle (2005:Fig. 3) bestätigten sich mit der vorliegenden Arbeit. Die Bedeutungen der hell- und dunkelgrünen Visualisierungen auf der Karte 19 waren die gleichen wie beim vorherigen Talabschnitt.

Weiterhin zu den Befunden von Kuhle (2005:Fig. 3) wurden in diesem Talabschnitt folgende Formen ausgemacht: geschliffenes Anstehendes oft mit glazifluvialen Spülformen, glazifluviale Terrassen, weitere glaziäre Dreieckshänge, weitere deutlich erkennbare Moränenwälle bzw. übrig gebliebene zerschnittene Moränengrate sowie verschiedene Fächer/ Kegeltypen wie etwa Sturzschuttfächer / -kegel (Nummer 1 = welche, die Moränenmaterial überlagern (1a)) oder Sturzfächer / -kegel aus Moränenmaterial oder glazifluvialen Materialien (Nummer 2), Mischfächer / -kegel (Nummer 3 = welche, die präexistierendes Moränenmaterial überlagern (3c)), Murfächer / -kegel (Nummer 4 = Murmoränenfächer / kegel mit einem hohen Moränenanteil (4b)) sowie zerschnittene Moränen (Nummer 6). Die dargestellten Gletscherflächen basierten auf der topographischen Karte `Lukla to Everest Base Camp’ im Maßstab 1:60.000. 


\subsection{Befunde aus dem Solu}

\subsubsection{Dudh Khosi}

\subsubsection{Vom Ort Namche Bazar bis zum Ort Monjo}

Im Talabschnitt von Namche Bazar bzw. dem Konfluenzbereich zwischen Imja Khola und Bhote Khosi bis Monjo wurden 13 Fotos (Foto 137-149) aus einer großen Menge ausgesucht. Die Standorte für die Fotos und die Sedimentproben sowie der Verlauf der Talquerprofile können der Karte 20 entnommen werden. Die geomorphologische Analyse im oberen Dudh Khosi Talbereich ergab folgende Ergebnisse für die hocheiszeitliche Vergletscherung:

\section{TALQUERPROFILE UND SCHLIFFGRENZEN}

Das obere Dudh Khosi Tal talabwärts des Ortes Namche Bazar bis zum Ort Monjo stellte ein zweistufiges Trogtal mit einem trogförmigen oberen und einem schlucht- bis kerbsohlenförmigen unteren Hangbereich dar (Talquerprofil 8, Foto 138, 139, 140 und Talquerprofil 9, Foto 147). Auf den Fotos 38, 40 und 137 ist die Schliffgrenze beim Thamserku auf ca. $4.700 \mathrm{~m}$ Höhe ablesbar. Bei einem rezenten Talboden auf ca. 3.680 Höhenmetern ergab das eine hochglaziale Eismächtigkeit von ca. 1.020 m. Dieses Ergebnis stimmte in etwa mit dem von Kuhle (2005:Fig. 3) überein. Er kam durch das talaufwärtigere Profil 22 auf eine Eismächtigkeit von $1.250 \mathrm{~m}$ und im Nachbartal des Bhote Koshi durch das Profil 26 auf eine von 1.000 m. Bei der Schliffgrenze beim Berg Nupla (Foto 137, aber auch auf Foto 97, 110) auf einer ungefähren Höhe von 4.195 m konnte bei einem rezenten Talboden bei ca. $3.200 \mathrm{~m}$ eine hochglaziale Eismächtigkeit im Bhote Khosi von $995 \mathrm{~m}$ ermittelt werden. Nach Kuhle (2005:Fig. 3/Profil 26) bestand in diesem Talbereich eine Eismächtigkeit von $1.000 \mathrm{~m}$.

Im Solu bzw. im Dudh Khosi Tal wurden unterhalb des Ortes Namche Bazar folgende höchstliegende Schliffgrenzen ausgemacht: fünf Schliffgrenzen auf der orographisch rechten Talseite (Foto 194, 215, 220, 221, 224, 232, 238, 243, 244) und auch fünf auf der orographisch linken Talseite (Foto 224, 231, 238, 232, 239, 240, 242, 247). Die Schliffgrenzen im Dudh Khosi auf den Fotos 158, 160, 183, 185, 186, 189, 204, 217, 222, 225, teilweise auf Foto 232 und im Thado Khosi auf dem Foto 180 stellten hingegen keine hochglazialen Schliffgrenzen, sondern tieferliegende und also jüngere dar. Somit waren die Schliffgrenzen auf den Fotos 186, 189, 194, 204, 217, 222, teilweise auf Foto 232 im Gegensatz zu Kuhle (2005:Foto 229) keine Grenzen, die den Maximalstand des vorzeitlichen Haupttalgletschers anzeigten. 


\section{WEITERE GEOMORPHOLOGISCHE FORMEN}

Neben den ausgemachten Schliffgrenzen konnten talabwärts des Ortes Namche Bazar folgende Formen festgestellt werden: Ufermoränen (Foto 137), glaziäre Dreieckshänge (Foto 137, 139, 147), Grundmoränenmaterial (Foto 137, 142, 144, 145, 147, 148, 149), Sturzmoränenfächer / -kegel (Foto 145, 148), Murmoränenfächer / -kegel (Foto 147), glazifluviale Terrassen (Foto 138, 139, 140, 144) sowie Blöcke (Foto 143, 145, 148, 149), oft mit glazifluvialen Spülformen (Foto 143, 148, 149), und glazial überschliffenes anstehendes Gestein, oft mit glazifluvialen Spülformen (Foto 138, 140, 141, 143, 144, 146) bzw. Strudeltöpfe (Foto 146).

\section{SEDIMENTPROBEN UND AUFSCHLÜSSE}

Im Talabschnitt vom Ort Namche Bazar und zum Ort Monjo wurden keine Sedimentproben entnommen und kein Aufschluss untersucht.

\section{GEOMORPHOLOGISCHE KARTE}

Die geomorphologischen Formen wurden auf der Karte 21 visualisiert.

\section{ABGLEICH DER BEFUNDE MIT ANDEREN FORSCHUNGSARBEITEN}

Beim Ort Monjo nahmen Bäumler et al. (1991:Fig. 6) lediglich die Bodenprofile 3 und 4 auf 3.100 und $3.550 \mathrm{~m}$ Höhe und Heuberger, Weingartner (1985:Abb. 2) das Bodenprofil P5 auf $3.450 \mathrm{~m}$. Ausgemachte Schliffgrenzen und auch die angegebene hochglaziale Eismächtigkeit von 1.300 m von Kuhle (2005:Fig. 4, Profil 28) ließen erkennen, dass die Standorte der Bodenprofile der o.g. Forscher hochglazial eisbedeckt waren. Somit können Bodenbefunde allein zu keinem eindeutigen Ergebnis einer vorzeitlichen Vergletscherung führen - vielmehr sollten glazialgeomorphologische Befunde ausschlaggebend sein. Allein die Angabe von Heuberger, Weingartner (1985:78), dass der von ihnen angegebene Bodentyp nur kleinräumig auftrat, sollte ihre Befunde fraglich erscheinen lassen. Ebenso schrieben sie, dass sie Moränenblöcke bis in eine Höhe von $3.500 \mathrm{~m}$ auffanden und ein älteres Bodenprofil ab einer Höhe von $3.550 \mathrm{~m}$ ausmachten, zeichneten aber die vorzeitliche Vergletscherung in Abb. 2 unterhalb des Bodenprofilstandortes auf $3.450 \mathrm{~m}$ Höhe ein. Ebenfalls nahmen auch Bäumler et al. (1991:Fig. 5) erst in einer Höhe von 3.550 m ein älteres Bodenprofil auf. Sämtliche vorgenannte Forscher und auch andere als hier angeführte, bis auf Kuhle (2005), machten im Talabschnitt zwischen den Orten Namche Bazar und Monjo keine geomorphologischen Analysen. 
Weiterführend zu den Befunden von Kuhle (2005:Fig. 11) konnten im Talabschnitt zwischen den Orten Namche Bazar und Monjo weitere geomorphologische Formen ausgemacht werden: glazifluviale Terrassen (Foto 138, 139, 140, 144), glaziäre Dreieckshänge (Foto 137, 139, 147), geschliffenes Anstehendes bzw. Blöcke zumeist mit glazifluvialen Spülformen (Foto 138, 140, 141, 143, 144, 146, 148), zerschnittenes Grundmoränenmaterial (Foto 142, 145, 148, 149), Sturzfächer / -kegel aus Moränenmaterial (Foto 145, 148, 149), Strudeltöpfe (Foto 146) sowie Murmoränenfächer / -kegel (Foto 147).

\subsubsection{Vom Ort Monjo bis zum Ort Ghat}

Im Talabschnitt von Monjo bis Ghat wurden 17 Fotos (Foto 150-166) aus einer großen Anzahl ausgewählt. Die Standorte für die Fotos und die Sedimentproben sowie der Verlauf der Talquerprofile können der Karte 22 entnommen werden. Die geomorphologische Analyse im oberen Dudh Khosi Talbereich ergab folgende Ergebnisse für die hocheiszeitliche Vergletscherung:

\section{TALPQUERROFILE UND SCHLIFFGRENZEN}

Das obere Dudh Khosi Tal talabwärts des Ortes Monjo bei Phakding stellte ein Trogtal mit einer deutlich ausgebildeten Talsohle dar (Talquerprofil 10, Foto 161). Im Solu bzw. im Dudh Khosi Tal wurden unterhalb des Ortes Namche Bazar folgende höchstliegende Schliffgrenzen ausgemacht: fünf Schliffgrenzen auf der orographisch rechten Talseite (Foto 194, 215, 220, $221,224,232,238,243,244)$ und auch fünf auf der orographisch linken Talseite (Foto 224, 231, 238, 232, 239, 240, 242, 247). Die Schliffgrenzen im Dudh Khosi auf den Fotos 158, 160, 183, 185, 186, 189, 204, 217, 222, 225, teilweise auf Foto 232 und im Thado Khosi auf dem Foto 180 stellten hingegen keine hochglazialen Schliffgrenzen, sondern tieferliegende und somit jüngere dar. Also waren die Schliffgrenzen auf den Fotos 186, 189, 194, 204, 217 , 222, teilweise auf Foto 232 im Gegensatz zur Aussage von Kuhle (2005:Foto 229) keine Grenzen, die den Maximalstand des vorzeitlichen Haupttalgletschers anzeigten.

\section{WEITERE GEOMORPHOLOGISCHE FORMEN}

Neben den ausgemachten Schliffgrenzen konnten im oberen bis mittleren Teil des Imja Khola talabwärts der Orte Periche und Dingboche folgende Formen ausgemacht werden: glaziäre Dreieckshänge (Foto 158, 160), Grundmoränenmaterial (Foto 150, 151, 152, 153, 157, 158, 160, 161, 162, 163), Sturzmoränenfächer / -kegel (Foto 150, 161), Murmoränenfächer / -kegel (Foto 150), glazifluviale Terrassen (Foto 150, 151, 157, 160, 163) sowie Blöcke (Foto 150, 
152, 158, 161), oft mit glazifluvialen Spülformen (Foto 150, 161), und glazial überschliffenes anstehendes Gestein, oft mit glazifluvialen Spülformen (Foto 150, 152, 153, 154, 155, 156, 159, 161, 162, 164, 165, 166) bzw. Rundhöcker (Foto 152, 155) und Strudeltöpfe (Foto 153, $154,156,166)$.

\section{SEDIMENTPROBEN UND AUFSCHLÜSSE}

Im Talabschnitt vom Ort Monjo zum Ort Ghat wurden beim Ort Ghat drei Sedimentproben (8.-10. Probe) entnommen und ein Aufschluss (4. Aufschluss) untersucht.

\section{GEOMORPHOLOGISCHE KARTE}

Die geomorphologischen Formen wurden auf der Karte 23 visualisiert.

\section{ABGLEICH DER BEFUNDE MIT ANDEREN FORSCHUNGSARBEITEN}

Im Talbereich zwischen den Orten Monjo und Ghat machte Kuhle (2005:Fig. 11) detaillierte geomorphologische Analysen, andere Forscher jedoch nicht. Heuberger, Weingartner (1985:Abb. 2, 76) nahmen lediglich bei Phakdingma drei formfrische Ufermoränen im Panyali Drangka auf und bei diesem Ort und bei Monjo Bodenprofile. Die genannten Moränen waren Ufermoränen des ehemaligen Haupttalgletschers (ebd.:76); da die Moränen jedoch formfrisch auftraten, lag es nahe, dass diese keine hochglazialen Ufermoränen, sondern jüngere waren. Außerdem war es wahrscheinlicher, dass diese Moränen einem Panyali Drangka Nebentalgletscher entstammten. Zusätzlich zu den Befunden von Kuhle (2005:Fig. 11) konnten im Talabschnitt zwischen den Orten Monjo und Ghat weitere folgende geomorphologische Formen ausgemacht werden: zerschnittenes Grundmoränenmaterial (Foto 152, 157, 163), Sturzfächer / -kegel aus Moränenmaterial (Foto 150, 161), glazifluviale Terrassen (Foto 152), Blöcke mit glazifluvialen Spülformen (Foto 150, 151, 161), geschliffenes Anstehendes, oft mit glazifluvialen Spülformen (Foto 152, 153, 154, 155, 156, 159, 161, 162, 164, 165, 166), Strudeltöpfe (Foto 153, 154, 156, 166) und Rundhöcker (Foto 153). 


\subsubsection{Vom Ort Ghat bis zum Ort Lukla}

Im Talabschnitt von Ghat bis Lukla wurden 42 Fotos (Foto 167-208) aus einem großen Angebot ausgesucht. Die Standorte für die Fotos, der Sedimentproben sowie der Verlauf der Talquerprofile können den Karten 24, 26 und 28 entnommen werden. Die geomorphologische Analyse im mittleren Dudh Khosi Talbereich ergab folgende Ergebnisse für die hocheiszeitliche Vergletscherung:

\section{TALQUERPROFILE UND SCHLIFFGRENZEN}

Das mittlere Dudh Khosi Tal vom Ort Ghat bis Lukla stellte bei Ghat ein typisches Trogtal dar (Talquerprofil 11, Foto 238) sowie bei Chaunrikharka und Nakjung einen schluchtförmigen Trog (Talquerprofil 12, Foto 224; Talquerprofil 13, Foto 218). Im Solu bzw. im Dudh Khosi Tal wurden unterhalb des Ortes Namche Bazar folgende höchstliegende Schliffgrenzen ausgemacht: fünf Schliffgrenzen auf der orographisch rechten Talseite (Foto $194,215,220,221,224,232,238,243,244)$ und auch fünf auf der orographisch linken Talseite (Foto 224, 231, 238, 232, 239, 240, 242, 247). Die Schliffgrenzen im Dudh Khosi auf den Fotos 158, 160, 183, 185, 186, 189, 204, 217, 222, 225, teilweise auf Foto 232 und im Thado Khosi auf dem Foto 180 stellten hingegen keine hochglazialen Schliffgrenzen, sondern tieferliegende und damit jüngere dar. Somit waren die Schliffgrenzen auf den Fotos 186, 189, 194, 204, 217, 222, teilweise auf Foto 232, im Gegensatz zu denen von Kuhle (2005:Foto 229) keine, die den Maximalstand des vorzeitlichen Haupttalgletschers anzeigten.

Die höchstliegende Schliffgrenze auf der orographisch rechten Dudh Khosi Talseite im Bereich vom Ort Lukla (nach Kuhle 2005:Foto 224, 227 bei ca. 3.400 m Höhe) lag bei Lukla auf ca. $3.950 \mathrm{~m} / \mathrm{GE}$ Höhe, was in Bezug zum Haupttalboden (27 41.537'N 86 42.629'E) bei ca. $2.285 \mathrm{~m} / \mathrm{GE}$ (nach Kuhle 2005:Foto 224 bei $2.000 \mathrm{~m}$ ) eine hochglaziale maximale Eismächtigkeit von ca. $1.665 \mathrm{~m}$ zuließ (Foto 215, 220, 221, 224). Nach den angegebenen Daten von Kuhle (2005) berechnete sich eine hochglaziale Eismächtigkeit von 1.400 m. Die relative Höhe wies auf eine minimale hochglaziale Eismächtigkeit von ca. $700 \mathrm{~m}$ hin (Foto 194, 215, 220, 224).

\section{WEITERE GEOMORPHOLOGISCHE FORMEN}

Neben den ausgemachten Schliffgrenzen konnten im oberen bis mittleren Teil des Imja Khola talabwärts der Orte Periche und Dingboche folgende Formen ausgemacht werden: Ufer- bis Endmoränen (Foto 204, 205, 206), glaziäre Dreieckshänge (Foto 183, 189, 194), 
Grundmoränenmaterial (Foto 168, 169, 170, 172, 173, 175, 176, 178, 179, 181, 183, 184, 185, 186, 188, 189, 190, 191, 193, 194, 200, 201, 202, 203, 204, 205, 207, 208), Sturzmoränenfächer / -kegel (Foto 205), Murmoränenfächer / -kegel (Foto 173, 176, 178, 180, 184, 192, 207, 208), glazifluviale Terrassen (Foto 167, 168, 169, 171, 173, 176, 177, 178) sowie Blöcke (Foto 167, 169, 170, 173, 174, 178, 179, 180, 187, 188, 190, 195, 196, 198, 202, 203), oft in Rundhöckerform (Foto 173) oder mit glazifluvialen Spülformen (Foto 167, 169, 173, 174, 180), und glazial überschliffenes anstehendes Gestein, oft mit glazifluvialen Spülformen (Foto 168, 169, 175, 180, 183, 184, 187, 194, 195, 196, 197, 198, 199, 201, 202, 203, 205, 206, 207) bzw. Rundhöcker (Foto 173, 180) und Strudeltöpfe (Foto 187).

\section{SEDIMENTPROBEN UND AUFSCHLÜSSE}

Im Talabschnitt vom Ort Ghat zum Ort Lukla wurden beim Ort Ghat drei Sedimentproben (8.-10. Probe, Foto 168, 175, 177) entnommen und ein Aufschluss (4. Aufschluss, Foto 177) untersucht sowie beim Ort Lukla vier Sedimentproben (11.-14. Probe, Foto 192, 195, 196) entnommen und zwei Aufschlüsse (5.-6. Aufschluss, Foto 192, 195, 196) untersucht.

\section{GEOMORPHOLOGISCHE KARTE}

Die geomorphologischen Formen wurden auf der Karte 25 visualisiert.

\section{ABGLEICH DER BEFUNDE MIT ANDEREN FORSCHUNGSARBEITEN}

Im Talbereich zwischen den Orten Ghat und Lukla führten Kuhle (2005:Fig. 11), Fushimi (1978:Fig. 6) und zuletzt Götz et al. (2015:Fig. 2) geomorphologische Analysen durch. Heuberger, Weingartner (1985) nahmen lediglich Bodenprofile rund um Ghat auf. Ob jedoch ein beweiskräftiges Ergebnis für die vorzeitliche Vergletscherung dieses Tales allein durch Bodenprofile erzielbar ist, muss in Frage gestellt werden, da die Bodenentwicklung von enorm vielen Faktoren abhängig ist. Heuberger, Weingartner (1985:73) schlossen nicht aus, dass weitere Moränenwälle im Pharag - als die, die sie visualisierten - auszumachen seien. Bei Ghat waren beim Moränenmaterial vorwiegend Sande zu erkennen, die auf glazilimnisches Material und demnach auf einen vorzeitlichen See deuteten (Foto 168, 169, 172, 175, 178). Auch Fushimi (1978:Fig. 6) visualisierte neben zwei unterschiedlichen Trogtalprofilen U-1 und U-2 Seesedimente, aber auch Götz et al. (2015:Fig. 2). Heuberger, Weingartner (1985:77 f.) sprachen talaufwärts von Chaunrikharka ebenfalls von Stausedimenten, wobei sie aber die gesamte Akkumulation als Stausedimentterrasse 
ansprachen und nicht als eine Moräne. Bei Chaunrikharka sah Fushimi (1978:Fig. 6) die unterste Terrasse als Moräne der U-1 Serie und die obere als Sedimente, die glazial oder auch fluvial entstanden waren (Foto 186, 189, 193, 194, 204, 205, 206), an. Die Moräne im Handi Khola (Foto 204 und 205) nahmen Kuhle (2005:Fig. 11) und auch Götz et al. (2015:Fig. 2) auf. Heuberger, Weingartner (1985:73) gaben an, dass sich nördlich bis nordwestlich von Lukla Bergsturzablagerungen bei Chaunrikharka befanden. Götz et al. (2015:Fig. 2) kartierten hingegen im gesamten Gebiet von Lukla bis nördlich von Nachipang Bergsturzablagerungen. Auch die Terrassen unterschiedlichen Niveaus waren laut diesen Forschern polygenetische Bergsturzterrassen. Dass die bei Götz et al. (2015) visualisierten Bergsturzablagerungen nicht unbedingt solche darstellen müssen, zeigte sich bei der Betrachtung der Fotos 187 (Strudeltopf, kantengerundete Blöcke), 197 und 198 (Schmelzwasserrinne), 188, 190, 191, 193, 195, 196, 202 und 203 (kantengerundete Blöcke). Außerdem kamen in diesem Bereich erratische Blöcke vor, die nicht allein durch Bergstürze erklärbar waren. Geschliffenes anstehendes Gestein konnte zudem nur durch eine Vergletscherung der Talbereiche entstanden sein. Bei beiden Terrassen handelte es sich wohl eher um Grundmoränenpodeste bei der oberen mit darauf abgelagerten Murfächern / -kegeln - dies beschrieb auch Kuhle (2005:Fig. 11). Somit war den Befunden der Forschungsarbeiten von Kuhle und Fushimi in Hinsicht auf die Geomorphologie zuzustimmen, wobei die Analysen von Kuhle (2005) detaillierter waren. Bei Fushimi (1978) wurden viele geomorphologische Formen wie etwa Murfächer / -kegel nicht berücksichtigt. Ebenso unterschied er die Talprofile nicht genauer er trennte das Trog- vom Kerbtal ohne, im Gegensatz zu Kuhle (2005), auf die Spezialform schluchtförmiger Trog einzugehen. Somit wurde anhand der Berücksichtigung lediglich dieser einen Form deutlich, warum Kuhle gegenüber Fushimi ein viel weiter talabwärts reichendes vorzeitliches Gletscherende aufzeigen musste. Heuberger, Weingartner (1985:73) beschränkten sich lediglich auf das Gebiet Khumjung bis Lukla.

Ergänzend zu den Befunden von Kuhle (2005:Fig. 11) konnten im Talabschnitt zwischen den Orten Ghat und Lukla weitere folgende geomorphologische Formen ausgemacht werden: glazifluviale Terrassen (Foto 167, 168, 169, 171, 173, 176, 178), Blöcke mit glazifluvialen Spülformen (Foto 169, 173, 174, 178, 180, 199) sowie Mikroerosionsformen (Foto 173), zerschnittenes glazifluviales Material (Foto 177), zerschnittenes Moränenmaterial (Foto 169, $170,172,175,178,179,181,188,195,196,200,201,202,203)$, offen gelegtes Moränenmaterial (Foto 190, 191, 193), Sturzfächer / -kegel aus Moränenmaterial (Foto 205), Murmoränenfächer / -kegel (Foto 173 - auch Kuhle 2005:Fig. 11 verwies in diesem Bereich 
auf einen Schutt- und Murkegel, Foto 176, 178), geschliffenes Anstehendes, oft mit glazifluvialen Spülformen (Foto 187, 197, 198, 199, 201, 202, 203), Strudeltöpfe (Foto 187) sowie subglaziale Schmelzwasserrinnen (Foto 197, 198, 199).

\subsubsection{Vom Ort Lukla bis zum Ort Kharikhola}

Im Talabschnitt von Lukla bis Kharikhola wurden 29 Fotos (Foto 209-237) aus einer großen Auswahl ausgesucht. Die Standorte für die Fotos, der Sedimentproben sowie der Verlauf der Talquerprofile können der Karte 26 entnommen werden. Die geomorphologische Analyse im mittleren bis unteren Dudh Khosi Talbereich ergab folgende Ergebnisse für die hocheiszeitliche Vergletscherung:

\section{TALQUERPROFILE UND SCHLIFFGRENZEN}

Das mittlere bis untere Dudh Khosi Tal vom Ort Lukla bis Kharikhola stellte bei Surke und Poyan einen schluchtförmigen Trog dar (Talquerprofil 14, Foto 217; Talquerprofil 15, Foto 231; Talquerprofil 16, Foto 225). Im Solu bzw. im Dudh Khosi Tal wurden unterhalb des Ortes Namche Bazar folgende höchstliegende Schliffgrenzen erkannt: fünf Schliffgrenzen auf der orographisch rechten Talseite (Foto 194, 215, 220, 221, 224, 232, 238, 243, 244) und auch fünf auf der orographisch linken Talseite (Foto 224, 231, 238, 232, 239, 240, 242, 247). Die Schliffgrenzen im Dudh Khosi auf den Fotos 158, 160, 183, 185, 186, 189, 204, 217, 222, 225, teilweise auf Foto 232 und im Thado Khosi auf dem Foto 180 stellten hingegen keine hochglazialen Schliffgrenzen, sondern tieferliegende und demnach jüngere dar. Somit waren die Schliffgrenzen auf den Fotos 186, 189, 194, 204, 217, 222, teilweise auf Foto 232 im Gegensatz zu denen Kuhles (2005:Foto 229) keine, die den Maximalstand des vorzeitlichen Haupttalgletschers anzeigten.

Die höchstliegende Schliffgrenze auf der orographisch linken Talseite im Bereich vom Ort Poyan lag auf einer Höhe von ca. $3.850 \mathrm{~m}$. Zwei weitere hangabwärts, also tieferliegende jüngere Schliffgrenzen lagen auf ca. 3.200 und $2.700 \mathrm{~m}$ Höhe. Bei einem rezenten Haupttalboden auf ca. 1.800 Höhenmetern würden diese Schliffgrenzen Eismächtigkeiten von 900, 1.400 und maximal 2.050 m anzeigen. Im Gegensatz dazu lag bei Kuhle (2005:Foto 232) die hochglaziale Schliffgrenze in diesem Dudh Khosi Talbereich bei ca. $2.700 \mathrm{~m}$. Die mit der vorliegenden Arbeit hier ausgemachte höchstliegende Schliffgrenze würde gegenüber den Befunden von Kuhle (2005) einen Eismächtigkeitsunterschied von $1.150 \mathrm{~m}$ angeben (Foto $231,238)$. 


\section{WEITERE GEOMORPHOLOGISCHE FORMEN}

Es konnten im Dudh Khosi Tal talabwärts des Ortes Lukla neben vorgefundenen Schliffgrenzen, Erosionsrinnen, Abbruchgebieten im Anstehenden sowie Trog- und Schluchtprofilen folgende Formen ausgemacht werden: zerschnittenes Moränenmaterial (Foto 209, 210, 211, 212, 213, 219, 235), aufgeschlossenes Moränenmaterial (Foto 226, 227, 228, 229, 230, 234), Ufer- bis Endmoränen (Foto 214, 222, 224), Grundmoränen (Foto 214, 217 , 218, 219, 220, 221, 222, 224, 231), ein erratischer Block (Foto 233), Murmoränenfächer / kegel (Foto 218, 221, 222, 224, 229, 231), Sturzfächer / -kegel aus Moränenmaterial (Foto 222), geschliffenes Anstehendes, oft mit glazifluvialen Spülformen, oder abgeschliffene Blöcke (Foto 213, 214, 217, 218, 219, 220, 221, 222, 223, 224, 227, 236, 237), Anstehendes mit deutlich ausgebildeter glazifluvialer Erosionsrinne und Mikroerosionsformen (Foto 223) sowie Strudeltöpfe (Foto 214, 216, 222).

\section{SEDIMENTPROBEN}

Im Talabschnitt vom Ort Lukla zum Ort Kharikhola wurde eine Sedimentprobe (15. Probe, Foto 230) entnommen.

\section{GEOMORPHOLOGISCHE KARTE}

Die geomorphologischen Formen wurden auf der Karte 27 visualisiert.

\section{ABGLEICH DER BEFUNDE MIT ANDEREN FORSCHUNGSARBEITEN}

Im Talbereich zwischen den Orten Lukla und Kharikhola wendete Kuhle (2005:Fig. 11) geomorphologische Analysen an, andere Forscher jedoch nicht. Kuhle (2013a) verwies jeweils auf der orographisch rechten Talseite in den Tälern Poyan Khola auf $2.800 \mathrm{~m}$ Höhe und im Khari Khola auf 2.430 m Höhe auf Moränen mit nicht erratischen Blöcken. In Ergänzung zu den Befunden von Kuhle (2005:Fig. 11) und Kuhle (2013a:Foto 7 und 8, Sedimentproben) konnten im Talabschnitt zwischen den Orten Lukla und Kharikhola weitere folgende geomorphologische Formen ausgemacht werden: zerschnittenes Moränenmaterial (Foto 209-213, 235), weiteres aufgeschlossenes Moränenmaterial (Foto 226-230, 234), Grundmoränenmaterial (Foto 219, 222, 231), ein erratischer Block (Foto 233), Murmoränenfächer / -kegel (Foto 222, 229, 231), Sturzfächer / -kegel aus Moränenmaterial (Foto 222), ein Moränenzug (Foto 222), geschliffenes Anstehendes, oft mit glazifluvialen Spülformen, oder abgeschliffene Blöcke (Foto 213-216, 219-220, 222-223, 227-229, 236237), Anstehendes mit deutlich ausgebildeter glazifluvialer Erosionsrinne und 
Mikroerosionsformen (Foto 223) sowie Strudeltöpfe (Foto 215 - kleine Strudeltöpfe, 216, 222). Daneben wurden zu denen von Kuhle (2005) zusätzliche Schliffgrenzen ausgemacht.

\subsubsection{Vom Ort Kharikhola bis zum Ort Mukli}

Im Talabschnitt von Kharikhola bis Mukli wurden 18 Fotos (Foto 238-255) aus einer großen Anzahl ausgesucht. Die Standorte für die Fotos, der Sedimentproben sowie der Verlauf der Talquerprofile können der Karte 28 entnommen werden. Die geomorphologische Analyse im unteren Dudh Khosi Talbereich ergab folgende Ergebnisse für die hocheiszeitliche Vergletscherung:

\section{TALQUERPROFILE UND SCHLIFFGRENZEN}

Das mittlere bis untere Dudh Khosi Tal vom Ort Lukla bis Kharikhola stellte südlich von Bumburi, zwischen Lakhu und Budhubar, bei Budhubar, bei Bakhor, zwischen Mukli und Kangel einen schluchtförmigen Trog dar (Talquerprofil 17, Foto 239; Talquerprofil 18, Foto 240, 242; Talquerprofil 19, Foto 244; Talquerprofil 20, Foto 245; Talquerprofil 21, Foto 247; Talquerprofil 22, Foto 255). Im Solu bzw. im Dudh Khosi Tal wurden unterhalb des Ortes Namche Bazar folgende höchstliegende Schliffgrenzen ausgemacht: fünf Schliffgrenzen auf der orographisch rechten Talseite (Foto 194, 215, 220, 221, 224, 232, 238, 243, 244) und auch fünf auf der orographisch linken Talseite (Foto 224, 231, 238, 232, 239, 240, 242, 247). Die Schliffgrenzen im Dudh Khosi auf den Fotos 158, 160, 183, 185, 186, 189, 204, 217, 222, 225, teilweise auf Foto 232 und im Thado Khosi auf dem Foto 180 stellten hingegen keine hochglazialen Schliffgrenzen, sondern tieferliegende, also jüngere dar. Somit waren die Schliffgrenzen auf den Fotos 186, 189, 194, 204, 217, 222, teilweise auf Foto 232 im Gegensatz zu denen von Kuhle (2005:Foto 229) keine, die den Maximalstand des vorzeitlichen Haupttalgletschers anzeigten.

Eine höchstliegende Schliffgrenze auf der orographisch linken Dudh Khosi Talseite talabwärts der Khari Khola Konfluenz in einer Höhe von etwa 2.730 m ließ bei einem rezenten Haupttalboden auf ca. 1.370 Höhenmetern auf eine Eismächtigkeit von $1.360 \mathrm{~m}$ schließen (Foto 232). Südwestlich von Khari Khola bzw. südlich von Bumburi war eine weitere höchstliegende Schliffgrenze auf der orographisch linken Dudh Khosi Talseite in einer Höhe von etwa $2.280 \mathrm{~m}$ ausmachbar und zeigte eine hochglaziale Eismächtigkeit von $1.120 \mathrm{~m}$ - rezenter Haupttalboden auf ca. $1.160 \mathrm{~m}$ Höhe - an (Foto 239). Nach Kuhle (2005:Fig. 4) lag die Eismächtigkeit hier bei ca. $700 \mathrm{~m}$. Südlich von Lakhu war eine Schliffgrenze auf der orographisch linken Dudh Khosi Talseite auf einer Höhe von ca. 2.100 
m ausgebildet, was bei einem rezenten Haupttalboden bei ca. 1.000 m Höhe auf eine Eismächtigkeit von ca. $1.100 \mathrm{~m}$ hindeutete (Foto 240). Nach Kuhle (2005:Fig. 4) lag die Eismächtigkeit in diesem Talbereich ebenfalls bei ca. $700 \mathrm{~m}$. Auf Foto 247 wurde diese Schliffgrenze aus geringerer Entfernung fotografiert. Auf der orographisch rechten Talseite konnten ebenfalls Schliffgrenzen entdeckt werden. Die Schliffgrenze auf den Fotos 243 und 244 links im Bild auf ca. 2.250 Höhenmetern verwies bei einem rezenten Haupttalboden bei ca. 1.100 m Höhe auf eine vorzeitliche Eismächtigkeit von ca. 1.150 m. Die auf dem Foto 244 rechts im Bild auf ca. $2.950 \mathrm{~m}$ Höhe auf eine Mächtigkeit von ca. $1.800 \mathrm{~m}$ - rezenter Haupttalboden hier auf ca. 1.150 m Höhe; nach Kuhle (2005:Fig. 4) lag die Eismächtigkeit hingegen bei ca. $650 \mathrm{~m}$.

\section{WEITERE GEOMORPHOLOGISCHE FORMEN}

Neben aufgefundenen Schliffgrenzen und Erosionsrinnen konnten im oberen bis mittleren Teil des Imja Khola talabwärts der Orte Periche und Dingboche folgende Formen ausgemacht werden: Anrissbereiche (Foto 239, 240, 242, 243, 245, 247), geschliffenes Anstehendes, oft mit glazifluvialen Spülformen (Foto 241, 248, 249), Murschwemmfächer / -kegel (Foto 243), Mischfächer / -kegel (Foto 243), Sturzschuttfächer / -kegel (Foto 245, 247), ein erratischer Block (Foto 246) sowie Moränen (Foto 250, 251, 252, 253).

\section{SEDIMENTPROBEN}

Im Talabschnitt vom Ort Kharikhola zum Ort Mukli wurden drei Sedimentproben (16.-18. Probe, Foto 253) entnommen.

\section{GEOMORPHOLOGISCHE KARTE}

Die geomorphologischen Formen wurden auf der Karte 29 visualisiert.

\section{ABGLEICH DER BEFUNDE MIT ANDEREN FORSCHUNGSARBEITEN}

Im Talbereich zwischen den Orten Kharikhola und Mukli führte Kuhle (2005:Fig. 11) sowie Kuhle (2013a:Foto 8, Sedimentproben) im Gegensatz zu allen anderen Forschern geomorphologische Analysen durch. Die Befunde von Kuhle (2005) reichten talabwärts bis zum Deku Khola; die von Kuhle (2013a) bis unterhalb des Deku Khola ins Gebiet der Siedlung Jubing, wo er in $1.550 \mathrm{~m}$ Höhe 'washed ground moraine' aufnahm. Ergänzend zu den Befunden von Kuhle konnten im Talabschnitt talabwärts des Deku Khola alle o.g. geomorphologischen Formen ausgemacht werden. Die o.g. ausgemachten Schliffgrenzen 
ließen auf Eismächtigkeiten im Dudh Khosi Tal talabwärts der Khari Khola Konfluenz von $1.360 \mathrm{~m}$ (Foto 232, orographisch linke Talseite), $1.120 \mathrm{~m}$ (Foto 239, orographisch linke Talseite), $1.800 \mathrm{~m}$ (Foto 244 rechts im Bild, orographisch rechte Talseite), $1.150 \mathrm{~m}$ (Foto 243, 244 links im Bild, orographisch rechte Talseite) und von $1.100 \mathrm{~m}$ (Foto 240, orographisch linke Talseite) schließen. Nach Kuhle (2005:Fig. 4) lag die Eismächtigkeit hier in diesen Bereichen bei 700 bis $650 \mathrm{~m}$. Somit ergaben die in der vorliegenden Arbeit vorgefundenen Schliffgrenzen eine mächtigere hocheiszeitliche Eisbedeckung, als sie Kuhle (2005) sowie Kuhle (2013a) vorgab. Da Schliffgrenzen allein ohne weitere glazialgeomorphologische Befunde auch petrographisch erklärbar sein könnten, konnten weitere zusammen betrachtete ausgemachte glaziale Formen für eine eindeutige glaziale Entstehung der Schliffgrenzen gelten. Beispielsweise deuteten die Murmoränenfächer auf Foto 231 darauf, dass höherliegendes Moränenmaterial hangabwärts transportiert wurde; daneben war dieses Material auf dem Hang - durch Erosionsrinnen zerschnitten - erkennbar. Somit konnte diese Schliffgrenze durch das Moränenmaterial auf dem Hang als glazial gesehen werden. Auf Foto 239, 240, 242, 243 und 247 sind daneben Erosionsrinnen und Anrissbereiche hervorgehoben, die auf Lockermaterialien hindeuteten. Diese Lockermaterialien wiesen vorwiegend kantengerundete Blöcke auf, was auf Moränenmaterial hindeuten würde. Somit konnten diese Akkumulationen für die angedeuteten glazialen Schliffgrenzen sprechen. Der auf Foto 241 abgebildete Gletscherschliff mit strudeltopfartiger Ausformung deutete bei einer relativen Höhe von etwa $680 \mathrm{~m}$ auf eine Eismächtigkeit von über $680 \mathrm{~m}$, da der Gletscherschliff hangaufwärts weiter reichte. Die angegebene Eismächtigkeit von Kuhle (2005:Fig. 4) von ca. 700 m würde dafür nicht gänzlich ausreichen, wobei jedoch der glaziäre Flankenschliff mit strudeltopfartiger Erosionsform auf Foto 248 und der kantengerundete bis gerundete erratische Block auf Foto 246 für die angegebene Eismächtigkeit von Kuhle sprechen würde.

Da die am weitesten talabwärts liegende, hangaufwärts höchstausgemachte Schliffgrenze eine Eismächtigkeit von $1.100 \mathrm{~m}$ anzeigte, war es nicht ganz eindeutig, ob hier die maximale Vergletscherung nur bis zum Konfluenzbereich zum Hinku Khola reichte, so wie sie Kuhle (2005) in Fig. 4 mit der eingezeichneten weißen Gletscherfläche und einem Fragezeichen andeutete; hierbei legte er sich nicht fest, da seine geomorphologisch ausgemachten Formen nur bis zum Deku Khola reichten, bei Kuhle (2013a) bis unterhalb des Deku Khola bis zum Ort Jubing. Die von ihm angegebenen Eismächtigkeiten von 700 bis $650 \mathrm{~m}$ waren somit extrapoliert, da z.B. keine Schliffgrenzen angegeben wurden. Unterhalb der Hinku Khola Konfluenz wurden mit der vorliegenden Arbeit weitere Formen angesprochen, wie etwa ein 
möglicher glaziärer Flankenschliff mit glazifluvialen Spülformen (Foto 249) und eine Akkumulation - vermutlich Moränenmaterial (Foto 250-253) im Sikhu Khola (Foto 255), die auf eine glaziale Genese schließen lassen könnten.

Bei der erstgenannten Form war der Gletscherschliff als solcher in der Ansprache vermutbar, da zwar die Verwitterungsprozesse bzw. die Exfoliation bei den hier hauptsächlich anstehenden Gesteinen - wie Phyllit und Schiefer - eine Rolle spielen könnten, hingegen aber die konkav ausgebildeten Spülformen eher für einen Gletscherschliff bzw. eine Gletscherausspülung sprachen. Laut der geologischen Karten war bei dieser Form auf Foto 249 der vorliegenden Arbeit das Vorkommen folgender Gesteine möglich: graue, dunkelgraue und grüne Phyllite, Quarzite, aber auch Lagen von Schiefer, Marmor, Skarn (vgl. geologische Karte Solukhumbu) bzw. Schiefer, zwischengeschaltet mit Sandstein, Quarzit oder Marmor (vgl. geologische Karte Solukhumbu 1) bzw. Schiefer, Quarzit (7a, c) (vgl. geologische Karte Nepal).

Für eine zerschnittene Moränenablagerung würden folgende Punkte sprechen: kantige bis teilweise gerundete Blöcke (Foto 250-253) sowie die Mischung von Grob- und Feinmaterial (Foto 251-253). Die vielfach auftretenden kantigen Gesteine könnten allerdings mit der beteiligten Gesteinsart im Zusammenhang stehen. Es kamen hier nach den geologischen Karten folgende Gesteine vor: Quarzchloritschiefer, Quarzit (vgl. geologische Karte Nepal) bzw. graue, dunkelgraue und grüne Phyllite, Quarzite, aber auch Lagen von Schiefer, Marmor und Skarn (vgl. geologische Karte Solukhumbu) bzw. Schiefer, zwischengeschaltet mit Sandstein, Quarzit oder Marmor (vgl. geologische Karte Solukhumbu 1) bzw. Schiefer, Augengneis, Intrusionen von Granit (vgl. geologische Karte Solu). Die vorwiegend auftretenden Gesteinsarten Phyllit und Schiefer waren durch deren geologische Eigenschaften ungeeignet kantengerundete oder gar gerundete Gesteine auszuformen. Vorgefundene kantengerundete Blöcke müssten demnach eher Quarzit- oder Gneisgesteine sein. Die entnommene Sedimentprobe Nummer 18 verwies darauf, dass alle Korngrößen von Ton bis Sand neben den genannten Gesteinen bzw. Blöcken auftraten. In dieser Probe waren 6,26 \% Ton, 22,11\% Schluff (2,31\% Feinschluff, 6,99\% Mittelschluff, 12,81\% Grobschluff) und 71,63\% Sand (36,55 \% Feinsand, 22,30\% Mittelsand, 12,78 \% Grobsand) enthalten; somit war die Ablagerung unsortiert. Bei der Kornformenanalyse wurden insgesamt 615 Körner ausgezählt (149 in der Feinsand-, 363 in der Mittelsand- und 103 in der Grobsandfraktion). Somit lag das Hauptaugenmerk der Untersuchung auf der Mittelsandfraktion. Die Kornformenanalyse deutete durch das Auftreten von kantigen bis rundkantigen, rundkantigen 
bis angerundeten und gerundeten Körnern auf eine Einordnung in die Gruppe glazial gebrochen / frisch verwittert mit Anteilen an fluvialer Polierung hin. Da bei diesem Standort wie bei der Korngrößenanalyse gezeigt werden konnte - Korngrößen von Ton bis Sand und wenige kantengerundete Blöcke vorkamen, wird es wohl so sein, dass die Körner glazial gebrochene sind. Es wurde auch neben dem höchstwahrscheinlichen glazialen Einfluss eine glazifluviale Einwirkung auf die Sedimente - da die Körner hin zum fluvial polierten Korn tendierten - deutlich. Generell würde die Ablagerung aufgrund ihres terrassenähnlichen Auftretens für eine Grundmoränenakkumulation sprechen. Auch das Talquerprofil Nummer 22 des Tales Sikhu Khola - welches einem schluchtförmigen Trog nahe kam - würde für eine vorzeitliche Vergletscherung dieser Talbereiche sprechen. Der weiter im Dudh Khosi talabwärts gelegene aufgefundene See Baluwa Pokhri (Foto 254) könnte hierbei auf die Staufähigkeit der Sedimente hindeuten. Diese genannten Formen müssen jedoch in der Zukunft genauer untersucht werden, da sie eine enorme letztglaziale oder aber auch vorletztglaziale Vergletscherung anzeigen würden. Die relativen Höhenangaben beim geschliffenen Anstehenden und der Moränenablagerung würden hierbei auf eine minimale vorzeitliche Gletschermächtigkeit hinweisen. 


\subsection{Kurzzusammenfassung}

Das Hauptuntersuchungsgebiet Solukhumbu wurde talabwärts der Ortschaften Thokla und Chhukhung bis talabwärts des Konfluenzbereiches Dudh Khosi und Hinku Khola untersucht. Hierbei wurden im Khumbu und Solu geomorphologische Analysen mit Sedimentanalysen durchgeführt, wobei im erstgenannten Gebiet auch Satellitenbildanalysen zur Anwendung kamen.

Im Khumbu bzw. im Talbereich zwischen den Orten Thokla / Chhukhung und Namche Bazar konnten folgende Formen ausgemacht werden: Trogtal, schluchtförmiger Trog, Schliffgrenze, glaziärer Dreieckshang, glaziärer Flankenschliff, glazial überschliffenes anstehendes Gestein, oft mit glazifluvialer Spülform bzw. Strudeltopf, glazifluviale Schotterflur / Terrasse, Moräne (zumeist hochglaziale Grundmoräne gegenüber jüngerer Ufermoräne, Seitenmoräne, Endmoräne), zerschnittene Grundmoräne, Grundmoränenpodest, Erosionsrinne, Fächer- / Kegelform (Sturzschutt-, Sturzmoränen-, Misch-, Murschutt-, Murmoränen-, Murschwemm-, Schwemmschuttfächer / -kegel), Sturz- und Murfächer / kegel aus Moränenmaterial und glazifluvialem Material, Sander, Lawinenkegel, Fels- / Bergsturzablagerung, Abbruch- / Abrutschbereich, Anrissbereich im Moränenmaterial, erratischer Block, Block mit deutlicher glazifluvialer Spülform, kantengerundeter bis gerundeter Block, Block, oft in Rundhöckerform, sowie Solifluktionsform. Bis auf die reinen Schuttfächer / -kegel waren die Fächer / Kegel nur in Verbindung mit Grundmoränenmaterial zu erklären; somit stellten allein diese letztgenannten Formen ein Indiz für eine ehemalige Vergletscherung dar.

Talabwärts gesehen konnte anhand unterschiedlicher Schliffgrenzen ein vorzeitlicher hochglazialer Gletscher im Khumbu bzw. im Imja Khola rekonstruiert werden: mit einer jeweils ungefähren Eismächtigkeit von 1.430 sowie von $1.040 / 1.050$ bis $1.100 \mathrm{~m}$ im Talbereich zwischen den Orten Thokla und Periche, von $1.200 \mathrm{~m}$ im Talbereich etwa zwischen den Orten Chhukhung und Dingboche, von 1.020, 1.040 / 1.050 bis $1.200 \mathrm{~m}$ im Talbereich zwischen den Orten Dingboche / Periche und Pangboche, von 800, 1.000 bis 1.020 $\mathrm{m}$ im Talbereich zwischen den Orten Pangboche und Phortse / Tengboche, von 1.020 bis $1.500 \mathrm{~m}$ im Talabschnitt zwischen den Orten Phortse / Tengboche und Namche Bazar. Diese Befunde der vorliegenden Arbeit stimmten in etwa mit denen von Kuhle (2005) überein.

Die zeitlichen Einordnungen der von Kuhle (2005) untersuchten Moränen waren unter Betrachtung der jeweils umgebenden Formen gegenüber denen der parallel aufgeführten Forschungsarbeiten am wahrscheinlichsten bzw. am eindeutigsten nachvollziehbar. Die 
Rechtfertigung dieser Feststellung war das Resultat der Berücksichtigung enorm vieler geomorphologischer Formen inklusive deren Lagebezug bzw. der angewendeten Methode / Arbeitstechnik durch Kuhle. Es wurden Moränen relativ, aber auch durch ${ }^{14} \mathrm{C}$-Datierungen und Lichenometrie von ihm datiert. Anderweitige zeitliche Einordnungen von Formen konnten sowohl anhand der Indikatoren von Kuhle (2005) als auch der ergänzenden Indikatoren durch die vorliegende Arbeit widerlegt werden. Hierdurch konnte z.B. hochglazial ausgelegten Ufermoränen oft selbst ein spätglaziales Alter nicht zugesprochen werden. Untermauert wurde die kritische Sicht verschiedentlicher Einordnungen auch dadurch, dass die hier aufgeführten Forscher aus dem glazialen Formeninventar lediglich Moränen - oft nur Wallmoränen - als Indizien betrachteten. Zudem gingen sie häufig nicht auf den genauen Moränentyp ein oder derselbe wurde anderweitig angesprochen, wie es z.B. bei der Ufermoräne der Fall war, auf welcher der Ort Tengboche lag. Andererseits aber legten sich einige Forscher zeitlich nicht genau fest. Bei Übereinstimmung der zeitlichen Einordnung anderer Forscher mit der von Kuhle (2005) wurde in der vorliegenden Arbeit der von letztgenanntem mehr Bedeutung gegeben, da diese infolge einer detaillierten Bestandsaufnahme am aussagekräftigsten war. Einige von Forschern visualisierte Verläufe von Moränenzügen konnten in natura nicht genau nachvollzogen werden, andere wurden durch sie nicht kartiert. Die nach Barnard, Owen, Finkel (2006) visualisierten Formen 'fans' und 'landslides' wurden durch die vorliegende Arbeit genetisch zugeordnet. Einige der von ihnen aufgenommenen Formen konnten entweder nicht als solche bestätigt werden - wobei sich z.B. die Form 'fan’ oft als glaziärer Dreieckshang mit darauf lagernden Grundmoränen darstellte, oder wurden nicht in der Legende aufgeführt und waren demnach nicht zuordbar. Ufermoränen nach Heuberger, Weingartner (1985) waren nicht, wie sie angaben, durch die Haupttalgletscher des Imja Khola und des Bhote Khosi zu erklären, sondern vielmehr durch Nebentalgletscher. Somit handelte es sich z.B. bei den Ufermoränen bei Khumjung um keine hochglazialen, sondern um jüngere. Probenahmestellen von Forschern - wie z.B. Richards et al. (2000), Finkel et al. (2003) und Barnard, Owen, Finkel (2006) - konnten im Gelände nicht genau aufgefunden werden; genaue Koordinatenangaben hätten dieses ermöglicht.

Dahingegen bestätigten sich enorm viele Formen von Kuhle (2005), einige konnten in Gänze aufgrund der Fülle seiner Befunde nicht überprüft werden. Lediglich an einer Stelle rund um Dingboche musste die durch Kuhle als Grundmoräne mit nicht erratischen Blöcken angesprochene Form als Grundmoräne mit erratischen Blöcken ausgelegt werden. Ergänzend zu den Befunden von Kuhle (2005) wurden mit der vorliegenden Arbeit im gesamten Gebiet 
des Khumbu folgende Formen ausgemacht: glaziäre Dreieckshänge, Rundhöcker bzw. Blöcke in Form eines Rundhöckers oder mit deutlich glazifluvialen Spülformen, geschliffenes Anstehendes zumeist mit glazifluvialen Spülformen, Strudeltöpfe, durch Schmelzwasserabflüsse entstandene Anrissbereiche im Moränenmaterial, Anrissbereiche von Sturzschuttfächern / -kegeln, weitere Grundmoränenreste bzw. durch Erosionsrinnen zerschnittene Grundmoränen oder zerschnittenes disloziertes Moränenmaterial, zerschnittenes Ufermoränenmaterial, Ufer- bis Endmoränen, weitere deutlich erkennbare Moränenwälle bzw. übrig gebliebene zerschnittene Moränengrate, Fels- / bzw. Bergsturzablagerungen, Solifluktionsformen (Blockgletscher / Schuttloben), glazifluviale Terrassen, gerundete bis gut gerundete Gesteine sowie verschiedene Fächer- / Kegeltypen wie etwa Sturzschuttfächer / kegel (Nummer 1 = welche, die Moränenmaterial überlagern (1a) oder von Schnee, Lawinen überlagerte (1b)) oder Sturzfächer / -kegel aus Moränenmaterial oder glazifluvialen Materialien (Nummer 2), Mischfächer / -kegel (Nummer 3 = hauptsächlich aus Schutt (3a), hauptsächlich aus Moränenmaterial (3b), welche, die präexistierendes Moränenmaterial überlagern (3c) oder von anderen Prozessen überlagerte (3d)), Murfächer / -kegel (Nummer 4 = Murschuttfächer / -kegel mit einem hohen Schuttanteil (4a), Murmoränenfächer / -kegel mit einem hohen Moränenanteil (4b), Murschwemmfächer / -kegel mit viel Feinmaterial (4c) oder von anderen Prozessen überlagerte (4d)), Schwemmfächer / -kegel (Nummer $5=$ Schwemmschuttfächer / -kegel mit Schutt- und Moränenmaterial (5a), Sander aus Moränenmaterial mit Bezug zum Gletscherrand (5b), Schwemmfächer / -kegel aus hauptsächlich Moränenmaterial (5c)) und zerschnittene Moränen (Nummer 6).

Die vom Khumbu erstellte Oberflächenbedeckungskarte führte zum Ergebnis, dass die topographische Karte gegenüber der wirklichen Ausgestaltung der Oberflächen weniger detailliert war. Vor allen Dingen ließen sich Unterschiede in der Schuttbedeckung ausmachen.

Im Solu bzw. im Talbereich zwischen dem Ort Namche Bazar bis talabwärts des Konfluenzbereiches zum Hinku Khola konnten folgende Formen ausgemacht werden: Trogtal, schluchtförmiger Trog, Schliffgrenze, glaziärer Dreieckshang, Ufer- bis Endmoräne, Grundmoränenmaterial, zerschnittenes Moränenmaterial, aufgeschlossenes Moränenmaterial, Erosionsrinne, Sturzschuttfächer / -kegel, Sturzmoränenfächer / -kegel, Mischfächer / -kegel, Murmoränenfächer / -kegel, Murschwemmfächer / -kegel, glazifluviale Terrasse sowie Blöcke, oft in Rundhöckerform bzw. abgeschliffene Blöcke oder mit glazifluvialen Spülformen und glazial überschliffenes anstehendes Gestein, oft mit glazifluvialen 
Spülformen, Rundhöcker, Strudeltopf, Anstehendes mit deutlich ausgebildeter glazifluvialer Erosionsrinne und Mikroerosionsformen, erratischer Block sowie Anrissbereich.

Talabwärts gesehen konnte im Solu bzw. im Dudh Khosi Tal ein vorzeitlicher hochglazialer Gletscher rekonstruiert werden: mit einer ungefähren Eismächtigkeit von $1.020 \mathrm{~m}$ im Talbereich zwischen den Orten Namche Bazar und Monjo und von $1.665 \mathrm{~m}$ im Talbereich zwischen den Orten Ghat und Lukla. Diese Befunde stimmten in etwa mit denen von Kuhle (2005) überein. Die höchstliegende Schliffgrenze im Talbereich beim Ort Poyan sowie zwei tieferliegende verwiesen auf Eismächtigkeiten von 900, 1.400 und maximal $2.050 \mathrm{~m}$. Im Gegensatz dazu lag bei Kuhle (2005) die hochglaziale Schliffgrenze in diesem Dudh Khosi Talbereich bei ca. 2.700 Höhenmetern. Die in der vorliegenden Arbeit gezeigte am Hang höchstliegende Schliffgrenze bedeutete $\mathrm{zu}$ den Befunden von Kuhle (2005) einen Eismächtigkeitsunterschied von 1.150 m. Talabwärts der Khari Khola Konfluenz ließen die ausgemachten Schliffgrenzen im Dudh Khosi Tal auf Eismächtigkeiten in der Reihenfolge von 1.360, 1.120, 1.800, 1.150 und $1.100 \mathrm{~m}$ schließen. Nach Kuhle (2005) lag die Eismächtigkeit hingegen hier in diesen Bereichen bei 700 bis $650 \mathrm{~m}$. Da die am weitest haupttalabwärts liegende am Hang höchstausgemachte Schliffgrenze eine Eismächtigkeit von $1.100 \mathrm{~m}$ anzeigte, war nicht ganz eindeutig, ob hier die maximale Vergletscherung nur bis zum Konfluenzbereich zum Hinku Khola reichte, so wie sie Kuhle (2005) mit der visualisierten weißen Gletscherfläche und einem Fragezeichen andeutete. Es würden auch unterhalb der Hinku Khola Konfluenz weitere mit der vorliegenden Arbeit angesprochene glaziale Formen, wie etwa geschliffenes Anstehendes mit glazifluvialen Spülformen, Moränenmaterial sowie ein schluchtförmiger Trog im Sikhu Khola, für eine Vergletscherung zeugen. Um eine beweiskräftige Aussage über die letztglaziale Vergletscherung im Bereich talabwärts der Hinku Khola Konfluenz treffen zu können, wären jedoch weitere Geländearbeiten erforderlich.

Weitere Forscher, wie Heuberger, Weingartner (1985), nahmen im Solu Moränen bei Phakdingma auf, Bäumler et al. (1991) Bodenprofile. Bodenbefunde allein führen jedoch nicht $\mathrm{zu}$ einer eindeutigen bzw. beweiskräftigen Aussage über eine vorzeitliche Vergletscherung. Die durch Heuberger, Weingartner (1985) untersuchten Moränen sollten Ufermoränen des ehemaligen Haupttalgletschers sein - da hier die Moränen jedoch formfrisch auftraten, lag es adäquat zum Khumbu nahe, dass diese keine hochglazialen Ufermoränen, sondern jüngere waren. Außerdem war davon auszugehen, dass diese Moränen dem Panyali 
Drangka Nebentalgletscher entstammen. Heuberger, Weingartner (1985) schlossen nicht aus, dass weitere Moränenwälle im Pharag - als die, die sie visualisierten - auszumachen waren. Im Talbereich zwischen den Orten Ghat und Lukla führten Fushimi (1978) und Kuhle (2005) geomorphologische Analysen durch. Heuberger, Weingartner (1985) nahmen ausschließlich Bodenprofile rund um Ghat auf und Fushimi (1978) visualisierte bei Ghat Seesedimente. Heuberger, Weingartner (1985) sprachen talaufwärts von Chaunrikharka ebenfalls von Stausedimenten, wobei sie aber die gesamte Akkumulation als Stausedimentterrasse ansprachen und nicht als eine Moräne. Bei Chaunrikharka sah Fushimi (1978) die untere Terrasse als Moräne der U1 Serie und die obere als Sedimente, welche glazial oder auch fluvial entstanden waren, an. Heuberger, Weingartner (1985) gaben an, dass sich nördlich bis nordwestlich von Lukla Bergsturzablagerungen bei Chaunrikharka befanden. Dass es sich bei beiden o.g. Terrassen, wie in der vorliegenden Arbeit festgestellt, um Grundmoränenpodeste handelte - bei der oberen mit darauf abgelagerten Murfächern / -kegeln - belegte auch Kuhle (2005). Somit war den Resultaten von Kuhle und Fushimi in Hinsicht auf die Geomorphologie zuzustimmen, wobei die Analysen von Kuhle detaillierter waren, da bei Fushimi viele geomorphologische Formen wie etwa Murfächer- / kegel nicht einbezogen wurden. Ebenso unterschied letztgenannter die Talprofile nicht genauer: er trennte das Trogvom Kerbtal, ohne, wie Kuhle (2005), die Spezialform schluchtförmiger Trog einzubeziehen. Somit wurde sogar anhand der Berücksichtigung nur dieser einen Form deutlich, warum Kuhle gegenüber Fushimi ein viel weiter talabwärts reichendes vorzeitliches Gletscherende aufzeigte. Heuberger, Weingartner (1985) beschränkten sich auf das Gebiet Khumjung bis Lukla.

$\mathrm{Zu}$ den Forschungsergebnissen von Kuhle (2005) konnten im Solu ferner folgende geomorphologische Formen ausgemacht werden: Schliffgrenzen, glaziäre Dreieckshänge, geschliffenes Anstehendes bzw. Blöcke zumeist mit glazifluvialen Spülformen / Erosionsrinnen sowie Mikroerosionsformen, glazifluviale Terrassen, Grundmoränenmaterial, zerschnittenes Moränenmaterial, aufgeschlossenes Moränenmaterial, zerschnittenes glazifluviales Material, Sturzschuttfächer / -kegel, Sturzfächer / -kegel aus Moränenmaterial, Mischfächer / -kegel, Murschwemmfächer / -kegel, Strudeltöpfe, subglaziale Schmelzwasserrinnen sowie Murmoränenfächer / -kegel, erratische Blöcke, Moränenzug / Moräne sowie Anrissbereiche. 


\section{KRITISCHE AUSEINANDERSETZUNG MIT DEN}

ANGEWENDETEN METHODEN BZW. ARBEITSTECHNIKEN UND FORSCHUNGSARBEITEN ZUR VERGLETSCHERUNGSGESCHICHTE DES HAUPTUNTERSUCHUNGSGEBIETES SOLUKHUMBU

\subsection{Problematische Aspekte der Methoden bzw. Arbeitstechniken}

\subsubsection{Geomorphologische Analyse}

Die Methode der Geomorphologie hat wenige Fehlerquellen, da die Rekonstruktion des vorzeitlichen Eises auf einer Vielzahl von ausgemachten Formen und deren Lagebeziehung basiert. Somit sollte die geomorphologische Analyse umfassend sein. Ein Vorteil der geomorphologischen Bestandsaufnahme ist es, dass die Formen tatsächlich im Gelände wiederauffindbar sind. Es ist jedoch möglich zu wenige Formen in den Lagezusammenhang zusammenzubringen, Formen anderweitig anzusprechen, unterschiedlich zu benennen oder einen Oberbegriff der Formen zu nennen, ohne dass eine Genese nachvollziehbar ist. Es gibt auch diesen Fall, dass einige Forscher zwar die Form an sich zutreffend ansprachen, aber nicht auf das Material der Form eingingen, wodurch z.B. ein indirekter Beleg für eine Vergletscherung hätte geliefert werden können. Außerdem werden bei einer undetaillierten Ausführung dieser Methode Formen (z.B. glaziäre Dreieckshänge, glazigene Kerbtäler) oder Zwischenformen (z.B. schluchtförmiger Trog oder trogförmige Schlucht) nicht mit einbezogen. Kuhle wiederum berücksichtigte solche letztgenannten Formen in den Untersuchungsgebieten. Eine Schwierigkeit dieser Methode stellen ältere Formen dar, die oft nicht mehr erkennbar sind oder von neuen Prozessen überlagert worden sind. Somit ist es ein Problem komplexe Formen zu untersuchen, die nicht unter heutigen Bedingungen entstanden (vgl. Leser 1977:2).

Bei den Grob- und Feinsedimentanalysen können beispielsweise folgende Fehlerquellen auftreten: Bei den Gesteinsformen liegen sie bei der Methode nach Reichelt (1961) zitiert nach: Köster (1964:174) in der visuellen Anwendung, in unterschiedlichen Gesteinsarten oder in einer zu kleinen Messreihe, wobei erstgenannte Fehlerquelle sehr gering sein soll. Auch eine genaue Abstufung in die einzelnen Zurundungsklassen soll nicht immer möglich sein (vgl. Winkler 1996:273). Bei der Formenanalyse sowie auch bei der Situmetrie muss darauf geachtet werden, dass die Gesteine eine bestimmte Längenausdehnung besitzen und dass die Messreihe nicht zu klein ist. 
Bei der Betrachtung der petrographischen Zusammensetzung kann es sein, dass z.B. innerhalb fluvialer Akkumulationen, infolge veränderter fluvialer Anschüttungen sowie solifluidaler Zufuhr und Überprägungen, vertikale petrographische Zusammensetzungsänderungen übereinanderliegender Schichten existieren. Die petrographische Zusammensetzung kann zudem von den Gesteinseigenschaften (Ausgangsgestein, Resistenz, Verwitterung und Transport) abhängen; Quarze kommen somit beispielsweise in älteren Ablagerungen häufiger vor. Aber auch die Gesteinsgrößenklassen spielen eine Rolle, die den Vergleich nur bei etwaiger Gleichheit der Größenklasse möglich macht. (vgl. Stäblein 1970:33, 35, 39)

Beim Siebverfahren zur Korngrößenbestimmung können folgende Fehlerquellen auftreten: nicht alle Körner passieren das Sieb bzw. größere Körner klemmen fest (vgl. Köster 1960:44, 111; vgl. Leser 1977:262), Sedimente in Plättchenform wie etwa Glimmer gelangen in größere Korngrößenbereiche (vgl. Schlichting, Blume, Stahr 1995:115) sowie der Mahleffekt beim Sieben (vgl. Leser 1977:262). Allgemein können die Körner miteinander reagieren (vgl. Syvitski 1991:195). „Die günstigste Form der Mineralkörner für die Siebung wäre die von Kugeln und Würfeln. “(Leser 1977:261). Längliche oder elliptische Körner können hingegen, wenn die größte Kornachse die Maschen der Siebe senkrecht passiert, in kleinere Bereiche gelangen (ebd.:261). Letztendlich wird eine komplette Sortierung des Materials durch Siebung selten erreicht (vgl. Gee, Bauder 1986:393). Fehlerquellen des Pipettverfahrens liegen darin, dass die Sedimentationszeiten für Körner mit Kugelgestalt gelten - somit Körner mit Plättchenform aufgrund breitseitiger Bewegung und höherer Reibung in feinere Korngrößen einsortiert werden können, dass Temperaturschwankungen die Sedimentation stören (vgl. Schlichting, Blume, Stahr 1995:115), dass beim Aufschütteln Luftbläschen entstehen, die durch Verbindung mit Sedimentteilchen deren Fallgeschwindigkeit verändern können (vgl. Köster 1960:100), und in jeglichem abwegigen Umgang mit der Pipette (vgl. Köster 1964:125). Zudem werden die Interaktionen der Partikel untereinander nicht beachtet (vgl. Gee, Bauder 1986:394). Ebenfalls können Temperaturschwankungen, die Viskositätsveränderungen und Konvektionsströme auslösen, auftreten (vgl. Köster 1964:70, $122 \mathrm{f}$.$) .$

Bei der Kornformenanalyse kann es infolge unterschiedlich verwendeter Einteilungen der verschiedenen Korngruppierungen $\mathrm{zu}$ verschiedenen Ergebnissen kommen. Bei der Betrachtung der Korngrößenbereiche Fein-, Mittel- und Grobsand muss drauf geachtet werden, dass diese individuell interpretiert werden und ausreichend Körner untersucht werden. 


\subsubsection{Relative Datierungen}

Relative Datierungen beispielsweise anhand der Verwitterung stellen ein methodologisches Problem dar, da sie aufgrund des hydrothermalen Zersatzes des Ausgangsgesteins nicht anwendbar sind. Dieser Zersatz kann vor den Verwitterungsprozessen und vor dem Transport so stark auftreten, dass die Blöcke einer Moräne innerhalb einiger tausend Jahre zerfallen, ohne dass sie einer längeren Verwitterungsperiode ausgesetzt waren. Somit sind die meist bei den TCN-Datierungen verwendeten Granitblöcke oder unstratifizierten Blöcke auch nicht für absolute Datierungen geeignet. (vgl. Kuhle 2007b:113)

Da viele methodische Fehler bei der Lichenometrie auftreten können, ist auch diese Methode umstritten (s.h.a. Leser 1977:126).

Datierungen anhand von Bodenentwicklungen sind aufgrund der Abhängigkeit vom Klima nicht bei quartären Sedimenten geeignet, besonders aber nicht im monsunbeeinflussten Himalaja. Es gibt keine Möglichkeit, die Bodenentwicklung im Himalaja zu kalibrieren. Die Dauer der Bodenentwicklung und der Verwitterung von Moränen ist aufgrund der unterschiedlichen petrographischen Zusammensetzung und der speziellen klimatischen Situationen in Bezug auf Höhe, Topographie, Lage zu Gletschern, Niederschläge, Winde und tektonische Verhältnisse seit 20.000 Jahren mit Veränderungen der Schneegrenzlage nur ungenau bestimmbar. (vgl. Kuhle 2007b:113; vgl. Wagner 2005, 2007)

Auch Bremer (1989:362) meinte, dass sich Böden generell zonal unterscheiden, wobei ein Boden in gemäßigten Breiten nach ca. 2.000 bis 5.000 Jahren komplett entwickelt sein soll.

\subsubsection{Absolute Datierungen}

Im Gegensatz zur geomorphologischen Analyse weisen absolute Datierungen bedeutende Fehlerquellen auf:

${ }^{14} \mathrm{C}$

Die ${ }^{14} \mathrm{C}$-Datierungen sind heutzutage sehr gut kalibriert, aber das dafür notwendige organische Material ist nur sehr spärlich in Hochasien aufzufinden und die maximale Datierungsgrenze liegt bei etwa 60.000 Jahren v.H. (vgl. Kuhle, Kuhle 2010:108; s.h.a. Kuhle 2011b:959 und Kuhle 2012a:173). Radiokarbon- bzw. ${ }^{14}$ C-Datierungsmethoden sind aufgrund der gering verfügbaren organischen Substanz demnach in vergletscherten Gebieten nicht immer anwendbar (vgl. Hubbard, Glasser 2005:340), sodass viele vorzeitliche 
Gletschervorstöße nur unzureichend festgelegt sind (vgl. Owen et al. 2008:527). Außerdem sind diese Datierungen auf die feuchten Gebiete in Hochasien und auf holozäne proglaziale Akkumulationen beschränkt, die nur wenig die Vergletscherungszeiträume definieren (Röthlisberger, Geyh 1985'132; Lehmkuhl 1995, $1997^{133}$ zitiert nach: Owen et al. 2008:518). Außerdem gibt diese Methode generell nur Minimalalter an; „Die Werte dienen der Festlegung nacheiszeitlicher Minimalstände. “(Leser 1977:126). Kuhle (2011b:945) gab an, dass ${ }^{14} \mathrm{C}$-Daten für die monsunbeeinflusste Himalajaseite wie im Khumbu representativ sind. Die ${ }^{14} \mathrm{C}$-Methode soll geeignet sein, da sie sich nur indirekt auf die Produktion der ${ }^{14} \mathrm{C}$ Isotope in der Erdatmosphäre bezieht (vgl. Kuhle, Kuhle 2010:110).

Aber auch bei Vorhandensein geeigneten Materials würden die Daten nicht mehr als eine Altersbegrenzung vieler glazialer Ablagerungen zulassen, da die Gletscheraktivität oft nur indirekt mit dem Kohlenstoffkreislauf in Verbindung steht. Somit würde das RadiokarbonAlter nicht immer das Gletscherereignis anzeigen, sondern Ereignisse vor oder nach einem solchen. (vgl. Abramowski 2004:26)

Ein Vorteil der ${ }^{14} \mathrm{C}$-Methode wäre, dass das Vorkommen von ${ }^{14} \mathrm{C}$ in der Atmosphäre aufgrund dessen Durchmischung während oder seit der Eiszeit global messbar wäre und nicht - wie bei TCN-Datierungen - nur lokale Produktionsraten bestimmbar wären. Jedoch schwankt in der Atmosphäre auch der ${ }^{14} \mathrm{C}-$ Gehalt an sich (vgl. Abramowski 2004:26).

\section{OSL UND TCN}

Die absoluten Datierungsmethoden OSL und TCN erlauben Korrelationen mit MilankovicZyklen, aber weisen oft methodologische Probleme auf (vgl. Owen et al. 2008:527). Kuhle, Kuhle (2010:105 f.) schrieben, dass OSL- und TCN-Datierungen erst seit einigen Jahren in Hochasien in Anwendung gekommen, aber dass diese nicht kalibriert sind. Auch Kuhle (2011b:959; 2012a:173 f.; 2014:254) ging darauf ein, dass keine Kalibrierung der TCNDatierungen für Hochasien existiert. Laut Reuther (2007:24) wird bei der Bestimmung des TCN-Alters angenommen, dass die kosmische Strahlung konstant ist. Jedoch wird die Intensität der kosmischen Strahlung durch das Sonnen- und Erdmagnetfeld beeinflusst bzw. moduliert (vgl. Kuhle, Kuhle 2010:105; vgl. Reuther 2007:24). Im Abgleich mit ${ }^{14}$ C-Daten und glazialgeomorphologischen Indizien stellten Kuhle, Kuhle (2010) fest, dass die unkalibrierten Daten altersüberschätzt sein müssen. Gründe für die Überschätzung der TCN-

\footnotetext{
${ }^{132}$ siehe Quelle Röthlisberger, Geyh (1985) in der Fußnote

133 siehe Quellen Lehmkuhl $(1995,1997)$ in der Fußnote
} 
und OSL-Daten könnten vor allen Dingen die zu gering angenommene kosmische Strahlung in den Kaltzeiten - die da generell höher sein soll, die fehlerhafte Berechnung vom `scaling factor' und von Produktionsraten sowie die fehlende Kalibrierung mit vorhandenen quartärgeologischen Chronologien sein (vgl. Kuhle, Kuhle 2010:116).

\section{OSL}

Bei der OSL-Methode sind diverse Fehlerquellen bekannt: es wird eine vollständige Bleichung der Materialien vor der Ablagerung angenommen; das Mischverhältnis von unterschiedlichen bzw. fehlenden Bleichungsgraden der Akkumulationen und das Verhältnis der auftreffenden kosmischen Strahlung nach der Ablagerung der Materialien ist unbekannt bzw. kann nur ungenau - und höchstwahrscheinlich oft zu niedrig, sodass eine Überschätzung der Daten eintritt - berechnet werden, wobei die Veränderungen der kosmischen Strahlung selber bis heute nicht sicher bestimmt werden können (vgl. Kuhle, Kuhle 2010:108, 110; vgl. Kuhle 2011b:959 f.). 'Partial bleaching', wodurch eine solche Altersüberschätzung bzw. ein maximales Alter eintreten kann, ist laut Owen et al. (2008:518) vermutlich das größte Problem bei der OSL-Datierung. Demnach ist die Methode nur für vollständig gebleichte Materialien gut kalibriert, sodass es bei Vorkommen von weniger gebleichten Materialien zu einer Überschätzung der Daten kommt (vgl. Kuhle, Kuhle 2010:108; vgl. Owen et al. 2008:518). Auch Abramowski (2004:26 f.) meinte, dass der Fall der guten Bestrahlung des feinen sandig-siltigen Materials während des Transportes sowie die Abschottung dieses nach der Ablagerung bei Moränen wohl eher nicht vorkommt.

Weitere Fehlerquellen sind laut Owen et al. (2008:518): “These include partial bleaching, dose rate changes over time (particularly with regard to changing moisture content), and in the case of Himalayan sediments, poor sensitivity and the low brightness of quartz.". Diese Fehlerquellen könnten durch Überprüfungen von Forschungsberichten, Methoden und Berechnungen der OSL-Datierungen bewertet werden, was aber oft nicht möglich ist, da viele Forscher keine detaillierten Beschreibungen, Datenangaben und Berechnungen aufzeigen (ebd.:518). Ein inkorrektes Bestimmen des Feuchtigkeitsgehaltes kann u.a. zu einer Veränderung des Alters führen: “An incorrect estimate for moisture content, for example, can result in a $1 \%$ difference in age for every $1 \%$ difference in moisture content." (Owen et al. 2008:518).

Die schuttbedeckten Gletscher des Himalaja mit dem vorrangig supraglazialen Transport sollen für die OSL-Datierungsmethode geeignet sein (vgl. Hubbard, Glasser 2005:345 f.). 
Nach Gemmel (1988) ${ }^{134}$ zitiert nach: Hubbard, Glasser (2005:345) ist diese Methode jedoch bei glazigenen Sedimenten, vor allen Dingen am Grund eines Gletschers, mit Bedacht anzuwenden, da die Sedimente beim Transport nicht dem Licht ausgesetzt gewesen sein können und diese somit nicht gebleicht wurden. Folgendes Zitat beschreibt dieses Problem: "Material that is both subglacially derived and subglacially transported to the glacier margins, either within the basal ice or by the glacial drainage system, will not be bleached during transportation and is therefore unsuitable for the purposes of OSL dating." (Hubbard, Glasser 2005:345).

\section{TCN}

Die ${ }^{10}$ Be-Datierung wird laut Abramowski (2004:28) zwar oft u.a. in der Geomorphologie angewendet, sollte aber noch verbessert werden. Kuhle (2011b:959) führte aus, dass neben dem Fehler, dass die TCN-Datierungsmethode für die Quartärgeologie angewendet wird, außerdem die TCN-Datierung die Feldarbeit zu ersetzen beginnt. Owen et al. (2008:519) und Reuther (2007:37) gaben mögliche Fehlerquellen für die TCN-Datierung an. Hierbei gingen sie auf Aspekte wie Verwitterung, Exhumierung / Freilegung, Erosion, Verlagerung, Strahlungsabschirmung durch Schnee- und / oder Sedimentbedeckung sowie vorherige Bestrahlung ein, die bis auf die letztgenannte zu einer niedrigeren Altersangabe führen. Es existieren geologische Prozesse, sodass kaum stabile Oberflächen in den aktiven Gebirgen erhalten sind (vgl. Owen et al. 2008:527). Auch Abramowski (2004:3) schrieb folgendes: „Die Fehler von ${ }^{10}$ Be-Expositionsaltern werden derzeit bestimmt von den Fehlern des Skalierfaktors, der Erosionsrate und der tektonischen Hebungsrate. Solange Erosionsrate und tektonische Hebungsrate nicht innerhalb von 10\% ihres Wertes festgelegt werden können, sind Expositionsalter >30-40 ka mit Fehlern von 20\% und mehr behaftet und können lediglich als grobe Näherungen an das tatsächliche Alter aufgefasst werden. “. Es werden aber auch Erosionsraten oder der hydrothermale Zersatz nicht berücksichtigt: Kuhle (2012a:194) nannte unter Berücksichtigung des hydrothermalen Zersatzes eine Erosionsrate von $5 \mathrm{~mm} / 1.000$ Jahre und berechnete aus einem TCN-Alter von Owen et al. von etwa 45.000 Jahren - diese Forscher lassen die Erosionsrate unberücksichtigt - ein Alter von mindestens 600.000 bis 850.000 Jahren. Zudem deutete Kuhle (2012a:194) darauf hin, dass ein heutiger Block der Maße 100 x 80 x $35 \mathrm{~cm}$ bei einem Volumen von 0,28 $\mathrm{m}^{3}$ eine Originalgröße von rund $19 \mathrm{~m}^{3}$ gehabt haben würde (Erosionsrate etwa $\left.1 \mathrm{~m}\right)$. Die Intensität der

134 Gemmel, A.M.D. (1988): Thermoluminescence dating of glacially transported sediments: Some considerations. Quaternary Science Reviews, 7. (S. 277-285) 
kosmischen Strahlung, die auf eine Blockoberfläche trifft, und somit auch die oberflächenspezifische Produktionsrate, hängt vom umgebenden Relief bzw. von der Neigung, von der Oberflächenmorphologie des Blockes und der möglichen Abschirmung durch z.B. Schnee, Löss, Lockermaterial, Boden und Vegetation ab (vgl. Reuther 2007:32, 37). Außerdem ist die lokale Produktionsrate von der Größe und der Form des Blockes beeinflusst und variiert innerhalb der Blockoberfläche (Masarik, Wieler $2003^{135}$ zitiert nach: Reuther 2007:34). Beprobung von kleinen Blöcken soll nicht die Qualität der Datenreihe verbessern (vgl. Reuther 2007:64). Blöcke können durch Erosion und periglaziale Prozesse freigelegt werden (ebd.:58). Durch eine ausreichende glaziale Erosion der Blöcke soll das Alter auf Null gestellt sein (ebd.:58). Ist dieses jedoch immer der Fall? Ist die Erosionsrate von unterschiedlichen Blöcken bekannt? Kuhle (2014:254) kam zu dem Ergebnis, dass die Oberflächenerosion nicht bekannt sein kann. Die Produktionsrate der TCN nimmt mit der Tiefe unterhalb der Oberfläche bzw. mit der Blocktiefe ab, wodurch sich die Produktionsrate bei einer Oberflächenabschirmung direkt an der Oberfläche verringert (vgl. Reuther 2007:35). ${ }^{10} \mathrm{Be}$ kann in den oberen ein bis drei Metern der Lithosphäre produziert werden (vgl. Abramowski 2004:5). Die Bedeckung einer Oberfläche über die gesamte Zeit kann nur ungenau bestimmt werden, da sich diese z.B. in Bezug auf die Schneebedeckung bzw. mächtigkeit ständig ändert (vgl. Reuther 2007:35 f.). Es werden nur die oberen Bereiche der Gesteinsoberflächen beprobt. Da bekanntermaßen die Strahlung tiefer in das Gestein hinunter reicht - wie sieht es dann mit Strahlungseinflüssen in Gesteinsschichten unterhalb der Gesteinsoberflächen aus? Würden diese Bereiche auf andere Alter verweisen? Laut Owen et al. (2008:519) wurde versucht diese natürlich verursachten Altersunterschiede durch eine multiple Probenahme der zu untersuchenden Fläche bzw. Blöcke einzugrenzen, wobei eine etwaige Übereinstimmung der ermittelten Daten als Beweis für die korrekte Altersbestimmung gesehen wurde. Multiple Datierungsmethoden sollen zudem in kritischen Regionen angewendet werden (ebd.:527). Um eine Verlagerung der Blöcke, eine Bedeckung mit Moränenmaterial und eine Schneebedeckung infolge größerer Windexponiertheit weitestgehend auszuschließen, werden große massive Blöcke auf horizontalen Moränen beprobt (vgl. Reuther 2007:41). Oft sollen jedoch Angaben über die datierten Blöcke nicht beschrieben sein, z.B. welche Größe oder welche Gesteinsart sie aufzeigen oder von welcher geomorphologischen Form diese stammen (vgl. Kuhle 2011b:959). Die sog. Vererbung bzw. vorherige Bestrahlung der Blöcke tritt dadurch auf, dass vorher bestrahlte Blöcke

\footnotetext{
${ }^{135}$ Masarik, J.; Wieler, R. (2003): Production rates of cosmogenic nuclides in boulders. In: Earth Planet Sci Lett 216. (S. 21-208)
} 
weitertransportiert werden oder eine unvollständige Erosion der Oberfläche stattfindet; sie soll im Gelände nicht erkennbar und für ein einzelnes TCN-Alter schwierig zu beheben sein (vgl. Reuther 2007:40). Laut verschiedenen Forschern tritt Vererbung vor allen Dingen in Gebieten auf, wo das Eis am Boden festgefroren ist und 'non-erosive, cold-based ice' auftritt (ebd.:40). Eine Vererbung kann schon allein unter Betrachtung der Tatsache mehrerer Eiszeiten möglich sein. Außerdem ist die Interpretation der Daten ein Problem (vgl. Abramowski 2004:6).

Eine weitere Fehlerquelle ist die der Berechnung der TCN-Produktionsrate für das Untersuchungsgebiet. Die ${ }^{10} \mathrm{Be}$ Produktionsrate im Mineral hängt von der Menge der kosmischen Strahlung ab, die auf die Probe trifft (Gosse, Phillips $2001^{136}$ zitiert nach: Abramowski 2004:28). Die Produktion von kosmogenen Nukliden variiert zeitlich, da diese von der Strahlung abhängt (vgl. Reuther 2007:27). Da die kosmische Strahlung nicht konstant ist, die kosmische Strahlungsintensität vom veränderbaren Erdmagnetfeld und der Sonnenaktivität abhängig ist, sind lokale TCN-Produktionsraten nicht exakt, sondern nur ungenau zu bestimmen (vgl. Kuhle, Kuhle 2010:105, 108). Generell sind die Veränderungen des Erdmagnetfeldes mit dem Einfluss auf die lokale Produktionsrate nicht rekonstruierbar (vgl. Kuhle 2014:261). Außerdem werden beispielsweise Turbulenzen in der Heliosphäre wie etwa Sonnenwinde und Sonneneruptionen (vgl. Kuhle 2011b:960) sowie Supernoven (alle 25 bis 100 Jahre) und verschiedenste Strahlungen - darunter auch solche, die nicht vom Erdmagnetfeld abgeschirmt werden - nicht mit berücksichtigt (vgl. Kuhle 2014:255 f.). Eine abweichende angenommene Produktionsrate kann zu Berechnungsfehlern führen (ebd.:255). Das Erdmagnetfeld reflektiert alle niedrigenergetischen Strahlen unter einem bestimmten Schwellenwert (vgl. Abramowski 2004:29), wobei diese Reflexion mit geomagnetischem Längen- und Breitengrad sowie mit der Stärke des geomagnetischen Feldes variiert (Gosse, Phillips $2001^{137}$ zitiert nach: Abramowski 2004:29). Lokale Variationen, z.B. dass die kosmische Strahlungsintensität mit der Höhe zunimmt, sind zudem schwer mit einzubeziehen (vgl. Kuhle, Kuhle 2010:109). Ausgerechnet in Hochasien sind die stärksten Erdmagnetfeldschwankungen zu erwarten und sind nicht in die Berechnungen mit einbezogen (ebd.:109) ${ }^{138}$. Auch Reuther (2007:26 f.) gab an, dass die Nuklidproduktion in höheren Lagen am größten ist und die TCN-Produktionsraten u.a. mit der geographischen Lage und Höhenposition variieren bzw. in hohen geographischen Breitenlagen höher sind als in

\footnotetext{
${ }^{136}$ siehe Quelle Gosse; Phillips (2001) in der Fußnote

${ }^{137}$ siehe Quelle Gosse, Phillips (2001) in Fußnote

138 "In High Asia we would therefore, on theoretical grounds, expect to find the strongest effects from geomagnetic field variations, which are, however, at this point de facto not taken into account in the calculation of TCN ages." (Kuhle, Kuhle 2010:109)
} 
niedrigen. Die lokale Produktionsrate jeder Beprobungsstelle auf der Erde wird meist unter Anwendung des derzeit angemessensten Skaliersystems von Lal (1991) ${ }^{139}$ in Bezug zu einem Referenzpunkt gesetzt, der eine flache, unabgeschirmte und unbedeckte Oberfläche auf Meeresspiegelniveau und in hoher geographischer Breitenlage darstellt (vgl. Reuther 2007:26; vgl. Abramowski 2004:3). In Gebieten mit langanhaltenden Hoch- und Tiefdruckgebieten kann die lokale aktuelle Produktionsrate wegen der Berücksichtigung des atmosphärischen Druckes der Standardatmosphäre variieren (Stone $2000^{140}$ zitiert nach: Reuther 2007:31). Bei tektonischen Prozessen kann sich die aktuelle Produktionsrate ebenfalls deutlich unterscheiden (vgl. Reuther 2007:31). Um die Methode der TCN-Datierung wirklich nutzen zu können, müssten diese sämtlichen vorstehenden Aspekte mit einbezogen werden. Ein exakter Korrekturfaktor müsste festgelegt werden, wobei die Veränderungen der kosmischen Strahlung bis heute nicht eindeutig berechnet werden können (vgl. Kuhle, Kuhle 2010:110). Eine genaue Messung der Strahlung wäre notwendig, was jedoch schwierig sein wird, da diese nicht kontinuierlich ist. Auch Seguin (2013) ${ }^{141}$ zitiert nach: Kuhle (2014:255) schlussfolgerte, dass keine einheitlichen Standards der Bemessungen existieren. Kuhle (2014:255) gab an, dass z.B. nur einige der Parameter wie Höhenlage, Breitenlage, Bestrahlungsgeometrie und Abschirmung mit in die Berechnung eingehen und diese dann nur in Form von Durschnittswerten. Nach Seguin (2013) ${ }^{142}$ zitiert nach: Kuhle (2014:255) sind alle Simulationen für die Bestimmung der Produktionsrate ungenau.

Ein Problem ist der `scaling factor', der in niedrigen und hohen Lagen unterschiedlich ist (vgl. Kuhle, Kuhle 2010:108). Dieser Faktor bezieht sich nur auf das rezente geomagnetische Feld ohne Veränderungen zu berücksichtigen (ebd.:109). In Hochasien sollen aber wie o.g. die größten Erdmagnetfeldschwankungen auftreten (ebd.:109). Auch Owen et al. (2008:527) wiesen darauf hin, dass Unsicherheiten mit den 'scaling models' existieren. Die größte Unsicherheit der 'scaling models' besteht in niedrigen Breitenlagen und sehr hohen Höhenlagen (Balco et al. $2008^{143}$ zitiert nach: Owen et al. 2008:519). Somit sind TCNDatierungen relativ ungenau (vgl. Owen et al.2008:522). Bevor TCN-Datierungen anwendbar

\footnotetext{
139 siehe Quelle Lal (1991) in der Fußnote

140 siehe Quelle Stone (2000) in der Fußnote

141 Seguin, J. (2013): Anwendbarkeit und Grenzen der Voraussetzungen kosmogener Nukliddatierungen Analyse anhand von Literaturauswertung. Unveröffentlichte Bachlor of Arts - Arbeit im Department Geographie und Hochgebirgsgeomorphologie (GHG) des Geographischen Institut der Universität Göttingen. (S. 1-59)

142 siehe Quelle Seguin (2013) in der Fußnote

143 Balco, G.; Stone, J.O.; Lifton, N.A.; Dunai, T.J. (2008): A complete and easily accessible means of calculating surface exposure ages or erosion rates from $10 \mathrm{Be}$ and $26 \mathrm{Al}$ measurements. In: Quaternary Geochronology 8. (S. 174-195)
} 
würden, müssten die astrophysikalischen Gegebenheiten der TCN-Produktion eindeutig geklärt sein (vgl. Kuhle 2014:262).

Fig. 5 bei Owen et al. (2008:519) zeigt die Effekte, wenn vier unterschiedliche zeitabhängige `scaling models' und geomagnetische Korrekturen für ${ }^{10} \mathrm{Be}-\mathrm{TCN}$-Alter vierer verschiedener Gebiete Hochasiens verwendet werden, woraus sich ein Unterschied zwischen den `scaling models’ bis zu $30 \%$ der letzten 70.000 Jahre widerspiegelt. Der größte Unterschied besteht zwischen dem zeitkonstanten - ohne Korrektur des geomagnetischen Feldes - Modell nach Lal (1991) ${ }^{144}$ und Stone (2000) $)^{145}$ und den anderen Modellen (zitiert nach: Owen et al. 2008:519). Unterschiede zwischen den Modellen variieren um ca. $20 \%$ mit den signifikantesten Unterschieden nach ca. 20.000 Jahren. Im Khumbu-Himal, welches sich am niedrigsten Breitengrad und in der höchsten Lage im Gegensatz zu den anderen Regionen aus Fig. 5 befindet, sind die Unterschiede am deutlichsten sichtbar. Es gibt ebenfalls eine große Altersvarianz zwischen den `scaling models’ mit der Änderung der Höhe (Fig. 6). Der größte Unterschied ist in einer Höhe von ca. $2.500 \mathrm{~m}$ zu erkennen. Altersunterschiede von $12 \%$ sind zwischen den zeitabhängigen Modellen erkennbar und treten oft über ca. $4.500 \mathrm{~m}$ auf. Derzeit werden nach Owen et al. (2008:519) Debatten über die Korrektur der 'scaling models' und über die geomagnetische Korrektur für TCN-Produktionsraten zur Bestimmung der TCNAlter geführt. (vgl. Owen et al. 2008:519)

Die Forscher - zumeist aus Nachbarwissenschaften der Geomorphologie, die absolute Datierungen wie OSL- und TCN-Datierungen anwendeten, bezogen die Befunde von Kuhle nicht mit ein oder widerlegten diese mit den TCN- und OSL-Daten zu Lasten der Methode der Quartärgeologie. Sie fokussierten sich auf die herausgefundenen Daten und grenzten die untersuchten Formen nicht eindeutig voneinander ab bzw. nannten nur das Wort 'diamict' und gaben oft keine Blockgröße und Gesteinsart an. (vgl. Kuhle, Kuhle 2010:105 f.)

Jedoch sind glaziale Geschehnisse von enorm vielen Prozessen begleitet. Ein mögliches Szenario wäre: Ein Block - der schon vorher bestrahlt wurde - bricht aus einer Felswand heraus auf einen Gletscher. Dieser kann dann auf dem Gletscher, im Gletscher und unter dem Gletscher auf vielfältige Art und Weise transportiert werden, wobei dieser Transportprozess nicht genau geklärt werden kann. Auch die auf den Block eintreffende Strahlung kann nicht genau nachvollzogen werden. Es gibt verschiedene Möglichkeiten, wie die Bestrahlung von Blöcken und deren Intensität beeinflusst worden sein kann, was aber nicht rekonstruierbar ist.

\footnotetext{
144 siehe Quelle Lal (1991) in der Fußnote

145 siehe Quelle Stone (2000) in der Fußnote
} 
Der Block kann der Strahlung von allen Seiten ausgesetzt gewesen sein, jedoch ist ungeklärt, wie lange und von welcher Seite er bestrahlt wurde. Außerdem können die Winkel des Blockes zur Strahlung hin und die Strahlung an sich sehr verschieden sein. In einem weiteren Fall kann der Block innerhalb des Transportes zersplittern, wobei er ab dann nur noch eine geringere Zeit lang bestrahlt wird als andere Blöcke, die nicht zersplittern. Bei Gletscherrückzug werden die Blöcke z.B. in einer Lateralmoräne abgelagert, bei einem Vorstoß können die Lateralmoränen auch vom Gletscherrand unterschnitten und umgelagert werden und somit die Blöcke wieder aufgenommen und transportiert werden. Somit können die Blöcke innerhalb verschiedener Perioden bedeckt oder an der Oberfläche sein. Während der Interglazialen können kleine Gletscher, Solifluktionsprozesse, ‘debris flows’ und fluviale Prozesse dafür sorgen, Blöcke umzulagern. Außerdem sind die Höhen der Meeresspiegel und die Dauer aller Bestrahlungen, die während der Zwischenlagerung auftraten, nicht bekannt. Das Material von z.B. Endmoränen, das datiert wurde, hat keinen Zusammenhang zum Alter der Form; dieses kann viel älter, aber auch infolge einer Desquamation viel jünger sein. Weiterhin spielt die Abrasion der Blockoberflächen während des mehrfachen Transports eine Rolle. Durch den unterschiedlichen Abtrag des Blockes resultiert, dass die Strahlungstiefen modifiziert sein können. Der Zerfall der Blöcke kann nicht berechnet werden und führt somit zu einer Verfälschung des Alters. Auf einer Endmoräne z.B. sind die Blöcke weiteren folgenden Veränderungen ausgesetzt: Denudationsprozessen (etwa 30-80 cm eines Moränenhanges sind in 1.000 Jahren verlagert) bzw. Verlagerungsprozessen (Bedeckung mit Sediment, Vegetation oder Schnee bzw. Nichtbedeckung; Beschattung oder Nichtbeschattung im Tal - Veränderung der Strahlungseinwirkung). Abgesehen von diesen genannten Faktoren ist selbst die Strahlung nicht konstant, wodurch die TCN-Datierungen keine Basis haben. (vgl. Kuhle 2007b:115)

Die datierten Blöcke auf einer Moräne müssen somit nicht unbedingt das Alter der Moräne anzeigen, sondern sie können älter oder jünger sein. Wenn z.B. Permafrost unter dem Gletschereis existiert, werden die Blöcke nicht vom Eis verlagert, sondern festgehalten. Somit könnten Blöcke mehrere Eiszeiten lang in ihrer Lage und Form erhalten bleiben.

Auch Reuther (2007) beschrieb, dass das TCN-Alter der Blöcke oft mit dem Alter der Moräne bzw. der Form in Verbindung gebracht wurde, jedoch soll dieses durch geomorphologische Prozesse komplex sein. Es werden z.B. multiple Gletschervorstöße, komplexe Moränenstratigraphien, Überformungen der Moränen, Herausbrechen der Gesteinsoberfläche oder Vererbung genannt, die alle schwierig zu quantifizieren sind. In den Modellen sollen die 
Formentstehung bzw. die geomorphologischen Prozesse vereinfacht worden sein; Moränendegradation soll als ein linearer Erosionsprozess angenommen sein. (vgl. Reuther 2007:57 f.)

Reuther (2007) äußerte sich abschließend: "The summary of processes that influence exposure ages shows that a distribution of exposure ages from any single moraine does not necessarily portray the age of the moraine." (ebd.:62); "However, the processes that lead to the distribution of ages on a moraine cannot unequivocally be reconstructed." (ebd.:62); "Detailed geomorphological mapping of the landforms and an understanding of the deposition processes is needed to interpret an age distribution for a single landform and to chose the right approach to ascertaining the landform age." (ebd.:63).

Es werden die Daten auf drei verschiedene Weisen interpretiert: Bildung eines Mittelwertes (wenn die Werte normal verteilt sind), Nehmen des ältesten Wertes (Annahme, dass Moränendegradation überwiegt) und Angabe eines Zeitintervalls. Es bleibt zu diskutieren, ob es sich bei den interpretierten Daten wirklich um die Zeiten der maximalen Vergletscherung oder aber des Einsetzens der Deglaziation handelt. (vgl. Reuther 2007:62)

Somit sind die TCN-Datierungen in Bezug auf eine Aussage über die vorzeitliche Vergletscherung nicht geeignet. Auch bei den OSL-Datierungen von glazifluvialen Sedimenten bestehen in Bezug auf den Transport der Sedimente und die Bleichung dieser viel zu viele Unbekannte. Wie weiter oben beschrieben, sind auch die relativen Datierungen im Gegensatz zur geomorphologischen Analyse weniger geeignet. So argumentieren auch Kuhle (2007b) sowie Kuhle, Kuhle (2010) folgendes: "In this context, the discussed OSL and TCN datings do neither provide good evidence, nor can they be considered proper arguments because, whatever the methodological point of view, nevermore do they pass as indicators of the nonexistence of a Tibetan ice sheet." (ebd.:119); "This self-conceit based on the "dating fallacy", as we call it, should be avoided since it goes decidedly against the standards of the scientific method established in Quaternary geology and makes a fundamental scientific discussion impossible." (ebd.:105); "[...] there is not a single glaciation on earth which has not been reconstructed on the basis of this method." (ebd.:107); "Surface datings fulfil the necessary chronological frame, but due to rearrangements, weathering and exhumation they do not reveal the chronological connection as to the time when the moraine was deposited and thus to the age of the past glaciation." (Kuhle 2007b:97); "For over 150 years, glacier history and the reconstruction of the Ice Age glacier cover has been pursued with great 
success by glacio-geological and glacio-geomorphological methods. Thus, our knowledge of an at least three-times greater land-ice-cover of the earth during the Ice Age is only based on investigations of this kind." (ebd.:92); "Only the three-dimensional arrangement of the positions of the individual key forms of a glaciation to each other provides evidence of a past glaciation.” (ebd.:92). Auch Bremer (1989:28) merkte an: „Darüber hinaus zeigt die Zusammensetzung der Sedimente, welche Gesteine im Einzugsgebiet entblößt sind, wie sie verwittert sind (Leitgerölle). Methodische Schwierigkeiten liegen in der Alterszuordnung, da unterschiedlich altes Material in den Transport eingehen kann. ".

\subsection{Forschungsarbeiten der Jahre 1950 bis 1970}

\section{HEUBERGER (1956)}

Die Arbeit von Heuberger (1956) mit dem Titel 'Beobachtungen über die heutige und eiszeitliche Vergletscherung in Ost-Nepal' wurde in der vorliegenden Dissertation nicht berücksichtigt, da Heuberger laut Kuhle (2007b:97) diese 1979 öffentlich zurücknahm: "Heuberger, who in 1956 has published a short study on a section of the research area, has repeatedly retracted his findings and ice margin positions; so, e.g., on the 'German Geographers' Day’ in Göttingen, 1979. (Quotation: 'Diese Moränen erfreuen sich inzwischen einer anderen Genesé.). So, his opinion stated here cannot be considered as still valid.". Heuberger (1956:356) verwies auf eine Eisrandlage in ca. 2.500 m Höhe im Dudh Koshi Nadi südlich von Ghat.

Heuberger, Weingartner (1985:71 f.) führten aus, dass die bis dahin unveröffentlichten Arbeiten von Heuberger 1954 und 1966 ohnehin nur spät- und postglaziale Gletscherablagerungen beschrieben ohne Einbeziehung der maximalen Vergletscherung. Auch Heuberger (1956) untersuchte laut Iwata (1976:109) nur spätglaziale bis rezente Moränen ${ }^{146}$. Somit hätte die Arbeit von Heuberger (1956) im Kontext einer maximalen letzteiszeitlichen Vergletscherung nicht berücksichtigt werden können.

Auch Kuhle (1982 a:152) schrieb zu den Befunden Heuberger (1956) folgendes: „, Heuberger konnte im $300 \mathrm{~km}$ E-lich gelegenen Cho Oyu-Gebiet eine 600-700 m betragende Schneegrenzdepression feststellen, die er, nach meinen Befunden zu Recht, als Rückzugsstadien zugehörig interpretiert (1956: 363). v. Wissmann (1959: 243 u. 161)

\footnotetext{
146 "In the Khumbu region Heuberger (1956) observed the Late Glacial moraines and the recent moraines which correspond to the 1850 moraines in the Alps." (Iwata 1976:109)
} 
hingegen bezweifelt diese Zuordnung und meint, die Depression - ohne eigenen Geländebefund - für eiszeitlich halten zu müssen, was getrost auszuschließen ist.”.

\section{MÜLLER (1959)}

\section{UNTERSUCHUNGSGEBIET}

Müller (1959) untersuchte schwerpunktmäßig das Gebiet des Khumbu Gletscher. Auch der Pumori Gletscher (Eisbewegung und Rundhöckerentstehung) und das Gebiet um den Gorakshep See wurden genauer betrachtet.

Ende Oktober 1956 reiste er zum Nangpa La und im November zum Imja Khola Kessel. Auf dem Rückweg nach Kathmandu Anfang Dezember des gleichen Jahres erkundete Müller das Dudh Khosi Tal bis talabwärts von Aisyalukharka. (ebd.:216)

\section{METHODE BZW. ARBEITSTECHNIK}

Müller (1959) machte während der 3. schweizerischen Mt. Everest Expedition im Jahre 1956 unter der Leitung von Eggler in insgesamt acht Monaten, zur Vormonsunzeit, Monsunzeit und im Herbst, erstmals langfristige Wetterbeobachtungen im nepalischen Hochhimalaja. Vom 12. April bis 25. November wurde eine Wetterstation in der Nähe des Basislagers beim Khumbu Gletscher aufgebaut und Temperatur, Niederschlag, Luftfeuchtigkeit, Bewölkungsgrad, Windgeschwindigkeit sowie Höhe, Richtung und Geschwindigkeit des Wolkenzuges bestimmt. In den Hochlagern erfolgten ebenfalls Wetterbeobachtungen. Stationen in Namche Bazar, Chaunrikharka, Aisyalukharka und Okhaldhunga ließ Müller betreuen, wobei die Daten der erstgenannten Station nicht durchgängig analysiert wurden. Weiterhin schloss er neun Stationen des indischen Wetterdienstes mit ein, wodurch er ein Niederschlagsprofil erstellen konnte. (ebd.:199 f., 202 f., 206)

Außerdem wurden die Ablation und Akkumulation sowie die Oberflächengeschwindigkeit des Khumbu Gletscher in der Höhe des Basislagers auf $5.400 \mathrm{~m}$ und unterhalb des Basislagers gemessen, wobei letztgenannte auch im Lager I auf $5.800 \mathrm{~m}$ beim Khumbu Eisfall, oberhalb des Eisfalles und unterhalb der Lhotseflanke bestimmt wurde. Unterschiede in den Abschmelzprozessen wurden anhand von Feldexperimenten in Bezug auf Auswirkungen von Schuttauflagen verschiedener Mächtigkeit, Korngröße und petrographischem Gehalt erforscht bzw. wurde die Temperaturseite dieser Vorgänge erfasst. Im Westbecken bestimmte er die Vorjahrfirnmächtigkeit und den Wasserwert. Insgesamt maß Müller acht Querprofile - sieben am Khumbu und eines am Chakri Gletscher - zur Bestimmung der Oberflächengeschwindigkeiten der Gletscher ein. Spezialuntersuchungen über Frostboden 
bzw. den Verlauf des Bodenfrostes erfolgten besonders beim Gorakshep-See. (ebd.:202 f., 207 f.)

Der Khumbu Gletscher wurde morphologisch aufgenommen, was durch die abgedruckte Karte vom Khumbu Gletscher mit Seitengletschern und jüngeren Moränen bei Müller (1959) ersichtlich wird. Hierbei visualisierte Müller Schnee und Firn, Gletscherspalten und Eisrampen, Schmelzlöcher und Eisflanken, Eistürme, Seen, Wasserläufe, Wetterstationen, Profile, Moränen, Schutt / Schuttströme, Schuttstrukturen und Alphütten. Im Text wurden die heutige und vorzeitliche Vergletscherung bzw. ältere Gletscherstände beschrieben (ebd.:200).

\section{ERGEBNISSE}

Müller (1959) kam zum Ergebnis, dass das Mt. Everest Gebiet arid ist, mit ungefähr $39 \mathrm{~cm}$ Niederschlägen im Jahr gegenüber Chaunrikharka mit $166 \mathrm{~cm}$ im Jahr und Sirha in der indischen Ebene mit $225 \mathrm{~cm}$ im Jahr, jedoch sollen die Werte laut dem indischen Wetterdienst als normal $\pm 17 \%$ anzusprechen sein. Unterhalb des Eisfalles bestimmte Müller (1959) eine Oberflächengeschwindigkeit des Khumbu Gletscher von mehr als $50 \mathrm{~m}$ im Jahr. Auf der Höhe von Lobuje kam er auf eine Rückwärtsbewegung des Eises. 2,5 km talabwärts vom Basislager beim Konfluenzbereich von Chakri und Khumbu Gletscher auf $5.300 \mathrm{~m}$ beobachtete Müller (1959) während der Monsunzeit zwei gegenläufige Wetterereignisse: von Süden der Monsun und von Norden ein trockener Wind aus Tibet. Beobachtungen über den Verlauf des Jetstreams wurden erwähnt. (ebd.:205-208)

Müller (1959:210 f.) beschrieb neben dem aktuellen Zustand des Khumbu Gletscher ältere Moränenstände bzw. subrezente Seiten- und Stirnmoränen - die vor 4 bis 5 Jahrzehnten entstanden, ältere Moränen bei Pheriche und noch ältere Moränenreste bzw. Schliffspuren und eisfreie Kare.

Außerdem sollen ${ }^{14} \mathrm{C}$-Datierungen bei Pflanzenresten einer zwischenstadialen Ablagerung beim Gorakshep-See, Jahrringanalysen an Wurzelstöcken von Wacholderbüschen einer 1850iger Moräne des Khumbu Gletscher, zwei Warvenprofile am See im Chola-Khola-Tal und Lichenometrie ausgeführt worden sein. Die Ergebnisse aller letztgenannten Methoden waren im Text jedoch noch nicht erwähnt. (ebd.:211)

\section{KRITIK}

Die Arbeit von Müller (1959) mit dem Titel `Acht Monate Gletscher- und Bodenforschung im Everestgebiet' enthielt in Bezug zur letzteiszeitlichen Maximalvergletscherung einige 
Aussagen. Müller (1959:210 f.) beschrieb drei unterschiedliche Moränenstände: subrezente Seiten- und Stirnmoränen, die vor 4 bis 5 Jahrzehnten entstanden, ältere - Moränen bei Pheriche und noch ältere - Moränenreste, Schliffspuren, eisfreie Kare als Hinweis auf die ehemalige Firnlinie. Wo die angegebenen Schliffspuren, eisfreien Kare und alle Moränenreste vorkamen, blieb offen. Beispielsweise fand er Moränenreste bei Phaphlu, wobei er unterhalb dieses Ortes aber keinerlei eindeutige Indikatoren einer ehemaligen Vergletscherung ausmachte $^{147}$. Auf dem Rückweg nach Kathmandu Anfang Dezember erkundete Müller das Dudh Khosi Tal bis unterhalb der Siedlung Aisyalukharka in Bezug auf die maximale Vergletscherung ${ }^{148}$. Im Dudh Khosi Tal traten viele Quartärablagerungen auf, jedoch keine eindeutig zuordbare ${ }^{149}$. Müller war sich nicht einig darüber, ob diese Ablagerungen teilweise oder ganz durch fluviale Prozesse wegtransportiert oder ob sie von Schutt überlagert waren (ebd.:201). Den Moränenwall, auf dem der Ort Tengboche lag, erwähnte Müller (ebd.:201). Bei Taksindhu in einem Nebental des Dudh Khosi Tales fand Müller Erratika und an den Hängen Terrassen unbekannter Entstehungsart ${ }^{150}$. Müller (1959:211) wies darauf hin, dass die pleistozänen Gletschervorstöße weiterführend genauer anhand von fluvioglazialen Akkumulationen im Vorland erforschbar wären ${ }^{151}$. Somit blieb anhand der dargestellten Befunde von Müller (1959) offen, wo alle angesprochenen Moränenreste, Schliffspuren und eisfreien Kare auftraten bzw. was diese Formen für eine Vergletscherung angezeigt hätten. Ebenfalls wurde nicht deutlich, um was es sich für Erratika bei Taksindhu handelte, um so eine Aussage über die ehemalige Vergletscherung treffen zu können. Da die Terrassen genetisch nicht zugeordnet worden waren, war auch anhand derer keine Aussage möglich.

Die zeitliche Einordnung der älteren Moränen bei Pheriche konnte Müller mit seinen Ausführungen nicht klären. Hierzu ist folgendes Zitat $\mathrm{zu}$ nennen: „Leider wird es kaum möglich sein, das Alter des Pheriche-Stadiums, das die Everesttäler so sehr dominiert, näher zu bestimmen. Möglicherweise korrespondiert jener Gletscherstand mit dem Maximum des 1600er Vorstosses in den Alpen; wahrscheinlich ist er aber bedeutend älter." (Müller

147 „Bis an die erste Hauptkette hielt das Auge vergeblich Ausschau nach wirklich beweiskräftigen Reminiszenzen einer Vergletscherung. Erst bei Phaphlu traf ich einige moränenartige Überreste; [...]. ” (Müller 1959:201)

148 „Der Zweck dieses letzten Abstechers war, nach Zeugen der eiszeitlichen Vorstösse der Everestgletscher auf der Achse ihrer direkten Verlängerung nach Süden zu suchen.” (ebd.:216)

${ }^{149}$ „Das Dudh-Khosi-Tal, in das wir nun abstiegen und durch das die Everestwasser fliessen, überraschte durch eine ganze Menge von Quartärablagerungen, von denen aber keine einzige als unzweideutiges Überbleibsel eines Haupttalgletschers identifiziert werden konnte. " (ebd.:201)

150 , [...] bei Taksindhu lagen erratische Blöcke in den Wäldern, und an den Hängen unterhalb dieses herrlich gelegenen Klosters liessen sich ausgedehnte Terrassensysteme unbestimmten Ursprungs erkennen." (ebd.:201)

151 „Die volle Geschichte des pleistozänen Verhaltens dieser Gletscher muss hingegen an Hand der fluvioglazialen Ablagerungen des Vorlandes abgeklärt werden.” (ebd.:211) 
1959:211). Somit war auch über die zeitliche Einordnung der o.g. noch älteren Moränenstadien keine Aussage zu treffen.

\section{MILLER (1970)}

\section{METHODE BZW. ARBEITSTECHNIK}

Miller (1970) betrieb geomorphologische Analysen, lichenometrische Analysen von Randmoränen des Khumbu Gletscher sowie glaziologische, meteorologische und glaziothermische Messungen beim Khumbu Gletscher wie etwa Oberflächenbewegungs-, Temperatur- und Niederschlags-, Strahlungs- bzw. direkte Sonnenstrahlungsmessungen, außerdem Spektral- und geophysikalische Tiefenmessungen (Eistiefenprofile / Eismächtigkeiten, Stratigraphie, Dichte, Gletscherinnentemperatur, Schmelzwasseruntersuchungen wie etwa Tritiumgehaltsbestimmungen) (ebd.:153-158, Fig. 2).

Die Ergebnisse der angewendeten glaziologischen Standardtechniken und geophysikalischen Messungen (Schwerkraft, seismische Profile, Oberflächenbewegungsuntersuchungen) waren Inhalt eines anderen Papers (ebd.:154). In Fig. 2 war zu erkennen, dass Moränen kartiert wurden. Im Text auf Seite 162 erwähnte Miller Spülformen ('scour zones`) und Lateralmoränen entlang der Talwände beim Khumbu Gletscher.

\section{UNTERSUCHUNGSGEBIET}

Miller (1970) untersuchte bei einer amerikanischen Expedition zum Inneren Himalaja und Mt. Everest bzw. zum Mahalangur-Himal im Winter und Frühling 1963, die von Norman Dyhrenfurth angeleitet wurde, die Gebiete des Khumbu Gletscher (ebd.:153, 155 f.). Die ungefähre Route war in Fig. 1 dargestellt und verlief von Kathmandu über Namche Bazar in Richtung Mt. Everest (ebd.:155). Vor 1950 wurde der Mt. Everest hauptsächlich von der nördlichen Seite erforscht (ebd.:153).

Die meteorologischen Messungen erfolgten an fünf Orten zwischen ca. 5.300 und $7.300 \mathrm{~m}$ Höhe. Bei Lobuche errichtete Miller ab 25. März eine Wetterstation, Anfang April eine am Camp I beim Khumbu Eisfall und eine am Camp II, aber führte auch Oberflächenbewegungsund geophysikalische Tiefenmessungen durch. Bei Gorak Shep wurden ein Thermograph und beim Basecamp ebenfalls Instrumente aufgestellt. An den zwei höchsten Camps bestimmte er sowohl Stratigraphie und Dichte des Gletschers als auch seine Innentemperatur. In der Nähe des Gletscherzentrums wurden zwei Monate lang Daten zu Tagesgängen und 
geophysikalischen Beobachtungen erhoben. Die Strahlungs- und Spektralmessungen bis auf ca. 6.000 m führte Miller im April und Mai durch. (ebd.:156, Fig. 2)

\section{ERGEBNISSE}

Millers Ergebnisse zu einigen der o.g. angewendeten Methoden waren nachlesbar auf den Seiten 156 bis 164. Beispielsweise zeigten Fig. 4 die Temperatur-, Niederschlags- und Strahlungswerte bei der Basecampstation und Fig. 6 die Tritiumgehalte des Khumbu Gletscher. Somit machte Miller regionale klimatische Beobachtungen während der Geländebegehungen und erforschte beim Khumbu Gletscher Schwankungen in Bezug auf den regionalen Klimawandel (ebd.:154 f.). Die Geologie des Khumbu wurde in einer anderen Veröffentlichung berücksichtigt (ebd.:154).

\section{KRITIK}

Miller (1970) schlussfolgerte, dass aufgrund der immer noch stattfindenden tektonischen Hebung des Himalaja die Vergletscherung während des Spätpleistozäns (Jungpleistozän) umfangreicher gewesen sein könnte als die während des Frühpleistozäns (Altpleistozän) ${ }^{152}$. Geomorphologische Indikatoren sprachen für eine solche Hebung dieses Gebietes (ebd.:164). Anhand dieser angenommenen maximalen Vergletscherung schloss Miller darauf, dass die rezenten Gletscherpositionen u.a. eine Klimasituation darstellen, die sich nur wenig von den Bedingungen während des Pleistozäns unterscheidet ${ }^{153}$. Demnach ging Miller von einer pleistozänen Vergletscherung aus, die sich nicht maßgeblich von der rezenten Vergletscherung abhob. Jedoch wurden in Bezug auf die Maximalvergletscherung keine Analysen betrieben und somit die von ihm durchwanderten Talbereiche unterhalb des Khumbu Gletscher nicht untersucht. Fig. 2 deutete ebenso darauf hin, dass keinerlei hochglaziale Moränen kartiert wurden.

\footnotetext{
152 "This may explain the paradox of extensive glaciation developed here late in Pleistocene time, in contrast to the early Pleistocene Maxima known in many other formerly glaciated regions." (Miller 1970:164)

153 "The suggestion of a maximum glaciation in fairly recent time also connotes that the present glacial position in the Everest region and it polythermal character represent a climatic situation only slightly less severe than the more expanded conditions of the Pleistocene." (ebd.:164)
} 


\subsection{Forschungsarbeiten der Jahre 1971 bis 1990}

\section{BENEDICT (1976)}

\section{METHODE BZW. ARBEITSTECHNIK}

Benedict (1976:178) ermittelte im Bereich südlich des Khumbu Gletscher drei ${ }^{14} \mathrm{C}$-Daten auf 4.260, 4.245 und 4.235 m Höhe.

\section{UNTERSUCHUNGSGEBIET}

Benedict (1976:177) untersuchte die Gletscherserien des Khumbu Gletscher südlich der Gletscherzunge bei $27^{\circ} 54^{\prime} \mathrm{N}$ und $86^{\circ} 49^{\prime} \mathrm{E}$.

\section{ERGEBNISSE}

Benedict (1976) kam zu folgenden Daten: vor $550 \pm 85$ Jahren bzw. 1400 n. Chr. (bezogen auf das Jahr 1950) auf $4.260 \mathrm{~m}$ Höhe; vor $530 \pm 165$ Jahren bzw. 1420 n.Chr. auf $4.245 \mathrm{~m}$ Höhe und vor $1155 \pm 160$ Jahren bzw. 795 n.Chr. auf 4.235 m Höhe.

\section{KRITIK}

Da es sich bei Benedict (1976) nur um eine Datenliste der erfassten ${ }^{14} \mathrm{C}$-Daten im Khumbu handelte, konnte nicht viel über diese Arbeit ausgesagt werden. Es war nicht ganz eindeutig, wo die drei ${ }^{14} \mathrm{C}$-Daten bestimmt wurden. Die angegebenen Koordinaten waren zu grob, deuteten aber auf den Bereich nordwestlich von Periche.

\section{IWATA (1976)}

\section{UNTERSUCHUNGSGEBIET}

Iwata (1976) untersuchte in seiner Forschungsarbeit 'Late Pleistocene and Holocene Moraines in the Sagarmatha (Everest) Region, Khumbu Himal' das obere Einzugsgebiet des KhumbuHimalaja. Davor wurden laut ihm nur wenige Forschungen über die Vergletscherung des nepalischen Himalaja betrieben, was, unter Betrachtung des Forschungsüberblicks, stimmt. Es wurden von Iwata keinerlei Bereiche des Solu, sondern nur der obere Khumbu untersucht. In Fig. 1 konnte mit Hilfe der Maßstabsleiste eine maximale Fläche des Untersuchungsgebietes von 10,8 mal 12,3 km ermittelt werden. Allein durch diesen einen Aspekt wurde deutlich, dass diese Arbeit für eine Maximalvergletscherung der letzten Vereisung nur behutsam herangezogen werden konnte. Bei Iwata (1976:110/Fig. 1) lag der Schwerpunkt auf dem Gebiet des oberen Imja Khola und des Lobuche Khola. Daneben wurden von Iwata (1976) auch Gebiete des mittleren Imja Khola erforscht: der von ihm verwendete Begriff 
Thyangboche für ein Moränenstadium ließ auf die Ortschaft Thyangboche im mittleren Imja Khola schließen; auch in Fig. 6 war zu erkennen, dass Iwata (1976) Moränen bis nach Thyangboche kartierte. Auch Fort (2004:265) schrieb, dass die Gletscher bis nach Thyangboche reichten.

\section{METHODE BZW. ARBEITSTECHNIK}

Es handelte sich laut Iwata um eine detaillierte Kartierung von Moränen ${ }^{154}$, die mit Hilfe von Fotografien, ohne Luftbilder, erfolgte. Dass er keinerlei Luftbilder oder Satellitenbilder verwendete, konnte ihm nicht vorgeworfen werden, da diese nicht verfügbar waren: "As air photographs were not available, mapping of the moraines was done during the field survey with the aid of ground photographs." (Iwata 1976:109). Ebd.:110/Fig. 1 stellte in beiden vorstehend genannten Schwerpunktgebieten neben den Moränen nur noch die heutigen Gletscher grafisch dar. Somit wurden andere wichtige Indikatoren einer vorzeitlichen Vergletscherung nicht mit einbezogen. Nur die Täler des Imja Khola und des Lobuche Khola bezeichnete er als typische breite Trogtäler (ebd.:109, 111). Daher war nicht klar, ob überhaupt weitere Formen oder welche weiteren Formen in diesem Gebiet auftreten und wie diese zueinander in Beziehung stehen, wodurch eine deutlichere Aussage über die einzelnen Vergletscherungsstadien gegeben werden könnte.

Jegliche anderweitige geomorphologische Formen wurden demnach von Iwata (1976) nicht berücksichtigt. Dementsprechend sollten die Befunde von ihm über die eiszeitliche Vergletscherung schon allein aufgrund der nicht angewendeten geomorphologischen bzw. glazialgeomorphologischen Detailanalyse und aufgrund des zu kleinen Untersuchungsgebietes kritisch betrachtet werden. Schon Heuberger und Weingartner (1985:71) machten auf das Problem des eingeschränkten Untersuchungsgebietes aufmerksam: „Über die Reichweite der eiszeitlichen Vergletscherungen im Dudh-Kosi-Tal enthält die bisherige Literatur, [...], keine greifbaren Hinweise. Alle bisherigen Arbeiten über Eiszeitprobleme dieses Gebietes beschränkten sich mehr oder weniger auf das Talgebiet des Khumbu oberhalb des Zusammenflusses von Imja Drangka (von NE) und Nangpo Dsangpo (von NW) bei Namche Bazar. “.

Die einzelnen Moränen teilte Iwata (1976:Fig. 1) in verschiedene Kategorien ein: Moränenrücken, vier Stadien als Lobuche-, Thuklha-, Periche- und Thyangbochestadium, unklassifizierte Moräne und Plattform, wobei er auch die Gletscher als schuttbedeckt oder -

154 “Detailed field mapping of moraines in the Sagarmatha (Everest) region [...].” (Iwata 1976:109) 
frei unterschied. Desweiteren betrachtete Iwata (1976:111/Fig. 2-4, 112/Fig. 5-6) anhand von zwei Fotos und einem Querprofil den Khumbu Gletscher, anhand eines Bodenprofils eine Moräne bei Periche und anhand eines Moränenprofils das Khumbu Tal vom Khumbu Gletscher talabwärts bis zur Ortschaft Thyangboche genauer. Beim erstgenannten Gletscher wurde bei den Fotos das Vorkommen von Thyangboche Moränen aufgezeigt, hauptsächlich aber von Lobuche und Thuklha Moränen, und bei dem Profil (Fig. 3) u.a. auch auf Periche und Plattform Moränen hingewiesen, wobei letztgenannte mit einem Fragezeichen versehen wurden. Die von Iwata (1976) verwendeten Fragezeichensymbole in Fig. 1 in Verbindung mit den unklassifizierten Moränen und in Fig. 3 in Verbindung mit der Plattform sprachen dafür, dass er entweder eine genauere Untersuchung der Formen nicht bewerkstelligte oder er sich bei der Festlegung nicht ganz sicher war. Bei den unklassifizierten Moränen könnte er eine zeitliche Einordnung für nicht sinnvoll erachtet haben, sonst hätte er diese in die verschiedenen Kategorien eingeordnet. Was er jedoch mit dem Fragezeichen in Fig. 3 meinte, war nicht eindeutig: war Iwata sich der Zuordnung zur Form Plattform Moräne nicht sicher bzw. hat er diese Form nicht näher erforscht oder bedeutete es, dass diese von ihm als Plattform Moräne erkannte Form durchmischt war und / oder er die zeitliche Einordnung problematisch sah? Beim fünfstöckigen Bodenprofil der Periche Moräne - Silt mit Huminstoffen ( 0 bis $10 \mathrm{~cm}$ Tiefe), graubraunem Silt (bis $15 \mathrm{~cm}$ Tiefe), braunem Silt (bis 20 $\mathrm{cm}$ Tiefe), dunkelbraunem Silt mit Huminstoffen und organischem Material (bis $25 \mathrm{~cm}$ Tiefe), Löss (bis > $45 \mathrm{~cm}$ Tiefe) - entdeckte Iwata (1976:112) eine dünne humose oberflächennahe Bodenschicht mit organischem Material. Auch bei der Thyangboche Moräne auf der Lhajung Station sollte eine bedeckte Bodenschicht existieren (ebd.:112). Nicht geklärt wurde, wo das Bodenprofil genau aufgenommen wurde. Iwata (1976:112/Fig. 5) beschrieb es lediglich folgendermaßen: "Soil profile on the Periche stage moraine behind Periche.". Außerdem stellte sich die Frage, wie sich in $20 \mathrm{~cm}$ Tiefe eine Schicht mit organischem Material entwickeln konnte? Und wie hätte eine mögliche Erklärung seine Auswertung der Befunde beeinflusst? Der Forscher ging im Text inhaltlich nicht näher darauf ein. Zudem war unklar, warum diese Moräne mit solchem Bodenprofil als eine Periche Moräne angesehen wurde. Iwata machte keine Vergleiche mit der Bodenentwicklung der Thuklha Moräne, die laut ebd.:109 ebenfalls eine Bodenbedeckung aufwies. Die Periche Moräne sollte, wenn diese wie bei Heuberger, Weingartner (1985) und Heuberger (1986) nur anhand der Bodenentwicklung eingeordnet werden würde, aufgrund der geringen Bodenentwicklung eine viel jüngere darstellen. Es ist aber klar, dass eine solche Einordnung nur anhand der Bodenentwicklung nicht gemacht werden sollte, da diese von enorm vielen Faktoren, wie z.B. 
von der Höhe über NN, abhängt. Vielmehr kann wohl eher durch geomorphologische Aspekte - hier durch die Ausgestaltung dieser Moräne als deutlicher Rücken (vgl. Iwata 1976:Fig. 1) auf ein jüngeres Alter geschlossen werden. Anhand des Moränenprofils des Khumbu Tales vom Khumbu Gletscher bis zur Ortschaft Thyangboche (Fig. 6) konnten die etwaigen Höhenlagen der Lobuchestadium-, Thuklhastadium-, Perichestadium- und Thyangbochestadiumendmoränen und somit die maximale Vergletscherungsausdehnung zum jeweiligen Zeitabschnitt abgelesen werden. Ungewiss war, was Iwata mit der gepunkteten Linie meinte, da diese nicht in der zugehörigen Legende erschien, und warum die Endmoräne nicht auf den Talboden skizziert wurde. Möglicherweise verweist die gepunktete Linie auf Reste der jeweiligen Stadium-Moränen. Die Endmoränen der Lobuche Moränen reichten laut der Angaben in Fig. 6 bis auf ca. 4.500 m Höhe. Der angegebene Höhenwert der Khumbu Gletscher Endmoräne des Lobuche Stadiums stimmte, wenn dies mittels Höhenangaben von Karten dieses Gebietes überprüft wurde, mit der eingezeichneten Moräne in Fig. 1 überein. Jedoch waren in dieser Abbildung weitere Lobuche Moränen eingezeichnet, die bei Überprüfung im Gegensatz zum Khumbu Gletscher tiefere Werte anzeigten: Tshola Gletscher (ca. 4.400 m), Tsuro Gletscher (ca. 4.200 m), Nuptse Gletscher (ca. 4.700 m), Lhotse Nup Gletscher (ca. 4.800 m), Lhotse Gletscher (ca. 4.500 m), Kyuwo Gletscher (ca. 4.700 m), Ama Dablam Gletscher (ca. 4.500 m). Die maximalste Tieflage der Lobuche Moränen ließ sich also bei ca. $4.200 \mathrm{~m}$ talaufwärts der Ortschaft Ralha ablesen. Das würde einen Höhenunterschied von $300 \mathrm{~m}$ bedeuten. Warum wiesen größere Gletscher, gegenüber kleineren, höher liegende Lobuche Moränen auf? Wie konnte es sein, dass die Lobuche Moränen beim Khumbu Haupttalgletscher nicht so weit herunter reichten wie beim Tshola Gletscher oder dem Tsuro Gletscher? Müssten die Moränen gleichen Alters nicht ungefähr auf derselben Höhenlage enden? Dieses Phänomen war aber beispielsweise bei den von Iwata (1976) ausgewiesenen Lobuche Moränen tatsächlich der Fall. Dort unterschieden sich diese in ihrer Entfernung zum Gletscher beim Khumbu Gletscher, beim Ama Dablam und beim Lhotse Gletscher, lagen aber alle ungefähr auf derselben Höhenlage. Laut der Annahme derselben Höhenlage gleicher Moränenstadien würde es bedeuten, dass die angegeben Lobuche Moränen vom Khumbu Haupttalgletscher gegenüber dem Tshola Gletscher oder dem Tsuro Gletscher bei Iwata (1976) unterschiedlichen Alters sind. Würden die Moränen ungefähr auf derselben Höhenlage enden, würde das aussagen, dass die Lobuche Moränen der kleineren Gletscher höher liegen müssten oder dass die des Khumbu Gletscher auf mindestens $4.200 \mathrm{~m}$ enden würden. Das würde wiederum bedeuten, dass die von Iwata (1976) ausgelegten Periche Moränen als Lobuche Moränen anzusprechen wären. Daraus 
schlussfolgernd würde die Maximalvergletscherung der letzten Vereisung viel weiter talabwärts gereicht haben, als es von Iwata (1976) beschrieben wurde.

Beim Thuklha Stadium reichten die Endmoränen laut Fig. 6 bis auf ca. 4.500 m Höhe. Der angegebene Höhenwert der Khumbu Gletscher Endmoräne des Thuklha Stadiums stimmte mit der eingezeichneten Moräne in Fig. 1 überein und reichte talabwärts der Ortschaft Thukla maximal bis auf ca. $4.470 \mathrm{~m}$. Weitere in Fig. 1 dargestellte Thuklha Moränen reichten zwischen dem Ama Dablam Gletscher und dem Lhotse Gletscher maximal bis auf ca. $4.600 \mathrm{~m}$ Höhe, was einem Höhenunterschied von 100 m entsprach. Irritierend bei Fig. 1 war die von ihm ausgewählte Schraffierung für die Thuklha Moränen ebenso wie für die Schuttbedeckung der Gletscher. Es handelte sich hierbei um die gleiche grafische Darstellung, was eigentlich darauf schließen lassen würde, dass Iwata die Obermoränen in den Zeitraum des Thuklha Stadiums legte, was jedoch unlogisch wäre.

Die Periche Moränen reichten nach dem Moränenprofil in Fig. 6 bis auf ca. 4.200 m Höhe. Bei der Betrachtung der grafisch in Fig. 1 dargestellten Moränen insgesamt und bei der Überprüfung der Höhenwerte mittels Kartenmaterial fiel auf, dass die als Periche Moränen dargestellten Moränen bis auf ca. $4.180 \mathrm{~m}$ talabwärts der Ortschaft Periche reichten. Andere weiter talabwärts visualisierte Periche Moränen reichten maximal bis auf ca. $4.100 \mathrm{~m}$. Hierbei stellte sich einmal mehr die Frage, warum der Khumbu Gletscher als Haupttalgletscher während dieses Stadiums weiter höher reichte, als ein Nebentalgletscher, nämlich der Tsuro Gletscher. Die in Fig. 1 dargestellten Periche Stadium Moränenrücken nördlich und westlich von Dingboche ließen darauf schließen, dass die Gletscher des Imja Khola zu dieser Zeit auch bis etwa auf $4.200 \mathrm{~m}$ reichten. Jedoch passten in dieses Szenario die Periche Moränenzüge des Kyuwo Gletscher und die unterhalb des Nuptse Gletscher nicht. Diese würden durch die Haupttalgletscher anders geformt worden sein. Somit könnte diesen Moränen ein jüngeres Alter zugesprochen werden - passend wäre in diesem Zusammenhang hier der Zeitraum des Thuklha Stadiums.

Die Thyangboche Moränen reichten bis auf ca. 3.625 m Höhe (ebd.:112/Fig. 6). Nach Fig. 1 reichten die Thyangboche Moränen im Khumbu Tal aber maximal nur bis auf ca. $4.100 \mathrm{~m}$ talabwärts der Ortschaft Periche herunter. Dieser Höhenunterschied von 475 m war jedoch dadurch zu erklären, dass Iwata die Thyangboche Moränen bei Thyangboche nicht mehr in dieser Grafik darstellte. Auffallend bei Fig. 1 war, dass die visualisierte Thyangboche Moräne südlich von Dingboche in Betrachtung zu den in der Umgebung ebenfalls visualisiert festgelegten Periche Moränen nicht dort vorkommen dürfte, da der vorzeitliche 
Haupttalgletscher des Imja Drangka während des jüngeren Periche Gletschervorstoßes diese hätte umgestalten bzw. zerstören müssen, sodass diese Thyangboche Moräne das Alter des Periche Stadiums haben oder jünger sein müsste. Weiterhin fiel zudem auf der orographisch rechten Seite des Khumbu Gletscher folgendes auf: es waren dort keine Periche Moränen, nur an Thuklha Moränen angrenzende Thyangboche Moränen vorhanden und die Höhenlage der Thyangboche Moränen stimmte nicht mit der Höhenlage der Thyangboche Moränen bei Periche überein. Dass würde nämlich bedeuten, dass der Khumbu Gletscher zur Zeit des Thyangboche Stadium in der Nähe seines Ursprungsgebietes eine beträchtlich geringere Mächtigkeit aufgewiesen haben musste als in der Nähe seiner Gletscherzunge. Jedoch war nicht auszuschließen, dass weitere Thyangboche Moränen in der Umgebung des Khumbu Gletscher auftraten - die mit Fragezeichen versehenen unklassifizierten Moränen könnten stellenweise diesen Aspekt untermauern. Doch stellte sich insgesamt weiterhin die Frage, was die letztgenannten für Moränen waren.

Die o.g. fehlende geomorphologische bzw. glazialgeomorphologische Detailanalyse und der örtlich zu begrenzte Untersuchungsraum ließen annehmen, dass weitere Moränen talabwärts dieser Untersuchungsgebiete vorkommen, was ohnehin schon durch Fushimi (1978), Heuberger und Weingartner (1985), Heuberger (1986), Kuhle (1987b, 1988a, 1998, 2001a, 2005, 2007a, 2011a, 2013a) belegt wurde. Vielleicht waren weitere aber auch nur mit Akkumulationen bedeckt, wie es Iwata (1976:112) ebenfalls angab: "The lateral moraine of the Thyangboche stage was covered with the moraines pushed out from the Mingbo and the Omoga valleys, $3 \mathrm{~km}$ down from Periche. Accordingf to the moraine profiels along the valley (Fig. 6), the moraine continues to the huge terminal moraine on which the monastery of Thyangboche stands. “.

Iwata (1976) deutete das Vorkommen zumindest einer weiteren talabwärtig gelegenen Moräne mittels der als unklassifizierte Moräne mit Fragezeichen gekennzeichneten Fläche unterhalb der tiefstreichenden Thyangboche Moränen in Fig. 1 an, wobei auch Fig. 6 durch die Höhenlage der Thyangboche Endmoräne in Bezug zum Talboden - sie lag nicht direkt auf dem Talboden - auf eine solche Annahme schließen ließ. Auch die Tatsache, dass er als Möglichkeit erwähnte, dass die Periche und Thyangboche Moränen spätglazialen Alters sein könnten, deutete darauf. Zudem wiesen die von Iwata (1976:Fig.1) an den orographisch linken und rechten Talflanken kartierten Thyangboche Moränen und die unklassifizierten Moränen auf einen mächtigeren vorzeitlichen Khumbu Gletscher hin. Auch der Aspekt der Nichtbetrachtung anderer glazialgeomorphologischer Formen würde dafür sprechen, dass es bei den Ausführungen von Iwata (1976) nicht eindeutig war, ob glaziale Kennformen 
talabwärts vorkamen bzw. wie die Lagebeziehung der Formen zueinander war. Nichtsdestotrotz ging Iwata (1976:113) inhaltlich im Text davon aus, dass unterhalb der von ihm aufgefundenen Moräne bei Thyangboche keinerlei End- oder Lateralmoränen aufzufinden waren ("The huge terminal moraine at Thyangboche preserves its original form and beyond it there is no apparent terminal or lateral moraine down the Dudh Kosi valley").

Zum vorstehenden Zitat traten folgende Fragen auf:

- Müsste nicht eine so gut erhaltene Endmoräne in das Zeitalter des Spätglazial oder jünger eingeordnet werden? Wäre es eine Moräne aus dem Hochglazial, dürfte diese in einer solchen Höhenlage nicht so gut erhalten sein.

- War die Endmoräne genauso gut, besser oder schlechter erhalten als talaufwärtige End- oder Lateralmoränen? Jegliche Angaben zu den Eigenschaften bzw. visuelle Darstellungen dieser Moräne wurden von Iwata (1976) nicht gegeben.

- Waren nur keine auffälligen End- oder Lateralmoränen talabwärts der Thyangboche Moränen aufzufinden oder tatsächlich gar keine? Wurde dieser Aspekt von Iwata genau überprüft oder wurden unauffällige Moränen nur nicht erwähnt? Hierüber waren dem Text von Iwata (1976) keinerlei Informationen zu entnehmen. Kartendarstellungen des Gebietes unterhalb von Fig. 1 mit Angaben zur Route der Forschungsreise insgesamt waren zudem nicht gegeben. Dadurch war eine Eingrenzung der bezüglich der Äußerungen in Frage kommenden Route unterhalb von Thyangboche und somit die spätere Überprüfung dieses Gebietes nicht möglich: das gegebenenfalls doch vorhandene Auftreten auffälliger oder unauffälliger End- und Lateralmoränen entlang seiner damaligen Route blieb unüberprüfbar. Dass Endmoränen weiter talabwärts vorkommen, bestätigte Kuhle (2005). Damit wäre die zeitliche Einordnung von Iwata (1976) in Frage zu stellen.

Auch dem folgenden Zitat von Iwata (1976:113): “The glacial chronology mentioned above is insufficient in aspects of regional correlation and age determination. The complete glacial fluctuation will not be known until detailed field work is extended throughout the Himalayas." war zu entnehmen, dass die zeitliche Einordnung der Moränen nach Iwata (1976) nicht unbedingt richtig sein muss bzw. unzureichend ist. 
Desweiteren machte Iwata (1976) glaziale Formen aus der vorletzten Eiszeit aus ${ }^{155}$. Wie hat er jedoch diese Formen zeitlich festgelegt und wo traten diese auf? Waren diese Formen die unklassifizierten Moränen? Auf diese Aspekte ging Iwata (1976) nicht ein, wodurch die zeitliche Einordnung anzweifelbar wurde. Ebenfalls zeigte das Zitat: "The extent and patterns of all of the glacial moraines have not yet been investigated and no attempt has been made to correlate the moraine stages with those of other parts of the world." (Iwata 1976:109), dass nicht alles untersucht wurde. Bei den verschiedenen Moränenstadien fiel folgendes auf: Sie wurden anhand der Lagebeziehung zum Gletscher, der Moränenhöhe, der Formausbildung, des Frische- / Verwitterungsgrades (Moräne, Blöcke an der Oberfläche) und der Vegetationsund Bodenbedeckung zeitlich voneinander unterschieden (ebd.:109).

\section{GLETSCHERSTADIEN}

Die Lobuche Moränen stammten aus den letzten Jahrhunderten, das Alter der Lobuche II Moränen gab Iwata (1976) jedoch nicht an, es wurde nur ein etwaiger Entstehungszeitraum zwischen Lobuche I (19.-20. Jhd.) und Lobuche III (Kleine Eiszeit) - deutlich. Die Unterscheidung der Stadium I bis III Lobuche Moränen anhand der Faktoren Vegetationsbedeckung, Verwitterungsgrad der Oberflächenblöcke und Firsthöhe war nachvollziehbar (ebd.:109 f.).

Die Unterscheidung der Thuklha von den Lobuche Moränen muss wohl schwieriger gewesen sein, da er folgendes äußerte: "The advances of the glaciers in this stage were almost to the same extent as those of the Lobuche stage but the surface positions were lower." (Iwata 1976:111). Jedoch schrieb Iwata (1976:113) an einer anderen Textstelle, dass eine Trennung anhand von Eigenschaften möglich war ${ }^{156}$. Das Alter der Thuklha Moränen - 2.000-6.000 v.H. - wurde ebenso nur ungenau festgelegt ${ }^{157}$.

Darüber hinaus stellte sich die Frage, ob ein Vergleich der Moränen im Himalaja mit denen aus Europa, Nordamerika, Arktis, Patagonien und damit eine zeitliche Einordnung dieser anhand anderer Moränen möglich ist. Iwata (1976) meinte, dass rezente Schwankungen in

\footnotetext{
155 "The existence of older landforms, considered to be related to glaciers, suggests that the Khumbu region was also glaciated before the Last Inter-Glacial." (ebd.:109)

156 "In terms of the degree of weathering, modification, and vegetation cover, the sharp contrast between the Lobuche stage and the Thuklha stage moraines suggests that the stages are clearly of different ages." (ebd.:113) 157 "Tentative correlation with dated moraines having similar features and relative positions in North America and Europe would date them at 2000-6000 years B.P." (ebd.:113); "Comparison with Europe and North America suggests that the Lobuche and the Thuklha stages correspond to Neoglacial readvances which culminated a few hundred and also several thousand years ago." (ebd.:109)
} 
verschiedenen Erdteilen übereinstimmen und dass das Himalaja Gebiet mit Europa und Nordamerika vergleichbar ist ${ }^{158}$.

Iwata (1976) fand die Periche Moränen in seinem Untersuchungsgebiet nur sehr sporadisch $^{159}$. Verwirrend war, dass Moränen aus der Zeit der letzteiszeitlichen Maximalvergletscherung eine so geringe Verbreitung aufweisen sollten. Es wäre logischer, dass diese Moränen im Gegensatz zu den jüngeren aufgrund der flächenmäßig viel größeren Gebietsabdeckung der Vergletscherung, trotz der längeren Erosionsdauer im hier betrachteten Gebiet, absolut auf mehr Fläche auftreten, aber meist zusammenhängender sind.

Die Periche und Thyangboche Moränen unterschieden sich laut Iwata nicht so deutlich voneinander ${ }^{160}$. Auch die Verwitterungsintensität und die Vegetationsbedeckung war bei beiden gleich entwickelt: "Both the Periche and the Thyangboche stage moraines which show well weathered and vegetation-covered surfaces lie at the valley far down the glaciers." (Iwata 1976:109). Wie konnte er diese Moränen dann untereinander abgrenzen?

Thyangboche Moränen stammen laut Iwata (1976:113) also nicht aus der vorletzten Eiszeit, wohl eher die Plattformen. Die Periche und Thyangboche Moränen entstanden in der Zeit des Spät- oder Hochglazial ${ }^{161}$. Bei diesen Aussagen wurde jedoch nicht eindeutig geklärt, welche Moränen aus welchem Zeitraum stammen oder ob die Moränen aus beiden genannten Zeiträumen stammen können. Außerdem wurde bei letztgenanntem Zitat die zeitliche Einordnung dieser Moränen durch die Annahme, dass talabwärts von Thyangboche keine Moränen mehr existierten, festgelegt. Da dort jedoch wie o.g. solche vorkommen, war diese zeitliche Aufteilung kritisch zu hinterfragen und die Periche und Thyangboche Moränen in jüngere Zeiträume einordbar. Auch in Fig. 3 waren die Periche und Thyangboche Moränen nicht genau voneinander getrennt ${ }^{162}$ oder es wurde in Fig. 2 das Vorkommen der Thyangboche Moränen nur vermutet ${ }^{163}$. Zudem sei durch die beschriebene Bodenbildung der beiden Moränen keine zeitliche Unterscheidung möglich: "The Periche and the Thyangboche

\footnotetext{
158 "The features of the moraines of each stage in this region are very similar to those of Europe and North America reported already. These facts suggest that it is possible to correlate the Himalayan glacial sequence with those of Europe and North America." (ebd.:113)

159 "The Periche stage moraines are located continuously along the left bank of the valley below the Khumbu Glacier, but are intermittent in the other valley of the studied area." (ebd.:111 f.)

160 "The difference of the deterioration of the forms between the Periche and the Thyangboche stage moraines is not so great that the Thyangboche stage cannot coincide with Pre-Interglacial stages.” (ebd.:113)

161 "The Periche and Thyangboche stages may be of the Late Glacial and the Last Glacial Maximum." (ebd.:109); "These facts suggest that the Periche and the Thyangboche stages correlate with the readvance and the maximum of the Last Glacial Period, respectively." (ebd.:113)

162 "5. Periche or Thyangboche stage moraine. " (ebd.:111/Fig. 3)

163 "The huge moraine which is assumed to belong to the Thyangboche stage lies behind. " (ebd.:111/Fig. 2)
} 
stage moraines were formed when glaciers had advanced to very far down below from their present limits. The buried soil which covers the above-mentioned moraines would have been formed in the Hypsithermal time which was warmer than the present." (Iwata 1976:113). Somit war letztendlich eine genaue zeitliche Trennung der Periche und Thyangboche Moränenstadien von Iwata (1976) nicht vorgegeben. Richards et al. (2000:1631) meinten jedoch, dass Iwata (1976) das Thyangboche Stadium in den Zeitraum vor etwa 40.000 bis 50.000 Jahren legte ${ }^{164}$.

Die Plattformen stammten nach Iwata (1976:113) aus dem Präinterglazial ${ }^{165}$. Hierbei stellte sich einmal mehr die Frage, wie er das Alter genau festlegte und um was es sich, wie auch bei den unklassifizierten, für Moränen handelte. Vor allem bei Betrachtung des Zitats: “[...], though it is not confirmed yet whether they consist of bed rock or till. " (Iwata 1976:112) konnte das Alter der Plattformen eben nicht nur in einen Zeitraum fallen, da die Plattformen auch aus Anstehendem bestehen können.

Die Plattformen kommen in einer Höhe über 5.000 m, entlang der Täler höher werdend, vor (ebd.:112). Hierbei blieb ungeklärt, in welche Richtung des Tales diese Plattformen höher werden sollten ${ }^{166}$. Nach Fig. 6 lagen die tiefsten Plattformreste aus der vorletzten Eiszeit zwischen Thukla und Lobuche jedoch auf ca. 4.875 m Höhe und nicht auf über $5.000 \mathrm{~m}$ (ebd.:112).

Die kritische Auseinandersetzung mit den Befunden von Iwata (1976) zeigte, dass keine sichere Aussage über die maximale Gletscherausdehnung im Gebiet des Solukhumbu anhand dieser möglich war. Die aufgezeigten Kriterien sprachen dafür, dass die Ausführungen von Iwata (1976) mit hoher Wahrscheinlichkeit nur eine spätglaziale Vergletscherung aufzeigten.

\section{FUSHIMI (1977)}

\section{METHODE BZW. ARBEITSTECHNIK}

Fushimi (1977) wendete geomorphologische Analysen an. Bei den heutigen Moränen wurden anhand der Eigenschaften der Moränen wie etwa Erhaltungs- bzw. Verwitterungsgrad, Lage, Höhe und Größe auf das Alter derselben geschlossen (ebd.:62 f.). Anhand von Gletscherschrammen auf Rundhöckern wurde eine ehemalige Gletscherfließrichtung

\footnotetext{
164 "Iwata (1976) presented evidence for an early, more extensive glaciation, the Thyangboche Glacial Stage, in the Khumbu and Imja Valleys, but this has yet to be numerically dated. However, on the basis of weathering characteristics, Iwata (1976) believed that this glaciation was probably ca. 40-50 ka." (Richards et al. 2000:1631)

165 "From the conspicuously subdued forms of the platforms, it is assumed that they were built in the PreInterglacial Glaciation. " (Iwata 1976:113)

166 "But to be exact, their altitude becomes higher along the valleys. This suggests that the platforms are caused by glacial erosion or deposition, [...]. “ (ebd.:112)
} 
abgeleitet (ebd.:63). Fushimi teilte die rezenten Thuklha Moränen anhand der Vegetationsbedeckung, der Bodenentwicklung, der Moränenhangneigung und des Toteisvorkommens in den Moränen in sechs Unterstadien ein (ebd.:64). Auf die Zusammensetzung, die Form und die Größe der Moränen ging er ebenfalls ein (ebd.:64 f.). Die Trogtalserien wurden anhand zusammenlaufender Moränen, der Form der Moränen, der 'locations of springs' und anhand der Bodenentwicklung - hier: Farbe und Mächtigkeit unterschieden (ebd.:66).

\section{UNTERSUCHUNGSGEBIET}

Fushimi (1977) untersuchte die Vergletscherung bzw. Gletscherveränderungen im KhumbuHimal und im Langtang-Himal seit dem Jahre 1970. Zum Beispiel wurde der Gyajo Gletscher nördlich von Khunde, der Dzonglha Gletscher, der Ngojumba Gletscher sowie der Lobuche Gletscher betrachtet und die Befunde den früheren Forschungen gegenübergestellt. (ebd.:61$63,65)$

\section{ERGEBNISSE}

Fushimi (1977) ging auf heutige - Entstehungszeitraum von vor einem Jahr bis einige Jahrzehnte früher - und rezente Moränen - Entstehungszeitraum von einigen Jahrzehnten bis einige Jahrhunderte - ein. Die heutigen Endmoränen waren 1 bis $2 \mathrm{~m}$ hoch sowie 2 bis $3 \mathrm{~m}$ breit und gut erhalten. Rezente Moränen teilte Fushimi dem Thuklha Stadium zu, welches sich in sechs Unterstadien teilen ließ. Das Thuklha VI Unterstadium war dabei das jüngste, gegenüber den Thuklha I bis VI Stadien. Solche Moränen setzten sich aus Ton, Sand, Gesteinsfragmenten und Blöcken zusammen, wobei die Oberfläche gröbere Fraktionen aufzeigte. Oft waren Seesedimente und flussterrassenähnliche Sedimente auf den Moränen gelagert. (ebd.:62, 64)

Die vorzeitlichen Trogtäler wurden in drei Serien - U1 und U2 mit je zwei Unterstadien A und B sowie U3 mit drei Unterstadien, welche wiederum weitere Unterteilungen aufwiesen eingeteilt. In der Nähe der Lhajung Station oberhalb von Dingboche waren die jüngeren Serien U2 und U3 gut erhalten, aber die älteste U1 nur teilweise. Das Periche Stadium bzw. U3B wurde in neun Unterstadien der nächsten Hierarchie gegliedert. Die Gesteinsarten der Periche Moräne bestimmte Fushimi. (ebd.:60, 66) 


\section{KRITIK}

Fushimi (1977) wendete geomorphologische Analysen an. Er unterschied die vorgefundenen Moränen anhand der Eigenschaften der Moränen wie etwa Erhaltungs- bzw. Verwitterungsgrad, Zusammensetzung, Vegetationsbedeckung, Bodenentwicklung, Moränenhangneigung, Lage, Höhe, Form, Größe und Toteisvorkommen und ordnete diese zeitlich in verschiedene Stadien ein. Über die rezenten Moränen schrieb Fushimi beispielsweise folgendes: "The older the side moraine is in age, the flatter it is on its top and it resembles a river terrace in shape. This indicates that there are plenty of eroded materials supplied from the near by mountain flanks and deposited in between side moraines and mountain flanks to make the tops of side moraines flat." (Fushimi 1977:64). Außerdem unterschied er verschiedene Trogtalserien. Anhand von Gletscherschrammen auf Rundhöckern von rezenten Moränen wurde eine ehemalige Gletscherfließrichtung beim Dzonglha Gletscher abgeleitet (ebd.:63). Fushimi (1977) ging auf folgende geomorphologische Formen in seiner Arbeit ein: heutige und rezente Moränen, Rundhöcker mit Gletscherschrammen - in der Nähe der Endmoräne des Dzonglha Gletscher (Fig. 5) - und Trogtäler. Diese Formen wurden anhand von abgebildeten Fotos, Skizzen und Karten nachvollziehbar: Fig. 1 - Foto von Schneeschichten im Firngebiet des Gyajo Gletscher; Fig. 2 - Skizze der Schneeschichten im Firngebiet des Gyajo Gletscher; Fig. 3 - Foto der heutigen Endmoräne des Dzonglha Gletscher; Fig. 4 - Skizze der Verteilung der heutigen Moränen und Beschreibung der Eigenschaften des Dzonglha Gletscher; Fig. 5 - Foto eines Rundhöckers mit zwei verschiedenen Gletscherschrammen; Fig. 6 - Karte von Rundhöckern mit Gletscherschrammen beim Dzonglha Gletscher mit drei verschiedenen Richtungen; Fig. 7 - Foto einer Moräne talabwärts des Lhotse Gletscher; Fig. 8 - Foto einer Moräne beim Ngozumpa Gletscher; Fig. 9 - Foto der Trogtalserien bei Dingboche; Fig. 10 - Skizze der Trogtalserien bei Periche mit Angaben über relative Höhen, Korngrößen und Farben der Moränen und Bodenmächtigkeit; Fig. 11 - Karte der Moränen und Vegetation in der Nähe der Lhajung Wetterstation und Fig. 12 - Foto von der Gesteinsartenzusammensetzung von 101 Gesteinen der Periche Moräne in der Nähe der Lhajung Wetterstation. Demnach untersuchte Fushimi im Khumbu die Gletscher Gyajo, Dzonglha, Ngozumpa und Lobuche. In der Einführung ging er auf die geologische Entstehung des Himalaja ein. Neben diesen geologischen Aspekten beschrieb er auch geomorphologische und klimatologische, wodurch die Gletscherstände variierten ${ }^{167}$.

\footnotetext{
167 "Glaciers of the Himalayas have never reached stable conditions, because geological, geomorphological and climatological changes occurred throughout the Quaternary." (Fushimi 1977:61)
} 
In Fig. 11 fiel auf, dass Fushimi ein Stadium angab, dass älter als das Periche Stadium war, welches aber nicht weiter im Text erwähnt wurde. Nun stellte sich hier die Frage, welches Alter diese Moränen hatten. Fushimi gab im Text das Alter der heutigen und rezenten Moränen wie folgt an: "The term 'present' means a time range of 1 to several tens of years and 'recent' that of several tens to several hundreds of years in this paper." (Fushimi 1977:62). Abgesehen davon, dass diese Altersangaben ungenau waren, wurden bei den anderen im Text genannten Periche Moränen keinerlei Angaben über das Alter gemacht. Demnach waren nicht nur die Periche, sondern auch die Moränen, die älter als das Periche Stadium waren, zeitlich nicht einordbar. Es war nur ableitbar, dass das Periche Stadium älter als das rezente Stadium war - also älter als einige Jahrzehnte bis einige Jahrhunderte - und desweiteren das Stadium älter als Periche, wie der Name schon sagt, älter als das Periche Stadium war. Somit könnte es sein, dass Fushimi (1977) mit dem Periche Stadium nicht unbedingt ein hochglaziales, sondern ein spätglaziales Stadium meinte. Da auch im Text keinerlei Angaben über die letzteiszeitliche Maximalvergletscherung in dem untersuchten Gebiet gemacht worden sind, war es anhand dieser Arbeit nicht möglich, Aussagen darüber zu treffen. Es konnte nur ausgesagt werden, dass es sich bei den Fushimi Stadien nicht unbedingt um hochglaziale handeln muss. Über die zeitliche Einordnung der Trogtalserien meinte Fushimi folgendes: "The two younger cliffs, $U-2$ and $U-3$, are well preserved but the older, U-1, is partly preserved." (Fushimi 1977:66); "The series of U-shaped valleys show that the younger the age of the U-shaped valley is, the deeper the cliff of the valley is, and also the smaller the scale is." (ebd.:60). Demnach sind auch über die Trogtalserien U1 bis U3 keine genauen Altersangaben gemacht worden. Somit blieb offen, wie alt die Periche Moränen, die Moränen älter als das Periche Stadium und die Trogtalserien waren. Zudem war sich Fushimi bei der Betrachtung dieses Zitats: "There are three different eroded cliffs, which possibly formed a part of a U-shaped valley in the past, [...]." (ebd.:66) offensichtlich nicht ganz sicher, ob es sich bei den aufgefundenen Formen eindeutig um vorzeitliche Trogtäler handelte.

\section{FUSHIMI (1978)}

\section{METHODE BZW. ARBEITSTECHNIK}

Fushimi (1978) wendete geomorphologische Analysen sowie absolute Datierungen ${ }^{14} \mathrm{C}$ an. 


\section{UNTERSUCHUNGSGEBIET}

Fushimi (1978) untersuchte zwei Monate lang im Jahre 1976 die Gebiete Khumbu, Hinku und Hongu in Ostnepal. Bei den Ausführungen wurden die Gegebenheiten der Geologie, Topografie und des Klimas in Beziehung zu den glazialen Phänomenen beschrieben, da er diese Zusammenhänge als fundamental für die Vergletscherungsgeschichte betrachtete. Der Himalaja begann sich während des mittleren Tertiär tektonisch zu heben und stellt eine Barriere für Geologie, Topographie, Klima und Lebensformen in Zentralasien dar. Es ist noch immer das sich meist verändernde Gebiet der Welt. Die Topographie hängt von den geologischen Gegebenheiten ab, wobei die unterschiedliche Topographie das lokale Klima lenkt. Es ist wichtig, die Zusammenhänge zwischen geologischen, topographischen und klimatischen Zuständen bis einschließlich die Gletschergeschichte herauszukristallisieren. Geologische Strukturen haben also einen immensen Einfluss auf topographische Formationen. Der Himalaja ist ein asymmetrischer Rücken mit mäßig einfallenden Nordhängen und steilen Südhängen. Das Hauptfaltensystem verläuft in N-S und E-W Richtung. Täler und Gletscher im Khumbu, Hinku und Hongu verlaufen durch die Ausbildung des Faltensystems auch in NS und E-W Richtung. Eine flache Oberfläche existiert zwischen 5.000 und $5.500 \mathrm{~m}$ auf der Südseite des hohen Himalaja und auf 5.500 und 6.500 m auf der Nordseite. Kartengrundlage der Untersuchungen von Fushimi waren hauptsächlich die Karten 'Khumbu Himal' von Schneider et al. (1967) ${ }^{168}$ und 'Shorong und Hinku' von Schneider et al. (1974) ${ }^{169}$. (vgl. Fushimi 1978:71, 72, 72/Fig. 2, 72/Fig. 3)

\section{KRITIK}

Im Paper 'Glaciations in the Khumbu Himal' gab Fushimi (1978:71) an, dass er die Gebiete Khumbu, Hinku und Hongu in Ostnepal untersuchte. Genauer erforschte er aber nicht - so wie im Titel angegeben - nur den Khumbu-Himal, sondern auch das Gebiet des Solu, da er die maximale Vergletscherung bis unterhalb von Lukla beschrieb. Zudem wurde bei seinen Ausführungen nicht klar, welche Route er nahm, sodass eine Aussage darüber nicht möglich war, welche Gebiete bzw. Talbereiche er tatsächlich genauer untersuchte. In Fig. 1 wurde nur die Übersicht über die Untersuchungsgebiete Khumbu, Hinku, Hongu mit dargestellter rezenter (Unterstadium T6) sowie Thuklha Vergletscherung (Unterstadium T1) und gekennzeichneter ${ }^{14} \mathrm{C}$-Probenahmestelle bei Lhajung gegeben. Da Fushimi die ${ }^{14} \mathrm{C}-$ Methode anwendete, wurde eindeutig geklärt, dass die Vergletscherung des Periche Stadiums eine sehr

\footnotetext{
168 Schneider, E. et al. (1967): The map of the "Khumbu Himal (Everest)". Ergebnisse des Forshungsunternehmens Nepal Himalaya, Band 1, Lieferung 5, München.

${ }^{169}$ Schneider, E. et al. (1974): The map of the "Shorong and Hinku".
} 
junge war und nicht, wie andere Forscher schrieben, die letzteiszeitliche Maximalvergletscherung im Khumbu anzeigte. Die Erhebungen von ${ }^{14} \mathrm{C}$-Daten waren nach Fushimi (1978:77) wichtig ${ }^{170}$. Von ihm wurden das älteste Thuklha und das Periche Stadium beprobt. Fushimi (1978:75) nahm an, dass die Proben das Alter der Gletschervorstöße anzeigten und in das 16. Jhd. und 8. Jhd. einzuordnen waren ${ }^{171}$. Wo die Probestellen jedoch genau zu verorten sind, wurde nicht eindeutig aufgezeigt; in Fig. 1 waren keine Koordinaten und Höhenlinien existent und zudem waren keine Fotos oder Skizzen der Probenahmestellen vorhanden. Es wurde nur in Fig. 1 die Probenahmestellen mit einem ' $\mathrm{K}$ ' gekennzeichnet und im Text die Angabe gemacht, dass die beiden Proben in der Nähe des Kyuwo Gletscher südöstlich von Lhajung und am unteren Rand der Moränen entnommen wurden ${ }^{172}$.

Positiv hervorzuheben war ferner, dass Fushimi (1978:71) die glazialen Phänomene mit geologischen, topographischen und klimatischen Gegebenheiten und letztgenannte auch untereinander in Beziehung setzte und diese nicht als voneinander unabhängige Faktoren betrachtet wurden ${ }^{173}$. Weiterhin wurden weiterreichende Angaben über diese Gegebenheiten gemacht, sodass ein umfangreicheres Bild als bei anderen Forschern über die Bedingungen in den untersuchten Gebieten entstehen konnte. Allerdings waren laut Fushimi (1978:77) weitere Forschungen von Wichtigkeit ${ }^{174}$. Jedoch fehlte bei den Ausführungen von Fushimi (1978) eine glazialgeomorphologische bzw. eine geomorphologische Bestandsaufnahme. Es wurden zwar heutige und ältere Gletscherstände in Fig. 1 (Solukhumbu, Hinku, Hongu), Fig. 9 (Hinku, Hongu) und Fig. 10 (Solukhumbu), Moränen in Fig. 8 (Hinku, Hongu), Moränen und andere Sedimente in Fig. 6 (rund um Lukla) sowie Tallängsprofile von Trog- und Kerbtal (Hongu) visualisiert, aber keine weiteren geomorphologischen Formen aufgezeigt. Somit blieb beispielsweise die Kennform schluchtförmiger Trog unberücksichtigt, die aber für die Deutung des Talprofils talabwärts von Lukla eine entscheidende Rolle spielt. Fushimi (1978:73) ging davon aus, dass Lukla im Übergangsgebiet zwischen Trogtal im Norden und

\footnotetext{
170 "The ${ }^{14} \mathrm{C}$ analyses are essential to understand the history of the Himalayan glaciers in relation to that of other regions in the world." (Fushimi 1978:77)

171 "The ages of the samples are thought to show the time when the glacier advanced and formed the moraines."; "[...], the age of the oldest Thuklha stage (T-1 substage) is thought to be 16th century and that of the Periche stage 8th century." (ebd.:75)

172 "Two samples of the ${ }^{14}$ C analyses were collected from the bottom of the moraines [...]." (ebd.:75)

173 "Geological, topographic and climatic conditions are fundamental in causing the glacial phenomena, and their characteristics and their relationships are discussed.” (ebd.:71)

174 "Since these observations have been done only in east Nepal, more work is needed to know the local characteristics of geology, topography and climate related to glacial phenomena." (ebd.:77)
} 
Kerbtal im Süden liegt ${ }^{175}$. Im Süden von Lukla lag die M.C.T. und die tiefen Kerbtäler reichten bis nach Khari Khola (ebd.:72). Die Kerbform brachte er ausschließlich mit fluvialen Prozessen in Verbindung ${ }^{176}$. Die von Fushimi verwendete Wortgruppe 'thought to be' wies jedoch darauf hin, dass es sich hierbei um eine Annahme handelte. Bei der Betrachtung der Befunde von Kuhle (2005) fiel auf, dass in diesem Bereich ein schluchtförmiger Trog besteht. Somit würde trotz der Kerbform eine glaziale Formung des Tales möglich und die letzteiszeitliche maximale Gletscherausdehnung nach Fushimi (1978) keine maximale, sondern wohl eher eine spätglaziale sein. Außerdem wurde anhand der Befunde von Fushimi (1978) nicht eindeutig geklärt, ob noch weitere Moränen oder andere glaziale / glazifluviale Formen talabwärts dieser maximalen Gletscherendlage vorkommen. Dass weitere Moränen talabwärts dieser Untersuchungsgebiete vorkommen, wurde ohnehin schon durch Kuhle belegt. Überdies wurden von Fushimi keine sedimentologischen Überprüfungen der vorgefundenen Sedimente gemacht.

Insgesamt verwendete Fushimi (1978) zehn Abbildungen und zwei Tabellen, wobei keine Fotos als greifbare Belege beigefügt wurden. Bei allen Kartenabbildungen fehlten, abgesehen von einer Maßstabsleiste, Höhenangaben und Koordinaten, sodass die Gletscherendlagen nur abgeschätzt werden konnten. In Fig. 1 wurden die Untersuchungsgebiete mit Gletscherverbreitung der Stadien T1 und T6 sowie die ${ }^{14} \mathrm{C}-$ Probestellen vorgestellt: Fig. 2 zeigte eine geologische Karte vom Khumbu; Fig. 3 ein Flächenhistogramm von Norden und Süden des Hohen Himalaja; Fig. 4 die Topografie in Nord- und Südrichtung vom Mt. Everest und vom Lho La; Fig. 5 ein Längsprofil vom vorzeitlichen Trogtal in der Nähe von Urpa im Hongu; Fig. 6 eine geomorphologische Karte rund um Lukla; Fig. 7 Höhenunterschiede der Vegetation, der Schneegrenze vom 4. Oktober 1976 und der Endmoränen (T1) westlich und östlich des Zatrwa La; Fig. 8 und Fig. 9 Vergletscherungskarten vom Hinku und Hongu; Fig. 10 eine Karte der Gletscherverteilung der Stadien im Khumbu; Tab. 1 Vergleichswerte vom Hinku und Hongu (Gebiet in $\mathrm{km}^{2}$ der heutigen Gletscher, Schneebedeckung, Gesteinswände, Moränen und Seen) und Tab. 2 Gletschergebiete der Serie U1 bis U3 vom Khumbu und Hinku / Hongu.

Die vorzeitlichen Vergletscherungen in den Untersuchungsgebieten von Fushimi (1978) wurden durch die topographischen Eigenschaften der Trogtäler und Endmoränen in die drei Serien U1, U2 und U3 eingeteilt (Fushimi 1977 zitiert nach: Fushimi 1978:74). Jedoch ging Fushimi nicht auf diese topographischen Eigenschaften ein und auch nicht auf die

175 "The Luklha region is located between the U-shaped valley in the north and the V-shaped valley in the south." (ebd.:73)

176 "The V-shaped valley is thought to be caused by fluvial erosions [...]." (ebd.:72) 
Unterschiede dieser drei Serien untereinander, weshalb nicht klar wurde, warum er eine dreiteilige Einordnung der Trogtäler machte oder ob diese sinnvoll erschien. Es wurde nur deutlich, dass je größer die angegebene Zahl einer Serie, desto jünger das Alter dieser ist (ebd.:76/Fig. 10). Das Thuklha Unterstadium T6 war beispielsweise das rezente Stadium (Fushimi 1977 zitiert nach: Fushimi 1978:71). Warum das heutige sowie die Periche und Thuklha Stadien der Serie U3 angehören und das Thuklha Stadium in sechs Unterstadien eingeteilt war, wurde ebenfalls nicht weiter von Fushimi kommentiert. Zudem wurde beim Thuklha Stadium nur auf die Unterstadien T1 und T6 eingegangen, die anderen wurden nicht erwähnt. Das T6 Unterstadium setzte Fushimi (1978:75/Tab. 2) beispielsweise mit dem Lobuche Stadium von Iwata (1976) gleich und die Plattformen von Iwata mit seiner U1 und U2 Serie, wobei er das Thyangboche Stadium von Iwata nicht anführte ${ }^{177}$. Hierbei traten die Fragen auf, welches Lobuche Stadium von Iwata (1976) Fushimi meinte und warum die Plattformen zwei unterschiedlichen U-Serien zugeordnet wurden. Nach der Altersangabe des T6 Unterstadium würde nur das Lobuche III Stadium aus der Zeit der Kleinen Eiszeit bzw. des 15.-16. Jhd. nach Iwata (1976) in Frage kommen, die Zuordnung der Plattformen zu zwei Serien erschien unlogisch. Außerdem fiel auf, dass Fushimi (1978) im Gegensatz zu Iwata (1976) die Befunde von Heuberger (1956) nicht berücksichtigte.

Fushimi (1978:72) vertrat die Sichtweise, je älter ein Trogtal ist, desto größer ist auch die Höhendifferenz zwischen Flussbett und Talboden des Trogtales. Das könnte mit der Zerschneidung des Tales durch fluviale oder auch glazifluviale Prozesse erklärt werden, was eine Verbindung zu einem schluchtförmigen Trog zulassen würde. Die von ebd.:72, 7) angegebenen Aspekte, dass das älteste Trogtal in der Nähe der M.C.T. stärker gehoben ist als andere und die Untersuchungsgebiete während der Maximalvergletscherung nicht in der heutigen Höhenlage lagen, sondern tiefer, waren einleuchtend. Jedoch missachtete der Forscher die Kennform des schluchtförmigen Troges.

Im Khumbu Gebiet zeigte Fushimi (1978:76/Fig. 10, 73, 73/Fig. 6) eine maximale letzteiszeitliche Eisrandlage (U1 Serie, Luklha Stadium) südlich von Lukla an. Müller (1080:87) meinte über Fushimi, dass er lediglich eine vier- bis sechsmal größere

177 “The T-6 substage is correlated [...] with Iwata's 'Lobuche stage' (1976). The Thuklha stage is also classified by them, but the stages of Ghat and Luklha in relation to the U-1 and U-2 series are not classified by them except Iwata's Platform topography. However, Iwata's Thyangboche stage has not been reported by Müller and this author." (ebd.:75/Tab.2) 
Vergletscherung als heute anzeigte ${ }^{178}$. Angaben über die Höhenlage, bis wohin das Eis reichte, gab er nicht, nur der Ortsname Lukla wurde als ungefähre Orientierung gegeben ${ }^{179}$. Auch wo die von Fushimi (1978) erwähnte Endmoräne zu diesem Stadium vorkommen soll, war unbekannt. In Fig. 6 und Fig. 10 waren keinerlei Koordinaten oder Höhenlinien dargestellt. Jedoch konnte anhand von Fig. 6 und einer topographischen Karte Nepals die Höhenlage des Übergangs vom Trog- zum Kerbtal ungefähr auf 2.120 m abgeschätzt werden. Die letztgenannte Höhenlage wurde der topographischen Karte genau dort entnommen, da er schrieb, dass das Kerbtal fluvialer Genese war, somit der glaziale Einfluss in diesem Talbereich ausgeschlossen werden konnte und Fushimi die Form des schluchtförmigen Troges nicht in die Analyse mit einbezog. Jedoch verwies Fig. 10 auf eine andere Höhenlage der maximalen Gletscherendlage, die anhand der Gratverläufe bei ungefähr $1.920 \mathrm{~m}$ festgelegt werden konnte. Auch bei den anderen Stadien wurden von Fushimi keine genauen Höhenangaben zur Gletscherendlage, nur Angaben zu den Orten, bis wohin das Eis reichte, gegeben. Jedoch war unter Berücksichtigung dieses Zitats: "The original down-stream of the $U$-shaped valley near the Main Central Thrust has been uplifted to become higher than the mid-stream of the U-shaped valley by thrust movements." (Fushimi 1978:77) anzunehmen, dass das Trogtal, wie im Hongu, über dem Kerbtal verläuft - da nach ebd.:72 die M.C.T. südlich von Lukla liegen soll - und der Übergang vom Kerb- zum Trogtal gar nicht das maximale Gletscherende darstellte. Somit könnte die U1 Endlage talabwärtiger liegen und das in Fig. 10 visualisierte Gletscherende auf ca. 1.920 m Höhe stimmen.

Indikatoren für eine Vergletscherung im Gebiet von Lukla waren die von Fushimi erwähnten Endmoränen der U1 Serie in der Nähe von Lukla und die ausgedehnten flachen U1 Moränenablagerungen rund um Lukla (ebd.:73, 73/Fig. 6). Um was für Moränentypen es sich bei diesen Ablagerungen handelte, überließ Fushimi dem Leser. Kantige Blöcke mit einer feinen Matrix sollen diese älteren Moränenoberflächen überlagern und eine ebene Fläche bilden (ebd.:73). In welcher Hinsicht diese Sedimente teilweise Bergsturzablagerungen, 'landslides' oder Fächern ähnelten, war nicht beschrieben. Die feine Matrix soll laut Fushimi stellenweise aus grauen Tonen bestehen, welche glazial sein könnten ${ }^{180}$. Die Sedimente

\footnotetext{
178 "Fushimi (1978, Table 2) claims that in the main valley south of Mt Everest the areas of the largest glaciers in the late Pleistocene (Luklha Stage) were only 4 to 6 times greater than the present ones." (Müller 1980:87) 179 "At the maximum expansion, which is correlated to the Luklha stage in the upper part of the Dudh Kosi (Fushimi, 1977), most of the mountains below $6000 \mathrm{~m}$ were covered by glaciers and some of the mountains are thought to have formed a 'Nunataks'." (Fushimi 1978:75)

180 "[...] fine grey clays which are thought to be glacier clays." (ebd.:73)
} 
könnten nach ebd.:73 aber auch fluvialer Genese sein ${ }^{181}$. Unter der Annahme, dass diese Sedimente glaziale sein sollten, stellte sich die Frage, ob es sich dann um Moränen der U2 oder U1 Serie handelte. Würde es sich um die U1 Serie handeln, müsste die dazu gehörige Endlage weiter talabwärts liegen als der Übergang vom Trog- zum Kerbtal, der in Fig. 6 dargestellt war. Denn diese Moränenablagerungen der U1 Serie in Fig. 6 reichten im Talabschnitt gesehen tiefer als das eingezeichnete Kerbtal, und müssen somit als Ende der glazialen Talgestaltung angesehen werden. Da die U1 Moränen sowieso unterhalb den o.g. Sedimenten bestehen sollen, war nicht klar, warum die Endlage überhaupt in diesem Gebiet und nicht weiter talabwärts lag. Es ist wohl eindeutig, dass diese flachen Moränenablagerungen keine Endmoränen darstellen, sondern Grundmoränen, wodurch das Gletscherende desgleichen weiter talabwärts liegen müsste. Wären die Moränen in die U2 Serie einzuordnen, müsste das Gletscherende dieses Stadium ebenfalls tiefer liegen, und nicht wie in Fig. 10 bei Ghat enden. Jüngere Moränen konnten anhand Fig. 10 in diesem Gebiet ausgeschlossen werden und ließen sich dort auch nicht in dieser Ausbildung erklären. In Fig. 6 waren Moränen des T1 Unterstadiums und heutige Gletscher eingezeichnet, welche aber in Fig. 10 nicht visualisiert wurden. Weitere Angaben zur Klärung der genannten Aspekte wurden von Fushimi nicht gemacht.

Da Fushimi das Periche Stadium (U3) anhand von ${ }^{14} \mathrm{C}$-Daten in den Zeitraum des 8. Jhd. einordnete und das Lukla Stadium (U1) als letztglaziales Maximum ansah, wurde nicht ganz klar, in welchen Zeitabschnitt das Ghat Stadium (U2), welches bis auf ca. $2.500 \mathrm{~m}$ reichte, fiel (ebd.: 74, 75, Fig. 1 K, Fig. 10). Schlüssig wäre ein spätglaziales Alter. Belege für dieses Vergletscherungsstadium wurden nicht erwähnt. Auch ob dort eine Endmoräne ausgebildet war, blieb ungenannt. Fushimi (1978:73, 73/Fig. 6) erwähnte dort nur Seesedimente, äußerte sich aber wiederum nicht dazu, wie der vorzeitliche See bzw. wann dieser See dort entstanden war und was für einen Umfang er dort hatte.

Im Hinku reichten die Gletscher während des letzteiszeitlichen Maximums nach Fig. 9 bis auf eine ungefähre Höhe von etwa 1.600 m ungefähr bei der Ortschaft Juge; im Hongu dagegen bis auf ca. 1.800 bis 2.000 m Höhe etwa beim Ort Mudi Kharka. Da in dieser Abbildung keinerlei Koordinaten oder Höhenlinien angegeben waren, konnte diese Höhenlage nur anhand der eingezeichneten Fluss- und Gratverläufe mit Hilfe einer topographischen Karte abgeschätzt werden. Die angegebene Maßstabsleiste war allerdings korrekt angegeben: die Messung der Luftlinie der zwei Berge Kanga Taiga und Naulekh ergab beispielsweise auf der Karte von Fushimi (1978) ca. 14 km und bei der Karte von Nepal ca. 14,25 km. Im Hongu

181 "The sediments are thought to be of glacial as well as fluvial origin." (ebd.:73) 
Khola soll nördlich der M.C.T. ein Kerbtal ausgebildet sein (ebd.:72), wo diese M.C.T. jedoch genau liegt, war nicht greifbar. Nur das Kerbtal war in Fig. 5 talabwärts von Urpa (4.209 m) eingezeichnet. Jedoch war dieses Kerbtal im Gegensatz zum südlich von Lukla ausgebildeten Tal, als 'heutiges Kerbtal' gekennzeichnet und verläuft in etwa parallel zum heutigen Flussbett. Talabwärts von Urpa waren allerdings in höheren Talbereichen noch weitere Täler, ältere Trogtäler der Serien U1 und U2, dargestellt, wobei U2 10 km talabwärts von Urpa endete und U1 noch weiter als $15 \mathrm{~km}$ von Urpa talabwärts reichte. Je älter das Tal, desto höher soll es liegen ${ }^{182}$. Nun stellte sich die Frage, ob das bei Lukla genannte Kerbtal nicht auch in höheren Talbereichen weitere Trogtalserien aufwies, oder ob dieses wirklich den Übergang vom Trog- zum Kerbtal darstellte. Wäre der erste Fall zutreffend, war das von Fushimi (1978) angegebene Maximalstadium kein Maximalstadium. Außerdem würde das in Fig. 5 dargestellte gemeinsame Vorkommen von Kerbtal im unteren und Trogtal im oberen Talbereich eindeutig auf einen schluchtförmigen Trog hindeuten, der wie bei Lukla laut Kuhle (2005) ausgebildet war. Zudem würde das Kerbtal nach Fushimi (1978:72) nach dem Zitat in Bezug auf das Kerbtal bei Lukla: "The V-shaped valley is thought to be caused by fluvial erosions [...]." eigentlich auch fluvialer Genese sein und das gemeinsame Auftreten von Trog- und Kerbtal in Frage stellen.

Gneise und Migmatite sollen im Hinku und Hongu Khola gut ausgebildet sein (ebd.:73), was jedoch für Gesteine im Solu vorkommen oder ob Erratika auftreten, wurde nicht erläutert. Es war lediglich eine geologische Karte vom Khumbu Gebiet abgebildet mit den Angaben: Sedimente der Tethys Formation; Gneise; intrusive Granite; Migmatite und Gneise; Migmatite; Hauptfaltensystem (ebd.:72/Fig. 2). Dass zu diesem Zeitpunkt die Gletscher im Hinku und Hongu auf der West- und Südseite nach Fushimi (1978:74, 74/Fig. 8) gegenüber dem T1 Unterstadium mehr zurückgegangen waren, war nachvollziehbar - ebenso wie die von ihm dafür angegebenen Gründe. Speziell auf die klimatischen Gegebenheiten hätte aber mehr eingegangen werden können.

Tab. 1 zeigte, dass u.a. in den oberen Talbereichen des Hongu eine höhere Moränenbedeckung (103 km²; $49 \%$ der Gesamtfläche) gegenüber denen des Hinku (46 km²; $34 \%$ der Gesamtfläche) auftritt (ebd.:75). Bei Gegenüberstellung dieser angegebenen Werte stellte sich aber die Frage, warum die vorzeitliche Vergletscherung laut Fushimi im Hongu dann geringer ausgebildet war als im Hinku: in Fig. 9 konnten die eingezeichneten Moränenstadien miteinander verglichen werden; diese lagen im Hongu immer talaufwärtiger

182 "The older the U-shaped valley is, the larger the height difference between the river bed and the bottom of the U-shaped valley, and the oldest U-shaped valley (U-1 series) is more uplifted downstream near the M.C.T., so the terminal position stays higher than the middle part of the U-shaped valley." (ebd.:72) 
als im Hinku (z.B. U1 Serie im Hinku auf etwa 1.600 m; im Hongu bis auf $1.800-2.000$ m Höhe).

Rezent ist das Khumbu Gebiet mit $170 \mathrm{~km}^{2}$ gegenüber den Regionen Hinku und Hongu mit zusammen $72 \mathrm{~km}^{2}$ mehr vergletschert (ebd.:75 f.). Zudem verwies Fig. 7 auf ein kälteres rezentes Klima im Dudh Khosi gegenüber dem Hinku Khola: die oberen Vegetationsgrenzen waren im Durchschnitt um 195 m niedriger am Westhang; die ehemalige T1 Endmoräne und Schneelinie von 4. Oktober 1976 durchschnittlich 140 m niedriger (ebd.:73). Auch dem Text war dieser Aspekt zu entnehmen: "These differences indicate that the west-facing slope has the colder climatic conditions." (Fushimi 1978:73). Warum war die Khumbu Region dann nicht auch während des letzteiszeitlichen Maximalstadiums am stärksten vergletschert? Tab. 2 verwies zwar auf eine stärkere vorzeitliche und rezente Vergletscherung im Khumbu als im Hinku und Hongu, jedoch reichten die vorzeitlichen Gletscher laut Fig. 9 und Fig. 10 im Hinku und Hongu weiter talabwärts als im Solu. Das erschien unlogisch und ist ohnehin bei der Betrachtung der unterschiedlichen Einzugsgebiete dieser Regionen nicht möglich. Somit waren die maximalen Gletscherstadien nach Fushimi (1978) anzuzweifeln. Jedoch wurde laut ebd.:76 das Volumen der rezenten und der vorzeitlichen Vergletscherung für genauere Aussagen noch nicht berechnet.

Die kritische Auseinandersetzung mit den Befunden von Fushimi (1978) zeigte, dass keine sichere Aussage über die maximale Gletscherausdehnung im Gebiet des Solukhumbu anhand dieser möglich war. Die aufgezeigten Kriterien sprachen dafür, dass die Ausführungen von Fushimi (1978) mit hoher Wahrscheinlichkeit nicht die maximale Vergletscherung aufzeigten.

\section{MÜLLER (1980)}

\section{METHODE BZW. ARBEITSTECHNIK}

Müller (1980:75 f.) machte eine Bestandsaufnahme von 451 Gletschern in der Mt. Everest Region, um diese in ein UNESCO Versuchsprojekt einzubinden. Er berechnete rezente Schneegrenzen, die mit spätpleistozänen Schneegrenzen verglichen wurden, um über die Klimaveränderungen während dieser Zeiten zu spekulieren (ebd.:76).

Diese rezenten Schneegrenzen wurden anhand verschiedener Berechnungen bestimmt: die Schneegrenzberechnung von Lichtenecker $(1938)^{183}$ führte laut Müller (1980) bei vielen Talgletschern in der Everest Region zu verlässlichen Schneegrenzdaten und wurde deswegen

183 Lichtenecker, N. (1938): Die gegenwärtige und die eiszeitliche Schneegrenze in den Ostalpen. In: Verhandlungen der III Internationalen Quartär-Konferenz, Vienna, September 1936 (edited by G. Götzinger). (S. 141-147): INQUA, Vienna, Austria. 
oft angewendet. Die für dieses Gebiet hohe Qualität der Karten und Fotos unterstützte diese Methode. Als Kontrolle oder als unabhängige Bestimmung der Schneegrenze wendete Müller (1980) die Methode nach Hess (1904) $)^{184}$ an. Die Anwendung dieser Methode war im Mt. Everest Gebiet laut Müller (1980) auf Kargletscher reduziert, da extrem steile Wandumrahmungen vieler Talgletscher zu einer Lawinenernährung beisteuern und dadurch unregelmäßige Oberflächen der Akkumulationsgebiete und irregulare Firnlinien auftraten. Ebenso existierten oft komplexe Topographien der Gletscherunterlage. Gegenüber den Talgletschern und einfach geformten Karen wurde die Methode nach Höfer (1879) ${ }^{185}$ und die Bergschrundmethode bei allen anderen Gletschern bei Müller (1980) angewendet. Bei letztgenannter Bergschrundmethode wurden statt der durchschnittlichen Kammumrahmungshöhen die durchschnittlichen Bergschrunde genommen. Die Höfer Methode soll laut Müller (1980) im Mt. Everest Gebiet generell anwendbar $\operatorname{sein}^{186}$, jedoch wurden auch hier, wie bei der Methode nach Kurowski (1891) ${ }^{187}$ zitiert nach: Müller (1980) keine einzelnen Gletschertypen unterschieden. Die letztgenannte Methode kann im Himalaja laut Müller nur sehr schwierig angewendet werden, da die Bedingungen dieser - lineare Ablations- und Akkumulationsgradienten und symmetrische hypsographische Kurve - selten existieren. Es kommen nämlich auch Gletscher ohne Akkumulations- oder ohne eindeutiges Ablationsgebiet vor. (vgl. Müller 1980:77)

In Tabelle 1 waren Eigenschaften der rezenten Gletscher im Nangpo, Dudh Khosi und Imja Khola wie Gletscherendhöhenlage, maximale Länge, gesamte Fläche und AAR angegeben. Hierbei fiel auf, dass die höchste Gletscherendhöhenlage in Süden und Südost, jedoch die größten Gletscher in Bezug auf die gesamte Fläche und Länge nach Süden - im Imja Khola nach Westen - verliefen, was mit den Niederschlägen hauptsächlich aus Süd bis Südwest und der Orographie in Verbindung stand (ebd.:77, 80). Das höchste durchschnittliche AAR betrug 0,5 bei Gletschern der Nord- bis Nordostexposition (ebd.:80). Fehler bei der Interpretation der Fotos und Karten und / oder bei der Methode können zudem die Standardabweichungen der Daten in Tabelle 1 und systematische Fehler die mittleren Werte beeinflusst haben.

\footnotetext{
${ }^{184}$ Hess, H. (1904): Die Gletscher. Friedrich Vieweg und Sohn, Braunschweig. (S. 67-70)

185 siehe Quelle Höfer (1879) in der Fußnote

186 "Nevertheless, when cautiously applied to small simple-shaped mountain glaciers, they may still produce useful ELA data for strongly mountainous areas such as the Mt Everest region, where this type of glacier is common." (Müller 1980:77)

187 Kurowski, L. (1891): Die Höhe der Schneegrenze mit besonderer Berücksichtigung der FinsteraarhonGruppe. Penck's Geogr. Abh. 5, no. 1. (S. 119-160)
} 
Die rezent eisfreien Kare dienten der Berechnung der vorzeitlichen Schneegrenze zur Zeit der Karentstehung ${ }^{188}$. Hierbei wurden die Höhen des Überganges von Karwand zu -boden von rezent eisfreien Karen bestimmt (ebd.:86). Die Daten waren gut zu ermitteln, da die Karwände in der Mt. Everest Region sehr steil ausgebildet waren (ebd.:86). Für die Einordnung des Dughla Stadiums der insgesamt vier festgelegten Gletschervorstöße wurden lichenometrische Messungen und ${ }^{14} \mathrm{C}$-Datierung (frühere unveröffentlichte Arbeit von Müller) durchgeführt (ebd.:86).

Demzufolge wendete Müller (1980) auch geomorphologische Analysen an - neben den Karen nahm er Moränenreste und glaziale Terrasse auf. Daneben machte er relative und absolute Datierungen in Form von Lichenometrie und ${ }^{14} \mathrm{C}$-Datierungen.

\section{UNTERSUCHUNGSGEBIET}

Müller (1980) schrieb, dass umfassende physiogeographische Geländeuntersuchungen im Jahre 1956 bei der 'Swiss Mt. Everest Expedition' erbracht wurden. Über acht Monate sammelte Müller glaziologische und klimatologische Daten der Gletscher im Imja Khola; daneben aber auch im Dudh Khosi und Bote Khosi. In Fig. 1 waren die untersuchten Gletscher dargestellt. Es wurden für das Versuchsprojekt Fotos (einzelne und Panoramen), terrestrische photogrammetrische Bilder, Karten und andere Expeditionsfotos verwendet. (ebd.:76, Fig. 1)

\section{KRITIK}

Die 17-seitige Arbeit - mit zusätzlich zwei Seiten Diskussion - von Müller (1980) mit dem Titel 'Present and former equilibrium-line altitudes near Mount Everest, Nepal and Tibet' hatte eine Bestandsaufnahme von Gletschern zum Ziel. Es wurden rezente und spätpleistozäne Schneegrenzen bestimmt, um über die Klimaveränderungen während dieser Zeiträume zu spekulieren ${ }^{189}$. Müller (1980:Fig. 1, Tab. 1) untersuchte viele Gletscher in der Mt. Everest Region, hauptsächlich im Imja Khola, im Dudh Khosi und im Bote Khosi. Für die Einordnung des Dughla Stadiums der insgesamt vier festgelegten Gletschervorstöße führte er lichenometrische Messungen und ${ }^{14} \mathrm{C}$-Datierungen (frühere unveröffentlichte Arbeit von Müller) durch. Für die rezente Schneegrenzbestimmung wurden verschiedene Berechnungsmethoden angewendet. Die rezente Schneegrenze ist hauptsächlich vom Niederschlag, aber auch von der Temperatur und von der Topografie abhängig, wobei die

188 "Based on the assumption that the elavations of the numerous empty cirques in the area represent the ELA at time of their formation, [...].” (Müller 1980:75)

189 “[...], in order to speculate on the climatic change [...]." (ebd.:76) 
Schneegrenzen in der Mt. Everest Region im Gegensatz zu anderen Gebieten von niedrigen zu hohen Breitengraden zunehmen (vgl. Müller 1980:82). Dieselben klimatischen Elemente sollen während des Spätpleistozäns dominiert haben ${ }^{190}$, wobei aber die Niederschläge auf der Nordseite während des Spätpleistozäns geringer waren ${ }^{191}$. Es wurde angenommen, dass der Monsun im Spätglazial existierte ${ }^{192}$.

Die rezent eisfreien Kare bzw. die Höhenlagen von Karwand zu -boden dienten der Berechnung der vorzeitlichen Schneegrenze zur Zeit der Karentstehung. Die bestimmten rezenten und vorzeitlichen Schneegrenzen sollen unsicher sein, jedoch sollen über die Haupteigenschaften der rezenten und vorzeitlichen Vergletscherung Kenntnisse gewonnen worden sein ${ }^{193}$. Da solche Kare auch während des Spätglazial entstanden sein konnten, wurde nicht eindeutig geklärt, ob es sich bei den von Müller (1980) ermittelten spätpleistozänen Schneegrenzen um hochglaziale oder spätglaziale handelte. Laut Müller entstanden die eisfreien Kare entweder vor oder nach dem Pheriche Stadium ${ }^{194}$. Das von Müller anhand von Lichenometrie und ${ }^{14} \mathrm{C}$-Datierungen bestimmte Dughla Stadium in die Zeit der Kleinen Eiszeit ließ darauf hindeuten, dass das Pheriche Stadium älter als dieser Entstehungszeitraum war. Da das Pheriche Stadium aber laut diesem Zitat: " [...] in age likely to correspond to those of the Egesen and Daun Stages in the Alps, [...]. " als spätglaziales Stadium angesehen wurde (ebd.:86), war es wie o.g. schwierig herauszubekommen, ob die angegebenen spätpleistozänen Schneegrenzen nun hochglaziale oder spätglaziale oder sogar noch jüngere Schneegrenzverläufe darstellten. Somit wurde nicht eindeutig, ob das angegebene Pheriche Stadium und das Stadium, das älter als Pheriche war, eine letzteiszeitliche Maximalvergletscherung anzeigten. Das letztgenannte Stadium, das mittels der Moränenreste und glazialer Terrasse festgelegt wurde, konnte somit zwar auf eine Zeit nach dem Spätglazial hindeuten, aber nicht eindeutig darauf, dass dieses eine maximale Eisrandlage symbolisierte. Auch die Aussage von Müller (1980:86), dass die Stadien Ghat und Lukla von Fushimi (1978) noch ältere Stadien darstellen sollen als das Stadium, das älter als Pheriche war, ließ

\footnotetext{
190 "The similarity of the shape of the ELA curves indicates that the same climatic elements were dominant during the late Pleistocene glaciation of the Mt Everest region as today." (ebd.:91); "Precipitation and temperature patterns have changed little compared to many other parts of the world." (ebd.:91)

191 "It seems that the decrease of precipitation northwards was slightly stronger in late Pleistocene times than today. Even if the height of the main mountain crest was lower than by $200 \mathrm{~m}$ (or possibly $500 \mathrm{~m}$ at the time of the maximum glaciation) the monsoonal transgression to the north of the range was still limited and occasional, as today, and not general." (ebd.:91)

192 "It is concluded that the present pattern of monsoonal moisture supply also existed during late glacial times." (ebd.:75)

193 "In spite of uncertainties about the accuracy of both the present ELA data and the 'cirque floor technique' of establishing past ELA values, much knowledge has been gained regarding the main characteristics of the present and the late Pleistocene glaciation of the area." (ebd.:91)

194 "The empty cirques must have been developed during and prior to the Pheriche Stage." (ebd.:86)
} 
darauf schließen, dass dieses Stadium jünger als das Hochglazial war. Zudem stellte sich die Frage, ob weitere tieferliegende eisfreie Kare - als die bei Müller betrachteten - existieren bzw. was diese für eine Vergletscherung anzeigen würden.

Es wurde eine Karte - Teile davon waren in Fig. 3 dargestellt - von holozänen und spätpleistozänen Moränen und der rezent eisfreien Kare des Imja Khola talaufwärts von Phortse und Tengboche erstellt (ebd.:86). Somit soll die spätpleistozäne Vergletscherung im Gegensatz zu anderen Teilen der Erde in der Mt. Everest Region nur gering ausgedehnt gewesen $\operatorname{sein}^{195}$. Nach Müller war diese Sichtweise generell vertreten ${ }^{196}$. In Fig. 3 wurden nach Müller (1980) letzteiszeitliche Moränen bis unterhalb von Periche auf ca. $4.200 \mathrm{~m}$ visualisiert. Hierbei stellte sich jedoch die Frage, warum weiter talabwärts auf dem orographisch rechten Hang ebenfalls solche Moränen ('Moraine of 'Pheriche Stage' and older') bis auf ca. 4.000 m Höhe existieren sollen. Das würde - genauso wie bei Iwata (1976) - bedeuten, dass der Khumbu Gletscher während der letzten Eiszeit 800 m weiter talabwärts reichte (4.800 m minus $4.000 \mathrm{~m}$ ), da Hängegletscher nicht weiter herabreichen können als ein größerer Hauptgletscher. Auch Meier äußerte bei der Diskussion: "The present equilibrium line altitude (ELA) on large valley glaciers is generally lower than the ELA on smaller cirque glaciers.” (Müller 1980:93). Somit wäre die Interpretation der Moränen von Müller (1980) in Frage zu stellen. Er schrieb, dass Daten für die Hebungsraten fehlen ${ }^{197}$ und in einem tektonisch stabileren Gebiet bessere bzw. brauchbarere paläoklimatische Ergebnisse möglich wären ${ }^{198}$.

Müller (1980) äußerte sich über verschiedene Forscher. Das Thyangboche Stadium von Iwata (1976) sowie die Moränenreste von Heuberger (1956) zweifelte er an: "The Thyangboche Stage proposed by Iwata (1976) is questioned by Fushimi (1978, p. 75, Table 2) and the present author." (Müller 1980:86); "The glacial origin of the remnants reported by Heuberger (1956) at an elevation of only $2100 \mathrm{~m}$ near Tschjaubas in the pre-Himalayas is doubtful.” (Müller 1980:86 f.). Genaue Gründe hierfür wurden allerdings nicht genannt.

\footnotetext{
195 "Glaciation in the late Pleistocene was - as it is today - small in comparison to that of the other ice-prone parts of the globe." (ebd.:75); "The late Pleistocene ELA depression for the Mt Everest area seems somewhat smaller than that for most other parts of the world." (ebd.:87)

196 "Thus the notion of a comparatively small-scale glaciation during the late, or probably the entire Pleistocene and Holocene times, for the central Himalayas, [...],, is gaining general support." (ebd.:87)

197 "However, lack of field data on the uplift rate makes it difficult to utilize this interesting hypothesis quantitatively." (ebd.:91)

198 "In a tectonically more stable area clearer results could be expected from such an investigation. There the glacier inventory would prove even more useful for the reconstruction of the plaeoclimate." (ebd.:91)
} 


\section{FUSHIMI (1981)}

\section{METHODE BZW. ARBEITSTECHNIK}

Fushimi (1981) betrieb geomorphologische Analysen, wobei er die Eigenschaften der Moränen berücksichtigte. Er fand Trogtalserien und Moränen in der Nähe von Pheriche und Lukla und fertigte davon eine Skizze an (Fig. 5).

\section{UNTERSUCHUNGSGEBIET}

Fushimi (1981) untersuchte das Gebiet des Solukhumbu. In Fig. 1 wurde dieses mit seiner Route abgebildet.

\section{KRITIK}

Fushimi (1981) wendete in seiner Arbeit mit dem Titel 'Glacial history in the Khumbu region, Nepal Himalayas, in relation to upheavels of the Great Himalayas' geomorphologische Analysen an. Jedoch ging er hierbei nur auf zwei Formen ein, auf Trogtäler und Moränen in der Nähe von Pheriche und Lukla. Weitere Formen wie etwa schluchtförmige Tröge berücksichtigte er nicht. Die von ihm aufgefundene teilweise erhaltene LGM Endmoräne auf der Höhe von Lukla auf $2.500 \mathrm{~m}$ Höhe muss somit nicht unbedingt das maximale Vergletscherungsausmaß darstellen. Unterhalb dieser Endmoräne können hier auftretende schluchtförmige Tröge oder auch andere glaziale Formen auf ein tieferes vorzeitliches Gletscherende hinweisen. Ob Fushimi weitere Untersuchungen unterhalb dieser Endmoräne machte, war dem Text nicht zu entnehmen. Somit war das von Fushimi angegebene vorzeitliche maximale Vergletscherungsausmaß bis auf $2.500 \mathrm{~m}$ Höhe anzuzweifeln. Auf welchen sonstigen Befunden - abgesehen von den o.g. Trogtalserien und Moränen - die in Fig. 6 dargestellten Vergletscherungsausmaße der verschiedenen Trogtalserien basierten, blieb offen.

Fushimi (1981) beschrieb in Bezug auf die Vergletscherung Zusammenhänge zwischen Tektonik, Topografie und Klima (ebd.:1641). Dabei ging er auf regionale Eigenschaften der Gletscher im Himalaja ein (ebd.:1641-1643). Fushimi meinte, dass die Vergletscherungsgeschichte des Himalaja immer noch nicht geklärt sei, da die tektonischen Hebungsraten, der damit verbundene Klimawandel und das Alter der Gletscherausdehnungen noch nicht genau erforscht seien (ebd.:1643 f.). In Fig. 4 waren die jährlichen Niederschlagsmengen in Ostnepal dargestellt. Fushimi war gegenüber anderen Forschern der Auffassung, dass nicht nur die Sommerniederschläge in Form des Monsuns aus Süden, sondern auch die Winterniederschläge aus Westen ein wichtiger klimatischer Faktor für die 
Vergletscherung waren ${ }^{199}$. Deswegen nahm er an, dass vorzeitlich - als der Himalaja noch unter der heutigen orographischen Schneegrenze lag - die Sommerniederschläge ohne eine Abkühlung nicht hätten als fester Niederschlag fallen können und die Winterniederschläge eine bedeutendere Rolle für die Vergletscherung gespielt haben sollen ${ }^{200}$. Als dann die Himalaja- und Mahabharat-Gebirgszüge tektonisch stiegen, sollen sich die Winterniederschläge auf den Westhimalaja und die Sommerniederschläge auf den Süden des Osthimalaja konzentriert haben ${ }^{201}$, wobei aber die gesamten Niederschläge für die Vergletscherung des Himalaja bedeutend blieben ${ }^{202}$.

\section{WILLIAMS (1983)}

\section{METHODE BZW. ARBEITSTECHNIK}

Williams (1983) wendete geomorphologische Analysen (Moränen, Kare, Trogtäler) an mit relativen Datierungen - Bodenbefunde und Verwitterungsunterschiede. Darüber hinaus machte er Karten- und Satellitenbildinterpretationen sowie Schneegrenzberechnungen. Im Gebiet des Solukhumbu leistete er keine Geländearbeiten.

\section{UNTERSUCHUNGSGEBIET}

Williams (1983) untersuchte das Gebiet rund um das Dudh Khunda Tal genauer, gab aber auch weitere Gebiete an.

\section{KRITIK}

Die Arbeiten von Williams (1983) mit dem Titel 'Present and former equilibrium-line altitudes near Mount Everest, Nepal and Tibet' waren kritisch zu hinterfragen, da er in einem gegenüber dem Imja Khola südlicher liegenden Gebiet eine flächenmäßig größere vorzeitliche Vergletscherung eines außerdem kleineren Gletschers annahm. Williams (1983) ging im

199 "It is mainly in the summer monsoon season that the present glaciers in east Nepal are accumulated, and the orographic snowline is situated at about $5,500 \mathrm{~m}$, but the snowcover is appears even at 2,500 $\mathrm{m}$ during the winter monsoon season." (Fushimi 1981:1645)

200 "It is considered that the past summer solid precipitations would not be formed without the prominent lowering of the air temperature when the average height of the Great Himalayas was lower than that of the present orographic snowline. When the average height of the Great Himalayas was lower, the topographic effects of the rain shadow were so weaker that the winter solid precipitations might reach to the further eastern part of the Himalayan regions than that seen today. The lower the average height of the Great Himalayas was in the older stage, the more the winter precipitations contributed for the formation of glaciers in the Central and East Himalayas." (ebd.:1645)

201 "Further more, the Great Himalayas and the Mahabharat ranges have risen, so the winter precipitation started to concentrate in the West Himalaya and the summer precipitation in the southern part of the East Himalaya." (ebd.:1645)

202 "As the Great Himalayas continued to rise and reached to the height of the present snowline, it is thought that the summer solid precipitation began to contribute the glacial phenomena in the Himalayan regions together with the winter precipitation." (ebd.:1645) 
Khumbu-Himalaja von einer sehr geringen Vergletscherung bis auf maximal 4.200 m Höhe unterhalb von Periche aus. Jedoch berechnete er im viel südlicher liegenden, westlich an das Dudh Kosi Tal angrenzende Dudh Khunda Tal eine maximale spätpleistozäne Schneegrenze auf $4.250 \mathrm{~m}$, wobei er in Bezug auf die heutige Schneegrenze auf $5.200 \mathrm{~m}$ eine Schneegrenzdepression von 950 m berechnete. (ebd.:209, Fig. 2)

Die von Williams (1983) gemachten Geländekartierungen unter Berücksichtigung von pedologischen Befunden und Verwitterungsunterschieden wurden nur im Gebiet rund um das Dudh Khunda Tal durchgeführt. Demnach war dieses Gebiet von $67 \mathrm{~km}^{2}$ sehr klein und die in Fig. 2 dargestellten Ergebnisse des insgesamt $61.880 \mathrm{~km}^{2}$ großen Untersuchungsgebietes nahezu keine Geländebefunde, sondern großenteils Karten- und Satellitenbildinterpretationen. Auf das südwestlich des Mt. Everest gelegene Untersuchungsgebiet bzw. auf die Positionen der Moränen dort bezog sich folgendes Zitat: "Except in the documented area southwest of Mount Everest, the positions of moraines in the Nepalese part of Figure 2 must be regarded as approximate." (Williams 1983:204). Vom Dudh Khunda Tal wurden zwei Fotos und vom Yuligolcha ein Foto als Beleg für eine vorzeitliche Vergletscherung aufgeführt.

Für die vorzeitliche Vergletscherung des Dudh Khunda Tals fand Williams (1983) Indikatoren nur in Moränen bzw. 'till' und Lateralmoränen. Weitere geomorphologische Formen, außer Kare und Trogtäler, nahm er nicht auf. Weiterhin machte Williams ebd.:203 nur zwei Endmoränenkomplexe aus: innere und äußere, wobei die äußeren mehr erodiert waren. Die Bodenprofile auf einigen Moränen verwiesen ebenfalls auf einen zeitlichen Unterschied (ebd.:203). Bei den inneren Moränen war kein B-Horizont, sondern lediglich ein $5 \mathrm{~cm}$ mächtiger A-Horizont ausgebildet, bei den äußeren hingegen ein deutlich brauner $20 \mathrm{~cm}$ mächtiger B-Horizont und ein ebenfalls $20 \mathrm{~cm}$ mächtiger A-Horizont zu erkennen (ebd.:203). Diese Bodenentwicklungszunahme von inneren zu äußeren Moränenkomplexen wurde laut Williams (1983:203) ebenfalls bei Iwata (1976:112) registriert. Jedoch musste unter Betrachtung des folgenden Zitats: "Soils developed slightly above present tree line $(3800 \mathrm{~m})$ [...]." (Williams 1983:203) die Frage gestellt werden, ob die Bodenentwicklung nicht von noch viel mehr Faktoren - wie hier angeführt etwa von der Höhenlage - abhängig ist, sodass eine Rekonstruktion der vorzeitlichen Vergletscherung allein anhand der Bodenbildung nicht ausreichend und somit nicht möglich wäre. 
Das Alter dieser Moränen vermutete Williams allerdings nur: für die äußeren Moränenkomplexe nahm er ein pleistozänes Alter ${ }^{203}$ an, bei der ältesten Moräne des inneren Moränenkomplexes ein spätpleistozänes Alter ${ }^{204}$ oder ein älteres holozänes Alter ${ }^{205}$, wobei er sich bei den anderen inneren Moränen den Befunden von Iwata (1976) und Benedict (1976) anschloss und diese in das Holozän einordnete. Die Altersangaben zu den Moränen waren vorläufig und basierten hauptsächlich auf den dort aufgefundenen Formen und deren Lage, wobei diese Alter durch detaillierte Bodenanalysen und Lichenometrie sowie eindeutige radiometrische Datierungen abgesichert sein $\operatorname{sollen}^{206}$. Ob es eine ausgedehntere Vergletscherung in dem von Williams untersuchten Gebiet gab, blieb offen ${ }^{207}$. Zudem meinte Williams, dass die inneren und äußeren Moränen in Tibet deutlich über LandsatSatellitenbilder zu erkennen waren - allerdings in manchen Regionen Nepals nur sehr schwierig $^{208}$. Ältere Moränen waren in Nepal sehr stark erodiert und mit Wald bedeckt (vgl. Williams 1983:204).

Die Moränen des Khumbu Gletscher waren die am besten erforschten glazialen Ablagerungen in der Sapta Kosi Region und stellten einen Standard zum Vergleich mit anderen Moränen dar (ebd.:208). Williams (1983:208, Tab. 1) schrieb, dass nur sieben radiometrische Daten von drei verschiedenen Forschern im Khumbu bestimmt und veröffentlicht wurden und Uneinigkeit über die Einteilung der Moränen zwischen Müller (1958), Tanaka (1971) ${ }^{209}$, Benedict (unveröffentlicht), Iwata (1976) und Fushimi (1977) bestand. Übereinstimmung soll aber bei der Einteilung der undatierten äußeren Moräne als ein spätpleistozänes Alter und der inneren Moräne als ein holozänes Alter (500 und $1.200{ }^{14} \mathrm{C}$ Jahre v.H.) herrschen (vgl. Williams 1983:208).

Beim Khumbu Gletscher machte auch Iwata (1976:112) innere und äußere Moränen aus, wobei Williams (1983:203 f.) meinte, dass nach Iwata die Bodenentwicklung auf der äußeren Moräne bei Periche eine nicht so starke Bodenentwicklung aufzeigte wie die beim Dudh Khunda Gletscher. Diesen Unterschied brachte Williams mit der Lössbodenentwicklung und mit einer höheren, kälteren und arideren Umgebung im Khumbu in Verbindung.

\footnotetext{
203 “[...], and suggest that the outer moraines are probably of Pleistocene Age.” (Williams 1983:203)

204 "The oldest moraine of the inner complex, however, appears much more eroded than the other moraines in this complex, and may be as old as late Pleistocene (Figure 4).” (ebd.:204)

205 “[...], an older Holocene or late Pleistocen glaciation (Tamba), [...].” (ebd.:210)

206 "The tentative ages of deposits and correlations suggested in this paper are based primarily on form and position, and are yet to be verified by detailed soils and lichenometric studies or unequivocal radiometric dating." (ebd.:210)

207 "It is questionable whether glaciations more extensive than that of the late Pleistocene have occurred." (ebd.:204)

208 “. [...], but were more difficult to see downvalley from glaciers in some parts of Nepal. “ (ebd.:204)

209 Tanaka, H. (1971): On preferred orientation of glacier and experimentally deformed ice. Master's thesis, University of Hokkaido, Sapporo, Japan.
} 
Die ermittelten rezenten bzw. vorzeitlichen Schneegrenzen sowie die Ausdehnungen vorzeitlicher Vergletscherungsgebiete wurden anhand verschiedener Methoden bestimmt, wobei bei der Betrachtung von Fig. 2 nicht ersichtlich war, wann welche Methode verwendet wurde. Im Text wurde zur Bestimmung der rezenten Schneegrenze lediglich erwähnt, dass wenn keine Moränen zu finden waren - der Übergang der Gletscherkontur von konkav zu konvex nach Andrews (1975) ${ }^{210}$ herangezogen wurde. Wann nun die Bestimmung dieser rezenten Schneegrenze anhand der mittleren Höhenlage der tiefsten Kargletscher oder anhand der höchsten Lateral- und Mittelmoränen der Talgletscher festgelegt wurde oder ob beide Methoden gleichzeitig zum Einsatz kamen, blieb offen. Ähnlich war der Fall bei der Bestimmung der vorzeitlichen Schneegrenze gelagert, da dort auch mehrere Methoden genannt wurden. Die angegebenen Höhenunterschiede der berechneten spätpleistozänen Schneegrenzen waren enorm, was mit den unterschiedlichen Klimabedingungen bzw. mit dem Monsun und der hohen topographischen Barriere, dem Himalaja, in Verbindung gebracht wurde (ebd.:209). Während der glazialen Perioden sollen diese Bedingungen wahrscheinlich verstärkt gewesen $\operatorname{sein}^{211}$.

Jedoch sah Williams (1983:201) die Bestimmung der exakten Höhenlage der rezenten Schneegrenzen als schwierig an, wobei vorzeitliche Schneegrenzen nur aus geologischen Beweisen abgeleitet werden konnten. Letztgenannte fehlten aber im Himalaja außer in der Mt. Everest Region und in Kashmir, da die glazialen Ablagerungen wenig erforscht, die Gebiete aufgrund von z.B. Reliefs oder politischen Aspekten nur schwer zugänglich oder gute Karten und Luftbilder nicht vorhanden waren (ebd.:201). Für dieses Gebiet standen Williams Landsat-Satellitenbilder, eine neue topographische Karte und auch geologische Arbeiten anderer Forscher zur Verfügung (ebd.:201). Diese Satellitenbilder sollen laut Williams (1983:209) für das Erkennen von Karen geeignet gewesen sein. Berechnungsfehler der rezenten Schneegrenzen in Bezug auf großmaßstäbliche Karten waren im Text auf Seite 208 näher angegeben. Nichtsdestotrotz waren die rezenten und vorzeitlichen Schneegrenzen unsicher $^{212}$, wobei zukünftige detaillierte Forschungen nötig seien ${ }^{213}$.

\footnotetext{
${ }^{210}$ Andrews, J.T. (1975): Glacial Systems - An Approach to Glaciers and Their Environments. North Scituate, Mass.: Duxbury Press. (191 Seiten)

211 "Cooler atmospheric and oceanic temperatures during glacial and Neoglacial periods probably decreased the amount of moisture reaching the high Himalayan Ranges, increased the strength of the Tibetan high, and increased the effectiveness of the Himalayan Range as an orographic barrier to moisture." (Williams 1983:210) 212 "The ELAs estimated for present and former glaciers in Tibet are relatively uncertain because of poor topographic control and lack of field checking. " (ebd.:210)

213 "The present improvement in access to Tibet will allow future detailed investigations that improve and expand on the observations reported here." (ebd.:210)
} 
In Bezug auf das Gebiet des Solukhumbu war in Fig. 2 zu sehen, dass Williams (1983), so wie vorher schon Iwata (1976) und Müller (1980), nur das obere Einzugsgebiet des KhumbuHimalaja - das Gebiet des Imja Khola - untersuchte und laut dem Vortext keine Geländearbeiten leistete. Somit konnte diese Arbeit nur behutsam bezüglich der hochglazialen Vergletscherung des Solukhumbu herangezogen werden. Auch Heuberger und Weingartner (1985:71) machten auf dieses Problem der Wahl des Untersuchungsgebietes aufmerksam.

Die von den Forschern der Literaturquelle Academia Sinica (1973) ${ }^{214}$ beschriebenen Moränen konnte Williams über die Landsat-Satellitenbilder nicht ausmachen. Ferner sollen die U1 und U2 Serien von Fushimi (1978) laut Williams $(1983: 204,207)$ nicht beweiskräftig sein, da diese im Dudh Khunda Tal nicht auftraten; außerdem soll dort ein kerbförmiges Talprofil unterhalb der spätpleistozänen Endmoräne vorkommen ${ }^{215}$. Hiermit wäre eventuell ein Hinweis auf ein schluchtförmiges Trogprofil und nicht unbedingt auf ein Kerbtal gegeben.

\section{KUHLE (1984)}

\section{METHODE BZW. ARBEITSTECHNIK}

Kuhle betrieb im Jahr 1982 Geländeanalysen im Gebiet des Khumbu-Himalaja. Demnach wendete er eine geomorphologische Analyse an, wobei er in seiner Arbeit von 1984 zwei Fotos und ein Satellitenbild aus dieser Region veröffentlichte und somit auch dieses Satellitenbild mit auswertete.

\section{UNTERSUCHUNGSGEBIET}

Kuhle (1984) betrachtete die Forschungsgebiete Khumbu-Himalaja und Kuenlun.

\section{KRITIK}

Kuhle lieferte in Bezug auf die Vergletscherung des Khumbu-Himalaja mit der Arbeit aus dem Jahr 1984 unter dem Titel `Auswertung von Spacelabaufnahmen aus Hochasien: Die

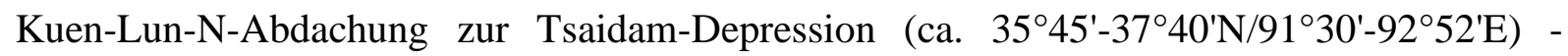
Ausdeutung einer Satellitenphotographie über Feldarbeitsbefunde benachbarter Areale mit analoger geomorphologischer Sequenz' folgende Aspekte: südlich der Berge Mt. Everest, Cho Oyo, Lhotse und Makalu existierten Trogtäler (Foto 1), die die rezenten Gletscher mit

\footnotetext{
${ }^{214}$ Academia Sinica (1973): Natural features and geologic history of the Mt. Everest area, southern Tibet, China, Tibetan scientific expedition. Kexue Tongbao (Scientia), 18. (Translation from Chinese by Plenum, New York, 1974) (S. 11-21)

215 "In the Dudh Khunda valley (Figure 7) such slope breaks are not evident, and valley walls narrow to form a $V$-shaped gorge immediately below the late Pleistocene terminal moraine.” (Williams 1983:207)
} 
ihren Ufermoränen und Ufermulden (Foto 1 und 3) nicht ganz ausfüllten, wobei talabwärts der Trogtäler aufgrund enormer Talbodenneigungen glazigene Kerbtäler ausgebildet waren. Eisrandlagen wurden im Untersuchungsgebiet von ihm registriert. Zu vorgenannten Tälern meinte er: „Sie unterscheiden sich allein in Feinheiten von fluvialen Kerbtälern. Deshalb sind auf dem Satellitenfoto (rechts unten) keine Eisrandlagenhinweise an den Talformen diagnostizierbar." (Kuhle 1984:300). Diese Aussagen ließen erkennen, dass Kuhle im Gegensatz zu allen anderen in der vorliegenden Arbeit aufgeführten Forschern - die keine Vergletscherung in einem Kerbtal für möglich hielten und den Eisrand beim Übergang vom Trog- zum Kerbprofil festlegten - diese geomorphologische Besonderheit berücksichtigte und folglich zu anderen Ergebnissen kommen musste. Allein bei der Betrachtung dieser einen Form wurde deutlich, warum Kuhle zu einer talabwärtigeren Vergletscherungsausdehnung dieser Himalaja Region kam.

\section{HEUBERGER UND WEINGARTNER (1985)}

\section{UNTERSUCHUNGSGEBIET}

Die Größe des Untersuchungsgebietes von Heuberger, Weingartner (1985) war unzureichend. Die bei ihnen in Abb.1 eingezeichnete Route von 1984 zeigte zwar, dass sich die Tour in den Talbereichen des Dudh Khosi, Imja Drangka und Bhote Khosi über die Ortschaften Pangpoche, Khumjung, Thame, Namche Bazar, Lukla, Jubing nach Dube, Halesi und Rumjatar erstreckte, aber das eigentliche Untersuchungsgebiet lediglich zwischen Khumjung und Lukla lag (hierzu Abb. 1 und 2). Die Forschungsarbeiten bezogen sich also nur auf den Talabschnitt Khumjung bis Lukla ${ }^{216}$, sodass glaziale Indizien oberhalb von Khumjung und unterhalb von Lukla fehlten.

\section{METHODE BZW. ARBEITSTECHNIK}

Die Forschungsarbeiten von Heuberger, Weingartner (1985) 'Die Ausdehnung der letzteiszeitlichen Vergletscherung an der Mount-Everest-Südflanke, Nepal' über die maximale Gletscherausdehnung im Gebiet des Solukhumbu waren anzuzweifeln, da sie abgesehen von zwei untersuchten Stellen - nur pedologische Befunde zur Eingrenzung des letzteiszeitlichen Vergletscherungsausmaßes heranzogen ${ }^{217}$. Hierbei gingen sie auf Verwitterungsgrade der Böden bzw. auf verschiedene Bodentypen ein, die sich inner- und außerhalb des Eisrandes als Braun- und Parabraunerde unterschiedlich entwickelt haben

\footnotetext{
216 „Die hier vorgeführten Beobachtungen beschränken sich auf den Talabschnitt Khumjung - Lukla (Abb. 2). “ (Heuberger, Weingartner 1985:73)

217 „Im übrigen mußten die Eisrandlagen pedologisch ermittelt werden. “ (Heuberger, Weingartner 1985:80)
} 
sollen, speziell die Braunerde nach dem Hochglazial ${ }^{218}$. Es ist bekannt, dass die Bodenbildungsprozesse vom Zusammenspiel enorm vieler Faktoren wie u.a. von der Höhe ü. NN bzw. vom Klima, vom Ausgangsmaterial und von geomorphologischen Prozessen abhängen. Somit ist dieses komplexe Zusammenspiel nicht eindeutig nach den beteiligten Faktoren trennbar und folglich eine genaue Einordnung der zeitlichen Abläufe nach auch nur einem Faktor nicht möglich. Zudem existiert laut Kuhle (2005:316) keine Kalibrierung der Bodenentwicklung im Himalaja. Ohnehin gaben Heuberger, Weingartner (1985:79) an, dass die Höhenlage des Zungenendes nicht genau festgelegt war und ungefähr bei Ghat unterhalb von $2.500 \mathrm{~m}$ verlief.

Hingegen wies jedoch die in Abb. 2 von Heuberger, Weingartner (1985:74) dargestellte maximale Ausdehnung der letzten Hauptvereisung im Pharag und im unteren Khumbu bei Überprüfung mittels anderen geografischen Kartenmaterials darauf hin, dass die Vergletscherung bis auf bereits ca. $2.450 \mathrm{~m}$ bei Ghat hinunter reichte, wobei die grafische Darstellung des Eises in dieser Abbildung einige Fragen zu einer typischen Gletscherformung aufwarf. Wie konnte es nämlich sein, dass das vorzeitliche Eis in Nebentälern unterschiedlich ausgebildet war bzw. unterschiedlich weit talaufwärts reichte? Wie kam es zu einer so ungleichmäßigen Vergletscherung des Haupttales? Hierbei war es fraglich, warum die orographisch linke Talseite viel stärker vergletschert gewesen sein soll als die orographisch rechte. Die Begrenzungen des Gletschereises im Khumbu nördlich, westlich und östlich von Khumjung waren laut Heuberger, Weingartner (1985:73) willkürlich gewählt. Viele andere Bereiche, vor allem die des Seitentales bei Ghat oder des Seitentales bei Monjo, müssten jedoch ebenfalls willkürlich gewählt gewesen sein, da sie dort keine weiteren Bodenprofile untersuchten und auch keinerlei glazialgeomorphologische Indikatoren aufzeigten. Somit waren eigentlich nur die von Heuberger, Weingartner (1985) anhand von Bodenprofilen untersuchten Talbereiche bzw. die Bereiche rund um die sechs Bodenprofile für eine grafische Darstellung geeignet. Die Vergletscherung der dazwischen liegenden Gebiete müsste anderweitig erforscht sein, um diese Abbildung zu rechtfertigen.

Es wurden generell im untersuchten Talabschnitt Khumjung bis Lukla - abgesehen der Hinweise auf zwei Moränen bei Khumjung und Phakdingma und das Heranziehen von Felsformen bei Khumjung (ebd.:73-76) - keine glazialgeomorphologischen Formen geliefert. Somit wurde nicht klar, ob weitere glaziale Indikatoren - wie etwa Moränen - im untersuchten Gebiet talaufwärts oder sogar weiter talabwärts auftraten. Dass weitere Moränen

218 „Die spät- und postglaziale Bodenbildung hat zur Entwicklung von Braunerde [...] geführt.“ (ebd.:80) 
talabwärts dieser Untersuchungsgebiete vorkamen, wurde ohnehin schon durch Kuhle belegt. Detaillierte glazialgeomorphologische Analysen bzw. eine Bestandsaufnahme fehlten demnach, wobei diese jedoch für eine Rekonstruktion von Gletscherausdehnungen unabdingbar wären. Zudem waren in der gesamten Forschungsarbeit (Heuberger, Weingartner 1985) nur zwei Abbildungen vorhanden: eine über die Lage des Arbeitsgebietes und die andere über die maximale Ausdehnung der letzten Hauptvereisung im Pharag und im unteren Khumbu. Auf der letztgenannten Abbildung waren jedoch nicht alle von ihnen untersuchten Formen und skizzierten Bodenprofile visualisiert. Fotos bzw. jegliche visuelle Beweisdarstellungen von diesen Formen oder Bodenprofilen fehlten. Heuberger, Weingartner (1985:73) fanden und kartierten nur ausgewählte Moränen: „Gewiß werden noch mehr Moränenwälle gefunden werden als die in Abb. 2 verzeichneten. Es ging ja nicht um eine lückenlose großmaßstäbige Kartierung. “. Diese ausgewählten Moränen befanden sich im Gebiet von Khumjung und Phakdingma. Bei Khumjung im Khumbu waren die Formen laut Heuberger, Weingartner (1985:71) sofort ausmachbar ${ }^{219}$. Obwohl sie schrieben, dass hocheiszeitliche Moränen bei Phakdingma im Pharag oft nicht erhalten oder überformt waren $^{220}$, fanden sie zwar dort drei Ufermoränen des Haupttalgletschers, unterließen dabei aber die Suche nach Grundmoränen. Dies ließ den Schluss zu, dass Heuberger, Weingartner (1985) die Moränen nur mit langgezogenen Rücken in Verbindung brachten; d.h. speziell nur Ufer- oder Endmoränen suchten. Grundmoränen, die in der Regel als flachere ausgedehntere Formen ausgebildet sind - z.B. als Podestmoräne bzw. Grundmoränensockel mit Terrassenstufe (vgl. Kuhle 2005) - wurden demzufolge weitestgehend ignoriert. Nur in einer Textpassage erwähnten Heuberger, Weingartner (1985:73), dass die hocheiszeitlichen Moränen von Khumjung stellenweise als zerschnittene Terrassen ausgebildet waren, gingen aber in den weiteren Beschreibungen von Khumjung und Phakdingma nur auf wallförmige Moränen ein. Die beschriebene Ausbildung der Moränen als langgezogene Rücken deutete darauf, dass es eher spät- als hochglaziale Formen waren. Wenn diese formfrischen Ufermoränen Formen aus dem Hochglazial darstellen würden, dürften diese heutzutage nicht in diesen Maßen bzw. der wallförmigen Ausformung erhalten sein, schon gar nicht bei den enormen Reliefverhältnissen in diesem Untersuchungsgebiet. Postglaziale Hangprozesse hätten diese ebenfalls zerstören müssen. Hierdurch konnte geschlussfolgert werden, dass die aufgefundenen gut erhaltenen Moränen nicht unbedingt hochglazialen Alters waren, sondern jüngere sein konnten.

219 „Dort fallen die Zeugen ehemaliger Vereisung auch sofort auf.“ (ebd.:71)

220 „Die Steilheit der Hänge, die Enge und z.T. jüngere Überformung des Talsohlenbereichs [...] haben dazu geführt, daß hocheiszeitliche Ufer- und Endmoränen im Pharag kaum erhalten sind. " (ebd.:73) 
Auf weitere geomorphologische Formen, wie die Bergstürze, gingen sie in dieser Veröffentlichung nur sehr sporadisch ein: „Dabei soll nicht näher auf die Bergstürze von Khumjung-Namche Bazar und von Chaunrikharka (nördlich/nordwestlich von Lukla) eingegangen werden, die auch schon von anderen Autoren kurz erwähnt wurden. Darüber ist eine gesonderte Veröffentlichung vorgesehen.” (Heuberger, Weingartner 1985:73). Somit fehlten geomorphologische Beschreibungen der Bergsturzmassen und es wurde nicht klar, anhand welcher Kriterien Heuberger, Weingartner (1985) diese Formungen zeitlich einordneten.

Im Pharag gab es also nach Heuberger, Weingartner (1985:71) nicht genügend glazialgeomorphologische Indikatoren bzw. waren aufgrund der Talenge, des schluchtartigen Talgrundes und der enormen Steilheit der Hänge diese schwierig zu erkennen und kaum erhalten. Dort waren die Felsformen nicht so eindeutig bzw. zweideutig, da der Vergletscherungszeitraum dieser Talabschnitte zu kurz und generell zeitlich - letzte Eiszeit gegenüber älterer Eiszeit - nicht auseinander haltbar bzw. nicht einordbar gewesen war (ebd.:73). Die Felsformen müssten jedoch, wenn sie zeitlich nicht in die letzte Eiszeit eingeordnet werden, schon längst verwittert oder aber von der letzten Eiszeit überarbeitet sein. Somit wäre eine zeitliche Einordnung der Felsformen höchstens zwischen den Zeiträumen des Spät- und Hochglazial plausibel. Im Khumbu waren die Formen hingegen, wie o.g., sehr auffällig (ebd.:71). Dabei stellte sich die Frage, warum Heuberger und Weingartner im Bereich des Khumbu keine detaillierte Bestandsaufnahme der geomorphologischen Formen erbrachten, wenn die Formen sehr deutlich zu erkennen waren. Obwohl ihre Route laut Abb. 1 darauf hinwies, dass sie im Khumbu-Gebiet die Ortschaften Namche, Khumjung, Thame, Pangboche bis zum Kala Pattar auf 5.545 m Höhe besichtigten, wurden im Text zu vielen Gebieten keine verwertbaren Details angegeben. Bei Khumjung im Khumbu fanden Heuberger, Weingartner (1985) widersprüchlicherweise jedoch trotz der genannten leichten Erkennbarkeit der Formen z.B. keine Erratika ${ }^{221}$. Die Neigungsverhältnisse der Talvergletscherung sollten ebenfalls keine Anhaltspunkte geben: „Die Gefällsverhältnisse der Talvergletscherung bieten hier keine weiteren Anhaltspunkte, denn der große Talgletscher floß verhältnismäßig steil ins Pharag hinab, wie sich bei P5 oberhalb von Monjo zeigt (siehe 3.5).” (Heuberger, Weingartner 1985:76). Die Befunde dieser Dissertation und die von Kuhle (2005) widerlegten die Aussagen der Nichterhaltung

221 „, Typische Granite oder Gneise oder Vertreter der Everest-Serie aus den inneren Tälern wurden jedenfalls nicht gefunden." (ebd.:75) 
von glazialen Formen im Pharag. Dort fanden sich enorm viele glaziale bzw. glazifluviale Indizien, wie beispielsweise Rundhöcker, Grundmoränen oder Strudeltöpfe.

Nach Heuberger, Weingartner (1985:73) waren aus dem Zusammenfluss der Talgletscher des Imja- und Nangpo-Tales bei Khumjung hocheiszeitliche Moränen entstanden, die als zerschnittene Terrassen oder als Wälle ausgebildet gewesen sein sollen. Die unterschiedlichen Ausformungen der Moränen könnten dementgegen jedoch auf verschiedene Entstehungsweisen und / oder auf ein unterschiedliches Alter hindeuten. Die dicht nebeneinander folgende Ausbildung der Wallformen verwies, wie Heuberger, Weingartner (1985:74) ausführten, auf eine dichte Zeitfolge. Eine genaue zeitliche Einordnung der nebeneinander gelagerten Moränen erfolgte von Heuberger, Weingartner (1985:73) jedoch nicht, lediglich die Angabe, dass es sich um hocheiszeitliche Eisrandablagerungen der Talgletscher handelte. Aber wie konnten zerschnittene Moränenterrassen, die wohl eher Grundmoränen darstellten, und Moränenwälle, die Ufer- und Endmoränen waren, gleichen Alters gewesen sein und so dicht nebeneinander zusammen auftreten? Hierbei wäre doch ein hochglaziales Alter für die Terrassenformen und ein jüngeres Alter der Wallformen passender. Aufgrund der dichten Aufeinanderfolge der Wallformen konnte tendenziell bei den Moränen von Khumjung auf spätglaziale bis neuzeitliche Stadien und nicht auf hochglaziale Stadien geschlossen werden, da eine solche Ausbildung eher bei geringeren Temperaturschwankungen typisch ist. Im Hochglazial dürften solche geringen Schwankungen nicht bestanden haben. Es sollten wohl eher hochglaziale Stadien mit sehr weit auseinanderliegenden spätglazialen Stadien erwartet werden. Die Moränen des Lokalgletschers, der - wie von Heuberger und Weingartner durch Ufermoränen belegt - den Hauptgletscher erreichte und die des Hauptgletschers selbst trennten Heuberger, Weingartner (1985:75) geomorphologisch voneinander, nicht aber sedimentpetrographisch, was sie selbst auch so angaben. Durch Geschiebeanalysen - hier Zurundung, Petrographie - kamen sie zu keinem Ergebnis (ebd.:75). Somit war die Unterscheidung der verschiedenen Vergletscherungen nicht eindeutig geklärt und es wäre möglich, dass alle hier beschriebenen Moränen - auch diese des Hauptgletschers - jüngeren Alters waren. Heuberger, Weingartner (1985:75) gaben in Bezug auf diesen Aspekt an, dass die mittlere Bastion auch für die Endmoräne eines Lokalgletschers des Khumbui Yul Lha gehalten werden könnte, was sie aber anhand der bei dieser Bastion auftretenden Verflachung mit einem darauf liegenden Moränenblock verneinten. Allerdings gingen sie nicht auf die Gesteinsart dieses im Durchmesser 8 bis $10 \mathrm{~m}$ großen Moränenblocks ein, wodurch eine Aussage über den 
Herkunftsort des Blocks und somit über die Vergletscherungsverhältnisse nicht gegeben war. Die Information beschränkte sich darauf, dass es dort schwer zu unterscheidende Migmatite gab und keinerlei typische Granite oder Gneise auftraten, wodurch die Herkunft von Block mit Moräne letztendlich nicht geklärt wurde. Zudem beschrieben sie auch andere Aspekte, wie etwa den Verwitterungszustand dieses Blocks nicht, was wiederum das etwaige Alter der Moräne hätte anzeigen können. Eisgeschliffene Formen oberhalb der Moränenablagerungen wurden mit dem Lokalgletscher des Khumbui Yul Lha der mittleren Bastion in Verbindung gebracht (ebd.:76). Ungeklärt hierbei war, wie sie diese zeitliche Einordnung festlegten. Auf Seite 73 schrieben sie, dass eine zeitliche Abgrenzung von Felsformen der letzten Eiszeit von älteren Eiszeiten, wie bereits o.g., schwierig sei. Infolgedessen blieb offen, wie zuverlässig die vorgenommene Trennung der Felsformen zwischen Lokal- und Hauptvergletscherung war. Eine eindeutige generelle und zeitliche Unterscheidung der verschiedenen Vergletscherungen gaben sie schlussendlich nicht an; auf Seite 76 beschrieben sie lediglich, dass die Eisrandablagerungen eine Folge von Gletscherständen nach dem Maximum des Hauptgletschers darstellten: „Die Eisrandablagerungen bilden offenbar eine Folge von Gletscherständen nach dem Maximum des Hauptgletschers ab, [...]. Während des Hauptgletscher-Maximums könnte es eine breitere Verbindung mit der Lokalvergletscherung des Khumbui Yul Lha gegeben haben. In Abb. 2 ist der letzteiszeitliche Eisrand hier, bezogen auf das abbrechende untere Ende der linken Lokalufermoräne, in 4150 m Höhe eingetragen. Wahrscheinlich lag er noch etwas höher." (Heuberger, Weingartner 1985:76). Wenn die Moränen nun wirklich nach dem Maximum entstanden und der Eisrand höher lag, könnten diese demnach in die Zeit des Hoch- bis Spätglazial, eher wohl aber in das Spätglazial eingeordnet werden. Die hocheiszeitliche Schneegrenze legten Heuberger, Weingartner (1985:79) anhand des Khumbui Yul Lha Gletscher oberhalb von Khumjung bei einer Schneegrenzdepression von ca. 1.000 bis $1.100 \mathrm{~m}$ auf etwa 4.400 bis $4.500 \mathrm{~m}$ Höhe fest, wobei sie aber auch hier angaben, dass die Lokalmoränen erst im ältesten Spätglazial, nach dem Höchststand, entstanden waren und der Einzugsbereich sowie der Lokalgletscher nicht klar festgelegt werden konnten. Damit war diese Schneegrenzrekonstruktion nur eine Abschätzung und für eine Aussage über die hochglaziale Vergletscherung des Solukhumbu nicht unbedingt verwendbar.

Die drei angeführten Moränen von Phakdingma beim Panyali Drangka waren lange, formfrische, gut ausgebildete Ufermoränen des Haupttalgletschers mit Blöcken, wobei ebenfalls zwei Wallreste auf $3.030 \mathrm{~m}$ und $3.060 \mathrm{~m}$ existierten (ebd.:76). Eine zeitliche Einordnung dieser Moränen wurde nur durch die Beschreibung ,[...] formfrische 
Ufermoränen des Haupttalgletschers." (Heuberger, Weingartner 1985:76) gegeben. Die Beschreibungen der Formfrische und der guten Ausbildung wiesen jedoch auf eine jüngere Entstehung hin. Zusätzlich deutete die in Abb. 2 eingezeichnete Längsausbildung der Moränenwälle von Nordost nach Südwest darauf, dass es Ufermoränen eines ehemaligen, wohl spätglazialen Seitengletschers aus dem Panyali Drangka sein konnten. Nach Heuberger, Weingartner (1985:76) bestand allerdings, gegenüber dieser Annahme, kein Seitengletscher in diesem Bereich. Südlich der Panyali Drangka waren die Eisränder am Haupttalhang stellenweise erhalten, wurden aber von ihnen nicht aufgesucht (ebd.:76). Was Heuberger, Weingartner (1985:76) bei folgendem Zitat mit aktiven Vorstößen meinten, war nicht eindeutig: „[...], die man aber hier aufgrund der Ufermoränenentwicklung als aktive Vorstöße bezeichnen тиß.”. Eventuell wurde hiermit textlich ein Hinweis auf ein jüngeres Alter der Moränen gegeben. Bei der Aussage von Heuberger, Weingartner (1985:76): „Höher hinauf gab es keine sicheren weiteren Anhaltspunkte für den Verlauf des letzteiszeitlichen Gletscherrandes. Mit Sicherheit erreichte dieser hier nicht mehr 3120 m [...].” war wiederum nicht klar, ob generell oberhalb der genannten Wallreste keinerlei Indikatoren existierten oder ob diese nur zu unsicher waren und aus diesem Grunde nicht aufgezeigt wurden.

In Abb. 2 waren die Moränen vom Pharag und unteren Khumbu eingezeichnet. Da jedoch keine Legende angegeben war, musste davon ausgegangen werden, dass alle schwarzen länglichen Symbole Moränen darstellten und alle schwarzen viereckigen Bebauungen der Ortschaften waren. Somit wären bei Phakdingma zwei und oberhalb von Khunde und Khumjung 14 Moränen eingezeichnet. Im Text wurden aber bei beiden Standorten jeweils nur drei Moränenzüge bzw. Formkomplexe beschrieben ${ }^{222}$. Im Bereich von Khumjung waren in Abb. 2 der im Text erwähnte lange Moränenrücken über Khumjung, die auffallende Bastion zwischen Khumjung und Khunde und die stark zergliederte Bastion über Khunde nicht eindeutig visualisiert. Oberhalb von Khumjung waren auf dieser Abbildung drei Moränenzüge visualisiert, die dicht übereinander gelagert von Nordwest bis Südost reichten: oberhalb von Khunde fünf (vier von West nach Ost und einer von Nord nach Süd) und oberhalb zwischen Khumjung und Khunde vier, von West nach Ost reichende nebeneinanderliegende Moränenzüge. Die beschriebenen Ufermoränen des Lokalgletschers wurden vermutlich durch die beiden von Nord nach Süd und von Nordwest nach Südost verlaufenden, etwas deutlicher dargestellten Symbole auf der Abbildung dargestellt.

222 „Diese Eisrandablagerungen sind in drei Formkomplexen erhalten: [...].” (ebd.:75); „Aus Maßstabsgründen sind in Abb. 2 nur zwei eingezeichnet." (ebd.:76) 
Wie dem Text zu entnehmen war, fußte die letztglaziale Rekonstruktion von Heuberger, Weingartner (1985) auf sechs Eckpunkten, den Bodenprofilen, wodurch die Aussagekraft dieser Veröffentlichung in Frage gestellt wurde. Zitate hierzu waren folgende: „Jene Punkte, an denen die ganze Rekonstruktion hängt, sind herausgehoben und werden im einzelnen besprochen.“ (Heuberger, Weingartner 1985:73); „Hier und an den anderen bezeichneten Stellen konnte der Verlauf des Eisrandes nur mit Hilfe von Bodenprofilen eingegrenzt werden.” (ebd.:76); „Wie gezeigt wurde, hängt die Rekonstruktion des letzteiszeitlichen Dudh-Kosi-Gletschers nur an wenigen Punkten, wo die Lage des Eisrandes einigermaßen befriedigend geklärt werden konnte. In diese Rekonstruktion gingen aber an manchen Stellen auch Überlegungen über den Verlauf der letzteiszeitlichen Schneegrenze zur Zeit des Hochstandes ein.” (ebd.:79). Die im letztgenannten Zitat erwähnten Überlegungen über den letzteiszeitlichen Schneegrenzverlauf im Hochglazial an einigen Stellen waren jedoch im Text nicht erläutert. Es wurde nur an einem Punkt, bei Bodenprofil $\mathrm{P}_{6}$ oberhalb von Khumjung, eine hochglaziale Schneegrenze, die wohl eher eine spätglaziale war, berechnet.

Desweiteren ist bekannt, dass nur ungestörte Bodenprofile für Bodenanalysen herangezogen werden sollten, jedoch war das bei den Ausführungen von Heuberger, Weingartner (1985) eher nicht der Fall und vor allem generell im Himalaja aufgrund der enormen Reliefenergie selten möglich: „Aufgrund der extremen Neigungsverhältnisse und weiterer abtragungsfördernder Rahmenbedingungen (monsunale Sommerregen, Rodung usw.) findet man selten ungestörte Bodenprofile.” (Heuberger, Weingartner 1985:77). Dieses Zitat könnte so verstanden werden, dass gestörte Böden bzw. ein gekappter oder zweistöckiger Aufbau der beschriebenen Bodenprofile vorrangig auf aktuellere bzw. spät- bis postglaziale Hangprozesse und nicht auf eine Ausräumung durch den Gletscher im Bereich des Eisrandes hinwiesen, was durch die Begriffe starke Hangneigung, Sommermonsun und Rodung deutlich wurde. Laut dem Text war nur das Bodenprofil $\mathrm{P}_{1}$ außerhalb des hochglazialen Eisrandes im wesentlichen ungestört und die Braunerde von $\mathrm{P}_{4}$ gut entwickelt. $\mathrm{P}_{2}$ soll auf jeden Fall ein gestörtes Bodenprofil sein. Bei den Bodenprofilen $\mathrm{P}_{3}, \mathrm{P}_{5}$ und $\mathrm{P}_{6}$ waren keine direkten Informationen über einen solchen Sachverhalt dem Text zu entnehmen.

Bei Abb. 2 fiel auf, dass die Bodenprofile $\mathrm{P}_{3}$ und $\mathrm{P}_{6}$ innerhalb des Eisrandes und $\mathrm{P}_{1}, \mathrm{P}_{2}, \mathrm{P}_{4}, \mathrm{P}_{5}$ außerhalb des Eisrandes liegen. Das ungestörte Bodenprofil $\mathrm{P}_{1}$ der Parabraunerde langer Verwitterungsdauer mit den Eigenschaften tiefgründig, grobanteilsfrei und tonreich war in Abb. 2 genauso wie im Text (ebd.:78 f.) beschrieben außerhalb des letztglazialen Eisrandes 
eingetragen. Mit dem Zitat von Heuberger, Weingartner (1985:77): „Denn hier kann ein unmittelbarer glazialer Einfluß zumindest für die letzte Eiszeit ausgeschlossen werden.” blieb wiederum ungeklärt, ob sie nun generell eiszeitliche Spuren fanden oder nicht, da sie nur Zeugnisse der letzten Eiszeit verneinten. Fraglich bei dem in Abb. 2 gekennzeichneten Punkt von $\mathrm{P}_{1}$ blieb, warum die Grenze des letzteiszeitlichen Eises so weit unterhalb dieses Bodenprofiles eingezeichnet wurde, da Heuberger, Weingartner (1985) unterhalb dieses Punktes keine weiteren Bodenprofile untersuchten. Somit war anzunehmen, dass die maximale Ausdehnung des Eises in diesem Bereich willkürlich - vermutlich in Abstimmung mit dem benachbarten Bodenprofil $\mathrm{P}_{2}-$ festgelegt wurde. Außerdem könnte die von ihnen beschriebene hohe Dichte in den Horizonten $B_{v 2}$ und $B_{v 3}$ auf eine vorzeitliche Eisauflast verweisen, wodurch eine größere letzteiszeitliche Ausdehnung des Eises nahe läge. Der vollständig abwesende Grobanteil könnte in diesem Zusammenhang anstatt mit einer langen Verwitterungsdauer eventuell eher mit einer anthropogenen Überarbeitung in Form von Herausgraben von Grobmaterialien in Verbindung gebracht werden, da der Standort bei dem Ort Ghat am Rande einer muldenartigen Hangverflachung liegen soll. Das Vorhandensein von Ton, Silt und Sand (Bodenart Lehm) sowie der wasserstauende Effekt des Bv2-Horizont könnten als weitere Anzeichen einer Moräne gelten. Das Bodenprofil $\mathrm{P}_{1}$ könnte aber auch lediglich eine Überlagerung - wie bei $\mathrm{P}_{2}$ der jüngere überlagerte Bodenbereich - darstellen, da der C-Horizont in den Angaben von Heuberger, Weingartner (1985:77) fehlte.

Das Bodenprofil $\mathrm{P}_{2}$ war im Text als Braunerde bzw. als Eisrand (Indizien: gestörte Bodenentwicklung, Um- und Überlagerung, zwei Böden übereinander, fossile Bv-Horizonte mit Eisrandablagerungen) beschrieben, wurde jedoch unverständlicherweise in Abb. 2 außerhalb des Eisrandes und nicht direkt auf dem Eisrand bzw. innerhalb des Eisrandes dargestellt. Dieser fossile Boden mit Eisrandablagerungen wurde laut Heuberger, Weingartner (1985:77) vom Eis der letzten Vergletscherung gekappt. Er könnte aber auch nur durch die Überlagerung von Hangprozessen erklärt werden und nicht unbedingt mit einer Kappung durch den Gletscher. Angaben zur Dichte und zum Grobanteil, die zur Moränenerkennung wichtig wären, wurden von Heuberger, Weingartner (1985:77) nicht gemacht. Das Zitat: „Alle Aufgrabungen oberhalb dieser Stelle lassen keinen unmittelbaren Einfluß der letzten Vereisung erkennen." (Heuberger, Weingartner 1985:77) würde den Gedanken der o.g. postglazialen Überlagerung untermauern, da sich das Bodenprofil im Übergang vom Steilhang zur Ebene befand. Potentiell würden sich in diesem Bereich postglazial enorm viele Hangakkumulationen ansammeln können. 
Das Bodenprofil $\mathrm{P}_{3}$ als Lockersedimentbraunerde hinter den Bergstürzen von Chaunrikharka war im Text sowie in der Abb. 2 eindeutig dem Vergletscherungsbereich zugeordnet. Hier sammelten sich oberhalb der Bergstürze Stausedimente $a^{223}$. Genauere Geländebefunde fehlten jedoch. Nach den Befunden der hier vorliegenden Dissertation und denen von Kuhle (2005) stellten die Ablagerungen rund um Ghat dort Grundmoränen dar. Das gemeinsame Auftreten von Ton, Silt, Sand und Grobmaterial (hier schwach lehmiger $\mathrm{B}_{\mathrm{v} 1}$, hoher Grobanteil vorwiegend im B-Horizont, Bodenart dominierend Feinsand) würde für solche Moränenablagerungen sprechen. Die Grobanteile bei $\mathrm{P}_{3}$ wiesen keine Verwitterungsspuren auf, jedoch wurde nicht beschrieben in welchen Horizonten dies der Fall war. Heuberger, Weingartner (1985:78) erklärten dieses mit der Jugendlichkeit oder mit den ungünstigen Verwitterungsbedingungen in den Stausedimenten. Eine genaue zeitliche Einordnung der Lockersedimentbraunerde lieferten sie jedoch nicht, es wurde nur angegeben, dass die Bergstürze von Chaunrikharka bei Lukla nach der letzten Hauptvereisung niedergingen (ebd.:73). Doch wie legten sie diese Bergstürze und die Stausedimente zeitlich fest? Zudem war vermerkt, dass die Stausedimente bzw. heutige Schwemmkegelterrassen über den Zeugen der letzten Hauptvergletscherung lagerten und diese verbargen ${ }^{224}$. Warum zeigte dieses Bodenprofil dann keinen zweistöckigen Aufbau mit jüngeren und älteren Akkumulationen? Wenn dieses Bodenprofil im Bereich der maximalen Eisausdehnung gelegen hat, dann müsste hier auch ein solches Profil sichtbar sein. Vor allem bei diesem beschriebenen Standort, am Rand einer Hauptterrasse, sollte ein sehr mächtiges Bodenprofil erkenn- und beschreibbar sein. Das Bodenprofil $\mathrm{P}_{2}$, welches im selben Talabschnitt und fast auf derselben Höhe $\left(\mathrm{P}_{2}\right.$ auf $2.780 \mathrm{~m}$ und $\mathrm{P}_{3}$ auf $2.660 \mathrm{~m}$ ) lag, zeigte hingegen ein zweistöckiges Profil. Warum war dies dann nicht beim hier beschriebenen Bodenprofil der Fall? Oder umgekehrt betrachtet, müsste der Boden von $\mathrm{P}_{2}$ wie $\mathrm{P}_{3}$ Stausedimente aufweisen, wobei auch $\mathrm{P}_{1}$ und $\mathrm{P}_{4}$ solche aufzeigen müssten, da sich diese ja laut Heuberger, Weingartner (1985) hinter den Bergstürzen sammelten.

Das typisch entwickelte Braunerde-Bodenprofil $\mathrm{P}_{4}$ eines gut erhaltenen Moränenwalles müsste laut ihnen, wie sie an anderer Stelle generalisiert sagten, aufgrund des Bodentyps Braunerde auf die Lage innerhalb des Eisrandes verweisen; im Text zum Bodenprofil $\mathrm{P}_{4}$ wurde dazu jedoch nichts Explizites angegeben. Auch in Abb. 2 war der Punkt $\mathrm{P}_{4}$ somit widersprüchlich außerhalb des Eisrandes eingetragen. Der Eisrand wurde auf einer Höhe von

223 „Das gesamt Pharag oberhalb der Bergstürze steht im Zeichen der Stausedimente, die sich hinter diesem Bergsturzriegel ansammelten." (ebd.:73)

224 „Heute sind es Terrassen, vor allem Schwemmkegelterrassen, unter denen die Zeugen der letzteiszeitlichen Hauptvergletscherung verborgen sind, eine weitere Schwierigkeit für die Eiszeitforschung in diesem Talabschnitt." (ebd.:73) 
$3.060 \mathrm{~m}$ beim Wallansatz festgelegt. Hierbei stellte sich die Frage, ob der Eisrand beim Wallansatz festlegbar war, da nicht eindeutig war, ob es sich bei den Moränenwällen um solche des Haupttales oder des Seitentales handelte? Eine genaue Lagebeschreibung bzw. die Streichrichtung der Moränenwälle war dem Text nicht $\mathrm{zu}$ entnehmen, wodurch die Eindeutigkeit gegeben wäre. Nur die Beschreibung des Felsrückens: „,[...] südwärts steil bis 2970 m ab und zieht dann in dieser Richtung weiter." (Heuberger, Weingartner 1985:76), auf dem die Moränen lagerten, und die Abb. 2 deuteten auf eine etwaige Ausrichtung der Moränenzüge hin. In dieser Abbildung gaben die Moränen eine Lage von Nordost bis Südwest vor. Wären diese Moränenwälle vom Seitental, müsste der hochglaziale Eisrand zwangsweise viel höher angesetzt werden. Ab einer Höhe von 3.120 bis 3.130 m wurde ein Bodenprofil von Heuberger, Weingartner (1985:78) untersucht, dass aufgrund der tiefgründigen Verwitterung, wie bei $\mathrm{P}_{1}$, auf die Lage außerhalb des Eisrandes schließen ließ. Die Formfrische der Moränen deutete jedoch auf jüngere Entstehungszeiträume hin, sodass diese nicht den letztglazialen Maximalstatus des Eises anzeigten. Somit wäre die hier dargestellte Bodenentwicklung der Braunerde mit dem Spätglazial in Verbindung zu bringen, wodurch die Parabraunerde in den Zeitraum des Hochglazial fallen würde. Somit würde es sich bei der in Abb. 2 dargestellten maximalen Ausdehnung um eine spätglaziale handeln. Kuhle (2005) ging ebenfalls von einer spätglazialen Gletscherausdehnung bis unterhalb von Ghat aus.

Das Bodenprofil $\mathrm{P}_{5}$ war ein seichtgründiger Braunlehm oberhalb von Monjo. Aufgrund dieser flachen Ausbildung könnte dieser Boden als sehr jung bezeichnet werden und deswegen innerhalb des Eisrandes zu sehen sein. Jedoch wiesen der abwesende Grobanteil in den oberen Horizonten, die durchverwitterten Steine im $\mathrm{B}_{\mathrm{v}}$-Horizont und die Moränenblöcke an der Oberfläche bis auf 3.500 m Höhe auf eine ältere Bodenbildung hin. Heuberger, Weingartner (1985:78) ordneten diesen Boden trotz dieser Befunde bis zu der Höhe von 3.500 m einer jungen Bodenbildung zu; auch die Abb. 2 zeigte das Bodenprofil außerhalb des Eisrandes. Andererseits gaben sie aber an, dass der Boden im Konfluenzbereich des Haupt- und Nebentalgletschers nicht erodiert, sondern nur gekappt wurde. Somit wurde nicht eindeutig geklärt, ob der Boden nun inner- oder außerhalb des Eisrandes einzuordnen ist. Auf Seite 79 gaben Heuberger, Weingartner (1985) wiederum an, dass es sich bei diesem Bodenprofil um eine Moräne handelte ${ }^{225}$. Somit ordneten sie diese innerhalb des Eisrandes ein. Ab einer Höhe von $3.550 \mathrm{~m}$ wurde ein weiteres Bodenprofil - tiefgründiger Lehm mit wenigen

\footnotetext{
225 „[...], konnte sich auf feinanteilreichem Moränenmaterial $\left(P_{5}\right)$ eine deutlich lehmige Braunerde bilden." (ebd.:79)
} 
durchverwitterten Steinen, wie bei $\mathrm{P}_{1}-$ von Heuberger, Weingartner (1985:78) aufgenommen, welches den Bereich außerhalb des Eisrandes darstellen soll. Im Widerspruch dazu wäre das Bodenprofil $\mathrm{P}_{5}$ gegenüber dem weiter höher liegenden Bodenprofil nun aber doch innerhalb des Eisrandes zu sehen. Wie konnte es aber sein, dass in dem letztgenannten Profil wenige durchverwitterte Steine auftraten und der Boden älter war und bei dem erstgenannten jüngeren Profil alle vorhandenen Steine durchverwittert waren? Die Beschreibung, dass das Bodenprofil $\mathrm{P}_{5}$ hier sehr kleinräumig und unzusammenhängend auftrat, ließ viele weitere Fragen entstehen. Beispielsweise war fraglich, wie ein Boden in diesem Zusammenhang nur kleinräumig auftritt, obwohl die Vergletscherung nach Heuberger, Weingartner (1985) für die Bodenbildung ein entscheidender Faktor gewesen sein soll. Würde dann nicht eine kleinräumige Bodenentwicklung auch auf eine kleinräumige Vergletscherung in Form einer Nebentalvergletscherung, wenn die Bodenentwicklung entscheidend und nur von dem Faktor Vergletscherung abhinge, hindeuten? War eine Aussage über die Hauptvergletscherung überhaupt lediglich anhand von Bodenbefunden möglich? Außerdem gaben Heuberger, Weingartner (1985) die Gesteinsarten der in den Horizonten enthaltenden Steine und der Moränenblöcke nicht an, wodurch eine gesteinsabhängige Aussage über den o.g. Verwitterungsgrad der Steine hätte getroffen werden können.

Das Bodenprofil $\mathrm{P}_{6}$ zwischen Khunde und Khumjung zeigte eine schwächere Bodenbildung auf den Eisrandablagerungen als $\mathrm{P}_{4}$. Da es sich bei diesem Bodenprofil $\mathrm{P}_{6}$ um Aufschlüsse einer Murrinne handelte,war nicht eindeutig geklärt, ob nun umgelagerte Moränenmaterialien in Form von jüngeren Murfächern oder aber ältere Moränenzüge untersucht wurden bzw. was generell untersucht wurde. Eigenschaften bzw. Horizontabfolgen wurden nämlich von Heuberger, Weingartner (1985:78, Abb. 2), im Gegensatz zu allen anderen von ihnen beschriebenen Bodenprofilen, nicht aufgezeigt. In Abb. 2 wurde der Punkt $\mathrm{P}_{6}$ auch nicht exakt festgelegt bzw. es fehlte der schwarze Punkt als Markierung. Im Text fanden sich ebenfalls nur wenige Informationen zu diesem Bodenprofil: es wurde nur ein Satz dazu geschrieben. Die o.g. schwächere Bodenbildung könnte darauf hindeuten, dass die Bodenbildung von der Höhe abhängt oder dass der Boden $\mathrm{P}_{6}$ jünger war. Bodenprofil $\mathrm{P}_{6}$ lag auf einer Höhe von $4.000 \mathrm{~m}$ und $\mathrm{P}_{4}$ auf $2.970 \mathrm{~m}$. In Bezug auf das jüngere Alter von $\mathrm{P}_{6}$ könnte der zeitlich spätere Eisrückzug bei $\mathrm{P}_{6}$, da Khumjung $\left(\mathrm{P}_{6}\right)$ talaufwärtiger und höher liegt als Monjo $\left(\mathrm{P}_{4}\right)$, eine Rolle gespielt haben. Generell könnte dieser Aspekt wohl für alle Bodenprofile - talabwärts ältere Böden als talaufwärts - eine Bedeutung haben $\left(\mathrm{P}_{2}\right.$ stärkere Bodenbildung als alle anderen 
Bodenprofile), es sei denn die Böden waren von jüngeren Akkumulationen überlagert, wie es bei Bodenprofil $\mathrm{P}_{3}$ der Fall war.

Bei der Betrachtung aller Bodenprofile insgesamt traten folgende Fragen auf:

- Wie tief waren die Bodenprofile im Allgemeinen? Es wurden keine Angaben über die Tiefe der Bodenprofile bzw. über die unterschiedlichen Horizonte gemacht. Nur bei $\mathrm{P}_{1}$ bestand eine Höhenangabe und allgemein wurden die Verwitterungstiefen der Braunerden angegeben, die jedoch alle keine genauen Anhaltspunkte geben ${ }^{226}$.

- Welche Ausgangsgesteine lagen den verschiedenen Profilen zu Grunde? Es wurden keine Informationen über die Gesteinsarten der Ausgangsgesteine, der im Bodenprofil enthaltenen Grobanteile und der Moränenblöcke gegeben.

- Warum soll die Bodenbildung nur innerhalb des Eisrandes gesteinsabhängig sein? Heuberger, Weingartner (1985) beschrieben diesen Sachverhalt auf Seite 79.

- Welche morphologischen Prozesse haben beim Aufbau der Bodenprofile eine Rolle gespielt? Waren die gekappten Bodenprofile auf andere Faktoren, z.B. auf Hangprozesse, und nicht auf einen teilweisen Abtrag durch Gletscher zurückzuführen? Wie können sämtliche anderen an der Bodenbildung beteiligten vielfältigen Faktoren ausgeschlossen werden?

- Warum wurden die Böden mancherorts durch den Gletscher nur gekappt und nicht überall beseitigt? Bei einem so engen Tal müsste der gesamte Boden wegtransportiert worden sein, da ja auch nach Heuberger, Weingartner (1985:80) alle weiteren Moränenreste im Pharag nicht erhalten waren. Gekappte Böden dürften somit eher auf Hangprozesse zurückzuführen sein.

- Wie konnte durch Bodenbildungsprozesse auf eine zeitliche Entstehung geschlossen werden, wenn keine zeitliche Zuordnung von Bodenentwicklungsstadien in den Gebieten des Himalaja bekannt war?

- Wieso sollten Braunerden nur im Bereich einer hochglazialen Vergletscherung und Parabraunerden außerhalb dieses Eisrandes auftreten? Könnten nicht andere Faktoren eine Rolle gespielt haben und die zeitliche Einteilung eventuell eine andere gewesen sein? Oder könnte eine tiefgründige Verwitterung, einhergehend mit einer längeren Eisfreiheit, nicht nur mit dem Zeitraum seit der vorletzten Eiszeit in Verbindung gebracht werden, sondern auch mit dem seit dem Spätglazial?

226 ,.[...]; in den tieferen Partien (etwa ab 80 cm) [...]." (ebd.:77); ,.[...] von Braunerde mit Verwitterungstiefen von 1-2 m (auf unverwittertem Ausgangsmaterial) geführt." (ebd.:80) 
- Wie konnten Bearbeitungen des Bodens anthropogenen Ursprungs ausgeschlossen werden?

- Warum wurden die Befunde nicht denen anderer Wissenschaftler gegenübergestellt?

Die kritische Auseinandersetzung mit den Befunden von Heuberger, Weingartner (1985) zeigte, dass keine sichere Aussage über die maximale Gletscherausdehnung im Gebiet des Solukhumbu anhand dieser möglich war. Die in dieser Dissertation aufgezeigten Kriterien sprachen dafür, dass die Ausführungen von Heuberger, Weingartner (1985) mit hoher Wahrscheinlichkeit nur eine spätglaziale Vergletscherung aufzeigten.

Folgende Punkte sprachen gegen eine gesicherte Annahme der letzteiszeitlichen Vergletscherung nach Heuberger, Weingartner (1985):

- Eingrenzung des Vergletscherungsgrades, abgesehen von zwei Standorten, lediglich durch Bodenbefunde, welche anhand von sechs Profilen erhoben wurden

- geringfügige Angaben bei den Bodenprofilen (z.B. Bodentiefe, Ausgangsgestein)

- zeitliche Einteilung lediglich anhand von zwei unterschiedlichen Bodentypen, obwohl keine genauen Angaben über die Bodenentwicklung aus dem Himalaja bekannt sind

- stellenweise Auswertung von gestörten Bodenprofilen

- Nichtberücksichtigung weiterer an der Bodenbildung beteiligter Faktoren (z.B. anthropogene Einflüsse)

- untypische Rekonstruktion des Gletschereises

- Anwendung in einem sehr kleinen Untersuchungsgebiet

- keine detaillierte glazialgeomorphologische bzw. geomorphologische Analyse, wobei selbst bei den aufgezeigten Moränen das Erscheinungsbild bzw. der Verwitterungsgrad nicht für eine Einordnung in die verschiedenen Zeiträume genutzt wurde

- hochglaziale Schneegrenzrekonstruktion anhand von Lokalmoränen

- kein Vergleich der Befunde mit denen anderer Wissenschaftler bzw. keine zeitliche Abstimmung

\section{HEUBERGER (1986)}

Die Arbeit von Heuberger (1986) war eine Kurzfassung über die viermonatige Forschungsreise des Jahres 1984, wobei Weingartner ihn den ersten Monat begleitete (ebd.:29). Somit konnten diese Forschungsergebnisse als Ergänzung zu denen von Heuberger, 
Weingartner (1985) angesehen werden, da hier auch auf ältere Hauptvergletscherungen und nicht nur auf die letzte Eiszeit - wie es bei Heuberger, Weingartner (1985) der Fall war eingegangen wurde. Naheliegend - aufgrund der ähnlichen Aussagen über das Vergletscherungsausmaß - wäre, dass es eine Kurzzusammenfassung der Arbeit 'Beobachtungen über die heutige und eiszeitliche Vergletscherung in Ost-Nepal' von Heuberger aus dem Jahr 1956 war. Diese Arbeit wurde 1979 jedoch öffentlich von ihm zurückgenommen, wie durch Kuhle (2005:316) belegt wurde. Ob nun die Befunde der Kurzfassung von Heuberger (1986) noch als gültig angesehen werden können, blieb offen und wurde auch nirgends erwähnt.

Das Vergletscherungsausmaß der letzten Hauptvereisung im Solukhumbu nach Heuberger (1986), bis auf ca. $2.500 \mathrm{~m}$ Höhe unterhalb von Ghat, musste hinterfragt werden, da er das Gletscherende lediglich anhand von Bodenbildungsprozessen festlegte, wobei der Verwitterungsgrad der Böden in Bezug auf Bodentyp und -mächtigkeit die bedeutende Rolle spielte $^{227}$. Auch die Forschungsergebnisse über die anderen angegebenen älteren Hauptvereisungen mussten kritisch gesehen werden. Es ist bekannt, dass die Bodenbildungsprozesse vom Zusammenspiel enorm vieler Faktoren wie u.a. von der Höhe ü. NN bzw. vom Klima, vom Ausgangsmaterial und von geomorphologischen Prozessen abhängen. Somit sind die Anteile der Faktoren zu diesem komplexen Zusammenspiel nicht eindeutig zuzuordnen und folglich eine genaue Einordnung der zeitlichen Abläufe generell und auch nur nach einem Faktor nicht möglich. Zudem ist laut Kuhle (2005:316) keine Kalibrierung der Bodenentwicklung im Himalaja bekannt. Wie hat nun Heuberger (1986) dieses Maximalstadium lediglich anhand von Bodenbefunden festlegen können? Er äußerte sich dazu nur sporadisch: ,, So war es schwierig, aber möglich, die größte Ausdehnung dreier letzteiszeitlicher Talgletscher einzugrenzen." (Heuberger 1986:29).

Grundsätzlich ging Heuberger (1986) bei dieser Kurzfassung nicht auf die Lage dieser Bodenvorkommen, auf die anzutreffenden Bodentypen bzw. auf die verschiedenen Bodenhorizonte mit Ausgangsgestein, die Mächtigkeitswerte der Böden und die der Bodenhorizonte ein. Zudem waren keine Informationen gegeben über: die genaue Lage und Größe des Forschungsgebietes, die Forschungsroute, die Anzahl der untersuchten Bodenprofile, die zeitliche Einordnung der Bodenprofile, den Verlauf des hochglazialen Eises des Haupttales und der Nebentäler, die Festlegung der Vergletscherungsgrenzen,

\footnotetext{
227 „Jedoch liefert die Bodenbildung gute Anhaltspunkte für die Reichweite der letzten Hauptvergletscherung.” (Heuberger 1986:29)
} 
aufgefundene geomorphologische Formen sowie darüber, welche Faktoren bei der Bodenbildung eine Rolle spielten. Ohne diese genannten Angaben waren die Forschungsergebnisse von Heuberger (1986) nicht hinreichend aussagekräftig. Zum Forschungsgebiet gab Heuberger (1986:29) im Text nur an, dass es sich um das Gebiet des Dudh Khosi Tal (Talschaften Khumbu und Pharag) und um das Seitental Solu Khola (Talschaft Shorong / Solu) handelte. Der Tabelle auf Seite 30 war jedoch zu entnehmen, dass das Hauptaugenmerk von Heuberger (1986) auf den Tälern Pharag (Dudh Khosi: Ghat bis etwa Khari Khola), Beni Khola (Shorong/Solu: Ringmo bis etwa Phera) und Basa Drangka (Junbesi Khola, Shorong/Solu: bei etwa Phukmoche) lag.

Außerdem legte Heuberger (1986) die drei Hauptvereisungen mit den Lokalnamen Tega, Surke und Ringmo - bei der Aufzählung beginnend mit der jüngsten - fest, obwohl keine Altersbestimmungen erfolgten ${ }^{228}$. Wie hatte er diese Hauptvereisungen festlegen können? Dieser machte die Zeiteinteilung lediglich anhand der unterschiedlichen Bodenbildung von Moränenablagerungen fest. Die älteste Hauptvergletscherung fand sich dementsprechend anhand der enorm intensiven Bodenbildung bei Ringmo (ebd.:29). Hierbei stellte sich die Frage, um was für Moränenablagerungen es sich hierbei handelte und welche Bodentypen dort auftraten. Warum zog er nicht die Verwitterungsgrade weiterer glazialgeomorphologischer Formen heran? Wagner (2007:177 f.) fand folgendes heraus: „, Südlich des Dhampus-Beckens verhindern die Ausgangssubstratunterschiede generell die pedochemische Relativdatierung. Außerdem schränken hier die für die HimalajaSüdabdachung typischen Eigenschaften, d.h. ein hohes Maß an Reliefenergie, Niederschlag und anthropogener Nutzung, eine sichere Ableitung des relativen Alters der glazigenen Akkumulationen aus dem relativen Bodenalter zusätzlich ein, da eine hierfür notwendige ungestörte Bodenentwicklung, d.h. eine primäre Formerhaltung der Akkumulationen, nahezu ausgeschlossen ist.". Heuberger (1986) ging in seiner Arbeit auf solche Aspekte nicht ein und gab keine möglichen Erklärungen, warum die Böden unterschiedlich entwickelt sein könnten. Er bezog sich nur auf eine einzige mögliche Deutung, nämlich auf die Vergletscherungsgeschichte. Die für diese Dissertation durchgeführten Geländebegehungen ergaben zwar, dass die Bodenbildung talabwärts von Lukla in Richtung Surke tatsächlich weiter fortgeschritten war, jedoch in diesem Bereich ebenfalls glazialgeomorphologische Indizien aufzufinden waren, die aufgrund des Erhaltungszustandes auf eine letzteiszeitliche und nicht auf eine vorletzteiszeitliche Vergletscherung schließen ließen. Auch die Kenntnisse 
über die geologischen Verhältnisse im Bereich von Surke bis Khumjung wiesen auf eine gesteinsabhängige Bodenbildung im Solukhumbu hin. Somit könnten die von Heuberger (1986) ausgelegten letzteiszeitlichen Gletscherenden auch z.B. ins Spätglazial und die vorletzten ins Hochglazial der letzten Eiszeit eingeordnet werden.

Laut Heuberger (1986) zeigten Moränenablagerungen also eine mächtigere Bodenbildung, was er mit einem Interglazial in Verbindung brachte ${ }^{229}$. Eine noch mehr intensivere Bodenbildung in Moränen, etwa bei Ringmo, ordnete Heuberger als noch ältere Ablagerungen ein, obwohl er sich mit dem verwendeten Wort 'wahrscheinlich' nicht eindeutig festlegte ${ }^{230}$. Laut Wagner $(2007: 177)$ waren jedoch für die typisch heterogen zusammengesetzten Moränen granulometrische Verwitterungsindizes oft ungeeignet.

Zudem wurden die Bodenbildungsprozesse von Heuberger (1986) im Himalaja mit denen der Alpen in Verbindung gebracht: „Die Bodenbildung seit der letzten Vereisung entspricht nach Bodentypen und Mächtigkeit ungefähr jener der Alpen seit der Würmvergletscherung." (Heuberger 1986:29), was sich u.a. im Vergleich der Höhenlage der Gebirge zueinander umfassender gestalten sollte. Nach dem Geschriebenen wurde ebenfalls nicht eindeutig geklärt, inwiefern sich die Böden in den von Heuberger (1986:Tab.) untersuchten benachbarten Gebieten des Pharag, Beni Khola und Basa Drangka untereinander unterschieden. Bodenprofile, Bodeneigenschaften, Karten, Fotos oder Skizzen vom Gebiet sowie von geomorphologischen Formen - demnach jegliche visuelle Darstellungen bis auf eine Tabelle - waren in der Forschungsarbeit von Heuberger (1986) nicht enthalten. Dieser Aspekt könnte möglicherweise damit in Verbindung gebracht werden, dass es sich hierbei um eine Kurzfassung handelte.

Infolge des Nichtvorhandenseins einer glazialgeomorphologischen Karte bei Heuberger (1986) und der in seinem Text angegebenen Informationen konnte geschlussfolgert werden, dass keine detaillierte geomorphologische Bestandsaufnahme und keine Schneegrenzberechnungen durchgeführt wurden. Laut ihm sollen in den schmalen Tälern des Pharag und des Shorong aufgrund einer kurzfristigen Eisverfüllung der Täler wenige glaziale Reste sowie keine auffallenden glazialen Felsformen vorhanden und die Erratika aufgrund verschiedener Migmatite nicht auszumachen sein (ebd.:29). Bei der Betrachtung des Zitats:

229 „Dort ist die Bodenbildung qualitativ und quantitativ entscheidend weiter fortgeschritten als jene seit der letzten Hauptvergletscherung. Das ist ein deutlicher Hinweis auf ein Interglazial zwischen den beiden Vereisungen." (ebd.:29)

${ }^{230}$ „[...], so daß es sich hier wahrscheinlich um den Zeugen einer noch älteren Hauptvergletscherung handelt." (ebd.:29) 
„In den engen, steilen Tälern des Pharag und Shorong sind nur wenige Reste von Moränenwällen und anderen Eisrandformen erhalten geblieben. [...]. Die vorherrschenden Migmatite wechseln dort auf engstem Raum stark in ihrem Gesteinsbild, so daß man auch nicht leicht richtige Erratika bestimmen kann." (Heuberger 1986:29) stellte sich die Frage, wie er, wenn doch nur Reste von Moränen und anderen Eisrandformen existierten, überhaupt ein Maximalstadium festlegen konnte. Für eine solche Rekonstruktion eines ehemaligen Gletschers werden enorm viele Indizien benötigt. Wenn Heuberger z.B. keinerlei Erratika ausmachte, konnte er auch keine Aussagen über die Herkunft des Eises geben. Dass nur unauffällige glaziale Felsformen existieren sollen, brachte er mit einer nur kurzfristigen eiszeitlichen Gletscherverfüllung in Verbindung. Könnte dieser Aspekt nicht auch mit einer postglazialen Überarbeitung oder einer unvollständigen bzw. nicht vorhandenen Bestandsaufnahme in Verbindung gebracht werden?

Generell erwähnte Heuberger Moränen zwar in Bezug auf die Bodenbildung, visualisierte sie aber nicht im Sinne einer Verortung. Laut den Geländebefunden dieser Dissertation waren außerordentlich viele Moränenreste in den Gebieten auszumachen; auch auffallende Felsformen in Form von glaziären Flankenschliffen oder Rundhöckern waren deutlich zu erkennen. Erratika ließen sich ebenfalls als Granite von den übrigen metamorphen Gesteinen unterscheiden. Zusätzlich konnten hierzu besonders die Ausführungen von Kuhle (2005) und die von Fushimi (1978) zur Überprüfung herangezogen werden. Auch andere geomorphologische Formungen wurden in der Ausarbeitung von Heuberger (1986) nicht beschrieben. Somit war unklar, ob auch unterhalb der festgelegten Gletscherenden Moränen oder andere glazialgeomorphologische Formen aus der letzten Eiszeit vorkamen.

Die von Heuberger (1986:Tab.) angegebenen Höhenwerte der Vergletscherungsausmaße der letzen und vorletzten Eiszeit im Pharag (Dudh Khosi), Beni Khola (Shorong / Solu) und Basa Drangka (Junbesi Khola, Shorong / Solu) deuteten darauf, dass in den drei benachbarten Tälern eine sehr unausgeglichene Vergletscherung auftrat. Für die letzte Eiszeit unterschieden sich nach Gegenrechnung der von ihm zugrunde gelegten Werte demnach die Höhenangaben der Gletscherzungen vom Pharag und Beni Khola um 50 m, vom Pharag und Basa Drangka um 700 m und vom Beni Khola und Basa Drangka um 650 m. In der vorletzten Eiszeit bestand hingegen ein Höhenunterschied im Pharag und Beni Khola von 900 m, im Pharag und Basa Drangka von 1.420 m und im Beni Khola und Basa Drangka von 520 m. Im Pharag selbst entsprach der Höhenunterschied zwischen der letzten und vorletzten Eiszeit 920 m, im 
Beni Khola 70 m und im Basa Drangka 200 m, wobei das Gletschereis im Pharag bei beiden Eiszeiten am weitesten hinab reichte und im Basa Drangka am wenigsten. Müssten nicht diese eng nebeneinander liegenden Gebiete während der Eiszeiten ähnlich weit vergletschert gewesen sein und ungefähr ähnliche Schneegrenzdepressionen aufgewiesen haben? Diese Höhenunterschiede waren zwar mit den unterschiedlich angegebenen Höhenwerten der Einzugsbereiche von Heuberger (1986:30) - Pharag (8.848 m, 8.501 m), Beni Khola (6.959 $\mathrm{m}, 6.511 \mathrm{~m})$ und Basa Drangka $(5.313 \mathrm{~m}, 5.085 \mathrm{~m})$ - in Verbindung zu bringen, aber da das Dudh Khosi Tal ein Haupttal und die beiden anderen Gebiete Nebentäler darstellen, sollte bei der nahen Lage zueinander dieser angegebene Höhenunterschied der Gletscherlängen kritisch betrachtet werden. Wie konnte sich der Dudh Khosi Haupttalgletscher gegenüber dem Shorong / Solu Nebentalgletscher bei der letzten Eiszeit bezüglich eines enormen Einzugsbereichsunterschiedes (z.B. Höhenunterschied höchster Gipfel Pharag und höchster Gipfel Beni Khola $=1.889 \mathrm{~m}$, Höhenunterschied zweithöchster Gipfel Pharag und zweithöchster Gipfel Beni Khola = 1.990 m) nur um 50 Höhenmeter und bei der vorletzten um 900 Höhenmeter unterscheiden? Und wie konnte sich der Dudh Khosi Haupttalgletscher gegenüber dem Junbesi Khola, Shorong / Solu Nebentalgletscher bei der letzten Eiszeit mit dem großen Einzugsbereichsunterschied (z.B. Höhenunterschied höchster Gipfel Pharag und höchster Gipfel Basa Drangka = 3.535 m, Höhenunterschied zweithöchster Gipfel Pharag und zweithöchster Gipfel Basa Drangka $=3.416$ m) nur um 700 Höhenmeter und bei der vorletzten um 1.420 Höhenmeter unterscheiden?

Die aufgezeigten Kritikpunkte zu den Befunden von Heuberger (1986) zeigten, dass keine gesicherte Aussage über die maximale Gletscherausdehnung anhand dieser möglich war.

\section{KUHLE (1986A)}

\section{METHODE BZW. ARBEITSTECHNIK}

Kuhle (1986a) wendete geomorphologische Analysen an, berechnete Schneegrenzen und Schneegrenzdepressionen von zehn Gletscherstadien mit Hilfe von 123 Endmoränen und den dazugehörigen Einzugsbereichen und klassifizierte holozäne Gletscherstadien anhand von ${ }^{14}$ C-Daten (Fig. 2), wobei viele ${ }^{14}$ C-Daten durch Lichenometrie (Rhizocarpon geographicum') bestätigt wurden. Anhand der Schneegrenzdepressionen schloss Kuhle auf Temperaturveränderungen während der Sommer der entsprechenden Stadien. Somit kam er zu zwölf spätglazialen, neoglazialen und rezenten Gletscherstadien im Himalaja, Kuen Lun und Quilian Shan, die anhand der von ihm entwickelten Schneegrenzberechnung, welche nämlich 
Reliefparameter berücksichtigte, überregional vergleichbar waren. (vgl. Kuhle 1986a:435, $440,453)$

Es waren geomorphologische Karten (Fig. 2 und 3) von der Cho Oyu Südabdachung und dem Animachin Massiv vorhanden.

\section{UNTERSUCHUNGSGEBIET}

Neben anderen genannten Forschungsgebieten wie etwa Dhaulagiri- und Annapurna-Himal, Gyanchung, Animachin und Kakitu untersuchte Kuhle (1986a:437) den westlichen KhumbuHimalaja bzw. das Gebiet südlich des Cho Oyu. Es war eine Übersichtskarte von den Untersuchungsgebieten existent (Fig. 1).

\section{KRITIK}

Der Fokus der Arbeit von Kuhle mit dem Titel `Former Glacial Stades in the Mountain Areas surrounding Tibet - in the Himalayas' aus dem Jahre 1986 lag auf dem Ngozumpa Gletschersystem mit angrenzenden Gletschern. Hierbei wurden die Gletscherstadien aus dem Dhaulagiri- und Annapurna-Himal (vgl. Kuhle 1986a:Tab. 1) auf die genannte Himalaja Region ausgedehnt. Die Gletscherstadien im Ngozumpa Talsystem konnten der Seite 439 Fig. 2 entnommen werden. Diese zehn Stadien wurden wie o.g. durch geomorphologische Befunde, Schneegrenzberechnungen und ${ }^{14} \mathrm{C}$-Datierungen zeitlich eingeordnet. Alle zehn ${ }^{14} \mathrm{C}$ Probenahmestellen im Khumbu waren auf Fotos (Fig. 5 bis 13) nachvollziehbar. Demnach wurden sie anhand dieser Methoden bzw. Arbeitstechniken genauestens bestimmt, wobei hier den geomorphologischen Befunden bzw. den relativen Befunden mehr Beachtung geschenkt wurde als den absoluten ${ }^{14} \mathrm{C}$-Daten. Bei den ${ }^{14} \mathrm{C}$-Daten traten nämlich Unstimmigkeiten zu geomorphologischen Gegebenheiten auf: Kuhle (1986a:440) schrieb beispielsweise, dass die absoluten ${ }^{14} \mathrm{C}$-Daten im westlichen Khumbu, die unterhalb von 5.000 m Höhe entnommen wurden, den relativen Daten entsprachen. In der Nähe der oberen Vegetationsgrenze auf 5.500 $\mathrm{m}$ Höhe sollen diese Daten jedoch jünger ausfallen, da sich dort die Pioniervegetation langsamer ansiedelte (ebd.:440). Kuhle hinterfragte demnach kritisch die ermittelten absoluten Daten im Kontext zu den geomorphologischen Befunden. Er meinte hierzu prinzipiell, dass ${ }^{14} \mathrm{C}$-Daten nur ein Minimalalter angeben können (ebd.:440). 


\section{KUHLE (1987A)}

\section{METHODE BZW. ARBEITSTECHNIK}

Kuhle (1987a:200 f.) wendete geomorphologische Analysen und ${ }^{14} \mathrm{C}$-Datierungen an, wobei einige der letztgenannten durch Lichenometrie ('Rhizocarpon geographicum’) untermauert wurden. Es waren geomorphologische Karten (Fig. 2 und 3) von der Cho Oyu Südabdachung und dem Animachin Massiv sowie ${ }^{14} \mathrm{C}$-Daten (Tab. 1) von der Cho Oyu und Gyanchung Kang Südabdachung und der Kakitu Südseite enthalten.

\section{UNTERSUCHUNGSGEBIET}

Kuhle (1987a:200) untersuchte das Ngozumpa Gletschersystem mit den Nebengletschern im westlichen Khumbu Gebiet - wobei er die Gletscherstände aus dem Dhaulagiri- und Annapurna-Himalaja auf dieses Gebiet übertrug - sowie Nord- und Osttibet.

\section{KRITIK}

Kuhle (1987a) beschrieb in seiner Arbeit mit dem Titel `Absolute Datierungen zur jüngeren Gletschergeschichte im Mt. Everest Gebiet und die mathematische Korrektur von Schneegrenzberechnungen', dass die ${ }^{14}$ C-Alter Mindestalter darstellen ${ }^{231}$ und die Vegetationsbesiedlung auf Moränen bezüglich der Lage zur Vegetationsgrenze unterschiedlich ablief ${ }^{232}$. Es sollen relative mit absoluten Datierungen nur unterhalb von 5.000 $\mathrm{m}$ übereinstimmen, da es oberhalb zu einer verzögerten Vegetationsbesiedlung kommt (ebd.:201). Die Mattenvegetationsobergrenze soll im Khumbu auf $5.500 \mathrm{~m}$ liegen (ebd.:201). Als Beispiele wurden die Proben 5, 6, 7 und 8 herangezogen, wobei bei den drei letztgenannten eine verzögerte Vegetationsbesiedlung stattgefunden haben soll (ebd.:201). Somit führen absolute Datierungen durch die auftretende Vegetationsverzögerung bei Moränen nicht immer zu einem genauen Ergebnis und müssten prinzipiell kritisch hinterfragt bzw. mit einer detaillierten geomorphologischen Analyse oder relativen Datierung - so wie es Kuhle in seiner Arbeit tat - überprüft werden. Die von Kuhle beachteten Stadien gaben einen guten Überblick über die vorzeitliche bzw. in dieser Arbeit über die historische und neoglaziale sowie spätglaziale Vergletscherung (Fig. 2 und 3). Die hier betrachtete Arbeit von Kuhle (1987a) konnte zu der umfassenderen Arbeit aus dem Jahr 2005 hinzugezählt werden.

\footnotetext{
231 „Betont wird, daß die 14C-Alter Eisrandlagenmindestalter belegen, zu denen die Zeitspanne der Pioniervegetationsbesiedlung zu rechnen ist." (Kuhle 1987:201)

232 „In Nähe der Gletscherzungenenden folgt die Vegetationsbesiedlung der Moränensedimentation recht unmittelbar. Immer größer jedoch wird der Zeitschlupf, je näher man der Vegetationsgrenze kommt.” (ebd.:201)
} 
Kuhle (1987a) ging weiterhin darauf ein, dass die Schneegrenzdepressionswerte nach der Schneegrenzbestimmungsmethode nach v. Höfer (1879) ${ }^{233}$ unterschiedlich waren: z.B. kam er beim Nauri Stadium im Khumbu auf $560 \mathrm{~m}$ gegenüber $240 \mathrm{~m}$ im Animachin-Massiv (ebd.:205). Somit wäre ein überregionaler Vergleich nicht immer möglich. Die Schneegrenzbestimmung nach Kuhle, die als einzige die Gletschertopographie berücksichtigte und zudem die Methoden von Louis $(1955)^{234}$ und die von v. Höfer $(1879)^{235}$ kombinierte, war jedoch für einen überregionalen Vergleich nutzbar (ebd.:205). Nach Kuhle (1987a:205) war ferner die Methode von Gross, Kerschner, Patzelt (1977) ${ }^{236}$ selbst für rezente Gletscher unbrauchbar.

Heuberger (1987) ${ }^{237}$ fasste die anschließende Diskussion des Vortrags von Kuhle (1987a) beim 45. Deutschen Geographentag in Berlin zusammen. Hierbei wurde Kuhle Kritik in Bezug auf das Alter einer Flechte, der angewendeten Schneegrenzberechnungsmethode (hohe systematische Fehler bei der Methode von v. Höfer und Louis) und der Bestimmung der ${ }^{14} \mathrm{C}$ Alter (Wurzelholz sei nicht verwendbar, keine Moräne sei wirklich datiert) zuteil. Kuhle verwies beim Alter der Flechte auf die Forschungen eines Botanikers (bestimmt auf Beschel), meinte, dass die Schneegrenzen mit den realen Schneegrenzen hoch korrelieren, die Position der Probenahmestellen für die ${ }^{14} \mathrm{C}$-Datierungen einwandfrei war und die Methode nur Mindestalter anzeigen kann. (vgl. Heuberger 1987:215 f.)

\section{KUHLE (1987B)}

\section{METHODE BZW. ARBEITSTECHNIK}

Kuhle machte im Gebiet des Mt. Everest im Jahre 1982 Oberflächentemperatur- sowie Solarstrahlungsmessungen und 1984 Schneegrenzbestimmungen. Er betrieb vor allem aber geomorphologische Analysen. (vgl. Kuhle 1987b:410-412)

\section{UNTERSUCHUNGSGEBIET}

Kuhle führte in seiner Veröffentlichung (1987b) viele Untersuchungsgebiete auf, wie etwa die Aconcagua Gruppe in den Anden, das Zagrosgebirge im Iran sowie Gebiete in Hochasien, darunter auch den Khumbu-Himalaja.

\footnotetext{
${ }^{233}$ siehe Quelle Höfer (1879) in der Fußnote

${ }^{234}$ Louis, H. (1955): Schneegrenze und Schneegrenzbestimmung. In: Geographisches Taschenbuch 1954/55. (S. 414-418)

${ }^{235}$ siehe Quelle Höfer (1879) in der Fußnote

${ }^{236}$ Gross, G.; Kerschner, H.; Patzelt, G. (1977): Methodische Untersuchungen über die Schneegrenze in alpinen Gletschergebieten. In: Zeitschrift für Gletscherkunde und Glazialgeologie, Bd. 12 (2). (S. 223-251)

${ }^{237}$ Heuberger, H. (1987): Zusammenfassung der Diskussion. In: Hütteroth, W.-D. (ed.): Tagungsbericht und wissenschaftliche Abhandlungen des 45. Deutschen Geographentages Berlin 1985. Steiner, Stuttgart. (S. 215216)
} 


\section{KRITIK}

Kuhle (1987b) ging in seiner Arbeit mit dem Titel 'Subtropical Mountain- and HighlandGlaciation as Ice Age Triggers and the Waning of the Glacial Periods in the Pleistocene' neben mehreren Gebieten auch auf die Khumbu-Himalaja Region ein. Der Fokus lag jedoch auf der von ihm entwickelten Eiszeittheorie. Im Khumbu-Himalaja ging Kuhle auf einen hochglazialen Kar beim Kongde Shar Bogen (Fig. 18), auf Ufermoränen mit glaziolimnischen Sanden $420 \mathrm{~m}$ über dem Talboden in der Nähe von Trashinga auf $3.650 \mathrm{~m}$ Höhe im Ngozumpa Drangka (Fig. 19), wobei solche Sedimente auch bei Namche Bazar existierten und auf eine hochglaziale Eismächtigkeit von 600 bis $850 \mathrm{~m}$ im Konfluenzbereich zum Imja Drangka schließen ließen, sowie auf das Gletscherlevel des hocheiszeitlichen Rongbuk Gletscher, der im Gegensatz zum rezenten nach Süden als Auslassgletscher floss (Fig. 20), ein. Kuhle kam während seiner dreimonatigen Geländearbeiten im Jahre 1982 auf der Südseite des Mt. Everest Gebietes auf eine eiszeitliche Schneegrenzabsenkung von 900 bis $1.000 \mathrm{~m}$ (Fig. 18), wobei glaziale Charakteristika aus früheren Arbeiten von Kuhle bei Namche Bazar, Nyambua Thyang, Chhutawa und Julming auf eine Vergletscherung bis auf 1.580 m Höhe hindeuteten (vgl. Kuhle 1987b:407 f.). Laut Kuhle (1988a:146) reichte der vorzeitliche Dudh Khosi Gletscher aber nur bis auf eine Höhe von $1.800 \mathrm{~m}$. Neuere detaillierter geomorphologisch hergeleitete Arbeiten von Kuhle - wie etwa Kuhle (2005) zeigten jedoch, dass der vorzeitliche Dudh Khosi Talgletscher sogar bis auf ca. $900 \mathrm{~m}$ hinab reichte. Desweiteren äußerte sich Kuhle bezugnehmend auf seine Geländearbeiten im Jahre 1982 kritisch gegenüber den Schneegrenzwertabsenkungen von v. Wissmann ${ }^{238}$ (ebd.:408). Somit basierte die Arbeit von Kuhle in Bezug auf den hier betrachteten Khumbu-Himalaja auf eindeutigen glazialen Indikatoren, die eine enorme vorzeitliche Vergletscherung dieser Bereiche - auch in Verbindung mit dem tibetischen Eis - nicht mehr ausschließen ließ.

\section{KUHLE (1988A)}

\section{METHODE BZW. ARBEITSTECHNIK}

Kuhle wendete geomorphologische Analysen an.

\section{UNTERSUCHUNGSGEBIET}

Kuhle verwies in der Arbeit aus dem Jahr 1988 auf mehrere Gebiete in Hochasien, darunter auch auf das Gebiet des Solukhumbu.

\footnotetext{
${ }^{238}$ Wissmann, H.v. (1959): Die heutige Vergletscherung und Schneegrenze in Hochasien mit Hinweisen auf die Vergletscherung der letzten Eiszeit. Akad. d. Wiss. u. d. Lit., Abh. d. math.-nat, wiss. KI. Nr. 14. Mainz. (S. 1103-1407)
} 


\section{KRITIK}

In der Arbeit von Kuhle (1988a) mit dem Titel 'Eine reliefspezifische Eiszeittheorie. Nachweis einer tibetischen Inlandvereisung und ihrer energetischen Konsequenzen’ lag das Hauptaugenmerk auf seiner Eiszeittheorie. Hierbei ging er auf mehrere Gebiete in Hochasien ein - vor allem aber auf Tibet und dessen Randgebiete - und argumentierte anhand von geomorphologischen Kennformen für die Möglichkeit einer solchen Eiszeittheorie. Im Bereich des Khumbu-Himalaja zeigte Kuhle, dass der Dudh Khosi Haupttalgletscher ein Auslassgletscher gewesen sein muss. Die umgekehrte Strömungsrichtung des rezenten Rongbuk Gletscher begründeten Schliffhohlkehlen und das Auffinden von nur jungen Moränen auf der Nordseite des Himalaja (vgl. Kuhle 1988a:146). Somit reichte der vorzeitliche Dudh Khosi Auslassgletscher nach Kuhle (1988a:146) über Transfluenzpässe wie etwa den Nangpa La und Lho La bis auf eine Höhe von 1.800 m. Zwischen Nangbug und Surke glättete jener Gletscher den Talbereich. Kuhle (1987b:407 f.) gab aber an, dass glaziale Indikatoren aus früheren Arbeiten von Kuhle bei Namche Bazar, Nyambua Thyang, Chhutawa und Julming auf eine Vergletscherung bis auf $1.580 \mathrm{~m}$ Höhe hindeuteten. Jüngere detaillierter geomorphologisch hergeleitete Arbeiten von Kuhle - wie etwa Kuhle (2005) zeigten jedoch, dass der vorzeitliche Dudh Khosi Talgletscher bis auf ca. 900 m hinab reichte.

\section{WEITERE FORSCHUNGSARBEITEN}

Yokoyama (1978)

\section{METHODE BZW. ARBEITSTECHNIK}

Yokoyama (1978:64) wendete eine geomorphologische Analyse an, wobei er zwei spezielle Moränentypen ausmachte.

\section{UNTERSUCHUNGSGEBIET}

Hierbei wurde das Gyajo Tal, das Gebiet rund um dem Ama Dablam Gletscher im Khumbu sowie das Gebiet rund um den Dudh Khunda Gletscher im Shorong untersucht. Die Untersuchungsgebiete waren in Fig. 1 dargestellt. Die Geländearbeiten erfolgten 1976 bei einer glaziologischen Expedition. (ebd.:64)

\section{ERGEBNISSE}

Yokoyama (1978) beschrieb zwei spezielle Moränenformen: eine direkt bei der Trogtalwand im mittleren Gyajo Tal auf $4.600 \mathrm{~m}$ im Khumbu und die andere als teilweise doppelt auftretender Moränenrücken beim Ama Dablam Gletscher im Khumbu und beim Dudh 
Khunda Gletscher im Shorong. Es handelte sich hierbei um bis dato unerforschte bzw. neu beobachtete modifizierte Lateralmoränen: 'moraine in contact with the valley wall' und 'partially doubled moraine ridge'. Die Moräne im Kontakt zur Talwand konnte von Fächern unterschieden werden, da sie vegetationsbedeckt, nicht frisch und kein aktueller Prozess der Ablagerung zu erkennen war. Bei den Fächern dagegen war ein aktueller Formungsprozess zu erkennen. Außerdem war die Moräne etwa $1 \mathrm{~km}$ lang, wodurch auf eine Lateralmoräne geschlossen wurde, und es existierte talaufwärts im Tal eine terrassenähnliche Moräne, die als spezielle Form einer Lateralmoräne angesehen wurde. Durch Erosionsprozesse wurde diese wie in Fig. 4 dargestellt - modifiziert. Die teilweise doppelt auftretenden kleinen Moränenrücken beim Ama Dablam Gletscher im Khumbu und beim Dudh Khunda Gletscher im Shorong gliederten sich in einen größeren und kleineren Wall, wobei letztgenannter in Kontakt zu den Gletschern stand. Die Moränenseiten zur Talwand hin waren vegetationsbedeckt und ohne großen Unterschiede, wobei auch das Material hauptsächlich gleich schien ${ }^{239}$. Die Hangseite des großen Walls zum Gletscher hin war sehr steil und vegetationsfrei, wobei durch Rutschung ein kleinerer Wall entstehen konnte (Fig. 6), so wie es hier der Fall war. (ebd.:64-66, Fig. 4 und 6)

\section{KRITIK}

Die Arbeit von Yokoyama (1978:64) mit dem Titel `Some modified forms of lateral moraines observed in the Khumbu and Shorong regions' hatte zum Ziel, die zwei in Ostnepal vorgefundenen speziellen Moränentypen $\mathrm{zu}$ beschreiben und Entstehungshypothesen aufzustellen. Demnach wendete Yokoyama eine geomorphologische Analyse an, wobei die Formen Moräne (mit Modifikationen), Fächer und Trogtal (Gyajo Tal) beachtet wurden. Die Moränen untersuchte Yokoyama punktuell an drei verschiedenen Untersuchungsstellen, die in Fig. 1 dargestellt waren. Yokoyama bezog sich im Khumbu auf die Befunde von Iwata (1976), in Bezug auf die Eigenschaften und Prozesse der Moränen auf Embleton und King (1968). Laut Yokoyama (1978:64) war es schwierig, Moränen anhand der allgemeingültigen Definition eindeutig zu bestimmen, da spezielle Formen vorkommen können ${ }^{240}$. Zwei spezielle Moränentypen bzw. modifizierte Lateralmoränen wurden mit dieser Arbeit erstmals aufgefunden, die anhand von drei Fotos - auf dem vierten Foto waren Fächer im Gyajo Tal zu erkennen - und zwei Skizzen nachvollziehbar wurden. Yokoyama machte darauf

239 “[...] seemed to be much the same." (Yokoyama 1978:66)

240 "Moraines are an important key to the study of the stage of glaciation. However since many kind of depositional land-forms can be observed in the Nepal Himalayas, in a considerable number of cases it can hardly be determined whether a deposit is a moraine or not form the usual classification. Thus, a new variety of moraine different from typical ones should be studied carefully." (ebd.:64) 
aufmerksam, dass die Moränen an der Talwand von anderen Forschern höchstwahrscheinlich als Fächer beschrieben sein könnten und die teilweise doppelten Moränenrücken als Gletscherveränderungen interpretiert wurden (ebd.:66). Jedoch zählte er Indizien dafür auf, dass erstgenannte eher Lateralmoränen waren und letztgenannte modifiziert waren. Bei erstgenannten kann folgendes Zitat genannt werden: "It is probably that such a deposit in the glaciated valley is a moraine." (Yokoyama 1978:65). Zudem schrieb er, dass weitere Spezialformen existieren könnten und weitere Forschungen nötig wären ${ }^{241}$.

Anhand der Arbeit von Yokoyama (1978) waren keine Aussagen über die letzteiszeitliche Maximalvergletscherung möglich. Es war lediglich ein Hinweis darauf gegeben, dass Fächer von Moränen deutlicher unterschieden werden müssen und nicht alle Moränenrücken auf Gletscherveränderungen hinweisen müssen, sondern Modifikationen darstellen können.

\section{Iwata (1984)}

Fort (2004:265) ging im Khumbu weiterhin auf die Befunde von Iwata (1984) ${ }^{242}$ ein; diese Literaturquelle konnte jedoch nicht aufgefunden werden.

\footnotetext{
241 "There may exist still other special forms of moraine besides these two. More extensive geomorphological study would be required in the Nepal Himalayas. " (ebd.:66) 


\subsection{Forschungsarbeiten der Jahre 1991 bis heute}

BÄUMLER ET AL. (1991)

\section{METHODE BZW. ARBEITSTECHNIK}

Bäumler et al. (1991:223) teilten Böden auf glazialen und glazifluvialen Ablagerungen anhand unterschiedlicher Verwitterungsintensitäten und Alter ein. Es wurden Eisenfraktionierung, Tonmineralanalysen und Verwitterungsindizes angewendet (ebd.:223). In Tabelle 1 war zu sehen, dass die Eigenschaften der Böden wie etwa Material, Horizonte, Farbe, pH-Wert, Kohlenstoffgehalt, Kationenaustauschkapazität und Korngrößenverteilung berücksichtigt wurden. Die Alter der jungen Böden P3 und P5 untermauerten sie mit ${ }^{14} \mathrm{C}$ Analysen (ebd.:223, 236). Die Beschreibungen der Labormethoden waren den Seiten 228 und 229 zu entnehmen.

\section{UNTERSUCHUNGSGEBIET}

Bäumler et al. (1991:225) untersuchten den oberen Talbereich des Dudh Khosi und Beni Khola - hier: im Solu - sowie das Imja Khola und Dudhkunda Khola im Khumbu. In Fig. 1 war das Untersuchungsgebiet von Ringmo im Süden bis nach Duglha im Norden dargestellt sowie die Route von 1987. Das Klima und die Gesteine des Untersuchungsgebietes wurden beschrieben (ebd.:225).

\section{KRITIK}

Die Arbeit von Bäumler et al. (1991) mit dem Titel 'Investigations on the intensity of weathering of soils developed from glacial and fluvioglacial deposits and their relationship with the history of the landscape in the Mt. Everest region' basierte im Bereich des Solukhumbu auf den Forschungsarbeiten von Heuberger $(1956,1986)$ und Heuberger, Weingartner (1985). Bäumler et al. (1991) kamen anhand von Bodenuntersuchungen auf glazialen und glazifluvialen Ablagerungen und von ${ }^{14} \mathrm{C}$-Analysen zum Ergebnis, dass zwei unterschiedlich alte Böden entwickelt waren. Zum einen waren junge aus der letzten Eiszeit oder dem Postglazial und zum anderen ältere Böden aus dem Interglazial unterschieden worden. Wie diese jungen Böden jedoch genau zeitlich untereinander abgegrenzt wurden, war nicht eindeutig. Bäumler et al. (1991:241) gingen anhand der Bodenbefunde davon aus, dass die alten Bodenprofile P1, P4 und P7 nicht mehr vom letztglazialen Eis erreicht wurden, da diese komplett entwickelt waren. Somit reichte das letzteiszeitliche Eis nach Bäumler et al. (1991) nicht mehr bis zu dem Ort Lukla hinab. Dort auf Seite 225 wurde angegeben, dass die Böden im Untersuchungsgebiet wohl auch auf fluvialen und nicht nur auf glazialen und 
fluvioglazialen Akkumulationen entwickelt waren und das einige Regionen, wie beim Profil 5, rezente und pleistozäne äolische Deckschichten aufwiesen.

Nördlich von Namche Bazar kamen glaziale Erosions- und Akkumulationsformen vor, die auf postglaziale Gletschervorstöße und die größte rezente Vergletscherung hindeuteten (ebd.:223). Hierbei verwiesen Bäumler et al. (1991:223) auf Heuberger (1956), Iwata (1976), Fushimi (1977) und (1978) sowie Röthlisberger (1986) ${ }^{243}$. Jedoch traten südlich von Namche Bazar keine deutlichen glazialen Formen aus dem Pleistozän auf ${ }^{244}$. Bäumler et al. (1991:223 f.) gaben für das Nichtauftreten dieser Formen in diesem Gebiet mehrere Erklärungen. Entweder waren die Formen im Rahmen von Erosions- und Umlagerungsprozessen zerstört bzw. war das Gebiet niemals vergletschert oder sie waren durch fluviale Ablagerungen überlagert, wobei letztere durch den 'landslide' bei Chaunrikharka blockiert wurden. Bäumler et al. (1991:224) verwiesen hierbei auf Heuberger (1986) und Heuberger, Weingartner (1985), die beschrieben, dass einige glaziale Akkumulationen vor der Erosion geschützt waren. Es stellte sich also die Frage, bis wohin das letztglaziale Eis nach Bäumler et al. (1991) nun genau reichte, ob dieses bis oberhalb von Lukla reichte oder aber viel weiter höher endete. Es wurde dazu anhand der Bodenentwicklung lediglich ausgesagt, dass Lukla nicht mehr vom Eis erreicht wurde. Somit lagen keinerlei geomorphologische Befunde über diesen Sachverhalt vor und Bäumler et al. schlossen sich den Schlussfolgerungen von Heuberger (1986) und Heuberger, Weingartner (1985) an.

Die Arbeit von Bäumler et al. (1991) stellte wie bei Bäumler, Zech (1998) gewissermaßen Ähnlichkeiten zur Arbeit von Bäumler, Kemp-Oberhettinger, Zech (1996) mit dem Thema `Bodengenetische Untersuchungen zur Moränenstratigraphie im Langtang-Tal (Zentralnepal) und im Solu/Khumbu (Ostnepal)' dar und wirkte wie eine Zusammenfassung oder Ergänzung dieser. Hierbei handelte es sich um Ergebnisse aus dem Gebiet des oberen Talbereiches des Dudh Khosi und des Beni Khola sowie des Imja Khola und des Dudhkunda Khola. In Bezug auf die angewendete Methode bzw. Arbeitstechnik ergeben sich gleiche Kritikpunkte wie zu den o.g. Forschern. Die Bodenentwicklung hängt von sehr vielen Faktoren ab, sodass Aussagen über die einstmalige Vergletscherung schwierig sind. Bäumler et al. (1991) führten

\footnotetext{
${ }^{243}$ siehe Quelle Röthlisberger (1986) in der Fußnote

244 "South of Namche Bazar (3440 m a.s. 1.) there is no clear evidence of Pleistocene glaciation." (Bäumler et al. 1991:223)
} 
beispielsweise aus, dass die Bodenentwicklung von der absoluten Höhe und den bioklimatischen Regionen abhängig ist ${ }^{245}$.

\section{BÄUMLER, KEMP-OBERHETTINGER, ZECH (1996)}

\section{METHODE BZW. ARBEITSTECHNIK}

Bäumler, Kemp-Oberhettinger, Zech (1996:Zus.) untersuchten - auf Basis der Forschungen von Heuberger - vorwiegend glaziale und fluvioglaziale Ablagerungen anhand bodengenetischer Untersuchungen auf Grundlage der Verwitterungsintensität. Hiermit wollten sie die Bodenprofile dieser Ablagerungen in Bezug auf eine relative Altersdatierung untereinander vergleichen (ebd.:28). Die Bodenentwicklung wurde bei dieser Arbeit als eine Funktion der Zeit und abhängig von Klima, Flora und Fauna, Topographie und Ausgangsmaterial gesehen (ebd.:28). „Da in der vorliegenden Arbeit der Faktor Zeit untersucht werden soll, ist es wichtig, die sonstigen Einflußfaktoren so konstant wie möglich zu halten.” (Bäumler, Kemp-Oberhettinger, Zech 1996:29). Infolgedessen wurden die Probenahmestellen in Gebiete mit geringen Klimaunterschieden gelegt ${ }^{246}$. Es wurden fast ausschließlich Böden auf deutlich erkennbaren Moränenwällen im Scheitelbereich oder im Oberhang und solche mit Zwergstrauchgesellschaften untersucht. Bäumler, KempOberhettinger und Zech erforschten Böden auf vergleichbarer Höhe und auf einheitlichem Ausgangsmaterial - das Material aus Untersuchungs- und Einzugsgebiet musste gleich sein und das Einzugsgebiet der Gletscher durfte sich nicht verändert haben ${ }^{247}$ (ebd.:29 f.). Die Probeorte oder die Bodenprofile wurden nach morphologischen Kriterien ausgewählt (ebd.:35). Die Profilbeschreibungen richteten sich nach den Richtlinien der Arbeitsgruppe Bodenkunde (1994); es wurde auf Mächtigkeit, Farbe, Bodenart, Gefüge, Dichte, Skelettanteil und Durchwurzelung eingegangen (vgl. Bäumler, Kemp-Oberhettinger, Zech 1996:36). Auf Profilinhomogenitäten wurde auf Seite $30 \mathrm{f}$. eingegangen; es wurden als Indikatoren der Bodenhomogenität lithogene Merkmale analysiert sowie glaziale und äolische Akkumulationen durch einen Quotienten unterschieden.

\footnotetext{
245 "The soil development is strongly influenced by the absolute altitude and the bioclimatic zonation." (ebd.:225)

246 „,Vergleiche zwischen dem Langtang- und dem Khumbu-Gebiet erscheinen aufgrund der ähnlichen Klimabedingungen (vgl. Kap. 2.4.) möglich, während ein Vergleich mit dem Solu-Gebiet nur bedingt durchführbar ist." (Bäumler, Kemp-Oberhettinger, Zech 1996:29)

247 „Im Langtang-Tal sind die geologischen Verhältnisse im Arbeits- und Einzugsgebiet einheitlich. Aufgrund der abgeschlossenen Lage ist auch nicht von einem Wechsel des Einzugsgebietes im Pleistozän auszugehen." (ebd.:30).
} 
Die angewendeten Laboranalysen waren: Kohlenstoff-, Stickstoffgehalt, pH-Wert, Kationenaustauschkapazität, austauschbare Kationen, Fraktionierung der pedogenen Oxide, Verwitterungsindizes, Korngrößenzusammensetzung und Gesamtelementanalyse mittels Röntgenfluoreszenz (ebd.:Zus.). Alle Bodenanalysen erfolgten mit dem Feinerdeanteil. Die Vorgehensweise im Labor konnte auf den Seiten 40 bis 42 nachgelesen werden. Zudem wendeten sie glazialmorphologische Analysen und ${ }^{14} \mathrm{C}$-Datierungen an, wobei letztere bei dieser Arbeit nur im Langtang-Himalaja ermittelt wurden.

Insgesamt wurden bei Bäumler (1988) ${ }^{248}$ zitiert nach: Bäumler, Kemp-Oberhettinger, Zech (1996:27) 19 Bodenprofile untersucht. Bei dieser Arbeit von Bäumler, Kemp-Oberhettinger, Zech untersuchten sie im Solukhumbu insgesamt sechs Bodenprofile: im Khumbu drei Moränen - eine bei der Konfluenz vom Thame- zum Nangpo-Tal, zwei beim OmogaGletscher im Imja Drangka - und im Solu einen Hang bei Tongnosa und zwei Moränen bei Basa (ebd.:Zus.).

\section{UNTERSUCHUNGSGEBIET}

Bäumler, Kemp-Oberhettinger, Zech (1996:Zus.) erforschten u.a. das Gebiet des Solukhumbu in Ostnepal. Die Geländearbeiten dienten als Ergänzung zu ihren Arbeiten aus dem Jahre 1987 mit Heuberger bzw. Bäumler (vgl. Bäumler, Kemp-Oberhettinger, Zech 1996:2). Es wurde kein abgeschlossenes Gebiet untersucht, sie entnahmen nur Proben an den Stellen, die im Jahre 1987 Fragen aufwarfen: der Bereich zwischen Thomde und Thame, bei Omoga, bei Ringmo und bei Basa (ebd.:12). Die Geländearbeiten wurden vom 23. März bis zum 12. Juni 1991 durchgeführt (ebd.:1); die Route konnte Abbildung 2 entnommen werden: sie reichte von Jiri über Ringmo, Basa, Tongnosa, Luglha, Phakdingma, Monjo, Namche Bazar nach Duglha. Heuberger leitete diese Geländearbeiten, die dort genannte Arbeitsgruppe aus Bayreuth die bodenkundlichen Untersuchungen (ebd.:2).

Die von Bäumler, Kemp-Oberhettinger, Zech (1996) bei dieser Arbeit genauer betrachteten Gebiete beschränkten sich auf sechs kleine Ausschnitte im Solukhumbu. Hier untersuchten sie Bodenprofile, die als Ergänzung zu den Geländearbeiten 1987 mit Heuberger dienten, deren Ergebnisse 1988 veröffentlicht wurden. Somit wurde nur der Bereich zwischen Thomde und Thame, bei Omoga, bei Ringmo und bei Basa untersucht.

\footnotetext{
248 siehe Quelle Bäumler (1988) in der Fußnote
} 


\section{KRITIK}

Bäumler, Kemp-Oberhettinger, Zech (1996) nahmen sich mit ihrer Arbeit unter dem Thema `Bodengenetische Untersuchungen zur Moränenstratigraphie im Langtang-Tal (Zentralnepal) und im Solu/Khumbu (Ostnepal)' bzw. Bäumler (1988) ${ }^{249}$ zitiert nach: Bäumler, KempOberhettinger, Zech (1996:27) nahm sich zum Ziel, die Bodenbildung auf glazialen und glazifluvialen Akkumulationen für eine relative Altersdatierung $\mathrm{zu}$ verwenden. $\mathrm{Da}$ Uneinigkeit über die Vergletscherungsgeschichte im Khumbu herrschte, gingen sie kurz auf die früheren Arbeiten von Fushimi (1977, 1978), Heuberger (1956), Heuberger, Weingartner (1985), Heuberger (1986) und Röthlisberger (1986) $)^{250}$ ein (vgl. Bäumler, KempOberhettinger, Zech 1996:24-27).

Die Forschungen von Bäumler, Kemp-Oberhettinger, Zech (1996) waren für eine hochglaziale Rekonstruktion eher weniger geeignet, umfangreiche Aussagen über die Maximalvergletscherung dieses Gebietes wurden nicht getroffen. Es wurde nur angegeben, dass nach Bäumler (1988) $)^{251}$ ältere Bodenprofile, die sich bei Lukla, Monjo und Ringmo befanden, nicht mehr vom Eis erreicht wurden, wobei die Eisrandhöhen einer älteren mittelpleistozänen Vergletscherung bei Monjo und Ringmo angegeben wurden. Lukla soll von der jüngsten Hauptvergletscherung nicht mehr erreicht worden sein. Der Standort des Bodenprofils Solu 1 soll gegebenenfalls eine hochglaziale Eisrandlage darstellen (vgl. Bäumler, Kemp-Oberhettinger, Zech 1996:85). Demnach waren nicht unbedingt neue Erkenntnisse über das Ausmaß der eiszeitlichen Maximalvergletscherung gewonnen worden, sie waren ergänzend.

Ob Aussagen über die Vergletscherung anhand von Bodenbefunden getroffen werden können, ist ungewiss. Beispielsweise war das Bodenprofil Khumbu 2 der insgesamt sechs untersuchten Bodenprofile intensiver verwittert als Khumbu 1 und demnach älter (ebd.:83). Jedoch war es auch intensiver verwittert als Khumbu 3, welches aber die äußere Moräne darstellt (ebd.:83). Hieraus ergab sich ein Widerspruch zwischen den Bodenbefunden und der Lagebeziehung $^{252}$. Sie erklärten dies mit einer unterschiedlichen Vorverwitterung der Deckschichten und damit, dass die Deckschichten auf der äußeren Moräne geringmächtiger waren (ebd.:83). Auch bei den Profilen Solu 2 und 3 spielte die Deckschicht eine Rolle: die

\footnotetext{
${ }^{249}$ siehe Quelle Bäumler (1988) in der Fußnote

${ }^{250}$ siehe Quelle Röthlisberger (1986) in der Fußnote

${ }^{251}$ siehe Quelle Bäumler (1988) in der Fußnote

252 „Es ergibt sich daraus ein Widerspruch der glazialgeomorphologischen Geländebefunde mit den analytischen Ergebnissen zur Einschätzung des Verwitterungsgrades der Böden. Ursache sind möglicherweise Unterschiede im Grad der Vorverwitterung der äolischen Deckschichten, aus denen sich beide Profile entwickelt haben. " (Bäumler, Kemp-Oberhettinger, Zech 1996:83)
} 
Profile Solu 2 und 3 im Basa Drangka Tal sollen jungen Alters sein, jedoch nicht neuzeitlichen oder mittelholozänen, wobei eine stark verwitterte Deckschicht die zeitliche Einordnung erschwerte, da nicht geklärt war, ob diese eventuell schon vorverwittert war (ebd.:85). Solu 3 soll stärker verwittert sein als Solu 2, was mit der Lage nicht in Einklang gebracht werden konnte (ebd.:85). Sie äußerten sich dazu wie folgt: „, Eine exakte Klärung ist letztlich nur durch eingehendere Untersuchungen der glazialgeomorphologischen Situation im Basa-Drangka-Tal möglich.” (Bäumler, Kemp-Oberhettinger, Zech 1996:85); „Die Profile der Moränen bei Basa sind aufgrund ihrer stark verwitterten Deckschicht, zu der die geringmächtige Profilentwicklung im Widerspruch steht, nur schwer einzuordnen." (ebd.:Zus.). Allgemein fiel auf, dass Bäumler, Kemp-Oberhettinger, Zech (1996) oft die Termini 'möglicherweise' und 'vermutlich' verwendeten und sich somit nicht genau festlegten.

Die Bodenbildung wird von einer Vielzahl an Faktoren beeinflusst, wie z.B. vom Klima ${ }^{253}$. Das Klima ist im Solukhumbu deutlich von dem im Khumbu unterscheidbar, die geologischen Verhältnisse hingegen eher nicht: es traten hauptsächlich Gneise auf (ebd.:15). Hierbei sollte sich die Frage gestellt werden, ob sich die Bodenprofile im Khumbu gegenüber dem Solu nicht ohnehin, auch ohne vorzeitliche Vergletscherung, unterscheiden würden und wie dann die Einflüsse dieser im Abschnitt vorgenannten Parameter einzuschätzen wären. Außerdem wurde nur der Boden auf deutlich erkennbaren Moränenwällen ${ }^{254}$ untersucht, wobei es interessant wäre, wie der Boden auf anderen Moränentypen wie etwa Grundmoränen entwickelt war. Da deutlich ausgebildete Moränenbögen auf ein eher jüngeres Alter schließen ließen, stellte sich die Frage, ob die dort untersuchten Bodenentwicklungen eine maximale hochglaziale Gletscherausdehnung anzeigen konnten. Eine detaillierte geomorphologische Analyse wurde nicht angewendet - es wurden nur Moränen beschrieben, andere Formen nicht. Alleinige geomorphologische Analysen waren im Himalaja jedoch aufgrund der enormen Höhenunterschiede bzw. der Erosionsleistung für die Rekonstruktion der Vergletscherungsgeschichte schwierig zu erheben, da die Zeugen oft zerstört wurden (ebd.:1). Hierbei wäre es von Vorteil gewesen, wenn die vielen dort vorhandenen verschiedenen geomorphologischen Formen in Bezug zueinander gebracht worden wären, da diese eben nicht alle zerstört wurden.

\footnotetext{
253 „Die unterschiedlichen klimatischen Bedingungen zeigen sich auch in der Vegetation und der Bodenbildung. “ (ebd.:14)

254 „Es wurden größtenteils klar erkennbare Moränenwälle im Scheitelbereich beprobt. “ (ebd.:38)
} 


\section{BÄUMLER, ZECH (1998)}

\section{METHODE BZW. ARBEITSTECHNIK}

Bäumler, Zech (1998:439) untersuchten 40 Bodentypen - Entisole, Inceptisole, Ultisole und Spodosole - auf glazialen und glazifluvialen Ablagerungen anhand der Eisenfraktionierung und der Verwitterungsindizes. Die angewendeten Labormethoden waren auf Seite 440 bis 441 beschrieben. Die relativen Alter wurden durch ${ }^{14} \mathrm{C}$-Datierungen untermauert (ebd.:439).

\section{UNTERSUCHUNGSGEBIET}

Bäumler, Zech (1998:439) untersuchten das Gebiet des Langtang-Himal in Zentralnepal und des Khumbu-Himal in Ostnepal auf einer Höhe zwischen 2.700 bis 5.000 m. Im Langtang wurden Bodenprofile bei Kyangjin und im Khumbu im oberen Talbereich des Dudh Khosi, Beni Khola sowie im Imja Drangka, Nangpo Tsangpo, Dudhkhunda Khola und Basa Drangka untersucht (ebd.:440).

\section{KRITIK}

Die Arbeit von Bäumler, Zech (1998) mit dem Titel 'Soils on Glacial and Glaciofluvial Deposits in Central and Eastern Nepal in Relation to Classification and Landscape History' soll laut ihnen Teil der Arbeiten von Heuberger (1986), Bäumler et al. (1991) und Bäumler, Zech (1994) $)^{255}$ im Khumbu und der Arbeit von Bäumler et al. (1996) ${ }^{256}$ gewesen sein. Sie stellte gewissermaßen eine Zusammenfassung der Arbeit bzw. Ergänzung von Bäumler, Kemp-Oberhettinger, Zech (1996) mit dem Thema `Bodengenetische Untersuchungen zur Moränenstratigraphie im Langtang-Tal (Zentralnepal) und im Solu / Khumbu (Ostnepal)’ dar. Demnach müssten auch die angewendete Methode, das Untersuchungsgebiet und die Ergebnisse gleich sein. Außerdem ergaben sich gleiche Kritikpunkte, wie z.B. zur angewendeten Methode bzw. Arbeitstechnik. Die Bodenentwicklung hängt von sehr vielen Faktoren ab, sodass Aussagen über die einstmalige Vergletscherung schwierig sind. Bäumler, Zech (1998:439) beschrieben, dass diese z.B. von der Höhe ${ }^{257}$ bzw. der Lage und somit auch

\footnotetext{
255 Bäumler, R.; Zech, W. (1994): Soils of the High Mountain Region of Eastern Nepal: Classification, Distribution and Soil Forming Processes. In: Catena 22. (S. 85-103)

${ }^{256}$ Bäumler, R.; Kemp-Oberhettinger, M.; Zech, W.; Heuberger, H.; Siebert, A.; Madhikarni, D.P.; Poudel, K.P. (1996): Soil Weathering on Glacial and Glaciofluvial Deposits in the Langtang Valley (Central Nepal) and Its relation to Glacial history. In: Z. Geomorph. N.F. 103. (S. 373-387)

257 "The analytical results show a clear differentiation of the investigated soils due to elevation." (Bäumler, Zech 1998:442); "The results indicate a significant influence of the elevation on soil development in the high mountain areas of Khumbu and Langtang Himal." (ebd.:444)
} 
vom Klima ${ }^{258}$ abhängt. Die Böden unterschiedlicher Höhe unterschieden sich anhand des Bodentyps und somit auch der Farbe sowie anhand der Vegetationsbedeckung (ebd.:442). Letztendlich wurden die untersuchten Böden in zwei Gruppen - jüngere und ältere unabhängig von der Höhe anhand der unterschiedlich entwickelten Verwitterungszonen der Horizonte und der Verwitterungsindizes eingeteilt (ebd.:444-446). Es wurden wenige Aussagen über die Maximalvergletscherung in den untersuchten Gebieten getroffen, nur auf Seite 447 wurde angenommen, dass das Bodenprofil Nummer 6 Moränen aufzeigte, die während des LGM abgelagert wurden, und die 190 bis 200 m höher liegenden Bodenprofile 7 und 8 nicht mehr vom Eis erreicht wurden. Jedoch blieb die maximale Vergletscherung in den anderen untersuchten Tälern durch ihre Arbeit ungeklärt.

\section{KUHLE (1998)}

\section{METHODE BZW. ARBEITSTECHNIK}

Kuhle wendete geomorphologische Analysen mit Schneegrenzbestimmungen an.

\section{UNTERSUCHUNGSGEBIET}

Kuhle (1998) führte Ergebnisse zu vielen Untersuchungsgebieten wie beispielsweise Tibet, Karakorum, Aghil Gebirge, Kuenlun, Tarim Becken, Pamir, Ladakh Range, Nanga Parbat, Tien Shan, Sayan Gebirge, Trans Baikal Gebirge, Zanskar-Himal, Garhwal-Himal, Khumbu/ Rongbuk-Himal, Kangchendzönga-Himal, Dhaulagiri- und Annapurna-Himal auf.

\section{KRITIK}

Kuhle ging in seiner Forschungsarbeit mit dem Titel 'Reconstruction of the 2.4 Million $\mathrm{km}^{2}$ Late Pleistocene Ice Sheet on the Tibetan Plateau and its Impact on the Global Climate' neben anderen Gebieten auf den Khumbu-Himalaja ein. Die Fakten über die vorzeitliche Vergletscherung des Solukhumbu waren ähnlich denen zur Veröffentlichung Kuhle (1988a): Kuhle (1998:85 f.) gab an, dass die Geländearbeiten im Mt. Everest Gebiet im Jahre 1982 hervorbrachten, dass ein vorzeitlicher hoch- bis spätglazialer Dudh Khosi Auslassgletscher bis zur Lumding Drangka Konfluenz auf 1.800 m Höhe hinab reichte. Belege hierfür sah er darin, dass nördlich des Himalaja keine älteren Moränen vorkamen, dass der Talbereich zwischen Nangbug und Surke durch Eis geglättet wurde und das bei Namche Bazar, Nyambua Thyang, Chhutawa und Julming eine Lateralmoräne mit glazilimnischen Sanden

\footnotetext{
258 "The analytical results indicate an influence of the elevation on soil types and soil-forming processes due to climatic conditions and bioclimatic zones." (ebd.:439)
} 
existierte. Hierbei betonte Kuhle, dass hochglaziale Endmoränen nur am Zungenende der Auslassgletscher, nicht aber im Nährgebiet bzw. in Tibet aufzufinden waren. (vgl. Kuhle 1998:85 f.)

Aktuellere Forschungen von Kuhle - wie etwa die von 2005 - zeigten jedoch, dass der Dudh Khosi Talgletscher bis zur Konfluenz zum Hinku Khola auf ca. 900 m Höhe hinab reichte. Somit waren die Befunde lediglich in Bezug auf die Angabe zur Maximalausdehnung von ihm selbst geändert worden, wobei aber die hier in dieser Arbeit aufgeführten glazialen Indikatoren wie z.B. die Lateralmoräne immer noch existent sind und bleiben.

\section{AOKI, IMAMURA (1999)}

\section{METHODE BZW. ARBEITSTECHNIK}

Aoki, Imamura (1999) wendeten TCN-Datierungen an. Sie entnahmen zwei Proben - PH1 und PH2 - bei Pheriche von zwei unterschiedlichen Moränentypen - 'main moraine' und 'recessional moraine'. CRN's werden durch das Auftreffen der kosmischen Strahlung auf Mineralien bei unbedeckten freiliegenden Gesteinen gebildet, wobei die Produktionsrate der CRN's im Verhältnis zur Intensität der primären kosmischen Strahlung steht. Diese Produktionsrate ist durch den Neutronenflux bestimmt, welcher sich anhand der geographischen Breite / Höhenlage ändert. Hierbei war es laut Aoki und Imamura wichtig, welche Breitenlagen berücksichtigt werden, die geomagnetischen nach Lal (1991) ${ }^{259}$ oder die geographischen nach Nishiizumi et al. $(1996)^{260}$. Die ${ }^{10}$ Be-Produktionsrate ist 1,7 mal höher bei der geographischen als bei der geomagnetischen Breitenlage. (ebd.:134 f.)

\section{UNTERSUCHUNGSGEBIET}

Aoki, Imamura (1999:134) untersuchten Moränen bei Pheriche 5 km talabwärts vom Khumbu Gletscher. Das Untersuchungsgebiet beschränkte sich somit auf den Khumbu-Himalaja bzw. auf das Gebiet rund um Pheriche (ebd.:Fig. 1).

\section{KRITIK}

Die Forschungen von Aoki, Imamura (1999) mit dem Titel 'Reconstructing the Glacial Chronology based on the ${ }^{10} \mathrm{Be}$ Exposure Age in the Khumbu Glacier, Eastern Nepal Himalayas - a Problem on the Production Rate of in-situ Cosmogenic Radionuclides -' basierten darauf, absolute TCN-Alter der Moränen des Khumbu Gletscher zu beurteilen. Sie

\footnotetext{
${ }^{259}$ Lal, D. (1991): Cosmic ray labeling of erosion surfaces: in situ nuclide production rates and erosion models. In: Earth and Planetary Science Letters 104. (S. 429-439)

${ }^{260}$ Nishiizumi, K. et al. (1996): J. Geophys. Res., 101.
} 
erläuterten, dass chronologische Studien über die Gletschergeschichte im Nepal-Himalaja für die Rekonstruktion des Paläoklimas unzureichend waren, da es nur wenige absolute Daten über die letzte Vergletscherung gab (ebd.:134). In der Forschungsarbeit von Aoki, Imamura (1999) waren zwei ${ }^{10}$ Be Datierungen von zwei unterschiedlichen Moränentypen $5 \mathrm{~km}$ talabwärts von Pheriche bestimmt worden, wobei beide Breitenlagen - geographisch und geomagnetisch - berücksichtigt wurden. Die Daten der Moränen ergaben Werte von 25.000 bis 20.000 bzw. von 15.000 bis 12.000 Jahren. Somit waren die Moränen auf ca. 4.250 Höhenmeter in den Zeitraum der letzten Eiszeit zu stellen. Das Untersuchungsgebiet war jedoch für eine Klärung der letzteiszeitlichen Maximalvergletscherung sehr klein. Außerdem war nicht ersichtlich, ob talabwärts gleichaltrige Moränen aufzufinden waren, da keine geomorphologische Analyse erbracht wurde bzw. außer den zwei Moränentypen keine weiteren Formen berücksichtigt wurden. Da darauf hingewiesen wurde, dass die Produktionsrate und somit die kosmische Strahlung regionale Unterschiede aufzeigt und die OSL-Datierungen ebenfalls von den Veränderungen der Intensität der kosmischen Strahlung abhängig sind, sollten generell TCN- und OSL-Daten genau betrachtet werden. Hierbei kommt es auch darauf an, welche Breitenlagen - geographisch oder geomagnetisch berücksichtigt werden. Die TCN-Daten stimmten unter Berücksichtigung der geomagnetischen Breitenlage für die ${ }^{10} \mathrm{Be}$-Produktionsrate mit den OSL-Daten von Richards überein und diese Breitenlage war für den Nepal-Himalaja besser geeignet. Jedoch ist grundsätzlich nicht geklärt, ob beide Verfahren folgerichtige Daten anzeigen. Eine Überprüfung von zwei absoluten Datierungen, die eine etwaige Übereinstimmung aufweisen, muss hierbei aber nicht unbedingt auf die Richtigkeit der Daten hinweisen. Aoki, Imamura (1999) gaben an, dass weitere Forschungen erforderlich sind und bestimmte Voraussetzungen für zukünftige Probenahmestellen beachtet werden sollten: freiliegende und unerodierte Oberflächen, absolute Datierungen $\left({ }^{14} \mathrm{C}\right.$-Datierungen sind geeigneter als OSL und TL) und quarzreiches Gestein (Quarz ist das beste Mineral für diese Analysen). Es fiel besonders auf, dass sie mehr Wert auf ${ }^{14} \mathrm{C}$-Datierungen gegenüber TCN- und OSL-Datierungen legten ${ }^{261}$.

\section{RICHARDS ET AL. (2000)}

\section{METHODE BZW. ARBEITSTECHNIK}

Richards et al. (2000) datierten Moränen südlich des Mt. Everest anhand von OSLDatierungen. Diese Daten und morphostratigraphische Eigenschaften führten dazu, dass sie drei Gletschervorstöße festlegten. (ebd.:1621)

261 “2) Absolute dating of the surface: ${ }^{14}$ C datings are better than OSL and TL.” (Aoki, Imamura 1999:135) 


\section{UNTERSUCHUNGSGEBIET}

Richard et al. (2000) untersuchten das Gebiet des Khumbu südlich des Mt. Everest und datierten in vier Testgebieten: Lhotse Nup Gletscherende (SK 04-06), Lhotse Moräne (SK 08), Dingboche / Periche / Khumbu Gletscherende (SK 09, 10, 13, 14) und Thyangboche Rücken (SK 16-18) (ebd.:1621, 1625 f.; Fig. 1, 2). Diese Gebiete lagen innerhalb zweier Forschungsgebiete A und B, die kartiert wurden. In beiden Gebieten waren neben Höhenlinien die OSL-Probenahmestellen, Moränen, Terrassen, Gletschereis und Blockgletscher visualisiert. Das Gebiet A bei Chhukung, Periche und Thokla war etwa 11 mal $7 \mathrm{~km}$ und das Gebiet B bei Thyangboche und Pangboche ca. 9 mal 6 km groß.

\section{KRITIK}

Die Arbeit von Richards et al. (2000) aus dem Khumbu-Himalaja, innerhalb derer glazifluviale und glazilimnische Sedimente untersucht wurden, soll laut Owen et al. (2008:518 f.) die umfassendste OSL-Anwendung darstellen und der erste Versuch gewesen sein, die Hypothesen über die Paläoklimatologie in Asien zu überprüfen. Jedoch sollen die Forschungen für eine völlige Klärung nicht ausreichend gewesen $\operatorname{sein}^{262}$. Richards et al. (2000:1621) wollten mit ihren Forschungen unter dem Thema 'Timing of late Quaternary glaciations south of Mount Everest in the Khumbu Himal, Nepal' OSL-Daten erheben, um die zeitliche Einteilung der Vergletscherung im Khumbu festzulegen sowie die klimatischen Mechanismen zu verstehen. Die Veröffentlichung umfasste elf Seiten. Die OSL-Datierungen können dazu verwendet werden, um das Ausmaß der vergangenen Zeit zu bestimmen, ab der eine Probe nicht mehr dem Tageslicht ausgesetzt war. Nach Godfrey-Smith et al. $(1988)^{263}$ zitiert nach: Richards et al. (2000:1622) erfolgt eine Bleichung durch Licht extrem schnell, wobei sich eine 10 sekündige Belichtung in einem 99-prozentigem Absinken der Lumineszenz äußert. Insgesamt wurden 14 Proben entnommen (ebd.:Tab. 3). Die angewendeten Laborschritte konnten den Seiten 1623 und 1625 entnommen werden.

'Partial bleaching', wodurch eine Altersüberschätzung bzw. ein maximales Alter eintreten kann, war laut Owen et al. (2008:518) vermutlich das größte Problem bei der OSL-Datierung. Diese Fehlerquellen könnten durch Überprüfungen von Forschungsberichten, Methoden und Berechnungen der OSL-Datierungen bewertet werden, was aber oft nicht möglich ist, da viele

\footnotetext{
262 "However, their study was not geographically extensive enough to adequately test these hypotheses fully." (Owen et al. 2008:519)

263 Godfrey-Smith, D.I.; Huntley, D. J.; Chen, W.H. (1988): Optical dating studies of quartz and feldspar sediment extracts. In: Quaternary Science Reviews, v. 7. (S. 373-380)
} 
Forscher keine detaillierten Beschreibungen und Berechnungen aufzeigen (ebd.:518). Owen et al. (2008:518) gaben an, dass es sehr schwierig sei, die veröffentlichten OSL-Daten einzuschätzen ${ }^{264}$. Weitere Fehlerquellen sind Dosisratenveränderungen - teilweise im Hinblick auf die Feuchtigkeitsänderung - und die Sedimente im Himalaja ${ }^{265}$.

Richards et al. (2000) verwiesen aber darauf, dass die Überschätzung der Daten durch partielle Belichtung gering wäre und die Proben vollständig ausgeblichen wären ${ }^{266}$. Zur Überprüfung des Verfahrens wurde eine zweite Probe von SK 09 (ABU-147) an einer weiteren Universität ausgewertet (ebd.:1625).

Die 14 Datierungen inklusive der Überprüfungsproben bezogen sich auf die Talbereiche bzw. nur auf Randmoränen. Folgendes Zitat belegte letztgenanntes: "All the samples described in the present paper were taken from stratified sediments in lateral-frontal moraine ridges, similar to those found around modern Himalaya valley glaciers." (Richards et al. 2000:1629). Grundmoränen mit oder ohne erratische Blöcke, die Kuhle (2005:Fig. 3) bis weit hoch auf den Talflanken kartierte, wurden von Richards et al. nicht beprobt und generell nicht betrachtet. Weitere von Kuhle (2005) ausgemachte geomorphologische Eiszeitindikatoren in diesem Gebiet wie etwa glaziäre Dreieckshänge, Kare, Trogtäler, schluchtförmige Tröge, glaziäre Flankenschliffe, Rundhöcker, Strudeltöpfe sowie Erratika erschienen nicht in den Karten von Richards et al. (2000:Fig. 2). Somit nahmen Richards et al. (2000) nur Moränen, Terrassen, Gletscher und Blockgletscher auf. Demnach wendeten sie keine geomorphologische Detailanalyse an. Hierbei blieb bei den Forschungen von Richards et al. (2000) offen, ob sich nicht weitere Periche Moränen talabwärts unterhalb der entnommenen Proben SK 16-18 auffinden ließen (ebd.:1624, Fig. 2). Außerdem könnten diese Periche

\footnotetext{
264 “This makes it extremely difficult to assess the validity of many published OSL ages." (ebd.:518)

265 "These include partial bleaching, dose rate changes over time (particularly with regard to changing moisture content), and in the case of Himalayan sediments, poor sensitivity and the low brightness of quartz. An incorrect estimate for moisture content, for example, can result in a $1 \%$ difference in age for every $1 \%$ difference in moisture content." (ebd.:518)

266 "Tests were undertaken to investigate the magnitude of the thermal transfer component in every quartz sample measured for this paper, and it was found to be insignificant. This leads us to expect any age overestimates due to partial bleaching to be not more than around a couple of thousand years. Furthermore, the two very young ages estimates, $1.1 \mathrm{ka}$ and $2.5 \mathrm{ka}$, indicate that these samples, at least, were well bleached at deposition and provide us with further confidence that the samples that were dated were adequately bleached. [...]. On Himalayan valley glaciers, the sediment that feeds ice-marginal moraines is largely of supraglacial origin and follows predominantly supraglacial transport paths. Furthermore, most of the sediments that were dated in this study were collected from shallow (<50-cm-deep), braided-channel fills that were deposited as stream discharges dropped from high to low flows late in the stream's history. Sediment making up such settings will have had a high chance of prolonged exposure to sunlight during entrainment, transport, and deposition and thus would have been bleached prior to deposition. The samples dated in the present study are therefore unlikely to have been only partially bleached." (Richards et al. 2000:1629)
} 
Randmoränen auch nur Rückzugsstadien bzw. spätglaziale Stadien darstellen und die eigentliche letzteiszeitliche Vergletscherung viel ausgedehnter im gesamten Tal vom Khumbu Gletscher bis unterhalb der datierten Periche Randmoränen unterhalb von Thyangboche gewesen sein. Hierfür konnten die ${ }^{14} \mathrm{C}$-Daten von Kuhle herangezogen werden, die auf jeden Fall gegen die OSL-Daten, aber auch gegen die TCN-Daten aus diesem Gebiet sprachen. Das würde bedeuten, dass anhand Richards et al. (2000) Forschungsarbeiten keine eindeutige Aussage über die maximale Gletscherausdehnung getroffen werden konnte; dazu hätte so wie bei Kuhle (2005) das gesamte Tal und die Talflanken überprüft werden müssen. Gegensätzlich zu diesen Altersbestimmungen ordnete Kuhle (2005:Fig. 3, Tab. 1) die Periche Moränen in das Stadium V bzw. Nauri Stadium (5.500-4.000 Jahre vor 1950) ein. Die letzteiszeitliche Maximalvergletscherung reichte bis auf ca. $880 \mathrm{~m}$ Höhe östlich der Bakhor Siedlung $\left(27^{\circ} 28^{\prime} 30^{\prime \prime} \mathrm{N} 8^{\circ} 43^{\prime} 20^{\prime \prime E}\right)$ in der Nähe des Inkhu Khola Konfluenzbereiches (ebd.:314, 315).

Die Altersangaben des Chhukhung Stadiums waren ungenau angegeben und die des Lobuche Stadiums wurden angenommen. Das Alter des Chhukung Stadiums vor ca. 10.000 Jahren v.H. fiel ins Spätglazial oder Frühholozän ${ }^{267}$ und das Alter des Lobuche Stadiums vor ca. 1.000 bis 2.000 Jahren v.H. aus dem Spätholozän wurde angenommen ${ }^{268}$.

Richards et al. (2000:1628 f.) gaben folgende Beweise für die Richtigkeit der Daten an: die doppelte Probe zeigte ähnliche Alter an, ebenso nebeneinander liegende Probenahmestellen wie z.B. SK 04 und SK 05, stratigraphische Abfolgen stimmten mit Altern überein wie z.B. bei SK 16-18, grob- und feinkörnige Quarzfraktionen einer Probe zeigten ähnliche Alter, die doppelte Probe bzw. eine Probenanalyse in zwei unterschiedlichen Laboren unter Betrachtung von Quarz und Feldspat zeigte ein ähnliches Ergebnis, die Verteilung der Daten stimmte mit den morphostratigraphischen und relativen Altersbestimmungen anhand von Verwitterungsgraden überein. Außerdem schrieben sie hierzu: "We believe that the degree of internal consistency lends strong support to the interpretation of a high degree of validity to these dates." (Richards et al. 2000:1629). Auch Tsukamoto et al. (2002) äußerten sich, dass die Daten verschiedener Quarzkornfraktionen und nebeneinanderliegende Probenahmestellen

\footnotetext{
267 “[...]; the Chhukhung Stage represents a late glacial or early Holocene glacial advance." (ebd.:1621); "The second glacial event that is dated at ca. 10 ka represents a late glacial or early Holocene advance." (ebd.:1629); "We propose the name Chhukung Stage for the event dated by samples SK04, SK05, and SK13 and assign it to a late glacial or early Holocene age." (ebd.:1629)

268 "Our results suggest a late Holocene advance that predates the Little Ice Age in the Khumbu." (ebd.:1629)
} 
von Richards et al. (2000) übereinstimmten ${ }^{269}$. Jedoch müssen die als Beweise genannten Aspekte nicht unbedingt Beweise für die Richtigkeit der Daten darstellen - diese Herleitung ließ sich nicht ableiten. Es könnten trotzdem alle Daten nicht geeignet sein.

Es fiel auf, dass die vier Testgebiete von Richards et al. (2000) sehr klein waren: Gebiet A war etwa 11 mal $7 \mathrm{~km}$ und das Gebiet B war ca. 9 mal 6 km groß. Es wurden im Khumbu Nangpo Tsangpo, Imja Khola, Dudh Khosi - die heutige Vergletscherung bzw. Eiskörper, schuttbedeckte Eiskörper sowie Blockgletscher in Fig. 1 visualisiert. In Fig. 2A und B waren neben Höhenlinien die geomorphologischen Formen wie Moränen, Terrassen, Gletscher, Blockgletscher sowie die Probenahmestellen dargestellt. Der genauere Standort der Probenahmestellen konnte den Profilskizzen sowie den Fotos in Fig. 3 und 4 für SK 04-06, in Fig. 5 für SK 08-10, SK 13-14 und SK 16-18 entnommen werden. Somit verwiesen zwei Karten (Fig. 2), sieben stratigraphische Zeichnungen (Fig. 3, 5) und ein Foto (Fig. 4) zwar etwas genauer auf die Entnahmeorte der Proben, ließen aber nur einen ungefähren Anhaltspunkt der exakten Entnahmestellen zu. Die Fotos in Fig. 6 zeigten keine Probenahmestellen. Letztere waren ohne Koordinatenangaben versehen, was eine exakte Überprüfung der Daten unter Anwendung der selbigen Methode schwierig machen würde.

Richards et al. (2000:1621) gingen in Fig. 1 auf die rezente Vergletscherung des Untersuchungsgebietes ein. In Bezug auf die letzteiszeitliche Vergletscherung verwiesen sie auf die Arbeiten bzw. auf die relativen Gletscherchronologien von Iwata (1976), Fushimi (1977, 1978), Müller (1980) und Williams (1983). In Tabelle 1 stellten sie neben ihre eigenen Befunde diese von Iwata (1976), Fushimi (1977), Williams (1983) und Burbank, Kang $(1991)^{270}$ aus dem Khumbu-Himal und Rongbuk Tal, die auf morphostratigraphischen Kriterien und relativen Verwitterungskriterien basierten. Die Befunde von Iwata (1976), Fushimi (1977) und Williams (1983) sind durch die vorliegende Arbeit relativiert worden, wobei die Forschungen von Burbank, Kang (1991) ${ }^{271}$ durch Kuhle (2007b:105 f.) auch anhand der Ergebnisse von Heydemann, Kuhle (1988:615) wie folgt kritisiert wurden: sie nahmen bei ihren Verwitterungdaten keinen Bezug zum hydrothermalen Zersatz, sie ignorierten talabwärts gesehen tiefer liegende Endmoränen und sie interpretierten die relative Chronologie wie eine absolute Datierung, was einen Methodenfehler darstellte. Ebenfalls

\footnotetext{
269 "The ages from different quartz size fractions and different samples collected adjacent to one another agreed well." (Tsukamoto et al. 2002:59)

${ }^{270}$ Burbank, D.W.; Kang Jian Cheng (1991): Relative dating of Quaternary moraines, Rongbuk Valley, Mount Everest, Tibet: Implications for an ice sheet on the Tibetan Plateau. In: Quaternary Research. V. 36. (S. 1-18)

${ }^{271}$ siehe Quelle Burbank, Kang (1991) in der Fußnote
} 
verwies Kuhle (2012a:193) darauf - bezugnehmend zur Forschungsarbeit Heydemann, Kuhle (1988), dass eine hohe Verwitterung infolge des hydrothermalen Zersatzes nicht unbedingt auf ein hohes Alter schließen lassen muss. Fraglich war, warum Richards et al. (2000) nicht andere Forscher, die im Solukhumbu relative Datierungen anwendeten, wie etwa Miller (1970), Müller (1980), Heuberger, Weingartner (1985), Heuberger (1986), Kuhle (1986a, 1987a) sowie Bäumler et al. (1991), Bäumler, Kemp-Oberhettinger, Zech (1996), Bäumler, Zech (1998) und Bäumler (2001) aufführten. Sieben spätholozäne ${ }^{14} \mathrm{C}$-Daten, die nur ein Minimumalter der Moränen repräsentieren, wurden laut Richards et al. (2000) im KhumbuHimalaja bestimmt, die bei Williams (1983) zusammengefasst waren. ${ }^{14} \mathrm{C}$-Datierungen im Solukhumbu wendete vor dem Jahr 1983 Müller (1980) an und danach bis zum Jahre 2000 weiterhin Kuhle (1986a, 1987a), auf die hier von Richards et al. (2000) nicht eingegangen wurde bzw. welche nicht widerlegt wurden. Desweiteren wurden von Kuhle (2005) ${ }^{14} \mathrm{C}$-Daten angegeben. Für ältere Moränen wurden keine ${ }^{14} \mathrm{C}$-Proben entnommen, da kein organisches Material ausgemacht wurde ${ }^{272}$. Diese Moränen wurden nur anhand deren Verwitterungsgrade der Oberflächenblöcke zeitlich mit Hilfe der Isotopenstadien festgelegt (vgl. Richards et al. 2000:1621). Hierbei wurde angenommen, dass die Vergletscherungen regional und global synchron waren und die Verwitterungsgrade verschiedener Regionen verglichen werden konnten (ebd.:1621). Andere Forscher, die auf der Seite 1621 bei Richards et al. genannt waren, waren jedoch der Überzeugung, dass die Vergletscherungen auch asynchron auftreten konnten, wobei von einigen gezeigt wurde, dass die Verwitterungskriterien innerhalb der Himalaja Täler variieren konnten (ebd.:1621).

Die von Richards et al. (2000) datierten drei Gletschervorstöße wurden nach Owen et al. (2008:523) von Finkel et al. (2003) durch TCN-Datierungen bestätigt. Dass die TCN-Daten jedoch widersprüchlicherweise zu der vorherigen Aussage jünger waren als die OSL-Daten, beschrieben Owen et al. (2008:523) auf derselben Seite. Dieses erklärten sie wie folgt: "This would be expected since the sediment that was dated using OSL methods should pre-date the overlaying boulders that were dated using TCN methods." (Owen et al. 2008:523). Außerdem waren Unterschiede in deren zeitlichen Einteilung zu erkennen. Nach Richards et al. (2000) waren die Stadien folgende: Periche (vor ca. 18.000-25.000 Jahren v.H., MIS 2 = LGM), Chhukung (vor ca. 10.000 Jahren v.H., Spätglazial oder Frühholozän) und Lobuche (vor ca. 1.000 bis 2.000 Jahren v.H., Spätholozän). Nach Finkel et al. (2003:Tab. 1) wurden historische Gletschervorstöße vor ca. < 500 Jahren v.H., ein Gletschervorstoß vor ca. 1.000

272 "No organic matter has been recovered from the older moraines." (Richards et al. 2000:1621) 
Jahren v.H., einer vor ca. $3.600 \pm 300$ Jahren v.H., einer vor $9.200 \pm 200$ Jahren v.H., zwei während des MIS 2 (Periche II vor ca. $16.000 \pm 2.000$ Jahren v.H., Periche I vor ca. $23.000 \pm$ 3.000 Jahren v.H.) und zwei während des MIS 3 beschrieben.

In Bezug auf die letzteiszeitliche Maximalvergletscherung gingen Richards et al. (2000:16251626, 1628) auf die Befunde von Iwata (1976) und Fushimi (1977) ein, wobei die Befunde von Iwata (1976) über die Thyangboche Moräne in Bezug auf eine solche Vergletscherung genauer betrachtet werden sollten. Sie gingen davon aus, dass die Thyangboche Moräne keinen maximalen Vorstoß des Khumbu Imja Gletscher anzeigte, sondern vielmehr eine Lateralmoräne des Phunki Gletscher darstellte ${ }^{273}$. Dieses machten sie anhand der Form des Moränenrückens und anhand des Talprofiles, welches oberhalb von Thyangboche kerbförmig war, fest ${ }^{274}$. Ebenfalls kartierten sie große Lateralmoränen im Minmo, Cholungche und Khonar Khola (Fig. 2). Die Lateralmoränen im Minmo und Cholungche deuteten auf ein ähnliches Alter wie diese bei Thyangboche ${ }^{275}$.

Richards et al. gingen davon aus, dass Khumbu und Imja Gletscher während des LGM bis zu deren Konfluenz reichten ${ }^{276}$. Die Lateralmoränen bei Periche reichten bis auf etwa maximal 5.400 m Höhe (ebd.:1629). Die Schneegrenze war lediglich etwa 200 bis 300 m abgesenkt, wobei diese Absenkung mit anderen Gebieten der Nordhemisphäre übereinstimmte und tektonische Hebung und / oder klimatische Faktoren anzeigen konnte (ebd.:1629). Der abgeschwächte Monsun zur Zeit des MIS 2 könnte eine enorme Rolle gespielt haben; laut Sirocko et al. (1991) ${ }^{277}$ zitiert nach: Richards et al. (2000:1631) war der Sommermonsun durch eine vorzeitliche Verlagerung der Druckgürtel gen Süden vor 27.000 bis 15.000 Jahren schwächer gewesen bzw. hatte weniger Einfluss gen Norden und Westen gehabt und stammte

273 "The planar form of the ridge, however, is more consistent with an origin as a lateral moraine of the Phunki Glacier." (ebd.:1626)

274 "The planar form of the ridge, however, is more consistent with an origin as a lateral moraine of the Phunki Glacier. This interpretation is supported by the fact that the trunk valley (Imja Khola) has a V-shaped lateral profile up the valley of Thyangboche. This profile contrasts to the parabolic, glacially eroded, lateral profiles of the Phunki Drangka and the valleys above the Periche moraines." (ebd.:1626)

275 "Large, paired lateral-moraine ridges occur at the northern ends of the Minmo and Cholungche Valleys, which enter the Imja Khola above Thyangboche. These moraines occupy similar topographic positions to the Thyangboche ridge and are probably of similar age." (ebd.:1626, 1628)

276 "The available dates and the morphostratigraphic similarity of the moraines at Thyanboche, Minmo, Cholungche, and Khonar (Fig. 2B) indicate that, at the Last Glacial Maximum, the Khumbu and Imja Glaciers advanced to their confluence, whereas glaciers in the major side valleys lower down the Dudh Kosi catchment reached as far as the trunk valley." (ebd.:1629)

277 Sirocko, F.; Sarnthein, M.; Lange, H.; Erlenkeuser; H. (1991): The atmospheric summer circulation and coastal upwelling in the Arabian Sea during the Holocene and the last glaciation: Quaternary Research, v. 36. (S. 72-93) 
aus West bis Südwesten - heute aus Südwest. Daraus schlossen Richards et al., dass die Sommerniederschläge im zentralen und östlichen Himalaja während der Kaltzeiten hoch genug gewesen sein könnten, sodass Gletschervorstöße eintreten konnten ${ }^{278}$. Jedoch wies die geringe Schneegrenzabsenkung im Khumbu darauf hin, dass die Niederschläge zu dieser Zeit reduziert gewesen waren ${ }^{279}$. Auch Owen et al. (2008:523) waren der Auffassung, dass Gletscher während der Kaltzeiten beeinflusst werden konnten ${ }^{280}$.

Höchstliegende Periche Lateralmoränen fanden Richards et al. (2000:1629) auf ca. 5.400 m, wodurch eine Schneegrenzdepression von etwa 200-300 m berechnet wurde. Für die Berechnungsgrundlage gaben sie Lichtenecker (1938) $)^{281}$, Meierding (1982) ${ }^{282}$ sowie Benn, Lehmkuhl (2000) ${ }^{283}$ an. Somit nahmen Richards et al. (2000) bei der Schneegrenzberechnung an, dass die höchste Lage der Lateralmoränen die letzteiszeitliche Schneegrenzlage repräsentierte. Die höchstreichenden Moränen waren in Fig. 2A auf ca. 5.200 auszumachen, ob es sich hierbei um Periche Lateralmoränen handelte, war nicht eindeutig. In Fig. 6B waren die höchstliegenden Moränen abgebildet (ebd.:1626). Dabei handelte es sich aber um keine datierten Moränen. In Fig. 2A lagen die höchstliegenden datierten Periche Lateralmoränen in 4.200 bis $4.400 \mathrm{~m}$ Höhe.

\section{BÄUMLER (2001)}

\section{METHODE BZW. ARBEITSTECHNIK}

Bäumler (2001) wendete Bodenanalysen an, um anhand dieser Erkenntnisse zur pleistozänen und holozänen Landschafts- und Klimageschichte beizusteuern (ebd.:Vorwort). Dabei berücksichtigte er die Bodenbildungen auf glazialen und glazifluvialen Akkumulationen bzw. den Verwitterungszustand von Sedimenten (ebd.:1). Neben der Betrachtung des Profilaufbaus, der Entwicklungstiefe, der Farbe, der Struktur und Textur des Bodens wurden Korngrößenverteilung, Eisenfraktionierung, Tonmineralanalyse und pedogeochemische

\footnotetext{
278 "This implies that summer precipitation in the central and eastern Himalayas, such as the Khumbu Himal, may have remained sufficiently high to allow glacier growth during times of regional cooling." (Richards et al. 2000:1631)

279 "The relatively small amount of lowering of the equilibrium-line altitude on the Khumbu Glacier relative to the present $(200-300 \mathrm{~m})$ indicates that the Khumbu region also may have experienced a reduction in precipitation." (ebd.:1631)

280 "However, glaciers may also have been influenced by cooling cycles during the late Quaternary, for example during the global LGM." (Owen et al. 2008:523)

${ }^{281}$ siehe Quelle Lichtenecker (1938) in der Fußnote

${ }^{282}$ Meierding, T.C. (1982): Late Pleistocene glacial equilibrium-line in the Colorado Front Range: A comparison of methods: Quaternary Research, v. 18. (S. 289-310)

${ }^{283}$ Benn, D.I.; Lehmkuhl, F. (2000): Mass balance and equilibrium-line altitudes of glaciers in high mountain environments: Quaternary International, v. 65/66. (S. 15-29)
} 
Verwitterungsindizes angewendet, um physikalische und chemische Verwitterungsprozesse zu erfassen (ebd.:5, 17, 40). Die Verwitterungsindizes kombinierte er mit chemischen und physikalischen Kenngrößen - er analysierte pH-Wert, Kationenaustauschkapazität, austauschbare Kationen, Gehalt an organischer Substanz, Grad der Entkalkung, einzelne Kornfraktionen und Ausmaß der Tonverlagerung (ebd.:17). Bäumler (2001) schloss in seine Arbeit morphologische Aspekte und absolute Datierungen mit ein.

\section{UNTERSUCHUNGSGEBIET}

Bäumler (2001:6-16) untersuchte in Ostnepal das Solu / Khumbu Gebiet, in Zentralnepal das Langtang Tal, im Tien Shan das Pskem Gebirge, das Hissar Gebirge sowie das Kichik Alay Gebirge und Süd Kamtschatka. Die Skizze des Arbeitsgebietes Solukhumbu wurde hier aus Bäumler et al. (1991) verändert (siehe Bäumler 2001:Abb. 1). Dieses Gebiet reichte von Ringmo im Süden bis nach Duglha im Norden und umfasste die Täler Dudh Khosi, Imja Drangka, Nangpo Tsangpo Tal, oberes Beni Khola Tal (Dudhkunda Tal) und das Basa Drangka-Tal (ebd.:7).

\section{KRITIK}

Bäumler (2001:107) setzte sich mit seiner Arbeit des Titels `Vergleichende bodenkundliche Untersuchungen in Hochasien und Kamtschatka' das Ziel, neue Informationen über die pleistozäne und holozäne Landschafts- und Klimageschichte zu liefern. Er untersuchte neben den genannten Gebieten - Zentralnepal, Tien Shan und Süd Kamtschatka - in Ostnepal die Täler Dudh Khosi, Imja Drangka, Nangpo Tsangpo Tal, obere Beni Khola Tal (Dudhkunda Tal) und Basa Drangka Tal des Gebietes Solukhumbu. Angaben über das Relief, die Geologie und das Klima waren dort auf den Seiten 6 bis 9 beschrieben. Anhand von Bodenanalysen wie etwa Korngrößenverteilung, Eisenfraktionierung, Tonmineralanalyse und pedogeochemische Verwitterungsindizes, in Verbindung mit morphologischen Aspekten und absoluten Datierungen anderer Forscher, kam er im Gebiet des Solukhumbu zum Ergebnis, dass dieses hochglazial geringer vergletschert war, als jemals zuvor angenommen (ebd.:103). Die angewendete Methode bzw. Arbeitstechnik der Bodenanalysen für eine Klimarekonstruktion war laut Bäumler nur teilweise geeignet ${ }^{284}$. Die drei verschiedenen angewendeten Methoden führten nicht in allen Fällen ${ }^{285}$ zum selben Ergebnis (ebd.:29-41). Im Text wurden mögliche

\footnotetext{
284 „Sind Böden geeignete Zeugen der quartären Landschafts- und Klimageschichte? Diese Frage kann zumindest teilweise mit ja beantwortet werden." (ebd.:2)

285 „Die über die gesamte Entwicklungstiefe gewichteten Ergebnisse der Eisen- und Körnungsfraktionen deuten dies an, die Verwitterungsindizes sowie die Eisenfraktionen der Hauptverwitterungszone ergeben jedoch einen
} 
Gründe hierfür angegeben, wie beispielsweise Nichterfassung der maximalen Bodenentwicklung und heterogenes Ausgangsmaterial bzw. heterogener Boden aus glazigenen Ablagerungen. Unterschiedliche Parkerindexwerte von Ablagerungen gleichen Alters verwiesen auf die Heterogenität der Böden und des Ausgangsmaterials sowie auf Variabilitäten der Verwitterungsbedingungen vor Ort (ebd.:37). Ein weiteres Beispiel dafür, dass die Bodenanalysen nicht immer mit anderen Analysen übereinstimmten, wurde im folgenden Zitat erläutert: „Bodenentwicklung und morphologische oder chronologische Befunde können allerdings auch inkonsistent sein. Untersuchungen im Gletschervorfeld des Austerdalen-Gletschers in Norwegen ergaben, daß die Verfüllungen von Hohlformen zwischen den Moränen nicht mit dem Alter der dazugehörigen Endmoränen übereinstimmten (Petch \&Whittaker 1997).” (Bäumler 2001:2 f.). Es gäbe Faktoren, die die kontinuierliche Bodenentwicklung stören könnten, wie etwa Überdeckung durch Solifluktion oder Löss sowie tektonische Aktivität (Änderung der Bodenbildungsbedingungen durch Hebung oder Vulkanismus), wobei ein Bodenvergleich bei der enormen Heterogenität der Böden besonders auf glazialen und fluvialen Akkumulationen erschwert wurde (ebd.:3). Auch die Höhe, das Klima und die Geologie spielt bei der Bodenentwicklung eine Rolle. Im Solukhumbu traten unterhalb von $2.000 \mathrm{~m}$ Höhe rubifizierte, tonreiche und teilweise pseudovergleyte Böden, zwischen 2.000 und $3.000 \mathrm{~m}$ hauptsächlich Braunerden mit hochwärts anschließenden podsolierten Böden und oberhalb von $4.500 \mathrm{~m}$ flachgründige, skelettreiche Böden auf (ebd.:9). In niedrigeren Bereichen kamen nach Bäumler (1993) ${ }^{286}$ zitiert nach: Bäumler (2001:30) aufgrund höherer Temperaturen stärkere Verwitterungsbedingungen vor. Das Klima beeinflusst somit die Bodenbildung und auch die Vegetation (ebd.:9). Die klimatischen und geologischen Verhältnisse ${ }^{287}$ waren im Langtang und im Khumbu in etwa gleich, wobei sich aber das Klima des Solu deutlich von dem des Khumbu unterschied (ebd.:11). Dennoch schätzte Bäumler diese Methode bzw. Arbeitstechnik als geeignet ein $^{288}$ und wendete diese in den Gebieten an ${ }^{289}$.

stärkeren Entwicklungszustand für K2.” (ebd.:37); „,Während die Eisenfraktionierung keine Unterschiede zwischen den beiden Profilen ergibt, zeigen Körnungsanalyse und Verwitterungsindizes einen fortgeschritteneren Entwicklungsstand für S6 aus den jüngeren Ablagerungen." (ebd.:38)

${ }^{286}$ Bäumler, R. (1993): Bodenbildung und Verwitterungsintensität auf Moränen und Gletscherablagerungen im Khumbu Himal und oberen Solu-Tal, Ostnepal. Innsbrucker Geographische Studien, Bd. 20: Der Geograph im Hochgebirge (Heuberger-Festschrift). (S. 29-45)

287 „Bei einem Vergleich von bodenkundlichen Untersuchungsergebnissen zwischen verschiedenen Arbeitsgebieten sind die klimatischen und geologischen Verhältnisse von besonderer Bedeutung." (Bäumler 2001:10).

288 „Das Ausmaß der Bodengenese sollte aufgrund ihres konservativen Charakters dennoch geeignet sein, einen Vergleich von Ablagerungen unterschiedlichen Alters oder unter verschiedenen standörtlichen Bedingungen zuzulassen, um daraus Informationen über die Landschaftsgeschichte zu erhalten.” (ebd.:3); „In diesen Regionen, in denen aufgrund dieser schwierigen Standortbedingungen morphologische Kriterien oder absolute 
Bäumler (2001) bezog sich im Hinblick auf geomorphologische Prozesse im Gebiet auf die Befunde von Heuberger (1956), Heuberger (1986a) ${ }^{290}$ und Ives (1986) ${ }^{291}$. Die Auswahl der Bodenbeprobungen fand auf der Grundlage der genannten Forschungsarbeiten von Heuberger und weiterer Arbeiten, darunter auch Heuberger, Weingartner (1985), statt (vgl. Bäumler 2001:24). Es wurden die Ablagerungen untersucht, die die maximalsten Gletschervorstöße anzeigten und morphostratigraphisch eindeutig zuordbar waren ${ }^{292}$. Die Bereiche außerhalb dieser wurden als nicht vergletschert bezeichnet oder es wurde angenommen, dass dort uneindeutige ältere glaziale Ablagerungen überprägt auftraten ${ }^{293}$. Nun stellte sich, wenn sich Bäumler auf die Befunde der o.g. Forscher verließ und keine weiteren geomorphologischen Analysen talabwärts dieser Bereiche unternahm, die Frage, wie er sicher sein konnte, ob diese eindeutigen Moränen das Maximalstadium anzeigten oder andere uneindeutige, überprägte älterquartäre glaziale Akkumulationen waren. Auch König (2002:137) verwies darauf, dass Bäumler keinerlei zusätzliche geomorphologische Analysen anwendete und nur die Befunde von Heuberger, Weingartner (1985) zeitlich relativ einordnete. Es könnte sein, dass es sich bei den eindeutig ausgebildeten Moränen um spätglaziale handelte und weiter talwärts vorkommende uneindeutige Moränen hochglaziale waren. Nach Bäumler (2001) wurde nicht geklärt, ob sich außerhalb der Bereiche eindeutiger Moränen überhaupt weitere Moränen oder andere glaziale Formen befanden. Auch dass Bäumler nur eindeutig ausgebildete Moränen beachtete, ließ darauf schließen, dass nur Lateral- oder Endmoränen betrachtet wurden und Grundmoränen keine Beachtung fanden. Hierzu ist folgendes Zitat $\mathrm{zu}$ nennen: „Erste eindeutige Ablagerungen einer Haupttalvergletscherung sind im Imja Drangka-Tal weiter talaufwärts bei Pheriche (4200 m ü.M.) und Dingboche (4270 m ü.M.) erhalten." (Bäumler 2001:26).

Datierungen nur bedingt anwendbar sind, sind bodengenetische Untersuchungen möglicherweise eine der derzeit besten Alternativen.” (ebd. 4 f.); „Diese konventionellen Methoden lassen in Gebieten hoher Morphodynamik, tektonischer Aktivität und permanenter Überprägung der Landschaft durch äolische oder pyroklastische Sedimente einen Beitrag zur Klärung der pleistozänen und holozänen Landschafts- und Klimageschichte erwarten.” (ebd.:5); „Die Bodenbildungsfaktoren waren mit Ausnahme der klimatischen Bedingungen und/oder der Zeit weitgehend konstant. Unter diesen idealen Gegebenheiten konnte gezeigt werden, daß der Verwitterungszustand von Böden aus quartären Ablagerungen für Relativdatierungen im Hinblick auf die pleistozäne und holozäne Landschafts- und Klimageschichte geeignet ist." (ebd.:3)

289 „Für die vorliegenden Untersuchungen wurden daher Arbeitsgebiete mit diesen natürlichen Komplikationen ausgewählt, in denen die Landschafts- und Klimageschichte bisher unzureichend geklärt ist." (ebd.:3)

${ }^{290}$ Heuberger, H. (1986a): Der Bergsturz von Khumdschung, Mount-Everest-Gebiet, Nepal. Material und Technik 3. (S. 175-181)

${ }^{291}$ Ives, J.D. (1986): Jökulhlaup disasters in the Himalaya and their identification. A case study: the Langmoche jökulhlaup of $4^{\text {th }}$ August 1985, Khumbu Himal, Nepal. ICIMOD, Kathmandu.

${ }_{292}^{2}$ „Dazu wurden die Ablagerungen der am weitesten in die einzelnen Täler vorgedrungenen Gletschervorstöße beprobt, die noch eindeutig morphostratigraphisch identifizierbar waren." (Bäumler 2001:24)

293 „Außerhalb dieser Ablagerungen, also in einem Areal, das entweder nicht mehr vergletschert war, oder in dem älterquartäre glazigene Ablagerungen überprägt wurden und morphologisch nicht mehr eindeutig zugeordnet werden konnten, [...]." (ebd.:24) 
$\mathrm{Da}$ es sich bei den untersuchten Moränen nicht immer um Endmoränen handelte, schlussfolgerte Bäumler (2001), dass sowieso keine gesicherten Aussagen über die Maximalvergletscherung möglich waren ${ }^{294}$. Bäumler (2001) gab auf Seite 1 an, dass glaziale und glazifluviale Ablagerungen untersucht wurden. In Bezug auf das Gebiet des Solukhumbu wurden jedoch nur Moränen untersucht. Hierbei muss darauf hingewiesen werden, dass sich Bäumler (2001) bei der Toposequenz nicht schlüssig war, um was es sich für Formen handelte. Da es sich bei den untersuchten Standorten im Khumbu um Profile handelte, die alle oberhalb von Namche Bazar lagen, konnte dieses Zitat: „Die Landschaft nördlich von Namche Bazar ist dagegen glazial überformt mit weiten Trogtälern und mächtigen glazigenen Ablagerungen." (Bäumler 2001:7) dazu herangezogen werden. Südlich von Namche Bazar sollen die Täler kerbförmig sein, was darauf hindeutete, dass Bäumler die Talform schluchtförmiger Trog oder glazigenes Kerbtal nicht mit in die Überlegungen einbezog, wodurch eine talabwärtigere glaziale Überprägung des Tales in Betracht kommen würde. Somit wäre ein weiterer Hinweis darauf gegeben, dass es sich bei den von Bäumler (2001) betrachteten Moränen nicht unbedingt um hochglaziale handeln muss.

Laut Bäumler (2001:41) wurden die Thame und Lhagyelwa Moränen nach Heuberger (1956), Heuberger, Weingartner (1985) dem Spätglazial und die Khumjung Moränen dem Hochglazial zugeordnet; die Pheriche Moränen nach Heuberger (1956) dem Spätglazial. Die Ablagerungen von Khumjung und Pheriche bzw. die Moränen zwischen 3.800 und $4.300 \mathrm{~m}$ Höhe werden nach Bäumler (2001:41) in das Spätpleistozän eingeordnet ${ }^{295}$. Jedoch war er sich, wie anhand dieser Zitate zu sehen, nicht ganz schlüssig über die zeitliche Einordnung der Moränen: „[...] vermutlich spätpleistozänen bis frühholozänen Ursprungs.” (Bäumler 2001:24); ,Die glazigenen Ablagerungen in Basa und Lhagyelwa repräsentieren dagegen die gleiche Generation von Böden wie im Khumbu-Gebiet vermutlich aus Ablagerungen der letzten Hauptvergletscherung.” (ebd.:35); „Die Untersuchungsergebnisse belegen ein spätglaziales bis spätpleistozänes Alter. Eine Trennung zwischen Spät- und Hochglazial war allerdings auf der Basis der verwendeten Methoden nicht möglich. Der Vergleich mit den

\footnotetext{
294 „Da es sich nicht an allen Standorten um Stirnmoränen handelt, sind anhand der Ergebnisse keine abschließenden Aussagen über die Maximalausdehnung der spätpleistozänen Vereisung in Ostnepal möglich." (ebd.:41)

295 „Allerdings haben die Ablagerungen bei Khumjung und Pheriche, die ins Hochglazial datiert wurden, im Vergleich mit den anderen Standorten dieser Generation nach den vorliegenden Ergebnissen den geringeren Entwicklungszustand. Aufgrund der Unterschiede zur nächstälteren Generation und zu den Böden aus holozänen Ablagerungen sowie aufgrund der Zuordnung des Duglha-Komplexes zum Spätglazial und jünger wurden die noch erhaltenen Moränen in 3800 bis $4300 \mathrm{~m}$ Höhe im Bezug auf ihre Bodenentwicklung während des Spätpleistozäns abgelagert.” (ebd.:41)
} 
anderen Arbeitsgebieten und die Einbeziehung von Ergebnissen aus morphologischen Untersuchungen deuten jedoch darauf hin, daß die Moränen während der Klima/Gletscherschwankungen abgelagert wurden, die dem Maximum der letzten Hauptvergletscherung in Nord- und Mitteleuropa oder N-Amerika entsprechen." (ebd.:103). Das letztglaziale Eis reichte laut Bäumler bis auf ca. 3.500 bzw. 3.800 m Höhe, was jedoch nur auf der Annahme basierte, dass talabwärtigere spätpleistozäne glaziale Indikatoren nicht vorhanden waren oder zerstört bzw. überprägt wurden ${ }^{296}$. Da er anführte, dass eine Trennung zwischen Spät- und Hochglazial anhand der Methode nicht möglich war, stellte sich die Frage, wie Bäumler (2001) anhand eines Vergleiches der Gebiete und morphologischer Befunde dann das letztglaziale Eis auf ca. 3.500 bis 3.800 m Höhe festlegen konnte, da doch ein spätglaziales Alter möglich wäre und hochglaziale Moränen weiter talabwärts vorkommen könnten. Bei den anderen Arbeitsgebieten lagen dieselben zeitlichen Einordnungsprobleme nahe und außerdem waren die morphologischen Untersuchungen hier nicht weiter beschrieben, wodurch ungeklärt bleiben muss, warum Bäumler diesen Moränen ein hochglaziales Alter zuordnete.

Da sich Bäumler hauptsächlich auf die Befunde von Heuberger, Weingartner (1985) verließ, war es unverständlich, warum er dann das letztglaziale Gletscherende nicht so wie die vorgenannten Forscher auf unterhalb von ca. $2.500 \mathrm{~m}$ festlegte. Glazialgeomorphologische Analysen - anhand derer dieses erklärlicher wäre - erfolgten nicht. König (2002:137) ging auf den Widerspruch bei Bäumler ein, der im Beni Khola das tiefste Gletscherende bei 2.670 $\mathrm{m}$ aus einem $5.800 \mathrm{~m}$ hohen mittleren Einzugsgebiet festlegte, wobei hingegen der vorzeitliche Gletscher im Dudh Khosi aus einem ca. 1.500-1.800 m höheren Einzugsgebiet etwa $1.000 \mathrm{~m}$ weniger herunter gereicht haben soll. Diese von Bäumler rekonstruierten Gletscherenden waren somit nicht ganz nachvollziehbar und nicht eindeutig belegt.

\section{KUHLE (2001A)}

\section{METHODE BZW. ARBEITSTECHNIK}

Die Ergebnisse von Kuhle entstammten geomorphologischen Analysen.

\section{UNTERSUCHUNGSGEBIET}

Kuhle beschrieb neben vielen anderen Forschungsgebieten das Gebiet des Solukhumbu.

\footnotetext{
296 „Das Ausmaß der Vergletscherung während der letzten Eiszeit reichte damit im Solu- und Khumbu-Gebiet in Ostnepal bis auf etwa 3500-3800 m ü.M. herab. Dies gilt allerdings nur unter der Annahme, daß tieferliegende Zeugnisse einer spätpleistozänen Vereisung entweder nicht vorhanden waren oder aufgrund der Reliefenergie zerstört oder überprägt wurden." (ebd.:41)
} 


\section{KRITIK}

In der Veröffentlichung von Kuhle (2001a) ging dieser darauf ein, dass er seine bisherigen Befunde in Bezug auf die letzteiszeitliche Maximalvergletscherung im Solukhumbu korrigieren musste. Wie schon in der vorliegenden Arbeit anhand der Kritiken von Kuhle (1987b, 1988a und 1998) festgestellt wurde, war Kuhle (2001a:391) überzeugt, dass der Dudh Khosi Haupttalgletscher nicht bis auf eine Höhe von 1.800 oder 1.580 m hinab reichte, sondern bis auf eine Höhe zwischen 1.100 und 900 m beim Konfluenzbereich zum Hinku Khola. Bei Jubing machte er glazigene Abrasionsformen aus. Jedoch schrieb er, dass dort keine eindeutigen Indikatoren aufgefunden wurden und dass Formen talaufwärts bis zum Ort Surke aufgrund der extremen Auswaschung bzw. fluvialen Überarbeitung oft nicht vorhanden waren. Bei Kuhle (2005) waren die glazialgeomorphologischen Befunde in den Talbereichen talabwärts von Surke nachvollziehbar.

\section{FINKEL ET AL. (2003)}

\section{UNTERSUCHUNGSGEBIET}

Finkel et al. (2003) gingen bei ihren Forschungsarbeiten mit dem Titel `Beryllium-10 dating of Mount Everest moraines indicates a strong monsoon influence and glacial synchroneity throughout the Himalaya' auf das obere Einzugsgebiet des Khumbu-Himalaja bzw. auf das Gebiet südlich des Mt. Everest ein. Demnach wurden von den Forschern die Talbereiche des oberen Imja Khola und des Lobuche Khola erforscht. Infolgedessen untersuchten sie keinerlei Gebiete des unteren Khumbu und des Solu, was in der vorliegenden Arbeit schon für die Forscher Iwata (1976), Müller (1980), Williams (1983) und Richards et al. (2000) festgestellt wurde. Auch wenn in den Ausführungen von Finkel et al. (2003) der Name Thyangboche was auf die Ortschaft Thyangboche im unteren Imja Khola Talbereich hindeutete - für das Vergletscherungsstadium Thyangboche verwendet wurde, waren keinerlei Informationen im Text über diesen Talbereich angegeben. Aus den Abbildungen wurde ebenfalls nicht ersichtlich, ob dieser Talbereich untersucht wurde. Zudem haben sie keine Angaben über ihre Route der Forschungsreise erbracht, wodurch erkennbar wäre, welche Strecken abgelaufen bzw. welche Talbereiche erkundet wurden. Und somit wurde nicht eindeutig geklärt, ob überhaupt weitere glaziale Formen oder aber welche Formen in diesen - von ihnen nicht untersuchten - Bereichen vorkommen. Wenn diese Formen beachtet worden wären, würde sich die Frage auftun, auf was für eine Vergletscherung diese Formen dann hingedeutet hätten. Dass weitere Moränen talabwärts dieser Untersuchungsgebiete vorkommen, war vor der Forschungsarbeit von Finkel et al. (2003) ohnehin schon durch Fushimi (1978), 
Heuberger und Weingartner (1985), Heuberger (1986), Kuhle (1987b), Kuhle (1988a) und Kuhle (1998) belegt worden. Doch die Befunde dieser Forscher wurden bis auf die von Fushimi (1978) nicht mit einbezogen. Allein bei der Betrachtung des Aspektes, dass der Solu gar nicht und, wie in Fig. 1 zu sehen war, nur ein sehr kleines Gebiet des Khumbu (etwa 11,1 mal 7,6 km) untersucht wurde, machte deutlich, dass die Arbeiten dieser Forscher für eine Klärung der Maximalvergletscherung des Solukhumbu nur unter Vorbehalt herangezogen werden konnten. Finkel et al. (2003) äußerten sich nicht zum vorzeitlichen Schneegrenzverlauf, es wurden keine Schneegrenzberechnungen durchgeführt. Es fiel bei eigener Nachmessung und Beachtung der Maßstäbe außerdem auf, dass die Abmessungen des in Fig. 1 im rechten unteren Bereich dargestellten Lagenüberblicks des Forschungsgebietes in Nepal nicht mit den Abmessungen des o.g. dargestellten Gebietes rund um Chhukhung, Dingboche, Periche und Thoklha übereinstimmten. Wie bereits ausgeführt, war das letztgenannte Gebiet etwa 11,1 mal 7,6 km groß, aber das eigentlich als Untersuchungsgebiet gekennzeichnete Gebiet ca. 40 mal 20 km groß. Hierbei kam die Frage auf, ob Finkel et al. doch noch weitere Gebiete untersuchten oder ob es sich hierbei um einen grafischen Fehler bezüglich der Karten handelte. Zudem stellte Fig. 1 das Gebiet des Khumbu mit nur sehr ungenauen Koordinatenangaben dar, wobei daneben Höhenlinien, eine Maßstabsleiste und der bereits o.g. Lagenüberblick des Forschungsgebietes in Nepal ebenfalls mit einer Maßstabsleiste abgebildet waren.

\section{METHODE BZW. ARBEITSTECHNIK}

Es wurde deutlich, dass Finkel et al. (2003) keine glazialgeomorphologische Bestandsaufnahme anwendeten. Laut der genannten Abbildung wurden nur Moränen, demnach also keine weiteren Formen kartiert. Dementsprechend müssen die Befunde von Finkel et al. (2003) über die eiszeitliche Vergletscherung schon allein aufgrund der nicht angewendeten geomorphologischen bzw. glazialgeomorphologischen Detailanalyse (s.h.a. Kuhle 2011b:945) und aufgrund des sehr kleinen Untersuchungsgebietes differenziert betrachtet werden, wobei auf vorgenannten Gesichtspunkt des eingeschränkten Untersuchungsgebietes bereits Heuberger und Weingartner (1985:71) aufmerksam machten.

Finkel et al. (2003:561) schrieben, dass die Probenahmestellen vor der Geländearbeit - unter Berücksichtigung der guten Zugänglichkeit für CRN-Datierungen und der vorherigen CRNArbeiten in diesem Gebiet - anhand von Luftbildern und im Gelände anhand der Morphostratigraphie ausgewählt wurden. Unerklärt bleibt, dass nur Blöcke innerhalb der 
Talbereiche und vor allen Dingen nur von in der Form jünger erscheinenden Moränenrücken und nicht von z.B. Grundmoränen beprobt wurden ${ }^{297}$. Kuhle (2005:Fig. 3) zeigte deutlich, dass auch an den Talflanken Moränen, speziell Grundmoränen mit erratischen oder nicht erratischen Blöcken, vorhanden waren. Diese wurden jedoch bei den Forschungen von Finkel et al. (2003) nicht betrachtet. Es wurden laut Finkel et al. (2003:561) mehrere Blöcke pro Moränenzug (s.o.) aufgrund der Reproduzierbarkeit der Ergebnisse beprobt. Jedoch wiesen viele Blöcke eines Moränenzuges auf unterschiedliche Gletscherstadien hin. Außerdem gaben Finkel et al. (2003) unzureichende Beschreibungen ihrer Probenahmestellen, woraus sich Spekulationen ergaben (vgl. Kuhle, Kuhle 2010:113; vgl. Kuhle 2011b:949).

In Fig. 1 waren die Verteilung der Moränen verschiedener Stadien im Khumbu bzw. die glazialen Landformen und die Probenahmestellen südlich des Mt. Everest visualisiert. Die von Finkel et al. (2003) angesprochenen glazialen Landformen bezogen sich wohl eher nur auf die o.g. Moränen und auf keine weiteren glazialen Kennformen. Eine vollständige glazialgeomorphologische Analyse war jedenfalls nicht $\mathrm{zu}$ erkennen. OSL-Daten von Richards et al. (2000) und CRN-Daten von Aoki und Imamura (1999) waren begleitend gekennzeichnet worden. In Fig. 2 waren die in Fig. 1 visualisierten Probenahmestellen zusammenhängend in den einzelnen untersuchten Moränenzügen anhand ihres ermittelten Alters in die Stadien Thyangboche I und II, Periche I und II, Chukhung, Thuklha sowie Lobuche und historisch eingeteilt. Demnach waren die CRN-Daten der Moränen, die Gletscherstadien und dazu außerdem die Sauerstoffisotopendaten der Dunde und Guliya Eisdeckenkerne aus Tibet (nach Thompson et al. 1989 298 , 1997) ${ }^{299}$, der simulierte Monsundruckindex für den Indischen Ozean und die simulierte Veränderung der Niederschläge (nach Prell und Kutzbach $1987^{300}$ ) sowie die Variationen der Einstrahlung der Nordhemisphäre (nach Prell und Kutzbach 1987 ${ }^{301}$ ) dargestellt.

\footnotetext{
297 "Several boulders were dated from each moraine ridge to provide a check on the reproducibility of the dating and to assess the possibility of CRN inheritance." (Finkel et al. 2003:561)

298 Thompson, L.G., Thompson, E.M., Davies, M.E., Bolzan, J.F., Dai, J., Gunderstrup, N., Wu, X., Klein, L., and Xie, Z. (1989): Holocene-late Pleistocene climatic ice core records from the Qinghai-Tibet Plateau: Science. V. 246. (S. 474-477)

${ }^{299}$ Thompson, L.G., Yao, T., Davis, M.E., Henderson, K.A., Mosley-Thompson, E., Lin, P.-N., Beer, J., Synal, H.A., Cole-Dai, J., and Bolzan, J.F. (1997), Tropical climate instability: The last glacial cycle from a QinghaiTibetan ice core: Science. V. 276. (S. 1821-1825)

${ }^{300}$ Prell, W.L., and Kutzbach, J.F. (1987): Monsoon variability over the past 150,000 years: Journal of Geophysical Research. V. 92. (S. 8411-8425)

${ }^{301}$ siehe Quelle Prell, Kutzbach (1987) in der Fußnote
} 
Beim Vergleich der Abbildungen Fig. 1 und Fig. 2 miteinander war folgendes zu erkennen:

- die Probenahmenummern 1-4, 12-28, 33-35, 42-44, 47-56, 60, 64-70, 72, 74 und 83 existieren generell nicht

- auf die Probenahmenummer 82 wurde nur in Fig. 2 eingegangen

- die in Fig. 1 visualisierten Probenahmenummern stimmten häufig nicht mit den Daten in Fig. 2 überein

○ 1. Moränenzug mit den Probenahmenummern 5, 6, 7, 71 und 73 (in Fig. 1 Periche II Moränen, aber in Fig. 2 nur 6 und 73 übereinstimmend)

○ 3. Moränenzug mit den Probenahmenummern 29-31 (in Fig. 1 Chhukhung Moränen, aber in Fig. 2 nur 30 und 31 übereinstimmend)

○ 5. Moränenzug mit den Probenahmenummern 39-41 (in Fig. 1 Periche I Moränen, aber in Fig. 2 nur 39 übereinstimmend)

○ 6. Moränenzug mit den Probenahmenummern 45-46 (in Fig. 1 Pereiche I Moränen, aber in Fig. 2 nur 45 übereinstimmend)

○ 7. Moränenzug mit den Probenahmenummern 57-59 (in Fig. 1 Periche I Moränen, aber in Fig. 2 nur 57 übereinstimmend)

○ 9. Moränenzug mit den Probenahmenummern 75-77 (in Fig. 1 Thyangboche II Moränen, aber in Fig. 2 nur 75 und 77 übereinstimmend)

○ 11. Moränenzug mit den Probenahmenummern 84 bis 89 (in Fig. 1 Thyangboche I Moränen, aber in Fig. 2 nur 84-87 übereinstimmend)

Zum besseren Überblick über den letztgenannten Aspekt war die Dateninkongruenz in der Tabelle 5 aufgelistet (nicht übereinstimmende Daten markiert).

Diese vorgefundene Dateninkongruenz der einzelnen Probenahmestellen ließen Ungewissheiten entstehen: Wo lagen die nicht visualisierten bzw. erwähnten Probenahmestellen? Wurden noch mehr Gebiete untersucht, in denen diese Probenahmestellen aufzufinden waren? $\mathrm{Zu}$ dieser Frage würde z.B. das o.g. größere Untersuchungsgebiet von 40 mal $20 \mathrm{~km}$ gegenüber dem in Fig. 1 dargestellten Gebiet des Khumbu passen. Wo lag die Probenahmestelle 82, die laut Fig. 2 in das Alter der Stadien Lobuche und historisch fiel? Warum stimmten die Daten aus Fig. 2 nicht mit den visualisierten Daten in Fig. 1 überein und warum wiesen Probenahmestellen eines Moränenzuges unterschiedliche Alter auf? Würde dies eventuell auf eine Durchmischung der Moränen schließen lassen? 
Weiterhin fiel in Fig. 1 folgendes auf: ältere Moränen kamen talaufwärts von jüngeren vor, was jedoch geomorphologisch nicht zu erklären war. Könnten diese Aspekte ebenfalls auf eine Durchmischung der Moränen hindeuten? In der Umgebung der Ortschaft Periche kamen z.B. Periche I Moränen in einem zusammenhängenden Moränenzug weiter talaufwärts vor als Periche II Moränen (PN 5 über PN 6, 7 und 73) sowie ebenso Thyangboche II Moränen oberhalb von Periche Moränen (PN 73 über PN 5-7; PN 73 auch über einem anderen Moränenbogen PN 9-11). Rund um Thokhla fanden sich in voneinander verschiedenen Moränenzügen Thyangboche I bis Thyangboche II Moränen über Thyangboche II Moränen (PN 76 über PN 77) oder Thyangboche I Moränen oberhalb von Thyangboche II, Periche I und II Moränen (PN 84-87 über PN 5-7, 71, 73, 75-77). Zwischen Nuptse Gletscher, Lhoste Nup und Lhotse Gletscher fanden sich in zusammenhängenden Moränenzügen: Thyangboche I über Periche I und Periche I bis Thyangboche II (PN 41 über PN 39-40); Periche I bis Thyangboche II Moränen über Chukhung Moränen (PN 58 über PN 59) und Periche I bis Thyanboche II Moränen über Periche I Moränen (PN 58 über PN 57).

Bei der Betrachtung der Tabelle DR1, die - wie im Text bei Finkel at al. angegeben - im Internet unter der Adresse 'www.geosociety.org/pubs/ft2003.htm' aufzufinden war, fiel auf, dass die Koordinatenangaben der Proben ungenau angegeben wurden. Somit waren diese Probenahmestellen über diese Angaben nicht ausmachbar. Beispiele für die Ungenauigkeit der Koordinaten waren die Probenahmestellen 29 und 32 sowie 77 und 81, die laut den Koordinaten denselben Ort angeben sollen, aber laut Fig. 1 etwa $1 \mathrm{~km}$ bei den erstgenannten und bis über $1 \mathrm{~km}$ bei den letztgenannten auseinander lagen. Zusätzlich der Angaben zu den 39 entnommenen Proben waren 92 Fotos von den beprobten Gesteinen von Finkel et al. (2003) angefügt. Jedoch war es unmöglich die Fotos den Blöcken zuzuordnen: es waren sowohl keine Fotobeschriftungen als auch keine Koordinaten angegeben und außerdem waren die Fotos in schlechter Qualität dargestellt. Es können diese Fotos laut Aussage von Finkel et al. zwar von ihnen in digitaler Form angefordert werden - es muss aber offen bleiben, ob, aufgrund der vorstehenden Aspekte der unzulänglichen Fotobeschreibungen, dies aufklärend wirken würde. Dass die Probenahmestellen nur sehr ungenaue Koordinatenangaben besaßen und lediglich in einer Karte (ebd.: 562, Fig. 1) - dazu sehr oberflächlich - visualisiert waren, machte eine exakte Überprüfung unmöglich. Zudem wurde die Probenummer 82 nicht dargestellt. In Tabelle DR1 waren zusätzlich Informationen über die CRNDatierungsmethoden und das CRN-Alter angegeben. 
Bei Vergleich der Tabelle DR1 mit Fig. 2 war folgendes anzumerken:

- die Werte stimmten weitestgehend überein

- bei der Probenahmestelle 45 lag aber der zeitliche Unterschied bei ca. 10.000 Jahren (in Tab. DR1 lag der Wert bei ca. 30.000 Jahren, aber in Fig. 2 bei ca. 20.000); diese Moräne würde dann in das Stadium Thyangboche II und nicht in das Periche I Stadium fallen

- bei der Probenahmestelle 46 lag aber der zeitliche Unterschied ebenfalls bei ca. 10.000 Jahren; diese Moräne würde dann in das Stadium Periche I und nicht in das Thyangboche II Stadium fallen

- $\quad$ somit würde eine ältere Moräne über einer jüngeren vorkommen (Fig. 1)

Aus diesen erkannten Unstimmigkeiten konnte vermutet werden, dass die beiden Probenahmestellen vertauscht wurden.

Zudem waren bei Überprüfung anhand der Altersangaben - 'Exposure Age' - und der Höhenangaben der einzelnen Probenahmestellen in Tab. DR1 deutliche Schwankungen der Daten und des Höhenbereichs innerhalb eines Moränenzuges festzustellen:

- 1. Moränenzug mit den Probenahmestellen 5-7, 71, 73: ca. 14.940 Jahre; $146 \mathrm{~m}$

- 2. Moränenzug mit den Probenahmestellen 9-11: ca. 100 Jahre; 0 m

- 3. Moränenzug mit den Probenahmestellen 29-31: ca. 7.930 Jahre; $82 \mathrm{~m}$

- 4. Moränenzug mit den Probenahmestellen 82, 32, 36-38: ca. 880 Jahre; 248 m

- 5. Moränenzug mit den Probenahmestellen 39 bis 41: ca. 36.990 Jahre; $14 \mathrm{~m}$

- 6. Moränenzug mit den Probenahmestellen 45-46: ca. 11.880 Jahre; 3 m

- 7. Moränenzug mit den Probenahmestellen 57-59: ca. 16.310 Jahre; 260 m

- 8. Moränenzug mit den Probenahmestellen 61-63: ca. 470 Jahre; 77 m

- 9. Moränenzug mit den Probenahmestellen 75-77: ca. $\underline{8.410 ~ J a h r e ; ~} 27 \mathrm{~m}$

- 10. Moränenzug mit den Probenahmestellen 79-81: ca. 170 Jahre; 4 m

- 11. Moränenzug mit den Probenahmestellen 84-89: ca. 64.130 Jahre; 296 m

Diese Datenschwankungen, vor allem die des 11. Moränenzuges mit 64.130 Jahren und die des 5. mit 36.990 Jahren, verwiesen bei angenommener Richtigkeit der Daten darauf, dass die Moränenzüge nicht einheitlich entstanden sein können, sondern durchmischt sein könnten. Es fiel andererseits auf, dass besonders die Moränenzüge 2, 8 und 10 der Stadien Periche, Chukhung und Thuklha Schwankungen unterhalb von 500 Jahren aufzeigten und die Proben immer nur einen möglichen Altersbereich anzeigten. Schwankungen unterhalb von 10.000 
Jahren zeigten die Moränenzüge 3, 4 und 9 der Stadien Chukhung (auch Periche I), Lobuche / historisch und Thyangboche II (auch Thyangboche I).

Etwa übereinstimmende Daten verschiedener Moränenrücken und die mit den Altern übereinstimmende Morphostratigraphie bedeutete laut Finkel et al. (2003:561), dass die Daten richtig waren und die Blöcke nur unbedeutend durch Erosion verändert waren ${ }^{302}$. Finkel et al. (2003:561) konnten aber bei alleiniger Nutzung dieser Daten einen möglichen einheitlichen Verlust vom Material aller Proben nicht ausschließen ${ }^{303}$. Für die Erosionsraten von 1-5 m / Mill. Jahre wurde ein Alter von 10.000 Jahren berechnet; bei unberücksichtigter Erosionsrate wäre eine Unterbestimmung des Alters bei 1-4 \%, bei 20.000 Jahren bei 2-9 \% und bei 40.000 bei 4-20\% gegeben (ebd.:561). Kuhle (2012a:194) schrieb, dass eine Erosionsrate von 5 mm / 1.000 Jahre infolge des hydrothermalen Zersatzes angebrachter wäre und berechnete aus einem TCN-Alter von Owen et al. von etwa 45.000 Jahren - da diese Forscher die Erosionsrate unberücksichtigt ließen - ein Alter von mindestens 600.000 bis 850.000 Jahren. Weiterhin verwies Kuhle (2012a:194) darauf, dass ein heutiger Block der Maße 100 x 80 x 35 $\mathrm{cm}$ bei einem Volumen von $0,28 \mathrm{~m}^{3}$ eine Originalgröße von rund $19 \mathrm{~m}^{3}$ gehabt haben würde (Erosionsrate etwa $1 \mathrm{~m}$ ). Eng nebeneinander liegende Probenahmestellen sollten nach den obigen Ausführungen von Finkel et al. (2003) in Bezug auf die Werte innerhalb eines Moränenrückens wohl am ehesten die gleichen Daten aufzeigen: bei PN 9-10, PN 10-11, PN 30-31, PN 36-38, PN 61-63, PN 79-80, PN 80-81, PN 84-85, PN 85-86, PN 88-89 wäre dieses der Fall. Bei PN 5 neben PN 6, PN 6 neben PN 7, PN 29 neben PN 30, PN 39 neben PN 40, PN 39 neben PN 41, PN 45 neben PN 46, PN 57 neben PN 59, PN 58 neben PN 59, PN 75 neben PN 76, PN 76 neben PN 77, PN 87 neben PN 88 wäre dies nicht der Fall. Warum existierten diese letzteren Unterschiede beim Auftreten von sonstiger Übereinstimmung? Sprach dieser Aspekt gegebenenfalls für die Nichtanwendbarkeit der Methode bzw. Arbeitstechnik der CRN-Datierung?

Da aber außerdem die Daten nur mit Ausnahme der ältesten Moränen übereinstimmten, wie Finkel et al. (2003:561) mit dem Zitat: "With the exception of the oldest moraines, the similarity of the ages of boulders on individual moraine ridges provides a good degree of confidence in the dating." andeuteten, konnte der vorherigen Aussage in Bezug auf die

\footnotetext{
302 "The tight clustering of ages on individual moraines, with the exception of the Thyangboche I glacial stage moraines, suggests that CRN inventories are not significantly altered by erosion. To the extent that it is a stochastic process, weathering produces scatter in the CRN concentrations." (Finkel et al. 2003:561)

303 "Uniform loss of material from all samples cannot be ruled out as a possibility using our data alone. For erosion rates of $1-5 \mathrm{~m} / \mathrm{m} . y$., an exposure age of $10 \mathrm{ka}$ calculated assuming zero erosion would underestimate the true age by 1\%-4\%; an age of $20 \mathrm{ka}$ by $2 \%-9 \%$; and an age of $40 \mathrm{ka}$ by $4 \%-20 \%$." (ebd.:561)
} 
Richtigkeit der Daten nicht zugestimmt werden. Warum wurden die ältesten Moränen bei der Betrachtung der Daten nicht berücksichtigt? Und selbst wenn diese nicht berücksichtigt wurden, wären die Daten nicht immer gleich (hierzu Tab. 5). Außerdem kann die Morphostratigraphie der Moränen mit den Daten übereinstimmen, ohne dass die gesamten Daten stimmen müssen (fehlende Kalibrierung). Die Morphostratigraphie könnte beispielsweise auch mit anderen Aspekten, wie z.B. Umlagerungsprozessen, die bei dieser Methode bzw. Arbeitstechnik nicht beachtet werden, in Verbindung gebracht werden. Somit ist die Aussage von Finkel et al. (2003:561): "Confidence in our dating is further supported by the fact that morphostratigraphically younger moraines have CRN dates that provide progressively younger ages (Figs. 1 and 2). " nicht unbedingt ein Beweis für die Richtigkeit dieser Methode.

Hierbei war zu bedenken, ob die Daten eines Moränenzuges bei so enormen Schwankungen besonders bei Werten über 10.000 Jahren - überhaupt für 'richtig' bzw. brauchbar oder sinnvoll angesehen werden können. Die von Finkel et al. (2003:562) für das LGM angegebenen Alter widerlegte Kuhle (z.B. 2005:Fig. 19, Tab. 2) mit ${ }^{14}$ C-Daten (s.h.a. Kuhle, Kuhle 2010:113; Kuhle 2011b:945). Kuhle, Kuhle (2010:113) nahmen eine Altersüberschätzung der Werte von Finkel et al. (2003) an: "Thus, when compared to the C14 dates, the TCN dates turn out to be overestimated by a factor of no less than 6.5. ". Somit könnten z.B. die Thyangboche I Moränen oberhalb $4.500 \mathrm{~m}$ in das Spätglazial gestellt werden (vgl. Kuhle, Kuhle 2010:113; vgl. Kuhle 2011b:949). Finkel et al. (2003:561, 564, Tab. 1) gingen nicht auf Kuhles Forschungsarbeiten im Khumbu-Himalaja von 1986 und 1987 ein und betrachteten somit auch nicht die erhobenen ${ }^{14} \mathrm{C}$-Daten im Khumbu und Tshola Drangka (s.h.a. Kuhle, Kuhle 2010:112 ff.; Kuhle 2011b:949 f.). Dahingegen gingen sie auf die Arbeiten von Benedict (1976), Iwata (1976), Fushimi (1978), Müller (1980), Aoki und Imamura (1999) und Richards et al. (2000) ein, die in der Hauptsache - wie sie selber absolute Datierungsmethoden anwendeten (vgl. Finkel et al. 2003:561). Somit rückte die für die vorzeitliche Vergletscherungsrekonstruktion notwendige geomorphologische Detailanalyse in den Hintergrund und auch ein Vergleich verschiedener CRN-Daten sowie dieser mit OSL-Daten in den Vordergrund. Folglich wurden die Daten nicht überprüft bzw. geomorphologisch gedeutet und einfach hingenommen. Es blieb offen, ob die Methode bzw. Arbeitstechnik bei Finkel et al. und den oben genannten Forschern wissenschaftlich korrekte Ergebnisse lieferte.

Fig. 3 zeigte eine Übersicht über die Vergletscherungsgeschichte des Himalaja anhand von numerischen Datierungen. Dabei wurde deutlich, dass sehr wenige Übereinstimmungen der 
Daten existieren. Die mit Symbolen versehenen Stadien deuteten zudem auf nicht anhand numerischer Daten überprüfte Zeiträume. Wenn diese Stadien nicht berücksichtigt werden würden, blieben nur wenige eindeutig bestimmte Daten der Forscher für den gesamten Himalaja übrig.

Laut Finkel et al. (2003:561) war die Vergletscherung während des MIS 3 und älter am stärksten $^{304}$. Hierbei musste angemerkt werden, dass das Eem (MIS 5) und das Holozän (MIS 1) von vornherein für eine Maximalvergletscherung auszuschließen waren. Somit müssten die in Fig. 2 dargestellten Probenahmestellen 41 aus dem Thyangboche I Stadium sowie 46, 71 und 77 aus dem Thyangboche II Stadium die Maximalvergletscherung während des MIS 3 anzeigen; die Probenahmestellen 5, 39, 45, 57 (Periche I Stadium) und 30, 31, 59, 79, 80, 81 (Chhukhung) hingegen die geringere. Da der Bereich des Thyangboche I Stadium in Fig. 2 die höchsten Niederschlagswerte anzeigte, müsste speziell die Probe 41 die maximalste Vergletscherung anzeigen. Unter Betrachtung von Fig. 1 fiel auf, dass diese Probe - hier als Periche I Stadium dargestellt - unmöglich die Maximalvergletscherung anzeigen konnte. Wo sich nun die Stelle der Maximalvergletscherung befinden sollte, war textlich von Finkel at al. nicht erwähnt. Auch bei Hinzunahme von Fig. 1 blieb diese Frage offen, da sich keine Probenahmestellen der Stadien Thyangboche I und II finden ließen, die talwärts gesehen am weitesten herunter reichten. Es waren nur Periche I und II Moränenzüge am weitesten talabwärts erkennbar.

In Fig. 2 wurde ersichtlich, dass der simulierte Monsundruckindex für den Indischen Ozean, die simulierte Veränderung der Niederschläge (nach Prell und Kutzbach 1987 ${ }^{305}$ ) und die Variationen der Einstrahlung der Nordhemisphäre (nach Prell und Kutzbach 1987 $7^{306}$ ) voneinander abhingen: die Sonneneinstrahlung, die simulierte Niederschlagsveränderung und der simulierte Monsundruckindex waren im Stadium Thyangboche I (MIS 5) am höchsten, gefolgt vom Chukhung Stadium (MIS 1) und Thyangboche I Stadium (MIS 4, im Übergang zum MIS 3); im Thyangboche II (MIS 3) hingegen waren sie am geringsten. Warmzeiten wurden im Thyangboche I Stadium bei etwa 80.000 v.H. (MIS 5) und bei etwa 60.000 v.H. (MIS 4, im Übergang zum MIS 3); im Thyangboche II Stadium bei etwa 30.000 v.H. (MIS 3) sowie im Chhukung Stadium bei etwa 10.000 v.H. (MIS 1) dargestellt. Finkel et al. (2003:564) gaben jedoch bei den Warmzeiten die Stadien Thyangboche II, Chhukung, Thuklha, Lobuche und historisch an; das Thyangboche I Stadium wurde nicht berücksichtigt.

\footnotetext{
304 "The CRN data show that glaciation was most extensive during the early part of the last glacial (marine oxygen isotype stage [MIS] 3 and earlier), but limited during MIS 2 (the global Last Glacial Maximum) and the Holocene." (ebd.:561)

305 siehe Quelle Prell und Kutzbach (1987) in der Fußnote

${ }^{306}$ siehe Quelle Prell und Kutzbach (1987) in der Fußnote
} 
Kaltzeiten fanden sich in den Stadien Periche I vor etwa 20.000 Jahren (MIS 2), Thyangboche I Stadium vor etwa 70.000 Jahren (MIS 4) sowie im Thyangboche I Stadium vor > 90.000 v.H. (MIS 5). Nach Fig. 2 zeigte das Periche I Stadium (MIS 2) die kältesten Temperaturen an. Nach Fig. 2 waren die Stadien Thuklha, Lobuche und historisch als Stadien mit abnehmenden Niederschlägen verzeichnet.

Die von Finkel et al. (2003:561, 562, 564) aufgezeigten Gletschervorstöße während der Warmphasen mit erhöhter Einstrahlung standen mit einer höheren Feuchtigkeit in dieser Region infolge des verstärkten Sommermonsuns sowie mit einer nachfolgenden positiven Gletschermassenbilanz in Verbindung. Laut dieser Theorie würde das nach Fig. 2 bedeuten, dass im Stadium Thyangboche I (MIS 5/Eem und MIS 4, im Übergang zum MIS 3), im Chukhung Stadium (MIS 1/Holozän) sowie auch im Thyangboche II (MIS 3) die höchsten Einstrahlungs- und Niederschlagswerte und somit die stärksten Vergletscherungen existiert haben müssen.

Da in Fig. 2 ablesbar - gegenüber dem Eem - im Holozän die zweithöchste Sonneneinstrahlung, die zweithöchste simulierte Niederschlagsveränderung und ebenso der zweithöchste simulierte Monsundruckindex verzeichnet war, stellte sich die Frage, weshalb theoretischerweise nicht in diesen Zeiten auch maximale Vergletscherungen auftraten, sondern wie es Finkel et al. (2003:561) angaben im MIS 3: "The CRN data show that glaciation was most extensive during the early part of the last glacial (marine oxygen isotype stage [MIS] 3 and earlier), but limited during MIS 2 (the global Last Glacial Maximum) and the Holocene.". Es war davon auszugehen, dass sich wie o.g. die Zeitabschnitte des Eem und des Holozän für eine Maximalvergletscherung ausschlossen. Aber in Bezug auf die Hypothese von Finkel et al. (2003) - hohe Einstrahlung und hohe Temperaturen gekoppelt mit hohen Niederschlägen in Form von Schneefall in hohen Lagen mit resultierender positiver glazialer Massenbilanz - müssen etwa Grenzwerte dieser voneinander abhängenden Faktoren oder weitere andere Faktoren für eine solche Vergletscherung während der Warmzeiten eine Rolle gespielt haben. Angaben oder Erklärungen zu diesen Aspekten wurden nicht gegeben. Somit blieb fraglich, warum der Himalaja - der allein schon heutzutage die am meisten vergletscherte Gebirgsregion der Welt darstellt - während der Warmzeiten stärker vergletschert gewesen sein soll als während der Kaltzeiten. Auch das Zitat von Finkel et al. (2003:561): "Despite the importance of Himalayan glaciation, the dynamics and controls on glaciation in this region are only vaguely understood. Quantifying the timing and extent of glaciation south of Mount Everest in the Khumbu Himal, and in the broader Himalaya, is a prerequisite for connecting Himalayan climate fluctuations to changes in global climate." 
verwies darauf, dass $\mathrm{zu}$ diesem Zeitpunkt immer noch nicht alle Aspekte der Vergletscherungsgeschichte des Himalaja eindeutig geklärt waren.

Somit argumentierten Finkel et al. (2003:563, 564) nur anhand der ermittelten Daten der Proben in Verbindung mit der Abschwächung des Sommermonsuns, warum das Periche I Stadium bzw. die letzteiszeitliche Vergletscherung weniger ausgeprägt war und die Eiszeit auf der Südseite des Mt. Everest nicht mit der der Nordhemisphäre synchron, sondern mit monsunbeeinflussten Himalaja Regionen synchron war $^{307}$.

Finkel et al. (2003) nannten acht Gletscherstadien. Wie die untersuchten Moränenzüge jedoch anhand der Morphostratigraphie in die jeweiligen Stadien eingeteilt wurden, war nicht erläutert, nur dass sie diese anhand der Morphostratigraphie und der CRN-Daten einordneten. Weshalb Finkel et al. (2003) die Stadien Thyangboche und Periche in die Stadien I und II unterteilten bzw. aufgrund welcher Aspekte, wurde bei der Betrachtung der restlichen Stadien nicht eindeutig.

Sie gaben unterschiedliche Entstehungszeiträume der Thyangboche Stadien an: in Tab. 1 das Thyangboche Stadium II mit $35.000 \pm 3.000$ Jahren v.H. und das Stadium I mit $86.000 \pm$ 6.000 Jahren v.H., in Fig. 2 das Thyangboche Stadium II mit ca. 25.000 bis ca. 35.000 Jahren v.H. und das Stadium I mit ca. 35.000 bis ca. 92.000 Jahren v.H. sowie im Text das Thyangboche Stadium II mit $35.000 \pm 3.000$ Jahren v.H. und das Stadium I mit $59.000 \pm$ 29.000 Jahren v.H.. Somit unterschied sich das Alter des Thyangboche Stadium I besonders voneinander. In Fig. 2 fiel beim Thyangboche I Stadium auf, dass es zeitlich weitgefasst definiert war, sodass Finkel et al. (2003) über das Alter der Moräne (11. Moränenzug) nur spekulierten: "The age of older glacial stage, Thyangboche I, is poorly defined (59 $\pm 29 \mathrm{ka}, n$ $=6)$, and the data cluster into two groups, $86 \pm 6 \mathrm{ka}(n=3)$ and $33 \pm 7 \mathrm{ka}(n=3)$. We can only speculate on the true age of this moraine, except to state that it is morphostratigraphically older than Thyangboche I and therefore must have formed prior to $35 \pm 3$ ka." (Finkel et al. 2003:561).

Beim letzten Teil dieses Zitats meinten Finkel et al. (2003) sicherlich Thyangboche II und nicht Thyangboche I, ansonsten würde dies keinen Zusammenhang ergeben. Da wie o.g. die

\footnotetext{
307 "These results show that glaciations on the south side of Everest were not synchronous with the advance of Northern Hemisphere ice sheets, yet glaciations within the Himalaya, the world's highest mountain belt, were synchronous during the late Quaternary. The existence of glacial advances during times of increased insolation suggests that enhanced moisture delivered by an active south Asian summer monsoon is largely responsible for glacial advances in this part of the Himalaya. These data allow us to quantify the importance of global climate change and monsoon influence on glaciation in the Himalaya." (ebd.:561)
} 
Thyangboche Stadien anhand der Morphostratigraphie und anhand der Daten in I und II eingeordnet wurden, war uneindeutig, warum Finkel et al. (2003) nun die Morphostratigraphie außer Acht ließen und sich auf einen Entstehungszeitraum vor $35.000+/-$ 3.000 v.H. einigten. Zudem beachteten sie nur beim Stadium Thyangboche I die Möglichkeiten der Altersüber- bzw. -unterschätzung der datierten Werte, die ja genauso auch bei allen anderen Daten möglich sein können. Zudem fiel in Fig. 2 auf, dass die Probenahmestellen 84-89 des Moränenzuges nicht nur in das Stadium der Thyangboche I fielen, sondern beide Bereiche des Thyangboche Stadium einnahmen, sodass keine trennscharfe Abgrenzung dieser Zeiträume sichtbar wurde. $\mathrm{Zu}$ den älteren Daten schrieben Finkel et al. (2003) folgendes: "The older CRN ages for this stage might be the result of inherited CRNs from preexposure boulders, while the younger ages may be the result of weathering, toppling of boulders, and/or exhumation. If all the boulders have been exhumed, weathered, and/or toppled, they could be older than $90 \mathrm{ka}$. In a similar setting, in the Hunza Valley of northern Pakistan, Owen et al. (2002a) showed that analyses of boulders having ages older than $60 \mathrm{ka}$ frequently produce young ages because they are commonly deeply weathered and may rapidly break down after $\sim 60$ k.y. We therefore believe that a similar effect exists here and that this moraine is much older than $35 \mathrm{ka}$." (Finkel et al. 2003:561 f.). Was für Effekte hier bei den TCN-Datierungen eine Rolle spielten, wurde demnach nicht eindeutig festgelegt. Bei stark verwitterten Blöcken sollen jüngere, bei vorher belichteten ältere Alter das Ergebnis sein. Beim Thyangboche II Stadium zeigte sich in Fig. 2 kein Moränenzug, der ausschließlich in diesen Zeitabschnitt fiel. Nur der 9. Moränenzug mit den Probenahmestellen 75-77 würde ungefähr - abgesehen von der enormen Schwankung des Alters der Probe Nummer 76 - in diesen Entstehungszeitraum fallen. Auch nach Fig. 1 war dieser Moränenzug ebenfalls der einzige im Thyangboche Stadium II.

Die Thyangboche Moränen waren auf erodierten Schultern und Rücken auf über $4.500 \mathrm{~m}$ Höhe begrenzt, aber unterhalb des Tsola Gletscher erodiert bzw. durch Hangprozesse zerstört. Diese Moränen stellten die größte Vergletscherung dar: "Glacial deposits from the Thyangboche glacial stages are confined to widely separated, eroded shoulders and ridges at altitudes of above $4500 \mathrm{~m}$ above sea level, but the extent of this glaciation can not be traced far down the Tsola Glacier because intense erosion and slope instability have destroyed much of the glacial evidence. Nevertheless, these must have been broad valley glaciations and they were the most extensive glaciation recognized in the Khumbu Himal." (Finkel et al. 2003:562). Unter Betrachtung der Thyangboche Moränen in Fig. 1 fiel auf, dass diese auf 
etwa 4.600 bis $4.800 \mathrm{~m}$ (Thyangboche I Moränen, Probenahmestellen 84-89) und auf ca. 4.600 m (Thyangboche II Moränen, Probenahmestellen 75-77) verteilt vorkamen. Unterhalb des Tsola Gletscher waren in Fig. 1 wie o.g. keinerlei Thyangboche Moränen, sondern nur Periche I und II eingezeichnet. Demnach fanden sie also keine Spuren der Thyangboche Moränen unterhalb von $4.500 \mathrm{~m}$ Höhe, nahmen aber trotzdem eine ausgedehnte Talvergletscherung an. Bis auf welche Höhe diese Vergletscherung jedoch hinunter reichte, wurde nicht angegeben. Es wurde nicht untersucht, ob sich noch weitere Moränen talabwärts befanden, wobei eine Aussage über die maximale Vergletscherung nicht nur des Khumbu, sondern auch des Solu möglich gewesen wäre.

Die Vergletscherung muss aber zwingend bis unterhalb von 4.500 Höhenmetern gereicht haben, da bis etwa in diesen Bereich allein schon der rezente Tsola Gletscher reichte (s.h.a. Kuhle, Kuhle 2010:113; Kuhle 2011b:949). Zudem zeigte die detaillierte geomorphologische Bestandsaufnahme von Kuhle (2005:Fig. 3) eine eindeutige vorzeitliche Vergletscherung in diesem Talbereich, besonders die durch Sedimentanalysen bestätigten Moränenreste entlang der Talflanken (s.h.a. Kuhle, Kuhle 2010:113). Laut Fig. 2 gehörten die Probenahmestellen 41, 76, 84-87 zum Thyangboche I Stadium und 46, 71, 75, 77, 88-89 zum Thyangboche II Stadium. Somit waren in jedem dieser beiden Moränenzüge unterschiedliche Stadien vertreten, was die Aussage über die maximale Vergletscherung fraglich erscheinen ließ. Bei Betrachtung der Lage der Probenahmestelle 71 auf ca. $4.400 \mathrm{~m}$ in Fig. 1 zeigte sich, dass sich doch noch weitere Thyangboche Moränen unterhalb von $4.500 \mathrm{~m}$ bzw. unterhalb des Tsola Gletscher befanden. Auch z.B. die Probenummern 5 oder 29 - Periche I Stadium, die oberhalb von Periche II Stadium (Probenummern 6, 7) lagen, sowie Probenummer 73 (Periche II) oberhalb von 71 (Thyangboche II) in gleicher Höhenlage, zeigten, dass diese zeitliche Einordnung geomorphologisch gesehen unterschiedlich sein muss. Die generelle Annahme, dass ältere Moränen in höheren Lagen als jüngere vorkommen, konnte schon in Bezug auf die Überfahrung der älteren Moränen durch den jüngeren Gletschervorstoß ausgegrenzt werden (s.h.a. Kuhle, Kuhle 2010:113). Owen et al. (2008:526, Fig.13B) zeigten ebenfalls, dass dieser Bereich komplett von Moräne, speziell von der Periche Moräne überdeckt gewesen sein muss, da sie das LGM im Khumbu-Himalaja als ein komplettes Khumbu Imja Gletschersystem darstellten, wo das besagte Tsola Drangka enthalten war (s.h.a. Kuhle, Kuhle 2010:113). Entweder könnten diese Moränen auf ca. $4.500 \mathrm{~m}$ ins Periche Stadium zu stellen sein oder die Proben waren aus über $4.800 \mathrm{~m}$ entnommen worden und könnten Reste älterer Moränen darstellen (ebd.:113). 
Das Nichtauffinden zugehöriger glazialgeomorphologischer Formen erklärten Finkel et al. wie folgt: "[...] because intense erosion and slope instability have destroyed much of the glacial evidence." (Finkel et al. 2003:562), wobei hier mit dem Ausdruck `much of the' nicht deutlich wurde, ob nun wirklich noch weitere Thyangboche Moränenreste vorkamen oder nicht, und weshalb diese, wenn sie vorkommen würden, dann nicht beschrieben wurden. Kuhle, Kuhle (2010:113) schrieben in Bezug auf dieses Zitat, dass Kuhle (2005) zeigte, dass glaziale Beweise existieren. Nur Fig. 1 verwies indirekt mit der Probenahmestelle 71 auf das Vorkommen von Thyangboche II Moränen unterhalb von 4.500 m. Kuhle, Kuhle (2010:113) waren sich sicher, dass gerade die hohen Erosionsraten in diesem Gebiet die Existenz glazialgeomorphologischer Formen einer noch älteren Eiszeit als der letzten unmöglich machen ${ }^{308}$. Außerdem verwiesen die ${ }^{14} \mathrm{C}$-Daten auf eine solche zeitliche Einordnung (ebd.:113).

Beim beschriebenen Periche Stadium (MIS 2) reichten die in Fig. 1 eingezeichneten Moränen bis auf ungefähr 4.200 m Höhe unterhalb von Periche. Dieses Stadium zeigte das letztglaziale Maximum an und wurde in zwei Gletschervorstöße Periche I und II eingeteilt: "However, field observations indicate two advances, and we interpret our CRN ages accordingly. We assign these moraines to the Periche I and Periche II glacial stages, respectively." (Finkel et al. 2003:562). Fraglich bei dieser Aussage war nur, warum die Daten an die Morphostratigraphie angepasst werden mussten. Würde die Methode bzw. Arbeitstechnik gesicherte Daten liefern, sollte die Morphostratigraphie nur als eine Art Überprüfung dieser gelten.

Bei den Gletschervorstößen des Holozän, z.B. beim Thuklha Stadium, fiel auf, dass es durch das Wort 'within' im Zitat: "This glacial advance, however, was restricted to within $1 \mathrm{~km}$ of the contemporary glaciers." (Finkel et al. 2003:563) zu Missverständnissen kommen kann. Zudem war in Fig. 1 zu sehen, dass viele Proben des Lobuche Stadiums nicht aufgelistet waren. Zum Stadium historisch wurden keine Daten erfasst und trotzdem Zeitangaben angegeben bzw. Daten von anderen Forschern übernommen. Zudem fiel in Fig. 1 auf, dass die Daten eines Moränenzuges in diesen Zeitabschnitten des Holozän einheitlicher waren, als die der älteren Stadien.

Bei der Betrachtung von Tab. 1 wurde ersichtlich, dass Finkel et al. (2003) die anderen Forscher teilweise verändert zitierten. Die Lobuche I-III Stadien von Iwata (1976) ordneten Finkel et al. (2003) in den Zeitraum des Spätholozän ein. Laut Iwata (1976) fielen die

308 "The extent and state of preservation of the moraine deposits (Photo 3) - located in a region commonly considered to be the most erosive region on Earth - make it impossible to attribute this ice stage to any other than the Last Glacial." (Kuhle, Kuhle 2010:113) 
Lobuche Moränen in das 19. bis 20. Jhd. (ca. 200 Jahre) und die Lobuche III Moränen in die Kleine Eiszeit (etwa ab dem 15. Jhd. - ca. 600 Jahre). Somit wäre der Zeitraum des Jungholozän (3. Jt. v. Chr. bis heute $=$ ca. 5.000 Jahre) bzw. des Spätholozän gleich angegeben. Für Iwata (1976) war aufgelistet, dass das Thuklha Stadium in den Zeitraum < 5.000 Jahre fiel, Iwata (1976:113) selbst gab dieses Stadium aber mit 2.000 bis 6.000 Jahren v.H. (Frühholozän) an. Wenn es sich hierbei um einen Mittelwert handeln würde, müsste dieser mit etwa 4.000 Jahren und nicht mit $<5.000$ Jahren angegeben sein. Weiterhin wurden laut Finkel et al. (2003) die Stadien von Iwata (1976) wie folgt beschrieben: Periche (ca. 20.000), Thyangboche (ca. 40.000-50.000), Plattform (> 150.000). Iwata (1976:109) machte aber in seinen Ausführungen über das Periche und Thyangboche Stadium folgende Angaben: "The Periche and Thyangboche stages may be of the Late Glacial and the Last Glacial Maximum.". Somit waren diese zeitlichen Angaben über das Periche und Thyangboche Stadium von Iwata (1976) verändert angegeben. Diese müssten in das MIS 2 (ca. 24.50018.000 v.H.) und nicht in das MIS 3 fallen. Über die zeitliche Angabe der Plattformen gab Iwata (1976:113) nur folgende Informationen: "From the conspicuously subdued forms of the platforms, it is assumed that they were built in the Pre-Interglacial Glaciation.". Die zeitliche Angabe von Finkel et al. (2003) über die Plattformen von Iwata (1976) würde ungefähr in diesen Zeitraum fallen.

Fuhimi (1977) wurde von Finkel et al. (2003) wie folgt aufgeführt: Thuklha 3-4 (Spätholozän), Thuklha 1 (< 5.000 Jahre), Periche (ca. 20.000 Jahre), U1, U2-U3. Dieser Forscher ging aber im Khumbu-Himalaja fast nur auf heutige und rezente Moränen ein, desweiteren aber auch - jedoch ohne zeitliche Angaben - auf Periche Moränen und Moränen, die älter als Periche waren. Die rezenten Thuklha Moränen wurden in sechs Unterstadien und die Trogtäler in drei Serien mit jeweils weiteren Unterteilungen eingestuft.

Williams (1983) wurde von Finkel et al. (2003) wie folgt aufgeführt: Yykugikcga I-III (Spätholozän), Tamba (< 5.000 Jahre), Lhaog (ca. 20.000 Jahre). Jedoch nannte Williams (1983:207) die drei jüngsten, am deutlichsten zu unterscheidenden, holozänen Moränen im Yuligolcha Tal Yuligolcha I, II und III und nicht Yykugikcga I-III. Die älteste Moräne des inneren Komplexes führte er als Tamba Moräne auf und nahm an, dass sie eine ältere holozäne oder spätpleistozänen Alters war (ebd.:207, 210). Hierbei gab Williams keinen genauen Entstehungszeitraum an. Die spätpleistozänen Ablagerungen - die auf eine maximale spätglaziale Vergletscherung schließen ließen (ebd.:201) - nannte Williams Lhaog. Somit war 
bei dem Stadium also ein spätglaziales und kein hochglaziales, so wie es Finkel et al. (2003) angaben, gemeint.

Fushimi (1978) wurde zusammen mit Müller (1980) und Benedict (1976) von Finkel et al. (2003) wie folgt aufgeführt: Outer moraine (Pumore) (ca. 410-550 ${ }^{14} \mathrm{C}$ Jahre v.H.), Outer moraine (Tsola) (ca. 1.150-1.200 ${ }^{14}$ C Jahre v.H.), Dhugla I und II. Bei der Betrachtung der Ausführungen von Fushimi (1978) bei Finkel et al. wurde deutlich, dass er die folgenden Gletscherstadien angab: Rezent (T6) / U3 (genauer Zeitraum nicht angegeben), Thuklha (T1) / U3 (16. Jhd. $-{ }^{14}$ C-Daten), Periche / U3 (8. Jhd. $-{ }^{14} \mathrm{C}$-Daten), Ghat / U2 (genauer Zeitraum nicht angegeben), Luklha / U1 (LGM). Somit kamen die von Finkel et al. (2003) angegebenen Stadien bei Fushimi (1978) gar nicht vor. Müller (1980:86) nahm vier Vergletscherungshauptstadien der oberen Khumbu Region an: Rezent, Dughla (Kleine Eiszeit $-{ }^{14} \mathrm{C}$, Lichenometrie), Periche sowie ein Stadium, das älter als Periche war. Das Periche Stadium wurde laut diesem Zitat von Müller (1980:86): “[...] in age likely to correspond to those of the Egesen and Daun Stages in the Alps, [...]. " als spätglaziales Stadium angesehen. Die Dughla Moränen mit zwei bis drei Unterstadien ordnete er durch lichenometrische Messungen und ${ }^{14} \mathrm{C}$-Datierung (frühere Arbeit von Müller) in die Kleine Eiszeit ein (ebd.:86). Die Moränen des rezenten Stadiums mit mehreren Unterstadien waren frisch und entstanden seit der Kleinen Eiszeit (ebd.:86). Warum Finkel et al. (2003) die o.g. Angaben über Müller machten, war nicht erklärbar. Benedict (1976) machte keinerlei Angaben über Stadien zur letzteiszeitlichen maximalen Vergletscherung.

Richards et al. (2000) wurde hingegen von Finkel et al. (2003) wie folgt unverändert aufgeführt: Lobuche (ca. 1.000-2.000 Jahre, OSL), Chhukhung (ca. 10.000 Jahre, OSL), Periche (18.000-25.000 Jahre, OSL). Genauso wie Aoki und Imamura (1999) und Richards et al. (2000) datierten Finkel et al. (2003:Fig. 1) Periche Moränen größtenteils ca. 5 km vom heutigen Khumbu Gletschereisrand entfernt (ebd.:562), nur dass sie diese in die Stadien Periche I (23.000 +/- 3000 v.H. = globales LGM) und Periche II (16.000 +/- 2.000 v.H.) unterteilten. Die Befunde von Richards et al. (2000) ließen sich in das Periche I Stadium einordnen. Zudem stimmten diese Daten laut Finkel et al. (2003:Tab. 1, 562) mit den Periche Daten von Iwata (1976) und Fushimi (1977) sowie den Lhaog Daten von Williams (1983) überein. Die CRN-Datierungen von Finkel et al. (2003) bestätigten laut ihnen die OSLDatierungen von Richards et al. (2000) in den drei Gletschervorstößen und die RadiokarbonDaten von Müller (1980), Benedict (1976) und Fushimi (1978) für einen Gletschervorstoß. 
Owen et al. (2008:523) schrieben, dass die TCN-Daten älter sein sollten, als die, die bei Finkel et al. (2003) veröffentlicht wurden: "This would be expected since the sediment that was dated using OSL methods should pre-date the overlaying boulders that were dated using TCN methods. The probability plots suggest the TCN ages should be a little older then those published in Finkel et al. (2003); however, they still support the view that glaciers advanced during MIS 3, the global LGM, Lateglacial, early Holocene, Neoglacial and late Holocene.".

Im Gegensatz zu diesen zeitlichen Einordnungen gab Kuhle (2001b:125/Tab. 1) für das Hochglazial der letzten Eiszeit die Zeiträume 60.000-18.000 Jahren v.u.Z., für das Spätglazial 17.000-13.000 oder 10.000 v.u.Z. an.

\section{KUHLE (2005)}

\section{METHODE BZW. ARBEITSTECHNIK}

Seit 1973 untersuchte Kuhle Gebiete Hochasiens, um geomorphologische und sedimentologische Indikatoren einer eiszeitlichen Vergletscherung dieser Gebiete zu entdecken und diese in Beziehung $\mathrm{zu}$ setzen. Kuhle (2005) wendete eine detaillierte geomorphologische Reliefanalyse bzw. quartärgeologische Geländeuntersuchungen an. Hierbei wurden Formen kartiert, analog fotografiert, beschrieben, beprobt und Profile bzw. Talquerprofile angelegt. Ebenfalls führte er sedimentologische Analysen - z.B. Korngrößen und -formen, Kalkgehaltsbestimmungen -, Schneegrenzberechnungen anhand von 130 Gletschern, teilweise ${ }^{14} \mathrm{C}$-Datierungen für spätglaziale bis historische Moränen sowie Lichenometrie durch (ebd.:193). Durch die letztgenannten Methoden bzw. Arbeitstechniken ${ }^{14} \mathrm{C}$ und Lichenometrie konnte das Alter der Moränen bestimmt bzw. eingegrenzt werden (ebd.:204). Zudem waren die Bestimmungen der jüngeren Moränen für die Einordnung der hochglazialen Moränen von großer Wichtigkeit (ebd.:204).

\section{UNTERSUCHUNGSGEBIET}

Kuhle (2005:Fig. 4, 193) untersuchte hauptsächlich das Gebiet des Khumbu und Khumbakarna-Himalaja zwischen Makalu und Cho Qyu, daneben aber auch das Gebiet des Solukhumbu.

\section{KRITIK}

Die Forschungsarbeit von Kuhle (2005) mit dem Titel `The maximum Ice Age (Würmian, Last Ice Age, LGM) glaciation of the Himalaya - a glaciogeomorphological investigation of 
glacier trim-lines, ice thicknesses and lowest former ice margin positions in the Mt. EverestMakalu-Cho Oyu massifs (Khumbu and Khumbakarna Himal) including informations on late-glacial, neoglacial, and historical glacier stages, their snow-line depressions and ages' war die ausführlichste Forschungsarbeit im Solukhumbu. In Fig. 1 war ein Überblick über die von dem Forscher untersuchten Gebiete in Hochasien seit dem Jahre 1973 gegeben. Hierdurch wurde ersichtlich, dass er enorm viele Gebiete durch Geländebegehungen erkundete. In Fig. 2 visualisierte er die hochglaziale Vergletscherung in Hochasien.

Es wurden auffallend viele geomorphologische Formen im Khumbu beachtet (Fig. 3), wie Rundhöcker und ähnliche Schliffformen, Grundmoränen mit erratischen Blöcken, Grundmoränen mit großen nicht erratischen Blöcken, Gletschertorschotterfluren und Gletschertorschotterflurterrassen, Schwemmschuttfächer und Schotterflurfächer, Schutt- und Murkegel, Transfluenzpässe, glaziäre Flankenschliffe, glaziäre Dreieckshänge, Kare, Endmoränen von Talgletschern, Ufer-, Mittel- und Endmoränen, glaziale Tröge ohne und mit Schottersohle oder Podestmoräne, schluchtförmige Tröge, große erratische und nicht erratische Blöcke, subglaziale Klammen im Trogtalgrund, Kerbtäler, glaziale Hörner, Podestmoränen / Grundmoränensockel mit Terrassenstufe, glazilimnische Seeterrassen, Talboden-Flächen mit Seesediment-Abdeckung, Blockgletscher, Felsnachbrüche an vorzeitlichen Flankenschliffen, Erdpyramiden, Bergstürze, Strudeltöpfe, Moränenrutschungen sowie Gletschertor-Schotterflur-Stadien und spätglaziale, neoglaziale bis historische Gletscherstände. Aber auch im Solu wurden geomorphologische Formen kartiert, wie glaziäre Dreieckshänge, Rundhöcker und ähnliche glaziäre Schliffformen, Strudeltöpfe, Grundmoräne mit erratischen Blöcken, Schutt- und Murkegel, glaziäre Flankenschliffe, Kare, Endmoränen von Talgletschern, glaziale Tröge ohne und mit Schottersohle oder Podestmoräne, schluchtförmige Tröge, subglaziale Klammen im Trogtalgrund, Podestmoränen / Grundmoränensockel mit Terrassenstufe, Grundmoränen mit großen nicht erratischen Blöcken, Felsnachbrüche und spätglaziale Gletscherstände. Diese waren in Fig. 11 visualisiert, wobei zwei Formen in der Legende nicht aufgeführt waren. Die erste war ein schwarz gefülltes, auf der rechten Ecke stehendes Hochrechteck, mit linksseitig nach links auslaufenden kurzen Strichen und befand sich oberhalb der Schrift Khari K. und das zweite war ein schwarz gefülltes Rechteck oberhalb der visualisierten Endmoräne. Bei der Form Podestmoräne / Grundmoränensockel mit Terrassenstufe fiel auf, dass davon zwei unterschiedliche, einmal mit und einmal ohne erratische Blöcke, visualisiert wurden, jedoch in der Legende nur Podestmoräne / Grundmoränensockel mit Terrassenstufe angegeben war. 
Bei den schwarzen langen, fast parallel verlaufenden visualisierten Bögen beim Handi Khola handelte es sich wohl eher um Lateralmoränenbögen und nicht, wie in der Legende angegeben, um Endmoränen. Was der dargestellte Pfeil in Fig. 11 kennzeichnen soll, war nicht eindeutig.

Im Zuge der Arbeit von Kuhle (2005) wurde besonders auf eine Form eingegangen, die, im Gegensatz zu der älteren Literatur, auch im kerbförmigen Talprofil (= schluchtförmiger Trog) einen Beleg für eine Vergletscherung lieferte. Wo Heuberger, Weingartner und Fushimi in der Nähe von Lukla auf ca. 2.500 bis 2.100 m einen Übergangsbereich von Trog- zu Kerbtal als eine Eisrandlage ansahen, gab Kuhle (2005:Fig. 11) nur einen spätglazialen und keinen hochglazialen Gletscherrand an. Zudem war bei Heuberger, Weingartner und Fushimi nicht geklärt, ob weitere Moränen talabwärts aufzufinden waren. Heuberger (1986) legte zwar trotz des Kerbprofils eine vorletzte Eisrandlage anhand pedologischer Befunde unterhalb von Surke fest, lieferte aber keine glazialgeomorphologische Indikatoren dafür. Auch bei Kuhle (2005) endeten die glazialgeomorphologischen Kennformen oberhalb des Deku Khola. Er äußerte folgendes dazu: “A reliable proof of the High Würmian glacier thickness down-valley from Profile 31 was not possible." (Kuhle 2005:315). Bei Kuhle (2013a) reichten die Kennformen jedoch bis unterhalb des Deku Khola beim Ort Jubing hinab. Auch anhand der Befunde der vorliegenden Arbeit wurde deutlich, dass das Ausmachen von glazialgeomorphologischen Formen in diesen Talbereichen sehr schwierig war. Nichtsdestotrotz waren die Ausführungen von Kuhle (2005), auch da unterschiedliche Methoden bzw. Arbeitstechniken kombiniert wurden, wie ${ }^{14} \mathrm{C}$-Datierung, Lichenometrie, Sedimentologie, geomorphologische Bestandsaufnahme, Fotografie und Erstellung von Talquerprofilen, am eindeutigsten $\mathrm{zu}$ verstehen. Somit basierte die Rekonstruktion auf belegten und nachvollziehbaren Indikatoren, womit diese Arbeit die detaillierteste und umfangreichste geomorphologische Arbeit zu diesem Untersuchungsgebiet darstellte. Vor allen Dingen waren die vielen, sehr gute beschrifteten Fotos, Talquerprofile und Diagramme der Sedimentanalysen als Belege positiv hervorzuheben. Alle Standorte der Fotos und der entnommenen Sedimentproben sowie der Verlauf der Talquerprofile mit der Angabe der vorzeitlichen Gletschermächtigkeit für den Bereich des Khumbu-Himalaja waren aus Fig. 3 ableitbar. Für den Solu waren Talquerprofilverläufe ebenfalls mit der Angabe der vorzeitlichen Gletschermächtigkeit in Fig. 4 dargestellt. Im Untersuchungsgebiet des Khumbu- und Khumbakarna-Himalaja zwischen Makalu und Cho Qyu bzw. im Solukhumbu waren folgende Aspekte von Kuhle (2005) neben umfassenden Beschreibungen als bedeutend anzusehen: viele Sedimentproben, detaillierte Diagramme und Tabellen von 
Sedimentanalysen bzw. Korngrößen- und Kornformenanalysen (Fig. 5-6, 37-45, 47-50, 58 und 60-95), viele Talquerprofile (Fig. 7-10, 12-16, 20-36, 46, 52-57 und 59), 233 analoge Fotos bzw. Panoramen, Schneegrenzhöhen in Hochasien (Fig. 17 und 18) bzw. Schneegrenzdepressionen im Ngozumpa Tal (Tab. 4) , $15{ }^{14} \mathrm{C}$-Daten im Khumbu-Himalaja (Tab. 2) sowie Angabe von Gletscherstadien im Ngozumpa Gletschersystem mit visualisierten Probenahmestellen der ${ }^{14} \mathrm{C}$-Analyse (Fig. 19) und angegebenen $135{ }^{14} \mathrm{C}$-Daten auf der Südseite des Cho Oyu Himalaja (Tab. 3). Zu den ${ }^{14} \mathrm{C}$-Proben im Khumbu-Himalaja (Tab. 2) wurden u.a. das Material, die Höhenlage, die Lokalität mit Angabe von Koordinaten, die Entnahmetiefe, das darunterliegende Substrat sowie die rezente Vegetationsbedeckung angegeben.

Andere Forscher beschränkten sich auf wenige Formen, meistens auf Moränen und führten keine Belege anhand von Fotos auf. Die von Kuhle (2005) erarbeiteten detaillierten geomorphologischen Karten des Solukhumbu (Fig. 3 und 11) waren im Gegensatz zu anderen Forschern bedeutend. Auch der Umfang des Untersuchungsgebietes war bei den Ausführungen von Kuhle (2005) enorm und für eine Aussage über die Maximalvergletscherung geeignet.

Die von Kuhle (2005) angewendeten sedimentologischen Analysen waren wichtig, um festzustellen, um was es sich für Ablagerungen handelte. Somit wurden Moränen bzw. die Indikatoren einer ehemaligen Vergletscherung eindeutig als solche identifiziert. Beispielsweise beschrieb er Grundmoränen durch folgende Merkmale: "Accordingly, the insignificant C-portion, the bi/trimodal and quadramodal grain size distribution, the lack in sorting and the very high percentage of glacially crushed quartz grains provide evidence of lodgement till (ground moraine) even up to very high positions in this steep valley relief." (Kuhle 2005:204). Durch die Lagebeziehung der Formen untereinander wurde die zeitliche Einordnung dieser Moränen verständlich, wobei die Methoden ${ }^{14} \mathrm{C}$ und Lichenometrie auf ein Minimalalter schließen ließen. Für eine solche zeitliche Gliederung soll auch die Ähnlichkeit $\mathrm{zu}$ anderen Gebieten auf der Erde sprechen: "The number of the glacier stages since the maximum glaciation approx. agrees with that e.g. in the Alps and the Rocky Mountains since the last glacial period." (ebd.:193). Kuhle verwies in Tab. 1 auf insgesamt 14 Gletscherstadien der vorletzten und letzten Vereisung mit Altersangaben und Schneegrenzdepressionen: -I Riß, O Würm, I-IV Spätglazial, V-'VII Neoglazial, VII-XI historische Gletscherstadien, XII rezente Gletscherstadien. Die oberen Hangbereiche bzw. nur die obersten Abrasions- oder Akkumulationsformen deuteten auf die ältesten Vergletscherungszeiten; somit waren sie länger eisfrei (ebd.:281, 285). Verwitterungsprozesse 
sowie auch inter- oder auch neoglaziale Kare können hochglaziale Formen zerstören (ebd.:281), hochglaziale Grundmoränen können durch jüngere Prozesse modifiziert sein.

In Fig. 11 war das hocheiszeitliche Gletscherende mit einem Fragezeichen versehen, was darauf hindeutete, dass direkt in diesem Bereich keine eindeutigen Indikatoren mehr aufgefunden wurden. Jedoch waren dort weiter talaufwärts u.a. Grundmoräne mit nicht erratischen Blöcken, glaziärer Flankenschliff und glaziäre Dreieckshänge visualisiert, die ein weiter talabwärts reichendes Gletscherende indizierten. Die talabwärts kartierte Gletschertorschotterflur passte zu einem Gletscherstand. Ob sich weiter talabwärts weitere glazialgeomorphologische Formen auffinden lassen, müsste weiterhin im Gelände überprüft werden. Jedoch würde es an der gesamten vorzeitlichen Eisrekonstruktion - gegenüber anderen Forschern, die den hocheiszeitlichen Eisrand in sehr geringem Abstand zum rezenten Gletscherende festlegen - nichts grundlegend ändern.

\section{BARNARD, OWEN, FINKEL (2006)}

\section{METHODE BZW. ARBEITSTECHNIK}

Barnard, Owen, Finkel (2006:Fig. 2) kartierten geomorphologische Formen im KhumbuHimalaja, wobei der Schwerpunkt auf Fächern und Terrassen lag, deren Blöcke sie in den Gebieten Pangboche Yaral, Orsho und Dingboche anhand der CRN-Methode datierten. Zusätzlich zu den genannten geomorphologischen Kartierungen und TCN-Datierungen machten sie sedimentologische sowie stratigraphische Analysen bei den spätpleistozänen bis holozänen Fächern und Terrassen (ebd.:383 f., 390). Talquerprofile wurden ebenfalls angelegt (ebd.:384). Die beprobten Blöcke waren hauptsächlich Leukogranite und lagen am Rand der Form, wo andere Prozesse wie Erosion, Steinschlag, Abschirmung und anthropogene Aktivitäten minimiert auftraten (ebd.:384). Die für die Datierung angewendeten Labormethoden waren dort auf Seite 385 beschrieben.

\section{UNTERSUCHUNGSGEBIET}

Barnard, Owen, Finkel (2006:383) untersuchten ein Gebiet im Größenverhältnis von ca. 10 mal $8 \mathrm{~km}$ im Khumbu-Himalaja südlich des Mt. Everest (Fig. 2), wobei drei kleinere Testgebiete (Pangboche Yaral - ca. 1 mal 0,6 km, Fig. 3; Orsho - 0,5 mal 1 km, Fig. 6; Dingboche - 0,5 mal 1 km, Fig. 7) detaillierter untersucht bzw. anhand der CRN-Methode datiert wurden. Dieses Gebiet wählten sie aus, da es gut erreichbar war und gut erhaltene Gletscherchronologien und sehr viele Fächer und Terrassen aufwies (ebd.:383). Die drei 
genannten kleineren Gebiete zeigten die meisten und am besten erhaltenen Fächer im oberen Imja Khola und gute Stellen für die TCN-Datierung wie etwa aufgeschlossene Sedimente und gut erhaltene Moränen auf ${ }^{309}$.

\section{KRITIK}

Das Ziel der Forschungen von Barnard, Owen, Finkel (2006) mit dem Titel `Quaternary fans and terraces in the Khumbu-Himal south of Mount Everest: their characteristics, age and formation' war es, anhand untersuchter Terrassen und Fächer Hinweise für das Einsetzen und die Raten der Erosions- und Denudationsprozesse im Hohen Himalaja zu erlangen (ebd.:383). Sie nahmen eine zeitliche und genetische Verbindung von Fächern und Terrassen mit der Vergletscherung an (ebd.:383). Es ergaben sich anhand der CRN-Datierungen der Blöcke Entstehungsperioden von vor ca. 16.000, 12.000, 8.000, 4.000 und 1.500 Jahren, wobei diese bis auf ein einziges Alter, nämlich vor 12.000 Jahren, auf einen zeitlichen Zusammenhang zwischen Entstehung der Formen und den Gletscherstadien bzw. den Gletscherrückzügen hindeuteten (ebd.:394 f.). Barnard, Owen, Finkel (2006:395-397) bezogen sich hierbei auf die Gletscherstadien von Finkel et al. (2003) und schlossen einen Gletschervorstoß oder Gletscherseeausbruch vor etwa 12.000 Jahren nicht ganz aus ${ }^{310}$.

Barnard, Owen, Finkel (2006) kartierten geomorphologische Formen im Khumbu-Himalaja und der Schwerpunkt lag auf den Fächern und Terrassen. Zudem wendeten sie TCNDatierungen, sedimentologische bzw. stratigraphische Analysen an, wobei sie auch Talquerprofile erstellten. Formen wie etwa Gletscher, Seen, Moränen, Moränenrücken, Fächer, 'landslides` und Paläokanäle waren auf einer geomorphologischen Karte (Fig. 2) im Khumbu von Dughla, Chhukhung und Pangboche visualisiert. Im Gegensatz zu Richards et al. (2000) und Finkel et al. (2003) gingen sie auch auf geomorphologische Kennformen außerhalb der datierten Bereiche ein (Fig. 2). Weitere geomorphologische Karten wurden für die Gebiete Yaral Pangboche, Orsho und Dingboche mit Talquerprofilen, Profilskizzen sowie Fotos erstellt. Ferner waren Fotos von Pheriche, Dingboche, Imja Khola (Schlucht) und von Gletscherseen (östlich von Chhukhung und nördlich des Tshola Gletscher) in der

\footnotetext{
309 "The three study areas contain the most extensive and best-preserved fan successions in the upper Imja Khola Valley, as well as excellent sites for CRN dating, exposed sedimentary sections and well-preserved moraines." (Barnard, Owen, Finkel 2006:384)

310 "However, lack of evidence for Younger Dryas-age moraines does not necessarily suggest absence of a Younger Dryas glacial advance. It is possible that a glacial advance at c. $12 \mathrm{ka}$ did exist and that subsequent advances eroded the moraine ridges. Fluvial incision downvalley could have helped preserve the correlative surfaces. Alternatively, a major lake burst might have occurred at c. $12 \mathrm{ka}$, and the resulting flood formed extensive deposits throughout the Khumbu Himal, including Pangboche, Orsho and Dingboche." (ebd.:396)
} 
Forschungsarbeit enthalten. Die Unterscheidung von Terrassen gegenüber Fächern anhand ihrer Neigung und Position war nachvollziehbar. Da die Fächer durch mehrere Prozesse entstehen konnten, verwendeten sie den ungenetischen Begriff 'fan', wodurch keinerlei spezifische Entstehungsweise ableitbar war. Eine genaue Zuordnung der einzelnen individuellen Formen $\mathrm{zu}$ den Prozessen war schwierig ${ }^{311}$. Geomorphologische und sedimentologische Aspekte zu den Fächern wurden dort aber auf den Seiten 385 bis 390 angeführt. Wann sich die Formen tatsächlich herausbildeten, wurde trotz der Datierungen nicht genau geklärt ${ }^{312}$.

Aufgrund des engen Tales bei den Erosionsterrassen schlossen sie darauf, dass bei diesem Bereich während des Spätpleistozäns keine ausgedehnten quartären Ablagerungen existierten $^{313}$. $\mathrm{Ob}$ anhand dieses beschriebenen engen Talprofiles, wobei sich die Erosionsterrassen und somit auch das Talprofil bei Tsadorje südwestlich von Pangboche befanden, ein Hinweis auf das maximale Ausmaß der letztmaligen Vergletscherung gegeben wurde, wurde nicht erläutert. Barnard, Owen, Finkel (2006:386) bezogen sich im Hinblick auf die Maximalvergletscherung des Khumbu auf die Befunde von Richards et al. (2000) und Finkel et al. (2003), die zum Ergebnis kamen, dass der Lateral- bis Frontmoränenkomplex im Imja Drangka, 2,5 km nordöstlich von Orsho, den maximalen Stand des Khumbu und Chhukhung Gletscher darstellte. Mit Ausnahme des datierten Fächers $\mathrm{f}_{\mathrm{p} 3}$ waren die datierten Formen nicht älter als das Spätpleistozän ${ }^{314}$.

Die Fehlerquellen der Datierungsmethoden, die etwa durch Erosion, Abschirmung, Exhumierung oder durch Veränderung der Lage des Blockes z.B. durch Hangsturz entstehen - wobei das Hauptproblem die Vorbelichtung / Vererbung darstellen soll - waren dort auf Seite 384 erläutert. Jedoch versuchten sie gegen diese Fehlerquellen anzugehen. Um vorbelichtete Blöcke festzustellen, nahmen Barnard, Owen, Finkel (2006) multiple Proben von jedem Fächer und jeder Terrasse und datierten die moderne Flutebene, um festzustellen, ob diese sehr junge Alter anzeigte. Sie beprobten zwei Sandproben bei Orsho (E 22) und Dingboche (E 120) und einen Block von der Orsho Flutebene (E 21) (ebd.:384). Anhand der Datierung einer Form, deren Alter bekannt war, ließ sich eine Vererbung überprüfen

\footnotetext{
311 "However, it is difficult to assign an unequivocal causal mechanism to individual units, particularly because of the continuum of processes and forms that characterize hyperconcentrated and debris flows and their products (Fig. 11)." (ebd.:394)

312 "The dating precision is insufficient to resolve whether the surfaces formed before, during or after the correlated glacial advance." (ebd.:383)

313 "Given that the valley is narrow at this point, it is unlikely that these strath terraces were sites of prolonged sediment storage during the Late Pleistocene (see Pratt et al. 2002)." (Barnard, Owen, Finkel 2006:390)

314 "With the exception of fp3 (c. $58 \mathrm{ka}$ ), no fan or terrace surfaces in the study area are older than Late Pleistocene." (ebd.:396)
} 
(ebd.:384). Eine Flutterrasse bei Pangboche von 1977 konnte als Nullalter dienen (ebd.:384). Das Alter dieser Flutterrasse $t_{\mathrm{p} 2}$ ergab $720 \pm 80$ Jahre v.H., was darauf schließen ließ, dass die Vorbelichtung weniger als 1.000 Jahre ausmachte (ebd.:388). Deswegen waren die ermittelten TCN-Alter nicht überschätzt ${ }^{315}$. Jedoch sollte sich die Frage gestellt werden, ob nicht alle Blöcke vorbelichtet sein konnten oder ob eine andere rezente Flutebene, z.B. bei Dingboche oder Orsho andere Werte aufzeigen würde. Die Exhumierung sollte dadurch ausgeschlossen werden, dass sie die größten Blöcke - größer als $1 \mathrm{~m}$ - auswählten, Blöcke auf dem Rücken einer Formoberfläche bestimmten und dabei den höchsten Punkt des Blockes beprobten (ebd.:385). Dem Problem der Veränderung der Lage des Blockes z.B. durch Hangsturz wirkten sie entgegen, indem sie solche Blöcke im Randbereich einer Form beprobten, die gut in die Form eingepasst waren, um also Beprobung von Hangsturz aus höheren Flächen zu vermeiden (ebd.:385). Bei der Betrachtung der letzten beiden Aussagen in Bezug auf die Fehlerquellenbehebung bezüglich der Exhumierung und der Veränderung der Lage kam die Frage auf, ob die Blöcke im Randbereich der Form wirklich immer die größten Blöcke waren und auf dem Rücken der Form lagen. Ob daher beide Fehlerquellen durch diese Methoden ausgeschlossen werden konnten, war ungewiss. Die Bestimmung der Alter der Fächer und Terrassen gestaltete sich bei der Aussage von Barnard, Owen und Finkel, dass die Formen eingeschnitten, stellenweise stark abgetragen und mit- bzw. untereinander verschachtelt sein konnten, als schwierig. Trotz der Fehler zwischen 10 und $20 \%$ stellten TCN-Datierungen dennoch eine Verbesserung gegenüber den relativen Datierungsmethoden dar und waren die einzige Möglichkeit, Daten in Gebieten zu bestimmen, bei denen aufgrund des nicht vorhandenen organischen Materials keine Karbondatierungen möglich waren $^{316}$. Für detaillierte Informationen über die Methode und die Berechnungen wurde dort auf der Seite 388 auf weitere Quellen verwiesen.

Die multiplen Daten - drei bis vier pro Form, insgesamt 47 - der einzelnen 16 Fächer und Terrassen wurden bestimmt, indem sie das gewichtete Mittel berechneten (ebd.:386). Die gesamte Anzahl der Daten war ausreichend (ebd.:386), jedoch ließ die kleine Anzahl der Proben jeder Form keine aussagekräftigen berechneten statistischen mittleren Altersangaben

\footnotetext{
315 "Therefore, the exposure ages measured do not significantly overestimate the true age of the landforms." (ebd.:388)

316 "Nevertheless, even if dating errors lie between 10 and 20\%, CRN dating is still a vast improvement over relative dating techniques, and the only viable option in an environment where carbon dating is not possible because of the poor production and preservation potential of organic material in the harsh, high Himalayan climate." (ebd.:388)
} 
der einzelnen Formen $\mathrm{zu}^{317}$. Dieses wurde durch die Anzahl der datierten Blöcke pro Form von einem Block $\left(f_{p 2}\right)$, zwei Blöcken $\left(t_{p 2}, f_{p 1}, f_{p 3}, t_{p 4}\right)$, drei Blöcken $\left(t_{o 6}, t_{d 1}, t_{p 3}\right)$, vier Blöcken $\left(t_{d 2}\right)$, sechs Blöcken ( $t_{03}$ - Orsho und Dingboche, $t_{04}, t_{p 6}-$ Yaral und Pangboche) bis maximal sieben Blöcken ( $\mathrm{t}_{\mathrm{p} 7}$ - Yaral und Pangboche) verständlich (Tab. 1). Die Forscher ließen aber auch Daten aus, da sie annahmen, dass die Blöcke vorbelichtet waren. $\mathrm{T}_{\mathrm{p} 7}$ ist im Mittel 12.000 Jahre, $\mathrm{t}_{\mathrm{p} 6} 8.100, \mathrm{t}_{\mathrm{p} 3} 1.500, \mathrm{t}_{\mathrm{p} 2}<1.000, \mathrm{f}_{\mathrm{p} 3}$ etwa 58.000, $\mathrm{f}_{\mathrm{p} 2} 17.000$ und $\mathrm{f}_{\mathrm{p} 1} 14.000$ (ebd.:388 f.). $\mathrm{F}_{\mathrm{p} 2}$ wurde aber auf Seite 395 mit ca. 16.800 angegeben. $\mathrm{T}_{\mathrm{o} 6}$ war vor durchschnittlich 11.000 v.H. entstanden und $t_{04}$ vor 4.800 (ebd.:389). Bei $t_{p 6}$ wurde der Block $\mathrm{E} 110$ bei der Berechnung nicht mit einbezogen und bei to4 die Blöcke E 15, E 17 und E 25 (ebd.:389). E 15 verwies auf ein Alter von 12.100 \pm 300 , E 17 auf $35.200 \pm 1.500$ und E 25 auf $10.100 \pm 300$ Jahre (ebd.:389). Diese Blöcke waren vorbelichtet, da sie viel älter waren und sogar das Alter der darüber liegenden Terrasse $t_{06}$ überstiegen ${ }^{318}$. $T_{\mathrm{d} 3}$ verwies auf ein Alter zwischen 12.200 und 14.700, $\mathrm{t}_{\mathrm{d} 2}$ und $\mathrm{t}_{\mathrm{d} 1} \mathrm{zwischen} 4.000$ und 5.000 Jahren (ebd.:389 f.). Bei $\mathrm{t}_{\mathrm{d} 3}$ fand der Block $\mathrm{E}$ $26(6.200 \pm 200)$ keine Berücksichtigung, bei $t_{\mathrm{d} 2}$ die Blöcke E 65 und E 66 (beide $3.000 \pm$ 100) sowie bei $t_{d 1}$ der Block E 68 (2.810 \pm 200 Jahre) (ebd.:390). Für die beiden unteren Flächen bei Dingboche nahmen sie ungefähr das Alter von $t_{04}$ und $t_{03}$ an (etwa 4.800 und 4.400 Jahre). Diese genannten acht ausgelassen Blöcke E 15, E 17, E 25, E 26, E 65, E 66, E 68 und E 110 waren in Tabelle 1 nicht als 'inheritance' markiert, nur weitere Blöcke wie E 21, E 22 und E 120 waren dort so benannt und wurden demnach eventuell ebenfalls nicht berücksichtigt. Unterschiede zwischen datierten Altern und der Morphostratigraphie, wie z.B. bei der Probe E 91 der Erosionsterrasse, wurden wie folgt erklärt: "This discrepancy may be due to errors in the dating, periods of high discharge and sediment loads that are not related to glacier fluctuations, or an unrecognized glacial stage." (Barnard, Owen, Finkel 2006:397). Die hauptsächlich auftretende Gesteinsart der datierten Blöcke wurde angegeben, jedoch war nicht eindeutig beschrieben, welcher Block genau welcher Gesteinsart entsprach.

Die ermittelten TCN-Alter der einzelnen Formen wiesen bedeutende Schwankungsbreiten auf, wenn alle Daten berücksichtigt worden wären (Tab. 1): $t_{06}$ zeigte einen Unterschied von ca. 4.520 Jahren (drei Werte) an, $\mathrm{t}_{04}$ von ca. 31.100 Jahren (sechs Werte), $\mathrm{t}_{03}$ von ca. 10.660 Jahren (sechs Werte, Orsho und Dingboche), $t_{\mathrm{d} 2}$ von ca. 2.800 Jahren (vier Werte), $\mathrm{t}_{\mathrm{d} 1}$ von ca.

\footnotetext{
317 "The small number of samples gathered from each surface precludes calculating statistically significant average ages for each surface, but the breadth of coverage allows us to make general conclusions about the temporal development of fans and terraces." (ebd.:386, 388)

318 "[...], because their ages are significantly older than the tightly clustered set of three CRN ages that seem to define the age of this terrace and they are equivalent to or exceed the CRN ages from the higher and older surface (to6)." (ebd.:389)
} 
1.420 Jahren (drei Werte), Erosionsterrassen von ca. 12.470 Jahren (vier Werte), $\mathrm{t}_{\mathrm{p} 7}$ von ca. 2.770 Jahren (sieben Werte, Yaral und Pangboche), $\mathrm{t}_{\mathrm{p} 6}$ von ca. 13.990 Jahren (sechs Werte, Yaral und Pangboche), $\mathrm{t}_{\mathrm{p} 3}$ von ca. 450 Jahren (drei Werte), $\mathrm{t}_{\mathrm{p} 2}$ von ca. 1.140 Jahren (zwei Werte), $f_{p 1}$ von ca. 4.620 Jahren (zwei Werte), $f_{p 3}$ von ca. 77.340 Jahren (zwei Werte) und $t_{p 4}$ von ca. 4.700 Jahren (zwei Werte). Die stärksten Abweichungen zeigten $\mathrm{f}_{\mathrm{p} 3}$ mit ca. 77.340 Jahren, $\mathrm{t}_{\mathrm{o} 4}$ mit ca. 31.100 Jahren und $\mathrm{t}_{\mathrm{p} 6}$ mit ca. 13.990 Jahren. Hierbei fiel auf, dass nicht unbedingt die Anzahl der beprobten Blöcke, hier ein bis sieben Stück, zu einem gesicherten Ergebnis führte. Die Darstellung der Werte in Fig. 9 ließ aufgrund der uneinheitlichen Skalierung die extremste Altersspanne bei der Probe $\mathrm{f}_{\mathrm{p} 3}$ nur schwer erkennen, wobei nicht alle Daten, so wie auch in den Berechnungen, berücksichtigt wurden. Dicht nebeneinander liegende Blöcke verwiesen ebenso auf Altersunterschiede von ca. 480 Jahren (E 19 und E 20), ca. 160 (E 100 und E 101), ca. 13.440 (Block E 110 und E 111), ca. 77.340 (E 116 und E 117) oder ca. 4.700 (E 118 und E 119).

Barnard, Owen, Finkel (2006:386) schrieben, dass in Fig. 3 neun Oberflächenlevel dargestellt sein sollen, jedoch konnten in Fig. 3 nur die Level bei Pangboche-Yaral $t_{\mathrm{p} 7}, \mathrm{t}_{\mathrm{p} 6}, \mathrm{t}_{\mathrm{p} 4}, \mathrm{t}_{\mathrm{p} 3}, \mathrm{t}_{\mathrm{p} 2}, \mathrm{f}_{\mathrm{p} 3}$, $f_{p 2}, f_{p 1}$ entdeckt werden. $T_{p 5}$ und $t_{p 1}$ waren nicht dargestellt. In Fig. 4 war zwar $t_{p 5}$, aber nicht $t_{p 1}$ visualisiert. Allgemein war nicht nachvollziehbar, warum einige Terrassen nicht durchweg nummeriert waren bzw. datiert wurden (Tab. 1). Es fehlten die Terrassen $t_{01}, t_{02}, t_{05}, t_{p 5}$ und $t_{p 1}$. Der größte Fächer soll $t_{p 6}$ bei Pangboche gewesen sein, obwohl das $t$ eigentlich für Terrasse stehen sollte. $F_{p 3}, f_{p 2}, t_{p}$ und $t_{p 6}$ auf der Pangboche-Seite entstanden durch Hangprozesse bei Pangboche, hingegen $t_{p 5}$ bis $t_{p 1}$ durch Sedimente auf dem Imja Drangka (ebd.:386). $\mathrm{F}_{\mathrm{p} 1}$ auf der Yaral Seite ging aus dem Nare Khola hervor (ebd.:386).

Barnard, Owen, Finkel (2006) gaben an, dass die Anzahl ihrer datierten Proben und die von Finkel et al. (2003) enorm wären, nämlich über 100, dass die Anzahl der datierten Formen übereinstimmt - 14 Fächer oder Terrassen und 15 Moränen, dass die Proben großräumig verteilt wären und dass die Formensedimentologie miteinbezogen wurde ${ }^{319}$. Bei Barnard, Owen, Finkel (2006:394, Tab. 1) waren es 54 Datierungen (drei Proben mit 'inheritance' gekennzeichnet und acht nicht berücksichtigt), wobei aber 56 Proben im Text auf Seite 384 und 47 Proben auf Seite 386 angegeben waren. Sie beprobten Fächer und Terrassen, aber auch drei rezente Oberflächen (ebd.:384). Finkel et al. (2003:Fig. 2) datierten 39 Blöcke,

\footnotetext{
319 "Our study of the fans and terraces in the Khumbu Himal and the related study on glacial stages by Finkel et al. (2003) are unique in the large number of samples dated (>100), number of landforms dated (14 fan or terrace surfaces, 15 moraines), great spatial distribution of the sampling (tens of kilometres), and integration with landform sedimentology." (Barnard, Owen, Finkel 2006:383)
} 
darunter welche von ca. 13 Moränen, bei einer Testgebietsgröße von ca. 5,5 mal 4 km, wobei hier nur einzelne Punkte auf Moränenzügen beprobt wurden. Dieses ergab aber im Gegensatz zu den oben getroffenen Aussagen von ihnen maximal 95 Daten, wobei bei Barnard, Owen, Finkel (2006) einige nicht berücksichtigt wurden. Diese Arbeiten stellten das größte TCNProjekt im Hohen Himalaja dar (ebd.:383). Bei Barnard, Owen, Finkel (2006) wurden insgesamt elf Terrassen und drei Fächer untersucht, bei Finkel et al. (2003:Fig. 1) zwölf Moränenrücken. Warum Barnard, Owen, Finkel (2006) von 14 Fächern oder Terrassen und 15 Moränen ausgingen, war nicht nachvollziehbar. Fachgemäß war, dass die Proben bei beiden Arbeiten großräumig verteilt waren und die Formensedimentologie mit einbezogen wurde.

Die CRN-Datierungen der Blöcke dieser Terrassen und Fächer deuteten auf Entstehungsperioden vor ca. 16.000, 12.000, 8.000, 4.000 und 1.500 Jahren hin, die allein bei der Betrachtung der Werte auf keinen genauen Entstehungszeitpunkt hinwiesen (Barnard, Owen, Finkel 2006:383, 385, 386). Auch Barnard, Owen und Finkel gingen wie folgt darauf ein: "The dating precision is insufficient to resolve whether the surfaces formed before, during or after the correlated glacial advance." (Barnard, Owen, Finkel 2006:383). Diese Alter deuteten aber bis auf eines auf einen zeitlichen Zusammenhang zwischen Entstehung der Form und den Gletscherstadien bzw. den Gletscherrückzügen hin (ebd.:394 f.).

Barnard, Owen, Finkel (2006) beschränkten sich bei ihren Forschungen auf die Formen in den Tälern des Khumbu ${ }^{320}$. Somit betrachteten sie das obere Einzugsgebiet des Khumbu ${ }^{321}$. Da Kuhle (2005) aber weitere glaziale Formen unterhalb von Pangboche ausmachte, war diese Arbeit für eine Aussage über eine maximale Vergletscherung weniger geeignet. Barnard, Owen, Finkel (2006) schlossen sich den Forschungen von Richards et al. (2000) und Finkel et al. (2003) an.

\section{KUHLE (2007A)}

\section{METHODE BZW. ARBEITSTECHNIK}

Kuhle (2007a) wendete im Khumbu-Himal geomorphologische Analysen mit Schneegrenzberechnungen an.

\footnotetext{
320 "As a first step in examining the relationship between climate change and landscape evolution, we focus our study on landforms within the valleys of the Khumbu Himal region, south of Mount Everest (Figs 1 and 2)." (ebd.:383)

321 "Three detailed study areas were chosen in the upper catchment of the Khumbu Himal [...]." (ebd.:384)
} 


\section{UNTERSUCHUNGSGEBIET}

Kuhle (2007a) ging neben vielen anderen Gebieten Hochasiens auf das Gebiet des KhumbuHimal ein.

\section{KRITIK}

Kuhle (2007a:125 f.) beschrieb im Abschnitt`Auslassgletscher zwischen Shisha Pangma, Cho Oyu und Mt. Everest' im Khumbu den vorzeitlichen Dudh Khosi Haupttalgletscher, welcher als Auslassgletscher mit dem tibetischen Eis über den Nangpa La und Lho La in Verbindung stand. Hinweise für die Existenz eines solchen Gletschers fand er im Jahre 1982 z.B. in Lateralmoränen bei Namche Basar, Nyambua Thyang, Chhutawa und Julming, aber auch in den nach Süden geneigten hoch- bis spätglazialen Lateralmoränen 900 m über dem rezenten Talboden des Rongbuk Tales. Seine früheren Forschungsergebnisse, dass der Dudh Khosi Haupttalgletscher auf der Südseite des Himalaja nur bis auf die Höhen 1.800 oder 1.560 m hinab reichte, konnte er anhand weiterer Indikatoren korrigieren und schlussfolgerte, dass dieser bis auf ca. 900 m Höhe hinab floss. Bei der Ortschaft Jubing wurden von Kuhle glaziale Abrasionsformen an den Talflanken ausgemacht. Jedoch führte er an - wie auch in der Forschungsarbeit Kuhle (2001a) so beschrieben, dass dort keine eindeutigen Indikatoren nachweisbar waren und sich talaufwärts bis zum Ort Surke Indikatoren aufgrund der extremen Auswaschung bzw. fluvialen Überarbeitung eindeutige oft nicht finden ließen. Bei Kuhle (2005) waren die glazialgeomorphologischen Befunde in den Talbereichen talabwärts von Surke nachvollziehbar.

\section{RAI, YOSHIDA, UPRETI (2007)}

\section{METHODE BZW. ARBEITSTECHNIK}

Rai, Yoshida, Upreti (2007) wendeten geomorphologische Analysen an bzw. gingen auf unterschiedliche Sedimenttypen bei unterschiedlichen Plattformen ein und machten Aussagen über deren Eigenschaften und Gesteinsarten.

\section{UNTERSUCHUNGSGEBIET}

Es wurden Befunde im Gebiet rund um Lukla, von Nachipan, Rondinma, Chaunrikharka, Muse, Nakchun, Tate und Surke und von Lukla selbst erbracht. 


\section{KRITIK}

Bei der Arbeit von Rai, Yoshida, Upreti (2007) mit dem Titel 'Geomorphological observations surrounded Lukla, eastern Nepal Himalaya' war nur eine Zusammenfassung auffindbar. Demnach kann keine abschließende Kritik formuliert werden. Auffällig war jedoch, dass in den beschriebenen Plattformen rund um Lukla - wie etwa bei Nachipan und Chaunrikharka - Moränen aufgefunden wurden, was für eine vorzeitliche Vergletscherung in diesen Talbereichen stand. Das verwendete Wort 'colluviums' war mit dem deutschen Wort Hangablagerungen zu übersetzen und ließ nur ein ungenaues Bild über die Ablagerungen zu. Bei der Beschreibung der Nachipan Plattform wurde dieses Wort mit dem Begriff 'landslides' gleichgestellt, was jedoch ebenfalls auf keine genaue Entstehungsart hinwies. Es konnte jedoch möglich sein, dass diese Hangablagerungen aus höherliegenden Moränen resultierten und somit eine viel stärkere Vergletscherung in diesen Talbereichen - so wie sie Kuhle (2005) angab - zulassen würden.

\section{OWEN ET AL. (2008)}

\section{KRITIK}

Owen et al. (2008) gingen mit ihrer Ausarbeitung 'Quaternary glaciation of the HimalayanTibetan orogen', aufbauend auf den Arbeiten von Owen, Lehmkuhl (2000) $)^{322}$, Owen, Zhou $(2002)^{323}$ und Yi, Owen (2006) ${ }^{324}$, auf die Gebiete Himalaja Tibet bzw. auf Hochasien ein. Hierbei gaben sie einen Forschungsüberblick über die Vergletscherungsgeschichte anhand von mehreren Forschern, um die zeitliche Einordnung und die Ausdehnung der Vergletscherung des 'late Quaternary' zu bestimmen. Die zusammengefassten glazialgeologischen Kennzeichen ergaben das Bild ausgedehnter Eiskappen und extensiver Talgletschersysteme. Ungeklärt blieb jedoch die Synchronität der maximalen Vergletscherung in dem gesamten Gebiet ${ }^{325}$. Hierbei nannten Owen et al. (2008:518) Forschungsarbeiten, die diesbezüglich von einer Asynchronität regionaler Gebiete ausgehen. Angewendete Methoden bzw. Arbeitstechniken in Hochasien waren TCN- und OSL-Datierungen, da es an organischem Material für ${ }^{14} \mathrm{C}$-Analysen mangelte. Lokale detaillierte Studien ergaben, dass dort beträchtliche Variationen in der Ausbreitung der Vergletscherung von einem Gebiet zum

\footnotetext{
322 Owen, L.A.; Lehmkuhl. F. (eds). (2000): Late Quaternary glaciation and paleoclimate of the Tibetan Plateau and bordering mountains. In: Quaternary International, 65/66. (S. 1-212)

${ }^{323}$ Owen, L.A.; Zhou, S. (eds). (2002): Glaciation in Monsoon Asia. In: Quaternary International, 97/98. (S. 1179)

${ }^{324}$ Yi C.; Owen L.A. (2006): Quaternary palaeoenvironmental change in Tibet and the bordering mountains. In: Quaternary International 154/155. (S. 1-157)

325 "However, it cannot yet be determined whether the timing of the extent of maximum glaciation was synchronous throughout the entire region or whether the response was more varied." (Owen et al. 2008:513)
} 
anderen während einer Vergletscherung bestanden. Gletscher im monsunbeeinflussten Tibet, Himalaja und Transhimalaja waren synchron mit den Klimaveränderungen, die aus dem südasiatischen Monsun sowie den Kältezyklen der Nordhemisphäre resultierten. Dagegen verhielten sich die Gletscher im Pamir nicht synchron $\mathrm{zu}$ den anderen Gebieten, die monsunbeeinflusst waren, und schienen hauptsächlich nur mit den Kältezyklen der Nordhemisphäre im Einklang gewesen zu sein. (ebd.:513)

In Fig. 9 bei Owen et al. (2008) zeigte sich, dass das westliche Hochasien das einzige Gebiet war, das einen deutlichen Peak für das globale LGM zeigte. Alle anderen hatten Peaks während des MIS 3 - obwohl der monsunbeeinflusste Himalaja durch die große Anzahl der jungen Alter eingeschränkt war, wobei das westliche Gebiet das einzige mit einem dominanten Peak während des MIS 4 aufwies. Diese Daten zeigten, dass das westliche Hochasien sich anders zu den anderen Gebieten verhielt. Es war mehr durch die Westwinde der mittleren Breiten beeinflusst und wurde wenig vom südasiatischen Monsun beeinflusst.

Owen et al. gingen desweiteren auf physikalische Gegebenheiten bzw. u.a. auf geologische (Tektonik) und klimatische Verhältnisse (klimatische Systeme, Niederschlagsverteilung, Vergletscherung / Gletschertypen, Schneegrenzverlauf) im Gebiet von Hochasien ein und schilderten den enormen Stellenwert dieses Gebietes in Bezug auf globale Klimaveränderungen (vgl. Owen et al. 2008:513 ff.).

Zudem setzten sie sich mit dem Forschungsstand zur Vergletscherungsgeschichte einiger wichtiger Gebiete Hochasiens auseinander. Hierbei gingen sie auf viele Forschungsarbeiten aus den Jahren 1849 bis 2007 ein. Auf die umfassende Arbeit von Kuhle (2005) aus dem Khumbu-Himalaja gingen sie jedoch nicht ein. Owen et al. (2008:515-518) nannten bezüglich dieser vorgenannten Forscher drei Gründe für die Unterschiedlichkeit der Forschungsergebnisse über Umfang und Zeiten der Vergletscherung in Hochasien:

\section{Grund}

- enorme Größe und Unzugänglichkeit des Gebietes hatten dazu geführt, dass Forscher früher die Gletscherränder extrapolierten und in diesen unerforschten Gebieten geologische Beweise nicht vorhanden waren

- die heutige gesteigerte Erreichbarkeit ab 1970 und die Verwendung von Fernerkundungstechnologien reduzierten das vorgenannte 


\section{Grund}

- Missinterpretation von Sedimenten und Landformen

- Owen et al. (1998) $)^{326}$ zitiert nach: Owen et al. (2008) zeigten, dass vieles fluvial und glazial erodiert wurde

- Moränen wurden mit 'debris flow' oder 'rock avalanche deposits' oder umgekehrt verwechselt

- dieses war teilweise problematisch, wenn Massenbewegungsakkumulationen facettierte und gekritzte Bruchstücke beinhalteten, wodurch sich die Frage stellte, ob die Sedimente direkt oder indirekt vom Gletschereis oder von überarbeiteten bzw. umgelagerten Moränen stammten

- weiterhin war es schwierig, wenn Moränenbruchstücke ungekritzt waren

- Owen et al. (1998) ${ }^{327}$ zitiert nach: Owen et al. (2008) bezeichneten dieses als das 'diamicton problem'

\section{Grund}

- geringe chronologische Kontrolle für glaziale Abfolgen

- das Bestimmen der Alter von Landformen und Sedimenten war teilweise schwierig in vielen Gebieten von Hochasien, da das organische Material für die ${ }^{14} \mathrm{C}$-Methode nicht vorhanden war

- daneben waren aber OSL- und TCN-Datierungen anwendbar

- viele der Rekonstruktionen basierten nur auf korrelierenden Landformen, die nicht numerisch datiert waren; die resultierenden Rekonstruktionen waren aber widersprüchlich, wenn die Landformen nicht dasselbe Alter aufwiesen

Kuhle (1985:36) gab an, dass von anderen Forschern unstimmige Moränenfunde in Tibet als Pseudomoränen bzw. als Bergrutschmassen ausgelegt wurden.

Owen et al. (2008:514) bewerteten einige Forschungsarbeiten bzw. schlossen diese anhand absoluter Datierungsmethoden aus. Jedoch sollte diese Vorgehensweise kritisch betrachtet werden: absolute Daten sollten nur zur Überprüfung detallierter geomorphologischer Forschungen herangezogen werden, aber sind für sich alleinstehend, im Gegensatz zur Geomorphologie, nicht hinreichend aussagefähig. Die bei Owen et al. (2008:515) genannten Forschungsarbeiten von Kuhle über die Inlandeisbedeckung von Tibet schlossen sie ebenfalls

\footnotetext{
326 in der vorliegenden Arbeit Owen, Derbyshire, Fort (1998) genannt

327 in der vorliegenden Arbeit Owen, Derbyshire, Fort (1998) genannt
} 
bei Gegenüberstellung anderer Arbeiten der Jahre 1986-1989, 1991-1993, 1995, 1998, 2002 , 2003 und 2005 aus, gaben aber keinerlei Gründe dafür $a^{328}$. Kuhle, Kuhle (2010:106) konterten zu diesem Zitat in der vorstehenden Fußnote von Owen et al. (2008), dass sich die Forscher und die, die dort zitiert wurden, nur auf die erhobenen Daten verließen, wenige glazialgeomorphologische Befunde lieferten, keine Äußerungen über die von Kuhle gebrachten Befunde der Vergletscherung abgaben bzw. keine Gegendarstellungen machten und keine Erklärungen über die Erhaltung von Ablagerungen, die älter als das LGM waren, brachten. Auch Kuhle (2011b:959) ging z.B. darauf ein, dass Owen et al. (2008) die wichtige Methode der Geomorphologie nicht ins Zentrum ihrer Forschungen stellten. Diesen Aussagen war zuzustimmen. Alle Forscher, die ausschließlich absolute Daten erhoben, leisteten keine oder keine detaillierten bzw. umfangreichen geomorphologischen Analysen. Kuhle hingegen erbrachte detaillierte umfangreiche geomorphologische Belege bzw. eindeutige Indikatoren für eine letzteiszeitliche Inlandeisvergletscherung Tibets mit randlich anschließendem Eisstromnetz sowie peripheren Längstalfüllungen durch Auslassgletscher im Himalaja. Er untersuchte enorm viele Gebiete Hoachsiens wie etwa das tibetische Plateau und die umliegenden Gebirge wie Kunlun, Qilian Shan, Karakorum und Himalaja (vgl. Kuhle 2002:3). Kuhle (1988a:142) fand in Tibet beispielsweise glaziale Formen wie glazigene Schliffe, Schliffgrenzen, Transfluenzpässe, Rundhöcker, Diamikte bzw. Grundmoränen und Erratika. Im Himalaja reichte das tiefste rekonstruierte letztglaziale Gletscherende bis auf eine Höhe von 460 m, auf der Nordseite Tibets im Qilian Shan bis auf 2.300 m Höhe sowie auf der Nordseite von Karakorum, Aghil und Kuen Lun bis auf 1.900 m Höhe hinab (vgl. Kuhle 1998:71). Somit rekonstruierte Kuhle flächenmäßig eine etwa 2,4 Mio. $\mathrm{km}^{2}$ große subtropische Gletscherbedeckung mit ca. 1.000 bis $2.700 \mathrm{~m}$ Mächtigkeit, welche die heutige global sehr wirksame Aufheizfläche Hochasiens - da $99 \%$ der Fläche aus Schutt besteht und Schutt / Fels $80 \%$ der Strahlung absorbiert - während der Eiszeit in eine ebenso wirksame Abkühlungsfläche verändert hat (vgl. Kuhle 1986c:52; vgl. Kuhle 1988a:147; vgl. Kuhle 2002:1; vgl. Kuhle 2013a:198 f.). Für ein solches Inlandeis sprachen auch Forschungen im Bereich Lössvorkommen, Seismologie, Monsunzirkulation, Paläolimnologie und Klimamodellierung (vgl. Kuhle 2012a:173). Außerdem besteht in Tibet heutzutage Permafrost und weite Teile Tibets liegen über der Baumgrenze (ebd.:173). Kuhle datierte das Inlandeis durch ${ }^{14}$ C-Daten auf ein letztglaziales Alter (vgl. Kuhle 1998:98 f.), es war hochglazial ein kalt-basiertes Tibeteis, das am Boden festgefroren war (vgl. Kuhle

\footnotetext{
328 "Now it is generally accepted that a large ice sheet did not cover the Tibetan Plateau, at least not during the past few glacial cycles.” (ebd.:515)
} 
2012a:174). Die letzthochglaziale Schneegrenze war um 1.200 bis $1.300 \mathrm{~m}$ abgesenkt (ebd.:173; vgl. Kuhle 2012b:197). Die Inlandeisdecke bestand aus drei Komplexen mit anschließendem Eisstromnetz: I1 mit Zentrum im Kakitu Gebirge getrennt durch den Tsaidam See von 12 mit Zentrum im Tanggula Shan getrennt durch die Tsangpo Depression vom Eisstromnetz I3 (vgl. Kuhle 1985:48; Fig. 3). Anhand seiner empirischen Befunde sowie seiner Globalstrahlungs- und Albedomessungen von Schutt- und Eisflächen - bei Kuhle (1988b:17) mit über 10.000 Werten angegeben bzw. ungefähr 25.000 Messungen beim Mt. Everst und K2 in den Jahren 1984 und 1986 (vgl. Kuhle 1998:71, 100) - leitete Kuhle eine Eiszeittheorie $a b$, wonach die Eiszeit durch die plattentektonische Hebung Hochasiens bis über die Schneegrenze verursacht wurde. Diese Theorie machte Kuhle aufgrund folgender Kriterien wahrscheinlich:

Vor ca. 8 Mio. Jahren setzte der Sommermonsun ein und vor etwa 2,8 bis 2,5 Mio. Jahren reichten teilweise Gebiete von Hochasien über die Schneegrenze, vor etwa 1 Mio. Jahren bereits große Teile, da dann der Sommermonsun zusammenbrach (vgl. Kuhle 2013a:205). Bei einer nach Kuhle rekonstruierten letzteiszeitlichen Maximaleisbedeckung bis auf eine Höhe von 6.600 bis $7.000 \mathrm{~m}$ entstand somit aus einer Aufheiz- eine Abkühlfläche (ebd.:204). Bei einer Sommertemperaturabnahme von 8,4 bis $10{ }^{\circ} \mathrm{C}$ mit gekoppeltem $400 \mathrm{~mm}$ Jahresniederschlag könnte sich bei angenommener Verdunstung von $50 \%$ ein Tibeteis in 5.000 Jahren aufgebaut haben (vgl. Kuhle 1988a:147). Durch eine Absenkung der Schneegrenze um $1.200 \mathrm{~m}$ - bei $500 \mathrm{~m}$ Absenkung ist Tibet um 1/3 eisbedeckt - bei einer Sommertemperaturabnahme von 8,4 bis $10{ }^{\circ} \mathrm{C}$ musste Tibet früheiszeitlich mit Eis bedeckt gewesen sein (ebd.:147). Im Tibeteis sollen 2,2 Mio. $\mathrm{km}^{3}$ Wasser gebunden gewesen sein, was einer Meeresspiegelabsenkung von 5,4 m entspricht (ebd.:146). Die Feuchtigkeit stammte aus Osten, Süden und Südwesten bzw. aus dem Arabischen Meer, dem Golf von Bengalen und dem Chinesischen Meer (vgl. Kuhle 1988b:17; vgl. Kuhle, Roesrath 1990:147). Außerdem soll der östliche tropische Strahlstrom durch das Tibeteis abgeschwächt gewesen sein, so dass die Sahara feuchter war (vgl. Kuhle 1988b:17). Es kann also bei der Hebung von Tibet bzw. Hochasien - infolge der Subduktion der indischen Platte unter die eurasische über die Schneegrenze mit resultierender Vergletscherung aufgrund der enormen Reflexion der subtropischen kurzwelligen Strahlung zur globalen Abkühlung der Atmosphäre gekommen sein (vgl. Kuhle 2013a:196, 204 f., 208). Kuhle führte in den Jahren 1984, 1986 und 1989 mehrere Tage bis Wochen an insgesamt 15 Klimastationen in einer Höhe von 3.000 bis $6.650 \mathrm{~m}$ auf der Nordseite des Zentralhimalaja in Südtibet sowie in Nordwesttibet bzw. im Karakorum, in Zentraltibet, in Südzentraltibet und Südosttibet Messungen der 
Klimaparameter bzw. Strahlungsmessungen durch, die aufzeigten, dass in diesen Gebieten viel höhere Strahlungen existierten als in den mittleren Breiten (ebd.:204). Die Globalstrahlung erreichte in Tibet aufgrund der Höhen- und Breitenlage 1.000 bis 1.200 / $1.300 \mathrm{~W} / \mathrm{m}^{2}$, was eine viermal höhere Energie als in nördlichen Breiten von 60 bis $70^{\circ}$ bedeutete (vgl. Kuhle 1986c:49; vgl. Kuhle 1988a:147). Ursachen hierfür waren die Lage in den Subtropen und die dünne Atmosphäre an diesen Orten (vgl. Kuhle 1986b:73). Ein eisfreies Plateau absorbierte $80 \%$ der Einstrahlung (vgl. Kuhle 2002:3), ein eisbedecktes reflektierte $95 \%$ (vgl. Kuhle 1986c:52). Der durch die Eisbedeckung herbeigeführte Einstrahlungsverlust von $70 \%$ führte zur weiteren globalen Abkühlung um ca. $1,5{ }^{\circ} \mathrm{C}$, so dass sich z.B. die nordischen Flachlandeise aufbauten, die wiederum abkühlend wirkten (vgl. Kuhle 1988a:147). Es bestanden die Flachlandeise 48 bis $75^{\circ}$ n.B. mit 26,3 Mio. $\mathrm{km}^{2}$ gegenüber den 3,2 Mio. $\mathrm{km}^{2}$ subtropischen Hochlandeisen (ebd.:147). Das Einsetzen der Eiszeit vor rund 2,75 Mio. Jahren bzw. deren steigende Intensität ab der Zeit vor ca. 1 Mio. Jahren - Tibet wurde auf die durchschnittliche Höhe von $4.600 \mathrm{~m}$ gehoben (vgl. Kuhle 2002:5) - kann laut ebd.:1 nicht nur durch orbitale Veränderungen erklärt werden. Gegen die veränderten Erdbahnelemente als Eiszeitauslöser sprachen die zyklischen Temperatursenkungen während eiszeitfreier Erdzeitalter (vgl. Kuhle 1988a:147). Der extraterrestrische Faktor erklärte nur die Interglaziale, stand also nur für die Periodizität, nicht aber für die Eiszeit selber (ebd.:150). Durch orbitale Veränderungen kam es zum Schmelzen dieser Eise und zum Intensivieren der erneuten Erwärmung, wobei ein komplettes Abschmelzen des Tibeteises nur durch Glazialisostasie erklärbar war (vgl. Kuhle 2013a:208 f.). Bei einer Eisauflast von $2.000 \mathrm{~m}$ wurde die Hebung beendet, wobei durch das Abschmelzen des Eises Tibet erneut gehoben wurde (vgl. Kuhle 1988a:147). Diese Glazialisostasie bei Eisauflast kann z.B. dadurch bezeugt werden, dass Altmoränen tiefer lagen als letztglaziale, was für eine Stagnation der Tibethebung sprach (ebd.:150). Eine Glazialisostasie von etwa 600 m muss existiert haben (vgl. Kuhle 2013a:199) - die 12 mm / Jahr Hebungsrate nach Hsu et al. (1998) $)^{329}$ zitiert nach: Kuhle (2013a:200) würde dafür sprechen. Somit waren laut Kuhle (2013:212) nicht die orbitalen Veränderungen, sondern die Vergletscherung Hochasiens ausschlaggebend für Eiszeiten. Tibet war während der Eiszeit feuchter als heute - das Tarim Becken, die Wüste Gobi und das Tsaidam Becken waren Schmelzwasserseen (ebd.:197).

\footnotetext{
${ }^{329}$ Hsu, H.; Zhang, C.; Wang, Y. (1998): Study on crustal movements of Tibetan plateau and its mechanism by geodetic methods. Intern. Symp. on the Qinghai-Tibet Plateau. Xining, China. (S. 4)
} 
Außerdem äußerten sich Kuhle, Kuhle (2010) wie folgt zur vorzeitlichen Vergletscherung des tibetischen Plateau: "The existence of a Tibetan ice sheet during the LGM was demonstrated in great detail (Kuhle 2004) through the identification of extensive moraine coverage as well as the existence of erratic boulders (Photos 4-6) and glacial polishing - in other words, the reconstruction of the Tibetan ice sheet was based on the identification of the same set of glacial geological indicators which had previously been exploited for the reconstruction of the respective large-scale glaciations in North America and Northern Europe." (Kuhle, Kuhle 2010:118); "Now the only available explanation for a high-glacial disruption of the monsoon cycle is that the Tibetan heating surface was during that period of time nonexistent - and this would be achieved if the entire Plateau was covered by a perennial snow sheet (cf. discussion in Kuhle 2002b).” (ebd.:119); “As the model calculations by Kuhle, Herterich \& Calov (1989: 204-206, Kuhle 1997: Figure 46-48) have shown, a precipitation of $100 \mathrm{~mm} / \mathrm{a}$ may already suffice under such conditions in order to make the development of an approx. $1000 \mathrm{~m}$ thick inland ice sheet within $10 \mathrm{ka}$ possible.” (ebd.:119); “[...], then how do they explain the fact that according to the C-14 datings by Kashiwaya et al. (1991), Van Campo \& Gasse (1993), Gasse et al. (1996) and Avouac et al. (1996) the lakes on the Plateau are all younger than the LGM?" (ebd.:119).

Owen et al. (2008:518-520, 523, 525) gaben einen Überblick über die Problematik der Schneegrenzberechnungen bzw. über die verschiedenen Datierungsmethoden ${ }^{14} \mathrm{C}$, OSL und TCN sowie deren Anwendung in Hochasien. Zudem setzten sie sich mit den Datierungsmethoden kritisch auseinander. Owen et al. (2008) bemerkten, dass die Methoden bzw. Arbeitstechniken der TCN- und OSL-Datierung nicht genau waren und Fehler aufwiesen $^{330}$. Andererseits erwähnten sie aber, dass TCN- und OSL-Datierungen genauer waren als Radiokarbondatierungen ${ }^{331}$. Im Vordergrund von absoluten Datierungen sollten jedoch im Hinblick auf diese Aussage dennoch geomorphologische Analysen stehen.

\footnotetext{
330 "Limits to the precision and accuracy available with these methods and, more importantly, geological uncertainty imposed by processes of moraine formation and alteration both conspire to limit the time resolution on which correlations can be made to Milankovitch timescales (several ka)." (ebd. 2008:513); "There are few opportunities to apply numerical dating tools, many of which have large errors, [...]." (ebd.:514); "Despite the vast application of TCN to defining the timing of glaciation, it is not yet possible to adequately determine whether glaciation is truly asynchronous throughout the region for the entire time for which ages are available." (ebd.:519)

331 "The newly developing techniques of optically stimulated luminescence (OSL) and terrestrial cosmogenic nuclide (TCN) surface exposure dating are now allowing glacial successions throughout Tibet and the bordering mountains to be dated and correlated more accurately (see next section)." (ebd.:516 f.); "New technologies, including remote sensing and geochronology, are rapidly helping us to resolve the nature and dynamics of glaciations throughout the region." (ebd.:525); "However, newly developing OSL and TCN methods are helping to expand the chronologies throughout the region." (ebd.:527)
} 
Die von Owen et al. (2008) anhand von unterschiedlicher Literatur betrachteten Gebiete im Himalaja Tibet Bereich zeigte Fig. 1. Bei der vorliegenden Arbeit wurde genauer auf das Gebiet des Solukhumbu und auf Vergleichsuntersuchungsgebiete eingegangen, sodass sich nicht mit allen anderen betrachteten Gebieten von den Forschern kritisch auseinandergesetzt werden konnte.

Beim Forschungsüberblick und dem Überblick der angewendeten Methoden über das Schlüsselgebiet Khumbu gingen Owen et al. (2008:523) auf die Arbeiten von Benedict (1976), Iwata (1976), Fushimi (1977), (1978), Müller (1980), van Williams (1983), Richards et al. (2000), Finkel et al. (2003) und Barnard et al. (2006) ${ }^{332}$ ein. Befunde, wie etwa die von Kuhle und somit vor allem die Radiokarbondatierungen von ihm, wurden jedoch nicht berücksichtigt. Um alle Forschungsarbeiten der OSL- und TCN-Datierungen vergleichbar zu machen, berechneten bzw. bewerteten Owen et al. (2008:513, 519, 527) diese Daten neu, was der Hauptpunkt der Ausarbeitung von Owen et al. war. Die von Owen et al. (2008) neuberechneten Daten der letztgenannten OSL- und TCN-Datierungen stimmten einigermaßen gut überein, außer in dem Punkt, dass die TCN-Daten mehrere hundert Jahre jünger waren. Dazu schrieben sie dort auf Seite 523, dass die TCN-Daten älter ausfielen, als die welche bei Finkel et al. (2003) veröffentlicht wurden ${ }^{333}$. Owen et al. (2008) unterstützten mit den neuberechneten Daten die Sicht, dass die Gletscher während Zeiten verstärkter Monsunaktivität vorstießen. Andererseits gaben sie aber trotzdem an, dass sich die Gletscher auch während der Kältephasen verändert haben könnten ${ }^{334}$. Die Daten nebeneinander liegender Sedimente schwankten jedoch bei Finkel et al. (2003:Fig. 2, 39 und 41) um ca. 27.000 Jahre sowie bei Richards et al. (2000) um ca. 2.100 Jahre, was bei angenommener Richtigkeit der Daten auf eine Durchmischung des Moränenmaterials schließen ließe und somit darauf hindeuten würde, dass alle Moränen auch unterhalb der hier kartierten durchmischt sein könnten. Und somit würden durch Datierungen nur schwierig Eisrandlagen bestimmbar sein.

Das Gebiet des Khumbu war wie in Fig. 13/B dargestellt. In Fig. 13/A war das Gebiet des Khumbu - als `part B’ bezeichnet - ebenfalls zu erkennen. Die Abb. A in Fig. 13 bei Owen et

\footnotetext{
332 in der vorliegenden Arbeit als Barnard, Owen, Finkel (2006) bezeichnet

333 "This would be expected since the sediment that was dated using OSL methods should pre-date the overlaying boulders that were dated using TCN methods. The probability plots suggest the TCN ages should be a little older then those published in Finkel et al. (2003); however, they still support the view that glaciers advanced during MIS 3, the global LGM, Lateglacial, early Holocene, Neoglacial and late Holocene." (Owen et al. 2008:523)

334 "However, glaciers may also have been influenced by cooling cycles during the late Quaternary, for example during the global LGM." (ebd.:523)
} 


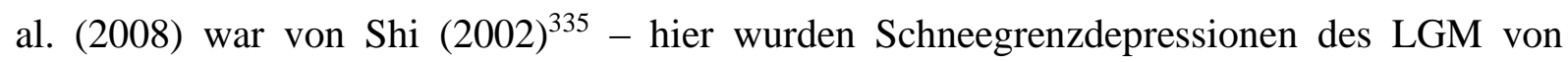
Hochasien dargestellt. Es war in vorgenannter Abbildung zu erkennen, dass das Khumbu Gebiet eine letzteiszeitliche Schneegrenzdepression von 500 bis 1.000 m nach Shi $(2002)^{336}$ anzeigte. Owen et al. (2008:Fig. 13) wiesen jedoch darauf hin, dass diese Werte nicht unbedingt korrekt sein müssen (s.h.a. ebd.:523, 525). Die Abbildung B zeigte hingegen eine Schneegrenzdepression von ca. 200-300 m an, sodass die vorzeitlichen Gletscher bis maximal auf ca. 4.200 m südlich von Periche reichten. Fig. 13/B müsste von Owen, Benn (2005) sein: in Fig. 13 stand zu dieser Abbildung, dass nur die hypsometrischen Kurven von Owen, Benn (2005) waren, aber nicht die Abbildung an $\operatorname{sich}^{337}$. Aus dem Text konnte aber entnommen werden, dass diese Grafik von Owen, Benn (2005) sein muss ${ }^{338}$. Demnach bezogen sich die Angaben über die letzteiszeitliche Vergletscherung während des LGM auf die Ausführungen von Shi $(2002)^{339}$ und Owen, Benn (2005) und nicht auf Owen et al. (2008). Nur die neuberechneten Daten aus den OSL- und TCN-Daten von Richards et al. (2000) und Finkel et al. (2003) waren von Owen et al. (2008).

In Fig. 13/B war zu erkennen, dass nicht das gesamte Khumbu Gebiet, sondern nur das obere Khumbu Gebiet bis auf ungefähr 4.200 m Höhe südlich von Periche betrachtet wurde. Der westliche und südliche Teil des Khumbu wurde demnach von Owen, Benn (2005) nicht weiter erforscht, was im Zug der vorliegenden Arbeit auch schon bei Iwata (1976), Müller (1980), Williams (1983), Richards et al. (2000), Finkel et al. (2003) und Barnard et al. (2006) festgestellt werden konnte. Die Größe des Untersuchungsgebietes Khumbu konnte mit

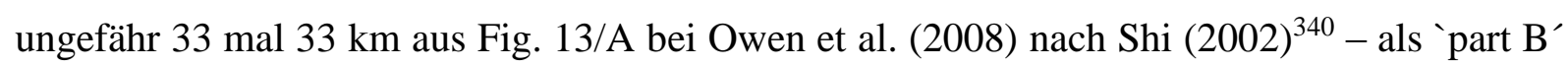
bezeichnet - entnommen werden, welche das Gebiet des Himalaja und von Tibet mit Koordinaten und einer Maßstabsleiste zeigte. Bei Fig. 13/B, die ebenso das Gebiet des Khumbu abbildete, waren allerdings keine Koordinaten oder Maßstabsleiste dargestellt, womit die Größe des Untersuchungsgebietes angegeben werden könnte. Also wurde das Gebiet des Solu von Owen, Benn (2005) nicht untersucht. Da sie somit nur das obere Einzugsgebiet des Khumbu-Himalaja - das Gebiet des Imja Drangka und des Lobuche Khola

\footnotetext{
335 siehe Quelle Shi (2002) in der Fußnote

336 siehe Quelle Shi (2002) in der Fußnote

337 "Reconstruction of the (B) Khumbu and Imja glacier systems in the Khumbu Himal and (C) the Batura glacier system in Hunza for the global LGM. The hypsometric curves are for the contemporary Khumbu Glacier (B) and Batura Glacier (C) (after Owen and Benn, 2005)." (Owen et al. 2008:526/Fig. 13)

338 "Owen and Benn (2005) recognised only two locations, the Hunza valley and the Khumbu Himal, where glaciers of the global LGM have been accurately dated (Fig. 13). They calculated ELAs for these regions and showed that $\triangle E L A s$ were considerably less $(200-300 \mathrm{~m}$ in the Khumbu and $\sim 100 \mathrm{~m}$ for the Batura Glacier; Fig. 13(B) and (C)) than had been previously estimated for the global LGM in these regions (»500 $\mathrm{m})$." (Owen et al. 2008:525)

339 siehe Quelle Shi (2002) in der Fußnote

340 siehe Quelle Shi (2002) in der Fußnote
} 
- erforschten, konnten sie nur wohlüberlegt für die Diskussion zur hochglazialen Vergletscherung herangezogen werden. Schon Heuberger und Weingartner (1985:71) machten auf das Problem des eingeschränkten Untersuchungsgebietes aufmerksam.

Owen, Benn (2005) zitiert nach: Owen et al. (2008) nahmen also im Khumbu-Himalaja eine sehr geringe Vergletscherung bis auf maximal $4.200 \mathrm{~m}$ unterhalb von Periche an. In Fig.13 A bei Owen et al. (2008) nach Shi (2002) ${ }^{341}$ wurden jedoch in diesem Gebiet - von höheren zu tieferen Höhenbereichen gesehen - Schneegrenzdepressionen für das letzte glaziale Maximum von 500 bis $1.000 \mathrm{~m}$ angezeigt. In Verbindung mit der aktuellen Schneegrenze auf $5.500 \mathrm{~m}$ im Khumbu berechnete sich allerdings eine tiefere maximale Vergletscherung bis auf etwa 3.800 bzw. $2.800 \mathrm{~m}$ Höhe (4.800 m minus $1.000 \mathrm{~m}$; $4.800 \mathrm{~m}$ minus $2.000 \mathrm{~m}$ ). Nach Achenbach (2011) waren Gletscherstände in Hochasien mit Längenunterschieden von wenigen Kilometern gegenüber heute und Schneegrenzdepressionen von 100-300 m nach glazialgeomorphologischen Befunden - nach verschiedenen Forschern und seinen eigenen Befunden mit angewendeter Radiokarbondatierung und Lichenometrie - nicht in die Zeit des letzten glazialen Maximums, sondern in die Zeit des Neoglazial (5.500-1.700 Jahre vor 1950) oder gar den historischen Zeitraum (<1.700 Jahre vor 1950) einzuordnen.

Neben der Festlegung der letzteiszeitlichen Vergletscherung in Fig. 13/B nach Owen, Benn (2005) äußerten sich Owen et al. (2008:513 f.) über die Ausbreitung und die zeitliche Festlegung der Vergletscherung aber wie folgt: "The extent and timing of glaciation and the associated hydrological and climatic responses in the Himalayan-Tibetan orogen are poorly defined owing to the inaccessibility to the region. Accurate reconstructions of former ice extent have been hindered by the difficulty in distinguishing glacial from non-glacial landforms.". Hierbei stellte sich die Frage, wie diese Rekonstruktion der Vergletscherung im Khumbu möglich war bzw. auf welchen Formen diese Rekonstruktion fußte, wenn es wie o.g. Schwierigkeiten bei der Unterscheidung der Formen untereinander gab. Waren dies die alleinigen Gründe für die verschiedenen Forschungsergebnisse zur eiszeitlichen Vergletscherung von Hochasien? Die Befunde der Forscher konnten bezüglich dieses Aspektes nicht untersucht werden, da sie keine geomorphologischen Indikatoren grafisch darstellten bzw. textlich erwähnten. Somit sollte diese Arbeit, da ihr keine detaillierte geomorphologische Analyse zugrunde lag (s.h.a. Kuhle 2011b:945), kritisch betrachtet werden.

\footnotetext{
${ }^{341}$ siehe Quelle Shi (2002) in der Fußnote
} 


\section{KUHLE (2011B)}

\section{METHODE BZW. ARBEITSTECHNIK}

Kuhle wendete im Gebiet Solukhumbu geomorphologische Analysen an, wobei er im Ngozumpa Drangka außerdem auch ${ }^{14} \mathrm{C}$-Datierungen hinzunahm.

\section{UNTERSUCHUNGSGEBIET}

Bei Kuhle (2011b) wurden Schlüsselregionen in Hoch- und Zentralasien (untersuchte Gebiete von 1973 bis 2009 - Fig. 68.1) wie z.B. Himalaja (darunter Khumbu- und KhumbakarnaHimal), Tibet und Karakorum aufgeführt.

\section{KRITIK}

In der Forschungsarbeit von Kuhle (2011b) stand die kritische Analyse der absoluten Datierungsmethoden OSL und TCN im Mittelpunkt. In verschiedenen Textstellen und Darstellungen ging er auf das Gebiet des Khumbu-Himal ein. In Bezug auf dieses Gebiet betrachtete er auf Seite 949 die Befunde von Finkel et al. (2003) und Owen et al. (2008) kritisch, wobei seine geomorphologischen Befunde eindeutig gegen die Ergebnisse der Datierungen dieser sprachen. Auslassgletscher - von Tibet kommend - sollen die Täler auf der Südseite des Himalaja verfüllt haben, wobei der Imja Dudh Khosi Hauptgletscher bis auf eine Höhe von ca. 900 m hinab reichte. Die detaillierte Rekonstruktion war bei Kuhle (2005) aufzufinden. Bei Kuhle (2011b) waren Abbildungen - Fig. 68.3 bis 68.8 - vorhanden, die ebenfalls in der Veröffentlichung von Kuhle aus dem Jahr 2005 vorkamen bzw. dieser entstammten. Fig. 68.3 zeigte die geomorphologische Karte vom gesamten Khumbu Gebiet, Fig. 68.4 war das Talquerprofil 16, Fig. 68.5 verwies auf acht morphometrische Analysen, Fig. 68.6 zeigte ein Foto einer Moräne beim Ort Lukla, Fig. 68.7 stellte die Korngrößenanalyse in der Nähe vom Ort Surke dar und Fig. 68.8 zeigte die geomorphologische Karte des Gebietes Solukhumbu bzw. Khumbakarna. Kuhle (2011b) erwähnte zusätzlich im Text auf Seite 945 sechs ${ }^{14} \mathrm{C}$-Daten der Stadien V, VI und VII aus dem Ngozumpa Drangka, wobei die ${ }^{14} \mathrm{C}$-Probenahmestellen (nach Kuhle aus den Jahren 1986 und 1987) in der geomorphologischen Karte vom Westkhumbu bzw. vom Ngozumpa Gletschersystem - Fig. 68.2 - visualisiert wurden. Diese hier genannten sechs Daten waren ebenfalls in Tab. 68.1 (nach Kuhle aus den Jahren 1986 und 1987) aufgelistet. Somit war die Veröffentlichung Kuhle (2011b) in Bezug auf die Befunde aus dem Solukhumbu eine Art Zusammenstellung oder Zusammenfassung, wobei die umfassendste sowie detaillierteste Ausführung zu diesem Gebiet die Arbeit Kuhle (2005) darstellte. Auf der Gletscherkarte TH 
33 waren die letzteiszeitlichen Eisränder von Kuhle für das Gebiet Ostnepal bis Westbhutan visualisiert.

\section{KUHLE (2013A)}

\section{METHODE BZW. ARBEITSTECHNIK}

Kuhle wendete geomorphologische Analysen an, wobei auch Sedimentproben analysiert wurden.

\section{UNTERSUCHUNGSGEBIET}

Neben vielen anderen genannten Forschungsgebieten untersuchte Kuhle (2013a:Fig. 7) im Gebiet des Khumbu-Himalaja bzw. des Shorong, Solu / Pharag und Hinku Talbereiche des Solu, Dudh und Hinku Khola.

\section{KRITIK}

Nach einer Forschungsreise im Jahr 2012 lieferte Kuhle 2013 zwei weitere Fotos (Nummer 7 und 8, Seite 24) und weitere drei Sedimentproben aus dem Gebiet des Khumbu-Himalaja bzw. des Solu. Hierbei wurden die bereits bei Kuhle (2005:Fig. 11) visualisierten Moränen mit nicht erratischen Blöcken in den Tälern Poyan Khola (Foto 7) auf 2.800 m Höhe und im Khari Khola (Foto 8) auf 2.430 m Höhe jeweils auf der orographisch rechten Talseite aufgenommen. In diesen Talbereichen entnahm Kuhle Sedimentproben, die bestätigten, dass es sich hierbei um Moränen handelte, aber auch bei der Ortschaft Jubing auf $1.550 \mathrm{~m}$ Höhe schloss er aufgrund einer Sedimentprobe auf 'washed ground moraine'. Beim Khari Khola schloss Kuhle (2013a:23) somit auf eine hochglaziale Eismächtigkeit des vorzeitlichen Dudh Khosi Haupttalgletschers von $800 \mathrm{~m}$ und beim Poyan Khola auf eine von ca. $1.000 \mathrm{~m}$. Die Befunde von Kuhle (2013a) reichten gegenüber denen von Kuhle (2005:Fig. 11) talabwärts gesehen im Solukhumbu bis unterhalb des Deku Khola ins Gebiet der Siedlung Jubing. Also beruhten die Ergebnisse von Kuhle auf nachweisbaren geomorphologischen Befunden. In den benachbarten Tälern Solu Khola bzw. beim Konfluenzbereich Junbesi und Beni Khola gab Kuhle (2013a:23) eine LGM Eisrandlage auf ca. 2.380 m Höhe an, im Hinku Khola eine auf ca. $1.680 \mathrm{~m}$. Als Zeugen einer vorzeitlichen Vergletscherung nannte er Moränenablagerungen bei beiden genannten Tälern sowie bei letztgenanntem außerdem ein Trogtalprofil. Desweiteren wurde in dieser Arbeit zusammenfassend aus älteren Arbeiten von Kuhle der Jahre 1988 und 2005 auf die vier Transfluenzpässe vom Rongbuk Gletscher zu den Gebieten Ngozumpa und Khumbu eingegangen (Kuhle 2013a:39). 
Kuhle (2013a:22) erwähnte das LGM Gletscherende auf etwa 4.200 m Höhe von Iwata (1976), Finkel et al. (2003) und Owen et al. (2008). Hierbei fiel auf, dass Kuhle auf Seite 22 angab, dass dieses Gletscherende auf Fig. 6 unter der Nummer 2 dargestellt war. Jedoch war dieses auf Fig. 7 unter der Nummer 2 erkennbar. Genauer betrachtet reichten bei Iwata (1976) Periche Moränen bzw. das LGM Gletscherende bei Überprüfung von Fig. 1 mittels Kartenmaterial jedoch talabwärts bis auf maximal 4.100 m Höhe. Da Iwata (1976:109) angab, dass die Periche und Thyangboche Moränen spät- oder auch hochglazialen Alters sein könnten, war hier nicht eindeutig, ob das tiefstreichende Periche Moränenvorkommen ein LGM Gletscherende anzeigte (siehe Kritik Iwata 1976 in der vorliegenden Arbeit). Finkel et al. (2003) und Owen et al. (2008) gaben den LGM Eisrand auf ca. 4.200 m Höhe an, wobei sich Owen et al. auf die Befunde von Owen, Benn (2005) bezogen.

\section{WEITERE FORSCHUNGSARBEITEN}

OWEN, FINKEL, CAFFEE (2002)

\section{Methode bzw. Arbeitstechnik}

Owen, Finkel, Caffee (2002) wendeten OSL- und TCN-Datierungen im Himalaja an. Die ermittelten Alter sollten in Verbindung mit umfangreichen Geländearbeiten die Zeiten und die Ausdehnungen der Vergletscherungen des Spätquartärs erzielen. (ebd.:147)

\section{Untersuchungsgebiet}

Owen, Finkel, Caffee (2002:148) gaben einen Überblick über die Vergletscherung des Himalaja. Da in nur sieben Himalaja Gebieten die o.g. Methoden bzw. Arbeitstechniken in Bezug auf das LGM zu zuverlässigen Daten führen sollten, waren auch nur diese genannt. Es waren die Gebiete Swat-Himalaja, mittleres Indus Tal und Nangpa Parbat-Himalaja, Hunza Tal, Zanskar, Garhwal-Himalaja, Khumbu-Himal und Kangchendzönga-Himal.

\section{Ergebnisse}

Im Himalaja war das Vergletscherungsausmaß während des globalen LGM (18.000-24.000 v.H., MIS 2) aufgrund der geringeren Einstrahlungsintensität und des schwächeren Sommermonsuns gering ausgeprägt ${ }^{342}$. Diese geringe Vergletscherung war das Resultat der niedrigen Temperaturen ${ }^{343}$. Einige Regionen im Himalaja waren dagegen während des einstrahlungsintensiven Zeitraumes des MIS 3 maximal vergletschert, was das lokale LGM

\footnotetext{
342 “[...], generally extending < $10 \mathrm{~km}$ from contemporary ice margins." (Owen, Finkel, Caffee 2002:147)

343 "The modest advances that nevertheless did occur at this time are the result of reduced temperatures." (ebd.:147)
} 
darstellte (ebd.:147, 156). Dabei sei es zu enormen Schneefällen in hohen Lagen und zu einer positiven Gletschermassenbilanz gekommen (ebd.:147). Demnach müssten die Gletscher in Hinsicht auf den globalen Klimawandel in den monsunbeeinflussten Regionen vorstoßen (ebd.:156). Heutzutage sollte Hochasien das am meisten vergletscherte Gebiet außerhalb der Pole sein (ebd.:147).

\section{Kritik}

Die Arbeit von Owen, Finkel, Caffee (2002) mit dem Titel `A note on the extent of glaciation throughout the Himalaya during the global Last Glacial Maximum’ gab einen Überblick über die bisherigen Forschungen in Himalaja Gebieten. Hierbei gingen sie besonders auf die Ergebnisse von TCN- und OSL-Datierungen ein. Owen, Finkel, Caffee (2002:147) sahen in diesen zwei neuen Techniken OSL und CRN die Möglichkeit der Klärung der Quartärchronologie des Himalaja bzw. des Vergletscherungsausmaßes und der zeitlichen Einordnung. Das Hauptaugenmerk lag auf der zeitlichen Einordnung der maximalen Vergletscherung (MIS 2, 3 oder 4) (s.h.a. Fort 2004:262). Die ermittelten OSL- und TCNAlter erbrachten in Verbindung mit umfangreichen Geländearbeiten die Zeiten und die Ausdehnungen der Vergletscherungen des Spätquartärs ${ }^{344}$. Hierbei war jedoch zu beachten, dass lediglich sieben Gebiete im Himalaja mit diesen Techniken überprüft wurden: “[...], there are only seven regions where reliable numerical dating has been undertaken on unambiguous glacial chronologies that are relevant to reconstructing the extent of ice during the LGM." (Owen, Finkel, Caffee 2002:148). ${ }^{14} \mathrm{C}$-Datierungen waren durch den Mangel an organischem Material nicht immer in diesen Gebieten möglich (ebd.:147).

Owen, Finkel und Caffee waren der Auffassung, dass das LGM anhand der OSL- und TCNDatierungen gut rekonstruiert wurde ${ }^{345}$. Vorherige Forscher sollten nur Hypothesen über die maximale Vergletscherung aufgestellt haben ${ }^{346}$. Zum Beispiel sollte Kuhle zitiert nach: Owen et al. (2008) die LGM Eisbedeckung überschätzt haben ${ }^{347}$. Weiterhin hätten Eisrekonstruktionen anderer auf Fehlinterpretationen von Formen - glazialer Formen gegenüber nicht glazialen Formen wie Massenbewegungsformen und Diamikten - basiert

\footnotetext{
344 "In conjunction with careful and extensive field observations, these ages allow the timing and extent of glaciation in Central Asia to be studied throughout the Late Quaternary." (Owen, Finkel, Caffee 2002:147)

345 "In addition, the extent of glaciation during the LGM has been adequately reconstructed." (ebd.:154)

346 "Prior to these studies, researchers were only able to hypothesize about the extent of glaciation during the LGM." (ebd.:154)

347 "Without geochronological information about the age of landforms and sediments, researchers have, in some instances, overestimated the extent of ice cover throughout the Himalaya and Tibet during the LGM (e.g. Kuhle, 1985)." (Owen, Finkel, Caffee 2002:154)
} 
(vgl. Owen, Finkel, Caffee 2002:148, 154). Jedoch hätten neuere sedimentologische und geomorphologische Analysen dieses Problem weitestgehend gelöst (ebd.:154, 156 ${ }^{348}$ ). Hierbei trat die Frage in den Vordergrund, welcher Art diese neuen sedimentologischen und geomorphologischen Analysen sein sollen und wie Kuhle die Eisbedeckung überschätzt haben soll, da er detaillierte umfassende geomorphologische Analysen - wie z.B. im Hauptuntersuchungsgebiet des Solukhumbu - anwendete.

Nichtsdestotrotz sollte es Datenunterschiede bei den OSL- und CRN-Techniken geben: "In addition, the reader should bear in mind the uncertainties associated with each dating technique. We refer the reader to Richards (2000) and Owen et al. (2001) for full discussions on the problems associated with OSL and CRN surface exposure dating of moraines and their associated landforms." (Owen, Finkel, Caffee 2002:148). Zudem sollte eine Erstellung einer vorzeitlichen Vergletscherungskarte des Himalaja erst dann möglich sein, wenn die Techniken in weiteren Himalaja Gebieten angewendet wurden ${ }^{349}$, und weitere Forschungen nötig sein, um das Zusammenspiel zwischen Klima und Vergletscherung im Himalaja besser verstehen zu können ${ }^{350}$.

Beispielsweise im Khumbu-Himal gingen Owen, Finkel, Caffee (2002:153) auf Iwata (1976) und Richards et al. (2000) ein, wobei sie bei den letztgenannten die datierten OSL-Daten angaben. In Fig. 6 visualisierten sie auf der Karte von Richards et al. (2000) die Vergletscherung des Khumbu während des LGM bis unterhalb von Periche auf ca. 4.200 m. Somit trafen sie keine eigenen Aussagen über die letztglaziale Vergletscherung im Solukhumbu. Im Kangchendzönga-Himal gingen sie auf Kuhle (1990a), Meiners (1999) und Asahi, Watanabe $(2001)^{351}$ ein, die jedoch keine numerischen Daten liefern sollten. Weiterhin schrieben sie: "However, recent OSL dates on tills show that glaciers advanced in this region at 6, 9 and 22-23 ka (Katsuhiko Asahi, pers. comm.; Asahi et al., 2000). The LGM ( 22$23 \mathrm{ka}$ ) ice limit within this region was within $\sim 10-15 \mathrm{~km}$ of the present ice margins." (Owen, Finkel, Caffee 2002:153).

\footnotetext{
348 "The OSL and CRN exposure dating in conjunction with new geomorphic and sedimentological analysis for selected regions of the Himalaya has enabled the determination of the extent of glaciation during the LGM (Fig. 7).” (ebd.:156)

349 "Only after such systematic studies have been completed throughout many more regions of the Himalaya will it be possible to produce a comprehensive map of the extent of glaciation for the Himalaya during the LGM and for other times, such as MIS-3, which is likely to be the local LGM in this Region." (Owen, Finkel, Caffee 2002:156)

350 "However, given the vastness of the region, the geologic data is still very sparse and much work is needed to complete a comprehensive database that will allow an exhaustive examination of the links between climate and glaciation in the Himalaya." (ebd.:156)

${ }^{351}$ Asahi, K., Watanabe, T. (2001): Past and recent glacier fluctuations in KanchenjungaHimal, Nepal. Journal of Nepal Geological Society.
} 
FORT (2004)

\section{Methode bzw. Arbeitstechnik}

Fort (2004:261) gab einen Überblick über die Forschungen im Himalaja, wobei die meisten auf detaillierten Geländeuntersuchungen basieren sollten.

\section{Untersuchungsgebiet}

Fort (2004) ging bei ihren Forschungen auf Gebiete in Nepal ein bzw. auf den Kangchendzönga-, Khumbu-, Shiptong-, Rolwaling-, Shorung-, Langtang-, Manaslu-, Annapurna- und Dhaulagiri-Himal.

\section{Ergebnisse}

Fort (2004) erbrachte in ihrer Ausarbeitung mit dem Titel 'Quaternary glaciation in the Nepal Himalaya' einen Überblick über die Forschungsarbeiten der quartären Vergletscherung in Nepal mit den Gebieten des Kangchendzönga-, Khumbu-, Shiptong-, Rolwaling-, Shorung-, Langtang-, Manaslu-, Annapurna- und Dhaulagiri-Himal. Ziel war es, die Verbindung zwischen der Vergletscherung und dem Monsun zu demonstrieren (ebd.:262).

\section{Kritik}

Die meisten Veröffentlichungen - die in der Arbeit von Fort beachtet wurden - sollten auf detaillierten Geländeuntersuchungen basieren (ebd.:261). Jedoch sollte nach Fort (2004:273) die Bestandsaufnahme der glazialgeomorphologischen Formen in Nepal nicht abgeschlossen gewesen sein und einige Gebiete - die heutzutage nicht begangen werden können - noch entdeckt und kartiert werden. Im Khumbu-Himalaja ging Fort in Bezug auf die vorzeitliche Vergletscherung auf die Arbeiten von Heuberger (1956), Iwata (1976, 1984 ${ }^{352}$ ), Fushimi (1978), Müller (1980), Williams (1983), Heuberger, Weingartner (1985) sowie auf Röthlisberger, Geyh (1986) ${ }^{353}$ ein, wobei die letztgenannte Arbeit und die von Williams Radiokarbondaten lieferten. Bei genauerer Betrachtung dieser Arbeiten fiel auf, dass sie im Gegensatz zu der von Kuhle (2005) nicht so detaillierte Geländeuntersuchungen aufwiesen. Somit blieb bei den von Fort genannten Forschern ungeklärt, ob sich unterhalb der von diesen ausgelegten Maximalvergletscherungsenden Moränen oder andere glaziale Formen befanden. Dieses wurde jedoch von Kuhle (2005) nachgewiesen. Für Täler, die in Nordsüdrichtung

\footnotetext{
${ }^{352}$ Iwata, S. (1984): Relative chronology of Holocene and Late Pleistocene moraines in the Nepal Himalaya. In: Li J.J., Zhang L.Y., Feng Z.D. (eds), Evolution of Quaternary glaciations. Journal of Lanzhou University Series, VI. (S. 47-57)

353 Röthlisberger, F.; Geyh, M.A. (1985): Glacier variations in Himalayas and Karakoram. Zeitschrift für Gletscherkunde und Glazialgeologie, 21. (S. 237-249)
} 
verlaufen, wie Ghunsa Khola Tamur, Buri Gandaki, Seti Khola und Kali Gandaki, gab Fort (2004:275) aufgrund der steilen topographischen und klimatischen Gradienten an, dass die vorzeitlichen Gletscher gering ausgedehnt waren. Die senkrecht zu diesen verlaufenden Täler im Khumbu, Rolwaling, Langtang und Marsyangdi sollten hingegen wohl eher längere Gletscher aufzeigen (ebd.:275). Fort (2004:264) brachte die in Nepal unterschiedliche heutige klimatische Situation - Ostnepal mit einem enormen Sommermonsuneinfluss gegenüber Westnepal mit stärkeren Winterniederschlägen - mit der vorzeitlichen Vergletscherung in Verbindung ${ }^{354}$. Fort (2004:276) sah komplexe Interaktionen der Vergletscherung mit klimatischen (Monsun, Westwinde, mediterrane Luftmassen), seismotektonischen und topographischen Aspekten, die bisher noch nicht komplett verstanden waren ${ }^{355}$. Sie führte aber dennoch gegenüber den aufgeführten Aspekten keine geomorphologischen Indikatoren einer solchen Vergletscherung an. Sie erwähnte nur, dass weitere Forschungen folgen mussten - besonders auch auf der lokalen und regionalen Ebene und in Bezug auf die Schuttbedeckung der Gletscher, um die vorzeitliche Vergletscherung zu rekonstruieren (ebd.:276 f.). Weiterhin beschrieb Fort (2004:265) die Befunde von Iwata (1976) wie folgt verändert: Kleine Eiszeit (Lobuche), Neoglazial (Thukla) und LGM (Periche). Zum Thyangboche Stadium von Iwata gab sie an, dass es älter als die letzte Vergletscherung sein sollte und vermutlich zum MIS 3 oder 4 gehörte.

Generell verwies Fort darauf, dass die vorzeitliche Vergletscherungsausdehnung von Nepal noch nicht genau geklärt war: "Knowledge of the extent of Quaternary glaciers in the Himalayan mountains of Nepal based on the accumulated evidence, still remains very fragmentary." (Fort 2004:261). Sie sah verschiedene Gründe für die unterschiedlichen wissenschaftlichen Auffassungen zur vorzeitlichen Vergletscherung Nepals. Die glazialen Materialien waren nach Fort (2004) nur wenig im Himalaja erhalten ${ }^{356}$ und komplex entstanden bzw. zusammengesetzt ${ }^{357}$. Somit sollten die Sedimente schwer zu identifizieren gewesen und die Formen 'tills', 'avalanche deposits' und 'debris cones' verwechselt worden sein, woraus die verschiedenen Interpretationen resultierten (ebd.:261 f.). Es stellte sich die Frage, wenn nach obigem Befund doch nur wenige glaziale Materialien erhalten waren, wie dann Kuhle (2005) viele dergleichen auffinden konnte. Da eine Unterscheidung der

\footnotetext{
354 "For this reason, the palaeoclimatology of the western and eastern Himalayas cannot be treated precisely the same." (Fort 2004:264)

355 “[...], are still far from being understood." (ebd.:276)

356 "This is because of the poor preservation of the glacial materials." (ebd.:261)

357 " [...] and glacial material is recycled as debris fans, rockfalls etc. This explains the extreme complexity of deposits that are preserved on the valley sides and bottoms." (ebd.:261)
} 
Materialien als schwierig beschrieben wurde, war es möglich, dass viele Forscher diese Moränen nicht als solche erkannten bzw. nicht in Erwägung zogen, dass andere Formen, wie etwa Murfächer, aus Moränenmaterialien bestehen können.

Ein weiteres Problem war das der Datierung der Formen bzw. Ablagerungen: viele basierten auf relativen Chronologien und ${ }^{14} \mathrm{C}$-Daten, wobei letztgenannte aufgrund des häufig nicht vorhandenen organischen Materials oft nicht anwendbar waren. Numerische Datierungsmethoden wurden bisher nur an Orten angewendet, die gut erreichbar waren, und bei vorteilhaften Materialien. Somit waren diese Methoden bzw. Arbeitstechniken und die Interpretationen der Daten mit Vorsicht zu betrachten. Besonders OSL-Daten waren mit Bedacht zu beurteilen, da sie eine gute Kenntnis über die Landschaft erforderten und mit sehr vielen Fehlerquellen oder Zweideutigkeiten behaftet waren. Infolge der unterschiedlichen angewendeten Datierungsmethoden bestanden Ungewissheiten über die zeitliche Einteilung des LGM. (vgl. Fort 2004:262, 273, 275)

\section{OWEN, DERBYSHIRE, FORT (1998) UND OWEN, BENN (2005)}

Die Arbeiten von Owen, Derbyshire, Fort (1998) mit dem Titel 'The Quaternary Glacial History of the Himalaya' und Owen, Benn (2005) mit dem Titel 'Equilibrium-line altitude of the Last Glacial Maximum for the Himalaya and Tibet: an assessment and evaluation of results' wurden in der vorliegenden Arbeit nicht betrachtet, da diese denen von Owen, Finkel, Caffee (2002) und Owen et al. (2008) sehr ähnelten.

\section{OWEN (2009)}

Die Veröffentlichung von Owen (2009) ähnelte sich in Bezug auf die Angaben zum Inlandeis denen von Kuhle und die zum Khumbu der Veröffentlichung von Owen, Dortch (2014) und wurde somit in der vorliegenden Arbeit nicht weiter betrachtet.

\section{OWEN, DORTCH (2014)}

\section{Methode bzw. Arbeitstechnik}

Die Forscher Owen und Dortch (2014:14) schrieben, dass die Gletschervorstöße anhand numerischer Datierungen sowie geomorphologischer und sedimentologischer Methoden im Detail erforscht werden können. Es waren die bisherigen Forschungsarbeiten im Himalaja und in Tibet anhand der verschiedenen angewendeten Methoden bzw. Arbeitstechniken wie etwa ${ }^{14} \mathrm{C}$, TCN und OSL beschrieben und in Tabellen aufgelistet. 


\section{Untersuchungsgebiet}

Owen, Dortch (2014) gingen auf das Gebiet Himalaja-Tibet ein.

\section{Kritik}

In ihrer Veröffentlichung von 2014 gaben Owen und Dortch einen Überblick über die Forschungsarbeiten im Gebiet Himalaja-Tibet in Bezug zur quartären Vergletscherung und über die angewendeten Methoden bzw. Arbeitstechniken. Darüberhinaus gingen sie auf geologische (Entstehung des Gebietes), klimatische (Westwinde, Monsun, Gletschertypen) und vegetative Aspekte des Gebietes ein (ebd.:15). Im Khumbu-Himalaja bezogen sie sich auf die Radiocarbondaten von Benedict (1976), auf die OSL-Daten von Richards et al. (2000) und auf die TCN-Daten von Finkel et al. (2003). Es wurde beschrieben, dass die Gletscher in ariden Gebieten während des globalen LGM weniger ausgebildet, demnach also in früheren Phasen des letzten glazialen Zyklus ausgedehnter waren und die Gletscher in monsunbeeinflussten Gebieten eher in späteren Phasen ausgedehnter waren, wobei letzteres noch genauer überprüft werden muss (vgl. Owen, Dortch 2014:14). In einigen Gebieten traten aber signifikante Gletschervorstöße im Spätglazial und frühen Holozän, weniger signifikante Gletschervorstöße im mittleren Holozän auf (ebd.:14). Zusammenhänge mit anderen Gebieten im Himalaja und Tibet oder mit anderen Gebieten der Erde zu konstruieren oder aber auch die einzelnen Klimamechanismen, die die Vergletscherung antrieben, sollten schwierig sein (ebd.:14).

Owen, Dortch (2014:15) gingen auf die Problematik ein, dass die zeitliche Einordnung und das Ausmaß der Vergletscherung noch wenig definiert und frühere Forschungsarbeiten durch logistische und politische Unzugänglichkeit der Gebiete eingeschränkt waren. Die Forschungsarbeiten von Kuhle, die auf das glaziale tibetische Inlandeis eingingen, standen im Gegensatz zu vielen anderen Auffassungen. Owen, Dortch (2014:19) führten mehrere Forschungsarbeiten auf, die viele Beweise dafür liefern sollten, dass während der letzten 500.000 Jahre kein tibetisches Inlandeis existierte. Außerdem missinterpretierte Kuhle laut verschiedenen dort genannten Forschern Formen und Sedimente, verwendete die Schneegrenzen für die Eisausdehnung falsch und seine Ergebnisse sollten wenig chronologisch kontrolliert gewesen sein. Diese o.g. Beweise und auch die von Kuhle missinterpretierten Formen und Sedimente wurden jedoch bei Owen, Dortch (2014:19) nicht näher erläutert, so dass nicht geklärt war, um was es sich für Formen oder Sedimente handelte bzw. wo diese vorkamen. Es wurde allgemein in einem weiteren Abschnitt darauf hingewiesen, dass beispielsweise glaziale Sedimente mit Massenbewegungsformen 
verwechselt wurden. Wie genau die Schneegrenzen falsch verwendet wurden, blieb offen. In Bezug auf die Chronologien gingen Owen, Dortch (2014:19) auf die numerischen Datierungen ein. Diese Daten zeigten, dass die meisten umfangreichen Gletscherausdehnungen in Tibet im frühen letzten Glazial - im vorletzten Glazial oder noch früher - bestanden haben sollen und ein tibetisches Inlandeis nicht im letzten Glazial existiert haben konnte oder andererseits die Moränen schon zerstört waren. Bei diesen Aussagen blieb jedoch ungeklärt, wie die gesamten geomorphologischen Indikatoren von Kuhle zu deuten waren. Owen, Dortch (2014:19) gaben nur an, dass Kuhle meinte, dass die numerischen Datierungen in solchen Höhenlagen nicht angewendet werden können und kalibriert werden sollten (83\% jünger). Owen und Dortch schrieben, dass seine Argumente zum Umrechungsfaktor falsch waren und dass es keine Gültigkeit für seine Vermutung gab.

Owen, Dortch (2014:19) meinten zudem, dass Kuhle seine Inlandeistheorie in späteren Forschungsarbeiten (letzte Literaturangabe 1995) nicht hinzuzog, aber es möglich gewesen sein konnte - obwohl es höchst unwahrscheinlich sei, dass ein Inlandeis über Tibet während des frühen bis mittleren Quartär existierte. Oberflächliche glaziale Formen dieser Periode wurden laut Owen und Dortch nicht identifiziert, aber in Zukunft würden die Meer- und Seekernstratigraphien einen weiteren Einblick liefern. Wiederum wurde hierbei nicht ersichtlich, wie die geomorphologischen Befunde von Kuhle letztendlich zu deuten waren. Außerdem ging Kuhle auch in späteren Forschungsarbeiten wie beispielsweise in Kuhle (1998:71, 98-100), (2002:1, 3, 5), (2012a:173 f.), (2012b:197), (2013a:196-200, 204 f., 208 f.) sowie in Kuhle, Kuhle (2010:118 f.) auf die Inlandeistheorie ein.

GÖTZ ET AL. (2015)

\section{Methode bzw. Arbeitstechnik}

Götz et al. (2015:1039) betrieben geomorphologische und morphometrische Analysen (Kartierung, Aufschlüsse / Sedimentanalysen, Interpretation Orthofotos, Analysen digitales Geländemodell) sowie hydrologische Analysen (Kartierung, Temperatur, pH, Leitfähigkeit, chemische Analysen wie Phosphate, Nitrate, Nitrite, Ammonium) mit elf Quellwasseranalysen. In Fig. 2 war ersichtlich, dass sie neben hydrologischen und anthropogeographischen Gegebenheiten Murfächer, Terrassen, Moränen, Steinschlagblöcke, Felssturzblöcke, Bergsturzablagerungen, Feuchtgebiete, Seesedimente, Schwemmsedimente, Rinnen, Dämme kartierten. 


\section{Untersuchungsgebiet}

Götz et al. (2015:1039, 1041, Fig. 1) untersuchten das Gebiet rund um die Orte Lukla und Namche Bazar / Khumjung / Kunde.

\section{Kritik}

In der Forschungsarbeit von Götz et al. (2015) mit dem Titel 'Geomorphologic and Hydrogeologic Characteristics of Populated Rockslide Deposits (Sagarmatha National Park, Khumbu Himal, Nepal)’ wurden zwei große Bergstürze in der Nähe der Orte Lukla und Namche Bazar, basierend auf den Arbeiten von Heuberger (1956), Heuberger und Weingartner (1985) sowie Heuberger (1986), näher betrachtet. Hierbei gingen Götz et al. (2015) besonders auf hydrogeologische Gegebenheiten und Konsequenzen für die Wasserqualität und -quantität ein. In Bezug auf das Untersuchungsgebiet nannten sie topographische, geologische, klimatische sowie siedlungsgeographische Aspekte. Die Morphologie der Ablagerungen deutete darauf hin, dass diese postglazial entstanden (vgl. Götz et al. 2015:1039). Siedlungen auf den gesamten Ablagerungen waren Namche Bazar, Lukla, aber auch kleinere Siedlungen wie z.B. Khumjung, Kunde, Kenjoma, Syangboche, Chaurikharka, Muse, Senma, Tate, Chheplung und Nachipang (ebd.:1041). Weiterhin waren zwischen den Ablagerungen kleinere Flussterrassen (z.B. Phakding), Murfächer von Nebenflüssen (z.B. TokTok) und Moränen (z.B. Debuche) besiedelt (ebd.:1041).

Der Lukla Bergsturz bzw. die Bergstürze vom Tado Kosi bis zum Surke Drangka wurden in Fig. 2 und die Khumjung-Namche Bergstürze in Fig. 3 detailliert in einer geomorphologischen Karte dargestellt, wobei sie jeweils ca. 5,5 km² groß waren (ebd.:1046). Götz et al. (2015:1041) nannten die Forschungsarbeiten von Uhlir (1998) ${ }^{358}$ und Weidinger $(2011)^{359}$, die einen ehemaligen See beschrieben, welcher durch die Ablagerungen bei Lukla aufgestaut wurde. Diese Seesedimente wurden in der vorliegenden Arbeit ebenfalls beschrieben und fotografiert (siehe Kapitel 3). Die Lukla Bergstürze, erstmals erwähnt von Heuberger und Weingartner (1985), wiesen Reste von Talverfüllungsablagerungen (Seesedimente, fluviale Materialien, Murablagerungen und möglicherweise Ablagerungen von Gletscherseeausbrüchen) auf und waren somit polygenetisch, was durch die drei

\footnotetext{
${ }^{358}$ Uhlir, C.F. (1998): Landslide-Dammed Lakes: A Case Study of the Lamabagar and Chaurikharka Landslide Deposits, Dolakha and Solukhumbu Districts, Eastern Nepal. Journal oft he Nepal Geological Society, 18. (S. 329-334)

${ }^{359}$ Weidinger, J.T. (2011): Stability and Life Span of Landslide Dams in the Himalayas (India, Nepal) and the Qin Ling Mountains (China). In: Evans, S.G., Hermanns, R.L., Strom, A. and Scarascia-Mugnozza, G., Eds., Natural and Artificial Rockslide Dams, Springer, Berlin. (S. 243-277)
} 
unterschiedlichen Terrassenlevel $(2.500-2.550 \mathrm{~m}, 2.650-2.750 \mathrm{~m}, 2.800-2.880 \mathrm{~m})$ deutlich wurde, die durch Bergstürze und / oder nachfolgende fluviale Erosion entstanden sein konnten (vgl. Götz et al. 2015:1041). Die Terrassen waren teilweise mit Blöcken bedeckt, die Terrassen der Ebene II und III mit Murfächern und alluvialen Ablagerungen (ebd.:1041).

Die bei Götz et al. (2015) aufgezeigten Bergsturzablagerungen konnten nicht in jedem Fall nur als solche ausgelegt werden, da in diesen Talbereichen mit der vorliegenden Arbeit beispielsweise Formen wie Strudeltopf, Schmelzwasserrinne, kantengerundete Blöcke sowie erratische Blöcke deutlich wurden.

Der Khumjung-Namche Bergsturz wurde erstmals von Heuberger (1956, 1986) erwähnt und stammt vom Khumbi Yul Lha (vgl. Götz et al. 2015:1043). Südlich von Kunde und Khumjung formten eckige bis zu 15 m große Blöcke den Bergsturzrücken, große Hügel kamen zwischen Syangboche und Kunde vor, im Norden existierten Murfächer, alluviale Ablagerungen und Seesedimente sowie an den Hängen Lokalmoränen, Schutthalden (teilweise zeigten diese frühere periglaziale Aktivität an) und Steinschlagblöcke (ebd.: 1043, Fig. 3). Die bei Götz et al. (2015:Fig. 3) eingezeichneten Moränen nördlich von Khumjung wurden ebenfalls in der vorliegenden Arbeit als solche erkannt. Gegen die visualisierten Bergsturzablagerungen sprachen jedoch die vielfach aufgefundenen kantengerundeten Blöcke sowie Anstehendes mit deutlich konkaven glazifluvialen Spülformen.

Götz et al. (2015) äußerten sich nicht über die Vergletscherung der untersuchten Talbereiche, obwohl sie in Fig. 2 und 3 Moränen darstellten. Demnach waren anhand dieser Forschungsarbeit keine Aussagen in Bezug auf eine Vergletscherung des Solukhumbu möglich. 


\subsection{Kurzzusammenfassung}

Die Betrachtung der Himalaja Gebiete zum Thema der letzteiszeitlichen Vergletscherung hat gezeigt, dass viele unterschiedliche Forschungsergebnisse existieren. Ausschlaggebend hierfür waren hauptsächlich Unterschiede in der jeweils angewendeten Methode bzw. Arbeitstechnik, aber auch Unterschiede in der Lage und der Größe des jeweils ausgewählten Untersuchungsgebietes (siehe Tab. I, Bildband). Die Forscher kamen dadurch zu einer differenten Vergletscherungsausdehnung (siehe Karte VIII, Bildband) und zeitlichen Einordnung von Formen. Ein Vergleich der verschiedenen Forschungsergebnisse stellte sich als schwierig heraus, da häufig umfassende Arbeiten gegenüber weniger umfassenden standen. Die Ergebnisse von Kuhle, die meist am ausführlichsten hergeleitet waren, standen in allen mit der vorliegenden Arbeit untersuchten Gebieten kontrovers gegenüber denen anderer Forschungen: Kuhle kam stets zu einer stärkeren letztglazialen Vergletscherung der Himalaja Gebiete. Da er infolgedessen immer haupttalabwärtigere Bereiche bzw. größere Untersuchungsgebiete erforschte und dort Kennformen einer vorzeitlichen Vergletscherung auffand, waren die Ergebnisse der hier weiter betrachteten Forschungsarbeiten kritisch zu überprüfen. Grundsätzlich standen sich die angewendeten Methoden bzw. Arbeitstechniken geomorphologische Reliefanalyse, relative Datierungen wie etwa Bodenanalyse und absolute Datierungen wie ${ }^{14} \mathrm{C}$, TCN bzw. OSL gegenüber, wobei die Frage gestellt werden sollte, ob die letztgenannten Methoden bzw. Arbeitstechniken im Gegensatz zur Geomorphologie für eine Vergletscherungsrekonstruktion benötigt werden bzw. geeignet sind. Die Methode der geomorphologischen Analyse stellte sich gegenüber den Datierungsmethoden als bislang zielführendste für die Rekonstruktion einer vorzeitlichen Vergletscherung heraus.

Angewendete Methoden bzw. Arbeitstechniken ausgewählter Forscher im Hauptuntersuchungsgebiet waren folgende: Müller (1959) - geomorphologische Formen (im Hauptuntersuchungsgebiet Moränen, Schliffspuren, Kare), Messungen; Miller (1970) geomorphologische Formen (Moränen und Spülformen), relative Datierungen (Lichenometrie), Messungen; Benedict (1976) - absolute Datierungen $\left({ }^{14} \mathrm{C}\right)$; Iwata (1976) geomorphologische Formen (Moränen und Trogtäler), relative Datierungen (z.B. Frische/Verwitterungsgrad, Querprofil, Bodenprofil, Moränenprofil); Fushimi (1977) geomorphologische Formen (Moränen, Rundhöcker mit Gletscherschrammen und Trogtäler), relative Datierungen (z.B. Verwitterungsgrad, Bodenentwicklung); Fushimi (1978) geomorphologische Formen (Moränen und andere Sedimente, Trog- und Kerbtal), absolute Datierungen $\left({ }^{14} \mathrm{C}\right)$; Müller (1980) - geomorphologische Formen (Kare, Moränenreste und 
glaziale Terrasse), Schneegrenzberechnungen, relative und absolute Datierungen (Lichenometrie, ${ }^{14} \mathrm{C}$ ); Williams (1983) - im Dudh Khunda Tal geomorphologische Formen (Moränen, Kare und Trogtäler), Karten- und Satellitenbildinterpretationen, Schneegrenzberechnungen, relative Datierungen (pedologische Befunde und Verwitterungsunterschiede); Kuhle (1984) - geomorphologische Analyse und Satellitenbildauswertung, geomorphologische Formen (Trogtäler, glazigene Kerbtäler, Ufermoränen, Ufermulden, Eisrandlagen); Heuberger, Weingartner (1985) geomorphologische Formen (Moränen, Bergsturzablagerungen und Felsformen), relative Datierungen (Bodenanalyse); Heuberger (1986) - geomorphologische Formen (Moränen), relative Datierungen (Bodenanalyse); Kuhle (1986a) - geomorphologische Analyse, relative und absolute Datierungen (Lichenometrie, ${ }^{14} \mathrm{C}$ ), Schneegrenzberechnungen; Kuhle (1987a) geomorphologische Analyse, relative und absolute Datierungen (Lichenometrie, ${ }^{14} \mathrm{C}$ ), Schneegrenzberechnungen; Kuhle (1987b) - geomorphologische Analyse (Formen wie z.B. Kare, Ufermoränen, glaziolimnische Sande), Schneegrenzberechnungen, Oberflächentemperatur- sowie Solarstrahlungsmessungen; Kuhle (1988a) geomorphologische Analyse; Bäumler et al. (1991), Bäumler, Kemp-Oberhettinger, Zech (1996), Bäumler, Zech (1998), Bäumler (2001) - geomorphologische Formen (Moränen, glazifluviale Ablagerungen, bei letztgenanntem Forscher auch Trogtäler genannt), relative und absolute Datierungen (Bodenanalyse, ${ }^{14} \mathrm{C}$ - im Langtang); Kuhle (1998) geomorphologische Analyse, Schneegrenzberechnungen; Aoki, Imamura (1999) geomorphologische Formen (Moränen), absolute Datierungen (TCN); Richards et al. (2000) geomorphologische Formen (Moränen, Terrassen, glazifluviale und glazilimnische Sedimente), absolute Datierungen (OSL); Kuhle (2001a) - geomorphologische Analyse, geomorphologische Formen (glazigene Abrasionsformen); Finkel et al. (2003) geomorphologische Formen (Moränen), absolute Datierungen (TCN); Kuhle (2005) geomorphologische Analyse (viele Formen, Sedimentanalyse, Talquerprofile, viele Fotos als Belege), Schneegrenzberechnungen, relative und absolute Datierungen (Lichenometrie, ${ }^{14} \mathrm{C}$ ); Barnard, Owen, Finkel (2006) - geomorphologische Formen (Moränen, 'landslides', Paläokanäle, Fächer und Terrassen, Talquerprofile), sedimentologische sowie stratigraphische Analysen, absolute Datierungen (TCN); Kuhle (2007a) - geomorphologische Analyse, geomorphologische Formen (glazigene Abrasionsformen), Schneegrenzberechungen; Rai, Yoshida, Upreti (2007) - geomorphologische Formen (unterschiedliche Sedimenttypen bei unterschiedlichen Plattformen, darunter Moränen); Owen et al. (2008) - Neuberechnung bestehender OSL- und TCN-Daten; Kuhle (2011b) - geomorphologische Analyse (viele 
Formen, Sedimentanalyse), absolute Datierungen $\left({ }^{14} \mathrm{C}\right)$; Kuhle (2013a) - geomorphologische Analyse (Formen wie Grundmoränen, Fotos, Sedimentanalyse).

Da die Arbeit von Kuhle (2005) die detaillierteste Arbeit von ihm im Hauptuntersuchungsgebiet darstellte, konnte besonders diese zum Vergleich mit anderen Forschungsarbeiten herangezogen werden. Wenn geomorphologische Analysen durch andere Forscher als Kuhle (2005) erfolgten, wurden oft keine detaillierten Analysen bzw. Bestandsaufnahmen, sedimentologische Untersuchungen der Moränen bzw. Bodenprofile, Belege in Form von Fotos bzw. jegliche visuelle Beweisdarstellungen dieser Formen sowie keine Schneegrenzberechnungen geliefert. Außerdem beschränkte sich die Anzahl der verschiedenen untersuchten glazialen Formen meist auf ein Minimum. Generell wurden oft keine Forschungsrouten angegeben. Die von einigen Forschern beschriebene Ausgestaltung der Moränen als deutliche Rücken ließ eher auf ein jüngeres Alter schließen. Oft gaben sie auch an, moränische Ablagerungen nicht eindeutig oder nur schwierig als solche erkannt zu haben oder es wurden generell keine Aussagen über die Maximalvergletscherung gegeben. Somit waren diese Forschungsarbeiten im Gegensatz zu denen von Kuhle - besonders Kuhle (2005, 2011b, 2013a) - in Bezug auf eine Maximalvergletscherung eher als ungeeignet anzusehen.

Es waren keine bzw. keine neuen Aussagen über die letztglaziale Vergletscherung anhand weiterer aufgeführter Forschungsarbeiten wie denen von Yokoyama (1978), Owen, Derbyshire, Fort (1998), Owen, Finkel, Caffee (2002), Fort (2004), Owen, Benn (2005), Owen (2009) und Owen, Dortch (2014) möglich, da darin entweder keine Aussagen getroffen wurden, sich Ergebnissen von bereits genannten Forschern angeschlossen wurde oder sie nur einen Überblick über die Forschungen im Himalaja gaben. Die Literaturquellen Iwata (1984), Owen, Derbyshire, Fort (1998) und Owen, Benn (2005) wurden in der vorliegenden Arbeit nicht weiter berücksichtigt, da sich erstgenannte nicht auffinden ließ und die letzteren beiden sich mit den Arbeiten von Owen, Finkel, Caffee (2002) und Owen et al. (2008) ähnelten.

\section{FORSCHUNGEN IM KHUMBU}

Da die Forscher Miller (1970), Iwata (1976), Fushimi (1977), Williams (1983), Kuhle (1986a, 1987a), Aoki, Imamura (1999), Richards et al. (2000), Finkel et al. (2003), Barnard, Owen, Finkel (2006) und Owen et al. (2008) im Hauptuntersuchungsgebiet des Solukhumbu nur das obere Einzugsgebiet des Khumbu-Himalaya - zumeist das Gebiet des oberen Imja Khola sowie des Lobuche Khola und dort meist nur die Talbereiche - untersuchten, konnten sie nur 
behutsam für eine hochglaziale Vergletscherung herangezogen werden. Heuberger und Weingartner (1985) machten bereits auf dieses Problem aufmerksam. Somit konnte es sein, dass weitere Moränen talabwärts dieser Untersuchungsgebiete vorkamen, was durch Heuberger (1956), Fushimi (1978), Heuberger und Weingartner (1985), Heuberger (1986) und Kuhle (1987b, 1998, 2005, 2007a, 2011b, 2013a) belegt wurde. Iwata (1976) zumindest deutete diese Problematik durch ein visualisiertes Fragezeichen unterhalb der tiefstreichenden Thyangboche Moränen an, wobei auch die Tatsache, dass die Periche und Thyangboche Moränen spätglazialen Alters sein konnten, auf ein solches Vorkommen schließen ließ. Zusätzlich wiesen die von Iwata (1976) an den orographisch linken und rechten Talflanken kartierten Thyangboche Moränen und die mit Fragezeichen versehenen Bereiche auf einen mächtigeren vorzeitlichen Khumbu Gletscher hin. Desgleichen könnten auch die von Barnard, Owen, Finkel (2006) kartierten Murfächer auf Moränenmaterial entlang dieser Hangbereiche deuten, da das zahlreich benötigte Lockermaterial für die von diesen Forschern so gesehene Murfächerentstehung nicht nur von Verwitterungsprozessen stammen konnte. Kuhle (2005) ging ohnehin davon aus, dass diese fächerartigen Bildungen zerschnittene Moränen darstellten. Müller (1980) stellte Periche Moränen unterhalb von Periche auf der orographisch rechten Talflanke dar, die ebenfalls wie bei Iwata (1976) darauf hindeuten könnten, dass der Khumbu Gletscher diese Moränen dort ablagerte, da es unwahrscheinlich wäre, wenn eventuelle vorzeitliche Hängegletscher auf diesem Hang 200 m weiter heruntergereicht hätten als ein größerer Talgletscher; auch das von ihm angegebene spätglaziale Alter dieser Moränen ließe ein tieferes vorzeitliches Khumbu Gletscherende zu. Zudem sollen bei Iwata (1976) auch die Thyangboche Moränen spät- oder hochglazial sein und diese nicht deutlich von den Periche Moränen unterscheidbar sein, wobei unterhalb der von ihm aufgefundenen Moräne bei Thyangboche keine End- oder Lateralmoränen aufzufinden sein sollen. Ein Kritikpunkt war beispielsweise folgender: Nach Iwata reichten Moränen gleichen Stadiums beim Khumbu Haupttalgletscher nicht so weit herunter wie die der Nebentalgletscher. Würden die Moränen ungefähr auf derselben Höhenlage enden, würde das aussagen, dass z.B. Lobuche Moränen der kleineren Gletscher höher liegen müssten oder dass die des Khumbu Gletscher auf mindestens 4.200 m Höhe enden würden. Das bedeutete wiederum, dass die von Iwata (1976) ausgelegten Periche Moränen als Lobuche Moränen anzusprechen wären. Daraus schlussfolgernd würde die Maximalvergletscherung der letzten Vereisung viel weiter talabwärts gereicht haben, als es von Iwata (1976) beschrieben wurde. Fushimi (1977) gab Periche Moränen und ein weiteres Stadium an, dass älter als das Periche Stadium sein soll. Es blieb jedoch offen, wie alt die Stadien und die Trogtalserien waren. Miller (1970) ging von 
einer pleistozänen Vergletscherung aus, die sich nicht maßgeblich von der rezenten Vergletscherung unterschied. Es wurden in Bezug auf die Maximalvergletscherung keine Analysen betrieben. Da Williams (1983) im Gegensatz zum Imja Drangka in einem südlicher liegenden Gebiet eine größere vorzeitliche Vergletscherung eines kleineren Gletschers vorgab, war diese Arbeit kritisch zu betrachten. Im Gebiet des Solukhumbu leistete er keine Geländearbeiten; somit war diese Arbeit für den Nachweis einer hochglazialen Vergletscherung des Solukhumbu wenig geeignet. Die Forschungsarbeiten von Kuhle (1984, 1986a, 1987a, b, 1988a, 1998, 2001a, 2007a, 2011b, 2013a) konnten zu der umfassenderen Arbeit aus dem Jahr 2005 hinzugezählt werden. Die datierten Moränen von Aoki, Imamura (1999) auf ca. 4.250 Höhenmetern waren in die letzte Eiszeit zu stellen.

\section{ABSOLUTE DATIERUNGEN}

Es lagen den Forschungen von Richards et al. (2000) OSL- sowie denen von Aoki, Imamura (1999), Finkel et al. (2003), Barnard, Owen, Finkel (2006), Owen et al. (2008) TCNDatierungen zugrunde. Es bestand hier die Problematik der umfangreichen Methodenfehlerquellen sowie der nicht angewendeten kritischen Überprüfung bzw. geomorphologischen Deutung. Etwa übereinstimmende Daten verschiedener Moränenrücken und die mit diesen Altern übereinstimmende Morphostratigraphie deuteten laut Finkel et al. darauf hin, dass die Daten korrekt und die Blöcke nur unbedeutend durch Erosion verändert waren. Beispielsweise schwankten aber die Daten nebeneinander liegender Sedimente bei Finkel et al. (2003) maximal um ca. 27.000 Jahre sowie bei Richards et al. (2000) um ca. 2.100 Jahre, was bei Richtigkeit der Daten auf eine Durchmischung des Moränenmaterials schließen ließ und somit darauf hindeutete, dass alle Moränen auch unterhalb der von ihnen kartierten durchmischt sein konnten. Innerhalb eines Moränenzuges schwankten die Daten bei Finkel et al. (2003) um maximal ca. 64.130 Jahre. Somit würden allein durch Datierungen Eisrandlagen nur schwierig bzw. nicht beweiskräftig bestimmbar sein. Ebenso schwankten bei Barnard, Owen, Finkel (2006) die Werte innerhalb der Fächer bis zu 77.340 Jahre. Hierbei fiel auf, dass nicht unbedingt die Anzahl der beprobten Blöcke, hier ein bis sieben Stück, zu einem genaueren Ergebnis führen muss. Außerdem zeigten die Ausführungen von Finkel et al. (2000), dass jüngere Moränen in tieferen Höhenlagen vorkamen als ältere: z.B. Thyangboche über Periche Moränen, Periche I über Periche II Moränen, was geomorphologisch gesehen durch eine Überfahrung ausschließbar wäre. In der Forschungsarbeit von Finkel et al. (2003) existierten in sich Widersprüche beispielsweise in den Darstellungen zur Abmessung der Untersuchungsgebiete, bei den zeitlichen Angaben des 
Thyangboche Stadiums oder bei den visualisierten Probenahmestellen gegenüber den aufgelisteten Daten: z.B. Dateninkongruenz. Letztgenannter Aspekt warf Fragen auf wie etwa die, warum die Probenahmestellen eines Moränenzuges unterschiedliche Alter aufwiesen, ob dies auf eine Durchmischung hindeutete oder warum die beprobten Blöcke nur innerhalb der Talbereiche und vor allen Dingen auf jünger erscheinenden Moränenrücken lagen. Bei einer Thyangboche Moräne legten sie sich auf einen Entstehungszeitraum fest. Zudem beachteten sie nur beim Stadium Thyangboche I die Möglichkeiten der Altersüber- bzw. -unterschätzung der datierten Werte. Generell wiesen viele Blöcke eines Moränenzuges auf unterschiedliche Gletscherstadien hin, was die Aussage über die maximale Vergletscherung fraglich erscheinen ließ. Bei den Periche Moränen war unerklärt, warum die Daten an die Morphostratigraphie angepasst werden mussten. Würde die Methode bzw. Arbeitstechnik korrekte Daten liefern, sollte die Morphostratigraphie nur als eine Art Überprüfung dieser gelten. Da laut den Forschern die Daten aber nur mit Ausnahme der ältesten Moränen übereinstimmten, konnte die Aussage in Bezug auf die Richtigkeit der Daten kritisch hinterfragt werden. Selbst wenn die ältesten Moränen nicht berücksichtigt werden, wären die Daten trotzdem nicht immer gleich. Außerdem kann die Morphostratigraphie der Moränen mit den Daten übereinstimmen, ohne dass die gesamten Daten stimmen müssen. Somit argumentierten Finkel et al. (2003) nur anhand der ermittelten Daten der Proben in Verbindung mit der Abschwächung des Sommermonsuns. Ein weiterer Kritikpunkt war, dass Finkel et al. teilweise Aussagen anderer Forscher zum Thema der vorzeitlichen Vergletscherung verändert haben bzw. abweichend zitierten. Richards et al. (2000) gingen davon aus, dass Khumbu und Imja Gletscher während des LGM bis zu deren Konfluenz hinab reichten. Die Befunde beschränkten sich auf die Talbereiche bzw. auf Randmoränen, wobei diese lediglich Rückzugsstadien bzw. spätglaziale Stadien darstellen könnten. Die von Richards et al. (2000) genannten Beweise für die Richtigkeit der Daten müssen nicht unbedingt welche sein; es könnten trotzdem alle Daten nicht korrekt sein. Barnard, Owen, Finkel (2006) bezogen sich in Bezug auf die Maximalvergletscherung des Khumbu auf die Befunde von Richards et al. (2000) und Finkel et al. (2003). Wann sich die Formen im Einzelnen herausbildeten, blieb trotz der Datierungen von Barnard, Owen, Finkel (2006) ungenau. Diese Datenalter sollen aber, mit einer Ausnahme, auf einen zeitlichen Zusammenhang zwischen Entstehung der Form und Gletscherstadium bzw. Gletscherrückzug hindeuten. Um vorbelichtete Blöcke festzustellen, nahmen sie multiple Proben von jedem Fächer und jeder Terrasse. Desweiteren datierten sie eine Flutterrasse und nahmen deren Alter als Nullalter an - das Alter ließ darauf schließen, dass die Vorbelichtung weniger als 1.000 Jahre betrug. Infolgedessen sollen die ermittelten 
TCN-Alter nicht überschätzt sein. Hierbei könnten jedoch alle Blöcke vorbelichtet sein oder eine weitere rezente Flutebene andere Werte aufzeigen. Die Bestimmung der Alter der Fächer und Terrassen erschien bei der Aussage, dass die Formen eingeschnitten, stellenweise stark abgetragen und mit- bzw. untereinander verschachtelt sein können, als schwierig. Sie bezogen aber auch Daten nicht mit ein, da sie davon ausgingen, dass die Blöcke vorbelichtet waren. Außerdem traten Unterschiede zwischen den datierten Altern und der Morphostratigraphie auf. Aus den multiplen Daten berechneten sie das gewichtete Mittel. Der geringe Probenumfang jeder Form würde jedoch keine aussagekräftigen berechneten statistischen mittleren Altersangaben der einzelnen Formen zulassen. Bei der Betrachtung der Aussagen in Bezug auf die Fehlerquellenbehebung der Exhumierung und der Veränderung der Lage war fraglich, ob die Blöcke im Randbereich der Form wirklich die größten Blöcke waren und auf dem Rücken der Form lagen. Ob daher beide Fehlerquellen durch diese Vorgehensweisen ausgeschlossen werden können, blieb ungewiss. Die von Owen et al. (2008) neuberechneten Daten der genannten OSL- und TCN-Datierungen stimmten einigermaßen mit denen überein. Zur letzteiszeitlichen Vergletscherung zitierten Owen et al. (2008) die Forschungsarbeiten Shi (2000) und Owen, Benn (2005). Owen et al. wiesen jedoch darauf hin, dass die Werte von Shi nicht unbedingt richtig sein müssen, welche auf eine stärkere Vergletscherung hinwiesen als die nach Owen, Benn (2005).

\section{FORSCHUNGEN IM SOLU}

Heuberger (1956), Müller (1959), Fushimi (1978), Müller (1980), Kuhle (1984), Heuberger und Weingartner (1985), Heuberger (1986), Kuhle (1987b, 1988a, 1998), Bäumler et al. (1991), Bäumler (2001), Kuhle (2001a, 2005, 2007a), Rai, Yoshida, Upreti (2007) und Kuhle (2011b, 2013a) konnten, da sie auch das Dudh Kosi Tal untersuchten, viel eher für die maximale Vergletscherung des Khumbu-Himalaya herangezogen werden, wobei erstgenannte Forschungsarbeit ausgeschlossen wurde, da Heuberger seine Befunde öffentlich zurücknahm. Kuhle (2005 einschließlich 2001a, 2007a, 2011b und 2013a) untersuchte das Dudh Khosi am weitesten talabwärts. Die Forschungsarbeiten von Müller (1959) bis talabwärts von Aisyalukharka lieferten das Ergebnis, dass glaziale Formen existieren; wo einige dieser Formen jedoch vorkamen, blieb ungeklärt. Beispielsweise fand er Moränenreste bei Phaphlu, wobei er unterhalb dieses Ortes aber keine eindeutigen Indikatoren einer ehemaligen Vergletscherung feststellte. Bei den älteren Moränen bei Pheriche vermutete Müller eine Verbindung zum Maximum des 1600er Vorstoßes in den Alpen. Somit war dieses Stadium kein hochglaziales, wobei über die zeitliche Einordnung der o.g. noch älteren Moränenstadien 
keine Aussage getroffen werden konnte. Da zur Berechnung der vorzeitlichen Schneegrenze eisfreie Kare - die vor oder nach dem Pheriche entstanden - dienten, war nicht eindeutig, ob es sich bei den von Müller (1980) ermittelten spätpleistozänen Schneegrenzen um hoch- oder spätglaziale oder sogar noch jüngere Schneegrenzverläufe handelte. Da das Pheriche Stadium als spätglaziales Stadium angesehen wurde, war ebenfalls unklar, ob das angegebene Pheriche Stadium und das Stadium, das älter als Pheriche war, eine letzteiszeitliche Maximalvergletscherung anzeigten. Zudem stellte sich die Frage, ob weitere tieferliegende eisfreie Kare - als die bei Müller betrachteten - existieren bzw. was diese für eine Vergletscherung anzeigen würden.

Die Forschungsergebnisse von Kuhle (2005) waren am detailliertesten. Hierbei wurde auf eine Form eingegangen, die, im Gegensatz zur älteren und auch neueren wissenschaftlichen Literatur, auch im kerbförmigen Talprofil, oft ausgebildet als schluchtförmiger Trog oder auch trogförmige Schlucht, einen Hinweis für eine Vergletscherung lieferte. Bereits Kuhle (1984) erwähnte, dass auf der Südseite des Himalaja talabwärts der Trogtäler glazigene Kerbtäler auftraten. Wo Heuberger, Weingartner und Fushimi in der Nähe von Lukla auf ca. 2.500 bis 2.100 m Höhe einen Übergangsbereich von Trog- zu Kerbtal als eine Eisrandlage ansahen, verwies Kuhle (2005) nur auf einen spät- und keinen hochglazialen Gletscherrand. Heuberger, Weingartner (1985) gaben an, dass die Höhenlage des Zungenendes nicht genau festgelegt war. Die grafische Darstellung des vorzeitlichen Eises warf einige Fragen zu einer typischen Gletscherformung auf, wobei die Rekonstruktion, abgesehen von zwei Standorten, an sechs Bodenprofilen festgemacht wurde. Sie fanden und kartierten nur ausgewählte hochglaziale Moränen als wallförmige langgezogene Rücken. Die zeitliche Einteilung basierte auf zwei unterschiedlichen Bodentypen, obwohl keine genauen Angaben über die Bodenentwicklung aus dem Himalaja bekannt waren. Hocheiszeitliche Moränen sollen im Pharag oft nicht erhalten oder überformt sein. Hierdurch konnte geschlussfolgert werden, dass die aufgefundenen gut erhaltenen formfrischen Moränen nicht unbedingt hochglazialen Alters waren, sondern jüngere sein könnten. Zusätzlich deutete die Längsausbildung der Moränenwälle darauf hin, dass diese Ufermoränen einem ehemaligen, wohl spätglazialen Nebentalgletscher entstammen konnten. Die Forscher äußerten sich, dass eine zeitliche Abgrenzung von Felsformen der letzten Eiszeit von denen älterer Eiszeiten schwierig sei. Infolgedessen blieb offen, wie zuverlässig die vorgenommene Trennung der Felsformen zwischen Lokal- und Hauptvergletscherung war. Sie gingen davon aus, dass die Eisrandablagerungen eine Folge von Gletscherständen nach dem Maximum des Hauptgletschers darstellten. Demnach konnten diese in die Zeit des Hoch- bis Spätglazial, 
eher wohl aber in das Spätglazial eingeordnet werden. Es konnte davon ausgegangen werden, dass das Gletscherende bei Fushimi (1978) auf ca. 1.920 m Höhe - wie in Fig. 10 visualisiert - lag, auch aus dem Grund, weil die Moränenablagerungen der U-1 Serie tiefer als das eingezeichnete Kerbtal hinab reichten. Fraglich hierbei war, warum die vorzeitlichen Gletscher im Khumbu nicht weiter talabwärts reichten als die in den Gebieten Hinku und Hongu. Heuberger (1986) legte trotz des Kerbprofils eine vorletzte Eisrandlage anhand pedologischer Befunde unterhalb von Surke fest, lieferte aber keine glazialgeomorphologischen Hinweise dafür. Laut ihm sollen in den schmalen Tälern des Pharag aufgrund einer kurzfristigen Eisverfüllung wenige glaziale Reste sowie keine auffallenden glazialen Felsformen vorhanden und die Erratika nicht auszumachen sein. Kuhle (1988a, 1998) ging gegenüber seiner früheren Forschungsarbeit Kuhle (1987b) - hier bis auf 1.580 m Höhe - von einer letzthocheiszeitlichen Vergletscherung bis auf eine Höhe von 1.800 $\mathrm{m}$ aus, wobei er durch weitere glazialgeomophologische Befunde eine talabwärtigere Vergletscherung bis auf 900 bis 1.100 m (Kuhle 2001a) bzw. bis auf ca. 900 m (Kuhle 2007a, 2011b, 2013a) rekonstruierte. Bäumler et al. (1991) gingen davon aus, dass das letzteiszeitliche Eis nicht mehr den Ort Lukla erreichte, jedoch sollen südlich von Namche Bazar keine deutlichen glazialen Formen aus dem Pleistozän vorkommen; letztendlich schlossen sie sich den Ergebnissen von Heuberger, Weingartner (1985) und Heuberger (1986) an. Es wurde nicht erläutert, wie die jungen Böden zeitlich voneinander unterschieden wurden. Bäumler, Kemp-Oberhettinger, Zech (1996) schlussfolgerten ebenfalls, dass Lukla von der jüngsten Hauptvergletscherung nicht mehr erreicht worden sein soll. Sie untersuchten fast ausschließlich Böden auf deutlich erkennbaren Moränenwällen und beschränkten sich auf sechs kleine Ausschnitte im Solukhumbu. Da diese Moränenwälle auf ein eher jüngeres Alter schließen ließen, werden die dort untersuchten Bodenentwicklungen kaum eine maximale hochglaziale Gletscherausdehnung anzeigen können. Auffallend war, dass in dieser Arbeit ein Widerspruch zwischen den Bodenbefunden und der Lagebeziehung von Moränen bestand. Alleinige geomorphologische Analysen sollen im Himalaja jedoch für die Rekonstruktion der Vergletscherungsgeschichte schwierig zu erheben sein. Die Arbeit von Bäumler, Zech (1998) stellte eine Zusammenfassung bzw. Ergänzung der Arbeit von Bäumler, Kemp-Oberhettinger, Zech (1996) dar. Bäumler (2001) kam zum Ergebnis, dass das Gebiet des Solukhumbu hochglazial bis auf ca. 3.500 bzw. $3.800 \mathrm{~m}$ Höhe vergletschert war. Die angewendete Methode bzw. Arbeitstechnik der Bodenanalysen soll für eine Klimarekonstruktion nur teilweise geeignet sein, da diese nicht in allen Fällen zum selben Ergebnis führt. Da sich Bäumler auf die Befunde anderer Forscher verließ und keine weiteren geomorphologischen 
Analysen talabwärts dieser Bereiche betrieb, musste unsicher bleiben, ob die untersuchten eindeutigen Moränen das Maximalstadium anzeigten oder andere uneindeutige, überprägte älterquartäre glaziale Akkumulationen waren. Es könnte sein, dass es sich bei den eindeutig ausgebildeten Moränen um spätglaziale handelte und weiter talwärts vorkommende uneindeutige Moränen hochglaziale waren. Auch dass Bäumler (2001) nur eindeutig ausgebildete Moränen beachtete, ließ darauf schließen, dass nur Lateral- oder Endmoränen betrachtet wurden. Da es sich bei den untersuchten Moränen nicht immer um Endmoränen handelte, schlussfolgerte Bäumler (2001), dass sowieso keine genauen Aussagen über die Maximalvergletscherung möglich seien. Er merkte an, dass eine Trennung der Moränen zwischen Spät- und Hochglazial anhand der Methode / Technik nicht möglich war, wodurch seine Festlegung der letztglazialen Eisgrenze fraglich erschien. Bäumler verließ sich hauptsächlich auf die Befunde von Heuberger, Weingartner (1985); hierbei war es unverständlich, warum er dann das letztglaziale Gletscherende nicht so wie ebendiese Forscher auf unterhalb von ca. 2.500 m Höhe festlegte. Die von Bäumler rekonstruierten Gletscherenden waren somit wenig nachvollziehbar und nicht eindeutig belegt. Der Umfang des Untersuchungsgebietes zu den Ausführungen von Kuhle (2005, einschließlich 2013a) war enorm und für eine Aussage über die Maximalvergletscherung ausreichend. Die von Kuhle (2005) angewendeten sedimentologischen Analysen waren wichtig, um festzustellen, um was es sich für Ablagerungen handelte. Somit waren Moränen bzw. die Charakteristika einer ehemaligen Vergletscherung eindeutig als solche identifiziert worden. Durch die Lagebeziehung der Formen untereinander wurde die zeitliche Einordnung dieser Moränen verständlich, wobei die Methoden bzw. Arbeitstechniken ${ }^{14} \mathrm{C}$ und Lichenometrie auf ein Minimalalter schließen ließen. Die glazialgeomorphologischen Kennformen endeten oberhalb des Deku Khola. In Fig. 11 war das hocheiszeitliche Gletscherende mit einem Fragezeichen versehen worden, was darauf hindeutete, dass direkt in diesem Bereich keine eindeutigen Kennformen mehr aufgefunden wurden. Bei Kuhle (2013a) waren glaziale Indikatoren auch talabwärts des Deku Khola beim Ort Jubing angegeben; Kuhle (2001a, 2007a) ging auf glazigene Abrasionsformen bei Jubing ein. $\mathrm{Ob}$ sich weiter talabwärts weitere glazialgeomorphologische Formen auffinden ließen, müsste weiterhin im Gelände überprüft werden. Jedoch würde sich an seiner gesamten vorzeitlichen Eisrekonstruktion nichts grundlegend ändern, da seine Ausführungen schlüssig waren. Bei den Forschern Rai, Yoshida, Upreti (2007) konnte keine abschließende Kritik formuliert werden, da nur eine Zusammenfassung zu dieser Literaturquelle auffindbar war. Bedeutend war jedoch, dass in 
den beschriebenen Plattformen rund um Lukla Moränen aufgefunden wurden, was für eine vorzeitliche Vergletscherung in diesen Talbereichen sprach.

\section{BETRACHTUNG AUSGEWÄHLTER LITERATUR ZU DEN VERGLEICHSUNTERSUCHUNSGEBIETEN ZUR ÜBER- PRÜFUNG GLEICHGEARTETER KRITIKPUNKTE ANALOG ZUM HAUPTUNTERSUCHUNGSGEBIET}

\subsection{Dhaulagiri- und Annapurna-Himal}

\subsubsection{Mayangdi Khola}

Im Tal Mayangdi Khola war auf die Arbeiten von Kuhle (1980, 1998, 2007a, 2013a) einzugehen.

KUHLE (1980)

METHODE BZW. ARBEITSTECHNIK

Kuhle (1980:246) wendete geomorphologische Analysen an, z.B. machte er Moränen im Gelände aus und legte 50 Talquerprofile an, wobei er elf spät- bis postglaziale Stadien nachvollzog.

\section{UNTERSUCHUNGSGEBIET}

Im Gebiet des Dhaulagiri und Annapurna-Himal untersuchte Kuhle (1980) die Täler Mayangdi Khola, Miristi Khola und Thulo Khola.

\section{KRITIK}

In der dreiseitigen Veröffentlichung unter dem Titel 'Klimageomorphologische Untersuchungen in der Dhaulagiri- und Annapurna-Gruppe (Zentraler Himalaya)' beschrieb Kuhle (1980:246) im Gebiet des Dhaulagiri und Annapurna-Himal eine Talvergletscherung bis auf einen Abschnitt im Inneren Himalaja, welcher ein Eisstromnetz aufwies (Gruppe des Mul Lekh und südlichen Sangda-Himal). Die tiefsten LGM Eisrandlagen bestanden bei 1.100 m Höhe, was Kuhle (1980:246) z.B. durch Moränen im Mayangdi Khola bestätigte. Die hocheiszeitliche Schneegrenze rekonstruierte er auf etwa $4.030 \mathrm{~m}$ Höhe bei einer Schneegrenzdepression von ca. $1.460 \mathrm{~m}$. Weiterhin beschrieb er elf Stadien: Ghasa, Taglung, Dhampu, Sirkung, Nauri, Älteres, Mittleres und Jüngeres Dhaulagiri, VIII, IX sowie X. Bei 
Kuhle (1980:246) besonders hervorzuheben war das Ergebnis, dass in einst vergletscherten Gebieten nicht immer Trogtäler entstehen müssen, sondern aufgrund der Steilheit des Geländes auch glazigene Kerbtäler auftreten können. Diese Talform war laut Kuhle (1980:247) in diesem Untersuchungsgebiet gegenüber den Gebieten der Alpen typisch. Gletscherschrammen entlang der Talflanken - wie in den hier erwähnten Tälern Mayangdi Khola, Miristi Khola und Thulo Khola bis auf eine Höhe von 1.800 m ausgebildet, was auf eine enorme vorzeitliche Gletschermächtigkeit schließen ließ (vgl. Kuhle 1980:246 f.) sicherten diese Erkenntnis ab. Kuhle (1980:246) äußerte sich zu diesen Talformen wie folgt: „Sie zeigen, mit der Ausnahme kurzer Flachstrecken, in denen Troganklänge auffallen, schluchtartig enge Profile.". Andere Forscher gingen $\mathrm{zu}$ den in der vorliegenden Arbeit behandelten Gebieten nicht auf solche spezielle Talformen ein - wohl auch nicht in weiteren Gebieten Hochasiens. Somit wurde deutlich, warum Kuhle im Himalaja zu talabwärts gesehen tiefer reichenden Eisrändern kam.

\section{KUHLE (1998)}

\section{METHODE BZW. ARBEITSTECHNIK}

Kuhle wendete geomorphologische Analysen mit Schneegrenzbestimmungen an.

\section{UNTERSUCHUNGSGEBIET}

Kuhle (1998) führte Ergebnisse zu vielen Untersuchungsgebieten wie beispielsweise Tibet, Karakorum, Aghil Gebirge, Kuenlun, Tarim Becken, Pamir, Ladakh Range, Nanga Parbat, Tien Shan, Sayan Gebirge, Trans Baikal Gebirge, Zanskar-Himal, Garhwal-Himal, Khumbu / Rongbuk-Himal, Kangchendzönga-Himal, Dhaulagiri- und Annapurna-Himal auf.

\section{KRITIK}

LGM Moränen machte Kuhle (1998:85) im Mayangdi Khola sowie im Thakkhola bis auf eine Höhe von 1.100 m aus, hierbei verwies er auf seine älteren Forschungsarbeiten. Die Eisränder auf der Südseite des Himalaja legte Kuhle (1998:85) vor allem anhand von Moränenterrassen, gut ausgeprägten Endmoränen mit Erratika und Trogprofilen mit Gletscherschrammen bis auf eine Höhe von 1.700 m fest. Somit waren glaziale Erosions- und Akkumulationsformen mit in die geomorphologische Analyse eingegangen, wodurch diese aussagekräftig war. 
KUHLE (2007A)

METHODE BZW. ARBEITSTECHNIK

Kuhle (2007a) wendete im Dhaulagiri- und Annapurna-Himal geomorphologische Analysen mit Schneegrenzberechnungen an.

\section{UNTERSUCHUNGSGEBIET}

Kuhle (2007a) ging neben außerordentlich vielen anderen Gebieten Hochasiens auf das Gebiet des Dhaulagiri- und Annapurna-Himal ein.

\section{KRITIK}

Nach Kuhle (2007a:124) floss der letzteiszeitliche hochglaziale Thakkhola Gletscher bis auf eine Höhe von $1.100 \mathrm{~m}$, die Schneegrenze lag allgemein betrachtet bei ca. $4.020 \mathrm{~m}$. Eindeutige Hinweise für Auslassgletscher auf der Südseite des Himalaja lieferte er anhand von glazialen Formen wie etwa Moränenterrassen, gut ausgeprägten Endmoränen mit Erratika und Gletscherschrammen bis auf eine Höhe von 1.700 m. Die Veröffentlichung von Kuhle war sehr ähnlich zu der von ihm aus dem Jahr 1998.

\section{KUHLE (2013A)}

\section{METHODE BZW. ARBEITSTECHNIK}

Kuhle wendete geomorphologische Analysen an.

\section{UNTERSUCHUNGSGEBIET}

Neben vielen anderen genannten Forschungsgebieten ging Kuhle (2013a:15-17) auf das Tal Mayangdi Khola ein.

\section{KRITIK}

Im Mayangdi Khola bzw. auf dessen orographisch rechter Trogtalseite fand Kuhle im Jahre 1977 (siehe z.B. Foto 2 bei Kuhle 2013a:16, 1982 publiziert) auf ca. 2.095 m Höhe $180 \mathrm{~m}$ über dem rezenten Talboden frisch erhaltene Gletscherschrammen und Polierungen vor. Der vorzeitliche Mayangdi Gletscher floss laut den genannten Befunden von Kuhle (2013a:15 f.) bzw. den Gletscherschrammen bis auf mindestens $1.800 \mathrm{~m}$ Höhe hinab bzw. anhand des ausgemachten Trogtalprofils und eines Grundmoränenpodestes bis auf $1.700 \mathrm{~m}$. Auf Seite 17 beschrieb Kuhle (2013a) ein weiteres tiefer reichendes bzw. das hochglaziale vorzeitliche Gletscherende auf ca. 1.150 bis $1.100 \mathrm{~m}$ Höhe beim Ort Dharbang, was mit einer 
Schneegrenzdepression von etwa 1.425 bis $1.450 \mathrm{~m}$ in Verbindung gebracht wurde. Kuhle verwies hierbei auf die Gletscherkarte TH23 aus Kuhle (2011b). Diese Ergebnisse basierten demnach auf eindeutig vor Ort ausgemachten glazialen Formen. Die Arbeit Kuhle (2013) stellte eine Zusammenstellung der Befunde der im Jahre 1982 veröffentlichen Arbeit mit dem Titel `Der Dhaulagiri- und Annapurna-Himalaya' dar.

\subsubsection{Kali Gandaki}

Im Tal Kali Gandaki wurden die Forschungsarbeiten Kuhle (1982), (1983), Iwata (1984), Fort (1985), Kuhle (1998, 2007a), Zech et al. (2009), Kuhle (2011a, 2013a, 2013b) betrachtet.

\section{KUHLE (1982), (1983)}

\section{METHODE BZW. ARBEITSTECHNIK}

Kuhle (1982) betrieb detaillierte geomorphologische Analysen mit Schneegrenzberechnungen, wobei über 180 Illustrationen wie etwa Fotos / Panoramen, eine Höhenkarte, geomorphologische Karten, Karten vom Untersuchungsgebiet auch mit Routenverlauf oder Profil- und Abbildungskennzeichnungen, eine Kammverlaufsskizze sowie Talquer- und -längsprofile in der Ausarbeitung enthalten waren. Die große geomorphologische Karte war in einem Maßstab von 1:85.000. Er kartierte auffallend viele geomorphologische Formen. In der Arbeit Kuhle (1982a) und (1983) waren die dazugehörigen Beschreibungen auffindbar.

\section{UNTERSUCHUNGSGEBIET}

Kuhle (1982:1) untersuchte acht Monate lang das Gebiet des Dhaulagiri- und AnnapurnaHimal (Expeditionen in den Jahren 1976 von Oktober bis Dezember und 1977 von Januar bis Februar und von Juni bis Oktober). Insgesamt dauerten die Forschungsarbeiten 3,5 Jahre (ebd.:III, 1). Er gab die Fläche des Untersuchungsgebietes mit 100 mal $100 \mathrm{~km}$ bei einer Vertikalspanne von $7.442 \mathrm{~m}$ an. In Abb. 2 konnte die Größe des Untersuchungsgebietes mit etwa 90 mal $100 \mathrm{~km}$ anhand der Routenverläufe abgelesen werden (ebd.:3). Das gesamte in Abb. 2 dargestellte Gebiet umfasst 100 mal $120 \mathrm{~km}$. Als nördlich an den Dhaulagiri- und Annapurna-Himal angrenzende Bereiche wurden, neben der Nilgiri Gruppe, Mukut-Himal, Mul Lekh-Himal, Sangda-Himal, Pukhung- und Muktinath-Himal sowie die Südabdachung des Chulu-Himal untersucht (ebd.:3). Südlich davon beging er folgende Gebiete: den GurjaHimal, den Kamm des Manapati und die Himalaja-Vorketten des Athhazar- und Baglung Parbat und des Kaski (ebd.:3). Diese genannten Untersuchungsgebiete wurden ebenfalls bei 
Kuhle (1983:2 f.) beschrieben. Die Forschungsroute war Abb. 2 zu entnehmen: Hauptroutenverläufe über die Orte Pokhara, Lumle, Kusma, Tatopani, Beni, Dharbang, Muna, Dhorpatan, Muri, Khibang, Gastkarker, Lete, Dhampu, Jomosom, Sangda, Dangarjong, Muktinath, Manang und Ngawal.

\section{KRITIK}

Kuhle (1982:1) untersuchte mit seiner Arbeit unter dem Titel 'Der Dhaulagiri- und Annapurna-Himalaya' bis dato unerforschte Talbereiche, machte demnach erste Bestandsaufnahmen in diesem Gebiet. Das Werk war anhand von zahlreichen Aufnahmen nachvollziehbar, wobei die Veröffentlichung aus dem Jahre 1983 die empirische Grundlage $\mathrm{zu}$ den Untersuchungen im Dhaulagiri- und Annapurna-Himal darstellte. Diese Forschungsarbeit war umfänglicher als der Textband aus dem Jahre 1982. Im Vergleich zu den anderen Forschern war die Bearbeitung von Kuhle (1982) - einschließlich der empirischen Grundlage Kuhle (1983) - die ausführlichste (s.h.a. Meiners 1999:342 und König 2002:137), die detaillierteste und flächendeckendste (s.h.a. Wagner 2007:2). Sie umfasste insgesamt gesehen 215 Seiten Text und über 180 Illustrationen, die Arbeit Kuhle (1983) nochmals 358 Seiten Text. Laut Zech et al. (2001:160) und Caine (1984:458) war sie detailliert $^{360}$ und gab laut letztgenanntem einen guten Überblick über die geomorphologische Geschichte und rezente Prozesse. Was Caine mit der Bezeichnung ’recent geomorphic history' meinte, war nicht erklärbar. Laut Caine war bei Kuhle (1982) jedoch ein Mangel an sedimentologischen, klimatischen und topographischen Daten und keine klare zeitliche Einordnung der Formen gegeben ${ }^{361}$. Hierzu war aufzuführen, dass Kuhle mit seiner empirischen Grundlage Kuhle (1983) - aber auch mit dem Text- bzw. Bildband von 1982 durch konkrete Beschreibung verschiedenster Akkumulationen etliche sedimentologische, aber sonst auch geologische, klimatische, glaziologische, geomorphologische, geographische bzw. topographische und orographische Aspekte angab und dass Kuhle in späteren Arbeiten über Hochasien Unmengen an solchen Daten lieferte und die Einordnung der Moränen in die verschiedenen Gletscherstadien auch in diesen Gebieten bestätigte. Miehe (1982:10) schrieb ebenso über das Werk von Kuhle, dass die Orographie eingehend erörtert und eine Bestandsaufnahme der rezenten Vergletscherung sowie der Morphologie erbracht wurde. Zech et al. (2001:160) schrieben über Kuhle (1982), dass er keine absoluten Daten bzw. ${ }^{14} \mathrm{C}$ -

\footnotetext{
360 „Eine derart detaillierte Erfassung der Gletschergeschichte ist bisher in keinem anderen Gebiet des NepalHimalaya möglich gewesen." (Zech et al. 2001:160); "This study provides broad, regional context within which detailed, quantitative work on such topics can proceed." (Caine 1984:458)

361 "A lack of sedimentologic, climatic, and even topographic data and a failure to define clearly the age of glacial and periglacial events in this presentation show the most obvious needs for future work." (ebd.:458)
} 
Daten angab und nur Geländebeobachtungen und Schneegrenzberechnungen machte. Auch Iwata (1984:39) deutete darauf, dass keine absoluten Daten in diesem Gebiet erhoben, aber relative Chronologien auf der Basis von geomorphologischen und morphostratigraphischen Methoden gemacht wurden. Iwata (1984:25) fand, dass das Gebiet auch nach der Bearbeitung durch z.B. Kuhle (1982) noch nicht genügend untersucht wurde ${ }^{362}$. Jedoch stellte die Untersuchung von Kuhle, sogar heute noch, die geomorphologisch am besten hergeleitete Arbeit dar. Kuhle erhob in seinen späteren Arbeiten ${ }^{14}$ C-Daten (s.h.a. Zech et al. 2001:16), die mit seiner zeitlichen Einordnung der Moränen anhand geomorphologischer Analysen übereinstimmten. Hierbei sollte sich außerdem die Frage gestellt werden, ob ${ }^{14} \mathrm{C}$-Daten bei der Arbeit von Kuhle (1982) zu einem anderen Ergebnis geführt hätten. Denn die ${ }^{14} \mathrm{C}$-Daten von Bodenschichten, die nur ein Minimalalter der Formenentstehung angeben können, würden doch zu keiner anderen Rekonstruktion führen, sondern nur das vorhandene Ergebnis der schon anhand der Geländebefunde gemachten Vergletscherungsrekonstruktion untermauern. Ob im Gegensatz dazu andere absolute Daten überhaupt zu einem Ergebnis oder auch zu einem anderen Ergebnis der Vergletscherungsrekonstruktion geführt hätten, sollte kritisch hinterfragt werden. Im Gelände aufgefundene glaziale Kennformen, die in Lagebeziehung zueinander gesetzt werden, sind eindeutigere Belege für eine Vergletscherung als die Alter von Blöcken, die auf den Moränengraten datiert wurden und nichts mit der Entstehung der eigentlichen Moränenform zu tun haben müssen. Bevor vom Alter dieser Blöcke auf das Alter der gesamten Form geschlossen werden kann, müssten die komplexen Vorgänge der Moränenentstehung genau nachvollzogen werden, was immer eine Schwierigkeit darstellen wird. Zudem gab Kuhle (1982:23) folgendes an: „Absolut datierbares Material fehlt bislang, so daß eine relative zeitliche Zuordnung aufgestellt wird. “. Laut Kuhle war sowieso kein größeres Alter als ein würm- bis rißzeitliches Alter nachvollziehbar ${ }^{363}$.

Unter Betrachtung des Lagebezuges und der ermittelten Schneegrenzen beschrieb Kuhle (1982) zwölf Stadien (ebd.:150-168) und Prä-Ghasa Stagnationen. Insgesamt zeigte er auf der geomorphologischen Karte aber 16 Stadien und zwei Prä Ghasa Stagnationen auf. Iwata (1984) gab an, dass Kuhle (1982) 18 Stadien angab ${ }^{364}$. Zech et al. (2009:1107) merkten an,

\footnotetext{
362 "However, the comprehensive history of the Quaternary geomorphological development has not been traced yet." (Iwata 1984:25)

363 „Aufgrund hoher Abtragungsintensitäten als Folge von bedeutenden Niederschlägen und großer Reliefenergie speziell auf der S-Abdachung ist ein größeres als würmzeitliches bis maximal rißzeitliches Alter der Ablagerungen nicht wahrscheinlich. " (Kuhle 1982:23)

364 "Kuhle (1982) classified the moraines and the river terraces into eighteen chronological stages, but his classification is largely different from the present author's interpretation." (Iwata 1984:39)
} 
dass nach Kuhle (1982) der letzteiszeitliche Gletscher im Kali Gandaki zehn km südlich von Tatopani (ca. $1.200 \mathrm{~m}$ ) bzw. bis auf $910 \mathrm{~m}$ hinab reichte und dass dies jedoch Owen et al. $(1998)^{365}$ und Fort $(2000)^{366}$ in Frage stellten. Gründe dieses Infragestellens wurden nicht näher angeführt. Wie o.g. reichte der Eisrand nach Kuhle (1982) auf ca. $1.010 \mathrm{~m}$ und nicht wie bei Zech et al. (2009) angegeben bis auf 910 m. Als Indikatoren Kuhles gaben Zech et al. (2009:1107) lediglich Moränenterrassen und Rundhöcker bei den Konfluenzbereichen Miristi und Ghaleti, die sich auf etwa 2.000 m Höhe und $600 \mathrm{~m}$ über dem Talboden befanden, an. Auf weitere von Kuhle kartierte Formen gingen sie nicht ein. Zech et al. (2001:160) schrieben, dass das Eis laut Kuhle (1982, 1998 ${ }^{367}$ ) während des LGM bis auf ca. $1.000 \mathrm{~m}$ Höhe ging bei einer Schneegrenzdepression von etwa $1.300 \mathrm{~m}$. Die unterschiedliche Sicht von Owen et al. (1998) ${ }^{368}$ und Fort (2000) $)^{369}$ gegenüber Kuhle wird wohl in der unterschiedlichen detaillierten Bearbeitung gelegen haben. Kuhle (1982) untersuchte das Gelände detailliert durch eine geomorphologische Bestandsaufnahme. Hierbei wurden Formen wie beispielsweise Moränen, Rundhöcker und verwandte Schliffformen, Gletscherschliff (Politur), Gletscherschrammen und vorzeitlicher Transfluenzpass gefunden, die bei den meisten Forschern nicht erfasst wurden. Bei einer Interpretation der vorzeitlichen Vergletscherung ist die Deutung einer Vereisung nur über ein Trogtalprofil nicht zielführend. Daneben können glazigene Kerbtäler, schluchtförmige Tröge oder trogförmige Schluchten existieren. Eine Aussage von Kuhle (1982) erläutert dieses näher ${ }^{370}$.

Die umfangreiche geomorphologische Karte reichte bei Kuhle (1982) nur bis unterhalb des Dana Khola oder Miristi Khola. In Abb. 10 war aber zu erkennen, dass die Fotos 96, 98 und 100-108 unterhalb des Dana Khola gemacht wurden. Somit waren auch unterhalb der Reichweite der geomorphologischen Karte eindeutige Indikatoren vorhanden. Diese ließen Gletscherschliff, hocheiszeitliches Ufermoränenmaterial (Foto 96), spätglaziale Schotterflurterrasse (Foto 98, 101, 105 und 107), hocheiszeitliche Ufermoränenterasse,

\footnotetext{
365 in der vorliegenden Arbeit mit Owen, Derbyshire, Fort (1998) angegeben

${ }^{366}$ siehe Quelle Fort (2000) in der Fußnote

367 Kuhle, M. (1998): Neuere Ergebnisse zur Eiszeitforschung Hochasiens in Zusammenschau mit den Untersuchungen der letzten 20 Jahre. Petermanns Geogr. Mitteilungen 142, 3-4. (S. 219-226)

368 in der vorliegenden Arbeit mit Owen, Derbyshire, Fort (1998) angegeben

${ }^{369}$ siehe Quelle Fort (2000) in der Fußnote

370 „Der Erhaltungszustand vorzeitlicher glazigener Täler variiert. Die aus großer Reliefenergie resultierenden steilen Hangneigungen beschleunigten eine postglaziale Überprägung. Neben abfließendem Wasser wirkten Steinschlag, Schnee- und Eislawinen überformend (S. 60). Die linienhafte Erosion in den Tiefenlinien setzte und setzt das Werk vorzeitlicher subglazialer Schmelzwasser fort und unterschneidet die Flanken der 'trogförmigen Schluchten', so daß die vielerorts erfolgten Nachbrüche schnell ein den präglazialen Kerntälern entsprechendes fluviatiles Talprofil wieder herstellen (S. 61). Dies gilt auch für Täler, die im Hochglazial Eisfüllungen von weit über 1000 m Mächtigkeit aufwiesen (Abb. 88, 130)." (Kuhle 1982:174)
} 
glaziären Flankenschliff (Foto 100), Gefällsknick, hocheiszeitliche Moräne (Foto 102), hocheiszeitliches Moränenmaterial (Foto 103), Moräne (Foto 104), hochglaziale Schotterflur (Foto 106), Erdgletscher (Foto 108) in diesem Bereich erkennen. Daneben waren in Abb. 7 hocheiszeitliche Moränen (vermutlich Würm) und hocheiszeitliche Schotterterrassen mit zum Teil glazilimnischen Ablagerungen (vermutlich Würm) und spätglaziale und holozäne Rückzugsmoränen dargestellt, wobei erstgenannte bis talaufwärts von Ranipauwa aufgefunden wurden. Die tiefstliegenden Moränenbefunde wurden auf dem Foto 104 (Standort $1.390 \mathrm{~m}$ ) dargestellt.

\section{IWATA (1984)}

\section{METHODE BZW. ARBEITSTECHNIK}

Iwata (1984) führte geomorphologische Untersuchungen durch bzw. erforschte relative Chronologien der Moränen (Lagebezug, Frischegrad) sowie paläomagnetische Chronologien. Die geomorphologische Analyse (hierzu Fig. 1) basierte hauptsächlich auf Geländearbeiten (Formen und Materialien), unterhalb von Tukche wurden Luftbilder hinzugenommen ${ }^{371}$. Die Hauptaufgabe der Forschungen von Iwata (1984:25 f.) war es, die Zusammenhänge zwischen Oberflächenformen und Ablagerungen zu erkunden, wobei die Ziele dieser Veröffentlichung die Erklärung der Landformenentstehung und der spätquartären Geschichte der Thakkhola Muktinath Region waren. Es wurden glaziale Formen, Massenbewegungsformen, Flussterrassen und Seesedimente untersucht (ebd.:25), wobei diese im Text beschrieben wurden. Krustenbewegungen, die seit dem Miozän vorkamen, standen ebenfalls im Fokus (ebd.:25). Die relative Chronologie der Moränen wurde auf Basis der geomorphologischen und morphostratigraphischen Methoden angewendet (ebd.:39). Paläomagnetische Chronologien spielten eine enorme Rolle. Glaziale Landformen wurden direkt mit den Flussterrassen in Verbindung gebracht (ebd.:39).

Enthalten in der Arbeit waren: eine geomorphologische Karte mit glazialen Formen wie Karen und Trogwänden, Moränen (verschiedene Stadien) und Till (ältere Vergletscherung); Profile von Moränen, Till, fluvioglazialen Ablagerungen sowie Flussterrassen; geologische Abrisse; fünf Fotos (Moränen, Terrassen, Till, Rutschungen, 'debris flow', Marpha Formation); eine Zeittabelle der Formenentstehung.

371 “Aerial-photographs [...], were used only for the area south of the Tukche village." (Iwata 1984:26) 


\section{UNTERSUCHUNGSGEBIET}

Iwata (1984:25) erkundete drei Jahre lang das Gebiet der Thakkhola Muktinath Region, in den Jahren 1980, 1981 und 1982. Die ersten beiden Jahre dienten der Beschreibung von glazialen Formen und Terrassen - beim Geländeaufenthalt des letzten Jahres lag der Fokus auf der Klärung der Beziehung zwischen geomorphologischer Oberfläche und Ablagerung, wobei Strukturen besonders untersucht wurden (ebd.:25). Das genaue Untersuchungsgebiet war Fig. 1 zu entnehmen; es reichte von ungefähr Kagbeni bis etwa nach Ghasa, wobei ebenfalls Nebentäler des Kali Gandaki untersucht wurden. Das entsprach einer Fläche von ungefähr $30 \mathrm{mal} 22 \mathrm{~km}$. Demnach wurden nur im oberen Bereich des Kali Gandaki die Entstehung und die relative Chronologie der Formen und Krustenbewegungen erforscht ${ }^{372}$. Ohnehin deutete die Bezeichnung Thakkhola auf ein Untersuchungsgebiet zwischen Kagbeni und Ghasa hin, da es sich bei diesem Teil des Kali Gandaki um die Thakkhola Region handelte.

\section{KRITIK}

Mit der 16-seitigen Ausarbeitung mit dem Titel 'Geomorphology of the Thakkhola-Muktinath region, central Nepal, and its late quaternary history' ging Iwata (1984) auf die regionale Geomorphologie (Materialien, glaziale Landformen, Massenbewegungsformen) und Geologie ein. Demnach wandte er geomorphologische Analysen an, jedoch im Gegensatz zu Kuhle (1982) nur im Gebiet zwischen Kagbeni und Ghasa, wobei auch Nebentäler des Kali Gandaki erforscht wurden. Das entsprach einer Fläche von ungefähr 30 mal 22 km. Im Vergleich zu dem von Kuhle (1982) untersuchten Gebiet war dieses Untersuchungsgebiet kleiner. Iwata (1984:25) erkundete also drei Jahre lang das Gebiet der Thakkhola Muktinath Region, in den Jahren 1980, 1981 und 1982. Hierbei wurde jedoch nicht eindeutig, wie lange und wann genau Iwata im Gelände war. Zudem war keine Forschungsroute angegeben, wodurch erfahrbar gewesen wäre, ob Iwata die Talbereiche, die Kuhle (1982) untersuchte, auch bereiste. Generell ging Iwata nicht näher auf die Befunde von Kuhle ein (s.h.a. Achenbach 2011:14), obwohl er Kuhle im Text auf Seite 25 erwähnte. Unterhalb von Tukche verwendete Iwata Luftbilder. Ob er für Auswertungen allein diese in dem Talabschnitt verwendete oder aber sie zusätzlich zu den Geländebefunden hinzunahm, war im Text nicht erläutert. Es wurde nur angegeben, dass einige 'landslides' hauptsächlich durch die Interpretation der Bilder

372 "[...], and the origin, relative chronology and crustal movement were discussed in the upper basin of the Kali Gandaki River.” (ebd.:25) 
identifiziert wurden ${ }^{373}$. Somit müssen die Befunde unterhalb von Tukche, wenn diese Arbeit von Iwata herangezogen wird, noch genauer überprüft und abgeglichen werden. Allgemein wurden glaziale Formen, Massenbewegungsformen, Flussterrassen und Seesedimente kartiert und beschrieben. Profile, geologische Abrisse und auch Fotos waren ebenfalls zu finden jedoch waren diese im Vergleich zu den Befunden von Kuhle (1982) nicht so umfangreich bzw. wurden nicht alle relevanten Formen für eine geomorphologische Reliefanalyse mit dem Ziel einer Aussage über die vorzeitliche Vergletscherung berücksichtigt. Demnach waren die Befunde von Iwata nicht so detailliert wie bei Kuhle (s.h.a. Wagner 2007:43, 169) bzw. nicht so umfassend. Wagner (2007:169) verglich die Befunde des Forschers und kam zum Ergebnis, dass die Befunde von Iwata (1984) lediglich im Thoron Khola und Madek Dumda Khola annähernd mit seinen Befunden übereinstimmten. Im Jhon Khola stimmte laut Wagner (2007:2) das Ausmaß der hocheiszeitlichen Vergletscherung von Iwata mit dem von Kuhle überein. Auf die durchgeführten paläomagnetischen Chronologien ging Iwata im Weiteren nicht ein, sodass diese nicht genau nachvollziehbar waren.

Die tiefste Eisrandlage bzw. die tiefstreichenden kartierten Moränen lagen nach Iwata (1984:Fig. 1 - 'Older Glaciations') im Bereich der Siedlung Ghasa auf 1.870 m Höhe. Jedoch blieb hierbei unbekannt, ob in tieferen Talbereichen weitere Moränen vorkamen. Laut Kuhle (1982) reichte das Eis viel weiter talabwärts, was durch Geländebefunde untermauert wurde. Somit sollte die zeitliche Einordnung der Moränen, die Iwata angab, hinterfragt werden. Außerdem könnte es sein, dass sein ausschlaggebender Punkt für die Festlegung der Eisrandlage nicht die aufgefundenen Moränen waren, sondern vielmehr der auf Seite 29 erwähnte Talübergang vom Trog- zum Kerbtalprofil ${ }^{374}$. Hierbei würde das Nichtbeachten der speziellen Formen schluchtförmige Tröge bzw. trogförmige Schluchten für ein Ausschließen vorzeitlicher Vergletscherungsspuren in den talabwärtigen Bereichen in Betracht kommen. Dieses jedoch hätte ihm aufgrund seiner Aussage: "A well-developed cirque and a glacial through with an existing glacier are rarely found in the studied area." auffallen können. Nach Wagner (2007:51, 93) kartierte Iwata im Thoron Khola keine Moränen, gab aber für dieses Tal Kar- und Trogtalformen an und beschränkte sich im Thini Khola mit seinen Untersuchungen bzw. Kartierungen und Profilzeichnungen auf den Unterlauf.

\footnotetext{
373 "The author recognized several landslide scarps and deposits mainly by aerial photograph interpretation." (ebd.:34)

374 “'At Ghasa, the Kali Gandaki flows in a narrow V-shaped gorge, [...]." (ebd.:26)
} 
Iwata unterschied vier Moränengruppen: rezente Moränen, Tukche Stadium (neoglazial), Khingar Stadium (frühe Unterteilung des letzten Glazials) sowie Moränen und Till von älteren Vergletscherungen. Somit wurden die festgelegten Stadien nicht so detailliert unterteilt wie bei Kuhle (s.h.a. Wagner 2007:43). Da das Khingar Stadium laut Geschriebenem in das letzte Glazial fiel, reichte das Eis laut tiefstreichenden kartierten Moränen (Fig. 1) zu dieser Zeit bis talabwärts von Lete auf ungefähr 2.180 m Höhe hinab. Jedoch zeigten die bestimmten Alter für die einzelnen Gletscherstadien in Fig. 14, dass das Khingar Stadium in den Zeitraum vor 4.000-5.000 Jahren und das Ältere Stadium in den vor etwa 10.000-15.000 Jahren fiel, sodass das letztgenannte Ältere Stadium die letztglaziale maximale Vergletscherung anzeigte. Im Text selbst wurde jedoch kein genauer Entstehungszeitraum für die ältere Vergletscherung angegeben; das Alter war nicht bekannt, jedoch deutete der Altersunterschied zum Khingar Stadium an, dass diese älteren Moränen aus dem vorletzten Interglazial stammten ${ }^{375}$. Das war in Bezug auf die Altersangabe in Fig. 14 widersprüchlich. In der vorliegenden Arbeit wurde das in Fig. 14 angegebene Alter als das Alter der Älteren Vergletscherungen angenommen. Ebenfalls verwies Wagner (2007:140) darauf, dass Iwata unbegründet Terrassen in ein deutlich älteres vorletzteiszeitliches Stadium einordnete. Nach Wagner (2007:46) könnte zudem das Khingar Stadium dem MIS 4 entsprechen und das Tukche Stadium in das Spätglazial einstufbar sein. Laut Iwata (1984) waren Moränen nur schwer von anderen Akkumulationen unterscheidbar ${ }^{376}$, wodurch sich die Frage stellte, ob tatsächlich alle Moränen erfasst wurden bzw. ob jene Moränen, die kartiert wurden, auch wirklich als solche anzusprechen waren. Überdies wurden keine Schneegrenzberechnungen angewendet (s.h.a. Wagner 2007:2).

Daneben war der benutzte Terminus 'landslide’ weniger aussagekräftig, da er nicht eindeutig war; es könnten mehrere Prozesse wie etwa Bergsturz / -rutsch, Steinschlag oder Murprozesse diesem Begriff zugeordnet werden. Die Alter der 'landslides' bei Dhampu und Lete waren zudem nicht genau bekannt ${ }^{377}$. Außerdem entsprach der 'Larjung landslide' laut Fort

\footnotetext{
375 "Subdued and slope-like landforms is clearly distinguished from the Khingar stage moraines and this suggests a great time interval between them." (Iwata 1984:30); "The ages of these older moraines and glacial sediments have not known yet. The time interval between these older moraines and the Kingar stage moraines, which is considerably large, indicates that they formed in the pre-Last Interglacial period. This, however, does not necessarily mean that these landforms are contemporaneous with the deposition of the sediments during the glaciation or cold period." (ebd.:31)

376 "The mass-movement deposits are hardly distinguished from the glacial till."; "The distinction between the glacial depositional landforms and other landforms, and the classification of the moraines themselves appeared to be difficult in this area." (ebd.:29)

377 "The ages of the large scale landslides at Dhampu and Lete are completely unknown, but they may have occured successively after the extreme down-cutting of the Kali Gandaki." (ebd.:40)
} 
$(1980)^{378}$ und Fort et al. (1981) $)^{379}$ zitiert nach: Iwata (1984) Tukche Stadium Moränen bei Iwata $(1984)^{380}$. Ob die im Text beschriebenen 'debris flow' Ablagerungen auch wirklich diese Formen darstellten, blieb offen ${ }^{381}$.

\section{FORT (1985)}

\section{METHODE BZW. ARBEITSTECHNIK}

Fort (1985:159-169) wendete geomorphologische Analysen an. Im Text wurde weiterhin auf geologische, pedologische, sedimentologische, topographische, klimatische, paläomorphologische und paläobiogeographische Aspekte eingegangen, die auf ein warmes Klima während des Spätneogen / frühen Pleistozäns und auf ein kaltes Klima während des mittleren bis späten Pleistozäns in diesem Gebiet bzw. auf der Südseite des Himalaja hinwiesen. Sie nutzte keine Datierungsmethoden; hierzu schrieb sie folgendes: "No good material to be dated is available so far." (Fort 1985:164).

\section{UNTERSUCHUNGSGEBIET}

Das Untersuchungsgebiet dieser Veröffentlichung beschränkte sich auf das Jhong Khola ${ }^{382}$ (siehe Fig. 24.58a) bzw. auf das Areal zwischen Kagbeni und Thorong La (siehe Fig. 24.58b). Andere erforschte Gebiete wurden zitiert, z.B. das Seti Khola und das Pokhara Becken (Fort 1983).

\section{KRITIK}

Die 29-seitige Arbeit von Fort (1985) mit dem Titel Contribution of sedimentary and geomorphic data to the knowledge of paleoclimates in Nepal Himalayas' bezog sich hauptsächlich auf das Gebiet des Jhong Khola bzw. das Gebiet zwischen Kagbeni und Thorong La. In der Arbeit waren sowohl zum Dhaulagiri und Annapurna Gebiet sechs Fotos enthalten als auch zum Thakkhola Mustang Graben eine geologische Karte und geomorphologische Karten sowie eine Tabelle über dessen Entstehung, wodurch ein guter Überblick über das Untersuchungsgebiet gegeben wurde. Eine solche Tabelle lag auch für das

\footnotetext{
378 siehe Quelle Fort (1980a) in der Fußnote

379 siehe Quelle Fort et al. (1981) in der Fußnote

380 "The main body of her 'Larjung landslide' seems to be corresponded with the Tukche stage moraine in this paper." (Iwata 1984:39)

381 "The layer seems to be a debris flow deposit related to glacier avalanching [...]." (ebd.:33); "Some of them are debris-flow deposits as mentioned before (e.g. Fig. 11-c), but others may be glacial deposits." (ebd.:37)

382 "In this part, I present data on Thakkhola-Mustang graben, [...].” (Fort 1985:159)
} 
Südtibetplateau vor. Desweiteren wurde in der Veröffentlichung auf das Pokhara Becken eingegangen (ebd.:175-185).

Nach Fort $\left(1976^{383}, 1980^{384}\right)$ und Dollfuss, Usselmann $(1971)^{385}$ zitiert nach: Fort (1985:164) reichte das Eis im Zeitraum des mittleren bis späten Pleistozän von Jhong Khola auf 3.200 m bis nach Ghasa auf 2.000 m Höhe hinunter. Die Arbeit von Fort (1985) war für eine Aussage über die letztglaziale Maximalausdehnung weniger geeignet, da sie eher ein zusammenfassendes Werk war. Fort zitierte lediglich die o.g. Forscher für die letztglaziale Ausdehnung. Jedoch war aus Fig. 24.58b - wie o.g. - die tiefste Ausdehnung der moränischen Ablagerungen - vermutlich aus dem letzten Glazial - bei Jhong entnehmbar. Fort (1985) führte aber die o.g. Forscher auf, die ein Gletscherende bei Ghasa festlegten. Außerdem verwies Fig. 24.58a auf einen Moränenbogen, der bei Jhong eingezeichnet war vermutlich aus dem letzten Glazial, da die Zeitangabe mit Fragezeichen dargestellt wurde. Bei dieser Darstellung waren jedoch Moränen (Nummer 10) und glazifluviale Schotter (Nummer 19) nur schwierig auseinanderzuhalten. Somit war nicht genau zu sagen, ob es sich talaufwärts von Kag auf der orographisch rechten Seite des Kali Gandaki um eine Moräne oder um glazifluviale Schotter handelte. Es blieb also uneindeutig, wo nun der letztglaziale Eisrand wirklich lag. Wagner (2007:169) untersuchte die Befunde von Fort und kam zum Ergebnis, dass die Befunde von ihr lediglich im Thoron Khola und Madek Dumda Khola annähernd mit seinen Befunden übereinstimmten. Im Jhong Khola soll das Ausmaß der hocheiszeitlichen Vergletscherung von Fort mit dem von Kuhle übereinstimmen, die festgelegten Stadien anhand der relativen Position und des Erhaltungszustandes der Moränen aber nicht so detailliert sein (ebd.:2, $42 \mathrm{f}$.).

Das Untersuchungsgebiet von Fort (1985) war nichtsdestotrotz zu klein bzw. zu weit talaufwärts gelegen, sodass glaziale Formen, die weiter talabwärts vorkamen und wie sie Kuhle auffand, nicht betrachtet wurden. Kuhle kam dadurch zu einem talabwärtigeren letztglazialen Gletscherende des Mustang-Thak Khola Auslassgletschers bis auf eine Höhe von 1.000 m (vgl. Kuhle 1982, 1998, 2007a, 2011a, 2013a, b). Zudem berechnete Fort keine Schneegrenzen (s.h.a. Wagner 2007:2). Auf die Befunde von Kuhle (1982, 1983) und Iwata (1984) ging sie nicht ein bzw. beachtete die Literatur nicht (s.h.a. Achenbach 2011:14). Außerdem schrieb Fort (1985:105), dass das Vergletscherungsausmaß auf der Südseite des Himalaja nur schwierig zu erfassen wäre, da intensive Erosions- bzw. rapide Verwitterungsund Massenbewegungsprozesse das glaziale Material zerstörten und katastrophal abgelagerte

\footnotetext{
383 siehe Quelle Fort (1976) in der Fußnote

384 siehe Quelle Fort (1980a) in der Fußnote; siehe Quelle Fort (1980b) in der Fußnote

385 im Literaturverzeichnis von Fort (1985) lediglich die Quelle Dollfuss, O.; Usselmann, P. (1972) angegeben
} 
Materialien den Moränen ähnelten. Als Beispiel hierfür sind 'GLOFs' zu nennen, die - vor allen Dingen hier ab dem Spätglazial - dazu führen können, dass etwa Moränenmaterial talabwärts transportiert wird (vgl. Kuhle 2012b:197-199, 204). Im Tal Mustang Thakkhola rekonstruierte Kuhle (2012b:210) einen $360 \mathrm{~m}$ tiefen und etwa $46 \mathrm{~km}$ langen spätglazialen Eisstausee, welcher ungefähr bei der Siedlung Chhairo abgedämmt wurde. In der Zusammenfassung der Abhandlung schrieb Fort (1985), dass weitere Forschungen in Nepal nötig sind ${ }^{386}$. Datierungen waren nicht möglich, da kein verwertbares Material aufgefunden wurde ${ }^{387}$.

\section{KUHLE (1998)}

\section{METHODE BZW. ARBEITSTECHNIK}

Kuhle wendete geomorphologische Analysen mit Schneegrenzbestimmungen an.

\section{UNTERSUCHUNGSGEBIET}

Kuhle (1998) führte Ergebnisse zu vielen Untersuchungsgebieten wie beispielsweise Tibet, Karakorum, Aghil Gebirge, Kuenlun, Tarim Becken, Pamir, Ladakh Range, Nanga Parbat, Tien Shan, Sayan Gebirge, Trans Baikal Gebirge, Zanskar-Himal, Garhwal-Himal, Khumbu/ Rongbuk-Himal, Kangchendzönga-Himal, Dhaulagiri- und Annapurna-Himal auf.

\section{KRITIK}

LGM Moränen machte Kuhle (1998:85) im Thakkhola sowie im Mayangdi Khola bis auf eine Höhe von 1.100 m aus, hierbei verwies er auf seine älteren Forschungsarbeiten (s.h.a Fig. 6). Die Ergebnisse waren demnach identisch $\mathrm{zu}$ denen der in der vorliegenden Arbeit aufgeführten Literaturquelle Kuhle (1998) zum Gebiet Mayangdi Khola. Somit waren die Eisränder auf der Südseite des Himalaja durch Indikatoren nachvollziehbar.

\section{KUHLE (2007A)}

\section{METHODE BZW. ARBEITSTECHNIK}

Kuhle (2007a) wendete im Dhaulagiri- und Annapurna-Himal geomorphologische Analysen mit Schneegrenzberechnungen an.

\footnotetext{
386 "For further progress in the knowledge of palaeoclimatic changes in Nepal Himalayas, a great deal of investigations remains to be carried out, in particular in palaeobiogeography and prehistory." (Fort 1985:187) 387 "No good material to be dated is available so far." (ebd.:164)
} 


\section{UNTERSUCHUNGSGEBIET}

Kuhle (2007a) ging neben vielen anderen Gebieten Hochasiens auf das Gebiet des Dhaulagiriund Annapurna-Himal ein.

\section{KRITIK}

Nach Kuhle (2007a:124) floss der letzteiszeitliche hochglaziale Thakkhola Gletscher bis auf eine Höhe von $1.100 \mathrm{~m}$, die Schneegrenze lag allgemein betrachtet bei ca. $4.020 \mathrm{~m}$. Die Forschungen waren übereinstimmend mit denen aus der in der vorliegenden Arbeit aufgeführten Literaturquelle Kuhle (2007a) zum Gebiet Mayangdi Khola. Die Eisränder auf der Südseite des Himalaja wurden durch Indikatoren verständlich. Die Veröffentlichung von Kuhle war außerdem sehr ähnlich zu der von ihm aus dem Jahr 1998.

\section{ZECH ET AL. (2009)}

\section{METHODE BZW. ARBEITSTECHNIK}

Zech et al. (2009:1106) wendeten ${ }^{10}$ Be-Datierungen an. Sie nahmen von 22 Blöcken vom Annapurna Gebiet ${ }^{10} \mathrm{Be}$-Daten, um die spätquartäre Landschaftsgeschichte und die geomorphologischen Prozesse zu verstehen ${ }^{388}$. Es wurden ca. 0,5 bis $1 \mathrm{~kg}$ der etwa $2 \mathrm{~cm}$ ebenen obersten Blockfläche von großen stabilen quarzhaltigen Blöcken ohne Erosions- und Verwitterungserscheinungen ${ }^{389}$ entnommen. Drei bis fünf Blöcke wurden von jeder Form beprobt, wobei die Blöcke fotografiert, per GPS verortet und die Lage der Blöcke beschrieben wurden. Fig. 2 und 3 verwiesen auf die Untersuchungsstellen. Acht Fotos aus dem Dhaulagiri und Annapurna Gebiet waren in Fig. 5 dargestellt. Sie berechneten die topographische Abschirmung durch umgebende Berge und für die Probenvorbereitung und -analyse wendeten sie Standardverfahren an. (ebd.:1106, 1110, Fig. 2, 3 und 5)

Die lokale Produktionsrate, die von der geographischen Breite und der Höhenlage abhängt (Gosse, Phillips $2001^{390}$ zitiert nach: Zech et al. 2009), wurde anhand eines Skalierungsfaktors von einer referenzierten Produktionsrate auf Meeresspiegelhöhe in hohen Breiten bestimmt (Lal 1991 ${ }^{391}$, Dunai $2000^{392}$, Stone $2000^{393}$ sowie Desilets, Zreda $2001^{394}$

\footnotetext{
388 "The ages improve understanding of the Late Quaternary landscape history and the geomorphological processes operating in this part of the Himalaya." (Zech et al. 2009:1106)

389 "[...] with no evidence of erosion and weathering." (ebd.:1110)

${ }^{390}$ Gosse, J.C.; Phillips, F.M. (2001): Terrestrial in situ cosmogenic nuclides: theory and application. In: Quaternary Science Reviews 20. (S. 1475-1560)

${ }^{391}$ siehe Quelle Lal (1991) in der Fußnote

${ }^{392}$ Dunai, T.J. (2000): Scaling factors for production rates of in-situ produced cosmogenic nuclides: a critical reevaluation. In: Earth and Planetary Science Letters 176. (S. 157-169)
} 
zitiert nach: Zech et al. 2009). Es werden von verschiedenen Forschern die Veränderungen im zeitabhängigen geomagnetischen Feld und für Solarmodulationen korrigiert (vgl. Zech et al. 2009:1110). Zech et al. bezogen sich auf das Skalierungssystem von Lifton et al. $(2005)^{395}$. (vgl. Zech et al. 2009:1110)

Der Grund, warum Zech et al. TCN-Datierungen anwenden wollten oder mussten und keine ${ }^{14} \mathrm{C}$-Analysen durchführten, war folgenden Zitaten zu entnehmen: "Material for radiocarbon dating is scarce, thus luminescence and surface exposure dating techniques must be used to establish event chronologies." (Zech et al. 2009:1106); "The above review highlights the need for more age control on deposits and landforms around Annapurna. During the past several years, surface exposure dating has become an important tool for dating Quaternary sediments." (ebd.:1108). ${ }^{10} \mathrm{Be}$ wurde ausgewählt, da es das meist verwendete TCN ist, weil die Probenbearbeitung relativ einfach ist (ebd.:1110).

\section{UNTERSUCHUNGSGEBIET}

Zech et al. (2009:1110-1112) untersuchten das Annapurna Gebiet bzw. das obere und untere Kali Gandaki Tal sowie das Dudh Khola und Bahundanda Tal. Einen Überblick über dieses Gebiet gaben die Satellitenbilder - ein Landsat Satellitenbild, alle anderen aus Google Earth bzw. Fig. 1, 2 und 3. In Fig.1 war das Untersuchungsgebiet im Dhaulagiri und Annapurna Gebiet etwa von Tatopani bis nach Jomosom dargestellt.

\section{KRITIK}

In der 11-seitigen Forschungsarbeit von Zech et al. (2009) mit dem Titel 'Deglaciation and landscape history around Annapurna, Nepal, based on 10Be surface exposure dating' waren Aspekte über Regionales, wie Tektonik, Klima, Geomorphologie, über die angewendete Methode bzw. Arbeitstechnik sowie über die Ergebnisse, die diskutiert wurden, zu finden. Sie verwiesen darauf, dass die Forschungen im Zentralhimalaja problematisch waren, da der Zugang zur Region schwierig war - Relief, Steilheit, politische Situation, die Akkumulationsformen aufgrund der enormen Erosion kaum erhalten waren, die Interpretation einiger Formen - besonders erschwerten 'landslides’ die glaziale Geschichte - nicht einfach war und keine Kontrolle über den Entstehungszeitraum existierte - Material für

\footnotetext{
${ }^{393}$ siehe Quelle Stone (2000) in der Fußnote

${ }^{394}$ Desilets, D.; Zreda, M. (2001): On scaling cosmogenic nuclide production rates for altitude and latitude using cosmic-ray measurements. In: Earth and Planetary Science Letters 193. (S. 213-225)

${ }^{395}$ Lifton, N.A.; Bieber, J.W.; Clem, J.M.; Duldig, M.J.; Evenson, P.; Humble, J.E.; Pyle, R. (2005): Addressing solar modulation and long-term uncertainties in scaling secondary cosmic rays for in situ cosmogenic nuclide applications. In: Earth and Planetary Science Letters 239. (S. 140-161)
} 
Radiokarbondatierungen war selten ${ }^{396}$ (ebd.:1106). Generell erwies es sich als schwierig, Relikte aufzufinden ${ }^{397}$. Hierbei stellten sich die Fragen, wie Kuhle (1982) die gesamten Formen auffinden konnte, ob die von Zech et al. (2009) angesprochenen Moränen wirklich solche oder die anderen Formen eventuell Moränen waren, ob die Forscher alle Ablagerungsformen kartierten und warum sie nicht Erosionsformen wie etwa Strudeltöpfe und Rundhöcker mit einbezogen, um anhand der Lagebeziehung der verschiedenen Formen untereinander Aussagen über die vorzeitliche Vergletscherung zu treffen. Zudem wurde von den Forschern keine Forschungsroute angegeben, anhand derer ablesbar gewesen wäre, wo diese angereist waren und ihre Forschungsreise begannen. Über Google Earth waren zwei Flugplätze in diesem Bereich erkennbar: Balewa Flugplatz auf ca. 990 m und Jomosom Flugplatz auf ca. $2.740 \mathrm{~m}$. Welche Talbereiche Zech et al. nun erforschten, blieb ungewiss.

Das Hauptproblem dieser Veröffentlichung war, dass Zech et al. (2009) TCN-Datierungen anwendeten und keine geomorphologischen Detailanalysen. Es wurde nicht eindeutig, ob sich talabwärts der untersuchten Bereiche weitere glaziale Formen befanden. Zudem verwiesen Zech et al. (2009) darauf, dass die angewendete Methode bzw. Arbeitstechnik der TCNDatierung Fehlerquellen aufwies: es passierte, dass die Altersbestimmungen ältere Daten ergaben - aufgrund von Vorbelichtung durch kosmische Strahlung bzw. Vererbung (sollte laut Shanahan, Zreda $2000^{398}$ zitiert nach: Zech et al. 2009 jedoch gering sein) - oder jüngere Daten durch Erosion, Landoberflächeninstabilität bzw. Umlagerung, Freilegung von Blöcken. Da die Altersüberschätzung der Daten gering zu sein schien, war anzunehmen, dass das älteste Alter eines Blockes auf einer Form oft das ungefähre Alter der entsprechenden Form angab $^{399}$. Ob diese Überschätzung jedoch wirklich gering war, konnte nicht eindeutig geklärt werden: es existieren viel zu viele Unbekannte, um Aussagen über diesen Aspekt zu treffen sodass die Sichtweise der Forscher eine Annahme bleiben musste. $\mathrm{Zu}$ deuten wäre, warum andere Forscher im Zentralhimalaja Mittelwerte der ermittelten TCN-Daten von Formen bildeten und nicht, wie hier geschehen, das älteste Alter als das Entstehungsalter annahmen. Müssten hier nicht einheitliche Vorgehensweisen bestehen? Wenn das datierte Alter jedoch

\footnotetext{
396 "Material for radiocarbon dating is scarce, thus luminescence and surface exposure dating techniques must be used to establish event chronologies." (Zech et al. 2009:1106)

397 "Moraines, terraces, and landslides deposits are easily eroded in this landscape." (ebd.:1106); "Because the landscape around Annapurna is so strongly affected by mass-wasting and fluvial erosion, it is difficult to establish reliable glacial chronologies." (ebd.:1115)

398 Shanahan, T.M.; Zreda, M. (2000): Chronology of Quaternary glaciations in East Africa. In: Earth and Planetary Science Letters 177. (S. 23-42)

399 "Given these possibilities, it is wise to assume that the oldest exposure age on a landform most closely approximates the age of the feature." (Zech et al. 2009:1110); "In the absence of more exposure ages, the oldest age provides best estimate of deposition age, but this approach possibly can result in large errors." (ebd.:1113)
} 
wirklich das Alter der gesamten Form angeben sollte, dann müssten alle ermittelten Alter in ein und derselben Form ungefähr gleich sein. Daneben waren die von Zech et al. (2009) ermittelten Daten, so wie sie es angaben, zu wenige und waren für eine umfassende Rekonstruktion nicht geeignet ${ }^{400}$. Hier waren es lediglich drei bis fünf Blöcke je Form, was statistisch bezüglich des Probenumfangs als sehr gering erschien. Bei anderen Forschern zum Forschungsgebiet Zentralhimalaja wurden ebenfalls nur wenige Alter einer Form bestimmt. Oft waren es drei Daten, aus denen ein Mittelwert gebildet wurde. Doch von diesen Forschern wurde nicht erwähnt, dass die Daten zu wenige für eine umfassende Aussage waren. Außerdem fiel auf, dass das Alter der Dhampu Chooya Ablagerung von $4.100 \pm 600$ Jahren anhand von anderen Daten interpretiert und nicht genau bestimmt wurde ${ }^{401}$. Zudem war die lokale Produktionsrate anhand eines Skalierungsfaktors von einer referenzierten Produktionsrate auf Meeresspiegelhöhe in hohen Breiten bestimmt worden (vgl. Zech et al. 2009:1110). Dieses Untersuchungsgebiet von Tatopani bis Jomosom (Fig. 1) befand sich aber auf einer ungefähren Höhe von 1.300 bis 2.700 m und lag auf einer nördlichen Breite von etwa $28-29^{\circ}$. Ob die erhobenen Daten dann für dieses Gebiet stimmten, war ungewiss. Zudem war eine geringe Übereinstimmung aller Skalierungssysteme bekannt. Die Daten der neu entwickelten Skalierungssysteme von Dunai (2001) ${ }^{402}$, Desilets, Zreda (2003) ${ }^{403}$ und Lifton et al. $(2005)^{404}$ stimmten laut Zech et al. (2009:1112) gut überein im Gegensatz zu den Skalierungssystemen von Lal $(1991)^{405}$ und Stone $(2000)^{406}$. Die topographische Abschirmung durch umgebende Berge wurde bei Zech et al. nach Dunne et al. $(1999)^{407}$ berechnet. Doch musste hierbei überlegt werden, ob diese während vergangener Zeiten immer gleich war. Zur Lösung der methodischen Probleme äußerten sich Zech et al. wie folgt: "Overall, we conclude that although local calibration sites should be established in the

\footnotetext{
400 "The new data are far too few for a comprehensive reconstruction of Quaternary landscape evolution, but they allow us to discuss (1) the role of landslides and debris flows in the landscape history, and (2) the role of climate in influencing erosion and glaciation in the Himalaya." (ebd.:1106); "[...], more effort should be made to reconstruct past events and to assess and model the impact of possible future masswasting events. Mass balance and modelling studies can improve our understanding of the role of temperature and precipitation, respectively, for current and past glaciation." (ebd.:1116)

401 "We do not have exposure ages directly from the top of this deposit, but boulders LE41 and LE51 likely date the landslide, with which it is associated, at $\sim 4.1 \pm 0.6 \mathrm{ka}$. This interpretation is supported by the exposure age on the moraine at the southern margin of the Dhampu-Chooya deposit $(4.8 \pm 1.2 \mathrm{ka})$ that pre-dates the landslide (Fort, 2000)." (Zech et al. 2009:1111)

${ }^{402}$ Dunai, T.J. (2001): Influence of secular variation of the geomagnetic field on production rates of in situ produced cosmogenic nuclides. In: Earth and Planetary Science Letters 193. (S. 197-212)

${ }^{403}$ Desilets, D.; Zreda, M. (2003): Spatial and temporal distribution of secondary cosmic-ray nucleon intensities and applications to in situ cosmogenic dating. In: Earth and Planetary Science Letters 206. (S. 21-42)

404 siehe Quelle Lifton et al. (2005) in der Fußnote

${ }^{405}$ siehe Quelle Lal (1991) in der Fußnote

${ }^{406}$ siehe Quelle Stone (2000) in der Fußnote

${ }^{407}$ Dunne, A.; Elmore, D.; Muzikar, P. (1999): Scaling factors for the rates of production of cosmogenic nuclides for geometric shielding and attenuation at depth on sloped surfaces. In: Geomorphology 27. (S. 3-11)
} 
Himalayas to reduce the systematic methodological uncertainties, neither the choice of the scaling system nor other systematic uncertainties affect the conclusions drawn in our study." (Zech et al. 2009:1112-1113); "There currently is no consensus about the choice of the calculation protocol, but efforts are being made to reduce possible errors in surface exposure ages (Balco et al., 2008).” (Zech et al. 2009:1110).

Die von Zech et al. (2009) datierten Blöcke wiesen keinerlei Erosions- und Verwitterungsspuren auf. Waren die Blöcke etwa frisch aus anstehendem Gestein herausgebrochen gewesen? Die abgebildeten Fotos der Blöcke waren sehr klein, sodass nicht alle Blöcke genau zu erkennen waren. Nichtsdestotrotz verwiesen die Fotos aber darauf, dass die Blöcke, im Gegensatz zur Aussage der Forscher, enorme Verwitterungsspuren aufwiesen. $\mathrm{Zu}$ den Blöcken wurden keine Angaben wie etwa die zu Gesteinsart oder -größe gegeben. Sie untersuchten 22 Blöcke, aber auf Seite 1110 gaben sie die Anzahl 26 an. Ob diese restlichen vier Blöcke untersucht wurden, blieb im Text ungeklärt. Auch die in Tabelle 1 aufgelisteten Probenummern beginnend bei LE 12, LE 32, LE 41 u.s.w. deuteten darauf, dass weitere Blöcke aufgesucht, untersucht oder beprobt wurden. In der Tabelle 1 war außerdem zu erkennen, dass die zuvor genannten vier restlichen Blöcke die Blöcke mit den Nummern GA 11, GA 12, KA 11 und KA 13 sein mussten. Zudem wurden nur die obersten $2 \mathrm{~cm}$ beprobt; es wäre von Vorteil gewesen, wenn tiefere Proben oder Proben an der Seite des Gesteins zum Vergleich entnommen worden wären.

Über die letzte Eiszeit äußerten sich Zech et al. (2009) wie folgt: “Accordingly, some glaciers advanced in-phase with Northern Hemisphere ice sheets, whereas others reached their maximum extent at times of increased monsoonal precipitation during Marine Isotope Stage 3 and the early Holocene." (ebd.:1106); “We speculate that the glacio-fluvial terrace east of Lete, dated at $\sim 28 \pm 3 \mathrm{ka}$, marks the end of the period of high monsoonal precipitation and the related maximum advances of the Dhaulagiri and Nilgiri glaciers (Fig. 6)." (ebd.:1115); "Although we were unable to obtain exposure ages on Pleistocene moraines around Annapurna, [...].” (ebd.:1116). Demnach erklärten Monsune nicht alle Vergletscherungsphasen, bei Lete befand sich der maximale Eisrand und pleistozäne Moränen konnten nicht datiert werden. Es wurden gewissermaßen nur Annahmen über die letztglaziale Vergletscherung getroffen und die rund $28.000 \pm 3.000$ Jahre alte glazifluviale Terrasse östlich von Lete auf etwa 2.500 m Höhe als Maximalstadium der Vergletscherung angesehen. Auch die im Text verwendeten Begriffe wie etwa 'tentatively interpret', 'we speculate', `seems to be' ließen erkennen, dass einige Aussagen nicht abgesichert waren. Doch wenn 
keine pleistozänen Moränen datiert wurden, wie konnten die Forscher dann eine Aussage über die Maximalvergletscherung geben? Dem folgt die Frage, wo sich die genannten pleistozänen Moränen rund um den Annapurna befanden. Sowohl dem Text als auch den Abbildungen war diesbezüglich nichts zu entnehmen. In Fig. 5 war ersichtlich, dass neben einer fluvioglazialen Terrasse (LE 61) und zwei Terrassen (GH 21, GH 24) Diamikte (GH 11, GH 12) datiert wurden und wo diese genau vorkamen. Die sog. pleistozänen Moränen wurden jedoch nicht erwähnt.

\section{KUHLE (2011A)}

\section{METHODE BZW. ARBEITSTECHNIK}

Kuhle (2011a) wendete geomorphologische Analysen mit Schneegrenzberechnungen bzw. glaziogemorphologische und glaziogeologische Arbeitstechniken unter Betrachtung der Lagebeziehungen der unterschiedlichen Formen zueinander an. Dabei erfolgten Geländeuntersuchungen, bei denen viele unterschiedliche Formen kartiert (siehe geomorphologische Karten bzw. Eisbedeckungskarten in Fig. 2, 3 und 6) sowie anhand analoger Fotos bzw. Panoramen (siehe Fig. 7 bis 9) dokumentiert wurden. Desweiteren erfolgten unterstützende Sedimentuntersuchungen (40 Proben von Moränen), wie etwa Kohlenstoff-, Stickstoff- und Kalkgehaltsbestimmungen, Korngrößenanalysen (Sieb- und Pipettmethode, Sortierungskoeffizient, siehe Fig. 5) und Morphoskopien (siehe Fig. 4a, b). (vgl. Kuhle 2011a:175-177, 181 f.)

${ }^{14}$ C-Proben konnten laut Kuhle (2011a:178) infolge der Aridität des Gebietes nicht entnommen werden, obwohl diese gegenüber anderen absoluten Datierungen wie TCN oder OSL glaziogeomorphologisch sicher gewesen wären.

\section{UNTERSUCHUNGSGEBIET}

Kuhle (2011a) untersuchte im Dhaulagiri- und Annapurna-Himal die Gebiete Mustang und Thak Khola. In Fig. 1 war zu erkennen und auf Seite 182 nachzulesen, dass Kuhle in den Jahren 1976, 1977, 1995, 1998, 2000, 2002 und 2005 dort Geländearbeiten leistete.

\section{KRITIK}

Kuhle (2011a:175, 198) rekonstruierte einen hochglazialen, über den Pass Kore La von Südtibet stammenden, $120 \mathrm{~km}$ langen und 26 bis $31 \mathrm{~km}$ breiten Auslassgletscher Mustang Thak Khola Gletscher bis auf ca. 1.000 m Höhe bei der Mayangdi Konfluenz, welcher von seinen umgebenden Nebentälern Eiszuflüsse erhielt. Im Spätglazial entstand dort 
Podestmoräne, die ab dann auch teilweise zerschnitten und verlagert wurde (ebd.:175). Insgesamt machte Kuhle neben dem hochglazialen Stadium sieben spät- bis neoglaziale (ebd.:178) bzw. vier bis sechs spätglaziale und drei neoglaziale (ebd.:182) und sechs historische Stadien aus (ebd.:178, 182). Tab. 1 zeigt zwei hochglaziale Stadien (Riss und Würm), vier spätglaziale, drei neoglaziale, fünf historische sowie ein rezentes Stadium.

Kuhle (2011a) beschrieb im Detail auf den Seiten 182 bis 184 anhand eindeutiger Indikatoren die höchsten Schliffgrenzen bzw. Gletschermächtigkeiten vom letzthochglazialen Mustang Thak Khola Auslassgletscher von Südtibet bis zu den Orten Lomathang und Maran, die zwischen den Orten Maran und Chaile auf Seite 185 bis 188 und die zwischen den Orten Chaile und Thini (dazu noch die Moränenablagerungen) auf Seite 188 bis 191 sowie auf 193. Die spätglazialen Lateral- und Grundmoränen sowie glazifluviale Terrassen vom oberen zum mittleren Mustang Thak Khola waren auf der Seite 185 und die Podestgrundmoränenreste im Thak Khola zwischen den Konfluenzbereichen zum Thini und Myagdi Khola auf den Seiten 193 bis 195 sowie 197 erläutert. Abschließend ging er auf den letzthochglazialen Gletscherstand sowie auf den durch den LGM Thak Khola Gletscher gedämmten 360 m tiefen und $46 \mathrm{~km}$ langen Gletschersee vom Tange Khola bis zum Ort Chhairo ein, da er - wie bei Kuhle 1982, 1983 beschrieben - im oberen Mustang Thak Khola viele Seesedimente bzw. glazilimnische Terrassen auffand.

In Fig. 2 und 3 war zu erkennen, dass Kuhle enorm viele geomorphologische Formen aufnahm, wie etwa Rundhöcker und ähnliche Schliffformen, Grundmoränen mit erratischen Blöcken, Gletschertorschotterfluren und Gletschertorschotterflurterrassen, Schwemmschuttfächer und Schotterflurfächer, Schutt- und Murkegel oder -fächer, durch fluviale Unterschneidung entstandene Felshohlkehlen, Kames und subglaziale Schotterablagerungen, Kare, Transfluenzpässe, glaziäre Flankenschliffe, glaziäre Dreieckshänge u.s.w..

Unter Betrachtung der o.g. Aussagen stellte die Forschungsarbeit von Kuhle (2011a) zum Gebiet Mustang und Thak Khola neben seinen diesbezüglich weiteren in der vorliegenden Dissertation genannten die detaillierteste Bearbeitung gegenüber anderen Forschern dar. Infolge der von ihm angewendeten Methode erfolgte die Rekonstruktion der letzthochglazialen Gletscherbedeckung dieses Gebietes sinnvoll, beweiskräftig und nachvollziehbar. Es wurden Rückschlüsse anhand der Lagebeziehung verschiedenster geomorphologischer Formen zueinander gezogen. 
KUHLE (2013A)

METHODE BZW. ARBEITSTECHNIK

Kuhle wendete geomorphologische Analysen mit Sedimentuntersuchungen an.

\section{UNTERSUCHUNGSGEBIET}

Neben vielen anderen genannten Forschungsgebieten ging Kuhle (2013a:17) auf das Tal Thak Khola bzw. Kali Gandaki ein.

\section{KRITIK}

Im Thak Khola bzw. im Mustang Thak Khola Durchbruchstal fand Kuhle Hinweise einer einstmaligen Vergletscherung, wie beispielsweise Reste von Podestgrundmoränen mit erratischen Blöcken. Von Südtibet stammend muss laut ihm das Eis während der letzten Eiszeit über den Kore La durch das Mustang Thak Khola bis zum Ort Ranipauwa bis auf ca. $1.100 \mathrm{~m}$ Höhe geflossen sein, da entlang dieser Strecke Reste von solchen Grundmoränenpodesten existieren. (vgl. Kuhle 2013a:17)

Weiterhin sprachen die von Kuhle - teilweise aus seinen verschiedenen älteren Literaturquellen - zitierten Zeugnisse wie etwa der $250 \mathrm{~m}$ hohe Grundmoränenhügel Bhanka Dada mit erratischen Blöcken, aber auch Flankenabrasionen und Polierungen für eine glazigene Gestaltung des Tales (vgl. Kuhle 2013a:43).

Kuhle (2013a:17) verwies in Bezug auf das genaue Gletscherende bei 1.010 m Höhe auf die Forschungsarbeiten Kuhle (1980 und 1982) und auf die Gletscherkarte TH23 aus Kuhle (2011b). Unterhalb der ältesten Podestmoräne machte er - in der Literaturquelle aus dem Jahr 1982 veröffentlicht - außerdem noch Gletscherschrammen und -polierungen auf 1.760 oder 1.798 m Höhe etwa 140 bis 214 m über dem Talboden aus. Diese Ergebnisse basierten demnach auf eindeutig ausgemachten glazialen Formen. Die Arbeit Kuhle (2013a) stellte eine Zusammenstellung der Befunde der im Jahre 1980, 1982 und 1983 veröffentlichten Forschungen dar. 


\section{KUHLE (2013B)}

\section{METHODE BZW. ARBEITSTECHNIK}

Kuhle (2013b) wendete geomorphologische Analysen mit Schneegrenzberechnungen sowie Sedimentanalysen an. Die ausgemachten Formen wurden hierbei nicht nur im Gelände kartiert, sondern auch fotografiert.

\section{UNTERSUCHUNGSGEBIET}

Kuhle ging in der Arbeit (2013b) auf das Gebiet Mustang-Thak Khola sowie auf das Marsyandi Khola ein.

\section{KRITIK}

Die Ausarbeitung von Kuhle (2013b) mit dem Titel 'Tibet and High Asia (VIII): Glaciogeomorphology and Former Glaciation in the Himalaya and Karakorum' war sehr ähnlich zu jener von Kuhle (2011a), nur dass in dieser umfänglicheren Veröffentlichung eine größere Anzahl an Belegen bzw. Fotos / Panoramen und Diagrammen der Sedimentanalysen - morphometrische Analysen, Korngrößenanalysen - zum Gebiet Mustang-Thak Khola geliefert werden konnte und zudem auf das Marsyandi Khola eingegangen wurde. Die Ergebnisse der beiden Veröffentlichungen waren gleich: Kuhle belegte einen $120 \mathrm{~km}$ langen LGM Mustang-Thak Khola Auslassgletscher, welcher von Südtibet stammend bis auf eine Höhe von ca. $1.000 \mathrm{~m}$ hinab floss.

In Fig. 5 war im Gebiet Mustang-Thak Khola erkennbar, dass Kuhle sehr viele unterschiedliche geomorphologische Formen aufnahm und anhand derer Rückschlüsse auf die Ausgestaltung des vorzeitlichen Mustang-Thak Khola Gletscher traf.

\subsubsection{Modi Khola}

Im Modi Khola wurden die Forschungsarbeiten von Kuhle (2001a, 2007a, 2013a) und die von Zech et al. (2001) ausgewählt.

\section{KUHLE (2001A)}

\section{METHODE BZW. ARBEITSTECHNIK}

Kuhle führte glazialgeomorphologische Analysen durch. Er nannte im Modi Khola verschiedene Indikatoren der Vergletscherung, nämlich glazialgeomorphologische Formen wie etwa Trogtalprofil, Kamesterrasse, Moräne und subglazialer Strudeltopf. (vgl. Kuhle 2001a:176) 


\section{UNTERSUCHUNGSGEBIET}

Kuhle (2001a) gab an, dass das Modi Khola 1995 und 1998 von ihm untersucht wurde. Auch bei Kuhle (1982:Abb. 8) wurden Angaben über die Vergletscherung in diesem Gebiet gemacht. Jedoch versah er das Gletscherende mit einem Fragezeichen. Die Forschungsroute wurde damals innerhalb des o.g. Bereiches von Lumla nach Tatopani, Beni und Kusma angegeben.

\section{KRITIK}

In der Arbeit von Kuhle (2001a) mit dem Titel 'Tibet and High Asia (VI): Glaciogeomorphology and Prehistoric Glaciation in the Karakorum and Himalaya' wurde dort auf einer Seite das Gebiet des Modi Khola beschrieben. Er ging hierbei auf seine damaligen Befunde von 1982, 1995 und 1998 ein, womit es sich im weitesten Sinne um eine Zusammenfassung handelte. Im Gegensatz zu anderen Forschern wurden weitere Formen wie Kamesterrasse und Strudeltopf betrachtet und nicht nur - wie so oft - auf Akkumulationsformen eingegangen. Das Trogtalprofil reichte nach Kuhle (2001a:176) gegenüber den Befunden von Zech et al. (2001) in diesem Gebiet bis in das untere Modi Khola Tal bis etwa nach Dobila hinunter. Vor allen Dingen deuteten die von Kuhle ausgemachten Grundmoränen auf etwa 1.450 m Höhe beim Konfluenzbereich des Bhurungdi Khola auf eine einstmalige Vergletscherung hin. Zwei Fotos machten die Befunde von Kuhle (2001a) nachvollziehbar. Somit waren die Ergebnisse von Zech et al. (2001) überdenkbar. Die von Kuhle angegebene vorzeitliche Eismächtigkeit bei Birethanti entsprach aber ungefähr der von Zech et al. (2001).

\section{ZECH ET AL. (2001)}

\section{METHODE BZW. ARBEITSTECHNIK}

Zech et al. (2001:159, 162) wendeten glazialgeomorphologische Analysen, bodenkundliche, vegetationskundliche und pollenanalytische Untersuchungen sowie ${ }^{14} \mathrm{C}$-Analysen (konventionelle Alter der Gesamtfraktion) und Schneegrenzberechnungen (nach Höfer $1879^{408}$ und Louis $1955^{409}$ ) an. Glaziale und kolluviale Akkumulationen wurden somit relativ datiert (vgl. Zech et al. 2001:159). Sie gruben Moränen und glazifluviale Ablagerungen auf, es folgten Bodenansprachen und es wurden Mischproben pro Horizont entnommen (ebd.:161). Sämtliche Laboranalysen - wie etwa Korngrößenanalyse, Kohlenstoff-, Stickstoff-

\footnotetext{
408 siehe Quelle Höfer (1879) in der Fußnote

${ }^{409}$ siehe Quelle Louis (1955) in der Fußnote
} 
und Gesamtelementgehalt, pH-Wert, Kationenaustauschkapazität, Eisenfraktionierung, Verwitterungsindex, Tonmineralanalyse - erfolgten am Feinboden und waren dort auf Seite 162 und 163 beschrieben. Außerdem wurden Herbarien angelegt, wodurch die Pollen und Sporen untersucht werden konnten (ebd.:162). Sie zählten in den Bodenproben zwischen 190 bis 250 Pollen aus und stellten diese in Beziehung zur Gesamtpollenzahl (ebd.:163). Die genannten ${ }^{14} \mathrm{C}$-Analysen wurden anhand von humosen Horizonten bei den Bodenprofilen 97/11, 11a, 12, 12a, 13 durchgeführt (ebd.:182).

\section{UNTERSUCHUNGSGEBIET}

Zech et al. (2001:159, Abb. 1) untersuchten das Gebiet des Modi Khola im Bereich der Südabdachung des Annapurnamassivs. Die Untersuchungen reichten vom Annapurna I Gletscher über das Gebiet rund um Chomrong und rund um Tarapani bis nach Birethanti und Kusma.

\section{KRITIK}

In der 30-seitigen Abhandlung mit vier Fotos und sieben Abbildungen unter dem Titel 'Zur pleistozänen und holozänen Landschaftsgeschichte des Modi Khola-Tals (Annapurna, Nepal)' gingen Zech et al. (2001) auf die vorzeitliche Vergletscherung des Modi Khola ein. Vor diesen Untersuchungen existierten laut ihnen keinerlei genauere Untersuchungen ${ }^{410}$; sie gaben nur die Arbeit von Fort (1995) $)^{411}$ an. Im Jahre 2001 schrieb Kuhle jedoch auch über dieses Gebiet. Auf die Arbeit von Kuhle (1982) aus dem Annapurna- und Dhaulagiri-Himal gingen sie ein.

Zech et al. (2001) rekonstruierten das letzteiszeitliche Eis anhand von geomorphologischen, aber auch morphostratigraphischen Geländebefunden (ebd.:178) und Bodenbefunden bzw. relativen und absoluten Altersdatierungen. $\mathrm{Zu}$ den angewendeten Methoden bzw. Arbeitstechniken von Zech et al. (2001) wie glazialgeomorphologische Analysen, Schneegrenzberechnungen, bodenkundliche, vegetationskundliche und pollenanalytische Untersuchungen sowie ${ }^{14} \mathrm{C}$-Analysen war folgendes anzumerken: glazialgeomorphologische Analysen und Schneegrenzberechnungen sind für eine Rekonstruktion vorzeitlicher Vergletscherungsausdehnungen unumgänglich, jedoch lassen diese nur Aussagen zu, wenn viele unterschiedliche Formen berücksichtigt und in Lagebeziehung zueinander gesetzt

\footnotetext{
410 „Das zwischen dem Kali Gandaki- und Seti Khola-Tal gelegene Modi Khola-Tal (Abb. 1) wurde bisher unseres Wissens nicht genauer untersucht. “ (Zech et al. 2001:160)

${ }^{411}$ Fort, M. (1995): The Himalayan glaciation: myth and reality. J. Nepal Geological Society, spec. issue. (S. 257-272)
} 
werden. Zech et al. (2001) gaben zwar an, dass sie glazialgeomorphologische Analysen betrieben haben, untersuchten aber lediglich Moränen und glazifluviale Terrassen ${ }^{412}$. Außerdem gingen sie auf das Trogtalprofil nördlich von Chomrong mit geschliffenen Trogwänden und auf das annähernd ausgebildete Trogtalprofil bei Birethanti ein (ebd.: 166, 179). Jedoch schrieben sie, dass oberhalb von Birethanti ein enger Talgrund existierte. Hierbei wäre zu klären, ob es sich bei Birethanti wohl eher um die Talform schluchtförmiger Trog handelte. Außerdem machten sie konglomeratisierte Schotterterrassen mit sehr großen kantengerundeten fluvioglazialen Gneisblöcken, die erst unterhalb von Birethanti vorkamen, aus. Den Beginn von Terrassenniveaus nahmen sie als Indiz der letztglazialen Eisrandlage $\mathrm{an}^{413}$. Rubifizierte Böden und mit rötlich braunem Verwitterungslehm gefüllte Karstorgeln ließen ein mittelpleistozänes Alter annehmen (ebd.:181). Belege dieser Befunde waren anhand von vier Fotos (Ufermoräne des Annapurna I Gletscher, Moränen unterhalb des Machhapuchhare Basecamp, Karstformen westlich der Mündung des Kyumnu Khola und fluvioglaziale Schotter unterhalb von Birethanti) nachvollziehbar. Jedoch sollten für eine Aussage über die letzteiszeitliche Vergletscherung, so wie bei Kuhle, mehrere Formen darunter neben Akkumulations- auch mehrere Erosionsformen - betrachtet werden. Die für die Aussage über die vorzeitliche Vergletscherung zudem verwendeten bodenkundlichen Analysen (s.o.) waren kritisch zu hinterfragen. Die Bodenentwicklung, welche für das Bestimmen des Alters der Form verwendet wurde ${ }^{414}$, kann von enorm vielen Faktoren wie etwa der Höhe abhängen. Zudem beeinflusst nach Zech et al. (2001:171) der Humusgehalt das $\mathrm{Fe}_{0} / \mathrm{Fe}_{\mathrm{d}}-$ Verhältnis.

Zech et al. (2001) drückten sich über die vorzeitliche Vergletscherung nur sehr vage aus ${ }^{415}$. Demnach basierte diese Arbeit auf Annahmen, was sie selber in Bezug auf die Nichterhaltung von Stirnmoränen zugaben: „Die Annahmen über die maximale Ausdehnung der LGMGletscher (s.o.) sind deshalb mit Unsicherheiten behaftet. “ (Zech et al. 2001:160). Moränen waren zudem nicht eindeutig von anderen Akkumulationsformen - wie etwa durch Bergrutsche oder Schlammströme entstandenen Formen - unterscheidbar (ebd.:161). LGM Stirnmoränen waren nach Zech et al. (2001:160 f.) aufgrund der enormen Schmelzwässer hochliegender Gletscher und der Prozesse wie Bergrutsche und Schlammströme in den Tälern

\footnotetext{
412 ,Während der Geländearbeiten wurden die geomorphologisch relevanten Formen wie Moränen und die fluvioglazialen Terrassen erfaßt, [...]. “ (Zech et al. 2001:161)

413 „, [...] und der Beginn der oberen und mittleren Terrassenniveaus nahe Birethanti läßt vermuten, daß die maximale Gletscherausdehnung im Modi Khola-Tal etwa bis 1100 m herabreichte. “ (ebd.:182)

414 ,Um ihr Alter abschätzen zu können, prüften wir die Intensität der Bodenbildung. “ (ebd.:163)

415 „Die geomorphologischen Befunde machen aber wahrscheinlich, dass die maximale Gletscherausdehnung [...]. " (ebd.:159)
} 
Kali Gandaki, Modi Khola, Seti Khola, Madi Khola und Dudh Khosi wohl eher nicht erhalten. Sie trafen Aussagen über die letzteiszeitliche Vergletscherung, fanden aber keine eindeutigen Moränen im Bereich der Konfluenz Kyumnu Khola zum Kali Gandaki ${ }^{416}$ und generell keine eindeutigen Moränenwälle: „Eindeutige spätglaziale und hochglaziale Moränenwälle konnten nicht identifiziert werden. “ (Zech et al. 2001:159). Hierbei stellte sich die Frage, ob sie nur wallförmige Moränen aufsuchten. Die Grundmoränen würden in diesem Fall nicht berücksichtigt worden sein, wobei diese jedoch für die Rekonstruktion einer hochglazialen Gletscherausdehnung bedeutend gewesen wären. Bei Chomrong fanden sie keine eindeutigen Wallmoränen, aber nördlich von Chomrong ein Trogprofil mit glaziärem Flankenschliff; Moränen waren aufgrund von Hangschutt nicht eindeutig identifizierbar (ebd.:166). Jedoch ließen geomorphologische Befunde den Schluss zu, dass die maximale Gletscherausdehnung bis auf ca. 1.100 bis $1.200 \mathrm{~m}$ Höhe bei einer Schneegrenzdepression von 1.250 bis $1.300 \mathrm{~m}$ reichte (ebd.:159). Zum Beispiel waren talaufwärts von Birethanti Aufschlüsse in Form steinig-schluffiger phyllitreicher Substrate mit Blöcken (Augengneise aus den glazialen Einzugsgebieten) auszumachen, die jedoch auch 'flow debris' darstellen konnten ${ }^{417}$. Wenn die Augengneisblöcke aus den Gletschereinzugsgebieten stammen, warum waren diese dann nicht als Erratika angesprochen und als eindeutige Zeugen einer einstmaligen Vergletscherung herangezogen worden? Selbst wenn diese Blöcke der Form der 'flow debris' angehörten, würden diese Blöcke vorher doch trotzdem durch einen Gletscher transportiert worden sein. Zusammengefasst betrachtet konnte die maximale Gletscherausdehnung von den Forschern nicht geklärt werden und auch nicht der genaue Zeitpunkt der maximalen Vergletscherung, sodass ungeklärt blieb, in welches Sauerstoffisotopenstadium - 2 oder 4 - diese fiel (ebd.:188). Zudem erstellten sie nur eine ungenaue Chronologie der historischen Gletschervorstöße (jünger als 1.700 Jahre v.H.), da die Wetterlage die Untersuchungen verhinderte (ebd.:163).

$\mathrm{Zu}$ den Bodenprofilen konnte folgendes beobachtet werden: In Abb. 2 waren die untersuchten Bodenprofile 4 bis 7 dargestellt. Die Ufermoräne im Umfeld des Machhapuchhare Basecamps wurde fotografiert (Foto 1). Nummer 4 und 6 waren 'Eutric Cambisole' und morphologisch vergleichbar, wobei die Nummer 7 eine Braunerde war. Diese drei Profile waren vermutlich $^{418}$ gleich alt und gehörten möglicherweise ${ }^{419}$ zum Neoglazial. Dieses wurde mit

\footnotetext{
416 „[...], fanden wir bisher keine eindeutigen Moränen. “ (ebd.:179)

417 ,Wir können jedoch nicht mit Sicherheit entscheiden, ob es sich um Moränenmaterial oder um Reste von flow debris handelt." (ebd.:181)

418 „, Wir nehmen deshalb an, [...]. “ (ebd.:165)
} 
einem berechneten Aktivitätskoeffizienten untermauert, wobei dieser aber bei allen drei Profilen nicht gleich war. Es fiel auf, dass das Bodenprofil 7 laut diesem Koeffizienten das älteste war, wobei das 6. und das 4. folgten. Zech et al. (2001) merkten aber an, dass sie annähernd gleich waren und deshalb dasselbe Alter hatten ${ }^{420}$. Moränen beim Annapurna Basecamp waren ebenfalls neoglazial (ebd.:163). Auch bei den jüngeren neuzeitlichen Moränen wurde das Alter nur vermutet ${ }^{421}$. Die drei Profile 4,6 und 7 wiesen eine große Ähnlichkeit auf. Vor allen Dingen Profil 4 und 6 waren gleicher Genese ${ }^{422}$. Unter genauer Betrachtung der Profile und deren Lage in Abb. 2 fiel auf, dass die Profile auch Unterschiede aufwiesen - Profil 4 (A-Horizont 0-17 cm, Bw 17-37 cm, C ab $37 \mathrm{~cm}$ ), Profil 6 (A-Horizont 0-10 cm, AB 10-13 cm, Bw 13-33 cm, C ab $33 \mathrm{~cm}$ ) und Profil 7 (A 0-10 cm, Bw1 10-30 cm, Bw 2 30-45 cm, C ab $45 \mathrm{~cm}$ ) - und das Profil 5 Ähnlichkeiten (A 0-10 cm, Bw 10-25 cm, C ab $25 \mathrm{~cm}$ ). Im Text war bei Zech et al. (2001) aber nichts über das Profil Nummer 5 angegeben. Das Profil 5 müsste, da es lagebezugsmäßig viel weiter weg vom Gletscher lag und somit auf älterem Material auflag, eine viel stärkere Bodenentwicklung aufzeigen; auch weil es schon allein viel tiefer als die Profile 4 und 6 lag. Da die Profile 4, 6 und 7 gleichen Alters waren, müssten sie jedoch laut dem Grundgedanken der angewendeten Methode bzw. Arbeitstechnik genau dieselben Bodenprofile anzeigen. Auffällig war aber, dass die Bodenprofile mit der Höhe in Verbindung zu bringen waren: Bodenprofil 7 auf $3.570 \mathrm{~m}$ Höhe war weiter entwickelt als die Bodenprofile 4 auf $3.745 \mathrm{~m}$ und 6 auf $4.200 \mathrm{~m}$. Bodenprofil 5 auf 3.720 m hatte gegenüber Bodenprofil 4 auf 3.745 m einen Höhenunterschied von 25 m und musste älter sein. Eigentlich müsste der Boden Nummer 5 demnach eine viel stärkere Bodenentwicklung aufzeigen. Dieses war aber nicht der Fall. Somit deutete die von Zech et al. (2001) angewendete Methode bzw. Arbeitstechnik auf mögliche Fehler hin.

Das Bodenprofil 97/8 aus vermutlich hoch- bis spätglazialen Ablagerungen ließ eine ungefähre Eismächtigkeit von 300 bis 350 m nordöstlich von Chomrong annehmen ${ }^{423}$. Es war älter als die Profile 4 und 6, da es mehr gut kristallisierte Oxide aufwies (ebd.:177). Da es hier

\footnotetext{
419 „Ihre Solummächtigkeit lässt vermuten, [...]. “ (ebd.:163)

${ }^{420}$, ,...] Berechnung der Aktivitätskoeffizienten [...]. Für die B-Horizonte [...].Da sie annähernd vergleichbar hoch sind folgt, dass auch die entsprechenden Moränen ungefähr das gleiche Alter haben. “ (ebd.:166) 421 „Die Bodenentwicklung auf diesen jungen, vermutlich neuzeitlichen Ablagerungen [...]. “ (ebd.:163)

${ }^{422}$ „Das Ausmaß der Pedogenese ist praktisch identisch. [...] als vergleichsweise junge, gleichaltrige Bodenbildungen aus. “ (ebd.:177)

${ }^{423}$ „, Wir nehmen deshalb an, dass sich diese Braunerde 97/8 aus älteren, evtl. hoch-bis spätglazialen Ablagerungen gebildet hat, die durch Rückstau des Chomrong-Gletschers sedimentiert wurden. Bei einer Obergrenze der glazigenen Sedimente in $2200 \mathrm{~m}$ und einer heutigen Talbodenhöhe von $1750 \mathrm{~m}$ an der Einmündung des Chomrong Khola in den Modi Khola unterhalb von Profil 97/8, ergibt sich eine ungefähre (hochglaziale?) Eismächtigkeit von 300-350 m im Modi Khola-Tal bei Chomrong. “ (ebd.:166)
} 
hieß, dass es entweder spät- oder hochglaziale Akkumulationen waren, auf denen sich der Boden entwickelte, blieb offen, ob dieses nun wirklich eine hochglaziale Eismächtigkeit angab oder nicht. Die Profile 97/1 und 97/2 auf 2.570 m und 2.460 m Höhe wurden laut den Forschern während der letzten maximalen Vergletscherung nicht mehr vom Eis erreicht (Abb. 3). Die Böden 1 und 2 müssten demnach viel älter als die Böden 3 und 8 sein, da diese nicht vom Eis überfahren wurden. In Tabelle 2 konnten die Aktivitätskoeffizienten 0,58 für den Boden 1, 0,32 für den Boden 2, 0,60 für den Boden 3 sowie 0,20-0,25 für den Boden 8 abgelesen werden. Laut diesen Daten war der Boden 8 tatsächlich der älteste, gefolgt von den Böden 2, 1 und 3. Demnach war der Boden 3 der jüngste. Bei der Betrachtung von Abb. 3 wurde deutlich, dass der Boden 3 nördlicher und viel höher lag als alle anderen Böden. Würden diese Profile mit der Höhenlage in Verbindung gebracht werden, wäre der Boden 8 ebenfalls der älteste, gefolgt von den Böden 2, 1 und 3. Laut den Angaben der Forscher muss die Eismächtigkeit von Chomrong bis nach Birethanti unter den angegebenen 300 bis $350 \mathrm{~m}$ Dicke gelegen haben. Wie konnte es aber sein, dass der Boden 3, welcher oberhalb des Eises gelegen hat, eine so geringe Bodenentwicklung aufwies bzw. so jung war; dieser Boden müsste älter als der Boden 8 sein. Im Text wurde erwähnt, dass im Bodenprofil 3 äolische Sedimente vorkamen und der fossile Ah-Horizont vermutlich das mittelholozäne Klimaoptimum darstellte. Zu dem hohen Aktivitätskoeffizienten des Boden 1 schrieben die Forscher, dass der hohe Humusgehalt des Bodens meist diesen Koeffizienten beeinflussen würde (ebd.:171). Zudem kann nach Zech et al. (2001:177) die Bestimmung pedogener Eisenoxide und somit des Aktivitätskoeffizienten nicht nur vom Alter, sondern auch vom Gesamteisengehalt, vom Wasserhaushalt und somit auch von Verlagerungsprozessen abhängig sein. Auf den noch höheren Wert von Boden 3 gingen sie jedoch nicht weiter ein. Somit konnte nur darüber spekuliert werden, warum der Boden 3 so jung war bzw. ob dies durch den Eintrag der äolischen Sedimente erklärbar wäre. Bei der Betrachtung der weiteren untersuchten Bodenprofile war ersichtlich, dass das Profil 10 im Text nicht erwähnt wurde.

Die Bodenprofile 9, 14 und 15 bei Tarapani waren aufgrund ihres enormen Gehaltes an gut kristallisierten Eisenoxiden viel älter als die anderen (ebd.:177). Die hydromorphen Profile 11 und 13 wiesen jedoch geringere gut kristallisierte Eisenoxide auf, da diese durch Reduktionsund Umverteilungsprozesse entweder durch Grundwasserstromabfuhr oder durch Umwandlung in weniger gut kristallisierte Eisenformen reduziert wurden (ebd.:177). Diese hydromorphiebedingten Unterschiede in der Eisenfraktionierung wurden durch die bestimmten Verwitterungsindizes ausgeglichen, welche weitestgehend die Ergebnisse der 
Eisenfraktionierung und der morphostratigraphischen Geländebefunde bestätigten: die Böden 4, 6 und 7 waren sehr junge Böden bzw. wiesen sehr geringe Bodenentwicklung auf, wobei der Boden 8 deutlich älter war; 11, 13 und 14 waren vermutlich interglazial entstanden. Die Verwitterungsindizes verwiesen jedoch im Gegensatz zur Eisenfraktionierung bei Bodenprofil 9 auf eine sehr geringe Bodenbildung. Hierbei wurde unterschiedliches Ausgangsgestein als Grund angeführt (ebd.:178). Die Forscher wendeten tonmineralogische Analysen an, welche auch zu den Ergebnissen der Eisenfraktionierung führten (ebd.:179). Jedoch gaben sie an, dass weitere Forschungen nötig sind ${ }^{424}$. Das Profil 15 bei Chitepani lag deutlich außerhalb des letztglazialen Eisrandes und vermutlich auch von früheren Eisrändern (ebd.:177), mit Sicherheit aber außerhalb der vorletzten Eiszeit (ebd.:179). Schlussendlich wurde bei der Betrachtung der Aussagen von Zech et al. (2001) deutlich, dass viele derselben Annahmen waren.

\section{KUHLE (2007A)}

\section{METHODE BZW. ARBEITSTECHNIK}

Kuhle (2007a) wendete im Dhaulagiri- und Annapurna-Himal geomorphologische Analysen mit Schneegrenzberechnungen an.

\section{UNTERSUCHUNGSGEBIET}

Kuhle (2007a) ging neben sehr vielen anderen Gebieten Hochasiens auf das Gebiet des Dhaulagiri- und Annapurna-Himal ein.

\section{KRITIK}

In der Arbeit von Kuhle aus dem Jahre 2007 mit dem Titel `The past valley glacier network in the Himalayas and the Tibetan ice sheet during the last glacial period and its glacial-isostatic, eustatic and climatic consequences' wurden auf der Seite 125 in einem Satz Informationen über das Tal Modi Khola gegeben. Dabei bezog er sich auf eine ältere Literaturquelle aus dem Jahr 2005. Es wurde lediglich erwähnt, dass der LGM Modi Gletscher bis auf ca. $800 \mathrm{~m}$ Höhe in der Nähe des Ortes Dobila - bei der Konfluenz zum Jahre Khola - hinab floss. Somit waren in dieser Arbeit keine glazialgeomorphologischen Befunde aufgelistet.

\footnotetext{
424 „Die Ergebnisse müssen allerdings durch weitere Untersuchungen bestätigt werden, da von dieser Region des Himalaya bisher keine Ergebnisse über die Zusammensetzung der Tonmineralfraktion aus der Literatur bekannt sind. " (ebd.:179)
} 
KUHLE (2013A)

METHODE BZW. ARBEITSTECHNIK

Kuhle wendete geomorphologische Analysen an.

\section{UNTERSUCHUNGSGEBIET}

Neben vielen anderen genannten Forschungsgebieten ging Kuhle (2013a:17) auf das Tal Modi Khola ein.

\section{KRITIK}

Bei Kuhle (2013a:17) wurde zum Tal Modi Khola erwähnt, dass der tiefste LGM Eisrand bei einer Höhe von etwa $800 \mathrm{~m}$ lag, wobei er sich auf ältere eigene Forschungen bezog. Somit waren in dieser Arbeit keine glazialgeomorphologischen Befunde, die zu diesem Ergebnis führten, beschrieben.

\subsubsection{Madi Khola}

Im Madi Khola waren die Arbeiten von Kuhle (1998, 2001a, 2007a und 2013a) bekannt.

\section{KUHLE (1998)}

\section{METHODE BZW. ARBEITSTECHNIK}

Kuhle wendete geomorphologische Analysen mit Schneegrenzbestimmungen an.

\section{UNTERSUCHUNGSGEBIET}

Kuhle (1998) führte Ergebnisse zu vielen Untersuchungsgebieten wie beispielsweise Tibet, Karakorum, Aghil Gebirge, Kuenlun, Tarim Becken, Pamir, Ladakh Range, Nanga Parbat, Tien Shan, Sayan Gebirge, Trans Baikal Gebirge, Zanskar-Himal, Garhwal-Himal, Khumbu/ Rongbuk-Himal, Kangchendzönga-Himal, Dhaulagiri- und Annapurna-Himal auf.

\section{KRITIK}

Kuhle (1998:87) äußerte sich in einem Satz über das Tal Madi Khola. Hierbei beschrieb er den tiefsten Eisrand in diesem Tal auf ca. 630 m Höhe, was durch eine über zwei km lange Lateralmoräne und erratische Blöcke begründet wurde. Kuhle äußerte sich aber nicht dazu, ob es sich hierbei um einen letztglazialen Maximalstand handelte. 


\section{KUHLE (2001A)}

\section{METHODE BZW. ARBEITSTECHNIK}

Kuhle führte glazialgeomorphologische Analysen durch. Er nannte die verschiedenen Hinweise auf Vergletscherung, nämlich glazialgeomorphologische Formen wie etwa Moränen bzw. erratische Blöcke. (vgl. Kuhle 2001a:391)

\section{UNTERSUCHUNGSGEBIET}

Kuhle (2001a) ging neben vielen anderen Untersuchungsgebieten auf das Tal Madi Khola ein.

\section{KRITIK}

Im Madi Khola rekonstruierte Kuhle (2001a:391) das Gletscherende des vorzeitlichen Madi Gletscher auf ca. 630 m Höhe, was er durch Auffinden von Lateralmoränen und erratischen Blöcken bereits vor dieser Veröffentlichung belegte. Durch das verwendete Wort 'probably' legte sich Kuhle zeitlich nicht genau fest, somit blieb offen, ob es sich hierbei um einen hochglazialen Gletscherstand handelte.

\section{KUHLE (2007A)}

\section{METHODE BZW. ARBEITSTECHNIK}

Kuhle (2007a) wendete im Dhaulagiri- und Annapurna-Himal geomorphologische Analysen mit Schneegrenzberechnungen an.

\section{UNTERSUCHUNGSGEBIET}

Kuhle (2007a) ging neben vielen anderen Gebieten Hochasiens auf das Gebiet des Dhaulagiriund Annapurna-Himal ein.

\section{KRITIK}

In der Arbeit von Kuhle aus dem Jahre 2007 mit dem Titel `The past valley glacier network in the Himalayas and the Tibetan ice sheet during the last glacial period and its glacial-isostatic, eustatic and climatic consequences' wurden auf der Seite 125 in einem Satz Informationen über das Tal Madi Khola gegeben. Dabei bezog er sich auf ältere eigene Forschungen. Es wurde erwähnt, dass die mehr als zwei km lange Lateralmoräne sowie große erratische Blöcke Hinweise zur tiefsten Eisrandlage auf ca. $630 \mathrm{~m}$ Höhe darstellten (vgl. Kuhle 2007a:125). Somit basierte diese Aussage auf eindeutigen glazialgeomorphologischen Befunden. 
KUHLE (2013A)

METHODE BZW. ARBEITSTECHNIK

Kuhle wendete geomorphologische Analysen an.

\section{UNTERSUCHUNGSGEBIET}

Neben vielen anderen genannten Forschungsgebieten ging Kuhle (2013a:17) auf das Tal Madi Khola ein.

\section{KRITIK}

Bei Kuhle (2013a:17) wurde zum Tal Madi Khola lediglich erwähnt, dass der tiefste LGM Eisrand bei einer Höhe von etwa $630 \mathrm{~m}$ lag, wobei er sich auf ältere Literaturquellen bezog. Somit waren in dieser Arbeit keine glazialgeomorphologischen Befunde, die zu diesem Ergebnis führten, beschrieben.

\subsubsection{Seti Khola}

Im Seti Khola wurden die Arbeiten von Fort (1986) und Kuhle (2001a, 2007a, 2013a) untersucht.

\section{FORT (1986)}

\section{METHODE BZW. ARBEITSTECHNIK}

Fort (1986) nutzte geomorphologische Analysen (ebd.:108/Fig. 2) mit Sedimentbeschreibungen, wobei sie zudem Radiokarbondatierungen (ebd.:116/Tab. 1) im Pokhara Becken anwendete. Ihre Indikatoren einer vorzeitlichen Vergletscherung im Annapurna-Himalaja waren insbesondere Moränen.

\section{UNTERSUCHUNGSGEBIET}

Fort (1986) untersuchte das Gebiet des Seti Khola als Nachbartal des Modi und des Madi Khola. Die Größe des Untersuchungsgebietes betrug 30 mal 40 km (z.B. ebd.:109/Fig. 3), wobei die Forschungsroute und die Aufenthaltsdauer nicht angegeben wurden.

\section{KRITIK}

Die 15-seitige Arbeit von Fort (1986) mit dem Titel 'Glacial extension and catastrophic dynamics along the Annapurna front, Nepal Himalaya' beinhaltete insgesamt vier Fotos der Dhiprang und Pokhara Formation sowie sieben Abbildungen - Untersuchungsgebiet und 
lithostrukturelle Einheiten; eine geomorphologische Karte des Seti Khola; eine Verteilung der Gharjati / Thak Bhaise Brekzie, der Rithepani Formation, der Kahure Gachok Akkumulation, der Dhiprang Pokhara Akkumulation sowie die Geometrie der Akkumulationen im Pokhara Tal - und eine Tabelle $\left({ }^{14} \mathrm{C}\right.$-Daten $)$.

Die Ausarbeitung von Fort (1986) war für eine Aussage über die maximale Vergletscherung während der letzten Eiszeit wenig geeignet, da von ihr keine Aussagen direkt über das Hochglazial getroffen wurden, sondern nur über das Spätglazial. Kuhle (2007b:107) machte ebenfalls darauf aufmerksam, dass Fort (1986) eine spätglaziale Gletscherausdehnung bis auf ca. 1.150 m Höhe angab und dieses Ergebnis nicht mit ihren Befunden aus dem Jahre 2000 im Miristi Khola - tiefster letztglazialer Eisrand auf 2.800 bis $3.000 \mathrm{~m}$ - übereinstimmte. Somit war sich Kuhle (2007b:107) nicht sicher, ob Fort die maximalsten hochglazialen Gletscherenden beschrieb. Aus Fig. 2 bei Fort (1986) konnte eine Eisrandlage bei ca. $1.100 \mathrm{~m}$ Höhe in der Nähe von Gachok entnommen werden. Diese dort vorkommenden Ablagerungen bzw. kalkhaltigen Brekzien von Kahure Gachok mit Moränencharakter sollten einer vermutlich spätglazialen Ausdehnung angehören. Die Altersangabe wurde durch das verwendete Wort 'might' sehr ungenau und war demzufolge nicht abgesichert. Zudem gab es bei verschiedenen Forschern wie o.g. Uneinigkeiten über die zeitliche Einordnung der Gachok Formation, die entweder aus der vorletzten oder letzten Vergletscherung stammte. Auch bei der geomorphologischen Einordnung der Pokhara Formation und folglich auch der Gachok Formation war sich Fort (1986) nicht schlüssig ${ }^{425}$.

Fort untersuchte insbesondere Moränen, beispielsweise sehr gut erhaltene Endmoränenrücken. Jedoch konnten diese nicht datiert werden, da das Material dazu nicht vorhanden war $^{426}$. Der hohe Frischegrad und die geringe Bodenbedeckung ließen aber ein rezentes Alter vermuten, wobei ein neoglaziales Alter angenommen wurde ${ }^{427}$.

\footnotetext{
425 "If the previous assumptions are correct, then it follows that the Pokhara Formation is not a true glaciofluvial outwash, in spite of the fact its aggradation most probably occurred during a period of glacial advance and involves the reworking of till material. Rather, it has to be considered as a debris-flow, deposited in a glaciofluvial environment in a context of high geodynamic instability. On the basis of this conclusion, the interpretation of the Gachok Formation can also been questioned. The description given above show that the Pokhara and Gachok Formations resemble each other in their petrographic composition (material mostly derived from the Sabche cirque), in their sedimentary context (superposition upon till-like material) and in their geomorphic effects (flooding of tributary valleys). Accordingly, the Gachok conglomerates might well represent a debris-flow accumulation." (Fort 1986:117 f.)

426 "No datable material has been found so far." (ebd.:107)

427 "[...], which might be related to Neoglacial stages." (ebd.:107)
} 
Daneben machte sie aber auch Angaben über polierte und geschrammte Schluchtwände. Weitere glazigene Formen fanden keinen Eingang in die Ausführungen. Ältere glaziale Belege waren oft nicht mehr erhalten ${ }^{428}$. Auch Kuhle (2007b:107) schrieb, dass sich Fort (1986) in Bezug auf die Genese der Gachok Formation - Moräne gegenüber `debris flow accumulations' - widersprach. Es gab nach Fort (1986:105) Schwierigkeiten beim Erkennen vorzeitlicher Vergletscherungsausdehnung auf der Südseite des monsunbeeinflussten Himalaja: Erosionsprozesse, Verwitterungs- und Massenbewegungsprozesse können die Merkmale der glazialen Ablagerungen verändern und katastrophale Akkumulationen - die oft konvergente Eigenschaften aufweisen - können zu einer Verwechslung mit glazialem Material führen. Als Beispiel hierfür sind 'GLOFs' zu nennen, die - vor allen Dingen hier ab dem Spätglazial - dazu führen können, dass etwa Moränenmaterial talabwärts transportiert wird (vgl. Kuhle 2012b:197-199, 204). Fort (1986) merkte an, dass weitere Forschungen, darunter auch eine größere Menge absoluter Datierungen, nötig sind ${ }^{429}$.

\section{KUHLE (2001A)}

\section{METHODE BZW. ARBEITSTECHNIK}

Kuhle (2001a:176) nannte die Erratika als Indikatoren der Vergletscherung, wendete demnach also eine glazialgeomorphologische Analyse im Seti Khola an.

\section{UNTERSUCHUNGSGEBIET}

Kuhle (2001a:176) gab an, dass über das Seti Khola bereits im Jahr 1982 von ihm Angaben über die vorzeitliche Vergletscherung gemacht wurden. Jedoch war das Gletscherende mit einem Fragezeichen versehen. Bei Kuhle (1982:Abb. 8) verlief die Forschungsroute in diesem Bereich von Pokhara nach Lumle.

\section{KRITIK}

In der Forschungsarbeit von Kuhle (2001a) mit dem Titel 'Tibet and High Asia (VI): Glaciogeomorphology and Prehistoric Glaciation in the Karakorum and Himalaya' wurde dort auf einer Seite auf das Gebiet des Seti Khola eingegangen. Er ging hierbei auf seine damaligen Befunde von 1982 ein, brachte aber andererseits auch neue. Im Gegensatz zu anderen Forschern betrachtete er die Form Erratika, die anhand eines Fotos nachvollzogen

\footnotetext{
428 "Older glacial evidence is more contentious. Since the landforms are no longer preserved, the recognition of former glacial expansion has to be based on the nature and fabric of the sediments alone." (ebd.:107)

429 "Therefore, careful studies at all scales and more absolute dating should, in the near future, help to improve our present understanding of the geodynamic and bioclimatic evolution of the HHF during the last few thousand years." (ebd.:118)
} 
werden konnte. Fort (1986:108, 118) zitiert nach: Kuhle (2001a:176) bezeichnete hingegen diese Erratika als 'mudflow' und ordnete sie ins Spätglazial ein. Erratika sind eindeutige Indikatoren einer Vergletscherung, die keine andere Erklärungsmöglichkeit zulassen würden. Kuhle (2001a) widerlegte diese Ergebnisse von Fort (1986) anhand seiner aufgefunden Erratika $^{430}$.

\section{KUHLE (2007A)}

\section{METHODE BZW. ARBEITSTECHNIK}

Kuhle (2007a) wendete im Dhaulagiri- und Annapurna-Himal geomorphologische Analysen mit Schneegrenzberechnungen an.

\section{UNTERSUCHUNGSGEBIET}

Kuhle (2007a) ging neben vielen anderen Gebieten Hochasiens auf das Gebiet des Dhaulagiriund Annapurna-Himal ein.

\section{KRITIK}

In der Arbeit von Kuhle aus dem Jahre 2007 mit dem Titel `The past valley glacier network in the Himalayas and the Tibetan ice sheet during the last glacial period and its glacial-isostatic, eustatic and climatic consequences' wurden dort auf Seite 125 in drei Sätzen Informationen über das Tal Seti Khola gegeben. Dabei bezog er sich auch auf die ältere Literaturquelle 1982 und gab an, dass der LGM Eisrand im Seti Khola unsicher ('uncertain’) war. Zwei erratische Blöcke bei Gachok auf 1.500 bis 1.540 m Höhe 350 bis 390 m über dem rezenten Talboden ließen darauf schließen, dass die vorzeitliche Seti Khola Gletscherzunge bis auf etwa $1.000 \mathrm{~m}$ Höhe hinab reichte, wobei die Seti und Yamdi Khola Konfluenz höchstwahrscheinlich erreicht wurde. Somit basierte diese Aussage auf eindeutigen glazialgeomorphologischen Befunden, nämlich auf Erratika. Ob talabwärts noch weitere glazialgeomorphologische Kennformen auffindbar wären, müsste durch Geländearbeiten geklärt werden.

\section{KUHLE (2013A)}

\section{METHODE BZW. ARBEITSTECHNIK}

Kuhle wendete geomorphologische Analysen an.

430 "Both of them can be ruled out by these erratics. " (Kuhle 2001a:176) 


\section{UNTERSUCHUNGSGEBIET}

Neben vielen anderen genannten Forschungsgebieten ging Kuhle (2013a:17) auf das Tal Seti Khola ein.

\section{KRITIK}

Bei Kuhle (2013a:17) wurde zum Tal Seti Khola erwähnt, dass der tiefste LGM Eisrand bei einer Höhe von etwa $1.000 \mathrm{~m}$ lag, wobei er sich auf ältere eigene Literaturquellen bezog. Es waren in dieser Arbeit keine glazialgeomorphologischen Befunde, die zu diesem Ergebnis führten, beschrieben.

\subsubsection{Marsyandi Khola}

Im Marsyandi Khola waren die Forschungen von Kuhle (1997a, 1998, 2007a, 2013a, 2013b, 2014) bedeutend.

\section{KUHLE (1997A)}

\section{METHODE BZW. ARBEITSTECHNIK}

Kuhle wendete in dem Forschungsgebiet geomorphologische Analysen (Karten und Fotos enthalten) mit Sedimentanalysen und Schneegrenzberechnungen sowie ${ }^{14} \mathrm{C}$-Datierungen an.

\section{UNTERSUCHUNGSGEBIET}

In der Arbeit von Kuhle (1997a) wurden die Gebiete Ostpamir, Nanga Parbat, Tibet sowie Zentralhimalaja - darunter z.B. die Täler Marsyandi und Arun - beschrieben.

\section{KRITIK}

Kuhle lieferte im Jahre 1997 neue Befunde zur LGM Eisbedeckung der o.g. Untersuchungsgebiete. Im Gebiet Zentralhimalaja bzw. im Tal Marsyandi rekonstruierte er einen hochglazialen Marsyandi Khola Auslassgletscher, welcher bis zum Ort Dumre auf 460 m Höhe hinab floss. Dieses stellte die tiefste von Kuhle rekonstruierte Eisrandlage in Asien dar. Hinweise hierfür fand Kuhle in Grund- und Endmoränenlandschaften mit erratischen Blöcken. (hierzu Kuhle 1997a:127)

Damit wurden eindeutige Indikatoren einer solchen hochglazialen Vergletscherung dieses Tales aufgezeigt. 


\section{KUHLE (1998)}

\section{METHODE BZW. ARBEITSTECHNIK}

Kuhle wendete geomorphologische Analysen mit Schneegrenzbestimmungen an.

\section{UNTERSUCHUNGSGEBIET}

Kuhle (1998) führte Ergebnisse zu vielen Untersuchungsgebieten wie beispielsweise Tibet, Karakorum, Aghil Gebirge, Kuenlun, Tarim Becken, Pamir, Ladakh Range, Nanga Parbat, Tien Shan, Sayan Gebirge, Trans Baikal Gebirge, Zanskar-Himal, Garhwal-Himal, Khumbu/ Rongbuk-Himal, Kangchendzönga-Himal, Dhaulagiri- und Annapurna-Himal auf.

\section{KRITIK}

Der Marsyandi Auslassgletscher floss laut Kuhle (1998:87) von Südtibet zwischen Manaslu und Annapurna bis auf eine Höhe von 460 m beim Ort Dumre hinab, was den tiefsten LGM Eisrand in Hochasien darstellte. Charakteristika hierfür lieferte er z.B. anhand glazialgeomorphologischer Formen wie etwa Trogtäler, glazialer Hörner, Flankenabrasionen und -polierungen sowie Grund-, Lateral- und Endmoränen mit großen bis sehr großen erratischen Blöcken. Demnach wurde dieser Eisrand durch eine Vielzahl verschiedener Formen glazialgeomorphologisch hergeleitet.

\section{KUHLE (2007A)}

\section{METHODE BZW. ARBEITSTECHNIK}

Kuhle (2007a) wendete im Dhaulagiri- und Annapurna-Himal geomorphologische Analysen mit Schneegrenzberechnungen an.

\section{UNTERSUCHUNGSGEBIET}

Kuhle (2007a) ging neben sehr vielen anderen Gebieten Hochasiens auf das Gebiet des Dhaulagiri- und Annapurna-Himal ein.

\section{KRITIK}

Kuhle (2007a:127) beschrieb auf einer Seite seiner Forschungsarbeit das Tal Marsyandi Khola, wobei er hierbei Befunde aus früheren Forschungen von Kuhle verwendete. Im Marsyandi Khola existierte während des LGM ein Auslassgletscher - von Südtibet stammend, der auf der Südseite des Himalaja bis nach Dumre auf ca. 460 m Höhe hinab reichte. Belege hierfür waren Moränen mit erratischen Blöcken. 
KUHLE (2013A)

METHODE BZW. ARBEITSTECHNIK

Kuhle wendete geomorphologische Analysen an.

\section{UNTERSUCHUNGSGEBIET}

Neben vielen anderen genannten Forschungsgebieten ging Kuhle (2013a:18) auf das Tal Marsyandi Khola ein.

\section{KRITIK}

Bei Kuhle (2013a:18) wurde zum Tal Marsyandi Khola geschrieben, dass der tiefste LGM Eisrand bei einer Höhe von etwa $400 \mathrm{~m}$ lag und dort Grund- sowie Endmoränen mit erratischen Blöcken vorkamen (vgl. Kuhle 2013a:Foto 4), wobei er sich auf seine älteren Quellen bezog. Die dazugehörige Schneegrenze lag bei 3.900 bis 4.000 m Höhe (ebd.:18). Somit waren in dieser Arbeit glazialgeomorphologische Befunde, die zu diesem Ergebnis führten, beschrieben und anhand von Fotos dokumentiert.

\section{KUHLE (2013B)}

\section{METHODE BZW. ARBEITSTECHNIK}

Kuhle (2013b) wendete geomorphologische Analysen mit Talquerprofilen, Schneegrenzberechnungen sowie Sedimentanalysen an. Die ausgemachten Formen wurden hierbei nicht nur im Gelände kartiert, sondern auch fotografiert.

\section{UNTERSUCHUNGSGEBIET}

Kuhle ging in der Arbeit (2013b) auf das Gebiet Marsyandi Khola sowie auf das MustangThak Khola ein.

\section{KRITIK}

Die Ausarbeitung von Kuhle (2013b) mit dem Titel 'Tibet and High Asia (VIII): Glaciogeomorphology and Former Glaciation in the Himalaya and Karakorum' war sehr umfänglich. Sie beinhaltete viele Nachweise in Form von Fotos / Panoramen sowie Diagrammen der Sedimentanalysen - morphometrische und Korngrößenanalysen. Kuhle (2013b:1, 301) schrieb, dass im Einzugsgebiet des Marsyandi Khola ein dendritisches Eisstromnetz bestand. Die vorzeitlichen Gletscher des Nar, Dudh, Dana, Myardi und Nadi Khola flossen beispielsweise ins Marsyandi Khola, wobei in diesem Tal ein $120 \mathrm{~km}$ langer 
maximal 2.200 m mächtiger Auslassgletscher bis auf eine Höhe von 400 m existierte. Der Dudh Khola Gletscher war 32 km lang (vgl. Kuhle 2013b:296). Die heutige Schneegrenze liegt auf 5.400 bis $5.500 \mathrm{~m}$ Höhe, wobei die hochglaziale laut Kuhle (2013b:2) bei einer Schneegrenzdepression von rund $1.500 \mathrm{~m}$ auf 3.900 bis $4.000 \mathrm{~m}$ Höhe lag. Die Temperatur war um mehr als $9{ }^{\circ} \mathrm{C}$ abgesenkt (vgl. Kuhle 2013b:302).

Kuhle (2013b) ging im Marsyandi Khola auf den Talbereich zwischen dem Ort Bhraka und dem Konfluenzbereich zum Nar Khola, auf das Nar Khola, Dudh Khola und Dana Khola, die Talbereiche zwischen den Konfluenzbereichen zum Nar und Dudh Khola, zwischen den Konfluenzbereichen zum Dudh und Dana Khola, zwischen den Konfluenzbereichen zum Dana und Myardi Khola, zwischen den Konfluenzbereichen zum Myardi und Nadi Khola, zwischen dem Konfluenzbereich zum Nadi Khola und dem Tal von Besi Schahar, zwischen dem Tal von Besi Schahar bis zum Ort Dumre genauer ein. In Fig. 167 a-c waren detaillierte geomorphologische Karten dargestellt mit enorm vielen verschiedenen geomorphologischen Formen.

Kuhle nannte auf den Seiten 295 bis 296 frühere Forschungen von Jacobsen in diesem Gebiet, die jedoch laut Kuhle nur das Spätglazial anzeigten und aufgrund dessen in der vorliegenden Arbeit nicht weiter berücksichtigt wurden.

\section{KUHLE (2014)}

\section{METHODE BZW. ARBEITSTECHNIK}

Kuhle (2014) wendete die Methode der geomorphologischen Analyse an mit Sedimentanalysen (Fig. 7-35, Tab. 2-3) und Schneegrenzberechnungen (Fig. 36-37). Die aufgefundenen Formen wurden kartiert (Fig. 2-3) und fotografiert (Fotos 1-8), wobei auch Talquerprofile erstellt wurden (Fig. 5-6). Kuhle rekonstruierte Gletscherstadien (Tab. 1).

\section{UNTERSUCHUNGSGEBIET}

Kuhle (2014) untersuchte das Gebiet des Marsyandi Khola. In Fig. 1 war zu erkennen, dass Kuhle neben diesem Talbereich weite Teile Hochasiens erforschte.

\section{KRITIK}

Die Veröffentlichung von Kuhle (2014) mit dem Titel `The Glacial (MIS 3-2) Outlet Glacier of the Marsyandi Nadi-icestream-network with its Ngadi Khola Tributary Glacier (Manasluand Lamjung Himalaya). - The Reconstructed Lowering of the Marsyandi Nadi Ice Stream 
Tongue down in to the Southern Himalaya Foreland' war ähnlich zur Forschungsarbeit Kuhle (2013b), letztgenannte in Bezug auf die abgebildeten Belege in Form von Fotos jedoch umfänglicher. Kuhle beschrieb einen $120 \mathrm{~km}$ langen bis maximal $2.200 \mathrm{~m}$ mächtigen vorzeitlichen Marsyandi Haupttalgletscher bis auf eine Höhe von 400 m (vgl. Kuhle 2014:236, Fig. 4). Unter dem Punkt Methodik erwähnte Kuhle (2014) gegenüber der früheren Arbeit besonders die einzelnen glazialgeomorphologischen Erosions- und Akkumulationsformen, wobei er angab, dass z.B. im Tal hochliegende Strudeltöpfe ohne ein rezentes fluviales Einzugsgebiet harte Indikatoren für eine ehemalige Vergletscherung waren. 


\subsection{Langtang-Himal}

Im Langtang-Himal wurden die Forschungsarbeiten von Shiraiwa, Watanabe (1991), Bäumler, Kemp-Oberhettinger, Zech (1996), Kuhle (2001a), Barnard et al. (2006) und Kuhle (2013a) betrachtet.

\section{SHIRAIWA, WATANABE (1991) \\ METHODE BZW. ARBEITSTECHNIK}

Laut Barnard et al. (2006:2162) war die Forschungsarbeit von Shiraiwa, Watanabe (1991) die erste, die glaziale Chronologien im Langtang Gebiet erforschte. Shiraiwa, Watanabe (1991:404, 406) rekonstruierten glaziale Vorstöße zusätzlich zur ${ }^{14} \mathrm{C}-$ Methode anhand von sieben multiplen relativen Datierungen: Schmidthammerrückprallwerte der Blockoberflächen, Verwitterungskrustenmächtigkeit und Prozentzahl der Gesteine mit Oxidationsflecken, Mengen der Mineralprojektion und Verwitterungstiefen von Gesteinsoberflächen, Prozentzahl der verwitterten Blöcke, Bodenentwicklung / Bodenprofile auf Moränen und Bodenfarbindizes. Schmidthammerrückprallwerte der Blockoberflächen führten sie bei 30 Blöcken mit jeweils drei Messungen unter Bildung eines Mittelwertes durch (ebd.:406). Die Daten der Verwitterungskrustenmächtigkeit und der Prozentzahl der Gesteine mit Oxidationsflecken von insgesamt 25 Gesteinen wurden gemittelt (ebd.:406). Shiraiwa, Watanabe (1991:406) bestimmten mengenmäßig nach Birkeland (1973) ${ }^{431}$ die Verwitterung der Gesteine durch die Menge der Mineralprojektion auf der Gesteinsoberfläche und die Verwitterungstiefen der Gesteinsoberflächen, wobei auch Maximalwerte verzeichnet wurden.

Die Bodenprofile waren einzeln beschrieben (vgl. Shiraiwa, Watanabe 1991:406). Die Probenahmestellen lagen hierbei mit wenigen Ausnahmen auf den Rücken der Endmoränen oder in deren Nähe; es wurden als Gesteinsarten Gneis und Granit bestimmt (ebd.:406). Die Moränen unterteilten sie zuerst anhand der Lagebeziehungen in vier Moränenkomplexe innerster / rezent, innerer / Yala I, äußerer / Lirung und äußerster / Langtang; die relativen Datierungen folgten nach (ebd.:406). Bei älteren Moränen, die mit Schwemmmaterialien überlagert waren, konnten o.g. Methoden bzw. Arbeitstechniken nicht angewendet werden; es wurden Verwitterungstests durchgeführt - in einem 3 mal 3 m Raster 50 Gesteine untersucht und in die drei Kategorien unverwittert, geklüftet und sehr verwittert eingeteilt (ebd.:406 f.). ${ }^{14} \mathrm{C}$-Daten bestimmten sie vom oberen Till und von den äußersten bis zu den innersten Moränenkomplexen (ebd.:413).

\footnotetext{
${ }^{431}$ Birkeland, P.W. (1973): Use of relative age-dating methods in a stratigraphic study of rock glacier deposits, Mt. Sopris, Colorado. In: Arctic and Alpine Research, 5. (S. 401-416)
} 


\section{UNTERSUCHUNGSGEBIET}

Shiraiwa, Watanabe (1991) untersuchten das Langtang Tal talabwärts bis nach Lama (Fig. 1 und 7) in den Jahren 1987, 1988, 1989 anhand von Geländebegehungen und 1990 anhand von Fotografien, die von der japanischen glaziologischen Expedition von Nepal 1982 stammten. Das Langtang Tal, 60 km nördlich von Kathmandu, war von Gebirgszügen mit Höhen von 5.000 bis $7.200 \mathrm{~m}$ umgeben (ebd.:406).

\section{KRITIK}

Der Titel der Arbeit von Shiraiwa, Watanabe (1991) lautete 'Late quaternary glacial fluctuations in the Langtang valley, Nepal Himalaya, reconstructed by relative dating methods'. Im Einführungsteil gaben sie einen Überblick über frühere Forschungen aus den Jahren 1968, 1980 und 1984-1986 in diesem Gebiet (ebd.:404). Shiraiwa, Watanabe (1991:404) meinten, dass die Unstimmigkeiten in Bezug auf die Vergletscherungsgeschichte damit erklärt werden konnten, dass ${ }^{14} \mathrm{C}$-Daten und systematische relative Datierungen nicht vorhanden waren.

Shiraiwa, Watanabe (1991) wendeten sieben multiple relative Datierungen zusätzlich zur ${ }^{14} \mathrm{C}$ Methode an. Einige Fehlerquellen der Methoden bzw. Techniken gaben sie an. Die Schmidthammerrückprallwerte der Blockoberflächen basieren auf der Annahme verschiedener Forscher, dass die Verwitterungsprozesse der Blöcke erst nach deren Stabilisierung einsetzen, wobei ein Mittelwert aus jeweils drei ermittelten Messdaten der 30 beprobten Blöcke berechnet wurde. Auch die Daten aus Verwitterungskrustenmächtigkeit und Prozentzahl der Gesteine mit Oxidationsflecken von insgesamt 25 Gesteinen wurden gemittelt (ebd.:406). Ob nun Mittelwerte - aus zwei oder drei Daten gebildet - zu einem gesicherten Ergebnis führten, sollte hinterfragt werden. Ferner stimmten die Schmidthammerrückprallwerte einiger Moränen nicht immer mit denen des Komplexes überein (ebd.:409, Tab. 1 Fragezeichen). Innerhalb des Moränenkomplexes waren die Werte generell bei Gneis niedriger als bei Granit, was mit der unterschiedlichen Gesteinsoberflächentextur in Verbindung gebracht werden könnte ${ }^{432}$. Auch statistisch war es nur bei Granit möglich, anhand der Schmidthammerrückprallwerte deutliche Unterschiede zwischen den Moränenkomplexen festzustellen ${ }^{433}$. Bei der Bestimmung der

\footnotetext{
432 "The rebound values are generally lower in the gneissic sites than in the granitic sites when compared within the same moraine complex. This may be due to the different textures of rock surfaces, such as fine-grained granite, with a relatively higher rebound value compared to the coarse-grained gneiss." (Shiraiwa, Watanabe 1991:409)

433 "Statistically $(p<0.05)$, it is possible to differentiate between complexes when dealing with the granitic sites. However, no significant difference is apparent among the gneissic sites ( $p<0.05)$." (ebd.:409)
} 
Verwitterungskrustenmächtigkeit und der Prozentzahl der Gesteine mit Oxidationsflecken kam es bei den Moränenkomplexen zu unterschiedlichen Daten der einzelnen Probenahmestellen ${ }^{434}$, was nicht der Fall sein dürfte. Die maximale Menge der Mineralprojektion und die maximale Verwitterungstiefe unterschieden sich in Bezug auf die Gesteinsart für die innersten / inneren und für die äußeren / äußersten Moränenkomplexe, was mit der unterschiedlichen Oberflächentextur zusammenhängen konnte ${ }^{435}$. Diese Parameter stimmten bei den einzelnen Standorten nicht immer mit denen des Komplexes überein, so wie bei den Probenahmestellen 24-26, 29-30, 32, 39, 44-45 und 51 (ebd.:411). Die Bodenentwicklung des B-Horizontes war bei der Unterscheidung zwischen äußerster und äußerer Moräne schwierig ${ }^{436}$. Der innerste Moränenkomplex wies einen sehr dünnen AHorizont, der innere einen dicken A-Horizont, der äußere einen deutlichen Bt- und BwHorizont auf und der äußerste war ähnlich zur letztgenannten Bodenentwicklung (ebd.:411). Die Bodenfarbe führte zu brauchbaren Ergebnissen (ebd.:411).

Es wurden Proben nur von Endmoränen genommen, wobei unverständlich war, warum bei den Schmidthammerrückprallwerten 30 und bei anderen Methoden nur 25 Blöcke beprobt wurden. Die Lage aller Probenahmestellen war im Text nur ungenau angegeben ${ }^{437}$, wobei auch in Fig. 1 nur eine ungefähre Lage - nämlich im Bereich der Moränenrücken nachvollzogen werden konnte. Weitere Moränentypen betrachteten sie nicht. Die Moränen wurden zuerst anhand der Lagebeziehung in vier Moränenkomplexe unterteilt, die relativen Datierungen folgten nach. Das Zitat von Shiraiwa, Watanabe (1991:413): "However, in 50\% of the cases, one or more of the RD methods did not support this initial classification." bestätigte jedoch, dass die relativen Altersbestimmungen nicht in jedem Fall mit dem Lagebezug der Formen zueinander übereinstimmten. Somit veränderten sie im Nachhinein die Probenummer 24 von einem innersten zu einem inneren und die 44 sowie die 45 von einem äußeren zu einem inneren Moränenrücken ${ }^{438}$. Im Gegenzug dazu war es aber auch anhand der Lagebeziehung nicht möglich einige Stellen einzuordnen, es wurden diese anhand der

\footnotetext{
434 "Significant differences between the site- and complex-mean values are seen at locations 4, 5, 25, 26, 34, 35, 39,40 , and 54 for the weathering rind data, and locations 4, 24, 28, 39, and 45 for the oxidation stain data." (ebd.:411)

435 "That is, the values are smaller in the gneissic sites than in the granitic sites for the innermost and inner moraine complexes, while the converse is observed within the outer and outermost moraines complexes (Table 2). This may be due to differences in clast surface texture between the gneissic and granitic sites." (ebd.:411)

436 "It is rather difficult to differentiate the outermost moraine complex and the outer moraine complex by the thickness of the B horizons." (ebd.:411)

437 "With a few exceptions, the data sampling sites were set on or near the crest of the terminal moraines to minimize the errors related to site variances." (ebd.:406)

438 "In such instances, the moraines are reclassified according to the result which occurs most frequently among the seven RD methods." (ebd.:413)
} 
relativen Datierungsmethoden eingeordnet: 37 zum äußeren und 40, 53 und 54 zum äußersten Moränenkomplex (ebd.:413). Wie konnte es zu solch unterschiedlichen Ergebnissen kommen, dass also ein rezenter zu einem Yala I Moränenrücken und ein Lirung zu einem Yala I Moränenrücken werden konnte. Unbedingt sollten die angewendeten Methoden bzw. Techniken wie Schmidthammerrückprallwerte, Verwitterungskrustenmächtigkeit, Prozentzahl der Oxidationsflecken, Verwitterungstiefen, Höhe der Mineralprojektion auf der Oberfläche, Prozentzahl verwitterter Blöcke, Bodenentwicklung / Bodenprofile auf Moränen und der Bodenfarbindex im Einzelnen kritisch betrachtet werden. Für eine Vergletscherungsrekonstruktion waren diese genannten Methoden bzw. Techniken im Gegensatz zur geomorphologischen Detailanalyse ersichtlicherweise weniger geeignet.

Es fiel auf, dass fünf Stadien mit relativen Datierungsmethoden festgelegt wurden, aber für das Lama Stadium nur das Talprofil als Beweis zählte ${ }^{439}$. Es konnten in diesem Bereich keinerlei Moränen identifiziert werden (ebd.:414 f.). Schon unterhalb von Ghora Tabela (ca. $3.200 \mathrm{~m}$ Höhe) fanden sich laut Shiraiwa, Watanabe (1991) keine glazialen Akkumulationen ${ }^{440}$ und talabwärts des äußeren Moränenkomplexes des Lirung Gletscher nur wenige Moränen, lediglich die von Ono $(1986)^{441}$ benannte Shindum Oberfläche ${ }^{442}$. Die Deutung der maximalsten Vergletscherungsausdehnung von Shiraiwa, Watanabe (1991) anhand des Überganges vom Trog- zum Kerbtal war auch bei älteren Forschungen aus diesem Gebiet festzustellen. Außerdem wurde nur der Verwitterungsgrad der Endmoräne als Beleg für das Gora Tabela Stadium angesehen ${ }^{443}$, wobei glazifluviale Schotter auf ein Interglazial zwischen Lama und Gora Tabela und somit auf einen Altersunterschied verwiesen. Auch die enormen Verwitterungsunterschiede zwischen Gora Tabela und Langtang Stadium gaben Hinweise auf einen großen Altersunterschied (ebd.:416). Generell wurden wenige glaziale Formen - hier nur Moränen und das Talprofil - herangezogen, um Aussagen über das Vergletscherungsausmaß zu treffen. So konnte es sein, dass unterhalb des Überganges vom Trog- zum Kerbtal schluchtförmige Tröge, glazigene Kerbtäler oder auch weitere glaziale

\footnotetext{
439 "[...]; an older stage (Lama) is recognized only by the glacial-through configuration extending down to an altitude of approximately $2600 \mathrm{~m}$." (ebd.:404)

440 "There seems to be no glacial depositional form below the clear knick point of Gora Tabela (ca. $3100 \mathrm{~m}$ a.s.l.). No evidence sufficiently reliable to define the lowest limit of past glaciation maxima could, therefore, be obtained. Nevertheless, changing valley morphology and direction from an ambiguous $U$-shape to a V-shape along the Langtang Khola at an altitude of approximately $2600 \mathrm{~m}$ may indicate its former maximum extent." (ebd.:408)

${ }^{441}$ siehe Quelle Ono (1986) in der Fußnote

442 "Downvalley of the outer moraine complex of the Lirung Glacier, moraine landforms are scarsely preserved." (Shiraiwa, Watanabe 1991:407)

443 "The Gora Tabela Stage is defined by the deeply weathered Lower Till extending down to $3200 \mathrm{~m}$ a.s.l." (ebd.:404)
} 
Formen auftraten, die auf eine vorzeitliche Vergletscherung schließen ließen und somit diese vorgenannten Stadien nur einen spätglazialen Gletscherstand anzeigen würden. Nur das Vorhandensein eines Überganges vom Trog- zum Kerbtal oder eines glazifluvialen Schotters sagte wenig über das Alter der Form aus. Jegliche andere geomorphologische Formen für eine umfangreiche Rekonstruktion wurden nicht berücksichtigt.

Das von Shiraiwa, Watanabe (1991) untersuchte Gebiet Langtang Tal talabwärts bis nach Lama war für eine Rekonstruktion einer Maximalvergletscherung zu sehr hochgelegen. Die Forschungen von Shiraiwa, Watanabe (1991) basierten auf Geländebegehungen und Fotografien - hierbei wurde nicht eindeutig, in welchen Talbereichen genau Geländearbeiten durchgeführt wurden. Eine angegebene Forschungsroute für die Jahre 1987, 1988 und 1989 wäre hilfreich gewesen. Da Kuhle (2001a) Indikatoren einer ehemaligen Vergletscherung weit unterhalb dieses Gebietes auffand, war die Deutung der Befunde kritisch zu hinterfragen. König (2002:136) verwies darauf, dass Shiraiwa, Watanabe (1991) keine Hinweise auf eine potentielle LGM Eisrandlage beschrieben.

\section{BÄUMLER, KEMP-OBERHETTINGER, ZECH (1996)}

\section{METHODE BZW. ARBEITSTECHNIK}

Bäumler, Kemp-Oberhettinger, Zech (1996:Zus.) untersuchten - auf Basis der Forschungen von Heuberger - vorwiegend glaziale und fluvioglaziale Ablagerungen anhand bodengenetischer Untersuchungen in Bezug auf die Verwitterungsintensität. Hiermit wollten sie die Bodenprofile dieser Ablagerungen in Bezug auf eine relative Altersdatierung untereinander vergleichen (ebd.:28). Die Bodenbildung hängt laut Scheffer, Schachtschabel $(1992)^{444}$ zitiert nach: Bäumler, Kemp-Oberhettinger, Zech (1996:28) von Umwandlungsund Transformationsprozessen wie der Verwitterung, Mineralneubildung, Zersetzung und Humifizierung sowie von der Gefügebildung ab, wobei auch Verlagerungs- und Translokationsprozesse einen Einfluss haben. Kennzeichen einer fortschreitenden Bodenbildung sind die Anreicherung stabiler Minerale, Entbasung und Versauerung sowie die Mineralneubildung (ebd.:28). Gebildete pedogene Oxide transformieren im Laufe der Bodenbildung zu gut kristallisierten Formen (ebd.:28 f.). Die Bodenentwicklung wurde bei dieser Arbeit als eine Funktion der Zeit gesehen und abhängig von Klima, Flora, Fauna, Topographie und Ausgangsmaterial (ebd.:28). „, Da in der vorliegenden Arbeit der Faktor Zeit

444 Scheffer, Schachtschabel (1992): Lehrbuch der Bodenkunde. 13., durchgesehene Auflage von P. Schachtschabel, H.-P. Blume, G.Brümme, K.-H. Hartge und U. Schwertmann. Ferdinand Enke Verlag, Stuttgart. (491 Seiten) 
untersucht werden soll, ist es wichtig, die sonstigen Einflußfaktoren so konstant wie möglich zu halten." (Bäumler, Kemp-Oberhettinger, Zech 1996:29). Infolgedessen wurden die Probenahmestellen in Gebiete mit geringen Klimaunterschieden gelegt ${ }^{445}$. Ausgeschlossen weniger Ausnahmen untersuchten sie die Böden auf deutlich erkennbaren Moränenwällen im Scheitelbereich oder im Oberhang und Böden mit Zwergstrauchgesellschaften. Außerdem erforschten sie Böden auf vergleichbarer Höhe und auf einheitlichem Ausgangsmaterial; das Material aus Untersuchungs- und Einzugsgebiet musste gleich sein und das Einzugsgebiet der Gletscher durfte sich nicht verändert haben ${ }^{446}$ (ebd.:29 f.). Die Probeorte bzw. die Bodenprofile wurden nach morphologischen Kriterien ausgewählt (ebd.:35). Die Profilbeschreibungen folgten den Richtlinien der Arbeitsgruppe Bodenkunde (1994); es wurde auf Mächtigkeit, Farbe, Bodenart, Gefüge, Dichte, Skelettanteil und Durchwurzelung eingegangen (vgl. Bäumler, Kemp-Oberhettinger, Zech 1996:36). Profilinhomogenitäten wurden auf Seite 30 f. Beachtung geschenkt; es wurden als Indikatoren der Bodenhomogenität lithogene Merkmale analysiert sowie glaziale und äolische Akkumulationen durch einen Quotienten unterschieden.

Die angewendeten Laboranalysen waren folgende: Kohlenstoff-, Stickstoffgehalt, pH-Wert, Kationenaustauschkapazität, austauschbare Kationen, Fraktionierung der pedogenen Oxide, Verwitterungsindizes, Korngrößenzusammensetzung und Gesamtelementanalyse mittels Röntgenfluoreszenz (ebd.:Zus.). Alle Bodenanalysen erfolgten mit dem Feinerdeanteil. Die Vorgehensweise im Labor konnte dort auf den Seiten 40 bis 42 nachvollzogen werden. Zudem wendeten sie glazialmorphologische Analysen und ${ }^{14} \mathrm{C}$-Datierungen an.

\section{UNTERSUCHUNGSGEBIET}

Bäumler, Kemp-Oberhettinger, Zech (1996:1, 1/Abb. 1) untersuchten die Gebiete Helambu Gosainkund und Langtang. Die Geländearbeiten bzw. die genaueren Untersuchungen im Langtang Khola umfassten das Areal um Kyangjin an der Mündung des Lirung Tales in das Langtang Tal (ebd.:24, 35). Die Standorte der Profile konnten Abb. 4 entnommen werden. Dieses Gebiet wurde anhand von acht beschriebenen sowie beprobten Profilen, neun weiteren nur beschriebenen Profilen als auch fünf ${ }^{14} \mathrm{C}$-Daten zuzüglich einem ${ }^{14} \mathrm{C}$-Alter der Shingdum

\footnotetext{
445 „Vergleiche zwischen dem Langtang- und dem Khumbu-Gebiet erscheinen aufgrund der ähnlichen Klimabedingungen (vgl. Kap. 2.4.) möglich, während eine Vergleich mit dem Solu-Gebiet nur bedingt durchführbar ist. “ (Bäumler, Kemp-Oberhettinger, Zech 1996:29)

446 „Im Langtang-Tal sind die geologischen Verhältnisse im Arbeits- und Einzugsgebiet einheitlich. Aufgrund der abgeschlossenen Lage ist auch nicht von einem Wechsel des Einzugsgebietes im Pleistozän auszugehen. “ (ebd.:30).
} 
Terrasse untersucht (ebd.:35/Abb. 4; 79). Die Geländearbeiten fanden vom 23. März bis zum 12. Juni 1991 statt (ebd.:1). Heuberger leitete diese Geländearbeiten, eine Arbeitsgruppe aus Bayreuth die bodenkundlichen Untersuchungen (ebd.:2).

\section{KRITIK}

Die Forschungen von Bäumler, Kemp-Oberhettinger, Zech (1996) waren für eine hochglaziale Rekonstruktion weniger geeignet und direkte Aussagen über die Maximalvergletscherung dieses Gebietes wurden nicht getroffen - vielmehr wurde auf andere Literatur wie etwa Heuberger et al. (1984) und Shiraiwa, Watanabe (1991) verwiesen und hierbei Übereinstimmungen festgestellt. Demnach waren keine neuen Ergebnisse über das Ausmaß der eiszeitlichen Maximalvergletscherung gegeben. Sie wendeten glazialmorphologische Analysen und ${ }^{14} \mathrm{C}$-Datierungen an, wobei flankierend bodengenetische Untersuchungen in Bezug auf die Verwitterungsintensität gemacht wurden. Die Bodenentwicklung ist aber komplex und hängt von zu vielen Faktoren ab (Höhe, Temperatur, Niederschlag, Vegetation, anthropogene Nutzung) ${ }^{447}$, sodass die einzelnen Aspekte, in diesem Fall die Vergletscherung, schwierig $\mathrm{zu}$ bestimmen sind. Auch Umwandlungs- und Transformationsprozesse sowie Verlagerungs- und Translokationsprozesse sind nach Scheffer, Schachtschabel $(1992)^{448}$ zitiert nach: Bäumler, Kemp-Oberhettinger, Zech (1996:28) bekannt. Die Bodenentwicklung wurde bei dieser Forschungsarbeit zwar als eine Funktion der Zeit und abhängig von Klima, Flora, Fauna, Topographie und Ausgangsmaterial gesehen und die Probenahmestellen bis auf wenige Ausnahmen in Gebiete mit geringen Klima-, Topographie-, Vegetations-, Höhen- und Ausgangsmaterialunterschieden gelegt (ebd.:29 f.) - dennoch sollte kritisch hinterfragt werden, ob die Bodenentwicklung überhaupt mit Vergletscherungsereignissen in Verbindung gebracht werden kann. Außerdem wurde nur der Boden auf deutlich erkennbaren Moränenwällen untersucht, wobei es interessant gewesen wäre, wie der Boden auf anderen Moränentypen wie etwa Grundmoränen entwickelt war. Da deutlich ausgebildete Moränenbögen auf ein eher jüngeres Alter schließen lassen, stellte sich die Frage, ob die dort untersuchten Bodenentwicklungen eine maximale hochglaziale Gletscherausdehnung anzeigen können. Eine detaillierte geomorphologische Analyse wurde nicht angewendet - es wurden nur Moränen beschrieben, andere Formen nicht berücksichtigt

\footnotetext{
447 Bäumler, Zech (1994) untersuchten im Khumbu 11 Bodenprofile auf glazialen und glazifluvialen Akkumulationen verschiedener Höhen und fanden heraus, dass die Höhenlage enormen Einfluss auf die Bodenentwicklung und die Verwitterungsintensität hat (,Es ergab sich ein starker Einfluss der Höhenlage auf die Bodenentwicklung und die Verwitterungsintensität. Dabei sind die höhenabhängigen Faktoren wie Temperatur, Niederschlagsmenge, Vegetation und die anthropogene Nutzung von großer Bedeutung. " (ebd.:7)). ${ }^{448}$ siehe Quelle Scheffer, Schachtschabel (1992) in der Fußnote
} 
und die Radiokarbondatierung verwies nach Geyh (1983) $)^{449}$ und Geyh, Schleicher (1990) $)^{450}$ zitiert nach: Bäumler, Kemp-Oberhettinger, Zech (1996:78) nur auf ein Minimalalter. Zudem sei beispielsweise noch nicht geklärt, ob die Böden unterhalb von 2.000 m Höhe rezent oder reliktisch waren.

Bodengenetische Untersuchungen bezüglich der Verwitterungsintensität hauptsächlich glazialer und fluvioglazialer Ablagerungen sollten Rückschlüsse auf das Alter bzw. relative Alter geben. Hiermit wollten Bäumler, Kemp-Oberhettinger und Zech die Bodenprofile dieser Ablagerungen in Bezug auf eine relative Altersdatierung untereinander vergleichen (ebd.:28). $\mathrm{Zu}$ einem deutlicheren Vergleich der Ergebnisse untereinander bzw. für eine Einordnung der Ergebnisse wäre es von Vorteil gewesen, wenn auch Akkumulationen untersucht worden wären, die nicht durch Eis entstanden waren. Vorhergehende geomorphologische Analysen führten gegenüber den Datierungen zu anderen Ergebnissen ${ }^{451}$. Hierbei war ungeklärt, wie das möglich war und welcher Methode bzw. Technik mehr Bedeutung geschenkt werden sollte. Alleinige geomorphologische Analysen für die Rekonstruktion der Vergletscherungsgeschichte waren im Himalaja allerdings aufgrund der enormen Höhenunterschiede bzw. der Erosionsleistung schwierig zu erheben, da die Zeugen oft zerstört wurden (ebd.:1). Da dies der Fall war, wie konnten sie generell eindeutige Aussagen über die maximale Vergletscherungsausdehnung treffen? Wenn viele Formen nicht mehr existieren, dann sollte davon ausgegangen werden, dass die am tiefsten reichenden ältesten Formen erodiert waren und die maximale Vergletscherung nur vermutet werden konnte. Dennoch wurden die Probeorte oder die Bodenprofile nach geomorphologischen Kriterien ausgewählt bzw. angelegt, beprobt und analysiert (ebd.:1). Fehlerquellen der angewendeten Methode bzw. Technik in Bezug auf die Profilinhomogenitäten und Verwitterungsindizes konnten bei den Ausführungen von Bäumler, Kemp-Oberhettinger, Zech (1996) den Seiten 30-32 entnommen werden.

Das genauer betrachtete Untersuchungsgebiet war für eine Aussage über die Maximalvergletscherung des Langtang-Himalaja zu klein - nur das Gebiet um Kyangjin wurde untersucht. Sie verglichen ihre Ergebnisse mit anderen Forschungen. Die Basis der Arbeit waren die Forschungen von Heuberger (ebd.:2).

\footnotetext{
${ }^{449}$ Geyh, M. A. (1983): Physikalische und Chemische Datierungsmethoden in der Quartärforschung. Clausthaler Tektonische Hefte 19. Verlag Ellen Pilger, Clausthal-Zellerfeld.

${ }^{450}$ Geyh, M. A.; Schleicher, H. (1990): Absolute Age Determination. Springer Verlag, Berlin, Heidelberg, New York.

${ }^{451}$ „In beiden Gebieten haben vorgehende glazialmorphologische Untersuchungen widersprüchliche Ergebnisse für das Ausmaß der Gletschervorstöße und ihre Datierungen erbracht. " (Bäumler, Kemp-Oberhettinger, Zech 1996:Zus.)
} 
Die Klimarekonstruktionen anhand der Befunde von Bäumler, Kemp-Oberhettinger, Zech (1996) waren auf Seite 79-80 ihrer Forschungsarbeit dargestellt. Laut Franceschetti (1968) ${ }^{452}$ zitiert nach: Bäumler, Kemp-Oberhettinger, Zech (1996) und Bäumler, Kemp-Oberhettinger, Zech (1996:9) existierte talabwärts der Lama Lodge ein kerbförmiges Talprofil. Ob dieses nun ausschlaggebend für die Einordnung der maximalen Vergletscherung war, wurde im Text nicht erwähnt. Auch dass die Ergebnisse von Shiraiwa, Watanabe (1991) ungefähr mit denen von Bäumler, Kemp-Oberhettinger, Zech (1996) übereinstimmten, verwies auf eine Rekonstruktion anhand des Talprofilüberganges von Trog- zu Kerbtal, so wie es Shiraiwa, Watanabe (1991) ebenfalls taten. Hierbei könnte es sich aber um einen schluchtförmigen Trog handeln, der ein tiefreichenderes Gletscherende indizieren und somit nicht auf ein Maximalstadium hindeuten würde.

Die Bodenprofile 2 und 3 wurden zeitlich nicht eindeutig voneinander getrennt, obwohl sie auf zwei verschiedenen Moränenrücken lagen und 100 m Höhenunterschied aufwiesen; die Bodenentwicklung deutete jedoch auf gleiche Bodentypen hin (Profil 2: Braunerde-Regosol mit beginnender Podsolierung, Profil 3: schwach podsoliger Braunerde-Regosol). Das unterschiedliche Entwicklungsalter zum Bodenprofil 1 wurde durch die Lage zum Gletscher, durch die Höhenlage und durch die Angabe des Bodentyps (Regosol) verständlich. Seit etwa 2.200 bis 2.100 Jahren v.H. erreichte der Gletscher laut den Forschern das Gebiet des Profils Nummer 4 nicht mehr. Jedoch war es fraglich, warum die Profile 2 und 3 aus Ablagerungen der Vorstöße des Lirung Stadium vor 2.800 bis 550 Jahre v.H. entstanden sein sollten und nicht vor $<2.200$ Jahren v.H. entstanden waren, da sie viel näher zum Lirung Gletscher und zudem viel weiter talabwärts lagen als das Profil 4 (Profil 2 auf 3.860 m, Profil 3 auf $3.780 \mathrm{~m}$ und Profil 4 auf 3.960 m), was einem Höhenunterschied von 100 bis $180 \mathrm{~m}$ entsprach. Nicht nachvollziehbar war zudem, dass das Braunerde-Podsol Profil Nummer 5 auf 3.930 m Höhe in etwa gleich oder weiter fortgeschritten sein sollte als das Braunerde-Profil Nummer 6 auf $3.870 \mathrm{~m}$ und das Podsol-Profil Nummer 7 auf $3.857 \mathrm{~m}$. Bei Betrachtung des Gebietes in Google Earth fiel auf, dass das Profil 6 eine Terrasse kennzeichnete, die viel älter als die Moränen orographisch links vom Lirung Gletscher sein müsste. Da der Lirung Gletscher dieses Gebiet nicht erreichen würde, konnte diese Terrasse nur durch den vorzeitlichen mächtigeren Haupttalgletscher - der sich aus mehreren Gletschern vereinigte, wie dem Shalbachum-Gletscher, dem Langtang Gletscher oder dem Langshisa Gletscher - entstanden sein. Demnach müsste diese Terrasse viel älter gewesen sein als die frischeren Moränenleisten neben dem noch vorhandenen Lirung Gletscher. Laut Bäumler, Kemp-Oberhettinger, Zech 
(1996) bildete sich die Terrasse jedoch aus Bergsturzmaterial und Hangschutt. Aufgrund ihrer über Google Earth zu erkennenden Flachheit und der zum Hangbereich hin erkennbaren Erosionsrinnen wäre diese wohl eher als Grundmoränenterrasse mit überlagerndem Bergsturz- oder Hangschuttmaterial zu deuten. Vermutlich wurden hier nur die überlagernden Formen und nicht die eigentliche Form der Terrasse mit dem Bodenprofil erfasst. Die Entwicklung des Podsol-Bodenprofils Nummer 7 begann vor etwa $2.500 \pm 115$ Jahren v.H. ${ }^{453}$, wobei sich diese Aussage mit der Angabe in der Zusammenfassung ${ }^{454}$ widersprach. Welche Zeitangabe des Profils Nummer 7 nun wirklich korrekt war $-2.500 \pm 115$ oder 3.000 bis 3.500 Jahre v.H., blieb ungeklärt. Über die Deutung der dazugehörigen Form - eine Endmoräne des Langtang-Gletscher - wurden zudem nur Vermutungen gemacht. Wie in der Zusammenfassung beschrieben, gehörten die Bodenprofile 6 und 7 vermutlich dem Langtang Stadium an. Hierbei war wiederum keine eindeutige Aussage getroffen worden. Außerdem widersprach sich diese Aussage mit den Angaben in der Schlussfolgerung auf Seite 82. Dort wurde beschrieben, dass das Bodenprofil 6 weiter entwickelt als das Bodenprofil 7 und demnach früher entstanden war oder die Sedimente der Stauterrasse vorverwittert waren. Eine Tendenz zu einer der möglichen Entwicklungsweisen war im Text nicht zu erkennen.

Das Profil 8 auf 4.120 m Höhe verwies laut Bäumler, Kemp-Oberhettinger, Zech (1996:82) aufgrund der starken Bodenentwicklung und der Lage - 180 m über dem Talboden - auf eine spätglaziale oder sogar ältere Moränenablagerung, wie etwa das Gora Tabela oder Lama Stadium nach z.B. Shiraiwa, Watanabe (1991). Dieses Profil müsste laut den Beschreibungen von Bäumler, Kemp-Oberhettinger und Zech einen deutlichen Entwicklungsunterschied im Gegensatz zu den anderen viel jüngeren Profilen aufzeigen. Beim Vergleich des Podsol Profils 7 - Aeh 0-40 cm, Ahe 40-46 cm, II Bhs 46-51 cm, III Bs-Cv 51-81 cm, III 1Cv 81-ca. $131 \mathrm{~cm}$ - und des Braunerde-Podsol Profils 8 - Oh-Ah 0-3 cm, Aeh 3-7 cm, Bhs 7-25 cm, Bv 25-50 cm, II Cv-Bv 50-55 cm, II Bv-Cv 55-85 cm, II Cv 95-ca. $115 \mathrm{~cm}$ - fielen keine enorm großen Unterschiede auf. Die Lage der Profile I-IX konnte nicht nachvollzogen werden, da diese nicht visualisiert wurden, obwohl sie unter der Abb. 4 angegeben waren.

\footnotetext{
453 „Für eine nähere Eingrenzung bietet sich ein Vergleich mit Profil 7 auf dem Moränenwall in unmittelbarer Nähe der Flugpiste an, dessen Entwicklung vor etwa $2500 \pm 115$ Jahren BP begann. " (Bäumler, KempOberhettinger, Zech 1996:81)

454 „Die Aufschüttung der Kyangjin-Stauterrasse und die Ablagerungen des Langtang-Gletschers bei der Flugpiste sind vermutlich dem Langtang-Stadium (3000-3500 J. v. h.) zuzuordnen. “(ebd.:Zus.)
} 


\section{KUHLE (2001A)}

\section{METHODE BZW. ARBEITSTECHNIK}

Kuhle (2001a) nannte Grundmoränen als Hinweise einer vorzeitlichen Vergletscherung, somit wurde eine geomorphologische Analyse durchgeführt.

\section{UNTERSUCHUNGSGEBIET}

Kuhle (2001a) untersuchte im Langtang-Himal das Trisuli Tal, in welches das Langtang Tal überging.

\section{KRITIK}

In der Arbeit von Kuhle (2001a) mit dem Titel 'Tibet and High Asia (VI): Glaciogeomorphology and Prehistoric Glaciation in the Karakorum and Himalaya' wurde nur in einem kurzen Abschnitt auf Seite 391 auf das Gebiet des Langtang-Himal eingegangen. Er verwies hierbei auf die Indikatoren einer vorzeitlichen Vergletscherung in Form von Grundmoränen, welche auf einem Foto aus diesem Gebiet nachgewiesen werden konnten. Diese reichten laut Kuhle (2001a) maximal bis auf etwa 900 bis 1.000 m Höhe talabwärts, in die Nähe des Ortes Donga, wobei der vorzeitliche Gletscher bis zur Mailung Khola Konfluenz floss. Andere Forscher gingen hier zumeist nur auf wallförmige Moränen ein.

\section{BARNARD ET AL. (2006)}

\section{METHODE BZW. ARBEITSTECHNIK}

Barnard et al. führten geomorphologische Kartierungen der Moränen und der paraglazialen Fächer, sedimentologische und geomorphologische Analysen sowie multiple ${ }^{10} \mathrm{Be}-$ Datierungen (Moränen, paraglaziale Fächer, Terrassen) durch. Sie bestimmten 33 TCN-Alter für Fächer, Terrassen, Moränen und 'landslides' im Kyanjin Gompa, Tsergo Ri, Sindum, Langtang, Thyangshap und Gora Tabela, wobei sie Mittelwerte bildeten. Sie untersuchten demnach mittel- und spätholozäne Moränenchronologien, paraglaziale Fächer sowie Terrassen. Die TCN-Daten wurden mit früheren ${ }^{14} \mathrm{C}$-Daten anderer Forscher verglichen und stimmten mit diesen überein. Sie analysierten die Zeiten und die Beziehung der Vergletscherung mit einer 'debris fan' Entwicklung; die Raten der Denudation wurden berechnet. (vgl. Barnard et al. 2006:2162) 
Die Probenahmestellen platzierten Barnard et al. (2006) nach ihren Aussagen dort, wo Shiraiwa et al. (1990) $)^{455}$, Bäumler et al. (1997) ${ }^{456}$ und Watanabe et al. (1998) $)^{457}$ ebenfalls Proben entnahmen. Hierbei wurden Ablagerungen verschiedener Alter, Höhenlagen und Entstehungsweisen datiert ${ }^{458}$. Bei Fächern und Terrassen wurden die Probenahmestellen an die Ränder gelegt, sodass Erosion und Freilegung von Blöcken infolge von Denudation oder anthropogener Aktivität minimiert waren. Bei Moränen wurden Blöcke entlang der Grate beprobt, was den Effekt der Altersunterschätzung durch Abschirmung und Hangsturz minimieren sollte. Die Laborverfahren zur TCN-Datierung waren dort auf Seite 2166 beschrieben. (vgl. Barnard et al. 2006:2165 f.)

Es existierte eine geomorphologische Karte (ebd.:2165 f., Fig. 3) zum Gebiet zwischen Langtang und Kyanjin Gompa, wobei die Karten über das letztgenannte Gebiet und eine weitere über Sindum detaillierter ausgeführt waren (Fig. 4 und 5). Ebenfalls wurden Talquerprofile von Fächern und Terrassen erstellt (Fig. 4 und 5).

\section{UNTERSUCHUNGSGEBIET}

Barnard et al. (2006:2165) untersuchten das Langtang Khola. Das Untersuchungsgebiet erstreckte sich $25 \mathrm{~km}$ östlich vom Gora Tabela bis zum Tsergo Ri 'landslide’ oberhalb von Kyanjin Gompa. Kyanjin Gompa, Sindum, Langtang, Thyangshap und Gora Tabela lagen auf Fächern und / oder Terrassen (ebd.:2165). Der Fokus der Forschungsarbeit ruhte also, wie in Fig. 2 zu sehen war, auf dem Bereich von Langtang bis Kyangjin Gompa, da sie dort auch Kartierungen machten. Eine Forschungsroute wurde nicht angegeben.

\section{KRITIK}

Die Forschungen von Barnard et al. (2006) unter dem Thema 'Landscape response to deglaciation in a high relief, monsoon-influenced alpine environment, Langtang-Himal,

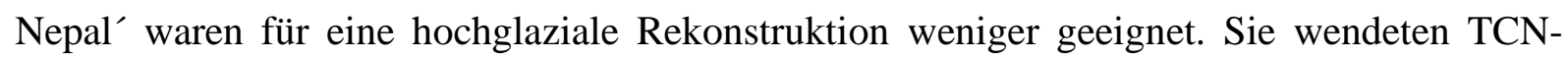
Datierungen an, um die Nutzbarkeit dieser Methode bzw. Arbeitstechnik im Himalaja im

\footnotetext{
${ }^{455}$ Shiraiwa, T.; Ono, Y.; Watanabe, T.; Nakamura, T. (1990): Implications of ${ }^{14} \mathrm{C}$ dates obtained in the Langtang Valley, Nepal Himalaya, in reference to the Holocene glacial fluctuations. Proceedings of the Annual Conference of the Japan Association for Quaternary Research, vol. 20. (S. 142-143)

${ }^{456}$ Bäumler, R.; Madhikermi, D.P.; Zech, W. (1997): Fine silt and clay mineralogical changes of a soil chronosequence in the Langtang Valley (Central Nepal). In: Zeitschrift für Pflanzenernährung und Bodenkunde 160. (S. 413-421)

${ }^{457}$ Watanabe, T.; Dali, L.; Shiraiwa, T. (1998): Slope denudation and the supply of debris to cones in Langtang Himal, Central Nepal Himalaya. In: Geomorphology 26. (S. 185-197)

458 "In such a dynamic environment, it is important to date landforms from a wide range of altitudes, ages and surfaces to ensure that erroneously young dates are not a result high rates of erosion and denudation on surfaces that may be more susceptible to erosion." (Barnard et al. 2009:2166)
} 
Hinblick auf ${ }^{14} \mathrm{C}$-Datierungen zu überprüfen (ebd.:2162). Wenn das datierte Alter wirklich etwas mit der Form zu tun haben sollte, dann dürften die Daten pro Form nicht schwanken. Die multiple Probenahme stand laut ihnen für eine genauere Altersbestimmung. Mittelwerte müssen jedoch nicht zu einem zielführenderen Ergebnis führen. In solchen Fällen müsste höchstens das jüngste Alter als Entstehungsalter gelten und nicht der Mittelwert, da das jüngste Alter eines Blockes der Gesamtform Moräne die letzte Aktivität bzw. den letzten Entstehungsprozess anzeigen würde. Jedoch würde auch dieses nicht das entsprechende Alter der Form anzeigen, da die gesamte Form einem Entstehungsprozess entspringt. Die von Barnard et al. ermittelten unterschiedlichen Alter einer Form eines Entstehungsprozesses wären demnach in Frage zu stellen. Zudem wies die Methode bzw. Technik enorme Fehlerquellen auf (vgl. Barnard et al. 2006:2166), wobei hier Vererbung keine große Rolle spielen sollte ${ }^{459}$. Die Daten wurden aber nicht weiter diskutiert - z.B. gab es keine Aussage über ältere Fächer - und es wurde nur auf die Befunde von Heuberger et al. $(1984)^{460}$ bzw. nur auf den Hinweis des Überganges vom Trog- zum Kerbtal auf ca. $2.600 \mathrm{~m}$ Höhe verwiesen, ohne auf Belege in Form von Moränen einzugehen. Barnard et al. (2006) betrieben weiter talabwärts keine weiteren Analysen. Geomorphologische Formen bei Gora Tabela, talaufwärts von Thyangshap, bei Sindum und bei Kyangjin Gompa wurden aber dort auf den Seiten 2166 bis 2170 gut beschrieben, wobei sie hier darauf aufmerksam machten, dass die Fächer und Terrassen aus Moränenmaterial entstanden waren, was zuvor schon andere Forscher feststellten (vgl. Barnard et al. 2006:2165). Online ${ }^{461}$ sollten Bilder zur Verfügung gestellt sein, die jedoch auf dieser niederländischen Internetseite direkt unter dieser Adresse nicht aufzufinden waren. Bei den geomorphologischen Beschreibungen führten sie keine Angaben über die Gesteinsarten auf. Geomorphologische Kartierungen machten sie nur rund um Langtang und Kyanjin Gompa. Eine Forschungsroute wurde nicht angegeben. Letztendlich enthielt die 13-seitige Forschungsarbeit keine neuen Aussagen über die letzteiszeitliche Maximalvergletscherung. Vielmehr wurden die Übereinstimmungen der bestimmten und beschriebenen Daten mit anderen früheren Datierungen betont, wobei das Lirung Stadium in dieser Arbeit nicht datiert wurde (ebd.:2170). Die Ergebnisse brachten sie mit weiteren Studien, auch aus anderen Gebieten, in Zusammenhang (ebd.:2171-2174).

\footnotetext{
459 "However, if erosion rates are high, such as in Langtang, inheritance is only a minimal concern." (ebd.:2174)

460 siehe Quelle Heuberger et al. (1984) in der Fußnote

${ }^{461}$ Internetseite: http://www.elsevier.nl/locate/quascirev
} 
Denudationsraten von fünf Fächern gaben Barnard et al. mit einer Spanne von 8-60 bzw. mit ca. $33 \mathrm{~mm} / \mathrm{Jahr}$ an (ebd.:2171), wodurch keine Ablagerungsform bis zu $250 \mathrm{~m}$ über dem Talboden älter als 5.000 Jahre sein konnte (ebd.:2162) bzw. diese ins mittlere bis späte Holozän gehörte (ebd.:2174). Jedoch verwiesen sie darauf, dass die $33 \mathrm{~mm} / \mathrm{Jahr}$ in den Zeitraum des Spätholozän (< 2.000 Jahre) fielen - was widersprüchlich zu vorgenannter Aussage war - und die Ergebnisse von Thyangshap bzw. die viel zu hohe Rate mit ca. 130 $\mathrm{mm} / \mathrm{Jahr}$ nicht mit in diesen Mittelwert einbezogen worden waren (ebd.:2171). Bei diesen Betrachtungen der Denudationsraten wurden anthropogene Einflüsse nicht quantifiziert (ebd.:2174). In Tab. 2 wurde deutlich, dass sie auch ältere Daten ermittelten: Sindum $7.470 \pm$ 470 Jahre (KTM 15) und Tsergo Ri $39.160 \pm 960$ (KTM 10), 22.430 4460 (KTM 11), 34.140 \pm 520 (KTM 12). Das erstgenannte Alter wurde von einem Fächer bzw. einer Terrasse bei Sindum ermittelt. Über Google Earth konnte eine ungefähre Höhe des Talbodens auf ca. $3.515 \mathrm{~m}$ abgelesen werden. Das würde bedeuten, dass diese Probenahmestelle KTM 15 bei angegebener Höhe von 3.584 m ungefähr 69 m über dem Talboden lag. Da Google Earth oft ungenaue Höhen anzeigt, könnten $\pm 20 \mathrm{~m}$ angenommen werden. Somit würde die Stelle ungefähr 49 bis $89 \mathrm{~m}$ über dem Talboden liegen. Wie konnte nun dieser Fächer oder diese Terrasse mit dieser Höhe über dem Talboden und mit diesem Alter überhaupt noch existieren, wenn doch laut Barnard et al. (2006) keine Ablagerungsform bis zu $250 \mathrm{~m}$ über dem Talboden älter als 5.000 Jahre war?

Die drei Datierungen des Tsergo Ri 'landslide' sollten die Nutzbarkeit der Datierung älterer Ablagerungen überprüfen (ebd.:2166). Die Daten vom Tsergo Ri 'landslide' auf $4.848 \mathrm{~m}$ Höhe verwiesen darauf, dass das ermittelte Alter nicht unbedingt stimmen muss ${ }^{462}$. Akkurate Altersbestimmungen konnten nur für Akkumulationen jünger als 1.000 Jahre möglich sein ${ }^{463}$. Bei der Betrachtung des 'landslide' in Google Earth wurde ersichtlich, dass dort dislozierte Moränen existierten. Hätte das von den Forschern ermittelte Alter wirklich etwas mit der Form an sich zu tun, dann müssten diese Moränen in dieser Höhe und in dieser Lage jünger sein, da sie dann aus der letzten Vereisungsphase stammen müssten. Da zudem aber nicht die Moränen mit dem ermittelten Alter gemeint waren, sondern die geomorphologische Form 'landslide', müsste diese noch viel jünger sein, da der genannte 'landslide' nur nach der Vergletscherungsphase entstanden sein konnte.

\footnotetext{
462 "The dating of the Tsergo Ri landslide to 29 ka shows that older CRN ages can be achieved, and the favorable comparison of radiocarbon dating from prior studies with the CRN dating in this study proves that CRN can be broadly accurate even for young landforms (e.g. < $1 \mathrm{ka}$ )." (Barnard et al. 2006:2174)

463 "[...] and thus accurate age approximations can be achieved for extremely young deposits $(<1 \mathrm{ka})$." (ebd.:2174)
} 
Weiterhin wurden für dieses Gebiet frühere Forschungen aus den Jahren 1990, 1991, 1993, 1996, 1997 und 1998 vorgestellt (ebd.:2163 f.).

\section{KUHLE (2013A)}

\section{METHODE BZW. ARBEITSTECHNIK}

Kuhle (2013a:21) beschrieb im Langtang-Himal Grundmoränen, demnach basierten seine Befunde auf geomorphologischen Analysen.

\section{UNTERSUCHUNGSGEBIET}

Kuhle (2013a:21) ging auf das Gebiet Langtang-Himal bzw. genauer auf das Trisuli Tal ein.

\section{KRITIK}

Kuhle (2013a:21) schrieb über den Langtang-Himal, dass der vorzeitliche Langtang Hauptgletscher bis zur Mailung Khola Konfluenz auf eine Höhe von ca. 930 m hinunter reichte, wobei er sich auf seine eigenen älteren Literaturquellen - in der vorliegenden Arbeit mit Kuhle 2001b und Kuhle 2011 (Gletscherkarte TH 33) aufgeführt - bezog. Grundmoränen in entsprechenden Lagen gaben laut ihm Anlass für ein solches Ergebnis. 


\subsection{Mahalangur-Himal}

Im Mahalangur-Himal bzw. im Aruntal waren lediglich die Forschungsarbeiten von Kuhle (1997a, 1998, 2005, 2007a) bekannt.

\section{KUHLE (1997A)}

\section{METHODE BZW. ARBEITSTECHNIK}

Kuhle wendete in den Forschungsgebieten geomorphologische Analysen (Karten und Fotos enthalten) mit Sedimentanalysen und Schneegrenzberechnungen sowie ${ }^{14} \mathrm{C}$-Datierungen an.

\section{UNTERSUCHUNGSGEBIET}

In der Arbeit von Kuhle (1997a) wurden die Gebiete Ostpamir, Nanga Parbat, Tibet sowie Zentralhimalaja - darunter z.B. die Täler Arun und Marsyandi - beschrieben.

\section{KRITIK}

Kuhle rekonstruierte den hochglazialen Arun Gletscher, welcher talabwärts bis auf $500 \mathrm{~m}$ Höhe hinab reichte. Bei der Veröffentlichung Kuhle (1997a) wurden in Bezug auf das Aruntal wenige Angaben gemacht bzw. nur ausgeführt, wie mächtig der vorzeitliche Gletscher war und bis wohin er hinab reichte. Da Kuhle die o.g. Methoden anwendete, waren die Befunde zu diesem Talbereich glazialgeomorphologisch hergeleitet.

\section{KUHLE (1998)}

\section{METHODE BZW. ARBEITSTECHNIK}

Kuhle wendete geomorphologische Analysen mit Schneegrenzbestimmungen an.

\section{UNTERSUCHUNGSGEBIET}

Kuhle (1998) führte Ergebnisse zu vielen Untersuchungsgebieten wie beispielsweise Tibet, Karakorum, Aghil Gebirge, Kuenlun, Tarim Becken, Pamir, Ladakh Range, Nanga Parbat, Tien Shan, Sayan Gebirge, Trans Baikal Gebirge, Zanskar-Himal, Garhwal-Himal, Khumbu/ Rongbuk-Himal, Kangchendzönga-Himal, Dhaulagiri- und Annapurna-Himal auf.

\section{KRITIK}

Der laut Kuhle (1998:87) vom tibetischen Eis stammende Aruntalauslassgletscher wies bei Kada eine Eismächtigkeit von ca. $2.000 \mathrm{~m}$ und bei Num eine von $700 \mathrm{~m}$ auf, was er seinen früheren Forschungsarbeiten entnahm. Die Vergletscherung des Aruntales auf der Südseite 
des Himalaja bis auf ca. 500 m oder tiefer belegte Kuhle beispielsweise anhand von großen erratischen Blöcken, Lateralmoränen, Rundhöckern und Strudeltöpfen. Demnach waren die Befunde zur letztglazialen Maximalvergletscherung durch mehrere Formen und deren Lagebeziehung zueinander sowie in Bezug $\mathrm{zu}$ den von ihm aufgeführten LGM Lateralmoränen durch relative Altersbestimmung abgeleitet.

\section{KUHLE (2005)}

Im Mahalangur-Himal wurde sich in der vorliegenden Arbeit bezüglich der Vergleichsuntersuchungsgebiete auf das Aruntal - nach Carter (1985) als 'Makalu Subsection' bezeichnet - beschränkt. In diesem Himalaja Bereich waren nur Forschungen von Kuhle (2005) über das eiszeitliche Vergletscherungsausmaß bekannt.

\section{METHODE BZW. ARBEITSTECHNIK}

Kuhle (2005:Fig. 11) wendete eine detaillierte geomorphologische Reliefanalyse an. Hierbei beachtete er extrem viele geomorphologische Formen wie etwa Moränen mit oder ohne erratische Blöcke, Podestmoränen, große erratische und nicht erratische Blöcke, Moränenrutschungen, Kamesterrassen, glaziäre Dreieckshänge, glaziäre Flankenschliffe, Gletschertorschotterfluren und -terrassen, Gletscherschrammen, Rundhöcker und ähnliche glaziäre Schliffformen, Kare, Trog- und Kerbtäler, schluchtförmige Tröge, subglaziale Klammen, Transfluenzpässe, glaziale Hörner, Felshohlkehlen durch fluviale Unterschneidungen, Bergstürze, Felsnachbrüche sowie Schutt- und Murkegel. Somit basierte die Rekonstruktion auf belegten und nachvollziehbaren Hinweisen wie analoge Fotografien, Kartierungen und Talprofile. Ebenfalls wurden neben sedimentologischen Analysen, wie z.B. Korngrößen, -formen und Kalkgehaltsbestimmungen, auch noch Schneegrenzberechnungen anhand von 130 Gletschern, teilweise ${ }^{14} \mathrm{C}$-Datierungen für spätglaziale bis historische Moränen sowie Lichenometrie durchgeführt (ebd.:193).

\section{UNTERSUCHUNGSGEBIET}

Kuhle (2005:Fig. 4; 193) untersuchte das Gebiet des Khumbu- und Khumbakarna-Himalaja zwischen Makalu und Cho Qyu.

\section{KRITIK}

Die Arbeit von Kuhle (2005) war bis dato die einzige Forschungsarbeit im Aruntal, die sich mit der eiszeitlichen Vergletscherung beschäftigte. Sie war sehr ausführlich, wobei enorm 
viele geomorphologische Formen wie o.g. beachtet wurden. Somit basierte die Rekonstruktion auf belegten und nachvollziehbaren Indikatoren. Eine derart detaillierte geomorphologische Reliefanalyse wendeten die anderen Forscher in den in dieser vorliegenden Arbeit betrachteten Gebieten nicht an. Diese beschränkten sich auf wenige Formen, meistens auf Moränen. Ebenso waren bei Kuhle die Erklärungen der Formentstehungen plausibel. Beispielsweise sah Kuhle (2005:241) in Steinschlägen einen Hinweis auf eine eiszeitliche Flankenversteilung oder in Murfächern - da sie aus ehemals hochliegendem Moränenmaterial bestanden - einen Hinweis auf die eiszeitliche Eisverfüllung eines Tales. Auch der große Umfang des Untersuchungsgebietes war bei den Ausführungen von Kuhle (2005) auffallend und für eine Aussage über die Maximalvergletscherung geeignet.

Die von Kuhle (2005) angewendeten sedimentologischen Analysen waren notwendig, um festzustellen, um was es sich für Ablagerungen handelte. Somit waren Moränen bzw. die Indikatoren einer ehemaligen Vergletscherung eindeutig als solche identifiziert worden. Durch die Lagebeziehung der Formen untereinander wurde die zeitliche Einordnung dieser Moränen verständlich, wobei die Methoden ${ }^{14} \mathrm{C}$ und Lichenometrie auf ein Minimalalter schließen ließen. Für eine solche zeitliche Gliederung sprach auch die Ähnlichkeit zu anderen Gebieten auf der Erde: "The number of the glacier stages since the maximum glaciation approx. agrees with that e.g. in the Alps and the Rocky Mountains since the last glacial period." (Kuhle 2005:193).

In Fig. 11 war das hocheiszeitliche Gletscherende von Kuhle mit einem Fragezeichen versehen worden, was darauf hindeutete, dass explizit in diesem Bereich keine eindeutigen Indikatoren mehr aufgefunden wurden. Jedoch waren weiter talaufwärts u.a. Grundmoräne mit erratischen Blöcken, glaziärer Flankenschliff und glaziäre Dreieckshänge zu erkennen, die ein weiter talabwärts reichendes Gletscherende indizierten. Die talabwärts kartierte Gletschertorschotterflur passte $\mathrm{zu}$ einem Gletscherstand. Ob sich nun weiter talabwärts weitere glazialgeomorphologische Formen auffinden lassen könnten, müsste weiterhin im Gelände überprüft werden. Jedoch würde es grundlegend an seiner gesamten vorzeitlichen Eisrekonstruktion - gegenüber der anderer Forscher, die den hocheiszeitlichen Eisrand in sehr geringem Abstand zum rezenten Gletscherende festlegten - nichts ändern. 
KUHLE (2007A)

METHODE BZW. ARBEITSTECHNIK

Kuhle (2007a) wendete im Mahalangur-Himal geomorphologische Analysen mit Schneegrenzberechnungen an.

\section{UNTERSUCHUNGSGEBIET}

Kuhle (2007a) ging neben auffallend vielen anderen Gebieten Hochasiens auf das Gebiet des Mahalangur-Himal bzw. auf das Aruntal ein.

\section{KRITIK}

Die Forschungsarbeit von Kuhle (2007a) über das Aruntal war sehr ähnlich zur Literaturquelle Kuhle (1998). Er bezog sich hierbei auf ältere eigene Forschungsarbeiten, die herausstellten, dass der vom tibetischen Eis stammende ca. $110 \mathrm{~km}$ lange Aruntalauslassgletscher bei Kada eine Eismächtigkeit von ca. $2.000 \mathrm{~m}$ und bei Num eine von $700 \mathrm{~m}$ aufwies. Die Vergletscherung des Aruntales auf der Südseite des Himalaja bis auf ca. 450 m Höhe hinunter dokumentierte Kuhle beispielsweise anhand von großen erratischen Blöcken und Lateralmoränen. 


\subsection{Kangchendzönga-Himal}

Im Kangchendzönga-Himal waren neben anderen die Forschungsarbeiten von Kuhle (1990a, 1998, 2001a, 2007a, 2013a), Meiners (1999) und Tsukamoto et al. (2002) bekannt.

\section{KUHLE (1990A)}

\section{METHODE BZW. ARBEITSTECHNIK}

Kuhle (1990a) führte eine detaillierte geomorphologische Analyse (Fotografie, Kartierung sowie Extrapolation der maximalen Eismächtigkeit anhand von Indikatoren) mit Schneegrenzberechnungen durch.

\section{UNTERSUCHUNGSGEBIET}

Kuhle (1990a:415) untersuchte im Winter 1988 / 89 das Gebiet des Tamur Ghunsa Talsystems von $600 \mathrm{~m}$ bis auf $5.300 \mathrm{~m}$ Höhe bzw. talabwärts bis nach Dhoban und die nördliche Seite des Kangchendzönga. In Fig. 9 war zu sehen, dass er auch im Simbuwa Khola Moränen kartierte.

\section{KRITIK}

Die Forschungsarbeit von Kuhle (1990a) mit dem Titel `New data on the pleistocene glacial cover of the southern border of Tibet: the glaciation of the Kangchendzönga Massif (8585 m E Himalaya)' gab Informationen über die heutige und eiszeitliche Vergletscherung im Kangchendzönga-Himalaja. Laut Fort (2004:264) war es die erste Arbeit, die die glazialmorphologischen Formen im Ghunsa und Shimbuwa Khola kartierte. Die geomorphologischen Analysen mit Schneegrenzberechnungen waren ausführlich. Hierbei wurden viele unterschiedliche geomorphologische Formen beachtet und in Beziehung zueinander gesetzt. Somit vollzog sich die Rekonstruktion der eiszeitlichen Vergletscherung anhand von belegten und somit nachvollziehbaren Indikatoren. Die Ausführungen bestanden aus insgesamt sieben Seiten, beinhaltend acht Fotos, eine Übersichtskarte über das Untersuchungsgebiet und eine detaillierte geomorphologische Karte. Was genau Kuhle in Fig. 8 mit TL-Proben ${ }^{464}$ meinte, war dem Text nicht zu entnehmen.

Tsukamoto et al. (2002:57) schrieben über Kuhle (1990a), dass er Moränen und andere glaziale Formen wie Rundhöcker oder subglaziale Strudeltöpfe auf der Basis der Morphostratigraphie in zehn Stadien einteilte (Tab. 1) und auf ein LGM Gletscherende im 
Tamur Ghunsa Khola auf $890 \mathrm{~m}$ Höhe hindeutete. Diese Aussagen waren treffend wiedergegeben; daneben machte Kuhle (1990a:Fig. 9) auch Gletscherschrammen und poliertes Anstehendes aus. Es war davon auszugehen, dass Kuhle diesen Eisrand der maximalen Eismächtigkeit anhand der o.g. Formen extrapolierte, da er schrieb, dass er direkt bei Thoma keine Endmoränen auffand ${ }^{465}$. Jedoch war es genau wie bei der Forschungsarbeit von Kuhle (1998) so, dass er auf Seite 420 beim Ort Thoma im dort ausgestalteten Trogtal 40 bis $120 \mathrm{~m}$ hohe Moränen mit Erdpyramiden beschrieb sowie in Fig. 8 angab, dass dort Marginal- oder Endmoränen vorkamen, wobei hier der Wechsel vom glazialen zu glazifluvialen Material für eine Eisrandlage entscheidend war. Ein solcher Materialwechsel war ausschließlich durch die Arbeit der Gletscher erklärbar. Auch in Fig. 9 wurde eindeutig eine Endmoräne Stadium 0 bei Thuma kartiert. Aufgrund der 1,2 km talabwärts ausgemachten polierten Formen könnte das letzteiszeitliche Gletscherende weiter talabwärts gereicht haben, war aber - wie er es andeutete - unzureichend belegbar: Kuhle fand dort beispielsweise keine Moränen. Außerdem wäre laut Kuhle (1990a:420) eine solche geringe Abweichung des LGM Eisrandes für eine Schneegrenzbestimmung unrelevant.

\section{KUHLE (1998)}

\section{METHODE BZW. ARBEITSTECHNIK}

Kuhle wendete geomorphologische Analysen mit Schneegrenzbestimmungen an.

\section{UNTERSUCHUNGSGEBIET}

Kuhle (1998) führte Ergebnisse zu vielen Untersuchungsgebieten wie beispielsweise Tibet, Karakorum, Aghil Gebirge, Kuenlun, Tarim Becken, Pamir, Ladakh Range, Nanga Parbat, Tien Shan, Sayan Gebirge, Trans Baikal Gebirge, Zanskar-Himal, Garhwal-Himal, Khumbu/ Rongbuk-Himal, Kangchendzönga-Himal, Dhaulagiri- und Annapurna-Himal auf.

\section{KRITIK}

Kuhle ging mit seiner Forschungsarbeit unter dem Titel 'Reconstruction of the 2.4 Mio. km² $^{2}$ Late Pleistocene Ice Sheet on the Tibetan Plateau and its Impact on the Global Climate' neben anderen Gebieten auf den Kangchendzönga-Himal ein (siehe Kuhle 1998:86 f.). Das Ghunsa und Simbua Tal wiesen laut Kuhle während des LGM lange Eisströme auf, die in Verbindung zum tibetischen Eis über den Jongsang La standen. Hinweise hierfür sah er in glazialgeomorphologischen Befunden, wie beispielsweise Trogtälern. Beim Konfluenzbereich 
der Ghunsa und Simbua Täler zum Tamur Tal auf etwa 1.500 m Höhe beim Ort Hellok fand Kuhle eine spätglaziale Stadium I Endmoräne (abgebildet bei Kuhle 1990a:Fig. 5). Das letztglaziale Maximalstadium reichte jedoch laut ihm bis auf eine Höhe von $890 \mathrm{~m}$ beim Ort Thuma herab, wobei er hier direkt laut Geschriebenem keine Endmoränen auffand ${ }^{466}$. Einen Satz zuvor gab er aber eine Endmoräne für den LGM Eisrand an - "The lowest glacial ice terminus (end moraine) (Last High Glacial Maximum) at 890 m a.s.l, [...].” (Kuhle 1998:86) - und einen Abschnitt weiter, dass beim Ort Thoma dort im ausgestalteten Trogtal 40 bis 120 m hohe Moränen mit Erdpyramiden vorkamen (siehe Fig. 8 bei Kuhle 1990a). Bei Betrachtung der Abbildung 8 bei Kuhle (1990a) fiel auf, dass dort diese Moränen als Marginal- oder Endmoränen beschrieben waren, wobei hier der Wechsel vom glazialen zu glazifluvialen Material für eine Eisrandlage entscheidend war. Auch in Fig. 5 wurde eindeutig eine Endmoräne Stadium 0 bei Thuma kartiert. 1,2 km talabwärts waren laut Kuhle abradierte und polierte Formen, aber keine Moränen mehr erkennbar. Somit könnte das letzteiszeitliche Gletscherende weiter talabwärts gereicht haben, war aber - wie er es andeutete unzureichend belegbar. Kuhle fand in der Nähe des Ortes Marijam auf 1.240 m Höhe eine Akkumulation, die auf eine weitere Zwischenrandlage - angenommen als Teil der Prä-Ghasa Stagnation - zwischen den Orten Tapethok und Chirwa schließen ließ. Doch sprachen auch andere Eisrandformen talaufwärts von Tapethok und Kkejinim für die rekonstruierte LGM Eisrandlage von Kuhle (siehe Fig. 5 bei Kuhle 1990a), wobei er diese durch Auffinden von Gletscherschliff an der orographisch linken Talseite und von Strudeltöpfen noch wahrscheinlicher machte (siehe Fig. 5 und 6 bei Kuhle 1990a). Zudem kartierte er 1,5 km talaufwärts der LGM Eisrandlage bis zu 250 m über dem Talboden Gletscherschrammen und Rundhöcker (siehe Fig. 7 bei Kuhle 1990a).

\section{MEINERS (1999)}

\section{METHODE BZW. ARBEITSTECHNIK}

Meiners (1999) wendete detaillierte geomorphologische Analysen (Lagebeziehung, Fotografie, Kartierung) und Schneegrenzberechnungen nach Kuhle $(1988)^{467}$ an, wobei sie

\footnotetext{
466 "No end moraines occur in this section, [...]." (Kuhle 1998:86)

467 Kuhle, M. (1988): Topography as a fundamental element of glacial systems. A new approach to ELAcalculation and typological classification of paleo- and recent glaciation. In: GeoJournal, 17 (4): Tibet and HighAsia, Results of the Sino-German Joint Expeditions (I). Kuhle, M., Wang Wenjing (eds.); Kluwer, Dordrecht. Boston, London. (S. 545-568)
} 
außerdem im Rolwaling-Himal eine ${ }^{14} \mathrm{C}$-Probe entnahm ${ }^{468}$. Die post- bis spätglazialen Gletscherstände von Meiners waren aufbauend auf der Klassifikation von Kuhle $(1994)^{469}$.

\section{UNTERSUCHUNGSGEBIET}

Meiners (1999) untersuchte die Gebiete des Kangchendzönga und des Rolwaling-Himal.

\section{KRITIK}

Die Arbeit von Meiners (1999) mit dem Titel 'The history of glaciation of the Rolwaling and Kangchenjunga Himalayas' war ausführlich. Mehrere Fotos wurden als Belege einer vorzeitlichen Vergletscherung beigefügt, eine geomorphologische Karte u.a. mit den verschiedenen Gletscherstadien im Kangchendzönga-Himal war auf Seite 369 abgebildet. Damit waren die Ergebnisse nachvollziehbar, wobei die geomorphologischen Formen Endmoränen, Lateralmoränen, glaziäre Flankenschliffe, subglaziale Strudeltöpfe, Rundhöcker, Schluchten, Till und Kare betrachtet wurden. Laut Fort (2004:264) zeigte die Arbeit gegenüber der von Kuhle (1982) aus dem Kali Gandaki weniger Modifikationen in Bezug auf die Gletscherstadien auf. Angaben über die rezente, historische / neoglaziale und spätglaziale Vergletscherung im Kangchendzönga-Himal wurden angeführt, ebenso solche über die hochglaziale Vergletscherung (vgl. Meiners 1999:368-371). In der Einführung ging Meiners (1999:341) auf mögliche Schwierigkeiten bei der eiszeitlichen Vergletscherungsrekonstruktion und auf frühere Forschungen in angrenzenden Himalaja Gebieten ein. Hierbei bezog sie sich neben anderen Gebieten auf den Langtang-Himalaja, wobei sie sich bei Shiraiwa, Watanabe (1991) wie folgt über das Lama Stadium äußerte: "Shiraiwa and Watanabe (1991) stressed out, that the Lama stage at $2600 \mathrm{~m}$ only allows a classification as Neoglazial and not Late Glacial." (Meiners 1999:341 f.). Zu dieser vorstehenden Äußerung sollte hinterfragt werden, warum das Lama Stadium nach diesen Forschern ein neoglaziales oder gar ein spätglaziales sein sollte, wenn das Lama Stadium nach Shiraiwa, Watanabe (1991:414-416) die stärkste Vergletscherung auf etwa 2.400 bis $2.600 \mathrm{~m}$ Höhe anzeigte und zwischen dem Lama und dem Gora Tabela Stadium ein

\footnotetext{
468 "14C samples were taken to determine absolute age, but most of the results are not yet available." (Meiners 1999:341); "An isolated remnant of a moraine directly before the frontal moraine of the Trakarding glacier was $14 C$ dated (Figure 2).” (ebd.:367)

${ }^{469}$ Kuhle, M. (1994): Present and Pleistocene Glaciation on the North-Western Margin of Tibet between the Karakorum Main Ridge and the Tarim Basin Supporting the Evidence of a Pleistocene Inland Glaciation in Tibet. In: GeoJournal 33 (2/3), Tibet and High Asia, Results of the Sino-German and Russian-German Joint Expeditions (III). Kuhle, M. (ed.); Kluwer, Dordrecht. Boston, London. (S. 133-273)
} 
Interglazial liegen sollte und demnach das Gora Tabela Stadium wohl das LGM auf einer Höhe von $3.200 \mathrm{~m}$ anzeigte.

Neben den post- bis spätglazialen Gletscherständen machte Meiners auch Moränenterrassen sowie einen polierten und abradierten Gebirgsrücken aus, was Hinweise auf die Maximalvergletscherung gab. Sie schloss sich den Forschungsergebnissen von Kuhle (1990a) an, was auch Tsukamoto et al. (2002) feststellten ${ }^{470}$.

\section{KUHLE (2001A)}

METHODE BZW. ARBEITSTECHNIK

Kuhle führte glazialgeomorphologische Analysen durch.

\section{UNTERSUCHUNGSGEBIET}

Kuhle (2001a) ging neben vielen anderen Untersuchungsgebieten auf den KangchendzöngaHimal ein.

\section{KRITIK}

Kuhle (2001a:391) beschrieb den LGM Tamur Gletscher bis zur Ortschaft Thuma auf 890 m Höhe und spätglaziale Stadium I Lateralmoränen bei Hellok, wobei er sich hierbei auf ältere eigene Befunde aus dem Jahr 1990 bezog. König (1999) ${ }^{471}$ bestätigte genau diese Befunde von Kuhle neben anderen Befunden. Bei Geländearbeiten im Jahre 1999 machte Kuhle desweiteren ein Grundmoränenpodest im oberen bis mittleren Simbua Khola aus. Daneben ging er auf Grundmoränenablagerungen im Simbua Khola ein. Daraus schlussfolgerte Kuhle, dass der mindestens 600 mächtige Simbua Khola Gletscher den Tamur Gletscher erreichte und den Lamite Bhanjyang ins Kabeli Khola überfloss. Es waren diese glazialgeomorphologisch hergeleiteten Befunde ergänzend zu den in der vorliegenden Arbeit aufgeführten Arbeiten von Kuhle zu betrachten.

\section{TSUKAMOTO ET AL. (2002)}

\section{METHODE BZW. ARBEITSTECHNIK}

Tsukamoto et al. (2002) führten insgesamt sieben OSL-Datierungen von glazialen Sedimenten bzw. von vier verschiedenen Moränen - darunter glazialfluviale Sedimente /

\footnotetext{
470 "Meiners (1999) followed this view and calculated the snowline depression for each glacial advance." (Tsukamoto et al. 2002:57)

${ }^{471}$ König, O. (1999): Preliminary results on the last high-glacial glaciations of the Rolwaling Himal and the Kangchenjunga Himal (Nepal, East-Himalaya). GeoJournal, 47 (1/2, Tibet and High Asia (V), Ed: Kuhle, M.). (S. 373-384)
} 
supraglaziale Ausschmelzmoräne und Deformationsmoräne - durch, wobei bei der ersten Lokalität nur eine OSL-Probe, aber zudem zwei ${ }^{14} \mathrm{C}$-Proben entnommen wurden. Beim Anstehenden handelte es sich um Granite und Gneise. Die Quarzkörner wurden für die weiteren Analysen aus den Proben entnommen. Im Labor folgten zwei Bestimmungsverfahren A und B: es wurden zum einen Quarzfraktionen 20 min. extra behandelt, damit das Feldspatsignal abnahm ${ }^{472}$ - und zum anderen Quarzfraktionen anhand der Standardprozedur mit starkem Feldspatsignal bestimmt. Das erstgenannte Verfahren wurde angewendet, da das Feldspatsignal im Quarz das Quarzsignal überdeckte ${ }^{473}$ und ein hoher Feldspatanteil zur Unterschätzung der Daten / Dosisrate führen sollte ${ }^{474}$. Von den vier Proben konnte aber das Alter von nur zwei Proben mit dem Verfahren A bestimmt werden ${ }^{475}$. Jedoch stimmten diese Daten aus den unterschiedlichen Bestimmungsverfahren ungefähr überein $^{476}$. (ebd.: 57,60$)$

Die einzelnen Laborschritte konnten unter dem Gliederungspunkt Methoden bei Tsukamoto et al. (2002:61-64) im Detail nachvollzogen werden. Zudem führten sie geomorphologische Analysen (Fig. 1-5) durch.

\section{UNTERSUCHUNGSGEBIET}

Tsukamoto et al. (2002) untersuchten im Kangchendzönga-Himal die Täler Ghunsa und Shimbuwa Khola, wobei sie sich aber lediglich auf kleinere Gebiete bzw. auf vier Lokalitäten beschränkten. Die ersten drei Lokalitäten befanden sich im Ghunsa Khola und die vierte entsprechend im Simbuwa Khola. (ebd.:58/Fig. 1)

Eine Nachmessung ergab eine maximale Ausdehnung des gesamten in Fig. 1 dargestellten Gebietes des Ghunsa und Shimbuwa Khola von 28,5 mal 44,1 km. Die erste Probenahmestelle lag talabwärts des Kanchenjunga Gletscher bzw. bei Ramtang auf dem Ende einer vorzeitlichen orographisch rechten Seitenmoräne dieses Gletschers bei $<4.600 \mathrm{~m}$ Höhe (ebd.:58/Fig. 1; 60). Eine genaue Höhenangabe von 4.520 m wurde im Text gegeben.

\footnotetext{
472 "After etching the fraction 20 min extra with HF, the natural infrared stimulated luminescence (IRSL) signal, which indicates the existence of feldspar, almost disappeared." (ebd.:57)

473 "However, the luminescence from feldspars existing as minor contamination and/or microinclusion in the quartz grains was so bright it masked the quartz signal." (ebd.:57)

474 "Such aliquots were omitted because the sensitivity of the feldspar is much higher than quartz and the difference in the sensitivity can cause $D_{E}$ underestimation." (ebd.:57)

475 "Out of 42 aliquots from four samples for fraction A, only six aliquots from two samples were remained." (ebd.:57); "Only two aliquots for 991109 C and four aliquots for $991028 B$ were remained, and the other aliquots for the two samples and all the aliquots for $991119 B$ and $991117 B$ were excluded from the DE estimation." (ebd.:64)

476 "Moreover, the calculated OSL ages for fractions A and B from the two samples agreed with each other." (ebd.:75)
} 
Diese Probenahmestelle bzw. die Probe 991109C stellte eine supraglaziale Ausschmelzmoränenablagerung bzw. ein `supraglacial meltout' Sediment dar (Tab. 2). Ein Foto und eine Skizze vom Entnahmeort waren in Fig. 2 zu sehen. Die OSL-Probe wurde aus einer Tiefe von 1,50 m und die beiden ${ }^{14} \mathrm{C}$-Datierungen von oberen Schichten aus 50 und 75 $\mathrm{cm}$ Tiefe entnommen. Letztgenannte verwiesen auf Alter von $160 \pm 60$ und $1.020 \pm 80$ Jahren v.H.. Über der Moräne kamen Löss, Bodenschichten und fluviale Schotter vor. Das Gebiet der Lokalität 1 war laut Fig. 1 bei Nachmessung 4,4 km mal 3,2 km groß, laut Fig. 1 (continued) aber 3,6 km mal 2,4 km. (ebd.:58, 59/Fig.1; 60/Fig. 2; 60, Tab. 2)

Lokalität 2 lag beim Yamatari Gletscher talabwärts von Ghunsa bei einem Seitenmoränenbogen auf ungefähr 3.500 m Höhe (Fig. 1). Im Text wurde die Höhenmeterzahl mit 3.600 angegeben. Es waren drei unterschiedliche Sedimenteinheiten zu erkennen (Fig. 3), wobei sie diese nach Asahi, Watanabe $(2000)^{477}$ als supraglaziale oder englaziale Ausschmelzmoräne, subglaziale Ausschmelzmoräne und Deformationsmoräne interpretierten $^{478}$. Tab. 2 und Fig. 3 verwiesen darauf, dass die Proben der Deformationsmoräne entnommen wurden. Das Gebiet war laut Fig. 1 bei Nachmessung 4,1 km mal 3,2 km groß, laut Fig. 1 (continued) aber 3,1 km mal 2,6 km. (vgl. Tsukamoto et al. 2002:58, 59/Fig.1; 61/Fig. 3; 60)

Lokalität 3 lag talabwärts von Killa bei Gyabla auf ungefähr 2.700 m Höhe (Fig. 1). Im Text wurde die Höhenmeterzahl mit 2.730 angegeben und in Fig. 4a mit 2.735 m. Tab. 2 verwies auf supraglaziale Ausschmelzmoränenablagerungen. Vier Lateralmoränen waren bei diesem Standort entwickelt, wobei die Proben auf dem innersten Bogen und unterhalb einer $25 \mathrm{~cm}$ mächtigen Löss- und Bodenschicht entnommen wurden (ebd.:61). Im Bereich der Lateralmoränen bestand ein Übergang von Trog- zu Kerbtal, wodurch diesen Ablagerungen ein maximales Gletscherende zugesprochen werden konnte, so wie es Asahi, Watanabe $(2000)^{479}$ zitiert nach: Tsukamoto et al. (2002:61) annahmen ${ }^{480}$. Das Gebiet war laut Fig. 1 bei Nachmessung 3,2 mal 2,9 km groß, laut Fig. 1 (continued) aber 2,7 mal 2 km. (ebd.:58, 59/Fig.1; 61)

\footnotetext{
477 Asahi, K.; Watanabe, T. (2000): Past and recent glacier fluctuations in Kanchenjunga Himal, Nepal. In: Journal of Nepal Geological Society 22. (S. 481-490)

478 "These units are interpreted as supraglacial or englacial meltout till, subglacial meltout till and deformation till, respectively (Asahi and Watanabe, 2000)." (Tsukamoto et al. 2002:60)

${ }^{479}$ siehe Quelle Asahi,Watanabe (2000) in der Fußnote

480 "This might indicate that the moraines are the evidence for the maximum extent of glaciers (Asahi and Watanabe, 2000)." (Tsukamoto et al. 2002:61)
} 
Lokalität 4 war talabwärts des Yalung Gletscher südlich des Kangchendzönga auf ungefähr $3.900 \mathrm{~m}$ auszumachen (Fig. 1). Im Text wurde die Höhenmeterzahl mit 3.785 bei Nangartza angegeben. Tab. 2 verwies auf glazifluviale Sedimente / supraglaziale Ausschmelzmoränenablagerungen. Der Aufschluss zeigte eine $50 \mathrm{~cm}$ bodenbedeckte Lateralmoräne an, wobei die Proben auf der Außenseite der Moräne in 4 m Tiefe entnommen wurden. Fig. 5a zeigte, dass dies der Grenzbereich zwischen Lateralmoräne und 'scree' war. Das Gebiet war laut Fig. 1 bei Nachmessung 4,1 mal 5,6 km groß, laut Fig. 1 (continued) aber 3,5 mal 2,8 km. (ebd.:58, 59/Fig.1; 61)

Bei allen Probenahmestellen (Fig. 2-4) erfolgte bei Tsukamoto et al. die Stratigraphie nach Eyles et al. $(1983)^{481}$.

\section{KRITIK}

Die insgesamt elf Seiten ${ }^{482}$ umfassende Arbeit von Tsukamoto et al. (2002) mit dem Titel 'Timing of past glaciations in Kanchenjunga-Himal, Nepal by optically stimulated luminescence dating of tills’ beabsichtigte zur Aufklärung vorzeitlicher Gletschervorstöße im Kangchendzönga-Himal beizutragen ${ }^{483}$. Die Arbeit war wie folgt gegliedert: Einführung Gebiet, Hinweis auf bestehende Literatur, OSL-Methode, Ziel der Arbeit; Proben Probennahmestellen, geomorphologische Interpretation; Methoden - OSL-Methode, Beschreibung Labormethoden; Ergebnisse - Darstellung der Daten; Diskussion - Deutung der Daten, Vergleich der Daten mit anderen Forschern wie Kuhle (1990a), Meiners (1999) und Asahi, Watanabe $\left(2000^{484}, 2001^{485}\right)$; Zusammenfassung. In Fig. 1 waren außer den vier Probenahmestellen bzw. Lokalitäten die rezente Vergletscherung, Moränenzüge und die Trogkante bzw. 'trough edge' der Trogtäler visualisiert.

Im Kangchendzönga-Himal sowie auch im gesamten Himalaja wurden absolute Daten der vorzeitlichen Gletschervorstöße nur unzureichend bestimmt, was hauptsächlich daran lag, dass es wenige Datierungsmethoden gab, die bei glazialen Formen anwendbar waren (vgl. Tsukamoto et al. 2002:58). OSL-Datierungen sollen aber das Potenzial haben, glazigene

\footnotetext{
${ }^{481}$ Eyles, N.; Eyles, C.; Miall, A.D. (1983): Lithofacies types and vertical profile models; an alternative approach to the description and environmental interpretation of glacial diamict and diamicttite sequences. Sedimentology 30. (S. 393-410)

48210 Seiten Text

483 "The aim of the study is to determine whether OSL dating of supraglacial meltout tills and/or deformation till in Kanchenjunga Himal can provide more information on glacial history." (Tsukamoto et al. 2002:60)

${ }^{484}$ siehe Quelle Ahahi, Watanabe (2000) in der Fußnote

${ }^{485}$ Asahi, K.; Watanabe, T. (2001): Late Quaternary glaciations in the Nepal Himalayas: a framework for reconstruction of the climate changes between monsoon and westerlies. Abstracts of Fifth International Conference on Geomorphology, Tokyo, C-12.
} 
Sedimente datieren zu können (ebd.:58). Tsukamoto et al. (2002) wendeten demnach zum ersten Mal ${ }^{486}$ die OSL-Datierungen nicht wie sonst üblich bei glazifluvialen oder -lakustrinen Sedimenten (z.B. Richards et al. 2000 im Khumbu-Himal), sondern bei Moränenmaterialien an.

Grundsätzlich muss überlegt werden, ob OSL-Datierungen für Vergletscherungsrekonstruktionen überhaupt geeignet sind. Dass geomorphologische Analysen inklusive der Lagebeziehungen zu einem brauchbaren Ergebnis führen, nämlich zu Beweisen, mit denen eindeutige Aussagen über die Vergletscherung gemacht werden können, ist wohl unumstritten. OSL-Datierungen basieren darauf, dass die Sedimente vor der Ablagerung vollständig ausbleichen. Es wird anhand der Methode die Zeit bestimmt, ab wann das Sediment zuletzt dem Sonnenlicht ausgesetzt war, was auf das Alter bzw. auf die Ablagerung dieses Sediments schließen lässt. Inwieweit die Ausbleichung als Basis solcher Methode bei dieser Arbeit gegeben war, war fraglich, da Tsukamoto et al. (2002) supraglaziale Ausschmelzmoränen und Deformationsmoränen untersuchten. Das Zitat: "Supraglacial meltout tills are likely to be bleached before deposition, because they have been transported on the surface of the glacier. In contrast, basal till such as deformation till and subglacial meltout tills are not likely to have been exposed to sunlight and would not be bleached." (ebd.:60) verwies zumindest darauf, dass sie sich dieser Problematik bei den Deformationsmoränen und den subglazialen Ausschmelzmoränen bewusst waren. Die Moränen wollten sie untersuchen, da sie unterschiedliche Prozesse und Grade der Bleichung dafür annahmen (ebd.:60). Jedoch musste sich auch bei den sonst immer mit dieser Methode bzw. Technik untersuchten glazifluvialen oder -lakustrinen Sedimenten oder auch bei den supraglazialen Ausschmelzmoränen die Frage gestellt werden, ob das vollständige Bleichen überhaupt möglich war bzw. ob alle Sedimentkörner vollständig oder ob nur vereinzelte Körner gebleicht worden waren. Hierbei musste auf die Aussagen von Tsukamoto et al. eingegangen werden: "1. Quartz and feldspar OSL of the supraglacial meltout tills in the Kanchenjunga Himal was probably fully bleached before deposition. They provide useful dating material for reconstructing past glacial history in Himalaya." (ebd.:66); "It is suggested that both quartz and feldspars grains or micorinclusions in quartz grains were likely to have been bleached, while glacial debris has been transported on the glacier." (ebd.:57). Das Wort 'probably' im ersten vorstehenden und das Wort `suggested' im zweiten vorstehenden Zitat ließen darauf schließen, dass das Bleichen der Sedimentkörner vor der Ablagerung, selbst der supraglazialen Ausschmelzmoränen, nur auf Hypothesen basierte.

486 “No published study exists on OSL dating of tills, [...]." (Tsukamoto et al. 2002:59) 
Somit war der zweite Satz des ersten Zitates nicht nachvollziehbar und die Sedimente eben nicht für eine Rekonstruktion der Vergletscherung geeignet. Wenn selbst der Ablagerungsprozess nicht exakt nachzuvollziehen ist bzw. wenn diese Sedimente auch durch andere Prozesse umgelagert worden sein konnten, kann nicht der genaue Bleichungsprozess geklärt sein. Es bestehen zu übermäßig viele Unbekannte, um genaue Aussagen über den Ablagerungs- und Bleichungsprozess von Sedimenten zu formulieren. Gletscher sind aktive Systeme - es kommt beispielsweise immer wieder neuer Schutt durch verschiedene Prozesse auf die Oberfläche - sodass selbst diese Prozesse allein nicht genau geklärt sein können. Zudem sehen die Forscher einen Beweis für das vollständige Ausbleichen der Sedimente in der Übereinstimmung der Daten der Fraktionen A und $\mathrm{B}^{487}$. Jedoch haben die zwei Bestimmungsverfahren nichts mit dem Prozess des Ausbleichens zu tun. Durch diese Verfahren ändert sich nichts an der Methode bzw. Technik an sich bzw. der Ungewissheit über den Bleichungsprozess. Tsukamoto et al. schrieben, dass der genaue Bleichungsprozess unbekannt war, es aber sein könne, dass die Sedimente in der Deformationsmoräne aus einer älteren supraglazialen Ausschmelzmoräne bestehen. Wenn dies der Fall war, würde das älteste Alter bei Probe 2 doch auf einen Gletschervorstoß vor 37.000-39.000 Jahren verweisen $^{488}$.

Tsukamoto et al. (2002) gingen mit ihren Forschungsarbeiten auf vier Lokalitäten im Ghunsa und Shimbuwa Khola genauer ein. Demnach wurden im Gegensatz zu den o.g. Forschern von diesen nur die Talbereiche weit oberhalb des auf $1.500 \mathrm{~m}$ Höhe liegenden Ortes Hellok erforscht. Zudem haben sie keine Angaben über ihre Route der Forschungsreise aufgeführt, wodurch erkennbar gewesen wäre, welche Strecken abgelaufen bzw. welche Talbereiche betrachtet wurden. Kuhle (1990a) machte dagegen Angaben über die untersuchten Höhenbereiche. Bei Kuhle (1990a) und Meiners (1999) konnte anhand der geomorphologischen Karte auf die ungefähre Wegstrecke geschlossen werden. Bei Tsukamoto et al. (2002) existierten demgegenüber keine Angaben darüber, ob überhaupt weitere glaziale Formen oder aber welche Formen in diesen - von Tsukamoto et al. nicht untersuchten - Bereichen vorkamen. Wenn diese Formen beachtet worden wären, würde sich

\footnotetext{
487 "The agreement of OSL ages between the OSL ages for fractions A and B indicate that both quartz and feldspar grains or microinclusions in the glacial samples were totally bleached at deposition. It is also suggested that fading of the feldspar BLSL is negligible." (ebd.:65)

488 "The DE values of twelve aliquots from 991117 A and 10 aliquots from 991117 from Yamatari-Tal (Location 2) showed little scatter and the averaged DE values of these paired samples agreed well. This seems to indicate that the OSL of quartz grains in the deforming bed till were once zeroed in a period older than the glaciation, which formed the ground moraine at Yamatari-Tal. The process of bleaching of the samples is unknown, but it is possible that the materials in the deformation till are derived from older supraglacial meltout till. If this is true, the two OSL dates from the deformation till indicate the existence of a glacial advance at 3739 ka." (ebd.:65 f.)
} 
die Frage auftun, auf was für eine Vergletscherung diese Formen dann eventuell hindeuten würden. Dass weitere Moränen und auch andere typische glaziale Formen talabwärts dieser Untersuchungsgebiete vorkamen, wurde ohnehin schon durch Kuhle und Meiners belegt. Allein bei der Betrachtung des Aspektes, dass die Bereiche südlich der Probenahmestellen 2 und 4 nicht und, wie in Fig. 1 abgebildet war, sonst nur sehr kleine Gebiete untersucht wurden, wurde deutlich, dass die Forschungsarbeiten von Tsukamoto et al. für eine Klärung der Maximalvergletscherung nur behutsam herangezogen werden konnten. Auch dass Beweise der Vergletscherung nur in Form von gut ausgebildeten Moränen und Till im Untersuchungsgebiet $^{489}$ aufgefunden worden waren, zeigte, dass weniger deutlich ausgebildete Moränen wie etwa flache hochglaziale Grundmoränen nicht in die Betrachtungen mit einbezogen wurden. Demgegenüber war die Arbeit von Kuhle (1990a) in Bezug auf die Maximalvergletscherung geeignet, die von Meiners (1999) in dieser Hinsicht aber weniger, da das Hauptaugenmerk hier auf post- bis spätglazialen Gletscherstadien lag. Diese letztgenannte Arbeit war aber als eine Ergänzung und als eine Zustimmung zu der Forschungsarbeit von Kuhle (1990a) anzusehen.

Hätten Tsukamoto et al. (2002) eine Forschungsroute angegeben, wären außerdem Aussagen darüber möglich gewesen, ob sie die Formen von Kuhle (1990a) nicht berücksichtigten oder ob sie in höherer Höhe ihre Forschungen begannen. Es war zwar eindeutig, dass sie in den genauer untersuchten Gebieten - dort wo Proben entnommen wurden - vor Ort gewesen sein mussten; ungeklärt blieb aber beispielsweise, auf welcher Talseite sie entlang gingen, um diese Probenahmestellen zu erreichen, oder in welcher Höhe sie starteten. Google Earth zeigte in diesem Gebiet den höchsten Flugplatz namens Suketar auf $2.420 \mathrm{~m}$ an. Falls nun Tsukamato et al. (2002) auf diesem Flugplatz gelandet sein sollten, hätten sie von dort aus die von Kuhle untersuchten Talbereiche durchwandern müssen. In diesem Falle hätten sie die von Kuhle (1990a) kartierten Formen talabwärts von Hellok wie etwa Moränen, glaziäre Flankenschliffe, Rundhöcker, subglaziale Strudeltöpfe und Gletscherschrammen übersehen oder nicht berücksichtigt. In ihrem Literaturverzeichnis waren jedoch die Arbeiten von Kuhle (1990a) und Meiners (1999) angegeben.

In Fig. 1 wurde das Untersuchungsgebiet ohne Koordinaten dargestellt - nur ungefähre Koordinaten von Nepal und von den vier untersuchten Gebieten in Fig. 1(continued) waren zu finden. Höhenmeterangaben wurden in Fig. 1 (continued) und im Text angegeben. Es fiel

489 "Throughout the region, evidence of past glaciations is apparent from well-developed moraines and tills (Fig. 1).” (ebd.:57) 
jedoch auf, dass diese jeweils sehr unterschiedlich waren (z.B. Unterschied bei der 1. Probe $80 \mathrm{~m}$; bei der 2. Probe $100 \mathrm{~m}$; bei der 3. Probe 30 bis $35 \mathrm{~m}$ und bei der 4 . Probe $115 \mathrm{~m}$ ). Somit muss wohl den Angaben im Text mehr Bedeutung geschenkt werden, da es sich eventuell um grafische Fehler in Fig.1 (continued) handelte. Ferner waren - wie oben einzeln aufgeführt - verschiedene Abmessungsdaten der untersuchten Gebiete von Fig. 1 gegenüber Fig. 1 (continued) zu konstatieren (Unterschied bei der 1 . Probe $5,44 \mathrm{~km}^{2}$; bei der 2. Probe $5,06 \mathrm{~km}^{2}$; bei der 3. Probe 3,88 $\mathrm{km}^{2}$; bei der 4. Probe $13,16 \mathrm{~km}^{2}$ ).

Bei Probe 3 im Bereich der Lateralmoränen auf 2.730 m Höhe bestand laut Tsukamoto et al. (2002:61) der Übergang vom Trog- zum Kerbtal, wodurch diesen Ablagerungen ein maximales Gletscherende zugesprochen wurde, so wie es auch Asahi, Watanabe $(2000)^{490}$ zitiert nach: Tsukamoto et al. annahmen. Ein Trogtal ist zwar ein harter Indikator für eine Vergletscherung, aber da noch viele weitere glaziale Formen unterhalb dieses Überganges von Kuhle (1990a) ausgemacht wurden, war diese obige Interpretation zu hinterfragen. Es gibt neben Trogtälern weitere Talformen, wie etwa schluchtförmige Tröge oder auch glazigene Kerbtäler, die genauso wie die Trogtäler für eine Vergletscherung herangezogen werden können. Es war davon auszugehen, dass der Übergang kein hochglaziales Gletscherende war, sondern eher, da noch weitere Formen talabwärts vorkamen, ein spätglaziales. Doch diese Formen wurden von Tsukamoto et al. (2002) nicht in Betracht gezogen bzw. es wurden keine Angaben darüber gemacht. Zudem blieb offen, ob sich ein Trogtalprofil unterhalb dieses Überganges weiter nachverfolgen ließ, da es wie in Fig. 1 angezeigt auch Talbereiche gab, wo dieses nicht ausgebildet war. Das Trogtal im Shimbuwa Khola war bis auf ungefähr 3.400 m Höhe in Fig. 1 visualisiert; ob das auch den Übergang vom Trog- zum Kerbtal bzw. das maximale Gletscherende darstellte, wurde nicht erläutert. Der Höhenunterschied dieses Überganges zum Ghunsa Khola betrug 670 m. Das wäre dadurch zu erklären, dass das Ghunsa Tal ein viel größeres Einzugsgebiet als das Shimbuwa Khola aufzeigte. Ein Übergang vom Trog- zum Kerbtalprofil kann nicht alleinig ausschlaggebend für eine zeitliche Einteilung sein. Die Moränen und das Alter des 2. Standortes verwiesen auf die stärkste Vergletscherung während des MIS $2^{491}$. Jedoch kamen laut Kuhle (1990a) und Meiners (1999) weitere Moränen unterhalb dieser Lokalität vor.

\footnotetext{
${ }^{490}$ siehe Quelle Asahi, Watanabe (2000) in der Fußnote

491 "The position of the moraines at Gyabla were the lowest among the glacial landforms in the Kanchenjunga Himal, and these OSL ages indicate the largest glacial advance in this region occurred during the MIS 2." (Tsukamoto et al. 2002:66)
} 
Kuhles Ausführungen sowie die von Meiners - hier mit dem Schwerpunkt der post- bis spätglazialen Gletscherstadien - waren gegenüber denen von Tsukamoto et al. sehr ausführlich. Kuhle und Meiners beachteten bzw. kartierten sehr viele geomorphologische Formen und vollzogen anhand der Lagebeziehungen der Formen zueinander die vorzeitliche Eisrekonstruktion. Bei Kuhle (1990a) wurden Formen wie End- und Lateralmoränen verschiedener Gletscherstadien, polierte Felswände, Gletscherschrammen, subglaziale Strudeltöpfe und Rundhöcker aufgefunden. Meiners (1999) machte ebenfalls solche Formen bis auf die Gletscherschrammen aus und markierte weiterhin Kare, Schluchten und Till. Somit waren diese Forschungen anhand von Belegen in Form etlicher Fotos nachvollziehbar. Tsukamoto et al. (2002:Fig. 1) beachteten vorzeitliche Lateral- bis Endmoränen, andere Formen berücksichtigten sie nicht. Desweiteren bestimmten sie OSL-Daten. Es wurden von ihnen, abgesehen von der Darstellung der Daten und des angegebenen TrogKerbtalüberganges, keine weiteren Aussagen über die Vergletscherungsgeschichte dieses Gebietes getroffen. Das Ziel der Forschungen war es, mehr Informationen über die glaziale Geschichte in diesem Himalaja Abschnitt zu bekommen ${ }^{492}$. Hilfreich wären dazu z.B. Schneegrenzberechnungen und detaillierte geomorphologische Analysen gewesen, statt nur gut erhaltene Lateral- oder Endmoränen zu beachten. Tsukamoto et al. verglichen zwar die OSL-Daten der verschiedenen Moränentypen mit geomorphologisch bestimmten Altern ${ }^{493}$, jedoch gaben sie keinerlei Daten dazu an, sodass nur die OSL-Daten zur Deutung der Befunde blieben. Wie das OSL-Alter der Formen aber in Zusammenhang mit der Vergletscherung zu bringen war, blieb ungeklärt. Diskutiert wurde nur über die Proben 2 und 4, letztendlich wurde aber ein Entstehungsalter einfach - nicht wie sonst üblich durch einen Mittelwert gestützt - auf 8.000-10.000 Jahre festgelegt. Diese Alter verwiesen auf die stärkste Vergletscherung während des MIS $2^{494}$. Probe 2 als Deformationsmoräne und 4 als glazifluvial / supraglaziale Ausschmelzmoräne unterschieden sich altersmäßig jedoch, ohne Abweichungen betrachtet, maximal um 30.700 Jahre (38.800 minus 8.100 Jahre) und minimal um 26.700 Jahre (36.500 minus 9.800 Jahre). Die Ermittler der Daten gaben aber an, dass sie davon ausgingen, dass die beiden Proben 8.000-10.000 Jahre alt sein müssten. Probe 4 würde nur ein Minimalalter sein, da es sich hierbei um glazifluviale Ablagerungen handelte, und

\footnotetext{
492 "The aim of the study is to determine whether OSL dating of supraglacial meltout tills and/or deformation till in Kanchenjunga Himal can provide more information on glacial history." (ebd.:60)

493 "We compare the OSL ages of the two different types of tills with geomorphologically estimated ages, because these tills are expected to have experienced different process and degree of bleaching." (ebd.:60)

494 "The position of the moraines at Gyabla were the lowest among the glacial landforms in the Kanchenjunga Himal, and these OSL ages indicate the largest glacial advance in this region occurred during the MIS 2." (ebd.:66)
} 
Probe 2 ein überschätztes Alter darstellen, da die Deformationssedimente vorher nicht voll gebleicht waren ${ }^{495}$. Verständlich war trotzdem nicht, warum Daten anhand der OSL-Methode ermittelt wurden und letztendlich ein anderes Alter einfach festgelegt wurde, das nicht einmal einen Mittelwert darstellte. Die Proben der Lokation 2 verwiesen auf OSL-Alter von $38.800 \pm$ 6.300 und $36.500 \pm 2.800$ Jahren v.H. (Tab. 3). In Tabelle 1 von Tsukamoto et al. (2002) waren jedoch diese Altersangaben nicht aufgelistet. Sie würden ins MIS 3 (20.000-60.000 Jahre) reichen. Das Alter der ersten Probenahmestelle stimmte, so wie es Tsukamoto et al. angaben, mit Kuhle (1990a) und Meiners (1999) - Älteres Dhaulagiri Stadium des Neoglazial - überein, andere Alter jedoch nicht. Unter Betrachtung der zeitlichen Einordnung der verschiedenen Gletscherstadien von Kuhle (2001b:125/Tab. 1) fiel auf, dass die erste Probe mit einem Alter von $5.300 \pm 1.200$ und $6.100 \pm 1.000$ Jahren aber mit dem neoglazialen Nauri Stadium (5.500-4.000 Jahre v.H.) übereinstimmte. Das Alter der Probe 3 fiel in den Zeitraum des MIS 2 (vgl. Tsukamoto et al. 2002:66) und stimmte nicht mit der Einordnung der anderen Forscher überein. In Tabelle 1 von Tsukamoto et al. (2002) wurde deutlich, dass Kuhle (1990a) und Meiners (1999) diese Moräne ins Spätglazial bzw. ins Ghasa (I) und Taglung (II) Stadium einordneten und Asahi, Watanabe $(2000,2001)^{496}$ ins MIS 4 bzw. in das vierte Gletscherstadium. Die Probe 4 von Tsukamoto et al. (2002) verwies in Tabelle 1 auf das MIS 1, Kuhle (1990a) und Meiners (1999) ordneten diese jedoch in das Nauri Stadium (V) bzw. in das früheste Neoglazial und Asahi, Watanabe $(2000,2001)^{497}$ in das Gletscherstadium III bzw. in die jüngere Dryas / LGM ein.

Datenschwankungen (1. Probe: Unterschied ca. 800 Jahre; 2. Probe: 2.300 Jahre; 3. Probe: 900 Jahre; 4. Probe: 1.700 Jahre) deuteten darauf - da sie davon ausgingen, mit diesem OSLAlter ein Alter der Formen bestimmen zu können, dass die Methode für eine Altersbestimmung von Formen jeglicher Art weniger geeignet war, da es sich eben immer um eine Form handelte und somit die Alter alle ungefähr gleich sein müssten. Folglich waren konkrete Aussagen über die einstige Vergletscherungsausdehnung anhand der OSL-Methode nicht möglich. Dies ließ sich auch aus dem Zitat von Tsukamoto et al. (2002) über Owen et al.

\footnotetext{
495 "The moraines at Yamatari-Tal (Location 2) and Nangartza (Location 4) have been assigned to the same glacial stage, and estimated them to have formed during MIS 2 (Asahi and Watanabe, 2000, 2001)." (Tsukamoto et al. 2002:65); "We think that is because only the OSL age from Nangartza had been fully bleached before deposition, and also because the OSL age from Nangartza indicate minimum age of the moraine formation, as the samples might be the glaciofluvial deposits from the tributary valley. The age from the deformation tills, however, were overestimated since deformation tills have been carried beneath the ice body, and they are not expected to have received enough solar radiation for zeroing. We think that the ages of both ground moraine at Yamatari-Tal and the lateral moraine at Nangartza are the same, about 8-10 ka or older." (ebd.:65)

${ }^{496}$ siehe Quellen Asahi, Watanabe $(2000,2001)$ in der Fußnote

${ }^{497}$ siehe Quellen Asahi, Watanabe $(2000,2001)$ in der Fußnote
} 
$(1997)^{498}$ aus dem Lahul-Himal entnehmen: "They used only ice distal sediments because these sediments are more likely to have been bleached before deposition, rather than tills and ice proximal sediments. Sometimes, however, it is difficult to correlate ice distal sediments with particular glacial events." (ebd.:58 f.). Gegenüber den genannten Aspekten, die alle eher gegen diese Methode bzw. Technik sprachen, schrieben Tsukamoto et al. (2002:66) jedoch zu den supraglazialen Ausschmelzmoränen folgendes: "Quartz and feldspar OSL of the supraglacial meltout tills in the Kanchenjunga Himal was probably fully bleached before deposition. They provide useful dating material for reconstructing past glacial history in Himalaya.".

\section{KUHLE (2007A)}

\section{METHODE BZW. ARBEITSTECHNIK}

Kuhle (2007a) führte im Kangchendzönga-Himal geomorphologische Analysen mit Schneegrenzberechnungen durch.

\section{UNTERSUCHUNGSGEBIET}

Kuhle (2007a) ging neben auffallend vielen anderen Gebieten Hochasiens auf das Gebiet des Kangchendzönga-Himal bzw. auf die Täler Ghunsa, Simbua und Tamur ein.

\section{KRITIK}

Kuhle (2007a) bezog sich auf Seite 126 bis 127 auf den Kangchendzönga-Himal. Hierbei ging er besonders auf die Befunde von Kuhle (1990a) ein. Über den Jongsang La standen die letztglazialen Eisströme der Täler Ghunsa und Simbua mit dem tibetischen Eis in Verbindung und reichten im Spätglazial Stadium I zusammen im Tamur Haupttal bis auf eine Höhe von $1.500 \mathrm{~m}$ - Konfluenzbereich in der Nähe des Ortes Hellok. Hinweise fand er in spätglazialen Lateral- bis Endmoränen. Über den Lamite Bhanjyang bestand zudem eine Eisstromverbindung zum Nachbartal Kabeli Khola. Der hochglaziale Eisrand lag bei Thuma auf 890 m Höhe. Zudem gab Kuhle Moränen bei Marijam an. Da der Text dem der Literaturquelle Kuhle (1998) sehr ähnlich war, war hier allerdings anzumerken, dass Kuhle in einem Satz schrieb, dass keine Endmoränen aufgefunden wurden, aber zuvor im Text eine Endmoräne für den LGM Eisrand erwähnte und im nächsten Abschnitt schrieb, dass beim Ort Thoma dort im ausgestalteten Trogtal 40 bis 120 m hohe Moränen bzw. Erdpyramiden

\footnotetext{
${ }^{498}$ Owen, L.A.; Mitchell, W.A.; Bailey, R.M.; Coxon, P.; Rhodes, E.J. (1997): Style and timing of glaciation in the Lahul Himalaya, Northern India: framework for reconstructing late quaternary paleoclimatic changes in the western Himalayas. In: Journal of Quaternary Science 12. (S. 83-109)
} 
vorkamen. 1,2 km talabwärts waren laut ihm abradierte und polierte Formen, aber keine Moränen mehr erkennbar. Somit könnte das letzteiszeitliche Gletscherende weiter talabwärts gereicht haben, war aber - wie er es andeutete - unzureichend belegbar.

\section{KUHLE (2013A)}

\section{METHODE BZW. ARBEITSTECHNIK}

Kuhle wendete geomorphologische Analysen an.

\section{UNTERSUCHUNGSGEBIET}

Neben vielen anderen genannten Forschungsgebieten ging Kuhle (2013a) auf den Kangchendzönga-Himal ein.

\section{KRITIK}

Kuhle (2013a:31, 35-36) beschrieb aus seiner eigenen Literaturquelle Kuhle (1990a), dass im Tamur Khola der tiefste LGM Gletscherrand auf ca. $890 \mathrm{~m}$ in der Nähe der Ortschaft Thuma lag; eine Endmoräne mit einem Sander stellten die Indikatoren hierfür dar. Talaufwärts machte er im Haupt- und in den Nebentälern Trogtalprofile, Flankenabrasionen, Strudeltöpfe, Rundhöcker sowie Moränenreste mit Erdpyramiden aus. Daher basierte die Rekonstruktion der vorzeitlichen Gletscher in diesen Talbereichen auf glazialgeomorphologischen Befunden, die daneben auch anhand von Fotos nachvollzogen werden konnten. 


\subsection{Kurzzusammenfassung}

In den Vergleichsuntersuchungsgebieten Dhaulagiri und Annapurna (Mayangdi Khola, Kali Gandaki, Modi Khola, Madi Khola, Seti Khola, Marsyandi Khola), Langtang, Mahalangur und Kangchendzönga-Himal waren die angewendeten Methoden bzw. Arbeitstechniken der Forscher folgende: Kuhle (1980) - geomorphologische Analyse (Moränen, Gletscherschrammen, Talquerprofile); Kuhle (1982 / 1983) - geomorphologische Analyse (viele Formen, Schneegrenzberechnungen, relative zeitliche Zuordnung); Iwata (1984) geomorphologische Formen (Kare, Trogwände, Moränen / Till, fluvioglaziale Ablagerungen, Massenbewegungsformen, Flussterrassen und Seesedimente), Luftbildanalyse, relative Datierungen (Frischegrad, paläomagnetische Chronologien); Fort (1985) geomorphologische Formen (z.B. Moränen, glazifluviale Ablagerungen); Fort (1986) geomorphologische Formen (polierte geschrammte Schluchtwände, besonders Moränen, z.B. Endmoränen), Sedimentbeschreibungen, relative und absolute Datierungen (Frischegrad, Bodenbedeckung, ${ }^{14} \mathrm{C}$ ); Kuhle (1990a) - geomorphologische Analyse (Fotografie, Kartierung, Schneegrenzberechnungen); Shiraiwa, Watanabe (1991) - geomorpholgische Analyse (Moränenrücken, Lagebeziehung, Talprofil, Geländebegehung und Fotografie), relative und absolute Datierungen (multiple relative Datierungen, z.B. Bodenentwicklung, Verwitterungstests, ${ }^{14} \mathrm{C}$ ); Bäumler, Kemp-Oberhettinger, Zech (1996) - geomorphologische Formen (Moränen, glazifluviale Ablagerungen), relative und absolute Datierungen (Bodenanalyse, ${ }^{14} \mathrm{C}$ im Langtang); Kuhle (1997a) - geomorphologische Analyse (Formen wie Grund- und Endmoränen sowie Erratika, Sedimentanalysen, Schneegrenzberechnungen), absolute Datierungen $\left({ }^{14} \mathrm{C}\right)$; Kuhle (1998) - geomorphologische Analyse (Formen wie Moränen, Erratika, Trogprofile mit Gletscherschrammen, glaziale Hörner, Flankenabrasion und -polierung, Rundhöcker und Strudeltöpfe, glazifluviales Material), Schneegrenzberechnungen; Meiners (1999) - geomorphologische Analyse (Lagebeziehung, Fotografie, Kartierung, Schneegrenzberechnungen), absolute Datierungen $\left({ }^{14} \mathrm{C}\right.$ im RolwalingHimal); Kuhle (2001) - geomorphologische Formen (Trogtalprofil, Kamesterrasse, Moränen und subglazialer Strudeltopf, Erratika); Zech et al. (2001) - geomorphologische Formen (Moränen, glazifluviale Ablagerungen / Terrassen, Trogtal, geschliffene Trogwände), relative und absolute Datierungen (boden-, vegetationskundliche und pollenanalytische Untersuchungen, ${ }^{14} \mathrm{C}$ ), Schneegrenzberechnungen; Tsukamoto et al. (2002) geomorphologische Formen (gut ausgebildete Moränen und Till, Lateral- bis Endmoränen, Trog- und Kerbtal, glazifluviale Sedimente), absolute Datierungen $\left({ }^{14} \mathrm{C}\right.$, OSL); Kuhle (2005) - geomorphologische Analyse (viele Formen, Sedimentanalyse, Talquerprofile, Fotografie, 
Schneegrenzberechnungen), relative und absolute Datierungen (Lichenometrie, ${ }^{14} \mathrm{C}$ ); Barnard et al. (2006) - geomorphologische Formen (Moränen, Fächer, Terrassen), sedimentologische Analysen, Talquerprofil, absolute Datierungen (TCN); Kuhle (2007a) - geomorphologische Analyse (Formen wie Moränenterrassen, Moränen wie etwa Lateral- oder Endmoränen, Erratika und Gletscherschrammen, abradierte und polierte Formen), Schneegrenzberechnungen; Zech et al. (2009) - geomorphologische Formen (z.B. Moränen), absolute Datierungen (TCN); Kuhle (2011a) - geomorphologische Analyse (viele Formen, Sedimentanalysen, Schneegrenzberechnungen); Kuhle (2013a) - geomorphologische Analyse (Formen wie Moränen, Erratika, Sander, Trogprofil, Gletscherschrammen, Strudeltöpfe, Rundhöcker, Flankenabrasion und Polierungen), Sedimentanalysen; Kuhle (2013b) geomorphologische Analyse (viele Formen, Talquerprofile, Fotos / Panoramen und Diagramme), Sedimentanalysen, Schneegrenzberechnungen; Kuhle (2014) geomorphologische Analyse (Karten, Fotos, Talquerprofile), Sedimentanalysen, Schneegrenzberechnungen.

Im Dhaulagiri- und Annapurna-Himal bzw. im Mayangdi Khola wurden die Forschungsarbeiten von Kuhle (1980, 1998, 2007a, 2013a) betrachtet, da diese geomorphologisch detailliert hergeleitet waren. Es wurden Formen wie etwa Moränen, Erratika, Gletscherschrammen, Polierungen, Trogtäler sowie glazigene Kerbtäler zueinander in Lagebeziehung gesetzt. Im Kali Gandaki war die Arbeit von Kuhle (1982 / 1983) im Vergleich zu den anderen ausgewählten Forschungsarbeiten die ausführlichste, detaillierteste und flächendeckendste. Die Kritik an dieser Arbeit durch Caine (1984) war nicht nachvollziehbar. Iwata (1984) untersuchte nur den oberen Bereich des Kali Gandaki. Es könnte sein, dass für die Festlegung seiner Eisrandlage anstatt der Moränen vielmehr der Talübergang vom Trog- zum Kerbtalprofil ausschlaggebend war. Laut Iwata waren Moränen nur schwer von anderen Akkumulationen unterscheidbar. Das Khingar Stadium fiel in das letzte Glazial, war jedoch in seiner Abbildung mit dem Zeitraum vor 4.000-5.000 Jahren und das Ältere Stadium mit dem vor etwa 10.000-15.000 Jahren aufgelistet. Der Altersunterschied zum Khingar Stadium deutete an, dass diese älteren Moränen aus dem vorletzten Interglazial stammten. Fort (1985) untersuchte das Jhong Khola. Diese Arbeit war für eine Aussage über die letztglaziale Maximalausdehnung weniger geeignet, da sie ein zusammenfassendes Werk darstellte. In den Arbeiten Kuhle (1998, 2007a) wurden Moränen im Kali Gandaki beschrieben, womit die Eisränder auf der Himalaja-Südseite durch Indikatoren nachvollziehbar waren. Zech et al. (2009) schrieben, dass die Forschungen im Zentralhimalaja problematisch waren; generell war es schwierig, Relikte aufzufinden. Da die 
Altersüberschätzung der Daten gering zu sein schien, war es annehmbar, dass das älteste Alter eines Blockes auf einer Form oft das ungefähre Alter der entsprechenden Form angab. Ob diese Überschätzung jedoch wirklich gering war, konnte nicht belegt werden. Zu hinterfragen wäre, warum einige Forscher im Zentralhimalaja Mittelwerte der ermittelten TCN-Daten von Formen bildeten und nicht das älteste Alter als das Entstehungsalter annahmen. Wenn das datierte Alter jedoch wirklich das Alter der gesamten Form angeben sollte, dann müssten alle ermittelten Alter in ein und derselben Form ungefähr gleich sein, was aber bei den Forschungsarbeiten nicht der Fall war. Daneben waren die von Zech et al. (2009) ermittelten Daten laut ihnen zu wenige und waren für eine umfassende Rekonstruktion nicht geeignet. Außerdem fiel auf, dass das Alter der Dhampu Chooya Ablagerung anhand von anderen Daten interpretiert und nicht genau bestimmt wurde. Zudem war die lokale Produktionsrate anhand eines Skalierungsfaktors von einer referenzierten Produktionsrate auf Meeresspiegelhöhe in hohen Breiten bestimmt worden und die datierten Blöcke sollten keine Erosions- und Verwitterungsspuren aufweisen. Es wurden gewissermaßen nur Annahmen über die letztglaziale Vergletscherung getroffen und die glazifluviale Terrasse östlich von Lete auf etwa $2.500 \mathrm{~m}$ Höhe als Maximalstadium der Vergletscherung angesehen; pleistozäne Moränen konnten aber nicht datiert werden. Die Arbeit von Kuhle (2011a) stellte neben seinen in der vorliegenden Dissertation genannten die detaillierteste gegenüber anderen Forschungsarbeiten dar. Infolge der von ihm angewendeten Methode bzw. Arbeitstechnik unter Betrachtung vieler geomorphologischer Formen und deren Lagebezug zueinander erfolgte die Rekonstruktion der letzthochglazialen Gletscherbedeckung dieses Gebietes sinnvoll, beweiskräftig und nachvollziehbar. Die Arbeit Kuhle (2013a) war eine Zusammenstellung der Befunde aus den in den Jahren 1980, 1982 und 1983 veröffentlichten Arbeiten. Die Ausarbeitung von Kuhle (2013b) war ähnlich zu der von Kuhle (2011a), nur dass in dieser umfänglicheren Veröffentlichung mehr Belege bzw. Fotos / Panoramen und Diagramme der Sedimentanalysen zum Gebiet Mustang-Thak Khola geliefert werden konnten und zudem auf das Marsyandi Khola eingegangen wurde. Im Modi Khola wurden die Forschungsarbeiten von Kuhle (2001) und Zech et al. (2001) betrachtet. Das Trogtalprofil reichte nach Kuhle gegenüber den Befunden von Zech et al. bis in das untere Modi Khola Tal hinunter. Vor allen Dingen deuteten die von Kuhle ausgemachten nachvollziehbaren Indikatoren, wie etwa Grundmoränen, auf eine einstmalige Vergletscherung hin. Die von Kuhle angegebene vorzeitliche Eismächtigkeit bei Birethanti entsprach demgegenüber aber ungefähr der von Zech et al. (2001); das Gletscherende war mit einem Fragezeichen versehen. Zech et al. (2001) beschrieben das annähernd trogtalförmige Profil bei Birethanti, schrieben 
jedoch, dass oberhalb von Birethanti ein enger Talgrund existierte, was nahe legte, dass es sich hierbei wohl eher um die Talform schluchtförmiger Trog handeln könnte. Außerdem konnten Unstimmigkeiten bei den Bodenprofilen festgestellt werden. Die Arbeit basierte in Bezug auf die letzteiszeitliche Vergletscherung auf Annahmen, was sie selber in Bezug auf die Nichterhaltung von Stirnmoränen angaben. Moränen waren zudem nicht eindeutig von anderen Akkumulationsformen unterscheidbar oder aufgrund von Hangschuttüberlagerung nicht eindeutig identifizierbar. Zech et al. trafen Aussagen über die letzteiszeitliche Vergletscherung, fanden aber keine eindeutigen Moränen im Bereich der Konfluenz Kyumnu Khola zum Kali Gandaki und generell keine eindeutigen Moränenwälle, wobei sie gegebenenfalls aber auch nur wallförmige Moränen aufsuchten. Bei Kuhle (2007a, 2013a) wurde lediglich erwähnt, dass der LGM Modi Gletscher bis auf ca. 800 m Höhe hinab reichte. Im Madi Khola waren die Arbeiten von Kuhle (1998, 2001a, 2007a, 2013a) bekannt. Bei Kuhle (1998, 2001a, 2007a) wurde über das Madi Khola lediglich der tiefste Eisrand beschrieben, wobei Moränen und Erratika als Indikatoren genannt wurden. Kuhle (2013a) stellte keine glazialgeomorphologischen Befunde dar. Im Seti Khola wurden die Arbeiten von Fort (1986) und Kuhle (2001) betrachtet. Die Ausarbeitung von Fort (1986) war für eine Aussage über die maximale Vergletscherung während der letzten Eiszeit wenig geeignet, da von ihr keine Aussagen direkt über das Hochglazial getroffen wurden, sondern nur über das Spätglazial. Außerdem machte sie ungenaue Angaben über die zeitliche Einordnung und war sich bei geomorphologischen Einordnungen von Formationen nicht schlüssig. Ältere glaziale Indikatoren waren oft nicht mehr erhalten oder es traten Schwierigkeiten beim Erkennen selbiger auf. Fort (1986) verwies darauf, dass weitere Forschungen, darunter auch eine größere Menge absoluter Datierungen, nötig sind. Im Gegensatz $\mathrm{zu}$ anderen Forschungsarbeiten wurde bei Kuhle (2001) die Form Erratika betrachtet, die eindeutiger Indikator einer Vergletscherung war und diesbezüglich keine andere Erklärungsmöglichkeit zuließ. Bei Kuhle (2007a, 2013a) wurden nur wenige Informationen - stammend aus seinen älteren Literaturquellen - über die Vergletscherung des Seti Khola gegeben. Erratika ließen auf eine Eisrandlage schließen. Ob jedoch talabwärts noch weitere glazialgeomorphologische Kennformen auffindbar wären, müsste durch Geländearbeiten abgeklärt werden. Im Marsyandi Khola wurden besonders die Arbeiten von Kuhle (1997a, 1998, 2007a, 2013a, b, 2014) betrachtet, da Kuhle die detaillierteste geomorphologische Analyse durchführte und gegensätzlich $\mathrm{zu}$ anderen Forschern das talabwärtigste maximale Gletscherende rekonstruierte. 
Im Langtang-Himal wurden die Forschungsarbeiten von Shiraiwa, Watanabe (1991), Bäumler, Kemp-Oberhettinger, Zech (1996), Kuhle (2001), Barnard et al. (2006) und Kuhle (2013a) ausgewählt. Shiraiwa, Watanabe (1991) bildeten bei ihren angewendeten multiplen relativen Datierungen Mittelwerte aus zwei oder drei Daten der betrachteten Moränenzüge. Die ermittelten Daten einiger Moränen stimmten nicht immer mit denen des gesamten Komplexes überein, wobei auch die relativen Altersbestimmungen nicht in jedem Fall mit dem Lagebezug der Formen zueinander übereinstimmten. Für eine Vergletscherungsrekonstruktion waren diese Methoden bzw. Arbeitstechniken der relativen Datierung im Gegensatz zur geomorphologischen Detailanalyse offensichtlich weniger geeignet. Das Lama Stadium bzw. die maximalste Vergletscherungsausdehnung wurde gegenüber anderen Stadien nur anhand des Talprofiles festgelegt. Schon unterhalb von Ghora Tabela ließen sich keine glazialen Akkumulationen auffinden. Außerdem wurde nur der Verwitterungsgrad der Endmoräne als Beleg für das Gora Tabela Stadium angesehen, wobei glazifluviale Schotter auf ein Interglazial zwischen Lama und Ghora Tabela und somit auf einen Altersunterschied verwiesen, welcher auch hier durch Verwitterungsunterschiede belegt wurde. Die Forschungen von Shiraiwa, Watanabe (1991) basierten auf Geländebegehungen und Fotografien; hierbei wurde nicht ersichtlich, in welchen Talbereichen sie Geländearbeiten durchführten. Die Forschungen von Bäumler, Kemp-Oberhettinger, Zech (1996) waren für eine hochglaziale Rekonstruktion eher ungeeignet, direkte Aussagen über die Maximalvergletscherung dieses Gebietes wurden nicht getroffen, vielmehr wurde auf andere wissenschaftliche Literaturquellen verwiesen. Sie untersuchten fast ausschließlich Böden auf deutlich erkennbaren Moränenwällen. Da solche Moränen aber eher auf ein jüngeres Alter schließen ließen, war fraglich, ob die dort untersuchten Bodenentwicklungen eine maximale hochglaziale Gletscherausdehnung anzeigen konnten. Bei den Bodenprofilen konnten Unstimmigkeiten entdeckt werden. Vorhergehende geomorphologische Analysen führten gegenüber den Datierungen zu anderen Ergebnissen. Alleinige geomorphologische Analysen waren laut ihnen im Himalaja allerdings für die Rekonstruktion der Vergletscherungsgeschichte schwierig zu erheben. Laut Bäumler, Kemp-Oberhettinger, Zech (1996) existierte talabwärts der Lama Lodge ein kerbförmiges Talprofil. Ob dieses nun ausschlaggebend für die Einordnung der maximalen Vergletscherung war, wurde nicht erwähnt. Kuhle (2001) begründete eine vorzeitliche Vergletscherung anhand von Grundmoränen. Nach Barnard et al. (2006) stand eine multiple Probenahme für eine genauere Altersbestimmung. Mittelwerte führen jedoch nicht unbedingt zu einem genaueren Ergebnis. Die drei Datierungen des Tsergo Ri 'landslide’ sollten die Nutzbarkeit der Datierung älterer 
Ablagerungen überprüfen und akkurate Altersbestimmungen jedoch nur für Akkumulationen jünger als 1.000 Jahre gemacht werden können. Der genannte 'landslide' konnte aber nur nach der Vergletscherungsphase entstanden sein und muss demnach viel jünger sein. Die Daten wurden auch nicht weiter diskutiert und es wurde nur auf die Befunde von anderen Forschern bzw. nur auf den Hinweis des Überganges vom Trog- zum Kerbtal auf ca. 2.600 m Höhe verwiesen, ohne auf Indikatoren in Form von Moränen einzugehen. Jedoch gingen sie davon aus, dass die Fächer und Terrassen aus Moränenmaterial entstanden. Bei den Denudationsraten wurden Daten nicht berücksichtigt sowie Widersprüchlichkeiten bei den Angaben erkannt. Kuhle (2013a) beschrieb anhand von Grundmoränen, dass der vorzeitliche Langtang Hauptgletscher bis auf eine Höhe von ca. 930 m hinunter reichte.

Im Mahalangur-Himal bzw. im Arun Tal wurden die für dort bekannten Forschungsarbeiten Kuhle (1997a, 1998, 2005, 2007a) betrachtet. Die Arbeit aus dem Jahr 2005 war sehr ausführlich, wobei enorm viele geomorphologische Formen bzw. Indikatoren beachtet wurden. Bei Kuhle (1997a, 1998, 2007a) wurde beschrieben, wie mächtig der vorzeitliche Gletscher war und bis wohin er hinab reichte, wobei in den beiden letztgenannten Arbeiten Nachweise angeführt wurden.

Für den Kangchendzönga-Himal wurden die Forschungsarbeiten von Kuhle (1990a, 1998), Meiners (1999), Kuhle (2001a), Tsukamoto et al. (2002) und Kuhle (2007a, 2013a) herangezogen. Die Forschungsarbeit von Kuhle (1990a) war ausführlich; hierbei wurden viele unterschiedliche geomorphologische Formen beachtet und in Beziehung zueinander gesetzt. Den Eisrand der maximalen Eismächtigkeit legte er anhand von glazialen Formen fest, wobei die von ihm talabwärts ausgemachten polierten Formen auf ein talabwärtigeres letzteiszeitliches Gletscherende hindeuten konnten. Auch bei Kuhle (1998, 2001a, 2007a, 2013a) wurden die in diesem Gebiet kartierten Formen beschrieben. Meiners (1999) erfasste neben den post- bis spätglazialen Gletscherständen auch Moränenterrassen sowie einen polierten und abradierten Gebirgsrücken, die Hinweise auf die Maximalvergletscherung gaben. Sie schloss sich den Ergebnissen von Kuhle (1990a) an. Tsukamoto et al. (2002) untersuchten lediglich vier Lokalitäten in den Tälern Ghunsa und Shimbuwa Khola. Erstmalig wurden hier OSL-Datierungen bei Moränen (supraglaziale Ausschmelzmoränen und Deformationsmoränen) angewendet. Das vollständige Bleichen der Sedimente vor der Ablagerung basierte jedoch nur auf Annahmen; sie schrieben, dass der genaue Bleichungsprozess unbekannt war. Daneben können selbst der Ablagerungsprozess der Sedimente durch den Gletscher bzw. die Prozesse des Gletschers nicht exakt nachvollziehbar 
sein. In der Übereinstimmung der Daten unterschiedlicher Bestimmungsverfahren sahen sie einen Beweis für das vollständige Ausbleichen der Sedimente. Jedoch muss diese Übereinstimmung nicht unbedingt etwas mit dem Prozess des Ausbleichens zu tun haben. Wie das OSL-Alter der Formen aber in Zusammenhang mit der Vergletscherung zu bringen war, blieb unbeschrieben. Diskutiert wurde nur über die Proben 2 und 4, letztendlich wurde aber ein Entstehungsalter - nicht wie sonst üblich durch einen Mittelwert gestützt - einfach festgelegt, obwohl sich diese Proben deutlich voneinander unterschieden. Generell wiesen die Daten enorme Schwankungen auf. Ferner waren Widersprüche bei Abbildungen bezüglich der Abmessungen der Untersuchungsgebiete und der Probenahmestellen festzustellen; das Stadium von Kuhle wurde verändert angegeben. Da Tsukamoto et al. nur gut ausgebildete Moränen und den Übergang von Trog- zu Kerbtal in Betracht zogen, war die Arbeit für eine Aussage über die maximale Vergletscherung weniger geeignet. 


\section{ZUSAMMENFASSUNG DER ERGEBNISSE DER KRITISCHEN ANALYSE UND EINORDNUNG DIESER IN DEN KONTEXT DER LETZTEISZEITLICHEN VERGLETSCHERUNG DES NEPAL- HIMALAJA}

Zielstellung der vorliegenden Arbeit war es, den heutigen Forschungsstand zur Vergletscherungsgeschichte Hochasiens aus inhaltlich- und methodenkritischer Sicht sowie bezüglich des Hauptuntersuchungsgebietes Solukhumbu durch geomorphologische Detailanalysen mit Testbegehungen im Gelände, Geländearbeiten und Satellitenbildanalysen zu überprüfen und zu bewerten, um im bestmöglichen Falle eine einheitliche Auffassung zu etablieren. Bis heute existieren zur eiszeitlichen Vergletscherungsart und zum Grad der Vergletscherung dieses Gebietes immer noch beträchtliche Unterschiede in den Forschungsergebnissen. Außerdem waren keine abschließenden kritischen Analysen über diesen Sachverhalt auffindbar, die zu einer einheitlichen Auffassung über die Vergletscherung Anlass geben könnten. Bei der vorliegenden Arbeit lag somit der Schwerpunkt auf der Gegenüberstellung der wissenschaftlichen Literatur in Bezug auf Quartärgeomorphologie und Gletschergeschichte im Himalaja und der damit verbundenen Suche sowohl nach Gründen der verschiedenen Forschungsergebnisse als auch nach Widersprüchen und eventuellen Fehlerquellen. Bei einer solchen kritischen Analyse wurden die von den Forschern verwendeten grundlegenden Methoden bzw. Arbeitstechniken, die beschriebenen Rekonstruktionen und Einordnungen sowie die sie unterstützenden Belege, wie etwa Daten, Abbildungen und Fotos, kritisch überprüft und anschließend bewertet. Zudem sollte anhand von Geländearbeiten und Satellitenbildanalysen zum ausgewählten Hauptuntersuchungsgebiet überprüft werden, in welchem Ausmaß eine Vergletscherung während der letzten Eiszeit stattgefunden hat bzw. wie die Befunde der hier relevanten wissenschaftlichen Literatur einzuordnen sind.

Für die jeweiligen Schlussfolgerungen der Forscher, vor allen Dingen zur zeitlichen Einordnung von Formen, waren bei allen Untersuchungsgebieten hauptsächlich die Unterschiede in der jeweils angewendeten Methode / Arbeitstechnik, aber auch in der Lage und der Größe des jeweils ausgewählten Untersuchungsgebietes ausschlaggebend. Ein Vergleich der verschiedenen Forschungsergebnisse stellte sich als schwierig heraus, da häufig umfassende Arbeiten und weniger umfassende existieren. Grundsätzlich standen sich die angewendeten Methoden bzw. Arbeitstechniken geomorphologische Reliefanalyse, relative Datierung wie etwa Bodenanalyse und absolute Datierung wie ${ }^{14} \mathrm{C}$, TCN bzw. OSL 
gegenüber. Im Hauptuntersuchungsgebiet wurden von den verschiedenen Forschern die absoluten Datierungen nur im Khumbu und die anderen genannten Methoden im Khumbu sowie auch im Solu angewendet (siehe Tabelle II, Bildband). Wurde die Methode Lichenometrie angewendet, reichte das letzthochglaziale Gletscherende zumeist, abgesehen von den Ergebnissen einer Forschungsarbeit, bis in das Gebiet des Solu, bei Anwendung von Bodenanalysen lag das letzthochglaziale Gletscherende im Khumbu und im Solu. Bei Anwendung von TCN- und OSL-Datierungen reichte das letzthochglaziale Gletscherende nicht weit von den heutigen Gletschern hinab, nur in das Gebiet des Khumbu, bei ${ }^{14} \mathrm{C}$ Datierungen reichte es zumeist - mit einer Aunahme - bis in das Gebiet des Solu. Die Methode der geomorphologischen Analyse stellte sich gegenüber den Datierungsmethoden als bislang zielführendste, aussageträchtigste, geringst fehlerbehaftete und ergebnisschärfste Methode für die Rekonstruktion einer vorzeitlichen Vergletscherung heraus. Anhand dieser Analyse werden zahlreiche geomorphologische Formen aufgenommen und in Lagebezug zueinander gesetzt. Sedimentologische Analysen - Grob- und Feinsedimentanalysen und auch Schneegrenzberechnungen untermauern diese geomorphologischen Befunde. Die geomorphologische Reliefanalyse führte demzufolge $\mathrm{zu}$ wissenschaftlich belastbaren Ergebnissen. Die Datierungsmethoden Bodenanalyse, ${ }^{14} \mathrm{C}$, TCN und OSL dienten der genaueren zeitlichen Einordnung der geomorphologischen Formen. Diese sollten, besonders die letzten beiden, nur ergänzend zu den Aussagen der geomorphologischen Detailanalyse herangezogen werden bzw. es sollten die damit erhobenen Daten immer kritisch überprüfend und zum geomorphologischen Kontext abwägend interpretiert werden. Zu den Daten aus dem nördlichen Gebiet Khumbu wären Vergleichsdaten aus dem südlich angrenzenden Solu von Vorteil. Eine Schlussfolgerung unter alleiniger Anwendung der genannten Datierungsmethoden und ohne Berücksichtigung jeglichen Formeninventars inklusive dessen Lagebezug zueinander würde demnach nicht $\mathrm{zu}$ wissenschaftlich belastbaren Forschungsergebnissen führen. Auch Kuhle (2014:252) verwies darauf, dass eine Gletscherchronologie allein auf Basis von TCN-Daten einen methodologischen Fehler darstellt bzw. Kuhle (2011b:959) darauf, dass die alleinige Anwendung von TCNDatierungen unzureichend ist. Generell sind TCN- und OSL- Datierungen von zu vielen unbekannten Faktoren abhängig wie u.a. von der kosmischen Strahlung, die wiederum durch das Sonnen- und Erdmagnetfeld beeinflusst wird, von der Verwitterung, Exhumierung / Freilegung, Erosion, Verlagerung, Strahlungsabschirmung sowie von der vorherigen Bestrahlung, von der geographischen Breite und Höhenlage und von geomorphologischen Prozessen (vgl. Kuhle 2007b:115; vgl. Kuhle, Kuhle 2010:105, 109; vgl. Owen et al. 
2008:519; vgl. Reuther 2007:24, 26 f., 37, 57 f.). Die OSL-Datierung ist nur für vollständig gebleichte Materialien gut kalibriert (vgl. Kuhle, Kuhle 2010:108; vgl. Owen et al. 2008:518). Die ${ }^{14} \mathrm{C}$-Methode sollte hingegen geeignet sein, da sie sich nur indirekt auf die Produktion der ${ }^{14}$ C-Isotope in der Erdatmosphäre bezieht (vgl. Kuhle, Kuhle 2010:110). In der vorliegenden Arbeit ergab die Ergebnisanalyse von TCN-Datierungen beispielsweise, dass die Methode ungleiche Daten in ein und demselben Moränenzug lieferte oder aussagte, dass jüngere Moränen in tieferen Höhenlagen vorkamen als ältere. Zudem traten Unterschiede zwischen den datierten Altern und der Morphostratigraphie auf. Diese Aspekte wiesen darauf hin, dass die ermittelten Daten geomorphologisch gedeutet werden sollten. Ungewiss blieb, warum einige Forscher Mittelwerte und einige die ältesten Alter verwendeten.

Die Ergebnisse von Kuhle, die immer am ausführlichsten geomorphologisch hergeleitet waren, standen $\mathrm{zu}$ allen mit der vorliegenden Arbeit präsentierten Gebieten kontrovers gegenüber denen anderer Forschungen: Kuhle kam durch die konsequent umfängliche Erfassung geomorphologischer Befunde stets $\mathrm{zu}$ einer stärkeren letztglazialen Vergletscherung der Himalaja Regionen. Dazu war insgesamt zu sagen, dass Kuhle die meisten Gebiete in Hochasien - beginnend 1973 im Zagrosgebirge (vgl. Kuhle 1997b:85) bereiste und erforschte (s.h.a. Kuhle 2014:Fig. 1). Kuhle untersuchte somit das größte Gebiet im Himalaja und tiefer gelegene Haupttalbereiche als andere Forscher, wodurch ersichtlich wurde, warum Kuhle zu anderen Forschungsergebnissen gelangen musste. Generell stand das Ausmaß des Untersuchungsgebietes mit der letzthochglazialen Gletscherendhöhenlage in Zusammenhang - je größer das Untersuchungsgebiet, umso tiefer reichte auch die letzthochglaziale Gletscherendhöhenlage hinab. Beispielsweise untersuchten einige Forscher nur das nördliche Gebiet, den Khumbu, und kamen zu einem Gletscherende nur dort im Khumbu, andere Forscher untersuchten das nördliche sowie das südliche Gebiet, den Solu, bzw. das gesamte Gebiet des Solukhumbu und kamen zu einem viel tieferen Gletscherende zumeist im Gebiet des Solu (siehe Tab. II und Diagramm 1, Bildband). Bei Betrachtung geomorphologischer Analysen auch anderer Forscher setzten sich davon die von Kuhle (besonders 2005) deutlich ab - durch die detaillierten Analysen bzw. Bestandsaufnahmen, die sedimentologischen Untersuchungen der Moränen, die Belege in Form von Fotos bzw. visuellen Beweisdarstellungen dieser Formen sowie durch die Schneegrenzberechnungen. In Zukunft wird es darüber hinaus möglich sein - beispielsweise durch den Einsatz von Drohnen im Gelände - unzugängliche Tal- oder Hangbereiche genauestens geomorphologisch aufzunehmen und zu deuten. Die von einigen Forschern beschriebene Ausgestaltung der 
Moränen als deutliche Rücken ließ eher auf ein jüngeres Alter schließen. Nach Kuhle (1986c:44) unterlagen nämlich besonders ältere hochglaziale Moränen der nacheiszeitlichen Überformung. Weiter talabwärts vom Konfluenzbereich Lobuche und Imja Khola vorgekommene Moränen deuteten ebenfalls darauf hin, dass die höhergelegenen von den Forschern untersuchten Moränen eher spätglazial waren. Bereits Kuhle (1986c:44) machte im Gebiet Tibet darauf aufmerksam, dass Forscher hochgelegene sichere Moränenbefunde nicht so sicheren vorzogen und demnach zu anderen Ergebnissen kamen. Daneben waren einige Forschungsarbeiten in Bezug auf eine Aussage über die Maximalvergletscherung weniger geeignet, da sie generell keine Aussagen bzw. nur Annahmen über die Maximalvergletscherung enthielten, sich darin Forschungsergebnissen angeschlossen wurde oder sie nur einen Überblick über die Forschungen im Himalaja gaben.

Alle Forschungsarbeiten, die ausschließlich Ergebnisse zum Khumbu und nicht zum Solu lieferten, konnten allein aufgrund dieser Tatsache in Bezug auf eine Aussage zur Maximalvergletscherung des Solukhumbu nur behutsam betrachtet werden. Vielmehr waren jene Forschungsarbeiten relevant, die auch in talabwärtigeren Bereichen, nämlich im Solu, Ergebnisse erbrachten. Kuhle (2005 einschließlich 2001a, 2007a, 2011b und 2013a) untersuchte das Dudh Khosi am weitesten talabwärts - seine Ergebnisse waren am detailliertesten. Hierbei wurde im Gegensatz zu allen anderen Forschungsarbeiten auf eine Form eingegangen, die auch im kerbförmigen Talprofil - etwa ausgebildet als glazigenes Kerbtal, schluchtförmiger Trog oder trogförmige Schlucht - einen Hinweis für eine Vergletscherung lieferte. Bereits in seiner Arbeit Kuhle (1984) wurde erwähnt, dass auf der Südseite des Himalaja glazigene Kerbtäler talabwärts der Trogtäler vorkamen und bei Kuhle (1986c:44), dass Formen wie z.B. das Talprofil - nur ein u-förmiges Tal war ein glaziales Anlass zu Missdeutungen gaben. Bereits Visser, Visser-Hooft (1938:140 f., Fig. 72. A und b) deuteten im Karakorum auf eine solche Talausformung hin. Daneben ging Kuhle als einziger auf weitere Formen wie beispielsweise glazigene Dreieckshänge ein. Solche Kritikpunkte beim Hauptuntersuchungsgebiet, die die Literaturanalyse $\mathrm{zu}$ den Vergleichsuntersuchungsgebieten ebenfalls ergab, waren dann hier gleich geartet; außerdem traten einige wenige weitere Kritikpunkte auf. Generell betrachtet kann gesagt werden, umso mehr Formentypen - vor allen Dingen mehr als 5 Typen bzw. wenn auch Mischformen im Hauptuntersuchungsgebiet beachtet wurden, desto tiefer reichte das letzthochglaziale Gletscherende hinab (siehe Tabelle II, Bildband). 
Das Hauptuntersuchungsgebiet Solukhumbu wurde mit der vorliegenden Arbeit talabwärts der Ortschaften Thokla und Chhukhung bis talabwärts des Konfluenzbereiches Dudh Khosi und Hinku Khola untersucht. Die zeitlichen Einordnungen der von Kuhle (2005) betrachteten Moränen unter Einbeziehung der jeweils umgebenden Formen gegenüber denen der parallel dazu aufgeführten Forscher waren deutlich nachvollziehbar. Einige zeitliche Einordnungen von Formen nach anderen Forschern konnten sowohl anhand der Indikatoren von Kuhle (2005) als auch der ergänzenden durch die vorliegende Arbeit nicht bestätigt werden; z.B. als hochglazial ausgelegte Ufermoränen erwiesen sich nicht einmal als spätglaziale. Die eigenen Geländebefunde im Hauptuntersuchungsgebiet Solukhumbu, die für die vorliegende Arbeit erhoben wurden, stimmten überwiegend mit denen von Kuhle (2005) überein - einige konnten in Gänze aufgrund der Fülle seiner Befunde nicht überprüft werden, ergaben aber talabwärts von Lukla eine mächtigere Vergletscherung als von Kuhle (2005) beschrieben. Allerdings konnte generell keine Endmoräne aufgefunden werden. Nach Kuhle (1986c:44) waren hochglaziale Endmoränen infolge der Erosion schlechter erhalten und schwerer zu diagnostizieren als jüngere bzw. müssen Endmoränen nicht eindeutig als Wallform ausgebildet sein. In Tibet traten eher schwemmschuttfächerähnlich ausgebildete Endmoränen auf, die als Bortensander bezeichnet wurden (vgl. Kuhle 1986c:45). Es existierten noch weiter talabwärts reichende mögliche Indizien einer letzteiszeitlichen Eisausdehnung zu jener Eisrandgrenze, die von Kuhle mit einem visualisierten Fragezeichen (Fig. 4) versehen wurde. Die Klärung der Lage des Gletscherendes bedarf hier letztlich noch weiterer Forschungen, was sich allerdings tatsächlich z.B. aufgrund von Boden- und Vegetationsbedeckung sowie Verwitterung der Formen in diesen tiefen Höhenlagen als schwierig gestalten dürfte.

Die Befunde von Fushimi (1978) stimmten bei den nahe Chaunrikharka gelegenen Moränenterrassen mit denen von Kuhle (2005) und denen der vorliegenden Arbeit überein. Allerdings konnten anderenorts einige der von Forschern kartierten Formen entweder nicht als solche bestätigt werden - wobei sich z.B. die Form 'fan' oft als glaziärer Dreieckshang mit darauf lagernden Grundmoränen darstellte, oder wurden dort nicht in deren Legende aufgeführt und waren demnach nicht zuordbar. Die Probenahmestellen von mehreren Forschern - wie z.B. die von Richards et al. (2000), Finkel et al. (2003) und Barnard, Owen, Finkel (2006) - konnten im Gelände anhand der Koordinatenangaben nicht genau aufgefunden werden.

Die vorliegende Arbeit zeigte, dass das Hauptuntersuchungsgebiet Solukhumbu, so wie es Kuhle belegte, stärker vergletschert war als vom Großteil der Forscher angegeben bzw. dass 
durch die eigenen Geländebefunde eine talabwärts von Lukla mächtigere Vergletscherung als bei Kuhle belegt und eine talabwärtigere Vergletscherung als bei Kuhle angenommen werden konnte. Die kritische Literaturanalyse zu den Vergleichsuntersuchungsgebieten ließ darauf schließen, dass hier der Sachverhalt gleich war bzw. dass die Vergletscherungsrekonstruktion nach Kuhle detailliert war und somit auch adäquate Schlussfolgerungen für weitere Gebiete Hochasiens, speziell des Himalaja, möglich sind. Da die Wirkung einer solchen Abkühlungsfläche durch das Ausmaß des Vergletscherungsgrades entscheidend beeinflusst wird, muss diese rekonstruierte mächtigere pleistozäne Eisbedeckung in Hochasien einen großen Einfluss auf das regionale oder gar globale Klima gehabt haben. 


\section{Literaturverzeichnis}

Abramowski, U. (2004): The use of ${ }^{10} \mathrm{Be}$ surface exposure dating of erratic boulders in the reconstruction of the late Pleistocene glaciation history of mountainous regions, with examples from Nepal and Central Asia. Dissertation, Bayreuth.

Achenbach, H. (2011): Historische und rezente Gletscherstandsschwankungen in den Einzugsgebieten des Cha Lungpa (Mukut-, Hongde- und Tongu-Himalaja sowie Tach Garbo Lungpa), des Khangsar Khola (Annapurna N-Abdachung) und des Kone Khola (Muktinath-, Purkhung- und Chulu-Himalaja). Dissertation, Universität Göttingen. (260 Seiten)

Ad-hoc-AG Boden (2005): Bodenkundliche Kartieranleitung. 5. Auflage. Hannover.

Auswärtiges Amt (2013): Nepal. Auswärtiges Amt, Berlin. http://www.auswaertigesamt.de/DE/Aussenpolitik/Laender/Laenderinfos/01-

Nodes_Uebersichtsseiten/Nepal_node.html Abruf am 12.07.2013

Aoki, T.; Imamura, M. (1999): Reconstructing the glacial chronology based on the ${ }^{10} \mathrm{Be}$ Exposure Age in the Khumbu glacier, Eastern Nepal Himalayas - a problem on the production rate of in-situ cosmogenic radionuclides. Proceedings of the Korea-Japan / Japan-Korea Geomorphological Conference.

Barnard, P.L.; Owen, L.A.; Finkel, R.C. (2006): Quaternary fans and terraces in the Khumbu Himal south of Mount Everest: their characteristics, age and formation. Journal of Geological Society of London 163.

Barnard, P.L.; Owen, L.A.; Finkel, R.C.; Asahi, K. (2006): Landscape response to deglaciation in a high relief, monsoon-influenced alpine environment, Langtang Himal, Nepal. Quaternary Science Reviews 25.

Baumhauer, R.; Winkler, S. (2014): Glazialgeomorphologie. Formung der Landoberfläche durch Gletscher. Gebhardt, H.; Baumhauer, R.; Bendix J.; Reuber, P. (Hrsg.). Studienbücher der Geographie. (262 Seiten)

Bäumler, R. (2001): Vergleichende bodenkundliche Untersuchungen in Hochasien und Kamtschatka. Böden als Zeugen der quartären Landschafts- und Klimageschichte. Relief, Boden, Paläoklima Band 16.

Bäumler, R.; Zech, W. (1998): Soils on glacial and glaciofluvial deposits in central and eastern Nepal in relation to classification and landscape history. Proceedings of the International Conference on Ecohydrology of High Mountain Areas, Kathmandu, Nepal, 24.-28. März 1996, ICIMOD Publ.. (S. 439-449)

Bäumler, R.; Kemp-Oberhettinger, M.; Zech, W. (1996): Bodengenetische Untersuchungen zur Moränenstratigraphie im Langtang-Tal (Zentralnepal) und im Solu/Khumbu (Ostnepal). Bayreuther Bodenkundliche Berichte 51. 
Bäumler, R.; Zech, W.; Heuberger, H.; Weber-Diefenbach, K. (1991): Investigations on the intensity of weathering of soils developed from glacial and fluvioglacial deposits and their relationship with the history of the landscape in the Mt. Everest region. In: Geoderma 48. Elsevier Science Publishers B.V., Amsterdam. (S. 223-243)

Benedict, J.B. (1976): Khumbu glacier series, Nepal. Zitiert nach: Buckley, J. (1976)

Bennett, M.R.; Glasser, N.F. (1996): Glacial Geology. Ice Sheets and Landforms. John Wiley \& Sons. Chichester, New York, Brisbane, Toronto, Singapore.

Bremer, H. (1989): Allgemeine Geomorphologie. Methodik-Grundvorstellungen-Ausblick auf den Landschaftshaushalt. Gebrüder Borntraeger. Berlin, Stuttgart.

Beschel, R. (1950): Flechten als Altersmaßstab rezenter Moränen. In: Zeitschrift für Gletscherkunde und Glazialgeologie, Vol. 1. (S. 152-161)

Buckley, J. (1976): Isotope`s radiocarbon measurements XI. Radiocarbon 18, No. 2.

Busch, P. (1986): Teil III: Geomorphologie. Grundriß allgemeine Geographie. Ferdinand Schöningh, Paderborn, München, Wien, Zürich.

Cady, J.G.; Wilding, L.P.; Drees, L.R. (1986): Petrographic Microscope Techniques. In: Klute, A. (ed.), (1986): Methods of Soil Analysis. Agron. Monograph No. 9 (1), Am. Soc. Agron., Madison, Wisconsin (USA).

Cailleux, A. (1952): Morphoskopische Analyse der Geschiebe und Sandkörner und ihre Bedeutung für die Paläoklimatologie . In: Geologische Rundschau, Vol. 40.

Caine, N. (1984): Review: Der Dhaulagiri- und Annapurna-Himalaya: Ein Beitrag zur Geomorphologie extremer Hochgebirge von Matthias Kuhle.

Carter, A. (1985): Classification of the Himalaya. The American Alpine Journal 1985.

DeCelles, P.G.; Kapp, P.; Gehrels, G.E.; Ding, L. (2014): Paleocene-Eocene foreland basin evolution in the Himalaya of southern Tibet and Nepal: Implications for the age of initial India-Asia collision. In: Tectonics 33. (S. 824-849)

Dittmann, E. (1970): Statistische Untersuchung zur Struktur der Niederschläge in Nepal. In: Hellmich, W. (Hrsg.): Khumbu Himal. Ergebnisse des Forschungsunternehmens Nepal Himalaya. Band 7. Lieferung 2. Universitätsverlag Wagner Ges. M. B. H. InnsbruckMünchen.

Dreimanis, A.; Vagner, U.J. (1971): Bimodal distribution of rock and mineral fragments in basal tills. In: Goldthwait, R.P. (ed.) (1971): Till / a symposium. Ohio State University Press.

Engelhardt, W.v. (1973): Die Bildung von Sedimenten und Sedimentgesteinen. In: Sediment-Petrologie. Vol. III. (hrsg. von Engelhardt, W. v., Füchtbauer, H., Müller, G.) E. Schweizerbart'sche Verlagsbuchhandlung, Stuttgart. 
Evenson, E.B. (1971): The Relationship of Macro- and Microfabric of Till and the Genesis of Glacial Landforms in Jefferson County, Wisconsin. In: Goldthwait, R.P. (ed.) (1971): Till / a symposium. Ohio State University Press.

Finkel, R.C.; Owen, L.A.; Barnard, P.L.; Caffee, M.W. (2003): Beryllium-10 Dating of Mount Everest moraines indicates a strong monsoon influence and glacial synchroneity throughout the Himalaya. Geology 31.

Fischer, K. (1966): Zur Anwendung der morphometrischen Schotteranalyse bei Untersuchungen in Alpentälern. In: Zeitschrift für Geomorphologie 10. (1966). Gebrüder Borntraeger Berlin-Nokilassee. Bakker, J.P.; Cailleux, A.; Linton, D.L.; Louis, H.; Macar, P.; Nielson, N.; Rathjens, C.; Russel, R.J.; Spreitzer, H.; Hövermann, J. (alle Hrsg.).

Flohn, H. (1958): Beiträge zur Klimakunde von Hochasien. In: Erdkunde. Band XII.

Fort, M. (1985): Contribution of sedimentary and geomorphic data to the knowledge of paleoclimates in Nepal Himalayas. Current Trends in Geology 4 (Climate and Geology of Kashmir).

Fort, M. (1986): Glacial extension and catastrophic dynamics along the Annapurna front, Nepal Himalaya. In: Kuhle, M. (ed), Intern. Symp. über Tibet u. Hochasien (8.-11. Oktober 1985), Geogr. Inst. Univ. Göttingen, Göttinger Geogr. Abh., Vol. 81, Göttingen.

Fort, M. (2004): Quaternary glaciation in the Nepal Himalaya. In: Ehlers, J. \& Gibbard, P.L. (Ed.) (2004): Quaternary Glaciations - Extent and Chronology, Part III: South America, Asia, Africa, Australasia, Antarctica. Developments in Quaternary Science, Vol. 2c.

Fushimi, H. (1977): Glaciations in the Khumbu Himal. Seppyo 39.

Fushimi, H. (1978): Glaciations in the Khumbu Himal. Seppyo 40.

Fushimi, H. (1981): Glacial history in the Khumbu region, Nepal Himalayas, in relation to upheavels of the great Himalayas. In: Glaciological and Ecological Studies of QinghaiXizang Plateau (ed. by D.-S. Liu) (Proc. Beijing Symp.), vol. 2. Science Press, Beijing. (S. 1641-1648)

Gardner, W.H. (1986): Water Content. In: Klute, A. (ed.), (1986): Methods of Soil Analysis. Agron. Monograph No. 9(1), Am. Soc. Agron., Madison, Wisconsin (USA).

Gee, G.W.; Bauder, J.W. (1986): Particle-size Analysis. In: Klute, A. (ed.), (1986): Methods of Soil Analysis. Agron. Monograph No. 9(1), Am. Soc. Agron., Madison, Wisconsin (USA).

Goldthwait, R.P. (1971): Indroduction to Till, Today. In: Goldthwait, R. P. (ed.) (1971): Till / a symposium. Ohio State University Press.

Goudie, A. [Hrsg.] (1998): Geomorphologie. Ein Methodenhandbuch für Studium und Praxis. Übersetzt von Häringer, K. und Stasch, A. unter wiss. Beratung von Kleber, A. Springer Verlag. Berlin, Heidelberg, New York. (645 Seiten) 
Götz, J.; Weidinger, J.; Kraxberger, S.; Hennecke, A., Buckel, J.; Adhikari, B. (2015): Geomorphologic and Hydrogeologic Characteristics of Populated Rockslide Deposits (Sagarmatha National Park, Khumbu Himal, Nepal). Jouranl of Water Resource and Protection, 7. (S. 1038-1048)

Greilich, S. (2004): Über die Datierung von Gesteinsoberflächen mittels optisch stimulierter Lumineszenz. Dissertation, Heidelberg.

Haffner, W. (1972): Khumbu Himalaya. Landschaftsökologische Untersuchungen in den Hochtälern des Mt. Everest-Gebietes. Erdwiss. Forsch. 4.

Hagen, T. (1954): Über die Gebirgsbildung und Talsysteme im Nepal Himalaya. In: Geographica Helvetica, 9. Kümmerly \& Frey, Geographischer Verlag - Editions géographiques. Bern.

Hagen, T.; Wahlen, F.T.; Corti, W.R. (1960): Nepal, Königreich am Himalaya. Kümmerly \& Frey. Geographischer Verlag. Bern.

Heuberger, H. (1956): Beobachtungen über die heutige und eiszeitliche Vergletscherung in Ostnepal. Zeitschrift für Gletscherkunde und Glazialgeologie 3.

Heuberger, H. (1986): Untersuchungen über die eiszeitliche Vergletscherung des Mt. Everest-Gebietes, Südseite, Nepal. Göttinger Geographische Abhandlungen 81 (Kuhle, M. (ed), Internationales Symposium über Tibet und Hochasien vom 8.-11.10.1985).

Heuberger, H.; Weingartner, H. (1985): Die Ausdehnung der letzteiszeitlichen Vergletscherung an der Mount-Everest-Südflanke, Nepal. Mitteilungen der Österreichischen Geographischen Gesellschaft Wien 127.

Heydemann, A.; Kuhle, M. (1988): The Petrography of Southern Tibet - Results of Microskopic and X-Ray Analyses of Rock Samples from the 1984 Expedition Area (Transhimalaya to Mt. Everest N Slope). In: GeoJournal 17 (4), Tibet and High-Asia, Results of the Sino-German Joint Expeditions (I). Kuhle, M., Wang Wenjing (eds.); Kluwer, Dordrecht/ Boston/ London. (S. 615-625)

Hubbard, B.; Glasser, N. (2005): Field Techniques in Glaciology and Glacial Geomorphology. John Wiley \& Sons.

Hövermann, J.; Poser, H. (1951): Morphometrische und morphologische Schotteranalysen. Proceedings of the third international congress of sedimentology. Groningen, Wageningen.

Iturrizaga, L. (1999): Die Schuttkörper in Hochasien. Eine geomorphologische Bestandsaufnahme und Typologie postglazialer Hochgebirgsschuttkörper im Hindukusch, Karakorum und Himalaya. In: Göttinger Geographische Abhandlungen. Heft 106. Verlag Erich Goltze GmbH \& Co. KG, Göttingen. (326 Seiten)

Iwata, S. (1976): Late Pleistocene and Holocene moraines in the Sagarmatha (Everest) region, Khumbu Himal. Seppyo 38. 
Iwata, S. (1984): Geomorphology of the Thakkhola-Muktinath region, Central Nepal, and its late quaternary history. In: Geographical Reports of Tokyo Metropolitan University, Vol. 19.

Jackson, M.L.; Lim, C.H.; Zelazny, L.W. (1986): Oxides, Hydroxides, and Aluminosilicates. In: Klute, A. (ed.), (1986): Methods of Soil Analysis. Agron. Monograph No. 9 (1), Am. Soc. Agron., Madison, Wisconsin (USA).

Joshi, S.C. (1986): Nepal Himalaya: A Physiographic Appraisal. In: Joshi, S.C. (ed.): Nepal Himalaya. Geo-ecological Perspectives. Himalayan Research Group. 1986.

Kleinert, C. (1973): Haus- und Siedlungsformen im Nepal Himalaya unter Berücksichtigung klimatischer Faktoren. In: Hochgebirgsforschung/High Mountain Research. Heft 4. Universitätsverlag Wagner. Innsbruck, München.

Kollmair, M. (1999): Futterbäume in Nepal. Traditionelles Wissen, Stellenwert in kleinbäuerlichen Betrieben und räumliche Verteilung. Kultur, Gesellschaft, Umwelt. Band 1. Lit.-Verlag, Münster. (186 Seiten)

Köster, E. (1960): Mechanische Gesteins- und Bodenanalyse. Leitfaden der Granulometrie und Morphometrie. Carl Hanser Verlag München.

Köster, E. (1964): Granulometrische und morphometrische Meßmethoden an Mineralkörnern, Steinen und sonstigen Stoffen. Ferdinand Enke Stuttgart.

König, O. (2002): Zur Vergletscherungsgeschichte des Rolwaling Himal und des Kangchenjunga Himal (Nepal, Himalaya Südabdachung). Dissertation, Göttingen. (154 Seiten)

Kraus, H. (1966): Das Klima von Nepal. In: Hellmich, W. (Hrsg.): Khumbu Himal. Ergebnisse des Forschungsunternehmens Nepal Himalaya. Band 1. Lieferung 4. Springer Verlag. Berlin, Heidelberg, New York.

Krumbein, W.C. (1938): Manual of sedimentary petrography: I. Sampling, Preparation for Analysis, Mechanical Analysis, and Statistical Analysis. In: The Century Earth Science Series. Mather, K. F. (ed.). Department of Geology, University of Chicago. D. Appleton-Century Company. New York, London.

Kugler, H.; Schwab, M.; Billwitz, K. (1980): Allgemeine Geologie, Geomorphologie und Bodengeographie. 1. Aufl. Studienbücherei Geographie für Lehrer. Band 4. VEB Hermann Haack Geographisch-Kartographische Anstalt, Gotha/Leipzig.

Kuhle, M. (1980): Klimageomorphologische Untersuchungen in der Dhaulagiri und Annapurna-Gruppe (Zentraler Himalaya). In: Tagungsbericht und wissenschaftliche Abhandlungen des 43. Deutschen Geographentag Göttingen. Steiner, Wiesbaden. (S. 244-247)

Kuhle, M. (1982a): Der Dhaulagiri- und Annapurna-Himalaya. Ein Beitrag zur Geomorphologie extremer Hochgebirge. In: Zeitschrift für Geomorphologie, Supplement, Vol. 41, Gebrüder Bornträger, Berlin-Stuttgart, Band I (Text). 
Kuhle, M. (1982b): Der Dhaulagiri- und Annapurna-Himalaya. Ein Beitrag zur Geomorphologie extremer Hochgebirge. In: Zeitschrift für Geomorphologie Supplement, Vol. 41, Gebrüder Bornträger, Berlin-Stuttgart, Band II (Abb.).

Kuhle, M. (1983): Der Dhaulagiri- und Annapurna-Himalaya. Ein Beitrag zur Geomorphologie extremer Hochgebirge. Empirische Grundlage; Ergänzungsbd. III. In: Zeitschrift für Geomorphologie Supplement Bd. 41; Gebrüder Bornträger; Berlin, Stuttgart. (S. 1-383)

Kuhle, M. (1984): Auswertung von Spacelabaufnahmen aus Hochasien: Die Kuen-Lun-NAbdachung zur Tsaidam-Depression (ca. $35^{\circ} 45^{\prime}-37^{\circ} 40^{\prime} \mathrm{N} / 9^{\circ} 30^{\prime}-92^{\circ} 52^{\prime} \mathrm{E}$ ) Ausdeutung einer Satellitenphotographie über Feldarbeitsbefunde benachbarter Areale mit analoger geomorphologischer Sequenz. In: Geographische Rundschau 36. (S. 299301)

Kuhle, M. (1985): Ein subtropisches Inlandeis als Eiszeitauslöser. Südtibet- und Mt. EverestExpedition 1984. In: Georgia Augusta, Nachrichten aus der Universität Göttingen 42. (S. 35-51)

Kuhle, M. (1986a): Former glacial stades in the mountain areas surrounding Tibet - In the Himalayas (27-29 N: Dhaulagiri-, Annapurna-, Cho Qyu-, Gyachung Kang-areas) in the south and in the Kuen Lun and Quilian Shan (34-38 $\mathrm{N}$ : Animachin, Kakitu) in the north. In: Joshi, S.C., Haigh, M.J., Pangtey, Y.P.S., Joshi, D.R., Dani, D.D. (eds.): Nepal-Himalaya - Geo-Ecological Perspektives. Himalayan Research Group. (S. 437473)

Kuhle, M. (1986b): Südtibet- und Mt. Everest-Expedition 1984 oder: Ein subtropisches Inlandeis als Eiszeitauslöser? In: Universitas 41, 1 (476); Stuttgart. (S. 64-78)

Kuhle, M. (1987a): Absolute Datierungen zur jüngeren Gletschergeschichte im Mt. EverestGebiet und die mathematische Korrektur von Schneegrenzberechnungen. In: Hütteroth, W.-D. (ed.): Tagungsbericht und wissenschaftliche Abhandlungen des 45. Deutschen Geographentages Berlin 1985. Steiner, Stuttgart. (S. 200-208)

Kuhle, M. (1987b): Subtropical Mountain- and Highland-Glaciation as Ice Age Triggers and the Waning of the Glacial Periods in the Pleistocene. In: GeoJournal 14 (4); Kluwer, Dordrecht/ Boston/ London. (S. 393-421)

Kuhle, M. (1988a): Eine reliefspezifische Eiszeittheorie. Nachweis einer tibetischen Inlandvereisung und ihrer energetischen Konsequenzen. In: Die Geowissenschaften 6 (5). (S. 142-150)

Kuhle, M. (1988b): Zur Auslöserrolle Tibets bei der Entstehung von Eiszeiten. In: Spektrum der Wissenschaften 1/88. (S. 16-20)

Kuhle, M. (1990a): New Data on the Pleistocene Glacial Cover of the Southern Border of Tibet: The Glaciation of the Kangchendzönga Massif (8585m, E-Himalaya). In: GeoJournal, Vol. 20.

Kuhle, M. (1990b): The Probability of Proof in Geomorphology - an Example of the Application of Information Theory to a New Kind of Glacigenic Morphological Type, 
the Ice-marginal Ramp (Bortensander). In: GeoJournal 21 (3); Kluwer, Dordrecht/ Boston/ London. (S. 195-222)

Kuhle, M. (1991): Glazialgeomorphologie. Wissenschaftliche Buchgesellschaft Darmstadt.

Kuhle, M. (1997a): New Findings concerning the Ice Age (Last Glacial Maximum) Glacier Cover of the East-Pamir, of the Nanga Parbat up to the Central Himalaya and of Tibet, as well as the Age of the Tibetan Inland Ice. In: GeoJournal 42 (2-3), Tibet and High Asia. Results of Investigations into High Mountain Geomorphology, Paleo- Glaciology and Climatology of the Pleistocene (Ice Age Research) IV. Kuhle, M. (ed.); Kluwer, Dordrecht/ Boston/ London. (S. 87-257)

Kuhle, M. (1997b, ed.): Tibet and High-Asia IV, Results of Investigations into High Mountain Geomorphology, Paleo-Glaciology and Climatology of the Pleistocene (Ice Age Research). Geojournal 42 (2/3); M. Kluwer, London/ Dordrecht/ Boston. (S. 85-86)

Kuhle, M. (1998): Reconstruction of the 2.4 Million $\mathrm{km}^{2}$ Late Pleistocene Ice Sheet on the Tibetan Plateau and its Impact on the Global Climate. In: Quaternary International 45/46: 71-108 (Erratum: Vol. 47/48:173-182 (1998) included)

Kuhle, M. (2001a, ed.): Tibet and High Asia (VI): Glaciogeomorphology and Prehistoric Glaciation in the Karakorum and Himalaya. GeoJournal 54 (2-4), 55 (1). Kluwer Academic Publishers, Dordrecht/ Boston/ London. (S. 107-475)

Kuhle, M. (2001b): The maximum Ice Age (LGM) glaciation of the Central- and South Karakorum: an investigation of the heights of its glacier levels and ice thicknesses as well as lowest prehistoric ice margin positions in the Hindukush, Himalaya and in EastTibet on the Minya Konka-massif. In: GeoJournal, Vol. 54 (1-4) 55 (1) (hrsg. von Kuhle, M.), (Glaciogeomorphology and Prehistoric Glaciation in the Karakorum and Himalaya). Tibet and High Asia (VI). (S. 109-396)

Kuhle, M. (2004): The High Glacial (Last Ice Age and LGM) ice cover in High and Central Asia. Development in Quaternary Science 2 (c, Quaternary Glaciation - Extent and Chronology, Part III: South America, Asia, Africa, Australia, Antarctica, Eds: Ehlers, J.; Gibbard, P.L.), 175-199. (Elsevier B.V., Amsterdam).

Kuhle, M. (2005): The maximum Ice Age (Wurmian, Last Ice Age, LGM) Glaciation of the Himalaya - a glacialgeomorophological investigation of glacier trimlines, ice thicknesses, lowest former ice margin positions and snow-line depression in the Mt. Everest-Makalu-Cho Oyu Massifs (Khumbu- and Khumbakarna Himal) including informations on late-glacial, neoglacial and historical glacier stages, their snow-line depressions and ages. GeoJournal 62 Nr. 3-4 (Tibet and High Asia (VII): Glaciogeomorphology and former Glaciation in the Himalaya and Karakorum).

Kuhle, M. (2007a): The past valley glacier network in the Himalayas and the Tibetan ice sheet during the last glacial period and its glacial-isostatic, eustatic and climatic consequences. In: Tectonophysics. (S. 116-144)

Kuhle, M. (2007b): Critical Approach to Methods of Glacier Reconstruction in High Asia and Discussion of the Probability of a Qinghai-Xizang (Tibetan) Inland Ice. In: Journal of Mountain Science (JMS) Vol.4, No. 2. (S. 91-123) 
Kuhle, M. (2011a): The High Glacial (LGP, LGM, MIS 3-2) southern outlet glaciers of the Tibetan inland ice through Mustang into the Thak Khola as further evidence of the Tibetan ice. Journal of Nepal Geological Society (JNGS), Vol. 43 (Special Issue). (S. 175-200)

Kuhle, M. (2011b): The High Glacial (Last Ice Age and Last Glacial Maximum) Ice Cover of High and Central Asia, with a Critical Review of Some Recent OSL and TCN Dates. Development in Quaternary Science, Vol. 15 (d, Quaternary Glaciation - Extent and Chronology, A Closer Look, Eds: Ehlers, J.; Gibbard, P.L.; Hughes, P.D.). (Elsevier B.V., Amsterdam). (S. 943-965)

Kuhle, M. (2012a): The Former Tibetan Ice Sheet. In: Ice Sheets. Eds: Müller, J.; Koch, L.; Hauppauge, NY, 173-203, Nova Science Publishers, Inc.

Kuhle, M. (2012b): The Early and Late Glacial High Mountain Glaciation Surrounding Tibet as Topographic-Climatic Cause of High-Energetic Glacial Lake Outburst Floods (GLOFs) and their Sedimentological Consequences in the Lower Mountain Forelands. In: Horizons in Earth Science Research. Volume 7. Eds. Benjamin Veress \& Jozsi Szigethy, 197 - 227; Nova Science Publisher, Inc. New York.

Kuhle, M. (2013a): The uplift of High Asia above the snowline and its Glaciation as an albedo-dependent cause of the Quaternary ice ages. Nova Science Publishers Inc., New York. (232 Seiten)

Kuhle, M. (2013b): Tibet and High Asia (VIII): glaciogeomorphology and former glaciation in the Himalaya and Karakorum. Shaker. (360 Seiten)

Kuhle, M. (2014): The Glacial (MIS 3-2) Outlet Glacier of the Marsyandi Nadi-icestreamnetwork with its Ngadi Khola Tributary Glacier (Manaslu- and Lamjung Himalaya). The Reconstructed Lowering of the Marsyandi Nadi Ice Stream Tongue down in to the Southern Himalaya Foreland. Journal of Mountain Science (JMS), J. Mt. Sci. 11(1). (S. 236-287)

Kuhle, M.; Kuhle, S. (2010): Review on Dating methods: Numerical Dating in the Quaternary of High Asia. In: Journal of Mountain Science (2010) 7. (S. 105-122)

Kuhle, M.; Roesrath, C. (1990): Geographie und Geologie der Hochgebirge. Deutscher Alpenverein in Zusammenarbeit mit dem Oesterreichischen Alpenverein. Schriftenreihe Alpin-Lehrplan; 11. BLV Verlagsgesellschaft mbH, München [u.a], 1990. (160 Seiten)

Kunze, G.W.; Dixon, J.B. (1986): Pretreatment for mineralogical analysis. (S. 91-100) In: Methods of Soil Analysis, Part 1. Physical and Mineralogical Methods (2nd edition). (Klute, A. ed.). American Society of Agronomy, Inc. and the Soil Science Society of America, Inc., Madison, Wisconsin, USA.

Leser, H. (1977): Feld- und Labormethoden der Geomorphologie. 1. Auflage. Walter de Gruyter. Lehrbuch. Berlin, New York.

Leser, H. (2009): Geomorphologie. Das Geographische Seminar. Bildungshaus Schulbuchverlage Westermann Schroedel Diesterweg Schöningh Winklers GmbH. Braunschweig. 
Leser, H. [Hrsg.]; Haas, H.-D.; Mosimann, T.; Paesler, R., Huber-Fröhli, J. (2001): DIERCKE-Wörterbuch Allgemeine Geographie. 12. Aufl. Deutscher Taschenbuch Verlag GmbH \& Co. KG, München und Westermann Schulbuchverlag GmbH, Braunschweig.

Lineback, J.A. (1971): Pebble Orientation and Ice Movement in South-Central Illinois. In: Goldthwait, R.P. (ed.) (1971): Till / a symposium. Ohio State University Press.

Louis, H.; Fischer, K. (1979): Allgemeine Geomorphologie. 4. Aufl., Walter de Gruyter, Berlin-New York.

Lüdecke, C. (1983): Ergebnisbericht. Himalaya-Konferenz '83. Zebhauser, H. (Hrsg.), Deutscher Alpenverein.

Mahaney, W.C. (1995): Glacial crushing, weathering and diagenetic histories of quartz grains inferred from scanning electron microscopy. In: Menzies, John (ed.) (1995): Modern glacial environments. Processes, dynamics and sediments. Volume 1. Butterworth-Heinemann. Oxford u.a.

Meiners, S. (1999): The history of glaciation of the Rolwaling and Kangchenjunga Himalayas. In: GeoJournal, Vol. 47 (1/2): Tibet and High Asia (V) (hrsg. von Kuhle, M.).

Miehe, G. (1990): Langtang Himal. Flora und Vegetation als Klimazeiger und -zeugen im Himalaya. Dissertationes Botanicae, Band 158. J. Cramer, Borntraeger Verlagsbuchhandlung, Berlin, Stuttgart. (529 Seiten)

Miehe, G. (1991): Der Himalaya, eine multizonale Gebirgsregion. In: Walter, H. \& Breckle, S.-W. (eds.): Ökologie der Erde, Geo-Biosphäre. Band 4: 181-230: Spezielle Ökologie der Gemäßigten und Arktischen Zonen außerhalb Euro-Nordasiens. Stuttgart, New York: Gustav Fischer.

Miller, M.M. (1970): Glaciology of the Khumbu Glacier and Mount Everest. In: National Geographic Society Projects, Research Reports 1961-1962, Washington, DC, National Geographic Society. (S. 153-165)

Müller, F. (1959): Acht Monate Gletscher- und Bodenforschung im Everestgebiet. Berge der Welt, 12. (S. 199-216)

Müller, F. (1980): Present and late Pleistocene equilibrium line altitudes in the Mt. Everest region - an application of the glacier inventory. In: Müller, F. (ed.) World Glacier Inventory 126. Proceedings of the Riederalp Workshop, September 1978, International Association of Hydrological Sciences. (S. 75-94)

Owen, L.A. (2009): Latest Pleistocene and Holocene glacier fluctuations in the Himalaya and Tibet. In: Quaternary Science Reviews 28. (S. 2150-2164)

Owen, L.A.; Benn, D.I. (2005): Equilibrium-line altitudes of the Last Glacial Maximum for the Himalaya and Tibet: an assessment and evaluation of results. In: Quaternary International 138/139. (S. 55-78) 
Owen, L.A.; Caffee, M.W.; Finkel, R.C.; Seong, Y.B. (2008): Quaternary Glaciation of the Himalayan-Tibetan Orogen. In: Journal of Quaternary Science 23.

Owen, L.A.; Derbyshire, E.; Fort, M. (1998): The Quaternary glacial history of the Himalaya. In: Owen, L.A. (ed.), Mountain Glaciation. Quaternary Proceedings 6. Wiley, Chichester. (S. 91-120)

Owen, L.A.; Dortch, J.M. (2014): Nature and timing of Quaternary glaciation in the Himalayan-Tibetan orogen. In: Quaternary Science Reviews 88. (S. 14-54)

Owen, L.A.; Finkel, R.C.; Caffee, M.W. (2002): A note on the extent of glaciation throughout the Himalaya during the global Last Glacial Maximum. In: Quaternary Science Reviews 21.

Pachur, H. (1966): Untersuchungen zur morphoskopischen Sandanalyse. In: Berliner Geographische Abhandlungen 4. Selbstverlag des II. Geographischen Instituts der Freien Universität Berlin.

Penck, A.; Brückner, E. (1909): Die Alpen im Eiszeitalter. Band 1. Die Eiszeiten in den nördlichen Ostalpen. Leipzig (Trauchnitz). (393 Seiten)

Pettijohn, F.J. (1938): Manual of sedimentary petrography. II. Shape Analysis, Mineralogical Analysis, Chemical Analysis, and Mass Properties. In: The Century Earth Science Series. Mather, K.F. (ed.). Department of Geology, University of Chicago. D. AppletonCentury Company. New York, London.

Poser, H.; Hövermann, J. (1952): Beiträge zur morphometrischen und morphologischen Schotteranalyse. In: Abh. d. Braunschw. Wiss. Gesellsch., Bd. IV, 1952. Schlichting, H. (Hrsg.). Friedr. Vieweg \& Sohn, Verlag, Braunschweig. (S. 12-36)

Rai, S.M.; Yoshida, M.; Upreti, B.N. (2007): Geomorphological observations surrounding Lukla, eastern Nepal Himalaya. Abstract. In: Journal of Nepal Geological Society 36 (Special Issue). (S. 29)

Ramsden, J.; Westgate, J.A. (1971): Evidence for Reorientation of a Till Fabric in the Edmonton Area, Alberta. In: Goldthwait, R.P. (ed.) (1971): Till / a symposium. Ohio State University Press.

Reichelt, G. (1961): Über Schotterformen und Rundungsanalyse als Feldmethode. In: Peterm. Geogr. Mitt. 105. Jg.. (S. 15-24)

Reichelt, G. (1964): Zur Frage pleistozäner Vergletscherung im Harz und Thüringer Wald. Erdkunde XVIII. Heft 1/4. Archiv für wissenschaftliche Geographie. Troll, C.; Hahn, H.; Kuls W.; Lauer, W. (1964). Ferd. Dümmlers Verlag Bonn.

Reuther, A.U. (2007): Surface exposure dating of glacial deposits from the last glacial cycle. Evidence from the Eastern Alps, the Bavarian Forest, the Southern Carpathians and the Altai Mountains. Relief, Boden, Paläoklima Band 21. 
Richards, B.W.M.; Benn, D.; Owen, L.A.; Rhodes, E.J.; Spencer, J.Q. (2000): Timing of Late Quaternary glaciations south of Mount Everest in the Khumbu Himal. Nepal. Geological Society of America Bulletin 112.

Rowell, D.L. (1997): Bodenkunde. Untersuchungsmethoden und ihre Anwendungen. Springer Verlag. Berlin, Heidelberg, New York.

Schlichting, E.; Blume, H.-P.; Stahr, K. (1995): Bodenkundliches Praktikum. Eine Einführung in pedologisches Arbeiten für Ökologen, insbesondere Land- und Forstwirte und für Geowissenschaftler. Verlag Paul Parey Hamburg und Berlin 1966. 2. Neubearbeitete Aufl. Blackwell Wissenschaftsverlag Berlin. Studientexte 81.

Schnitzer, W.A. (1957): Die Quarzkornfarbe als Hilfsmittel für die stratigraphische und paläogeographische Erforschung sandiger Sedimente (aufgezeigt an Beispielen aus Ostbayern). In: Erlanger Geologische Abhandlungen Heft 23, v. Freyberg, Prof. Dr. B. (Hrsg.), Erlangen 1957, Junge \& Sohn, Universitäts-Buchdruckerei, Erlangen.

Schreiner, A. (1997): Einführung in die Quartärgeologie. 2. Aufl. E. Schweizerbart'sche Verlagsbuchhandlung. Schweizerbart. Stuttgart.

Schweinfurth, U. (1956): Über klimatische Trockentäler im Himalaya. In: Erdkunde. Band $\mathrm{X}$.

Schweinfurth, U. (1957): Die horizontale und vertikale Verbreitung der Vegetation im Himalaya. In: Bonner Geographische Abhandlungen. Heft 20. Ferdinand Dümmlers Verlag. Bonn.

Shiraiwa, T.; Watanabe, T. (1991): Late Quaternary Glacial Fluctuations in the Langtang Valley, Nepal Himalaya, Reconstructed by relative Datings Methods. In: Arctic and Alpine Research, Vol. 23 (4).

Shrestha, A. B.; Aryal, R. (2011): Climate change in Nepal and its impact on Himalayan glaciers. In: Regional Environmental Change 11 (1). (S. 65-77)

Sindowski, K.-H. (1957): Die synoptische Methode des Kornkurven-Vergleiches zur Ausdeutung fossiler Sedimentationsräume. In: Geologisches Jahrbuch Band 73. Geologische Landesanstalten der Bundesrepublik Deutschland (Hrsg.). Hannover. 1958.

Soliva, R. (2002): Der Naturschutz in Nepal. Eine akteurorientierte Untersuchung aus der Sicht der politischen Ökologie. Münster.

Stainton, J.D.A. (1972): Forests of Nepal. Haffner, New York. (174 Seiten)

Statistisches Bundesamt (Hrsg.) (1993): Länderbericht Nepal. Metzler-Poeschel. Stuttgart.

Stäblein, G. (1970): Grobsediment-Analyse als Arbeitsmethode der genetischen Geomorphologie. In: Würzburger Geographische Arbeiten 27. Mitteilungen der Geographischen Gesellschaft Würzburg. Selbstverlag des Geographischen Instituts der Universität Würzburg in Verbindung mit der Geographischen Gesellschaft Würzburg. 
Steiger, J.R.; Holowaychuk, N. (1971): Particle-Size and Carbonate Analysis of Glacial Till and Lacustrine Deposits in Western Ohio. In: Goldthwait, R.P. (ed.) (1971): Till / a symposium. Ohio State University Press.

Syvitski, J.P.M. (ed.) (1991): Principles, methods, and application of particle size analysis. Cambridge University Press. Cambridge, New York, Port Chester, Melbourne, Sydney.

Tilman, H. W. (1952): Nepal Himalaya. Cambridge.

Tsukamoto, S.; Asahi, K.; Watanabe, T.; Rink, W.J. (2002): Timing of past glaciation in Kanchenjunga Himal, Nepal by optically stimulated luminescence dating of tills. Quaternary International 97/98.

Valeton, I. (1955): Beziehungen zwischen petrographischer Beschaffenheit, Gestalt und Rundungsgrad einiger Flussgerölle. Petermanns Mitteilungen 99. (1955). Neef, Ernst (Hrsg.). Veb Hermann Haack. Geographisch-Kartographische Anstalt Gotha.

Visser, P.C.; Visser-Hooft, J. (1938): Wissenschaftliche Ergebnisse der niederländischen Expeditionen in den Karakorum und die angrenzenden Gebiete in den Jahren 1922, 1925, 1929/39 und 1935. Band 2, Brill, Leiden, Holland.

Wagner, M. (2005): Geomorphological and pedological investigations on the glacial history of the Kali Gandaki (Nepal Himalaya). GeoJournal vol. 63 nos. 1-4 (Kuhle M. ed.), Tibet and High Asia (VII), Glaciogeomorphology and former Glaciation in the Himalaya and Karakorum.

Wagner, M. (2007): Zur pedologischen Relativdatierung glazialgeomorphologischer Befunde aus dem Dhaulagiri- und Annapurna-Himalaja im Einzugsgebiet des Kali Gandaki (Zentral-Nepal). Geography International 1. Shaker-Verlag, Aachen. (410 Seiten)

Wehlmann, B. (1955): Die heutige Schneegrenze und die Schneegrenze der letzten Eiszeit in Asien. Tübingen 1957.

Williams, V.S. (1983): Present and former equilibrium-line altitudes near Mount Everest, Nepal and Tibet. Arctic and Alpine Research 15/2.

Winkler, S. (1996): Frührezente und rezente Gletscherstandsschwankungen in Ostalpen und West-/Zentralnorwegen. Ein regionaler Vergleich von Chronologie, Ursachen und glazialmorphologischen Auswirkungen. In: Trierer Geographische Studien, Heft 15, Baumhauer, R. (Hrsg.). Im Selbstverlag der Geographischen Gesellschaft Trier in Zusammenarbeit mit dem Fachbereich VI - Geographie/Geowissenschaften der Universität Trier.

Yin, A.; Harrison, T.M. (2000): Geologic evolution of the Himalayan-Tibetan orogen. In: Annual Reviews of Earth and Planetary Sciences, 28. (S. 211-280)

Yokoyama, K. (1978): Some modified forms of lateral moraines observed in the Khumbu and Shorong regions. Glaciological Expedition of Nepal, Contribution 55. In: Journal of the Japanese Society of Snow and Ice 40 (Special). (S. 64-66) 
Zech, W.; Bäumler, R.; Madhikarmi, D.; Gerl, T.; Beck, E. (2001): Zur pleistozänen und holozänen Landschaftsgeschichte des Modi Khola-Tals (Annapurna, Nepal). Zeitschrift für Gletscherkunde und Glazialgeologie 37 (2).

Zech, R.; Zech, M.; Kubik, P. W.; Kharki, K.; Zech, W. (2009) Deglaciation and landscape history around Annapurna, Nepal, based on ${ }^{10} \mathrm{Be}$ surface exposure dating. Quaternary Science Reviews 28, Issues 11-12. 


\section{Karten- und Kartenwerksverzeichnis}

Alexander Pro Atlas (1996): 1. Aufl. Klett-Perthes. Gotha, Stuttgart.

Gefahrenkarte Solukhumbu (1:50.000)

Khumbu Area Nepal: Mountain Hazards Index-Map. Zimmermann, M.; Bichsel, M.; Kienholz, H. (1985). United Nations University Mountain Hazards Mapping Project. 1:50.000. Hallway AG, Bern.

\section{Geologische Karte Khumbu (1:50.000)}

Geological-Tectonic Sketch Map. Vuichard, D. In: (Gefahrenkarte Solukhumbu 1:50.000) Khumbu Area Nepal: Mountain Hazards Index-Map. Zimmermann, M.; Bichsel, M.; Kienholz, H. (1985). United Nations University Mountain Hazards Mapping Project. 1:50.000. Hallway AG, Bern.

Geologische Karte Khumbu 1 (1:50.000)

Esquisse géologique de la région de l'Everest et du Makalu. Bordet, P.; Latreille, M. (1954-1955). 1:50.000 (1958).

\section{Geologische Karte Nepal (1:125.000)}

Nepal Eastern Development Region, Nepal Geological Map / Canadian Assistance Program to Nepal. 1:125.000 (1985): Sheets No. 72-I-B und 72-I-D. Solukhumbu. H.M.G. Survey Dept., Top. Survey Branch, Kathmandu.

Geologische Karte Solu (1:250.000)

Geological Map of Eastern Nepal.

\section{Geologische Karte Solukhumbu (1:1.000.000)}

Geological Map of Nepal. Tater, J.M.; Kayastha, N.B.; Shrestha, J.N. 1:1.000.000 (1982). Department of Mines \& Geology, Lainchour, Kathmandu, Nepal.

\section{Geologische Karte Solukhumbu 1 (1:1.500.000)}

Geological Map of the Qinghai-Xizang (Tibet) and adjacent Areas. Chengdu Institute of Geology and Mineral Resources. China Geological Survey. Chengdu Cartographic Publishing House.

\section{Geomorphologische Karte Khumbu (1:50.000)}

Geomorphological Map of the Chomolongma. Modifiziert nach Kalvoda, J. (19711975). 1:50.000. (1978).

\section{Topographische Karte (1:50.000)}

Khumbu Himal. Schneider, E. Edition 1999. 1:50.000. Nepal-Kartenwerk der Arbeitsgemeinschaft für vergleichende Hochgebirgsforschung Nr. 2. 
Topographische Karte (1:60.000)

Lukla to Everest Base Camp. Pocket Map. 1:60.000 (2010). Himalayan Map House Pvt. Ltd., Kathmandu.

\section{Vegetationskarte Khumbu (1:70.000)}

Ökotopgefüge, Vegetation und Landnutzung im Imja Khola-Tal. Haffner (1972:Fig. 6). Topographische und geologische Grundlage: Bordet, P. (1961).

Zurick, D.; Pacheco, J. (2007): Illustrierter Atlas des Himalaya. Geologie \& Geographie. Gesellschaft \& Wirtschaft. Bergsteigen \& Trekking. AS Verlag. Zürich. 